\title{
PARAMETRIC STUDY OF CURVED STEEL I-GIRDER BRIDGES AT CONSTRUCTION PHASE
}

\author{
BY \\ Ihsan-ul Haq \\ B.Sc. Civil Engineering, University of Engineering and Technology, \\ Peshawar, Pakistan,1999
}

\author{
A Thesis \\ Presented to Ryerson University \\ In partial fulfillment of the \\ Requirement for the degree of \\ Master of Applied Science \\ In the program of \\ Civil Engineering
}

Toronto, Ontario, Canada, 2008

Cihsan-ul haq 2008

PROPERTY OF

RYERSON UNIUERSITY LIBRARY 
"Parametric Study of Curved Steel I-Girder Bridges at Construction Phase" By Ihsan-ul Haq Civil Engineering Department, Ryerson University Toronto, Ontario, Canada 2008

\begin{abstract}
The desire to conform to the existing terrain has largely increased the use of curved bridges for complex interchanges. Bridge curvature produces warping moments (lateral bending moments) in girder flanges under truck loading conditions and even during the construction phase. These warping moments increase girder flexural stresses at construction phase in case of un-shored construction. An extensive parametric study was conducted, using the finite-element analysis software "SAP2000", to examine the key parameters affecting warping stresses in curved girder bridges under construction loads. A strengthening technique "torsion box" at the girder supports was proposed and examined with respect to girder warping, flexural stresses and support reactions. The key parameters considered in this study included number of girders, girder spacing, number of cross bracing intervals, degree of curvature and girder span length. Based on this study empirical expressions for moment and shear distribution factors for the curved girder were developed.
\end{abstract}




\section{ACKNOWLEDGEMENTS}

The author acknowledges his deep appreciation to his advisor Dr. K. Sennah, for his valuable support and supervision during this research work. Dr. Sennah devoted his time and effort to make this study a success. His most helpful guidance is greatly appreciated. Also, the author is very grateful to his parents, brothers and wife for their great support and encouragement during the entire course of this study. 


\section{TO MY PARENTS}




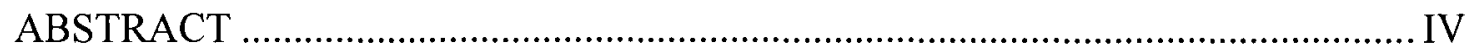

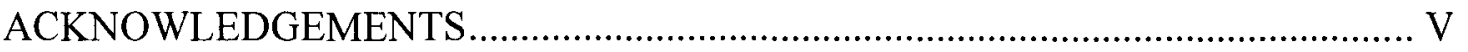

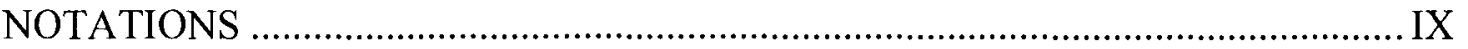

LIST OF TABLES................................................................................................

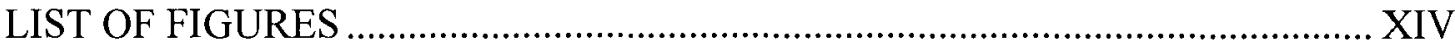

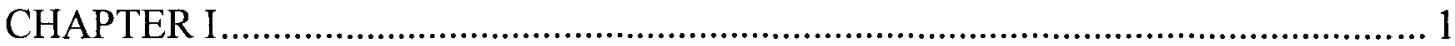

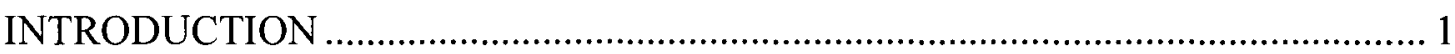

1.1 GENERAL

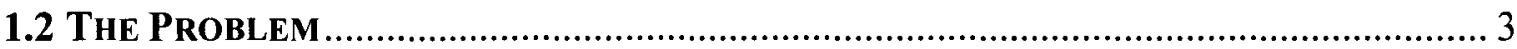

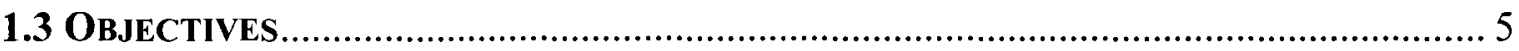

1.5 SCOPE

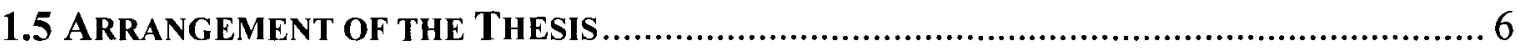

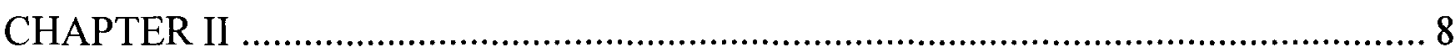

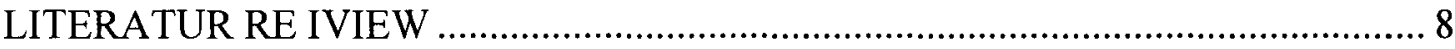

2.2 Review of Previous Research on Curved SteEl Bridges.............................. 11

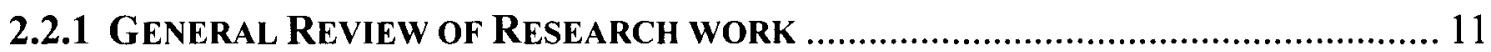

2.2.2 Canadian highway bridge code 2000 (CHBDC) ......................................... 14

2.2.3 OTHER RESEARCH STUDIES ........................................................................ 15

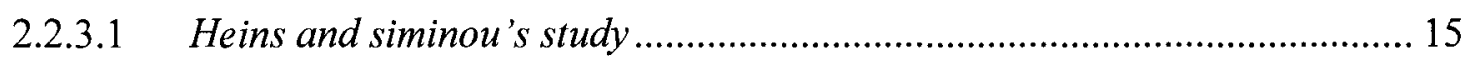

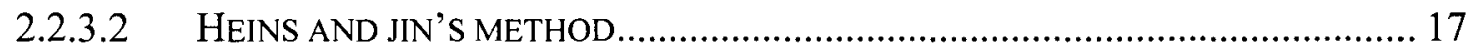

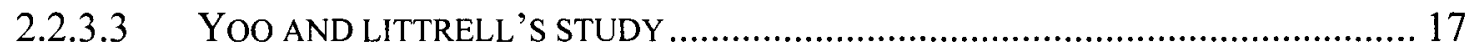

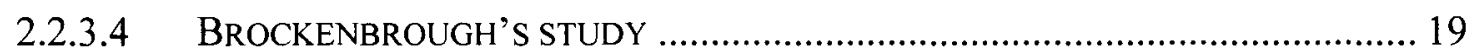

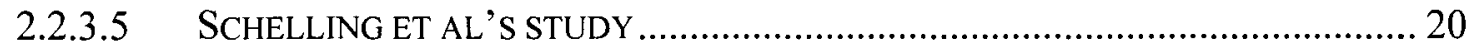

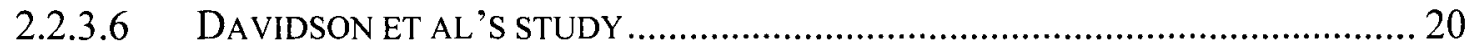

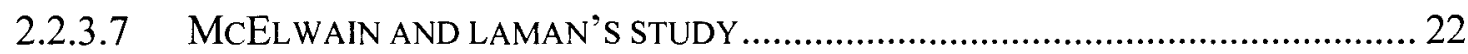

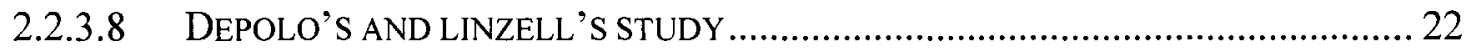

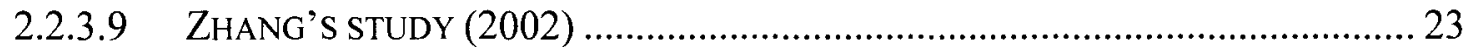

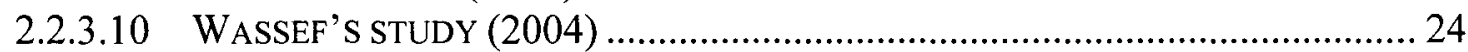

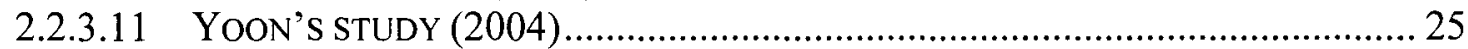

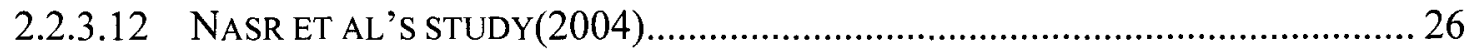

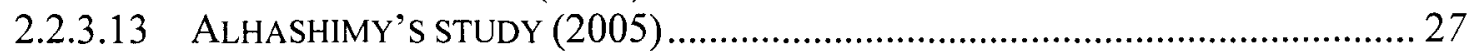

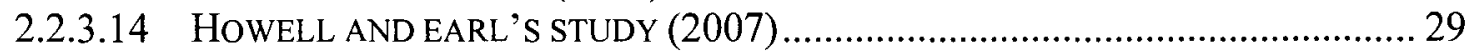

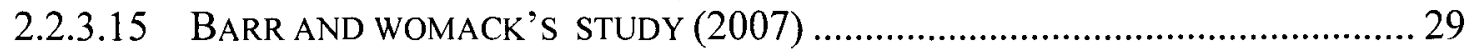

2.3 REVIEW OF ELASTIC BEHAVIOUR OF CURVED I- GIRDER SYSTEM ........................ 30

2.3.1 AASHTO guide method.................................................................. 31

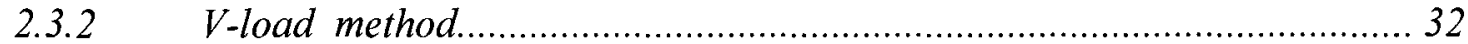

2.4 REVIEW OF ANALYSIS METHODS FOR CURVED SYSTEM ...................................... 34

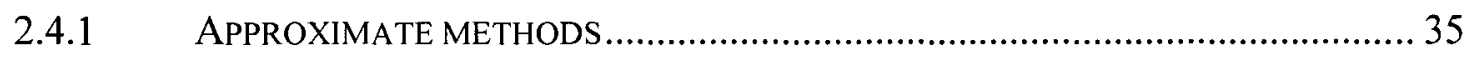




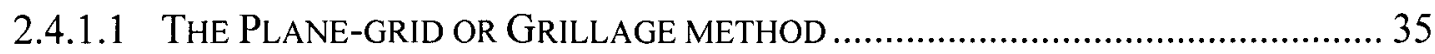

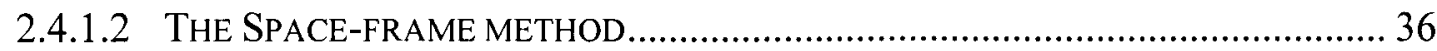

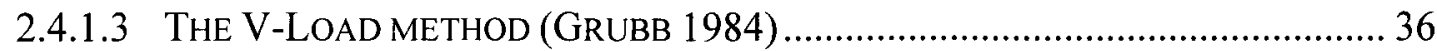

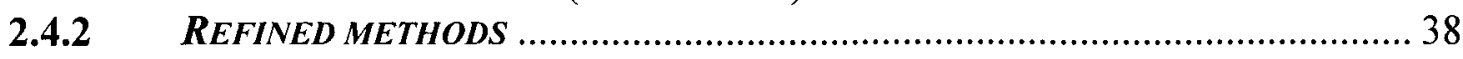

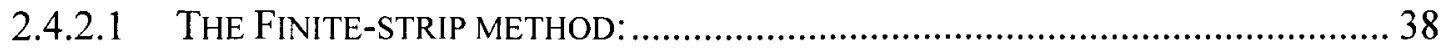

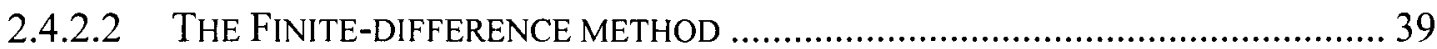

2.4.2.3 ANALYTICAL SOLUTION TO DIFFERENTIAL EQUATIONS …............................ 40

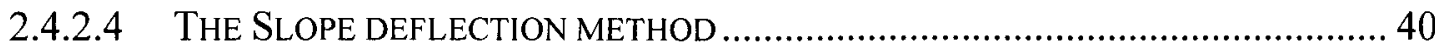

2.4.2.5 THE FINITE-ELEMENT METHOD (FEM) ……............................................ 41

2.4.2.5.1 Three-Dimensional Method ............................................................... 42

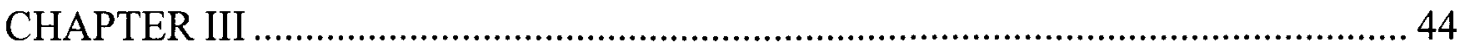

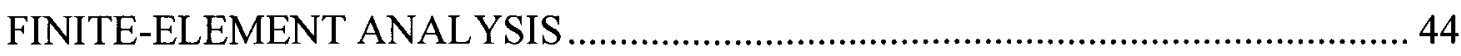

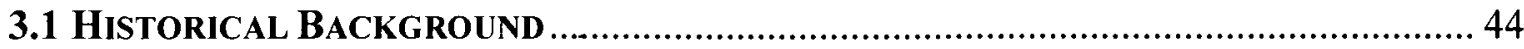

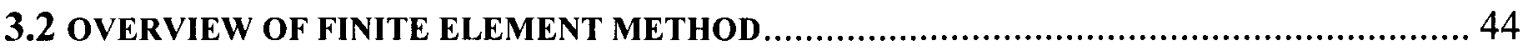

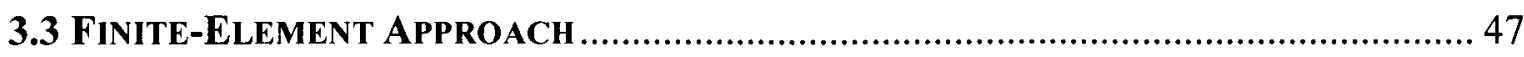

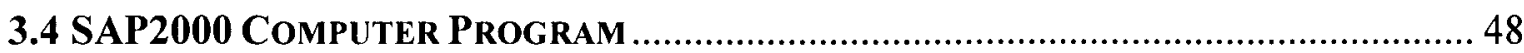

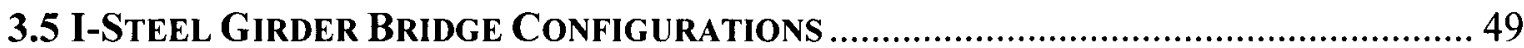

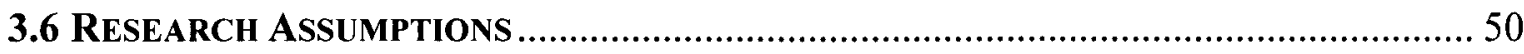

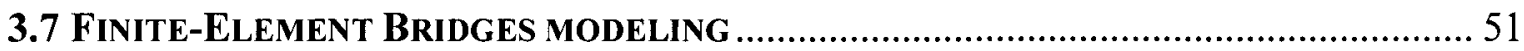

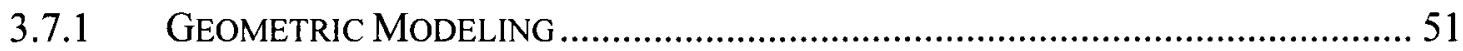

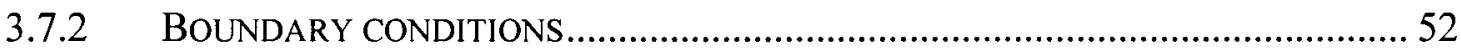

3.8 CALCULATION OF THE MOMENT DistRIBUTION FaCtORS.....................................5 52

3.9 CALCULATION OF WARPING TO-BENDING STRESS RATIO DURING CONSTRUCTION

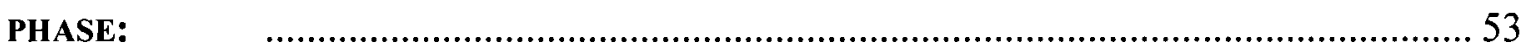

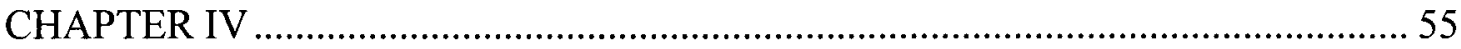

RESULTS FROM THE PARAMETRIC STUDY ………………............................. 55

4.1 GENERAL 55

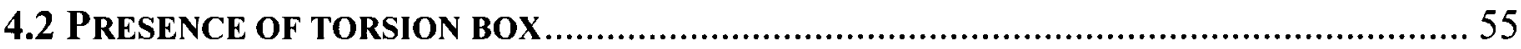

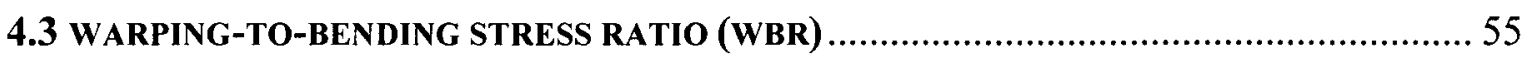

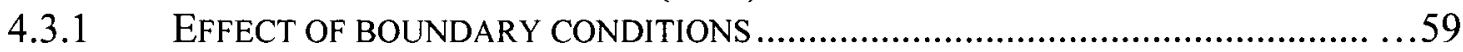

4.3.2 EFFECT OF VARIATION OF GIRDER FLEXURAL STIFFNESS ACROSS BRIDGE SECTION

.

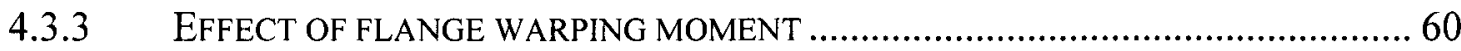

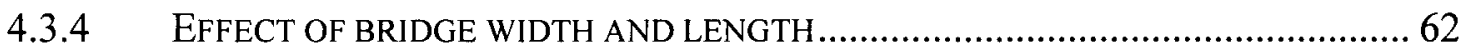

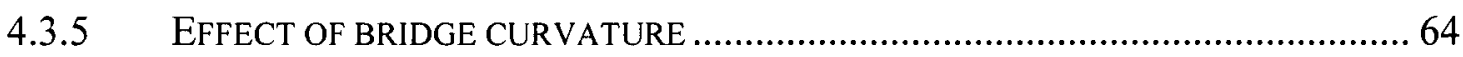

4.3.6 EFFECT OF NUMBER OF VERTICAL BRACING INTERVALS...................................6. 65

4.3.7 DEVELOPMENT OF EMPIRICAL EXPRESSION FOR MINIMUM NUMBER OF BRACING

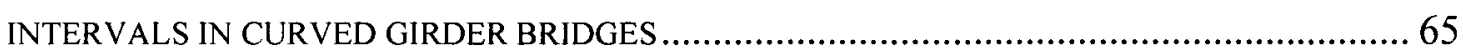

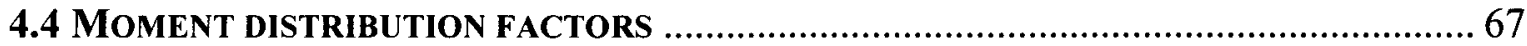

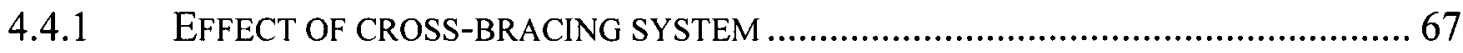

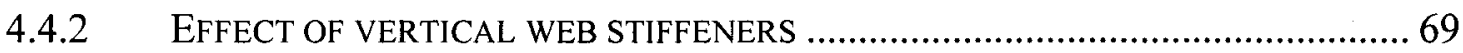

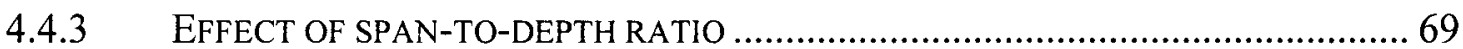

4.4.4 VARIATION OF GIRDER STIFFNESS VS. DEGREE OF CURVATURE ...................... 70

4.4.5 EFFECT OF BRIDGE ASPECT RATIO .................................................................. 71 
4.4.6 EFFECT OF NUMBER OF GIRDERS ...................................................... 72

4.4.7 EMPIRICAL FormUlas FOR THE MOMENT DisTRIBUTION FACTOR, $\mathrm{D}_{\mathrm{M}} \ldots \ldots \ldots . . . .73$

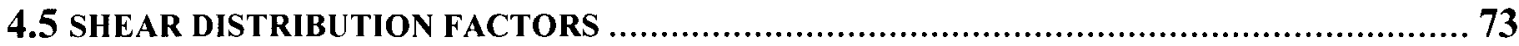

4.5.1 EFFECT OF SPAN-TO-RADIUS OF CURVATURE RATIO ................................ 74

4.5.2 EFFECT OF NUMBER OF GIRDERS ....................................................... 74

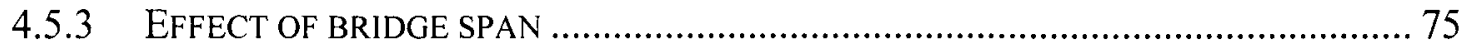

4.5.4 EFFECT OF GIRDER SPACING ............................................................... 75

4.5.5 EMPERICAL FORMULA FOR THE SHEAR DISTRIBUTION FACTOR, $\mathrm{D}_{\mathrm{V}} \ldots \ldots \ldots \ldots \ldots . . . . . .76$

CHAPTER V ...................................................................................... 78

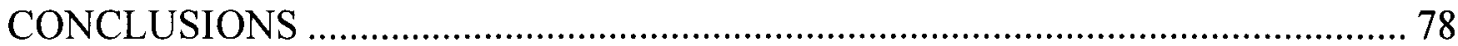

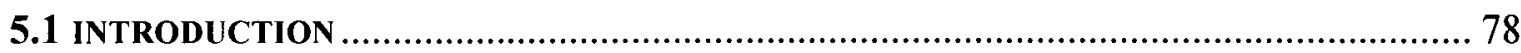

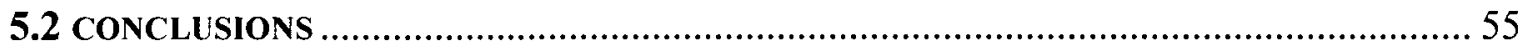

5.3 RECOMMENDATION FOR FUTURE RESEARCH .................................................. 79

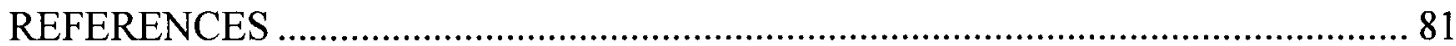




\section{NOTATIONS}
A
Bridge width
B
The clear spacing between girders
$\mathrm{Be}$
Effective concrete slab width
E
Modulus of Elasticity
$\mathrm{F}$
Width dimension factor
Fv
Shear distribution factor
$\mathrm{I}_{\mathrm{t}}$
The moment of inertia of the composite girder
[K]
The global stiffness matrix
L Centre line span of a simply supported bridge
$\mathrm{M}_{\mathrm{DL}} \quad$ The mid-span moment for a straight simply supported girder due to a single girder dead load
$\mathrm{M}_{\mathrm{T}} \quad$ The mid-span moment for a straight simply supported girder due to a single CHBDC truck loading
n Number of design lanes
$\mathrm{N} \quad$ Number of girders
[P] Applied loads vector at the nodes
$\mathrm{R} \quad$ Radius of curvature of the centre span of the curved bridge
$\mathrm{R}_{\mathrm{L}} \quad$ Multi-lane factor based on the number of the design lanes
$\mathrm{R}_{\mathrm{L}}{ }^{\prime} \quad$ Multi-lane factor based on the number of the loaded lanes
$\mathrm{S}_{\mathrm{G}} \quad$ Girders spacing 
[U] Displacement vector at the nodes

$\mathrm{W}_{\mathrm{c}}$

Deck width

$\mathrm{W}_{\mathrm{e}} \quad$ Width of design lane

$\mathrm{Y}_{\mathrm{b}} \quad$ The distance from the neutral axis to the bottom flange

$\mathrm{D}_{\mathrm{M}}(\mathrm{O}) \quad$ Moment distribution factor for outer girder

$D_{M}(C) \quad$ Moment distribution factor for middle/central girder

$\mathrm{D}_{\mathrm{M}}(\mathrm{I}) \quad$ Moment distribution factor for inner girder

$\mathrm{R}_{\mathrm{M}}(\mathrm{O}) \quad$ Shear/reaction distribution factor for outer girder

$R_{M}(C) \quad$ Shear/reaction distribution factor for middle/central girder

$\mathrm{R}_{\mathrm{M}}(\mathrm{I}) \quad$ Shear/reaction distribution factor for inner girder 


\section{LIST OF TABLES}

Table

Table 4. 1 Effect of the presence of torsion box on the warping-to-bending Stress ratio....86

Table 4. 2 Effect of the presence of torsion box on the moment distribution factors .87

Table 4. 3 Effect of the presence of torsion box on the reaction distribution factors .88

Table 4. 4 Effect of the presence of torsion box on the axial force in bracing members .....89

Table 4.5 Effect of boundary conditions on the warping-to-bending stress ratio.

Table 4.6 Effect of variation of girder flexural stiffness across the bridge section on warpingbending-stress ratio .91

Table 4.7 Effect of the change of flange warping moment of inertia on warping-to-bending stress ratio

Table 4.8a Warping-to-bending stress ratio (WBR) for for $10 \mathrm{~m}$ span three-girder bridges of 2-m girder spacing, with different number of bracing internals and flange width

Table 4.8b Warping-to-bending stress ratio (WBR) for $15 \mathrm{~m}$ span three-girder bridges of 2-m girder spacing, with different number of bracing internals and flange widths.

Table 4.8c Warping-to-bending stress ratio (WBR) for $25 \mathrm{~m}$ span three-girder bridges of 2-m girder spacing, with different number of bracing internals and flange widths.

Table 4.8d Warping-to-bending stress ratio (WBR) for $35 \mathrm{~m}$ span three-girder bridges of 2-m girder spacing, with different number of bracing internals and flange widths.

Table 4.9a Effect of number of girders, girder spacing and L/R ratio on WBR Warping-tobending stress ratio for $10 \mathrm{~m}$ span bridge.................................97

Table 4.9b Effect of number of girders, girder spacing and L/R ratio on WBR Warping-tobending stress ratio for $15 \mathrm{~m}$ span bridge.

Table 4.9c Effect of number of girders, girder spacing and L/R ratio on WBR Warping-tobending stress ratio for $25 \mathrm{~m}$ span bridge................................103

Table $4.9 \mathrm{~d}$ Effect of number of girders, girder spacing and L/R ratio on WBR Warping-tobending stress ratio for $35 \mathrm{~m}$ span bridge............................... 106

Table 4.10 Effect of number of cross-bracing intervals.................................109

Table 4.11 Effect of Effect of area of cross-bracings .................................. 110

Table 4.12 Effect of vertical web stiffeners..........................................111

Table 4.13 Effect of span-to-depth ratio ............................................112

Table 4.14 Effect of number of cross bracing intervals on reaction distribution factors....113

Table 4.15a Effect of girder spacing, L/R ratio and number of girder on Moment Distribution

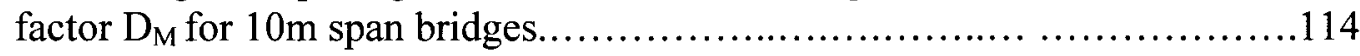


Table 4.15b Effect of girder spacing, $\mathrm{L} / \mathrm{R}$ ratio and number of girder on Moment Distribution

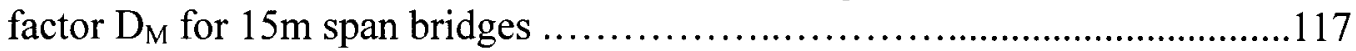

Table 4.15c Effect of girder spacing, L/R ratio and number of girder on Moment Distribution factor $D_{M}$ for $25 \mathrm{~m}$ span bridges ................................................120

Table 4.15d Effect of girder spacing, L/R ratio and number of girder on Moment Distribution factor $D_{M}$ for $35 \mathrm{~m}$ span bridges ......................................................123

Table 4.16a Effect of girder spacing, L/R ratio and number of girder on Reaction Distribution factor $\mathrm{R}_{\mathrm{M}}$ for $10 \mathrm{~m}$ span bridges .......................................126

Table 4.16b Effect of girder spacing, $L / R$ ratio and number of girder on Reaction Distribution

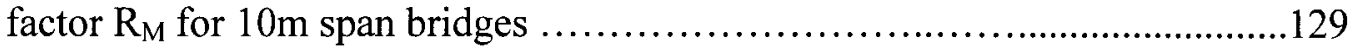

Table 4.16c Effect of girder spacing, L/R ratio and number of girder on Reaction Distribution factor $R_{M}$ for $10 \mathrm{~m}$ span bridges 132

Table 4.16d Effect of girder spacing, L/R ratio and number of girder on Reaction Distribution factor $R_{M}$ for $10 \mathrm{~m}$ span bridges 


\section{LIST OF FIGURES}

FIGURE 1. 1 VIEW OF CURVED AND STRAIGHT STEEL I-GIRDER BRIDGES DURING ERECTION . 142 FIGURE 1.2 HORIZONTAL BRACING IN CURVED STEEL I-GIRDER BRIDGE .................... 14238

FIGURE 1.3 TYPICAL I-GIRDER BRIDGE CROSS SECTION .......................................... 14239

FIGURE 2. 1 WARPING OF STEEL I-SECTION......................................... 140

FIGURE 2. 2 CROSS FRAMES EFFECT ON LATERAL BENDING MOMENTS IN FLANGE............... 140

FIGURE 2. 3 NORMAL STREE DISTRIBUTION IN CURVED I-GIRDER FLANGES ........................ 141

Figure 2. 4 EFFECT OF WARPING MOMENT APPLIED TO I-GIRDER ................................. 141

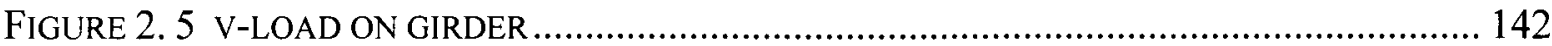

FigURE 2. 6 ASSEMBLAGE OF FINITE SUBDIVISIONS ................................................... 142

FIGURE 3. 1 FINITE ELEMENT REPRESENTATION OF BRIDGE CROSS SECTION AT CONSTRUCTION

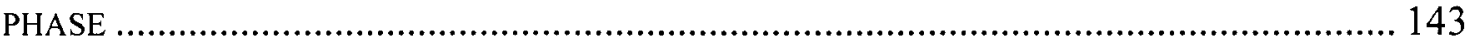

FIGURE 3. 2 PERSPECTIVE VIEWS OF SAP2000 FINITE ELEMENT MODEL FOR 3-GIRDER BRIDGE AT CONSTRUCTION PHASE ...................................................................... 144

Figure 3. 3 SteEl I-GiRders Bridge with Radial Cross Bracings ............................. 145

FIGURE 3. 4 BOUNDARY CONDITIONS FOR THE FINITE ELEMENT MODELS .......................... 145

FIGURE 3. 5 CROSS-SECTION DIMENSIONS OF THE STEEL GIRDER ................................. 146

FIGURE 4. 1 AXIAL FORCES IN BRACING MEMBERS OF A 25-M SPAN BRIDGE WITH VERTICAL BRACINGS ONLY....

FIGURE 4. 2 AXIAL FORCES IN BRACING MEMBERS OF A 25-M SPAN BRIDGE WITH VERTICAL BRACINGS AND TORSION BOX .................................................................... 148

FIGURE 4. 3 EFFECT OF VARIATION OF GIRDER STIFFNESS ON MOMENT DISTRIBUTION FACTOR OF THE OUTER GIRDER 149

FIGURE 4. 4 EFFECT OF VARIATION OF GIRDER STIFFNESS ON MOMENT DISTRIBUTION FACTOR OF

THE INNER GIRDER 149

FIGURE 4. 5 EFFECT OF SPAN LENGTH ON MOMENT DISTRIBUTION FACTOR FOR THE OUTER GIRDER OF CURVED STEEL I-GIRDER BRIDGES 150

FIGURE 4. 6 EFFECT OF SPAN LENGTH ON MOMENT DISTRIBUTION FACTOR FOR THE INNER GIRDER OF CURVED STEEL I-GIRDER BRIDGES 150

FIGURE 4. 7 EFFECT OF GIRDER SPACING ON MOMENT DISTRIBUTION FACTOR FOR THE OUTER GIRDER OF CURVED STEEL I-GIRDER BRIDGES 151

FIGURE 4. 8 EFFECT OF GIRDER SPACING ON MOMENT DISTRIBUTION FACTOR FOR THE INNER

GIRDER OF CURVED STEEL I-GIRDER BRIDGES .... 151

FIGURE 4.9 EFFECT OF NUMBER OF GIRDERS ON MOMENT DISTRIBUTION FACTOR FOR THE OUTER GIRDER OF CURVED STEEL I-GIRDER BRIDGES 152

FIGURE 4.10 EFFECT OF NUMBER OF GIRDERS ON MOMENT DISTRIBUTION FACTOR FOR THE INNER GIRDER OF CURVED STEEL I-GIRDER BRIDGES 152 
FIGURE 4.11 EFFECT OF CURVATURE ON REACTION DISTRIBUTION FACTOR 153

FIGURE 4.12 EFFECT OF NUMBER OF GIRDERS ON REACTION DISTRIBUTION FACTOR FOR OUTER GIRDER. 154

FIGURE 4.13 EFFECT OF NUMBER OF GIRDERS ON REACTION DISTRIBUTION FACTOR FOR INNER GIRDER. 154

FIGURE 4.14 EFFECT OF BRIDGE SPAN ON REACTION DISTRIBUTION FACTOR FOR OUTER GIRDER 155

FIGURE 4.15 EFFECT OF BRIDGE SPAN ON REACTION DISTRIBUTION FACTOR FOR INNER GIRDER

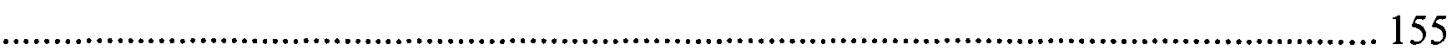

FIGURE 4.16 EFFECT OF GIRDER SPACING ON REACTION DISTRIBUTION FACTOR FOR OUTER GIRDER. 156

FIGURE 4.17 EFFECT OF GIRDER SPACING ON REACTION DISTRIBUTION FACTOR FOR INNER GIRDER. 156 


\section{CHAPTER I}

\section{INTRODUCTION}

\subsection{General}

Curved steel I-girders are frequently used in complex interchanges in today's congested urban areas due to high real state cost, alignment restrictions and excellent serviceability. They allow a smooth traffic flow and eliminate the right of way creating a painless directional transition at interchanges. These are mostly provided at on- and off-ramps of bridges with very tight radii of curvature and are characterized by complex vertical and horizontal geometries. Curved I-girder bridges also provide a very appealing aesthetic shape than the chorded structure and thus are more attractive to conform to the existing terrain. For this reason curved steel I-girder bridges are the preferred choice for practice and an interesting subject of research during the past few decades (Zureick and Naqib 1999).

Nowadays it become possible to design curved bridges with much greater spans because of available technology for design and fabrication while in the early days of curved bridge design and construction, bridge superstructures supporting curved roadway alignment were comprised of short straight girders linked at the supports. This resulted in inefficient use of very short spans between support piers. The cost of the curved girder system employing a series of straight girders is high compared to the total cost of the curved girder bridge system using curved girders, as a substantial portion of the substructure that would be necessary for the straight beams can be eliminated. Furthermore, using continuous curved girders permits 
the use of shallower sections as well as a reduction in the slab overhang of outside girders. However, due to the addition of curvature, the design and construction of bridges becomes immensely more complicated than that of straight bridges. The addition of curvature adds torsion to the system that results in significant warping and distortional stresses within the member cross sections. Furthermore, "secondary members" such as cross frames and diaphragms that provide stability in straight bridges become primary load carrying members in curved bridges. Figure 1.1 shows view of straight and curved steel girder bridges with vertical bracing only, while Fig. 1.2 shows view of the lateral wind bracing system used in some bridges to connect bottom flanges together allover the bridge length.

Although curved steel I-girders perform well in service, they are more susceptible to instability during construction phase than the straight girders and are more likely exposed to erection complications due to their distinct behaviour and three dimensional stress interactions. If proper sequence of erection, adequate bracing and shoring are not provided, torsion, warping and other second-order deformation may be developed which can cause structural deficiencies ranging from misalignment of members to premature yielding of flanges. To address these complications, few studies have been carried out on selected bridge prototypes during construction but there is so much more that need to be investigated further such as warping stresses which are affected by number of girders, spacing of girders, radius of curvature of girders and number of vertical cross-bracings between support lines. 


\subsection{The Problem}

Research has been carried out to evaluate the warping stresses in curved I-steel girders of bridges. Yoo and littrell (1985) developed an equation for the preliminary design of the cross-frame spacing of curved steel I girders. But as pointed out by keller (1994) there were several weaknesses in the research conducted by Yoo and littrell. Davidson et al (1996) has then refined the derived equation by considering the potential parameters such as girder flange width and using more refined mesh syștem and utilizing a more-realistic finiteelement modeling for the braced curved multi-girder system. Davidson et al finally provided the following equation for the maximum spacing of cross-bracing lines by limiting the warping-to-bending stress ratio to 0.25 .

$\mathrm{S}_{\max }=\mathrm{L}\left[-\ln \left(\frac{\mathrm{Rb}_{\mathrm{f}}}{2000 \mathrm{~L}^{2}}\right)\right]^{-1.52}$

Where $S_{\max }$ is the maximum bracing spacing in meters, $\mathrm{L}$ is the span length in meters, $R$ is the radius of curvature in meters, and $b_{f}$ is the flange width in millimeters. This modulation was based on bridges with three curved I-steel girders. In practice curved bridges may have more than 3-girders and the above equation will not be economical to use in this case. Therefore, it is important to examine the applicability of this equation to bridges with number of girders more than 3 . The other drawback of this equation is that it does not include the effect of increasing bridge width on the warping-to-bending stress ratio. Moreover, the equation was developed for a maximum span-to-radius of curvature ratio, $\mathrm{L} / \mathrm{R}$, of 0.5 which is not the case for longer spans. For example, the common practice in USA and Canada is to have the minimum permissible radius of curvature in bridge system 
as $30 \mathrm{~m}$ and $45 \mathrm{~m}$, respectively. In this study a minimum radius of $50 \mathrm{~m}$ was used, leading to a maximum $L / R$ ratio of $0.3,0.5$ and 0.7 for bridge spans of 15,25 and $35 \mathrm{~m}$, respectively.

Clause 10.11.4 of the Canadian Highway Bridge Design Code, CSA-S6-06 (CHBDC, 2006) specifies that bridges shall be examined for control of permanent deflection resulting from unshored construction. CHBDC specifies for composite girders that normal stress in either the top or bottom flanges of the steel section due to serviceability dead and live loads shall not exceed $0.9 \mathrm{~F}_{\mathrm{y}}$ where $\mathrm{F}_{\mathrm{y}}$ is the yield stress of steel. The following equation is specified in CHBDC in this regard.

$$
\frac{M_{d}}{S}+\frac{M_{s d}}{S_{3 n}}+\frac{M_{L}}{S_{n}} \leq 0.90 F_{y}
$$

Where $\mathrm{M}_{\mathrm{d}}$ = bending moment in a girder at SLS (serviceability state) due to dead loads (self-weight and wet concrete); $\mathbf{M}_{\mathbf{s d}}=$ bending moment in a girder at SLS due to superimposed dead loads (asphalt and barriers); $\mathrm{M}_{\mathrm{L}}$ = bending moment in a girder at SLS due to live load (truck loading including DLA); $\mathrm{n}=$ modular ratio; $\mathrm{S}=$ elastic section modulus of a steel section; $S_{3 n}=$ elastic section modulus of the section comprising of the steel section and the concrete slab computed using a modular ratio of $3 \mathrm{n}$; and $S_{n}=$ elastic section modulus of the section comprising of the steel section and the concrete slab computed using a modular ratio of $n$.

Most recently, Al-Hashimy (2005) developed empirical expressions for moment distribution factors for curved composite concrete deck-over steel I-girder bridges under dead load as well as CHBDC truck loading conditions. Figure 1.3 shows schematic view of 
the bridge cross-section analyzed in Al-Hashimy's study. Thus, $\mathrm{M}_{\mathrm{sd}}$ and $\mathrm{M}_{\mathrm{L}}$ values in equation (1-2) can be calculated. However, moment distribution factors for the curved noncomposite girder at the construction phase (i.e. the steel girder only) due to girder selfweight and weight of wet concrete deck slab before hardening are as yet unavailable. Also, Al-Hashimy developed empirical expressions for shear/reaction distribution factors for composite concrete-steel I-girder bridges under dead load and CHBDC truck loading conditions. These equations can be used to examine the ultimate limit state design of the web of composite girder for shear. However, to examine the shear strength of the girder due to self-weight and wet concrete deck, similar expressions for shear distribution factors must be developed for steel girders in the absence of the composite action with the deck slab.

\subsection{Objectives}

The main objectives of this study are:

1. Evaluate warping stresses in curved steel I-girders at construction phase using vertical bracing system only.

2. Evaluate the structural response of the curved steel I-girder at construction phase when strengthened with "Torsion Box" at the support lines.

3. Evaluate the moment and shear distribution factors of the curved steel I-girder at construction stage to assist in examining the bridge for permanent deflection control. 


\subsection{Scope}

The scope of this study included the following:

1. A literature review of previous related studies, books and codes of practice concerning this study,

2. Conducting a parametric study on the effect of key parameters on warping-tobending stresses of girders. The ranges of studied parameters included: radius of curvature, span length, number of girders, girders spacing, cross-bracing intervals, flange width and inclusion of "Torsion Box" at the support lines. The parametric study was performed using the commercially available Finite-Element Software "SAP2000".

3. Conducting parametric study on the moment and shear distribution factors of the steel-girder bridges under self-weight and wet concrete deck to generate database that can be used to develop empirical expressions for this design parameters.

\subsection{Arrangement of the Thesis}

Chapter II introduces a summary of the literature review pertained to analysis of curved bridges as well as warping stresses. Chapter III explains the finite-element approach and SAP2000 modeling for the analysis of curved steel girder bridges. Also, it includes the methodology used to determine the warping-to-bending stress ratio as well as the moment and shear distribution for the curved girders. Chapter VI presents discussions of the results obtained from the parametric study as well as database for the results that can be used to develop empirical expressions for design 
purposes. Chapter V presents the conclusions of this research as well as recommendations for further research. 


\section{CHAPTER II \\ LITERATURE REVIEW}

In curved bridges the curvature has a great effect on the stresses developed in the curved girders. It tends to increase the longitudinal moment in the outside girder, decrease it in the inside girder and have an intermediate effect on the remaining girders and causes torsion and consequently lateral bending (warping) in the flanges. Because the axial forces in the flanges of a curved girder are not collinear, radial forces are developed laterally along the length of the flange to maintain equilibrium. In the compression flange the radial force, that is developed, is directed radially outward and in the tension flange the force is directed in the inward direction. Due to these radial forces developed in each flange, which are equal in magnitude and opposite in direction, a twisting effect about the longitudinal axis of the girder is developed. So in curved bridges I-steel girders are subjected to combined bending and torsion and exhibit unique behaviour as compared to straight girder. Thus for horizontally curved I-girders it is well known that they undergo a coupled lateral bending moment in the flanges which is called torsional warping moment or bimoment. The bimoment induces warping of the cross-section as shown in the Fig. 2.1. This warping of the cross-section causes stresses in the flanges of an I-girder in addition to those resulting from the in-plane bending moment.

During construction phase a curved girder placed on two supports with uplift unrestrained will have a tendency to roll off its supports under the action of gravity. This tendency is caused due to the fact that the centre of gravity of the curved girder is not coplanar with the web of the girder. As a result torsion induced in the girder can twist the 
girder outward. In order to prevent this effect the concentrically arranged girders are connected by a series of cross frames, restraining the girders from twisting and flanges from deflecting laterally at the connection points. Along the un-braced length of the flange between the cross frames, the lateral bending moments cause an out-of-plane bending in the flanges. The magnitude and direction of the lateral bending of the flanges changes dramatically along the span of the bridge reaching to peak at the location of the cross frames where they are in compression at the outside of the curvature and in tension at the inside region. A typical representation of the lateral flange lateral bending moments along the non composite span is shown in Fig. 2.2. In positive lateral-moment regions of the span, such as at the cross frame locations, the bimoment increases the normal compressive stress on the outside of the curvature edge of the flange and decreases stress on the inside. In the interval between cross frames, the direction of the bimoment is reversed, and the highest compressive warping stresses occur on the inside edge of the flanges. These individual and combined warping stresses are shown in the Fig. 2.3. Figure 2.3a shows the in-plane bending stresses only for a flange of a straight girder loaded only in the plane of web, while Fig. $2.3 \mathrm{~b}$ shows the warping stresses due to the bi-moment. Finally, Fig. $2.3 \mathrm{c}$ shows the combined stress distribution in the flange due to bending and warping stresses. The lateral bending moment can be considered a direct measure of the bimoment (warping) in the girder because the lateral bending stiffness of the web can be neglected. The lateral bending moment in figure 2.2 can be seen to vary sharply along the span length with local maximum values at the cross frame intervals and at locations approximately halfway between the intervals. 
Velosov (1961) and Galambos (1968) derived a relation between bimoment and the angle of twist. The bimoment is related to the second derivative of angle of twist in the following form.

$$
\begin{aligned}
& B=E I_{w}\left(d^{2} \theta / d z^{2}\right) \\
& I_{w:}=\int_{t} w^{2} r d x
\end{aligned}
$$

Where $I_{w}=$ torsional warping constant and represents the geometric moments of Inertia with respect to the normalized warping function, or the sectorial coordinate $\omega$; $\theta=$ torsional angle or angle of twist of the cross section; and $\mathrm{z}$ is along the longitudinal axis of the beam. For the doubly symmetric cross section the torsional warping constant can be written as

$$
I_{w}=I_{f} d^{2} / 2
$$

Where $I_{f}=$ moment of inertia of the flange plates only; and $d=$ depth of the section. The bimoment for the I-shaped cross section used can be written as

$$
B=M_{f} d
$$

Where $M_{f}$ = self-equilibrating in-plane bending moments of the flange plates due to warping, usually known as lateral-flange moments.

Steel curved I-girder bridge systems may be more susceptible to instability during construction than bridges constructed of straight I-girders. The stability issue during construction was addressed by few authors (namely: Galambos and Hajjar, 2001; shelling et al, 1989; Davidson et al, 1996; Linzell, 2000). Zureick et al. (1998) showed experimentally the verification of the available numerical methods of analysis of curved girders at 
construction phase. Mclwain and Laman (2000) showed experimentally the behavior of steel I-girder bridges when subjected to a test truck and normal truck traffic. They found that AASHTO specifications are conservative for both dynamic load allowance and transverse bending moment distribution. The grillage models, developed by researchers, were found to predict with reasonable accuracy the behavior of a curved I-girder bridge.

\subsection{Review of Previous Research on Curved Steel Bridges}

\subsubsection{General Review of Research work}

Since the first work in 1843 on the analysis of curved beams presented by Barre' de Saint Venant, numerous articles appeared on the curved beams and girders analysis. Prior to 1960s, minimal design and construction of horizontally curved steel bridges occurred simply because of complicated calculation work and lack of specifications for the structural behaviour of these bridges. Curved bridges were used only when chorded structure proved to be uneconomical. Despite lack of specifications and regularities the advantages of curved steel girders were recognized after 1960s and curved bridges started its evolution. Serious design work for horizontally curved bridges has begun in 1969 when United States Federal Highway Administration (FHWA) formed the Consortium of University Research Teams called CURT. CURT was a large scale research project funded by 25 states of the United America and managed by United states Federal Highway Administration (FHWA). CURT conducted a series of scale model laboratory tests followed by theoretical work and analytical studies. CURT reviewed all existing publications on curved bridges and 
incorporated research results from ongoing states agency sponsored projects. Theoretical and analytical work completed by CURT projects focused on the following:

a) Overall strength of doubly symmetric curved girder I sections in bending (McManus 1970)

b) Local buckling behaviour of curved girder flanges (Nasir, 1970)

c) Behaviour of web panels in flexure (Brogan 1974, Culver et al 1972, 1973).

These research works by CURT resulted in a tentative set of Specification for Allowable stress design (ASD) of curved girder bridges (Culver, 1972; CURT, 1973)

The CURT research activity was followed by the development of Load Factor Resistance Design criteria by AASHTO. After CURT work the Task committee of ASCE-AASHTO combined the CURT specifications and the work conducted by AASHTO in the mid 1970s. They proposed AASHTO guide specifications. Load Factor Design (LFD) criteria were added to the specifications in 1973 which was called AASHTO Standard Specifications for Highway Bridges. LFD was the result of a research project sponsored by AISI (American Iron and Steel Institute). The first edition of AASHTO Specifications was published by incorporating the ASD and LFD criteria in 1980, called Guide Specifications. These Specifications were divided into two parts. Part I for ASD and Part II for LFD. After this initial edition the second edition was published in 1993 with eight revisions. FHWA in 1992 initiated a project. The goals of this project were as follows:

a) Collect and disseminate all curved bridges research in US and abroad

b) Address the behaviour of curved steel I girders experimentally and analytically in bending, shear and combined bending and shear. 
c) Address the construction issue for curved bridges

This project resulted in extensive research works and produced a number of research publications (Zureick et al., 1994; Linzell, 1999; Zureick, et al. 2000; Jung and White, 2001; Zureick et al., 2001).

National Cooperative Highway Research Program (NCHRP) initiated a project in 1993 to develop a set of improved specifications which is called Recommended Specifications (Hall and Yoo, 1998). The result of this project was published in NCHRP Report 424 (Hall et al., 1999). The recommendations of this reports were adopted by AASHTO in 1999 with minor modifications as a new Guide Specifications for Horizontally Curved Steel Girder Highway Bridges which is referred as 2003 Guide Specifications.AISI and FHWA jointly initiated a third project in 1999 which resulted in a research report providing an extensive review and discussion of the Curved I girder strength design equation and a set of modifications to AASHTO LRFD Bridge Design Specifications (AASHTO, 2001). A fourth project by NCHRP has been conducted resulting in recalibrating the 2003 Guide Specifications so that LRFD can be applied to Curved Steel Bridges. The 2003 Guide specifications include more detailed discussion related to the use of the specification and examples: one for a curved I girder bridge and one for curved box girder bridge. These specs include in-depth discussion for procedures for the preliminary and final analysis and design of curved steel bridges. 


\subsubsection{Canadian Highway Bridge Design Code 2000 (CHBDC)}

The Canadian Highway Bridge Design Code CAN/CSA-S6-06 (CHBDC) is the $10^{\text {th }}$ edition of the CSA Standard CAN/CSA-S6. It has superseded the first edition of CHBDC CAN/CSA-S6-00 which is the $9^{\text {th }}$ edition of CAN/CSA-S6. Also, it superseded the CAN/CSA-S6-88 (Design of Highway Bridges) and the OHBDC-91-01 (Ontario Highway Bridge Design Code $3^{\text {rd }}$ Edition). Ontario Ministry of Transportation has published the earlier editions of the Ontario Highway Bridge Design Code (OHBDC) in 1983 and 1979 while earlier editions of the CSA Standards were published in 1922, 1929, 1938, 1952, 1966, 1974 and 1978.

CAN/CSA-S6-06 uses the limit state design philosophy and introduced simplified methods for the analysis of different types of bridges after satisfying certain conditions. Using simplified methods of analysis CAN/CSA-S6-00 defines the lateral load distribution factors as amplification factors that are used to account for the transverse variation in maximum longitudinal moments and shear intensities. The moment distribution factor is $F_{m}$ and defined as:

$$
F_{m}=\frac{S N}{F\left(1+\frac{\mu C_{f}}{100}\right)} \geq 1.05
$$

And the shear distribution factor is $F_{v}$ and defied as:

$F_{v}=\frac{S N}{F}$ 
Where $\mathrm{S}$ is center to center girders spacing in meters, $\mathrm{N}$ is number of girders, $\mathrm{F}$ is a width dimension that characterize load distribution for a bridge, $C_{f}$ is a correction factor, in $\%$ obtained from tables in CHDBC, and $\mu$ is:

$$
\mu=\frac{W_{e}-3.3}{0.6} \text { but } \leq 1.0
$$

Where $W_{\mathrm{e}}$ is the width of the design lane in meters.

CHDBC-2006 also provides the following guidelines in the simplified method:

1) A curved bridge can be treated as a straight bridge in if $L^{2} / b R$ ratio is not greater than 0.5 .

2) The maximum span for curved girder should not be greater than 60 meters

3) Warping to Bending stress (WBR) ratio should not exceed 0.5

4) Un-braced length between cross frame should not exceed 25 times the width of the flange or 0.1 times the mean radius of the girders.

\subsubsection{Other Research Studies}

\subsubsection{Heins and Siminou's Study}

In their study, Heins and Siminou (1970) presented and explained a simplified method for evaluating the internal forces and deformations in radial curved girder system. They introduced equations and factors that permit the determination of required crosssectional properties in a single, two, and three-span curved girder system, which are necessary in utilizing various computer programs. A series of factors were developed by comparing single straight; single curved; and curved system. They used AASHTO HS20-44 
truck loading, and utilized two, three, and four trucks for four, six and eight girder system respectively. The introduced factors were:

Amplification Factor, $K_{1}=\frac{f_{s c}}{f_{s s}}$,

Distribution Factor, $K_{2}=\frac{f_{c s y}}{f_{s c}}$,

Reduction Factor, $K_{3}=\frac{f_{c s y}}{f_{s c}}$

Where $f_{s c}$ is the reaction on a single curved girder, $f_{s s}$ is the reaction on a single straight girder, and $f_{c s y}$ is the reaction on a system of curved girders. The studies, which were conducted, resulting in design equations, have the following limitations:

1. Girder spacing may be $2.1,2.4,2.7$ or $3 \mathrm{~m}$.

2. Individual girder span lengths varied from 15 to $30 \mathrm{~m}$.

3. The girders of the system must have a constant curvature limited to radii of 30 to $180 \mathrm{~m}$.

4. The number of girders in the system may be 4,6 or 8 .

5. Only two-and three-span continuous bridges were examined, with all interior end spans of equal length.

Heins and Siminou's concluded their study by introducing design charts for modification factors of moment, shear, deflection, rotation, and warping torsion. 


\subsubsection{Heins and Jin's Method}

Conrad and Jin (1984) studied the effect of cross bracing spacing on curved bridge distribution factors. They studied both single-span and continuous span girder systems for bridges. The response of live loads on these bridges was idealized by constructing a space model and used grid analysis for obtaining their results. They produced a number of graphs and equations that correlate the effect of the cross-bracing and distribution factor. The drawbacks of their works are: (i) The range of the bridge spans considered in their models were $(36 \mathrm{~m}$ to $90 \mathrm{~m})$ which are not practical for slab on steel I-girder bridges; and (ii) their empirical equations could be applied to the results obtained by 2-dimentional grid analysis method which means grillage analysis has to be conducted on the curved girder system leading to a length design procedure.

\subsubsection{Yoo and Littrell's Study}

Yoo and Littrell (1985) investigated five-girder horizontally curved bridge. They identified the relation between cross frame spacing and warping stress reduction of I-steel girders. They used finite element software (SAP) to study the response of I- girders bridge connected by cross bracing under dead load and live load. They considered different parameters like radius of curvature, length of girders and number of braced intervals. They developed empirical design equations to predict the ratio of: (a) Maximum bending stress; (b) maximum warping stress; and (c) maximum deck deflection. They concluded that (1) maximum bending stresses and maximum deck deflections stabilized with minimal bracing; (2) warping stresses were sensitive to the number of braced intervals. They also observed that partially loaded lanes; 2 trucks out of 3 trucks (deck width capacity) located near the 
outside edge of the bridge produced higher stresses and deflection in the curved bridges due to the tilting of the bridge deck created by the nonsymmetrical load distribution. They developed the following expression for the following expression for the maximum crossbracing spacing in the five-girder bridge as a function of warping-to-bending stress ratio, $F_{w s}$, bridge mean span, $L$, and mean radius or curvature, $R$.

Spacing $=\left[-\ln \left(\frac{F_{w s}}{18.890} \frac{R}{L}\right)\right]^{-1.3364}$

The drawback in this equation is as follows:

b. Only five-girder bridges of width $11.85 \mathrm{~m}$ and girder spacing of 2.7 were analyzed. However, warping stresses are expected to be greater in case of one-lane curved bridges and bridges with less number of girders (i.e. three girder for example). Also, smaller girder spacing may reduce bridge width in case of two-lane bridge cross-section leading to greater warping stresses.

c. Girder flange width was maintained constant (i.e. $45.7 \mathrm{~mm}$ ). However, increasing flange width or flange warping constant would decrease flange warping stresses.

d. Warping stresses were obtained for the composite concrete deck-over-steel Igirder system under dead load. This may be applicable in case of shored construction However, warping stresses may be larger when the braced steel girders carry their self-weight and weight of wet concrete before hardening in case of un-shored construction.

e. The finite-element modeling of the analyzed curved five-girder bridges, conduced by SAP VI software, composed entirely of eight-noded brick elements and truss elements. Also poor mesh refinement was observed since 
stresses were always measured at the mid-point of the elements, indicating that SAP VI software also approximates the beam element forces from the two end moments. This fact brings question to the refinement of the mesh used in their models.

f. In their regression analysis to estimate the reduction in warping stress with increasing number of cross-bracing intervals, no account was taken of the span length. The only variable associated with the regression was the number of braced intervals and the $L / R$ ratio.

\subsubsection{Brockenbrough's Study}

Brockenbrough (1986) conducted analytical research utilizing a 3-dimensinal finiteelement model and presented the effect of various parameters on the load distribution for 4-girder curved bridges. He investigated a 2-span continuous structure, symmetrical about a central radial pier with simple and radial end supports. The bridge comprised of composite concrete deck with steel I-shape girder and intermediate transverse cross frames between girders. His findings were as follows: (1) the central angle per span, which includes the combined effect of curvature and span length had larger effects, (2) the girder spacing, had larger effects identified; (3) variation in girder stiffness and cross-frame spacing had relatively small effects on live-load distribution factors. Brockenbrough also provided charts showing the variation of the distribution factors with the variation of these parameters. 


\subsubsection{Schelling et al's Study}

Schelling and Namini (1989) studied the response of simple and continuous span horizontally curved steel I-girder bridges with and without top and bottom cross bracing when subjected to self weight as well as the application of the concrete deck. 3-Dimensional space frame model for single span as well as continuous spans were used to determine the effect of the lateral bracing on curved bridges during construction. Their investigations resulted in a set of empirical equations for two, four, and six girders bridges. These equations define the dead load distribution throughout the superstructure system. They showed that the results from the simple-span can be applied conservatively to the continuous span bridges provided that the supports and radial span length ratios do not differ greatly from unity. The drawbacks of their works are:

a. Their empirical equation is to be used in conjunction with the results given by the 2-dimentional grid analysis method.

b. The range of the bridge spans considered in their models were $(36 \mathrm{~m}$ to $90 \mathrm{~m})$ which are not practical for slab on steel I-girder bridges.

\subsubsection{Davidson et al's study}

Davidson et al. (1996) investigated the effect of a number of design parameters including cross-frame spacing, span length, girder depth, number of girders, flange width, girder spacing and degree of curvature on the behavior of horizontally curved steel I-girder bridges. Their model comprised of 3-girder Bridge. They used shell elements to model the concrete deck and girders webs, whereas they used beam elements to model flanges, shear 
connectors and cross frames. ABAQUS, finite-element software, was utilized for their investigation. Their study resulted with the conclusions that the span length, radius of curvature, flange width and cross frame spacing have the greatest effect on the warping-tobending stress ratio. Based on this information, a regression analysis was performed to predict the effect of these parameters on the warping-to-bending stress ratio. Finally an equation was developed from this regression and proposed for the preliminary cross-frame spacing design:

$\mathrm{S}_{\max }=\mathrm{L}\left[-\ln \left(\frac{\mathrm{Rb}_{\mathrm{f}}}{2000 \mathrm{~L}^{2}}\right)\right]^{-1.52}$

Where $S_{\max }$ is the maximum bracing spacing in meters, $\mathrm{L}$ is the span length in meters, $R$ is the radius of curvature in meters, and $b_{f}$ is the flange width in millimeters.

The drawback of this equation is as follows:

b. The database used to develop this expression included only the threegirder bridge with girder spacing of $3.0 \mathrm{~m}$. The means that the equation covers only two-lane bridges of about $7.925 \mathrm{~m}$ bridge width. However, warping stresses may be greater for smaller bridge width (i.e. one-lane bridge width) or smaller girder spacing in the order or $2 \mathrm{~m}$.

c. The effect of varying the girder depth on warping stresses was not included in their study. However, the bi-moment is directly proportional to the torsional warping contact that is proportional to the square of the depth of the girder. 
d. It was not clear whether the girder depth was maintained constant if the finite-element modeling irrespective of changing the bridge span from 15 to $45 \mathrm{~m}$.

\subsubsection{McElwain and Laman's study}

McElwain and Laman (2000) showed experimentally the behavior of steel I-girder bridges subjected to a test truck and normal truck traffic. Numerical grillage models of three bridges were developed to determine if a simple numerical model will accurately predict actual field measured transverse bending distribution, de-flections, and cross-frame and diaphragm shear forces. They found that AASHTO specifications are conservative for both dynamic load allowance and transverse bending moment distribution. The grillage models were found to predict with reasonable accuracy the behavior of a curved I-girder bridge.

\subsubsection{Depolo's and Linzell's study:}

Depolo and Linzell (2002) studied the influence of live load on the lateral flange bending distribution for horizontally curved I-girders. Their findings were as follows:

- Live load lateral bending distribution factors in the positive moment region, calculated at three radial cross sections of girder, have similar trend to factors calculated using modified AASHTO factors with differences on the order of 10-30\%. When maximum values for each girder were examined the trends were identical for 4 of the 5 girders with only a 3 to $4 \%$ difference between factors. 
- The 1993 AASHTO Guide Spec. LBDF's produced conservative factors for all static tests at the examined radial cross sections. However, when maximum LBDF's from the numerical model and modified AASHTO procedure were compared to the 1993 AASHTO Guide Spec. LBDF equation, resulting LBDF's were reasonably close with levels of conservatism.

\subsubsection{Zhang's study}

Zhang (2002) studied the load distribution factors for curved I-girder bridges. He used the finite-element method for the analysis work and utilized the AASHTO truck loading. A total of 111 bridge models with radius of curvature less than $450 \mathrm{~m}$ were selected in his study. The following parameters were considered in his study:

$>$ Radius of Curvature: 45 to $450 \mathrm{~m}$;

Girder spacing: 1.8 to $5.0 \mathrm{~m}$;

Span length: 15 to $70 \mathrm{~m}$;

Slab thickness: 170 to $300 \mathrm{~mm}$;

Longitudinal stiffness: 32122 to $72226 \mathrm{~cm}^{4}$;

$>$ Number of girders: 3 to 7 ;

$>$ Cross frame spacing: 2 to $7 \mathrm{~m}$;

He showed that radius of curvature, girder spacing and number of girders had significant effect on the load distribution and span length, slab thickness, and longitudinal stiffness had slight effect. The effect of cross frame spacing and girder torsional inertia could be 
neglected. There is a similar trend in the shear distribution factors as that of moment distribution factors. It was quoted that the shear distribution factor of the outside exterior girder positive moment as per AASHTO Guide method (1993) for multiple-lane loading were less conservative as compared to the FEM analysis. However, the results obtained from AASHTO Guide Commentary were too conservative for other cases. Mr. Zhang developed simplified equations for positive moment, negative moment, and shear distribution factors for exterior and interior girders due to one-lane loading and multiple-lane loading. AASHTO-LRFD formulas for straight bridges led to either larger or smaller results when used for curved bridges. The Heins and Jin's formula was too conservative for all cases. Mr. Zhang's proposed formulas are recommended for preliminary design of curved steel girders bridges. As the formulas are calibrated with less number of real bridges so it could be applied accurately to bridges with similar restraints. For more accurate results detailed analysis id recommended for bridges with special cases or beyond the application ranges proposed by Zhang.

\subsubsection{Wassef's study}

Wassef (2004) has conducted a study on 192 simply supported straight and curved concrete slab-on-steel I-girder bridge prototypes to evaluate their structural response. His study showed the influence of several parameters on the moment, deflection, and warping stress distribution. He modeled these bridges in commercially available finite-element computer software SAP2000. In his study the bridge models were subjected to the Canadian Highway Bridge Design Code (CHBDC) CL-625 truck and lane loading and dead loading. The study considered the following parameters:

Span length: 15,25 , and $35 \mathrm{~m}$; 
$>$ Girder spacing: 2, 2.5, and $3 \mathrm{~m}$

$>$ Number of girders: $3,4,5,6, \& 7$ for $2 \mathrm{~m}$ girder spacing; $3,4,5, \& 6$ for $2.5 \mathrm{~m}$ girder spacing; 3, 4 \& 5 for $3 \mathrm{~m}$ girder spacing;

$>$ Span-to-radius ratio, $\mathrm{L} / \mathrm{R}: 0.0,0.1,0.2, \& 0.3$ for $\operatorname{span} \mathrm{L}=15 \mathrm{~m} ; 0.0,0.1,0.3, \& 0.5$ for $\operatorname{span} \mathrm{L}=25 \mathrm{~m} ; 0.0,0.1,0.4, \& 0.7$ for $\operatorname{span} \mathrm{L}=35 \mathrm{~m}$

The study showed the following:

(1) Curvature is the most critical parameter that influence the design of curved bridges;

(2) Parameters like span length, number of girders, and girder spacing affect the values of the moment and deflection distribution factors in general; (3) Loading the bridge with truck live loadings in all lanes does not necessary produce the extreme design values of the moment or deflection distribution factors; (4) warping-to-bending stress ratio values were acceptable and within the limits, except for bridge with $L / R$ ratio 0.7 and span length 35m; (5) CHBDC moment and deflection distribution factors underestimate the structural response of curved bridges as straight ones.

\subsubsection{Yoon et al's study}

An analytical study was carried out Yoon et al (2004) to study the effects of free vibration response of the horizontally curved steel I-girders. They considered seven degrees of freedom for each node of girders both ends including the warping degree of freedom. They considered Kang and Yoo's thin walled theory for the derivation of curved beam element. They used finite element software ABAQUS for the free vibration analysis. They composed the stiffness and the mass matrix of the curved and straight beam element 
including the warping degree of freedom and a computer program was developed to conduct a parametric study.

They concluded the following:

- The natural frequency of the bridge tends to decrease as the subtended angle becomes larger except the torsional behaviour.

- In the in plane behaviour, the natural frequency is affected with the constraint direction.

- Unlike straight bridges, the natural frequency is influenced by stiffness of cross frames especially in the out-of-plane behaviour.

\subsubsection{Nasr et al's study}

Nasr et al (2004) investigated the live load distribution on the curved steel I-girder bridges. They utilized the finite-element method to study the effect of wheel load distribution on various parameters. A parametric study was carried out using the selected finite element model to calculate the lateral load distribution factors based on AASHTO live loads. The parameters considered in this study were: radius of curvature, girder spacing, span length, slab thickness, number of girders, cross frame spacing, overhang width and girder longitudinal and torsional stiffness for curved steel I-girder bridges. The following conclusions were drawn by this study: 
- It was found that the distribution factors of outside exterior girder positive moment obtained from AASHTO (1993) Guide Commentary were un-conservative in some cases and conservative in other cases.

- The outside exterior girder has always the most maximum value of moment and twolane loading would generally produce the maximum girder response.

- It was showed that the for variable bridge width the radius of curvature, span length, girder spacing and distance from the centre of exterior girder to the inside edge of traffic barrier has a significant effect on the distribution factors.

\subsubsection{Al-Hashimy's study}

Al- Hashimy (2005) conducted a parametric study on various simply supported straight and curved slab-on-steel I-girder bridges to find out their structural behaviour and response. Using commercially available SAP2000 software. He modelled 320 prototype straight and curved bridges and examined the influence of several parameters on moment, shear, deflection and warping stress distribution. In his study the bridge prototype models were subjected to the Canadian Highway Bridge Design Code (CHBDC) CL-625 truck and lane loading and dead loading. The following parameters were considered in his study:

i. Span length: $10,15,25$, and $35 \mathrm{~m}$;

ii. Girder spacing: $2,2.5$, and $3 \mathrm{~m}$

iii. Number of girders: $3,4,5,6, \& 7$ for $2 \mathrm{~m}$ girder spacing; $3,4,5, \& 6$ for $2.5 \mathrm{~m}$ girder spacing; 3, 4 \& 5 for $3 \mathrm{~m}$ girder spacing; 
iv. Span-to-radius ratio, $\mathrm{L} / \mathrm{R}: 0.0,0.1,0.2, \& 0.3$ for $\operatorname{span} \mathrm{L}=15 \mathrm{~m} ; 0.0,0.1,0.3, \& 0.5$ for $\operatorname{span} \mathrm{L}=25 \mathrm{~m} ; 0.0,0.1,0.4, \& 0.7$ for $\operatorname{span} \mathrm{L}=35 \mathrm{~m}$

The study findings were:

1. Curvature is the most critical parameter which plays an important role in determining the lateral distribution factors and warping-to-bending stress ratio. The change in the span-to radius of curvature ratio $(L / R)$ leads to significant change in the shear distribution factors and warping-to-bending stress ratio for different girders.

2. The number of girders and girders spacing also affect the lateral load distribution factors. In general, the increase in the number of girders, as well as in girders spacing results in an increase in the shear distribution factor, moment distribution factor, and deflection distribution factor.

2. Span length affects slightly the shear distribution factors; however, span length shows significant effect when the $L / R$ ratio exceeds 0.10 .

3. There is a small effect on the shear distribution factors when The number of crossbracing intervals are over 3 ,

4. This study showed that CHBDC significantly underestimates the structural response of curved bridges by treating them as straight bridges when $L^{2} /(b . R)$ is not greater than 1. 


\subsubsection{Howell and Earl's study}

Howell and Earls (2007) investigated the effects of web plumbness under steel girder self loading condition during construction stage. They use finite element program ADINA to model three span bridge prototypes to find out the effects of the web rotation during construction. They considered web out of plumbness magnitude of $5^{\circ}$. They conclude that by increasing the web out of plambness will increase the lateral and vertical deflections. The outer most girder with longest span show the greatest amplification of deflection with the $2^{\circ}$ out-of-plumb case resulting in increase of the midspan total deflection of as much as $100 \%$ when subjected to steel dead load. The results of this investigation confirm the performance effects of increasing degrees of web out of plumbness in terms of flange tip stresses, lateral deflections, and cross-frame demands, within a typically proportioned curved bridge. They recommend more analysis work for the curved I-girders during construction stage.

\subsubsection{Barr and Womack's study}

Barr and Womack (2007) studied a three span curved five I-girders bridge. They observed the response of the bridge to live loads under three boundary condition states. For each boundary condition the response was then compared with calculated values using finite element models comprised primarily of shell elements. The finite element design moments 
were compared with those calculated using V-load method. They concluded results of the load test and analyses to the following:

- The calculated maximum positive and negative strain for each girder was within $5 \%$ of the positive measured strains but the overall comparison was much closer.

- By severing the integral approach slab and barriers increased the strains by an average of less than $2 \%$.

- Overall positive moment calculated using V-load method was $6.8 \%$ un-conservative for the exterior girders and $8.3 \%$ conservative for the interior girders in comparison with those calculated using finite element method.

- The difference between the negative moment of the V-load and finite element method is larger than the positive moment comparison.

\subsection{Review of Elastic Behaviour of Curved I- Girder System}

Since from long time the behavior of thin-walled members of open cross-section under flexure and torsion has been known and can be found in many books of elementary mechanics. Nakai and Yoo (1988) had presented a comprehensive work on the basic theory of thin-walled beams, including flexure, torsion, distortion, and stress distribution, in "Analysis and Design of Curved Steel Bridges". Curved bridges experience torsional forces that results in significant warping and distortional stresses within its member cross sections. Cross bracings (or diaphragms), provided in curved steel I-girder bridges, resist these warping stresses and become primary load carrying members. Correspondingly, cross bracings introduce restoring torques to the girders and therefore cause non-uniform torsions in the girders. The torsions are resisted partly by St.-Venant torsion and to some extent by 
warping torsion. The warping causes lateral bending moment of the top and bottom flanges. The product of the lateral flange moment and lever arm of the couple (less than girder depth) is often referred to as bimoment (in the unit of force $\mathrm{x}$ length ${ }^{2}$ ). This bimoment causes twisting of the curved girders about their longitudinal axes. For compression flange, the axial flange force tends to accentuate curvature while the lateral flange bending moment tends to reduce it. However, the net effect is always to increase curvature of the compression flange. For tension flange, the axial force tends to reduce the curvature and the lateral flange bending moment tends to increase it. The net effect can be either to increase or decrease the curvature of the tension flange, depending on flange stress and stiffness. To estimate the flange lateral bending moment, $M_{L A T}$, two approximate methods: AASHTO Guide Specifications for Horizontally Curved Bridges (1993) and V-load method (Grubb, 1986) can be used which are presented below.

\subsubsection{AASHTO Guide Method}

The expression for the flange lateral bending moment, $M_{L A T}$, according to AASHTO Guide (1993) is given as follows:

$M_{L A T}=M_{S} \times D F_{B} \times D F_{B i} \times\left[\frac{(0.35 \mathrm{~L}-15)}{0.108 \mathrm{~L}-1.68} \times \frac{\mathrm{L}}{\mathrm{DR}}\right] / \mathrm{D}^{\prime}$

Where

$\mathrm{M}_{\mathrm{s}}$ is the equivalent straight girder moment due to truck load, which straight girder will have a length equal to the arc length of the curved girder;

$D F_{B}$ is the distribution factor for bending moment;

$D F_{B i}$ is the distribution factor for bimoment; 
$D$ is the girder depth in feet; $R$ is the radius of curvature in feet; $L$ is the span length in feet; and $D^{\prime}$ is the arm from the centroid of girder top flange to the centroid of girder bottom flange in feet. This equation should satisfy that the radius of curvature is greater than $30 \mathrm{~m}$.

\subsubsection{V-Load Method}

The expression for the flange lateral bending moment, $M_{L A T}$, according to V-Load Method is as follows:

$$
\mathrm{M}_{\mathrm{LAT}}=\mathrm{MV}_{\mathrm{V}} \mathrm{x}\left[\frac{L^{2}{ }_{\mathrm{UN}}}{10 \mathrm{DR}}\right]
$$

Where $M_{V}$ is the vertical moment of curved girder, and $L_{U N}$ is the unbraced length.

The exact solution of lateral flange moment is discussed in the following sections.

From the classic strength of material theory, St. Venant torque, $T_{P}$, is commonly expressed in terms of the torsional rotation, $\emptyset$ at any cross section as

$$
T_{P}=G J \frac{\mathrm{d} \emptyset}{\mathrm{dx}}
$$

Where $\mathbf{J}$ is the St. Venant torsion rigidity; $\mathrm{G}$ is the elastic modulus in shear; $\mathbf{x}$ is measured along the member.

From warping theory, the warping torque, $T_{w}$, as shown in Fig. 2.4 can be expressed as:

$$
T_{w}=V h
$$

Where $V$ is the lateral shearing force in the flanges as shown in Figure 2.5; and $h$ is the distance from the top flange-shearing center to the bottom flange-shearing center. The equation of equilibrium for torsion of a thin-walled member is then 
$G J \frac{d \emptyset}{d x}+V h=T$

Where $\mathrm{T}$ is the total torsion at the cross section.

From the elastic curve equation, lateral bending moment in the lateral direction of the upper flange in Figure 2.4 is

$$
\frac{E I_{y} d^{2} y}{2 d x^{2}}=-M
$$

in which the $\mathrm{X}$ and $\mathrm{Y}$ axes are chosen with positive directions as shown in Figure 2.4; $M$ is the lateral bending moment in the flange at any section producing lateral bending in the flange; $E$ is the modulus of elasticity in tension or compression; and $\mathrm{I}_{\mathrm{y}}$ is the moment of inertia of the entire cross section of the beam with respect to the axis of symmetry in the web so that $1 / 2 I_{y}$ closely approximate the value of the moment of inertia of a flange cross section. In Figure 2.4, the deflection of the flange at section $A B$ is

$y=(h / 2) \varnothing$

Differentiation of Equation 2.26 twice with respect to $x$ gives

$$
\frac{d^{2} y}{d x^{2}}=\frac{h d^{2} \varnothing}{2 d x^{2}}
$$

Substituting this value of $\mathrm{d}^{2} \mathrm{y} / \mathrm{dx}^{2}$ into Equation 2.25 gives

$$
\frac{E I_{y} h d^{2} \varnothing}{4 d x^{2}}=-M
$$


Since $\mathrm{dM} / \mathrm{dx}=\mathrm{V}$ by differentiating both sides of Equation 2.28 with respect to $\mathrm{x}$ we obtain $\frac{E I_{y} h d^{3} \varnothing}{4 d x^{3}}=-V$

Substituting the value of $\mathrm{V}$ in Equation 2.29 into Equation 2.24, this then becomes

$\mathrm{JG} \frac{\mathrm{d} \varnothing}{\mathrm{dx}}-\frac{E I_{y} h^{2} d^{3} \varnothing}{4 \mathrm{dx}^{3}}=\mathrm{T}$

Let $I_{w}=E I_{y} h^{2} / 4$, the warping torque can be written as

$T_{w}=-E I_{w} \frac{d^{3} \emptyset}{d x^{3}}$

And Equation 2.30 can be rewritten as

$E I_{w} \frac{d^{4} \varnothing}{d x^{4}}-G J \frac{d^{2} \varnothing}{d x^{2}}=t$

Where $t$ is the distributed torque applied to the member; and $E I_{w}$ is warping rigidity.

Equation 2.32 along with two boundary conditions at each end can be used to describe the behavior of a thin-walled member subject to torsion. The boundary conditions at each end may be the rotation $\emptyset$ and warping $\mathrm{d} \emptyset / \mathrm{dx}$.

\subsection{Review of Analysis Methods for Curved System}

In practice, the exact solution of the above Equation 2.32 is neither easy nor simple. Therefore it is important to use other types of solutions which could be easier and accurate. The analysis methods found in the literature can be classified into two major categories: approximate and refined methods as follows, Zureick and Naqib, (1999): 


\subsubsection{Approximate methods}

Approximate methods are adequate for preliminary analysis and design purposes as it require minimal modeling efforts and are adequate for preliminary analysis and design purposes. The following are some of approximate methods which are most frequently used in the analysis of curved bridges:

- The Plane-grid method

- The Space-frame method

- The V-load method

\subsubsection{The Plane-grid or Grillage method}

Lavelle and Boick introduced this method in year 1965 and further developed in 1975 by Lavelle and Lasks. This method models the structure as an assemblage of twodimensional grid members. Each node of grid member has one translational and two rotational degrees of freedom. Plane grid method is the most appropriate approach but it does not account for warping (Zureick and Naqib, 1999). This method has the following advantages:

1) No integration of stresses are required, shear and moment values on girders can be obtained directly;

2) When loads are applied between the nodal points, simple beam theory can be used to distribute the wheel load to adjacent nodes; 
3) With a plain grid idealization the computer running time is comparatively short and only moderate effort is required for modeling.

Whereas the disadvantages of this method are:

1) This method is a non-rigorous and does not exactly converge to the exact solution of the mathematical model;

2) Hands on experience is required with the grillage method in order to obtain good solutions; and

3) Some discretion is required for assigning the cross section properties.

\subsubsection{The Space-frame method}

This method was first introduced in 1973 by Brennan and Mandel for the analysis of open and closed curved members. In this method the curved members are assumed as threedimensional straight members. Also the diaphragms and lateral bracing are assumed as truss members that can carry only axial loads. The warping effect is not usually included in this analysis (Zureick and Naqib, 1999), which makes this method practical only for preliminary design.

\subsubsection{The V-Load method (Grubb 1984)}

The V-Load method is a simplified approximate analysis method for curved I-girder bridges which is developed in the early 1960's. The V-load method is based on following two assumptions: 
- The curved structure is assumed to be straightened out so that the applied vertical loads are assumed to induce only ordinary bending stresses.

- Fictitious forces are applied to the straight structure so that the resulting internal forces are the same as that of the curved structure when subjected to vertical loading only.

To satisfy the requirement of static equilibrium the applied fictitious forces must be determined to get a no net vertical, longitudinal or transverse forces on the total structure. Thus in the V-load method the curvature forces on the equivalent straight structure are treated as self-equilibrating externally applied loads. These loads are dependent on the radius of curvature, the bridge width, and diaphragm spacing (refer to Equation 1.1 or 2.19). The V-load method was found suitable for approximate analysis of composite sections, variable radius of curvature, and skewed supports. The effects of bracing in the plane of the bottom flange are not considered. The dead load results obtained from the V-load method were proved to be very close to those obtained from the FEM analysis. For live load, the lateral load distribution factor used in the V-load analysis has a significant influence on the results. However; the V-load method has some drawbacks which are as follows:

- The V-Load method is not valid when lateral bracings are present,

- It is not accurate in predicting diaphragm shear forces (McElwain and Laman, 2000);

- It underestimate the innermost girder stresses,

- It does not consider bracing effect in the plane of the bottom flange,

- Its reliability depends on the selection of the proper live-load distribution factors. 
Thus the V-load method can only be recommended for preliminary analysis (Zureick et. al. 1998).

\subsubsection{Refined methods}

The refined methods are more accurate, computationally intensive, and time consuming in terms of modeling. These methods are used for final or detailed analysis after preliminary work. Some major refined methods are as follows:

The Finite-strip method

The Finite-difference method

Analytical solution to governing differential equations

The Slope deflection method

The Finite-element method

\subsubsection{The Finite-strip method:}

This method was developed in the late sixties. The philosophy of this method is more similar to Kantorovich method which is used mainly for reducing the partial differential equations to ordinary or partial differential equations of a lower order. This method, first developed in the context of thin plate bending analysis, is a semi-analytical finite element process. It takes advantage of orthogonal properties of harmonic functions in the stiffness matrix formulation to yield a block diagonal stiffness matrix. In static analysis it is used for structure with two opposite simply supported ends and with or without the intermediate 
elastic support. In dynamic analysis it is used for structure with all boundary conditions and with discrete supports. This method is based on the concept that the curved bridge is divided into many narrow strips in the circumferential direction which are supported in their radial direction. Membrane action, warping, and distortional effects are analyzed in this method [Hsu 1989]. This method has been successfully utilized to analyze composite curved box and plate girders with complete and incomplete interaction, using curved strip elements for the concrete slab and steel girder and spring elements for shear connectors (Arizumi et al, 1982). This method is simple and require small amount of input data because of small number of mesh lines involved due to reduction in dimensional analysis. However it is less powerful and versatile as compared to the finite element method (Zureick and Naqib, 1999).

\subsubsection{The Finite-difference method}

The finite difference method is another numerical technique frequently used to obtain approximate solutions of problems governed by differential equations. The finite difference method models the differential equation(s) of the problem and uses numerical integration to obtain the solution at discrete points. In this method a grid is superimposed on the structure and the governing differential equations are replaced by algebraic difference equations that are solved for each grid point. The difference between the finite element method and finite difference method is that, in the finite element method, the variation of the field variable in the physical domain is an integral part of the procedure. That is, based on the selected interpolation functions, the variation of the field variable throughout a finite element is specified as an integral part of the problem formulation. While in the finite difference method the field variable is computed at specified points only. This method was 
utilized in the dynamic analysis of curved bridges with large deflections and small rotations (Tene al et. 1975; Sheinman 1982).

\subsubsection{Analytical solution to differential equations}

This method was used in studying curved bridge dynamic response (Culver, 1967; Montalvao and Urgueira, 1988). In this method an analytical solution to the Governing Differential Equations (GDE) is obtained. The solution thus obtained is usually a closed form or a convergent series solution, such as a Fourier series.

\subsubsection{The Slope deflection method}

The partial differential equations are established in terms of slope-deflection equations, and the solution is assumed to be a Fourier series. The effects of curvature, nonuniform torsion, and diaphragms are included in the above analysis. The COBRA (Curved Orthotropic Bridge Analysis) program (Bell and Heins, 1969), developed by University of Maryland, is based on analytical techniques of the slop-deflection-Fourier series and it is recommended by AASHTO Guide Specifications of 1993 to study composite and non composite girder-slab action. This method was proved by experiment to be an accurate analytical method of curved orthotropic deck bridge systems (Heins and Bell, 1972). 


\subsubsection{The Finite-Element Method (FEM)}

(The finite element method is applicable to a wide range of boundary value problems in engineering and it dates back to the mid-1950s with the pioneering work of Argyris (1960), Clough (1993), and others. The method was first applied to the solution of plane stress problems and extended subsequently to the solution of plates, shells, and axisymmetric solids. The finite element method has proven to be a powerful tool. This method can be regarded as a natural extension of the matrix methods of structural analysis. It can accommodate complex and difficult problems such as non-homogeneity, nonlinear stressstrain behavior, and complicated boundary conditions). The finite element method is based on the representation of a body or a structure by an assemblage of subdivisions called finite elements, as shown in Figure 2.6. All of these elements have node points through which these elements are connected. Functions are chosen to approximate the variation over each finite element e.g. displacement. Principle of minimum potential energy is used to obtain equilibrium equations for each element. These equations are formulated for the entire body by combining the equations for the individual elements so that the continuity of displacements is preserved at the nodes. The resulting equations are solved by satisfying the boundary conditions to obtain the unknown displacements.

The entire procedure of the finite element method involves the following steps:

1. The given body is subdivided into an equivalent system of finite elements.

2. A suitable displacement function is chosen.

3. The element stiffness matrix is derived using a variational principle of mechanics such as the principle of minimum potential energy.

4. The global stiffness matrix for the entire body is formulated. 
5. The algebraic equations thus obtained are solved to determine unknown displacements.

6. Element strains and stresses are computed from the rodal displacements.

The finite element method became popular after the advent of high speed computers because the equations involved in the analysis are cumbersome to solve by hand. In 1956 Turner et al. was the first who introduced the solution for two-dimensional structural elements, he derived stiffness matrices for truss elements, beam elements, and twodimensional triangular and rectangular elements in plane stress. Martin, in 1961, developed tetrahedral stiffness matrix which became the base for the solution of three-dimensional problems in finite element method.

\subsection{Three-Dimensional Method}

Shore and Wilson (1973) of University cf Pennsylvania developed a computer program known as STACRB, which is characterized by a fully compatible threedimensional flat plate circular element. This program has provided a base for the development of other computer programs which have led to a vast study of various different elements and shape functions, including using segmental and quadrilateral element for plate bending, annular conforming and fully compatible four-node segment element for thin plates, horizontally curved three-node isoparametric beam element, three-dimensional beam element with axial and transverse displacements or arbitrary polynomial order, and so on. General finite element packages, such as ABAQUS, ADINA, ALGOR, ANASYS MSC/NASTRAN, DESCUS I, VANCK and SAP2000 are also used for curved bridges. Today's high tech computer in-term of speed and capacity allows the modeling of threedimensional curved bridges. Girder flanges are usually modeled as beam elements to include 
axial and bending strains in two directions and torsional effects. Girder web can be modeled as shell element to account for the bending stiffness. Cross bracings and wind bracings can be modeled as hinged bar element. While the bridge deck is usually modeled as shell element, including membrane and bending effects. Rigid beams are used to connect the deck slab to the girder flange and can simulate the composite action with slab. Three-dimensional plate/shell models can consider unusual geometry and complex configuration and can get the most accurate results. The disadvantages are: (a) since most of the programs do not allow loads to be placed at any point on the elements, equivalent nodal loads must be calculated with care and the mesh must be fine enough to minimize errors that may arise because of load approximations; (b) since the programs report stresses and strains other than shear and moment values, calculation of shear and moment values from the stresses must be carefully performed through integration over the beam section, and (c) integration of stresses at node points is normally less accurate and may lead to inaccurate results. 


\section{CHAPTER III \\ FINITE-ELEMENT ANALYSIS}

\subsection{Historical Background}

The basic ideas of the finite element method as known today were presented in the papers of Turner, Clough, Martin and Topp, Argyris and Kelsey. The name finite element was given by Clough. Zienkiewicz and Cheung presented the broad interpretation of the method and its applicability to any general field problem. With this broad interpretation of the finite element method, it has been found that the finite element equations can also be derived by using a weighted residual method such as Galerkin method or the least squares approach. This led to widespread interest among applied mathematicians in applying the finite element method for the solution of linear and nonlinear differential equations. The concept of combining incremental (predictor) and iterative (corrector) methods was introduced by Brebbia and Connor and Murray and Wilson who thereby adopted a form of 'continuation method'. Early work on non-linear material analysis of plates and shells used simplified methods with sudden plastification. Armen et al. traced the elasto-plastic interface while layered or numerically integrated procedures were adopted by, amongst others, Marcal et al. and Whang combined material and geometric nonlinearity for plates initially involved 'perfect elasto-plastic buckling'. One of the earliest fully combinations employed an approximate approach and was due to Murray and Wilson. A more rigorous 'layered approach' was applied to plates and shells by Marcal, Gerdeen et al. Over the years, several papers, conference proceedings, and books have been published on this method. In recent 
times, an approach similar to the finite element method, involving the use of piecewise continuous functions defined over triangular regions, was first suggested by Courant in 1943 in the literature of applied mathematics. Later in the mid 1950s and 60s the finite element method was extended to a wide range of boundary value problems in engineering with the pioneering work of Argyris (1960), Clough (1993), and others. The method was first applied to the solution of plane stress problems and extended subsequently to the solution of plates, shells, and solids.

\subsection{Overview of Finite Element Method}

With all the progress, today the finite element method is considered one of the wellestablished and convenient analysis tools by engineers and applied scientists. The finite element method has proven to be a powerful tool. This method can be regarded as a natural extension of the matrix methods of structural analysis. It can accommodate complex and difficult problems such as non-homogeneity, nonlinear stress-strain behavior, and complicated boundary conditions. The digital computer provided a rapid means of performing the many calculations involved in the finite element analysis and made the method practically applicable; due to this the finite element method has progressed at a very impressive rate. When compared to experimental findings finite element analysis proved to be a reliable source; this trust led the designers and code writers to implement the finite element method in the analysis and design of different engineering structures.

There are six different refined methods which are allowed by the Canadian Highway Bridge Design Code (CHBDC 2000), section 5.9, for the analysis of short and medium span 
bridges. The finite element method is one of the methods recognized by CHBDC. The finite element method is the most powerful and versatile of all the above-mentioned six permitted methods by the Canadian Highway Bridge Design Code (CHBDC 2000).

The most important advantages of the finite element method are:

1- Combination of various structural elements such as plates, beams and shells are possible.

2- Allows accurate representation of complex geometry and inclusion of dissimilar material properties

3- Every step involved can be fully automated.

4- Allows easy representation of the total solution.

Keeping in view all these aspects of the finite-element method, this method is found to be very suitable for the analysis of curved composite I-girder bridges. The versatility of the finite-element methods has facilitated to model a bridge in a very realistic manner and to provide a full description of its structural response within the elastic and post-plastic stages of loading. The models that intended to be analyzed by the finite-element method comprised of the steel top flanges, steel webs, steel bottom flanges, and cross-bracing as described in subsequent sections. The commercially available finite-element program, SAP2000 (Wilson and Habibullah, 2002), was utilized in this study to analyze and determine the structural response of the modeled bridge prototypes having different configurations and arrangements of girders, cross bracing members and radius of curvature. Non-uniform torsion is induced in the curved girder, due to the presence of curvature, which as a result produces lateral bending moment (warping or bi-moment) in the top and bottom flanges. Hence, the design 
of such girders becomes complicated. The methodology of how to obtain the warping-tobending stress ratio is presented at the end of this chapter.

\subsection{Finite-Element Approach}

A finite element generally has a simple one, two, or three-dimensional configuration. The boundaries of elements are often straight lines and the elements can be onedimensional, two-dimensional, or three-dimensional. While subdividing the continuum, one has to decide the number, shape, size, and configuration of the elements in such a way that the original body is simulated as closely as possible. Nodes must be located in locations where abrupt changes in geometry, loading, and material properties occur. A node must be placed at the point of application of a concentrated load because all loads are converted into equivalent nodal-point loads. It is easy to subdivide a continuum into a completely regular one having the same shape and size. But problems encountered in practice do not involve regular shape; they may have regions of steep gradients of stresses. A finer subdivision, which is also called discretization, may be necessary in regions where stress concentrations are expected to obtain a useful approximate solution.

Finite element method facilitates the formation of equations for each finite-element and it allows combining them at the end to obtain the solution of the whole body. To simplify the above stated equations matrix method is used. Matrix method is thus the base of the whole computation of finite element method and is used to structure the finite element method in the programs for computers.

Finite-element has two main approaches which are; 
(1) Force or flexibility method, and

(2) Displacement or stiffness method.

Displacement or stiffness method is more desirable due to its simpler formulation for most of the structural analysis problems. Using displacement formulation, the stiffness matrix of each element is derived and the global stiffness matrix of the entire structure can be formulated. This global stiffness matrix, along with the given displacement boundary conditions and applied loads, is then solved to get the displacements and stresses for the entire system. The global stiffness matrix represents the nodal force-displacement relationships and is expressed in a matrix equation form as follows:

$$
[P]=[K][U]
$$

Where:
$[\mathrm{P}] \quad=\quad$ nodal load vector;
$[\mathrm{K}]=$ the global stiffness matrix;
$[\mathrm{U}]=$ the nodal displacement vector;

\subsection{SAP2000 Computer Program}

SAP2000 is a commercially available computer software program for analysis and design of simple to complex structures. It provides linear and nonlinear, static and dynamic analysis and design of three-dimensional structures and utilizes the finite-element method. This program has a wide range of capabilities for bridge design and analysis. It has bridge templates for generating bridge models, automated bridge live load analysis and design, bridge base isolation, bridge construction sequence analysis, large deformation cable 
supported bridge analysis and pushover analysis. SAP2000 finite-element library consists of following six elements.

1- Two-dimensional PLANE element

2- Three-dimensional FRAME element.

3- Three-dimensional SHELL element

4- Two-dimensional SOLID element

5- Three-dimensional SOLID element

6- Three- dimensional NLLINK element

In addition, subsets of these elements with varying degrees of freedom are available in the form of truss, frame, membrane, beam, strain, gap, and hook elements.

\subsection{I-Steel Girder Bridge Configurations}

614 simply supported curved I-steel Girder Bridge prototypes were considered for finite-element analysis in this parametric study. Several major parameters were considered as follows:

Span length (L): 10, 15, 25, and $35 \mathrm{~m}$;

Girder spacing (S): 2, 2.5, and $3 \mathrm{~m}$

Number of girders $(\mathrm{N}): 3,4,5,6, \& 7$ for $2 \mathrm{~m}$ girder spacing; $3,4,5, \& 6$ for $2.5 \mathrm{~m}$ girder spacing; 3,4 \& 5 for $3 \mathrm{~m}$ girder spacing;

- Span-to-radius of curvature ratio (L/R): $0.0,0.1,0.2, \& 0.3$ for spans $=10 \mathrm{~m}$ and 15 $\mathrm{m} ; 0.0,0.1,0.3, \& 0.5$ for $\mathrm{span}=25 \mathrm{~m}$; and $0.0,0.1,0.4, \& 0.7$ for $\mathrm{span}=35 \mathrm{~m}$. 
Based on CHBDC code which specifies number of design lanes as a basis for bridge width some of the above diversity of parameters was determined. Other bridge configurations are listed as below:

$>$ The depth of the girder webs was taken $(1 / 20)$ of the centre line span except for spans length $=10 \mathrm{~m}$, the depth was taken $0.75 \mathrm{~m}$,

The girder web thickness was considered equal to $16 \mathrm{~mm}$,

The bottom and top steel flanges width and thickness were maintained $300 \mathrm{~mm}$, and $20 \mathrm{~mm}$, respectively.

$\mathrm{X}$-type cross-bracings, equally spaced between the supports, were considered in this study with top and bottom chords as shown in Fig. 1.3. These bracings were of steel angles with dimensions (L150xL150x25mm) and $0.0075 \mathrm{~m}^{2}$ cross sectional area. The spacing between these cross-bracings were based on equation 2.24, developed by Davidson et al. (1996), to reduce and limit the warping-to-bending stress ratio to 0.25 in case of noncomposite steel girders. Typical plan of curved girders with the distribution of the transverse bracings are shown in Figure 3.3.

\subsection{Research Assumptions}

This study was based on the following assumptions:

(1) All the bridges were simply supported,

(2) All materials were elastic and homogenous,

(3) Bridges had constant radii of curvature between support lines.

(4) The effect of road super-elevation, and curbs were ignored. 
(5) The modulus of elasticity of steel was taken as $200 \mathrm{GPa}$ with Poisson's ratio of 0.3 .

\subsection{Finite-Element Bridges modeling}

\subsubsection{Geometric Modeling}

Three-dimensional finite-element models were developed in SAP2000 to analyze and find the structural response of all the possible models of the above mentioned bridges. A bridge structure was divided into its major components which are as follows:

a) top steel flange,

b) steel web,

c) bottom steel flange, and

d) Cross-bracings.

Each of the top and bottom steel flanges and steel web of a girder were modeled as a four-node shell element with six degree of freedom at each node. Whereas cross-bracings with top and bottom chords were modeled as frame elements with pinned joints at both ends. Following previous work on finite-element modeling in past, four vertical shell elements were used for web and two horizontal shell elements were used for the upper and lower steel flanges. Figure 3.1 shows a finite-element model of four-girder cross section. Figures 3.2 visualized views of the SAP2000 finite-element models for 3-girder curved bridge.

Aspect ratio, being an important aspect in the finite-element modeling, is the ratio of the longer dimension to the shorter dimension of any quadrilateral finite element. Logan (2002) has showed that in many cases if the aspect ratio increases the inaccuracy of the solution increases. He presented a graph which shows that if the aspect ratio goes above 4 
the percentage of error from the exact solution will increases by more than $15 \%$. Therefore, this fact is considered in the present study and 15, 25, and 35 meter span lengths are divided into 72 elements whereas 10 meter span length is divided into 36 elements. This will result in an acceptable aspect ratio.

\subsubsection{Boundary conditions}

All the bridge models used in this study were modeled with the interior support at right end restrained against movements in all three directions as shown in Fig. 3.4. The interior support at the right end of the bridge is restrained against movements in vertical, lateral and longitudinal directions. The left end of the inner girder is restrained in the vertical and lateral directions only and the right side of the middle girder and exterior girder are also

restrained in vertical and lateral directions. However, all other girders supports were restrained only against vertical movement. Sample of input SAP2000 files are shown in Appendix A.

\subsection{Calculation of the Moment Distribution Factors}

The moment distribution factors (MDF) for curved girders were determined. The maximum flexural stresses ( $\left.\sigma_{\text {straight }}\right)_{\mathrm{DL}}$, were calculated for the straight simply supported beam own dead load. From the finite-element modeling, the maximum longitudinal moment stresses along the bottom flange for dead load were calculated. Consequently, the moment distribution factors (MDF) were calculated as follows: 


\section{For Exterior girders:}

$D_{M}(O)=\left(\sigma_{\text {FE. ext }}\right)_{D L} /\left(\sigma_{\text {straight }}\right)_{D L}$

For Middle girders:

$D_{M}(C)=\left(\sigma_{\text {FE. ext }}\right)_{D L} /\left(\sigma_{\text {straight }}\right)_{D L}$

For Interior girders:

$D_{M}(I)=\left(\sigma_{\text {FE. ext }}\right)_{D L} /\left(\sigma_{\text {straight }}\right)_{D L}$

Where $\mathrm{D}_{\mathrm{M}}$ is the moment distribution factor for dead load. Symbols ext, mid, and int. refer to the exterior, middle, and interior girders respectively. ( $\sigma$ FEA $)_{D L}$ is the average longitudinal dead load flexural stress, obtained from the finite-element modeling, at point 2 which is the average of the flexural stresses at bottom flange points 1 and 3 shown in Fig. 3.5.

\subsection{Calculation of warping to-bending stress ratio during construction phase:}

During construction phase curved steel I-girders are influenced by gravity loading. Radial forces equal in magnitude and opposite in direction are developed in each flange under the self load condition of girders and as a result a twisting effect about the longitudinal axis of the girder is produced. So curved I-steel girders are subjected to combined bending and torsion which produce lateral moments in top and bottom flanges. This lateral moment, also called "bimoment" or "torsional warping moment" induces warping stresses in the flanges which can cause distortion of the flanges along the length. To study the effect of this warping stress and its changes with different bridges parameters and load cases the ratio between warping stress to the average bending stress in the bottom 
flange is examined for bridges considered in this study. The following relationship is used for this purpose:

WBR $=\sigma_{\mathrm{w}} / \sigma_{\mathrm{b}}=\left(\sigma_{1}-\sigma_{3}\right) /\left(\sigma_{3}+\sigma_{1}\right)$

Where WBR: warping to bending stress ratio, $\sigma_{1}$ and $\sigma_{3}$ : the corresponding mid-span stresses at points 1 and 3 shown in Fig. 3.5; $\sigma_{\mathrm{w}}$ is the warping stress; and $\sigma_{\mathrm{b}}$ is the average bending stress in the bottom steel flange. 


\section{CHAPTER IV}

\section{RESULTS FROM THE PARAMETRIC STUDY}

\subsection{General}

A parametric study on few simply-supported curved steel I-girder bridge prototypes at construction phase was conducted to investigate the effects of key parameters on warpingto-bending stress ratio (WBR), moment distribution factors and reaction distribution factors. The finite-element program "SAP2000" was used to conduct this current research. These key parameters included the number of cross-bracing intervals between support lines, the presence of torsion box with horizontal bracings in the outer bracing panel close to support lines, bridge span length, number of girder, girder spacing, and the span-to-radius of curvature ratio $(\mathrm{L} / \mathrm{R})$. The above mentioned prototype bridges were analyzed at construction phase before laying the deck Slab. This chapter presents the results of the above parametric

studies in terms of (1) WBR (warping-to-bending stress ratio), (2) moment distribution factors, and (3) Reaction distribution factors. In this study the following major key parameters were considered:

(i). Bridge span length (L): 10,15,25 and $35 \mathrm{~m}$

(ii). Span-to-radius of curvature ratio ( $\mathrm{L} / \mathrm{R})$,
a) For $10-\mathrm{m}$ and $15 \mathrm{~m}$ bridge spans: $0.1,0.2$ and 0.3
b) For 25-m bridge span: $0.1,0.3$ and 0.5
c) For $25-\mathrm{m}$ bridge span: $0.1,0.4$ and 0.7

(iii). Number of girders $(\mathrm{N}): 3,4,5,6$ and 7 
(iv). Girder spacing (S): $2,2.5$ and $3 \mathrm{~m}$

(v). Number of cross-bracing intervals between support lines: ranging from 2 to 18 .

\subsection{Presence of torsion box}

Curved steel girders are usually constructed with vertical cross-bracing systems between the support lines as shown in Fig. 1.1. However, there may be a need to strengthen the steel girder system to increase it load carrying capacity and/or limit the girder deflection as a result of girder deterioration or to redesign the bridge to carry heavier trucks. As such, it is proposed to introduce horizontal bracings connecting the girders at the levels of the top and bottom flanges, as shown in Table 4.1. These horizontal bracings are introduced only in the outer panel close to the support lines to form a quasi-closed box to increase bridge torsional resistance at the supports. As such, this proposed horizontal bracing, along with the surrounding vertical bracings, is called herein "torsion box" for simplicity. The member size of the horizontal bracings (A) is maintained similar to that for the vertical bracings. Table 4.1 presents a summary of the effect of the presence of the torsion box on the warping-to-bending stress ratio (WBR) for different bridge geometries at construction phase. It should be noted that the area of the added horizontal bracings changed to $1.5 \mathrm{~A}, 2 \mathrm{~A}$ and $3 \mathrm{~A}$ to study the effect of increasing their axial stiffness on the response. Also, the number of vertical bracing intervals satisfies Davidson et al's equation. It can be observed that the for 10 and $15 \mathrm{~m}$ bridge spans, the WBR increased compared to those for bridges with vertical bracings only. However, for 25 and $35 \mathrm{~m}$ span bridges, the WBR generally decreased with the presence of torsion box. It can also be observed that the increase of the axial stiffness of the added horizontal bracings slightly changed the WBR in general. One may conclude that there may be no general trend of the effect of torsion box on WBR with increase in span length. However, this is not the case for moment distribution among girders.

Table 4.2 shows the effect of torsion box on the moment distribution factors of the outer, middle and inner girders of selected three-girder bridges. These bridges were analyzed first under dead load using vertical bracings only with number of bracing intervals satisfying Davidson's et al equation. Then, there bridges were analyzed again but after utilizing torsion box. The added horizontal bracings at the top and bottom flange levels in the outer bracing panel close to the support lines had a cross-sectional area of $\mathrm{A}, 1.5 \mathrm{~A}, 2 \mathrm{~A}$, and $3 \mathrm{~A}$ to examine the effect of there axial stiffness on the respotise. It can be observed that the moment distribution factor for the outer girders significantly decreased with the presence of torsion box, while the moment distribution factors for the inner girder significantly increased. This may support the quasi-box girder concept approached by utilizing the torsion box. The torsion box appeared to provide more uniform distribution of moments among girders compared to the case of a bridge with vertical bracing only. Also, the moment distribution factors considerably decreased for the outer and middle girders, leading to increased moment carrying capacities for such girder to carry heavier live load. As an example, for the 15 -m span bridge with $\mathrm{L} / \mathrm{R}$ of 0.5 , the moment distribution factor for the outer girder changed from 2.264 to 1.167 , a decrease of $48 \%$, when utilizing torsion box with vertical bracings to stabilize girders at the construction stage.

Table 4.3 presents the effect of torsion box on the reaction distribution factor of selected three-girder bridges of (i) vertical bracings only and (ii) vertical bracings and torsion box. It can 
(iv). Girder spacing (S): $2,2.5$ and $3 \mathrm{~m}$

(v). Number of cross-bracing intervals between support lines: ranging from 2 to 18 .

\subsection{Presence of torsion box}

Curved steel girders are usually constructed with vertical cross-bracing systems between the support lines as shown in Fig. 1.1. However, there may be a need to strengthen the steel girder system to increase it load carrying capacity and/or limit the girder deflection as a result of girder deterioration or to redesign the bridge to carry heavier trucks. As such, it is proposed to introduce horizontal bracings connecting the girders at the levels of the top and bottom flanges, as shown in Table 4.1. These horizontal bracings are introduced only in the outer panel close to the support lines to form a quasi-closed box to increase bridge torsional resistance at the supports. As such, this proposed horizontal bracing, along with the surrounding vertical bracings, is called herein "torsion box" for simplicity. The member size of the horizontal bracings (A) is maintained similar to that for the vertical bracings. Table 4.1 presents a summary of the effect of the presence of the torsion box on the warping-to-bending stress ratio (WBR) for different bridge geometries at construction phase. It should be noted that the area of the added horizontal bracings changed to $1.5 \mathrm{~A}, 2 \mathrm{~A}$ and $3 \mathrm{~A}$ to study the effect of increasing their axial stiffness on the response. Also, the number of vertical bracing intervals satisfies Davidson et al's equation. It can be observed that the for 10 and $15 \mathrm{~m}$ bridge spans, the WBR increased compared to those for bridges with vertical bracings only. However, for 25 and $35 \mathrm{~m}$ span bridges, the WBR generally decreased with the presence of torsion box. It can also be observed that the increase of the axial stiffness of the added horizontal bracings slightly changed the WBR in general. One may conclude that there may be no general trend of the effect of torsion box on WBR with increase in span length. However, this is not the case for moment distribution among girders.

Table 4.2 shows the effect of torsion box on the moment distribution factors of the outer, middle and inner girders of selected three-girder bridges. These bridges were analyzed first under dead load using vertical bracings only with number of bracing intervals satisfying Davidson's et al equation. Then, there bridges were analyzed again but after utilizing torsion box. The added horizontal bracings at the top and bottom flange levels in the outer bracing panel close to the support lines had a cross-sectional area of $\mathrm{A}, 1.5 \mathrm{~A}, 2 \mathrm{~A}$, and $3 \mathrm{~A}$ to examine the effect of there axial stiffness on the resporise. It can be observed that the moment distribution factor for the outer girders significantly decreased with the presence of torsion box, while the moment distribution factors for the inner girder significantly increased. This may support the quasi-box girder concept approached by utilizing the torsion box. The torsion box appeared to provide more uniform distribution of moments among girders compared to the case of a bridge with vertical bracing only. Also, the moment distribution factors considerably decreased for the outer and middle girders, leading to increased moment carrying capacities for such girder to carry heavier live load. As an example, for the 15 -m span bridge with $\mathrm{L} / \mathrm{R}$ of 0.5 , the moment distribution factor for the outer girder changed from 2.264 to 1.167 , a decrease of $48 \%$, when utilizing torsion box with vertical bracings to stabilize girders at the construction stage.

Table 4.3 presents the effect of torsion box on the reaction distribution factor of selected three-girder bridges of (i) vertical bracings only and (ii) vertical bracings and torsion box. It can 
be observed that the presence or torsion box decreased the girder reaction force of the outer girder and increased the reaction forces for the inner girder, close to the center of curvature. However, the middle girder reaction force increased consicierably. As an example, for the threegirder bridge of $25 \mathrm{~m}$ span and $\mathrm{L} / \mathrm{R}$ of 0.5 , the outer girder support reaction decreased by ??\% and the inner girder support reaction increased by ??\% with the presence of torsion box. This means that the addition of torsion box increased the torsion stability of the three-girder crosssection to be closer to that of the straight bridge. One may observe that the increase in the axial stiffness from $\mathrm{A}$ to $3 \mathrm{~A}$ makes this conclusion more sensible.

Table 4.4 shows the effect of the presence of torsion box on the maximum axial force in bracing members of selected three-girder bridges. One may observe that the presence of torsion box increased the maximum axial force in bracing members. This effect increased with the change of horizontal bracing cross-section area from A to $3 \mathrm{~A}$. As an example, for $25-\mathrm{m}$ span bridge with $L / R$ ratio of 0.5 , the maximum axial compressive force in bracing members increased from $27.23 \mathrm{kN}$ to $246.94 \mathrm{kN}$ and the maximum axial tensile force increased from $22.42 \mathrm{kN}$ to $255.67 \mathrm{kN}$ with the presence of torsion box. It is common practice to have similar axial stiffness for all bracing members in a curved bridge rather than designing each member for its respective axial force. This approach is supported when the axial forces in bracings members are small which the case for bridges with vertical bracings only is. This can be observed in Fig. 4.1 where the axial force in each member is plotted for a $25-\mathrm{m}$ span, threegirder, bridge with $\mathrm{L} / \mathrm{R}$ of 0.5 . However, this may not be the case when strengthening the girder system using torsion box. Figure 4.2 shows the plots of the bracing axial force distribution in the same bridge studied in Fig. 4.1 but with the presence of torsion box. It can be observed the maximum tensile and compressive forces presented earlier in Table 4.4 occurred in the horizontal bracings forming the torsion box. It was also observed the vertical bracing lines on the two sides of the torsion box exhibited a significant increase is axial forces that would lead to strengthening these members if their axial capacities are less that the applied factored forces. However, the rest of vertical bracings closer to the mid-span (i.e. between the right and left torsion box) exhibited slight change in their axial forces with the presence of torsion box, given the fact that there axial load carrying capacity may be very high compared to the applied axial force. This can be observed by comparing axial force values presented in Figs. 4.1 and 4.2.

4.3 Warping-to-bending stress ratio (WBR)

The following subsection summarizes the effect of key parameters on the WBR.

\subsubsection{Effect of boundary conditions}

To allow for temperature-free bridge superstructure, the boundary condition for straight bridges is treated in such a way the bridge can expand or contract with the change in temperature. This concept is explained in the diagram shown in Table 4.5. There are two types of boundary conditions considered herein. The left diagram in Table 4.5 shows that the right end of the inner girder is prevented from motion in the vertical, longitudinal and lateral directions (i.e. U1, U2 and U3) while the left end was restrained from moving vertically and laterally (i.e. U1 and U3). All other ends of the outer and middle girder are restrained vertically only (i.e. U3) and allowed to displace in all horizontal directions. One the other hand, the other type of boundary conditions shown in the right diagram in Table 4.5 is similar to the first type but with the middle girder ends as the points of restraints against horizontal movement as 
be observed that the presence or torsion box decreased the girder reaction force of the outer girder and increased the reaction forces for the inner girder, close to the center of curvature. However, the middle girder reaction force increased consicierably. As an example, for the threegirder bridge of $25 \mathrm{~m}$ span and L/R of 0.5 , the outer girder support reaction decreased by ??\% and the inner girder support reaction increased by ??\% with the presence of torsion box. This means that the addition of torsion box increased the torsion stability of the three-girder crosssection to be closer to that of the straight bridge. One may observe that the increase in the axial stiffness from $\mathrm{A}$ to $3 \mathrm{~A}$ makes this conclusion more sensible.

Table 4.4 shows the effect of the presence of torsion box on the maximum axial force in bracing members of selected three-girder bridges. One may observe that the presence of torsion box increased the maximum axial force in bracing members. This effect increased with the change of horizontal bracing cross-section area from A to $3 \mathrm{~A}$. As an example, for $25-\mathrm{m}$ span bridge with $L / R$ ratio of 0.5 , the maximum axial compressive force in bracing members increased from $27.23 \mathrm{kN}$ to $246.94 \mathrm{kN}$ and the maximum axial tensile force increased from $22.42 \mathrm{kN}$ to $255.67 \mathrm{kN}$ with the presence of torsion box. It is common practice to have similar axial stiffness for all bracing members in a curved bridge rather than designing each member for its respective axial force. This approach is supported when the axial forces in bracings members are small which the case for bridges with vertical bracings only is. This can be observed in Fig. 4.1 where the axial force in each member is plotted for a $25-\mathrm{m}$ span, threegirder, bridge with $\mathrm{L} / \mathrm{R}$ of 0.5 . However, this may not be the case when strengthening the girder system using torsion box. Figure 4.2 shows the plots of the bracing axial force distribution in the same bridge studied in Fig. 4.1 but with the presence of torsion box. It can be observed the maximum tensile and compressive forces presented earlier in Table 4.4 occurred in the horizontal bracings forming the torsion box. It was also observed the vertical bracing lines on the two sides of the torsion box exhibited a significant increase is axial forces that would lead to strengthening these members if their axial capacities are less that the applied factored forces. However, the rest of vertical bracings closer to the mid-span (i.e. between the right and left torsion box) exhibited slight change in their axial forces with the presence of torsion box, given the fact that there axial load carrying capacity may be very high compared to the applied axial force. This can be observed by comparing axial force values presented in Figs. 4.1 and 4.2.

\subsection{Warping-to-bending stress ratio (WBR)}

The following subsection summarizes the effect of key parameters on the WBR.

\subsubsection{Effect of boundary conditions}

To allow for temperature-free bridge superstructure, the boundary condition for straight bridges is treated in such a way the bridge can expand or contract with the change in temperature. This concept is explained in the diagram shown in Table 4.5. There are two types of boundary conditions considered herein. The left diagram in Table 4.5 shows that the right end of the inner girder is prevented from motion in the vertical, longitudinal and lateral directions (i.e. U1, U2 and U3) while the left end was restrained from moving vertically and laterally (i.e. U1 and U3). All other ends of the outer and middle girder are restrained vertically only (i.e. U3) and allowed to displace in all horizontal directions. One the other hand, the other type of boundary conditions shown in the right diagram in Table 4.5 is similar to the first type but with the middle girder ends as the points of restraints against horizontal movement as 
opposed to the inner girder for the first boundary condition type. Table 4.5 summarizes the WBR for the outer, middle and inner girders of a $25-\mathrm{m}$ span, three-girder, bridge with L/R of 0.3. It can be observed that the second type of boundary conditions slightly increased the WBR for all girders by about $6 \%$. It should be noted that the first boundary condition type was used in all bridges considered in the parametric study.

\subsubsection{Effect of variation of girder flexural stiffness across bridge section}

In designing composite concrete-deck over steel I-girder bridges, girders with the same flexural stiffness and geometry are used in case of bridges with light curvature. However, or bridges with large curvature, few bridge engineers tend to increase the flexural stiffness of the girders from the inner girder toward the outer girder, given the fact that the moment distribution factor for the outer girder is always more than that for the inner girder. To study the effect of the changer in flexural stiffness of the outer girders compared to the inner girders. A $25-\mathrm{m}$, three-girder bridge with $L / R$ of 0.3 was analyzed with flexural stiffness ration of the outer, middle and inner girders, respectively as I: I: I, 1.2I: 1.1I: I and 1.4I: 1.2I: I. Table 4.6 shows the WBR for the outer, middle and inner girders for each flexural stiffness ratios. It can be observed that the increase of flexural stiffness of the outer girders far away from the centre of curvature compared to the inner girders close to the centre of curvature decreased the WBR.

\subsubsection{Effect of flange warping moment}

It is known in horizontally curved I-girder bridges undergoes a coupled lateral bending moment of the top and bottom flanges due to curvature, termed as bi-moment or torsional warping moment. This induces warping of the girder cross-section as indicated in Fig. 2.1. For double symmetric I-girder, the torsional warping constant can be expressed as:

$I_{w}=I_{f} d^{2} / 2$

Where $I_{f}=$ moment of inertia of the flange plates only; $d$ = depth of I-girder.

The bi-moment for I-girder, B, can be written as:

$\mathrm{B}=\mathrm{M}_{\mathrm{f}} \mathrm{d}$

Where $\mathrm{M}_{\mathrm{f}}=$ self-equilibrating in-plane bending moment of the flange plate due to warping, and can be named lateral-flange moment.

The warping stress in girder flanges can be expressed as:

$\sigma_{\mathrm{w}}=\mathrm{B}_{\mathrm{w}} / \mathrm{I}_{\mathrm{w}} \quad$ where $\mathrm{w}=\mathrm{b}_{\mathrm{f}} \mathrm{d} / 4$

By substituting equation 4-1 and 4-2 into 4-3,

$\sigma_{\mathrm{w}}=6 \mathrm{M}_{\mathrm{f}} / \mathrm{b}_{\mathrm{f}}^{2} \mathrm{t}_{\mathrm{f}}$

Equation 4-4 shows that both the flange width and thickness affect the warping stresses. As such it was decided to study the effect of torsional warping constant, $I_{w}$, on the WBR. Table 4.7 shows the WBR of the outer, middle and inner girders of selected three-girder bridges of the same girder spacing but with different span length and number of cross-bracing intervals. The top and bottom flange warping constant changed based on changing the flange width from 300 to $450 \mathrm{~mm}$. Since the FEA model was based on certain width of the bottom and top flanges, it was difficult to change the flange width for all nodes forming these flanges. As such, it was decided to change the flange thickness for the same warping constant. For example, $I_{w}$ for $300 \times 20 \mathrm{~mm}$ flange plate is $1.265 \times 10^{13} \mathrm{~mm}^{6}$. While $I_{w}$ for the $450 \times 20 \mathrm{~mm}$ flange plate is $4.27 \times 10^{13} \mathrm{~mm}^{6}$. So, to increase $I_{w}$ to account for the increase of flange width from 300 to 450 
opposed to the inner girder for the first boundary condition type. Table 4.5 summarizes the WBR for the outer, middle and inner girders of a $25-\mathrm{m}$ span, three-girder, bridge with $L / R$ of 0.3. It can be observed that the second type of boundary conditions slightly increased the WBR for all girders by about $6 \%$. It should be noted that the first boundary condition type was used in all bridges considered in the parametric study.

\subsubsection{Effect of variation of girder flexural stiffness across bridge section}

In designing composite concrete-deck over steel I-girder bridges, girders with the same flexural stiffness and geometry are used in case of bridges with light curvature. However, or bridges with large curvature, few bridge engineers tend to increase the flexural stiffness of the girders from the inner girder toward the outer girder, given the fact that the moment distribution factor for the outer girder is always more than that for the inner girder. To study the effect of the changer in flexural stiffness of the outer girders compared to the inner girders. A $25-\mathrm{m}$, three-girder bridge with $L / R$ of 0.3 was analyzed with flexural stiffness ration of the outer, middle and inner girders, respectively as I: I: I, 1.2I: 1.1I: I and 1.4I: 1.2I: I. Table 4.6 shows the WBR for the outer, middle and inner girders for each flexural stiffness ratios. It can be observed that the increase of flexural stiffness of the outer girders far away from the centre of curvature compared to the inner girders close to the centre of curvature decreased the WBR.

\subsubsection{Effect of flange warping moment}

It is known in horizontally curved I-girder bridges undergoes a coupled lateral bending moment of the top and bottom flanges due to curvature, termed as bi-moment or torsional warping moment. This induces warping of the girder cross-section as indicated in Fig. 2.1. For double symmetric I-girder, the torsional warping constant can be expressed as:

$I_{w}=I_{f} d^{2} / 2$

Where $I_{f}=$ moment of inertia of the flange plates only; $d$ = depth of I-girder.

The bi-moment for I-girder, B, can be written as:

$\mathrm{B}=\mathrm{M}_{\mathrm{f}} \mathrm{d}$

Where $\mathrm{M}_{\mathrm{f}}=$ self-equilibrating in-plane bending moment of the flange plate due to warping, and can be named lateral-flange moment.

The warping stress in girder flanges can be expressed as:

$\sigma_{\mathrm{w}}=\mathrm{B}_{\mathrm{w}} / \mathrm{I}_{\mathrm{w}} \quad$ where $\mathrm{w}=\mathrm{b}_{\mathrm{f}} \mathrm{d} / 4$

By substituting equation 4-1 and 4-2 into 4-3,

$\sigma_{\mathrm{w}}=6 \mathrm{M}_{\mathrm{f}} / \mathrm{b}_{\mathrm{f}}^{2} \mathrm{t}_{\mathrm{f}}$

Equation 4-4 shows that both the flange width and thickness affect the warping stresses. As such it was decided to study the effect of torsional warping constant, $I_{w}$, on the WBR. Table 4.7 shows the WBR of the outer, middle and inner girders of selected three-girder bridges of the same girder spacing but with different span length and number of cross-bracing intervals. The top and bottom flange warping constant changed based on changing the flange width from 300 to $450 \mathrm{~mm}$. Since the FEA model was based on certain width of the bottom and top flanges, it was difficult to change the flange width for all nodes forming these flanges. As such, it was decided to change the flange thickness for the same warping constant. For example, $\mathrm{I}_{\mathrm{w}}$ for $300 \times 20 \mathrm{~mm}$ flange plate is $1.265 \times 10^{13} \mathrm{~mm}^{6}$. While $I_{w}$ for the $450 \times 20 \mathrm{~mm}$ flange plate is $4.27 \times 10^{13} \mathrm{~mm}^{6}$. So, to increase $I_{w^{\prime}}$ to account for the increase of flange width from 300 to 450 
$\mathrm{mm}$, the flange thickness in the FEA model changed from $20 \mathrm{~mm}$ to $67.5 \mathrm{~mm}$. Table 4.7 shows that the WBR decreased with the increase in warping constant for the outer, middle and inner girders. As an example, the $35-\mathrm{m}$ span bridge of $\mathrm{L} / \mathrm{R}=0.7$, the WBR decreased by $28 \%, 18 \%$ and $10 \%$ for the outer, middle and inner girder, respectively, when the warping constant or the flange thickness increased about 3.38 times. It should be noted that increased the flange width from 300 to $450 \mathrm{~mm}$ for the same flange thickness increases the warping constant 3.38 times. To develop an empirical expression for the WBR taking into account the change in warping constant a parametric study was conducted on all three-girder bridges with top and bottom flange width ranging from 300 to $450 \mathrm{~mm}$. A database for WBR for the outer and inner girders was tabulated in Table 4.8 for the $10,15,25$ and $35 \mathrm{~m}$ span bridges with different $\mathrm{L} / \mathrm{R}$ ratios. It should be noted that three different numbers of bracing intervals were considered herein, one of them satisfied Davidson et al's equation.

\subsubsection{Effect of bridge width and length}

There is no simple way to study the effect of bridge width since it involves the change in number of girders as well as girder spacing width the bridge width. This change in number of girders and girder spacing for the same bridge width would affect the overall flexural stiffness of the girder. It was decided to consider girder spacing as 2, 2.5 and $3 \mathrm{~m}$ as used in practice. For each girder spacing, the number of girders changed from 3 to 7 based on the number of design lanes in bridge cross-section. As such, adding more girders in bridge cross-section would increase bridge width while maintaining flexural stiffness per unit width. To have a great picture of the effects of these parameters, bridges of 10, 15, 25 and $35 \mathrm{~m}$ spans of different curvature ratios and number of cross-bracing intervals were analyzed and the database generated from this FEA analysis was tabulated in Table 4.9, rather than presenting them in graphs. This would assist in observing the trend in WBR values for all bridge geometries and for all the girders in bridge cross-section.

To examine the effect of increasing the number of girders with the same bridge width, three sets of analysis was conducted using girder spacing of $2,2.5$ and $3 \mathrm{~m}$. In each set, the number of girder changes from 3 to 7 for girder spacing of $2 \mathrm{~m}, 3$ to 6 for girder spacing of 2.5 $\mathrm{m}$ and 3 to 5 in case of girder spacing of $3 \mathrm{~m}$. This is to limit the number of bridge lanes to 4 lanes per CHBDC bridge width limitations. To ease the analysis of data in Table 4.9, an "*” was inserted in column 4 of that table denoting the number of vertical bracing intervals satisfying Davidson's equation. Column \# 4 in this table shows the change in number of girders for each bridge span and corresponding $L / R$ ratio. Looking at the WBR for the outer girder in column \# 6 and for the inner girder in the last column for bridge span of $10 \mathrm{~m}$ and $L / R$ of 0.1 , 0.2 and 0.3 , one may observe the increase of number of girder had negligible effect on the WBR, with a maximum reduction of $6 \%$. However, it decreases the WBR for the inner girder by a maximum of $15 \%, 5 \%$ and $6 \%$ for girder spacing of $2,2.5$ and $3 \mathrm{~m}$, respectively. Similar behavior was observed in case of $15-\mathrm{m}$ span bridges but with maximum reduction of WBR of $39 \%$ in case of $2-\mathrm{m}$ girder spacing with increase in number of girders. In case of the $25-\mathrm{m}$ span bridges, the increase of number of girders was observed to slightly decrease the WBR for the outer girder, with a maximum value of $9 \%$ in case of girder spacing of $2.5 \mathrm{~m}$. However, the inner girder exhibited a significant decrease in WBR with increase in number of girders, by about 2.78, 3.4 and 2.00 times, for girder spacing of $2,2.5$ and $3 \mathrm{~m}$, respectively, as compared to those for the three-girder bridges. Similar behavior was observed in case of the $35-\mathrm{m}$ span 
$\mathrm{mm}$, the flange thickness in the FEA model changed from $20 \mathrm{~mm}$ to $67.5 \mathrm{~mm}$. Table 4.7 shows that the WBR decreased with the increase in warping constant for the outer, middle and inner girders. As an example, the $35-\mathrm{m}$ span bridge of $\mathrm{L} / \mathrm{R}=0.7$, the WBR decreased by $28 \%, 18 \%$ and $10 \%$ for the outer, middle and inner girder, respectively, when the warping constant or the flange thickness increased about 3.38 times. It should be noted that increased the flange width from 300 to $450 \mathrm{~mm}$ for the same flange thickness increases the warping constant 3.38 times. To develop an empirical expression for the WBR taking into account the change in warping constant a parametric study was conducted on all three-girder bridges with top and bottom flange width ranging from 300 to $450 \mathrm{~mm}$. A database for WBR for the outer and inner girders was tabulated in Table 4.8 for the $10,15,25$ and $35 \mathrm{~m}$ span bridges with different $L / R$ ratios. It should be noted that three different numbers of bracing intervals were considered herein, one of them satisfied Davidson et al's equation.

\subsubsection{Effect of bridge width and length}

There is no simple way to study the effect of bridge width since it involves the change in number of girders as well as girder spacing width the bridge width. This change in number of girders and girder spacing for the same bridge width would affect the overall flexural stiffness of the girder. It was decided to consider girder spacing as 2, 2.5 and $3 \mathrm{~m}$ as used in practice. For each girder spacing, the number of girders changed from 3 to 7 based on the number of design lanes in bridge cross-section. As such, addirg more girders in bridge cross-section would increase bridge width while maintaining flexural stiffness per unit width. To have a great picture of the effects of these parameters, bridges of 10, 15, 25 and $35 \mathrm{~m}$ spans of different curvature ratios and number of cross-bracing intervals were analyzed and the database generated from this FEA analysis was tabulated in Table 4.9, rather than presenting them in graphs. This would assist in observing the trend in WBR values for all bridge geometries and for all the girders in bridge cross-section.

To examine the effect of increasing the number of girders with the same bridge width, three sets of analysis was conducted using girder spacing of $2,2.5$ and $3 \mathrm{~m}$. In each set, the number of girder changes from 3 to 7 for girder spacing of $2 \mathrm{~m}, 3$ to 6 for girder spacing of 2.5 $\mathrm{m}$ and 3 to 5 in case of girder spacing of $3 \mathrm{~m}$. This is to limit the number of bridge lanes to 4 lanes per CHBDC bridge width limitations. To ease the analysis of data in Table 4.9, an "*” was inserted in column 4 of that table denoting the number of vertical bracing intervals satisfying Davidson's equation. Column \# 4 in this table shows the change in number of girders for each bridge span and corresponding $L / R$ ratio. Looking at the WBR for the outer girder in column \# 6 and for the inner girder in the last column for bridge span of $10 \mathrm{~m}$ and $\mathrm{L} / \mathrm{R}$ of 0.1 , 0.2 and 0.3 , one may observe the increase of number of girder had negligible effect on the WBR, with a maximum reduction of $6 \%$. However, it decreases the WBR for the inner girder by a maximum of $15 \%, 5 \%$ and $6 \%$ for girder spacing of $2,2.5$ and $3 \mathrm{~m}$, respectively. Similar behavior was observed in case of $15-\mathrm{m}$ span bridges but with maximum reduction of WBR of $39 \%$ in case of $2-\mathrm{m}$ girder spacing with increase in number of girders. In case of the $25-\mathrm{m}$ span bridges, the increase of number of girders was observed to slightly decrease the WBR for the outer girder, with a maximum value of $9 \%$ in case of girder spacing of $2.5 \mathrm{~m}$. However, the inner girder exhibited a significant decrease in WBR with increase in number of girders, by about 2.78, 3.4 and 2.00 times, for girder spacing of $2,2.5$ and $3 \mathrm{~m}$, respectively, as compared to those for the three-girder bridges. Similar behavior was observed in case of the $35-\mathrm{m}$ span 
bridges but with maximum reduction in WBR by about $4.12,1.88$, and $1.9739 \%$ in case of 2 ,

2.5 and $3 \mathrm{~m}$ girder spacing, respectively. For example, WBR changes from 0.146 to 0.143 for the outer girder and from 0.615 to 0.221 for the inner girder when increasing the number of girders from 3 to 7 in case of a $25-\mathrm{m}$ span bridge with $L / R$ of 0.5 , girder spacing of $2 \mathrm{~m}$ and number of bracing intervals of 12 . As such, it can be concluded that the increase of number of girders for the same girder spacing (i.e. the increase in bridge width) decreases the warping effects, with rate of reduction increasing with increase of bridge span. A similar trend can be predicted when increasing the girder spacing with the same number of girders since the bridge width increases accordingly. For example, for a $25-\mathrm{m}$ span, three-girder, bridge with $L / R$ of 0.5 , girder spacing of $2 \mathrm{~m}$ and number of bracing intervals of 12 ,WBR values for the outer girder were $0.146,0.137$ and 0.131 for girder spacing of $2,2.5$ and $3 \mathrm{~m}$, respectively.

\subsubsection{Effect of bridge curvature}

To study the effect of curvature, a case study can be extracted from Table 4.9. For a 35$\mathrm{m}$, three-girder bridge with $2 \mathrm{~m}$ girder spacing and 8 cross-bracing intervals, WBR values are $0.1,0.469$ and 0.863 for the outer girder and $0.114,0.842$ and 0.965 for the inner girder for $L / R$ ratios of $0.1,0.4$ and 0.7 , respectively. Also, for a $25-\mathrm{m}$, three-girder bridge with $2 \mathrm{~m}$ girder spacing and 8 cross-bracing intervals, WBR values are $0.067,0.176$ and 0.465 for the outer girder and $0.074,0.28$ and 0.773 for the inner girder for $L / R$ ratios of $0.1,0.3$ and 0.5 , respectively. As such, it can be concluded the warping effects increase with increase in bridge curvature, as expected.

\subsubsection{Effect of number of vertical bracing intervals}

To study the effect of number of vertical bracing intervals on the WBR, a case study can be extracted from Table 4.9. For a $35-\mathrm{m}$ span, three-girder bridge with $L / R$ of 0.7 and girder spacing of $2 \mathrm{~m}$, WBR are $0.965,0.455$ and 0.258 for number of bracing intervals of 8 , 12,18 , respectively. This can conclude that the increase in number of bracing intervals decreases the warping effects on the curved girders.

4.3.7 Development of empirical expression for minimum number of bracing intervals in curved girder bridges

As it can be observed from the previous subsections, the key parameters affecting WBR are bridge span, span-to-radius of curvature ratio, and warping constant. It should be noted that AASHTO Guide for Horizontally Curved Bridges (1993) specifies a maximum WBR of 0.5 for flanges of curved girder system. However, Davidsor et al chose a desired value of 0.25 to develop their equation. They included the effect of the flange width into the developed equation, however, it is believed that this may not be enough to include the effect of warping on the bottom and top flanges of the curved girders since the warping constant of the flange include the lateral moment of inertia and girder depth. As such, a data generated from the parametric study was tabulated in Table 4.8 for three-girder bridges of $2-\mathrm{m}$ girder spacing and different warping constants. It was decided to include the results for the 2-m girder spacing since the latter provides the highest WBR as compared to the 2.5 and $3 \mathrm{~m}$ girder spacing. Also, the three-girder bridge can be only considered when considering WBR for the outer girder since the maximum reduction is WBR was observed to be $10 \%$ when increasing the number of girders from 3 to 7 . 
bridges but with maximum reduction in WBR by about $4.12,1.88$, and $1.9739 \%$ in case of 2 , 2.5 and $3 \mathrm{~m}$ girder spacing, respectively. For example, WBR changes from 0.146 to 0.143 for the outer girder and from 0.615 to 0.221 for the inner girder when increasing the number of girders from 3 to 7 in case of a $25-\mathrm{m}$ span bridge with $L / R$ of 0.5 , girder spacing of $2 \mathrm{~m}$ and number of bracing intervals of 12 . As such, it can be concluded that the increase of number of girders for the same girder spacing (i.e. the increase in bridge width) decreases the warping effects, with rate of reduction increasing with increase of bridge span. A similar trend can be predicted when increasing the girder spacing with the same number of girders since the bridge width increases accordingly. For example, for a 25 -m span, three-girder, bridge with $L / R$ of 0.5 , girder spacing of $2 \mathrm{~m}$ and number of bracing intervals of 12 , WBR values for the outer girder were $0.146,0.137$ and 0.131 for girder spacing of $2,2.5$ and $3 \mathrm{~m}$, respectively.

\subsubsection{Effect of bridge curvature}

To study the effect of curvature, a case study can be extracted from Table 4.9. For a 35$\mathrm{m}$, three-girder bridge with $2 \mathrm{~m}$ girder spacing and 8 cross-bracing intervals, WBR values are $0.1,0.469$ and 0.863 for the outer girder and $0.114,0.842$ and 0.965 for the inner girder for $L / R$ ratios of $0.1,0.4$ and 0.7 , respectively. Also, for a $25-\mathrm{m}$, three-girder bridge with $2 \mathrm{~m}$ girder spacing and 8 cross-bracing intervals, WBR values are $0.067,0.176$ and 0.465 for the outer girder and $0.074,0.28$ and 0.773 for the inner girder for $L / R$ ratios of $0.1,0.3$ and 0.5 , respectively. As such, it can be concluded the warping effects increase with increase in bridge curvature, as expected.

\subsubsection{Effect of number of vertical bracing intervals}

To study the effect of number of vertical bracing intervals on the WBR, a case study can be extracted from Table 4.9. For a $35-\mathrm{m}$ span, three-girder bridge with $L / R$ of 0.7 and girder spacing of $2 \mathrm{~m}$, WBR are $0.965,0.455$ and 0.258 for number of bracing intervals of 8 , 12,18 , respectively. This can conclude that the increase in number of bracing intervals decreases the warping effects on the curved girders.

4.3.7 Development of empirical expression for minimum number of bracing intervals in curved girder bridges

As it can be observed from the previous subsections, the key parameters affecting WBR are bridge span, span-to-radius of curvature ratio, and warping constant. It should be noted that AASHTO Guide for Horizontally Curved Bridges (1993) specifies a maximum WBR of 0.5 for flanges of curved girder system. However, Davidson et al chose a desired value of 0.25 to develop their equation. They included the effect of the flange width into the developed equation, however, it is believed that this may not be enough to include the effect of warping on the bottom and top flanges of the curved girders since the warping constant of the flange include the lateral moment of inertia and girder depth. As such, a data generated from the parametric study was tabulated in Table 4.8 for three-girder bridges of 2-m girder spacing and different warping constants. It was decided to include the results for the 2-m girder spacing since the latter provides the highest WBR as compared to the 2.5 and $3 \mathrm{~m}$ girder spacing. Also, the three-girder bridge can be only considered when considering WBR for the outer girder since the maximum reduction is WBR was observed to be $10 \%$ when increasing the number of girders from 3 to 7 . 
It should be noted that Davidson et al's equation was developed based on results of warping-to-bending stress ratio for the outer girder only. However, results presented earlier showed that in many cases, the WBR for the inner girder are considerably greater than those for the outer girder for 25 and $35 \mathrm{~m}$ span bridges and for large $\mathrm{L} / \mathrm{R}$ ratios, as depicted in Table 4.9. This approach can be accepted if the outer girder is to be designed based and other middle and inner girder will have the same size as the outer girder (i.e. bridge cross-section with uniform flexural stiffness among girders). This may be applicable for bridges with light curvature, and short spans. However, for bridges with longer spans (1.e. 25 to $35 \mathrm{~m}$ for example) and for sharp curvature (i.e. $\mathrm{R}=50 \mathrm{~m}$ for example), it may be common practice to design each girder per the applied bending moment. In this case, each girder will have different flexural stiffness. As such, it is advisable to develop an empirical equation for the minimum vertical baring intervals based on the WBR for the inner girders. This would entail more bracing intervals in the curved bridge system to make sure that WBR will be less that 0.5 (or other desired limit) for the bridge girders.

It should be noted that Davidson et al's equation for the minimum number of bracing intervals was based on limiting the warping-to-bending stress ratio, WBR, to 0.25 . By inspecting results presented in Table 4.9, it can be observed that all WBR values for the outer and inner girders corresponding to the studied number of vertical cross-bracing intervals that satisfy Davidson et's equation for the 10,15, 25 and $35 \mathrm{~m}$ span bridges were less or equal that 0.25 , except in case of bridges with $35 \mathrm{~m}$ span and L/R ration of 0.7 where WBR was 0.289 , and increase of $16 \%$ of the targeted WBR limit of 0.25 . On the other hand, Table 4.9 shows that WBR values for the inner girders corresponding to the studies number of bracing intervals satisfying Davidson et al's equation are less than or equal to 0.25 except for bridges of $25-\mathrm{m}$ span with $L / R \geq 0.3$ and for bridges of $35-\mathrm{m}$ span with $L . R \geq 0.4$. For example, WBR values were 0.28 and 0.615 for $25-\mathrm{m}$ span bridges with $L / R$ of 0.3 and 0.5 , respectively. Also, WBR value was 0.433 for $35-\mathrm{m}$ span bridges with $L / R$ of 0.7 .

\subsection{Moment distribution factors}

Results from the parametric study are presented in the following sections in the form of the moment and deflection distribution factor for each girder as well as maximum axial force in bracing members. The key parameters considered in this study are: degree of curvature, bridge span, number of girders, girder spacing, variation of flexural stiffness of individual girders, span-to-depth ratio, number and stiffness of cross-bracing members, and vertical stiffeners in the webs. A database of the moment distribution factors for all girder bridges considered in this study is tabulated in Table 4.15, based on maximum flexural stress at the bottom flange (i.e. at either point 1 or 3 in figure 3.5 )

\subsubsection{Effect of cross-bracing system}

$\mathrm{X}$-type bracings as well as top- and bottom-chords (lateral ties for the steel flanges) are usually used in the radial direction between girders, at equal intervals from the support lines. Davidson et al (Davidson et al, 1996) developed an equation, Eq. 2.19, for the maximum Xtype bracing spacing required to limit the warping-to-bending stress ratio in flanges of curved non-composite steel girder bridges, due to construction loading, to 0.25 . Further investigation is required to examine the effect of X-type bracing number and stiffness on the longitudinal bending moments carried by each girder. Table 4.10 shows effect of number of cross-bracing 
It should be noted that Davidson et al's equation was developed based on results of warping-to-bending stress ratio for the outer girder only. However, results presented earlier showed that in many cases, the WBR for the inner girder are considerably greater than those for the outer girder for 25 and $35 \mathrm{~m}$ span bridges and for large $\mathrm{L} / \mathrm{R}$ ratios, as depicted in Table 4.9. This approach can be accepted if the outer girder is to be designed based and other middle and inner girder will have the same size as the outer girder (i.e. bridge cross-section with uniform flexural stiffness among girders). This may be applicable for bridges with light curvature, and short spans. However, for bridges with longer spans (1.e. 25 to $35 \mathrm{~m}$ for example) and for sharp curvature (i.e. $\mathrm{R}=50 \mathrm{~m}$ for example), it may be common practice to design each girder per the applied bending moment. In this case, each girder will have different flexural stiffness. As such, it is advisable to develop an empirical equation for the minimum vertical baring intervals based on the WBR for the inner girders. This would entail more bracing intervals in the curved bridge system to make sure that WBR will be less that 0.5 (or other desired limit) for the bridge girders.

It should be noted that Davidson et al's equation for the minimum number of bracing intervals was based on limiting the warping-to-bending stress ratio, WBR, to 0.25 . By inspecting results presented in Table 4.9, it can be observed that all WBR values for the outer and inner girders corresponding to the studied number of vertical cross-bracing intervals that satisfy Davidson et's equation for the 10,15,25 and $35 \mathrm{~m}$ span bridges were less or equal that 0.25 , except in case of bridges with $35 \mathrm{~m}$ span and L/R ration of 0.7 where WBR was 0.289 , and increase of $16 \%$ of the targeted WBR limit of 0.25 . On the other hand, Table 4.9 shows that WBR values for the inner girders corresponding to the studies number of bracing intervals satisfying Davidson et al's equation are less than or equal to 0.25 except for bridges of $25-\mathrm{m}$ span with $L / R \geq 0.3$ and for bridges of $35-\mathrm{m}$ span with $L . R \geq 0.4$. For example, WBR values were 0.28 and 0.615 for $25-\mathrm{m}$ span bridges with $L / R$ of 0.3 and 0.5 , respectively. Also, WBR value was 0.433 for $35-\mathrm{m}$ span bridges with $\mathrm{L} / \mathrm{R}$ of 0.7 .

\subsection{Moment distribution factors}

Results from the parametric study are presented in the following sections in the form of the moment and deflection distribution factor for each girder as well as maximum axial force in bracing members. The key parameters considered in this study are: degree of curvature, bridge span, number of girders, girder spacing, variation of flexural stiffness of individual girders, span-to-depth ratio, number and stiffness of cross-bracing members, and vertical stiffeners in the webs. A database of the moment distribution factors for all girder bridges considered in this study is tabulated in Table 4.15, based on maximum flexural stress at the bottom flange (i.e. at either point 1 or 3 in figure 3.5 )

\subsubsection{Effect of cross-bracing system}

$\mathrm{X}$-type bracings as well as top-and bottom-chords (lateral ties for the steel flanges) are usually used in the radial direction between girders, at equal intervals from the support lines. Davidson et al (Davidson et al, 1996) developed an equation, Eq. 2.19, for the maximum Xtype bracing spacing required to limit the warping-to-bending stress ratio in flanges of curved non-composite steel girder bridges, due to construction loading, to 0.25 . Further investigation is required to examine the effect of $\mathrm{X}$-type bracing number and stiffness on the longitudinal bending moments carried by each girder. Table 4.10 shows effect of number of cross-bracing 
intervals on moment and deflection distribution factors of a curved girder bridge. Results show that an increase in number of cross-bracing increases the moment distribution factor for the outer girder, while it decreases it for the inner girders. Also, it can be observed that the deflection distribution factor for the outer girder decrease with increase of number of crossbracing spacing, as expected. For simplify the design process, it is better to consider the number of cross-bracing spacing provided by Eq. 2.19 to limit the warping effect, and then, develop expressions for moment and deflection distribution factors for different bridge configurations. Using number of cross-bracing spacing more than that obtained from Eq. 2.19 when designing a curved bridge at construction phase will not help reducing the cost for many reasons. Increasing number of cross-bracing spacing will decrease the maximum axial force in bracing members which is readily less than the nominal size of steel angles based on certain number of bracings obtained from Eq. 2.19, as will be explained later. Also, the decrease in dead load deflection with increase of cross-bracing intervals is not an issue herein since girders will be cambered by the same amount. Therefore, it was decided to conduct the parametric study with number of cross-bracing and top-chords intervals as obtained from Eq. 2.19, along with the cross-bracing requirements stated in the AASHTO-LRFD Specifications for straight bridges (AASHTO, 2004), i.e. minimum of four bracing intervals per span with maximum spacing of $7.5 \mathrm{~m}$

Table 4.11 shows the effect of area of bracing members on moment and deflection distribution factor. Three different cross-areas were used, namely: 4300, 6400 and $9600 \mathrm{~mm}^{2}$, representing steel angles $200 \times 100 \times 15.9,200 \times 150 \times 19$ and $200 \times 200 \times 25.4$, respectively. It should be noted that the cross-sectional shape of the bracing members has no effect since only the value of the cross-sectional area is required for truss elements. It can be observed that the change in cross-bracing area has insignificant effect on both moment and deflection distribution factors. However, the maximum axial force in bracing members' increases with increase in bracing area, as expected. To be in the conservative side, it was decided to continue the parametric study with bracing area of $6400 \mathrm{~mm}^{2}$ which is expected to be more than the bracing size required by the maximum axial force obtained from all bridge configurations considered in the parametric study

\subsubsection{Effect of vertical web stiffeners}

The effect of the presence and number of vertical web stiffeners on the structural response of braced curved non-composite I-girder bridges was investigated. Table 4.12 presents the moment and deflection distribution factors as well as the maximum axial force in bracing members of curved four-girder bridge prototype of $25 \mathrm{~m}$ span with 10 cross-bracing intervals. Three cased were considered namely: bridge with no vertical stiffeners, bridge with vertical stiffeners at a distance equal to twice time the web depth, and bridge with vertical stiffeners at a distance equal to the web depth. It can be observed that the presence of vertical web stiffeners has an insignificant effect on the structural response. Therefore, it was decided to continue the parametric study without the presence of the vertical stiffeners.

\subsubsection{Effect of span-to-depth ratio}

Table 4.13 presents the effect of span-to-depth ratio on moment and deflection distribution factors of the outer girder and maximum axial force in bracing members of fourgirder bridge of $25 \mathrm{~m}$ span. The span-to-depth ratios were taken 15,20 and 25 . It can be 
intervals on moment and deflection distribution factors of a curved girder bridge. Results show that an increase in number of cross-bracing increases the moment distribution factor for the outer girder, while it decreases it for the inner girders. Also, it can be observed that the deflection distribution factor for the outer girder decrease with increase of number of crossbracing spacing, as expected. For simplify the design process, it is better to consider the number of cross-bracing spacing provided by Eq. 2.19 to limit the warping effect, and then, develop expressions for moment and deflection distribution factors for different bridge configurations. Using number of cross-bracing spacing more than that obtained from Eq. 2.19 when designing a curved bridge at construction phase will not help reducing the cost for many reasons. Increasing number of cross-bracing spacing will decrease the maximum axial force in bracing members which is readily less than the nominal size of steel angles based on certain number of bracings obtained from Eq. 2.19, as will be explained later. Also, the decrease in dead load deflection with increase of cross-bracing intervals is not an issue herein since girders will be cambered by the same amount. Therefore, it was decided to conduct the parametric study with number of cross-bracing and top-chords intervals as obtained from Eq. 2.19, along with the cross-bracing requirements stated in the AASHTO-LRFD Specifications for straight bridges (AASHTO, 2004), i.e. minimum of four bracing intervals per span with maximum spacing of $7.5 \mathrm{~m}$

Table 4.11 shows the effect of area of bracing members on moment and deflection distribution factor. Three different cross-areas were used, namely: 4300,6400 and $9600 \mathrm{~mm}^{2}$, representing steel angles $200 \times 100 \times 15.9,200 \times 150 \times 19$ and $200 \times 200 \times 25.4$, respectively. It should be noted that the cross-sectional shape of the bracing members has no effect since only the value of the cross-sectional area is required for truss elements. It can be observed that the change in cross-bracing area has insignificant effect on both moment and deflection distribution factors. However, the maximum axial force in bracing members' increases with increase in bracing area, as expected. To be in the conservative side, it was decided to continue the parametric study with bracing area of $6400 \mathrm{~mm}^{2}$ which is expected to be more than the bracing size required by the maximum axial force obtained from all bridge configurations considered in the parametric study.

\subsubsection{Effect of vertical web stiffeners}

The effect of the presence and number of vertical web stiffeners on the structural response of braced curved non-composite I-girder bridges was investigated. Table 4.12 presents the moment and deflection distribution factors as well as the maximum axial force in bracing members of curved four-girder bridge prototype of $25 \mathrm{~m}$ span with 10 cross-bracing intervals. Three cased were considered namely: bridge with no vertical stiffeners, bridge with vertical stiffeners at a distance equal to twice time the web depth, and bridge with vertical stiffeners at a distance equal to the web depth. It can be observed that the presence of vertical web stiffeners has an insignificant effect on the structural response. Therefore, it was decided to continue the parametric study without the presence of the vertical stiffeners.

\subsubsection{Effect of span-to-depth ratio}

Table 4.13 presents the effect of span-to-depth ratio on moment and deflection distribution factors of the outer girder and maximum axial force in bracing members of fourgirder bridge of $25 \mathrm{~m}$ span. The span-to-depth ratios were taken 15, 20 and 25 . It can be 
observed that the span-to-depth ratio has insignificant effect on the moment distribution factors.

However, an increase in span-to-depth ratio generally decreases the deflection of the outer girder, while it increases the maximum axial force in bracing members. It was decided to conduct the parametric study with span-to-depth ratio of 20 , representing the practical depth used in curved I-girder bridges.

\subsubsection{Variation of girder stiffness vs. degree of curvature}

In general, the effect of curvature is to increase the loading on girders outside the longitudinal centre line of the bridge and to decrease the loading on girders inside the centre line. Thus, the outmost girder has its loading most heavily augmented by curvature and the innermost girder undergoes the most relief. In terms of longitudinal bending moment, this effect means that all girders in the cross-section of a curved girder bridge have substantially different longitudinal bending moments and therefore, different cross-section requirements. Thus, each girder should be individually designed to obtain the least self-weight of bridge cross-section. This can be accomplished by fixing the depth of bridge cross-section and changing the cross-sectional areas of steel top and bottom flanges. Obviously, the superelevation can be achieved by elevating the individual girders by the angle of super-elevation. Other method of applying the super-elevation is by fixing the level of the bottom of the girders and impose the super-elevation to the concrete deck slab by varying its depth along the bridge width or by providing haunches with different depths over each steel girder. This will increase the total depth of each girder towards the outmost one, thus increasing the bending stiffness. Super-elevation was not considered herein since it was proved elsewhere that it has insignificant effect on the structural response (Huang et. a1. 1995; Guide 1993; Brennan 1970).
In the present study, for example in case of $25 \mathrm{~m}$ span bridge, to change the stiffness of each girder with respect to the stiffness of the inner girder, the top and bottom flange thicknesses of each girder changed to produce ratios of outer girder stiffness-to-inner girder stiffness of $1,1.1$, $1.2,1.3,1.57$ and 1.96 , considering linear increase in bending stiffness from the inner girder towards the outer girder. Figure 4.3 shows the effect of curvature as well as the change in bending stiffness of girders in bridge cross-section in moment distribution factor of the outer girder of four-girder Bridge of $25 \mathrm{~m}$ span. It can be observed that the moment distribution factor of the outer girder increases with increase in span-to-radius of curvature ratio. Also, it can be observed that outer girder exhibits an increase in moment distribution factor with increase in its bending stiffness with respect to that of the inner girder. In the other hand, Fig. 4.4 presents the effect of curvature and the variation of girder bending stiffness in moment distribution factor of the inner girder of the same bridge prototype. For curved bridges, it can be observed that the moment distribution factor of the inner girder decreases, as expected, with increase in span-to-radius of curvature ratio. Also, the moment distribution factor of the inner girder decreases with increase in bending stiffness of the outer girder with respect to that of the inner girder.

\subsubsection{Effect of bridge aspect ratio}

Bridge aspect ratio is presented her as the ratio of the span length to the bridge width. It is not easy to study the effect of the aspect ratio since interference will occur when having short span with narrow bridge and long span with wide bridge. Therefore, it was decided to study the effects of bridge span and bridge width separately. Figures 4.5 and 4.6 show the effect of span length on the moment distribution factors of the outer and inner girders of curved four-girder 
observed that the span-to-depth ratio has insignificant effect on the moment distribution factors.

However, an increase in span-to-depth ratio generally decreases the deflection of the outer girder, while it increases the maximum axial force in bracing members. It was decided to conduct the parametric study with span-to-depth ratio of 20 , representing the practical depth used in curved I-girder bridges.

\subsubsection{Variation of girder stiffness vs. degree of curvature}

In general, the effect of curvature is to increase the loading on girders outside the longitudinal centre line of the bridge and to decrease the loading on girders inside the centre line. Thus, the outmost girder has its loading most heavily augmented by curvature and the innermost girder undergoes the most relief. In terms of longitudinal bending moment, this effect means that all girders in the cross-section of a curved girder bridge have substantially different longitudinal bending moments and therefore, different cross-section requirements. Thus, each girder should be individually designed to obtain the least self-weight of bridge cross-section. This can be accomplished by fixing the depth of bridge cross-section and changing the cross-sectional areas of steel top and bottom flanges. Obviously, the superelevation can be achieved by elevating the individual girders by the angle of super-elevation. Other method of applying the super-elevation is by fixing the level of the bottom of the girders and impose the super-elevation to the concrete deck slab by varying its depth along the bridge width or by providing haunches with different depths over each steel girder. This will increase the total depth of each girder towards the outmost one, thus increasing the bending stiffness. Super-elevation was not considered herein since it was proved elsewhere that it has insignificant effect on the structural response (Huang et. a1. 1995; Guide 1993; Brennan 1970).
In the present study, for example in case of $25 \mathrm{~m}$ span bridge, to change the stiffness of each girder with respect to the stiffness of the inner girder, the top and bottom flange thicknesses of each girder changed to produce ratios of outer girder stiffness-to-inner girder stiffness of $1,1.1$, $1.2,1.3,1.57$ and 1.96 , considering linear increase in bending stiffness from the inner girder towards the outer girder. Figure 4.3 shows the effect of curvature as well as the change in bending stiffness of girders in bridge cross-section in moment distribution factor of the outer girder of four-girder Bridge of $25 \mathrm{~m}$ span. It can be observed that the moment distribution factor of the outer girder increases with increase in span-to-radius of curvature ratio. Also, it can be observed that outer girder exhibits an increase in moment distribution factor with increase in its bending stiffness with respect to that of the inner girder. In the other hand, Fig. 4.4 presents the effect of curvature and the variation of girder bending stiffness in moment distribution factor of the inner girder of the same bridge prototype. For curved bridges, it can be observed that the moment distribution factor of the inner girder decreases, as expected, with increase in span-to-radius of curvature ratio. Also, the moment distribution factor of the inner girder decreases with increase in bending stiffness of the outer girder with respect to that of the inner girder.

\subsubsection{Effect of bridge aspect ratio}

Bridge aspect ratio is presented her as the ratio of the span length to the bridge width. It is not easy to study the effect of the aspect ratio since interference will occur when having short span with narrow bridge and long span with wide bridge. Therefore, it was decided to study the effects of bridge span and bridge width separately. Figures 4.5 and 4.6 show the effect of span length on the moment distribution factors of the outer and inner girders of curved four-girder 
Bridge of $2 \mathrm{~m}$ spacing of different curvature, respectively. It was observed that the moment carried by the outer girder increases with increase in span length, while it decreases for the inner girder. It can be observed that the rate of increase in moment distribution factor or decrease in moment distribution factor generally increase with increase of bridge curvature. The change in bridge width was investigated by changing the girder spacing. Girder spacing was taken as 2, 2.5 and $3 \mathrm{~m}$. Figures 4.7 and 4.8 show the effect of girder spacing of moment distribution factors for the outer and inner girders of three-girder bridges of $25 \mathrm{~m}$ span, respectively. For curved bridges, it can be observed that the moment distribution factor for the outer girder decreases with increase in girder spacing, while the moment carried by the inner girder increases.

\subsubsection{Effect of number of girders}

To study the effect of number of girders on moment distribution factor carried by each girder, the models were created by keeping the spacing between girders constant and adding girders, thereby increasing the width of the system but preserving girder stiffness per unit width, constant span and radius of curvature. Figures 4.9 and 4.10 show the effect of number of girders on moment distribution factor for the outer and inner girders of I-girder bridges of $35 \mathrm{~m}$ span and $2 \mathrm{~m}$ girder spacing, respectively. For curved bridges, it can be observed that the moment carried by the outer girder decreases with increase in number of girders, while the moment carried by the inner girder increases.

\subsubsection{Empirical Formulas for the Moment Distribution Factor, $\mathrm{D}_{M}$}

From the results of the parametric study, it became evident that the moment distribution factor, $D_{M}$, for simply-supported curved composite concrete-deck steel I-girder bridges at construction phase is governed by the following parameters: (i) span-to-radius ratio, L/R; (ii) bridge span, $\mathrm{L}$; (iii) number of girders, $\mathrm{N}_{\mathrm{G}}$; and (iv) girder spacing, $\mathrm{S}_{\mathrm{G}}$. Using statistical package of best fit, empirical expressions were generated for moment distribution factors for the outer, central, and inner girders. All dimensions used in these expressions are in meters. For proper use of these expressions in design, a minimum number of bracing spacing provided by Eq. 2.19 is required, along with a condition that at least four bracing spacing with a spacing not exceeding $7.5 \mathrm{~m}$, as specified by the AASHTO-LRFD. It should be noted that the term bracings herein indicated X-type bracing with top and bottom chords.

(a) Moment distribution factor for the outer girder, $\mathrm{D}_{\mathrm{M}}(\mathrm{O})$ :

$D_{M}(\mathrm{O})=1+0.81 \mathrm{~L}^{0.65}(\mathrm{~L} / \mathrm{R})^{0.94} \mathrm{~N}^{-0.62} \mathrm{~S}_{\mathrm{G}}^{-0.81}$

(b) Moment distribution factor for the central girder, $\mathrm{D}_{\mathrm{M}}(\mathrm{C})$ :

$\mathrm{D}_{\mathrm{M}}(\mathrm{C})=1+0.62 \mathrm{~L}^{-0.22}(\mathrm{~L} / \mathrm{R})^{2} \mathrm{~N}^{0.20} \mathrm{~S}_{\mathrm{G}}{ }^{0.22}$

(c) Moment distribution factor for the inner girder, $\mathrm{D}_{\mathrm{M}}(\mathrm{I})$ :

$\mathrm{D}_{\mathrm{M}}(\mathrm{I})=1-0.22 \mathrm{~L}^{0.64}(\mathrm{~L} / \mathrm{R})^{0.51} \mathrm{~N}^{-0.40} \mathrm{~S}_{\mathrm{G}}^{-0.75}$

\subsection{Shear distribution factors}

The following sub-sections summarize the effects of key parameters on shear distribution factors of the studies curved steel I-girders at construction stage. It should be noted that the reaction forces at supports were assumed to be the maximum shear forces in girder webs. Table 4.14 shows the effect of number of bracing intervals on the shear distribution 
Bridge of $2 \mathrm{~m}$ spacing of different curvature, respectively. It was observed that the moment carried by the outer girder increases with increase in span length, while it decreases for the inner girder. It can be observed that the rate of increase in moment distribution factor or decrease in moment distribution factor generally increase with increase of bridge curvature. The change in bridge width was investigated by changing the girder spacing. Girder spacing was taken as 2, 2.5 and $3 \mathrm{~m}$. Figures 4.7 and 4.8 show the effect of girder spacing of moment distribution factors for the outer and inner girders of three-girder bridges of $25 \mathrm{~m}$ span, respectively. For curved bridges, it can be observed that the moment distribution factor for the outer girder decreases with increase in girder spacing, while the moment carried by the inner girder increases.

\subsubsection{Effect of number of girders}

To study the effect of number of girders on moment distribution factor carried by each girder, the models were created by keeping the spacing between girders constant and adding girders, thereby increasing the width of the system but preserving girder stiffness per unit width, constant span and radius of curvature. Figures 4.9 and 4.10 show the effect of number of girders on moment distribution factor for the outer and inner girders of I-girder bridges of $35 \mathrm{~m}$ span and $2 \mathrm{~m}$ girder spacing, respectively. For curved bridges, it can be observed that the moment carried by the outer girder decreases with increase in number of girders, while the moment carried by the inner girder increases.

\subsubsection{Empirical Formulas for the Moment Distribution Factor, $\mathrm{D}_{\mathrm{M}}$}

From the results of the parametric study, it became evident that the moment distribution factor, $D_{M}$, for simply-supported curved composite concrete-deck steel I-girder bridges at construction phase is governed by the following parameters: (i) span-to-radius ratio, L/R; (ii) bridge span, $\mathrm{L}$; (iii) number of girders, $\mathrm{N}_{\mathrm{G}}$; and (iv) girder spacing, $\mathrm{S}_{\mathrm{G}}$. Using statistical package of best fit, empirical expressions were generated for moment distribution factors for the outer, central, and inner girders. All dimensions used in these expressions are in meters. For proper use of these expressions in design, a minimum number of bracing spacing provided by Eq. 2.19 is required, along with a condition that at least four bracing spacing with a spacing not exceeding $7.5 \mathrm{~m}$, as specified by the AASHTO-LRFD. It should be noted that the term bracings herein indicated X-type bracing with top and bottom chords.

(a) Moment distribution factor for the outer girder, $\mathrm{D}_{\mathrm{M}}(\mathrm{O})$ :

$\mathrm{D}_{\mathrm{M}}(\mathrm{O})=1+0.81 \mathrm{~L}^{0.65}(\mathrm{~L} / \mathrm{R})^{0.94} \mathrm{~N}^{-0.62} \mathrm{~S}_{\mathrm{G}}^{-0.81}$

(b) Moment distribution factor for the central girder, $\mathrm{D}_{\mathrm{M}}(\mathrm{C})$ :

$\mathrm{D}_{\mathrm{M}}(\mathrm{C})=1+0.62 \mathrm{~L}^{-0.22}(\mathrm{~L} / \mathrm{R})^{2} \mathrm{~N}^{0.20} \mathrm{~S}_{\mathrm{G}}{ }^{0.22}$

(c) Moment distribution factor for the inner girder, $\mathrm{D}_{\mathrm{M}}(\mathrm{I})$ :

$\mathrm{D}_{\mathrm{M}}(\mathrm{I})=1-0.22 \mathrm{~L}^{0.64}(\mathrm{~L} / \mathrm{R})^{0.51} \mathrm{~N}^{-0.40} \mathrm{~S}_{\mathrm{G}}{ }^{-0.75}$

\subsection{Shear distribution factors}

The following sub-sections summarize the effects of key parameters on shear distribution factors of the studies curved steel I-girders at construction stage. It should be noted that the reaction forces at supports were assumed to be the maximum shear forces in girder webs. Table 4.14 shows the effect of number of bracing intervals on the shear distribution 
factors for the $25-\mathrm{m}$ span bridge with different $L / R$ ratios. Is can be observed that the increase in the number of bracing intervals has no effect on the shear distribution factors irrespective of the degree of curvature. As such, it was decided to continue this parametric study with number of bracing intervals as dictated Eq. 2.19. A database of the shear distribution factors for all girder bridges considered in this study is tabulated in Table 4.16 .

\subsubsection{Effect of span-to-radius of curvature ratio}

The effect of curvature on the reaction forces carried by each girder was investigated. Figure 4.11 shows the effect of span-to-radius of curvature ratio, $L / R$, on the shear distribution factor of each girder of a five-girder curved bridge prototype of span $35 \mathrm{~m}$ and girder spacing of $3 \mathrm{~m}$. It was observed that the reaction distribution factor increases with an increase in the span-to-radius ratio for the outer girder far away from the center of curvature. While it decreases with an increase in the span-to-radius ratio for the inner girder close to the center of curvature. This is attributed to the high torsional moments associated with curvature.

\subsubsection{Effect of number of girders}

To study the effect of number of girders on reaction distribution factor carried by each girder, the bridge prototypes were created by keeping the spacing between girders constants and adding girders, thereby increasing the width of the system but preserving a constant span length and radius of curvature. Figure 4.12 shows the effect of number of number of girders on the reaction distribution factor carried by the outer girder of the curved system. It was observed that the shear distribution factor carried by the outer girder decreases with increase in number of curved girders. However, Fig. 4.13 shows that the shear distribution factor for the inner girder increases with increase of number of girders. This may be attributed to the increase in bridge width that counteracts the torsion moment effects at the support line.

\subsubsection{Effect of span length}

When investigating the effect of span length on the behavior of the curved girder system, the number of girders and girder spacing were maintained constant. Figures 4.14 and 4.15 show the effect of span length on the reaction distribution factor of the outer and inner girders, respectively, for a number of radii of curvature. For the outer support far away from the center of curvature, it was observed that the reaction distribution factor increases with increase in span length. While for the inner support, reaction distribution factor decreases with increase in span length. This rate of change increases with increase in bridge curvature

\subsubsection{Effect of girder spacing}

To determine the effect of girder spacing has on the behavior of a curved system, the spacing of the girders was varied from $2 \mathrm{~m}$ to $3 \mathrm{~m}$ while maintain the span length, number of girders of the system constant. The increase in girder spacing effectively stiffened the system and reduced the resulting stresses and deflections in much the same manner as increasing the number of girders. Figures 4.16 and 4.17 show the effect of girder spacing on reaction distribution factor for the inner and outer girders, respectively. It was observed that 
factors for the $25-\mathrm{m}$ span bridge with different $L / R$ ratios. Is can be observed that the increase in the number of bracing intervals has no effect on tie shear distribution factors irrespective of the degree of curvature. As such, it was decided to continue this parametric study with number of bracing intervals as dictated Eq. 2.19. A database of the shear distribution factors for all girder bridges considered in this study is tabulated in Table 4.16 .

\subsubsection{Effect of span-to-radius of curvature ratio}

The effect of curvature on the reaction forces carried by each girder was investigated. Figure 4.11 shows the effect of span-to-radius of curvature ratio, $L / R$, on the shear distribution factor of each girder of a five-girder curved bridge prototype of span $35 \mathrm{~m}$ and girder spacing of $3 \mathrm{~m}$. It was observed that the reaction distribution factor increases with an increase in the span-to-radius ratio for the outer girder far away from the center of curvature. While it decreases with an increase in the span-to-radius ratio for the inner girder close to the center of curvature. This is attributed to the high torsional moments associated with curvature.

\subsubsection{Effect of number of girders}

To study the effect of number of girders on reaction distribution factor carried by each girder, the bridge prototypes were created by keeping the spacing between girders constants and adding girders, thereby increasing the width of the system but preserving a constant span length and radius of curvature. Figure 4.12 shows the effect of number of number of girders on the reaction distribution factor carried by the outer girder of the curved system. It was observed that the shear distribution factor carried by the outer girder decreases with increase in number of curved girders. However, Fig. 4.13 shows that the shear distribution factor for the inner girder increases with increase of number of girders. This may be attributed to the increase in bridge width that counteracts the torsion moment effects at the support line.

\subsubsection{Effect of span length}

When investigating the effect of span length on the behavior of the curved girder system, the number of girders and girder spacing were maintained constant. Figures 4.14 and 4.15 show the effect of span length on the reaction distribution factor of the outer and inner girders, respectively, for a number of radii of curvature. For the outer support far away from the center of curvature, it was observed that the reaction distribution factor increases with increase in span length. While for the inner support, reaction distribution factor decreases with increase in span length. This rate of change increases with increase in bridge curvature.

\subsubsection{Effect of girder spacing}

To determine the effect of girder spacing has on the behavior of a curved system, the spacing of the girders was varied from $2 \mathrm{~m}$ to $3 \mathrm{~m}$ while maintain the span length, number of girders of the system constant. The increase in girder spacing effectively stiffened the system and reduced the resulting stresses and deflections in much the same manner as increasing the number of girders. Figures 4.16 and 4.17 show the effect of girder spacing on reaction distribution factor for the inner and outer girders, respectively. It was observed that 
the reaction distribution factor decreases with increase in curved girder spacing for the outer girder. While it increases for the inner girder with increase of girder spacing.

4.5.5 Empirical Formulas for the shear distribution factor, $D_{\mathrm{V}}$

The empirical expression of reaction distribution factor is governed by following parameters: (i) span-to-radius ratio (L/R), (ii) span length (L), (iii) number of girders $\left(\mathrm{N}_{B}\right)$, (iv) girder spacing $\left(G_{s}\right)$. Using statistical computer program (Microsoft excel), empirical expressions were generated for the reaction distribution factors at supports on outer, central, and inner girders. All the dimensions used in these expressions are in meters. For proper use of these expressions in design, a minimum number of bracing intervals provided by eq. 2.19 is required. The empirical expressions are shown as follow:

(a) Shear distribution factor for the outer girder, $\mathrm{D}_{\mathrm{M}}(\mathrm{O})$ :

$\mathrm{D}_{\mathrm{V}}(\mathrm{O})=1+0.43(\mathrm{~L})^{0.85}(\mathrm{~L} / \mathrm{R})^{0.94}(\mathrm{~N})^{-0.79}\left(\mathrm{G}_{\mathrm{s}}\right)^{-0.92}$

(b) Shear distribution factor for the central girder, $D_{M}(C)$ :

$\operatorname{Dv}(\mathrm{C})=1+0.11(\mathrm{~L})^{0.44}(\mathrm{~L} / \mathrm{R})^{1.51}(\mathrm{~N})^{1.01}\left(\mathrm{G}_{\mathrm{S}}\right)^{0.13}$

(c) Shear distribution factor for the inner girder, $\mathrm{D}_{\mathrm{M}}(\mathrm{I})$ :

$D_{\mathrm{V}}(\mathrm{I})=1-0.50(\mathrm{~L})^{0.70}(\mathrm{~L} / \mathrm{R})^{1.07}(\mathrm{~N})^{-0.43}\left(\mathrm{G}_{\mathrm{S}}\right)^{-0.72}$

\section{Limitation of the equations $4.4,4.5 \& 4.6$}

The above derived equations are applicable for the following conditions

a) Span length (L): span length should be equal to or greater than $10 \mathrm{~m}$ and should be less than or equal to $35 \mathrm{~m}$

b) Radius of curvature R: Radius of curvature should be greater than $50 \mathrm{~m}$ c) No of bracings: no of bracing intervals should be according to davidson's eq. 1.1

d) No of girders: NO of girders should be more than 3 .

e) Girder spacing: girder spacing should be equal to or more than $2 \mathrm{~m}$ and less than or equal to $3 \mathrm{~m}$. 
the reaction distribution factor decreases with increase in curved girder spacing for the outer girder. While it increases for the inner girder with increase of girder spacing.

4.5.5 Empirical Formulas for the shear distribution factor, $\mathrm{D}_{\mathrm{V}}$

The empirical expression of reaction distribution factor is governed by following parameters: (i) span-to-radius ratio (L/R), (ii) span length (L), (iii) number of girders $\left(\mathrm{N}_{B}\right)$, (iv) girder spacing $\left(G_{s}\right)$. Using statistical computer program (Microsoft excel), empirical expressions were generated for the reaction distribution factors at supports on outer, central, and inner girders. All the dimensions used in these expressions are in meters. For proper use of these expressions in design, a minimum number of bracing intervals provided by eq. 2.19 is required. The empirical expressions are shown as follow:

(a) Shear distribution factor for the outer girder, $\mathrm{D}_{\mathrm{M}}(\mathrm{O})$ :

$\mathrm{D}_{\mathrm{V}}(\mathrm{O})=1+0.43(\mathrm{~L})^{0.85}(\mathrm{~L} / \mathrm{R})^{0.94}(\mathrm{~N})^{-0.79}\left(\mathrm{G}_{\mathrm{s}}\right)^{-0.92}$

(b) Shear distribution factor for the central girder, $\mathrm{D}_{\mathrm{M}}(\mathrm{C})$ :

$\operatorname{Dv}(\mathrm{C})=1+0.11(\mathrm{~L})^{0.44}(\mathrm{~L} / \mathrm{R})^{1.51}(\mathrm{~N})^{1.01}\left(\mathrm{G}_{\mathrm{s}}\right)^{0.13}$

(c) Shear distribution factor for the inner girder, $\mathrm{D}_{\mathrm{M}}(\mathrm{I})$ :

$\operatorname{DV}(\mathrm{I})=1-0.50(\mathrm{~L})^{0.70}(\mathrm{~L} / \mathrm{R})^{1.07}(\mathrm{~N})^{-0.43}\left(\mathrm{G}_{\mathrm{s}}\right)^{-0.72}$

Limitation of the equations $4.4,4.5 \& 4.6$

The above derived equations are applicable for the following conditions

a) Span length (L): span length should be equal to or greater than $10 \mathrm{~m}$ and should be less than or equal to $35 \mathrm{~m}$.

b) Radius of curvature R: Radius of curvature should be greater than $50 \mathrm{~m}$ c) No of bracings: no of bracing intervals should be according to davidson's eq. 1.1

d) No of girders: NO of girders should be more than 3 .

e) Girder spacing: girder spacing should be equal to or more than $2 \mathrm{~m}$ and less than or equal to $3 \mathrm{~m}$. 


\section{CHAPTER V}

\section{CONCLUSIONS}

\subsection{Introduction}

An extensive parametric study was conducted, using the finite-element analysis software "SAP2000", to examine the key parameters affecting warping stresses in curved girder bridges under construction loads when shoring is not used. Previously available empirical equations for minimum number of cross-bracing intervals to limit warping stresses in curved girders were examined in this study. A strengthening technique using "torsion box" at the girder supports was proposed and examined with respect to girder warping and flexural stresses as well as support reactions. This study was extended to investigate the moment and shear distribution factors of each girder under construction loads. The key parameters considered in this study included number of girders, girder spacing, number of cross bracing intervals between support lines, degree of curvature and girder span length. Th following section summarizes the outcome of this research.

\subsection{Conclusions}

Based on the results obtained in this research, the following conclusions can be drawn:

1- The increase of number of girders for the same girder spacing (i.e. the increase in bridge width) decreases the warping effects. A similar trend can be predicted when increasing the girder spacing with the same number of girders since bridge width increases accordingly.

2- Warping-to-bending stress ration in girder flanges increase with increase in bridge curvature.

3- Warping-to-bending stress ratio decreases with increase in flange warping constant.
4- It is advisable to include the flange warping constant rather than its flange width in developing empirical expression for the minimum number of bracing interval since it includes the lateral moment of inertia of the girder flange as well as girder depth

5- Utilizing "Torsion Box" in the form of added horizontal bracing members joining girders' top and bottom flanges enhances the load distribution characteristics of the curved system but it has insignificant effect on the flange warping-to-bending stress ratio. This technique can be used to strengthen existing bridges to carry overloads since it provides less girder flexural stresses to satisfy CHBDC design provision for permanent deflection control due to sequence of construction.

7- Span length, radius of curvature, number of girders, and girder spacing have significant effect on the longitudinal bending moments carried by each girder, girder deflection, maximum axial force in bracing members, and maximum girder shear forces

8- Empirical expressions was proposed for computing the maximum longitudinal bending moments carried by each girder as well as maximum shear force for girder web design and bridge bearing design, provided that the minimum number of cross-bracing intervals obtained from Davidson et al's equation is utilized in the curved girder system. This is in addition to the condition that at least four bracing intervals with a spacing not exceeding 7.5 $\mathrm{m}$, as specified by the AASHTO-LRFD, be used. It should be noted that the term bracings herein indicated X-type bracing with top and bottom chords.

\subsection{Recommendation for future research}

Further study is required to include following: 


\section{CHAPTER V}

\section{CONCLUSIONS}

\subsection{Introduction}

An extensive parametric study was conducted, using the finite-element analysis software "SAP2000", to examine the key parameters affecting warping stresses in curved girder bridges under construction loads when shoring is not used. Previously available empirical equations for minimum number of cross-bracing intervals to limit warping stresses in curved girders were examined in this study. A strengthening technique using "torsion box" at the girder supports was proposed and examined with respect to girder warping and flexural stresses as well as support reactions. This study was extended to investigate the moment and shear distribution factors of each girder under construction loads. The key parameters considered in this study included number of girders, girder spacing, number of cross bracing intervals between support lines, degree of curvature and girder span length. Th following section summarizes the outcome of this research.

\subsection{Conclusions}

Based on the results obtained in this research, the following conclusions can be drawn:

1- The increase of number of girders for the same girder spacing (i.e. the increase in bridge width) decreases the warping effects. A similar trend can be predicted when increasing the girder spacing with the same number of girders since bridge width increases accordingly.

2- Warping-to-bending stress ration in girder flanges increase with increase in bridge curvature.

3- Warping-to-bending stress ratio decreases with increase in flange warping constant.
4- It is advisable to include the flange warping constant rather than its flange width in developing empirical expression for the minimum number of bracing interval since it includes the lateral moment of inertia of the girder flange as well as girder depth.

5- Utilizing "Torsion Box" in the form of added horizontal bracing members joining girders' top and bottom flanges enhances the load distribution characteristics of the curved system but it has insignificant effect on the flange warping-to-bending stress ratio. This technique can be used to strengthen existing bridges to carry overloads since it provides less girder flexural stresses to satisfy CHBDC design provision for permanent deflection control due to sequence of construction.

7- Span length, radius of curvature, number of girders, and girder spacing have significant effect on the longitudinal bending moments carried by each girder, girder deflection, maximum axial force in bracing members, and maximum girder shear forces.

8- Empirical expressions was proposed for computing the maximum longitudinal bending moments carried by each girder as well as maximum shear force for girder web design and bridge bearing design, provided that the minimum number of cross-bracing intervals obtained from Davidson et al's equation is utilized in the curved girder system. This is in addition to the condition that at least four bracing intervals with a spacing not exceeding 7.5 $\mathrm{m}$, as specified by the AASHTO-LRFD, be used. It should be noted that the term bracings herein indicated X-type bracing with top and bottom chords.

\subsection{Recommendation for future research}

Further study is required to include following: 
1- The effect of bridge span continuity on the minimum number of bracing intervals to limit the warping-to-bending stress ratio to a desired value.

2- The effect of skew supports in curved bridge system.

\section{REFERENCES}

Al-Hashimy, M. 2005. Load Distribution in Curved Concrete Slab-on-Steel I-Girder Bridges. M.A.Sc. Thesis, Civil Engineering Department, Ryerson University.

American Association for State Highway and Transportation Officials, AASHTO. 1980 Guide Specification for Horizontally Curved Highway Bridges. Washington, D.C.

American Association for State Highway and Transportation Officials, AASHTO. 1993. Guide Specification for Horizontally Curved Highway Bridges. Washington, D.C.

American Association of State Highway and Transportation Officials, AASHTO. 1996. Standard Specifications for Highway Bridges. Washington, D.C.

American Association for State Highway and Transportation Officials, AASHTO. 2003. Guide Specification for Horizontally Curved Highway Bridges. Washington, D.C.

American Association of State Highway and Transportation Officials, AASHTO. 2004. AASHTO LRFD Bridge Design Specifications. Washington, D.C.

Arizumi, Y., Oshiro, T., and Hamado, S., 1982. "Finite-Strip Analysis of Curved Composite Girders with incomplete interaction", Computers \& Structures, 15(6): 603-612.

Bakht, B., and Moses, F., 1982. "Lateral Distribution Factors for Highway Bridges", Journal of Structural Engineering ASCE, 114(8): 1785-1803.

Barr, P.J. and Womack, K.C. 2007. Live-Load Analysis of a curved I-Girder Bridge, Journal of Bridge Engineering, ASCE, 12(4). 477-484.

Bell L. C., and Heins C.P., 1969. "Curved Girder Computer Manual", Report No. 30, Program Report on the Design of Curved Viaducts, University of Maryland. 
1- The effect of bridge span continuity on the minimum number of bracing intervals to limit the warping-to-bending stress ratio to a desired value.

2- The effect of skew supports in curved bridge system.

\section{REFERENCES}

Al-Hashimy, M. 2005. Load Distribution in Curved Concrete Slab-on-Steel I-Girder Bridges. M.A.Sc. Thesis, Civil Engineering Department, Ryerson University.

American Association for State Highway and Transportation Officials, AASHTO. 1980 Guide Specification for Horizontally Curved Highway Bridges. Washington, D.C.

American Association for State Highway and Transportation Officials, AASHTO. 1993. Guide Specification for Horizontally Curved Highway Bridges. Washington, D.C.

American Association of State Highway and Transportation Officials, AASHTO. 1996. Standard Specifications for Highway Bridges. Washington, D.C.

American Association for State Highway and Transportation Officials, AASHTO. 2003. Guide Specification for Horizontally Curved Highway Bridges. Washington, D.C.

American Association of State Highway and Transportation Officials, AASHTO. 2004. AASHTO LRFD Bridge Design Specifications. Washington, D.C.

Arizumi, Y., Oshiro, T., and Hamado, S., 1982. "Finite-Strip Analysis of Curved Composite Girders with incomplete interaction", Computers \& Structures, 15(6): 603-612.

Bakht, B., and Moses, F., 1982. "Lateral Distribution Factors for Highway Bridges", Journal of Structural Engineering ASCE, 114(8): 1785-1803.

Barr, P.J. and Womack, K.C. 2007. Live-Load Analysis of a curved I-Girder Bridge, Journal of Bridge Engineering, ASCE, 12(4). 477-484.

Bell L. C., and Heins C.P., 1969. "Curved Girder Computer Manual", Report No. 30, Program Report on the Design of Curved Viaducts, University of Maryland. 
Brennan, P. J., and Mandel, J. A., 1973. 'Users Manual-Program for Three-Dimensional Analysis of Horizontally Curved Bridges”, Syracuse University Report, Research Project HPR-2(111). Brockenbrough, R. L., 1986. "Distribution Factors for Curved I-Girder Bridges", ASCE Journal of Structural Engineering, 112(10): 2200-2215

Canadian Standard Association, "Canadian Highway Bridge Design Code", CHBDC. 2000. Etobicoke, Ontario, Canada.

Canadian Standard Association, "Canadian Highway Bridge Design Code", CHBDC. 2006. Etobicoke, Ontario, Canada.

Culver, C. G., 1967. "Natural Frequencies of Horizontally Curved Beams", Journal of Structural Division, ASCE, 93(2): 189-203.

Davidson, J. S., Keller, M. A., and Yoo, C. H., 1996. "Cross-frame Spacing and Parametric Effects in Horizontally Curved I-Girder Bridges", ASCE Journal of Structural Engineering, 122(9): 1089-1096.

DePolo, David S. and Linzell, Daniel G. 2002. Evaluation of Live Load Lateral Flange Bending Distribution for a Horizontally Curved I-Girder Bridge, U.S Army Corps. of Engineers.

Galambos, T.V., 1978. "Tentative load factor design criteria for curved steel bridges", Research Report No. 50, School of Engineering and Applied Science, Civil Engineering Department, Washington University, St. Louis.

Grubb, M. A., 1984. "Horizontally curved I-girder bridge analysis: V-load method", Transportation Research Board Record 982, National Research Council, 26-35.

Hayes, C. O., Jr., Sessions, L. M., and Berry, A. J., 1986. "Further studies on lateral load distribution using finite element methods", Transportation Research Record, (1072), Transportation Research Board, Washington, D.C., 6-14.
Heins, C. P., and Siminou, J., 1970. "Preliminary Design of Curved Bridges", AISC Engineering Journal, 7(2), 50-61

Heins, C. P., and Bell, L. C., 1972. "Curved Girder Bridge Analysis", Journal of Computers and Structures, 2: 785-797

Heins, C. P., and Jin, J. O., 1984. "Live Load Distribution on Braced Curved I-Girders", ASCE Journal of Structural Engineering, 110(3): 523-530.

Howell and Earls 2007. Curved Steel I-Girder Bridge Response during Construction Loading; Effects of Web Plumbness. Journal of Bridge Engineering, ASCE, 12(4) 484-493.

Ketchek, K.F., 1969. "Discussion of Horizontally curved girders - state of the art by McManus PF et al.", Journal of Structural Division, ASCE, 95 (ST12): 2999-3001.

Kostem, C.N., and DeCastro, E.S., 1977. "Effect of diaphragms on lateral load distribution in beam-slab bridges", Transportation Research Record, Bridge Test, No. 645, 6-9.

Lavelle, F. H., and Lasks, R. J., 1975. "CUGAR2 and CUGAR3 user's Manuals", CURT Final Report, Research Project HPR-2(111), University of Rhode Island.

Logan, D., 2002. "A first course in the finite element method", $3^{\text {rd }}$ Edition, Text Book,

McElwain, Brett A., and Laman, A. Jeffrey, 2000. "Experimental Verification of Horizontally curved I-girder Bridge Behavior", Journal of Bridge Engineering, Vol.5, No.4.

McManus, P.F., Nasir, G.A., and Culver, C. G., 1969. "Horizontally curved girders - state of the art", Journal of Structural Division. ASCE, 95(ST5): 853-870.

Montalvao, E Silva, J. M., and Urgueira, A., 1988. “Out-of-Plane Dynamic Response of Curved Beams", an Analytical Model. International Journal of Solids and Structures, 24(3): 271284. 
Brennan, P. J., and Mandel, J. A., 1973. 'Users Manual-Program for Three-Dimensional Analysis of Horizontally Curved Bridges", Syracuse University Report, Research Project HPR-2(111). Brockenbrough, R. L., 1986. "Distribution Factors for Curved I-Girder Bridges", ASCE Journal of Structural Engineering, 112(10): 2200-2215

Canadian Standard Association, "Canadian Highway Bridge Design Code", CHBDC. 2000. Etobicoke, Ontario, Canada.

Canadian Standard Association, "Canadian Highway Bridge Design Code", CHBDC. 2006. Etobicoke, Ontario, Canada.

Culver, C. G., 1967. "Natural Frequencies of Horizontally Curved Beams", Journal of Structural Division, ASCE, 93(2): 189-203.

Davidson, J. S., Keller, M. A., and Yoo, C. H., 1996. "Cross-frame Spacing and Parametric Effects in Horizontally Curved I-Girder Bridges", ASCE Journal of Structural Engineering, 122(9): 1089-1096

DePolo, David S. and Linzell, Daniel G. 2002. Evaluation of Live Load Lateral Flange Bending Distribution for a Horizontally Curved I-Girder Bridge, U.S Army Corps. of Engineers.

Galambos, T.V., 1978. "Tentative load factor design criteria for curved steel bridges", Research Report No. 50, School of Engineering and Applied Science, Civil Engineering Department, Washington University, St. Louis.

Grubb, M. A., 1984. "Horizontally curved I-girder bridge analysis: V-load method", Transportation Research Board Record 982, National Research Council, 26-35.

Hayes, C. O., Jr., Sessions, L. M., and Berry, A. J., 1986. "Further studies on lateral load distribution using finite element methods", Transportation Research Record, (1072), Transportation Research Board, Washington, D.C., 6-14.
Heins, C. P., and Siminou, J., 1970. "Preliminary Design of Curved Bridges", AISC Engineering Journal, 7(2), 50-61

Heins, C. P., and Bell, L. C., 1972. "Curved Girder Bridge Analysis", Journal of Computers and Structures, 2: 785-797.

Heins, C. P., and Jin, J. O., 1984. "Live Load Distribution on Braced Curved I-Girders", ASCE Journal of Structural Engineering, 110(3): 523-530.

Howell and Earls 2007. Curved Steel I-Girder Bridge Response during Construction Loading; Effects of Web Plumbness. Journal of Bridge Engineering, ASCE, 12(4) 484-493.

Ketchek, K.F., 1969. "Discussion of Horizontally curved girders - state of the art by McManus PF et al.", Journal of Structural Division, ASCE, 95 (ST12): 2999-3001.

Kostem, C.N., and DeCastro, E.S., 1977. "Effect of diaphragms on lateral load distribution in beam-slab bridges", Transportation Research Record, Bridge Test, No. 645, 6-9.

Lavelle, F. H., and Lasks, R. J., 1975. "CUGAR2 and CUGAR3 user's Manuals", CURT Final Report, Research Project HPR-2(111), University of Rhode Island.

Logan, D., 2002. "A first course in the finite element method", $3^{\text {rd }}$ Edition, Text Book,

McElwain, Brett A., and Laman, A. Jeffrey, 2000. "Experimental Verification of Horizontally curved I-girder Bridge Behavior", Journal of Bridge Engineering, Vol.5, No.4.

McManus, P.F., Nasir, G.A., and Culver, C. G., 1969. "Horizontally curved girders - state of the art", Journal of Structural Division. ASCE, 95(ST5): 853-870.

Montalvao, E Silva, J. M., and Urgueira, A., 1988. "Out-of-Plane Dynamic Response of Curved Beams", an Analytical Model. International Journal of Solids and Structures, 24(3): 271284. 
Mounir, E., and Kassim, M., 1997. "Finite-Element Analysis of steel I-girder Highway Bridges", Journal of Bridge Engineering, Vol. 2, No. 3.

Nakai, H. and Yoo, C.H., 1988. "Analysis and Design of Curved Steel Bridges”, McGraw Hill Book Co., Inc., New York, N.Y.

Nasr, A. M. 2004. Live Load Distribution for Curved Steel I-Girder Bridges. M.Sc. Thesis, Structural Engineering Department, Faculty of Engineering, Cairo University.

Pandit, G.S., Ceradini, G., Garvarini, P., and Eremin, A.A., 1970. "Discussion of Horizontally curved girders - state of the art", Journal of Structural Division, ASCE, 96(ST2): 433-436.

Poellot, W. J., 1987. "Computer aided Design of Horizontally Curved girders by the V-load Method", Engineering Journal, American institute of steel construction, first quarter.

Salmon, C. G., and Johnson, J. E., 1996. "Steel Structures: Design and Behavior, Emphasizing Load and Resistance Factor Design", $4^{\text {th }}$ Edition, HarperCollins College Publishers Inc., New York, N.Y.

Schelling, D., Namini, A. H., and Fu, C. C., 1989. "Construction Effects on Bracing on Curved IGirders", ASCE Journal of Structural Engineering, 115(9): 2145-2165.

Shahawy, M., and Hunag, D. Z., 2001. "Analytical and field investigation of lateral load distribution in concrete slab-on-girder bridges", Structural Journal, ACI, 98 (4): 590-599.

Sheinman, I., 1982. "Large Deflection of Curved Beam with Shear Deformation. Journal of Engineering Mechanics Division", ASCE: 108(4): 636-647.

Shore, S., and Wilson, J. L., 1973. "Users' Manual for Static analysis of Curved Bridges (STACRB)", CURT Report No. T0173, Research Project HPR-2(111), Graduate Division of Civil \& Environmental Engineering, University of Pennsylvania.
Stegmann, T.H., and Galambos, T.V., 1976. "Load factor design criteria for curved steel girders of open section", Research Report 23, Civil Engineering Department, Washington University, St. Louis.

Tarshini, K.M., and Frederick, G.R., 1992. "Wheel load distribution in I-girder highway bridges", Journal of Structural Engineering, ASCE, 118(5): 1285-1294.

Tene, Y., Epstein, M., and Sheinman, T., 1975. "Dynamics of Curved Beams involving Shear Deformation. International Journal of Solids and Structures", 11(7): 827-840.

Wassef, J., 2004. "Simplified Design Method of Curved Coiicrete slab-on-steel I-girder Bridges", M.A.Sc. thesis, Civil Engineering Dept., Ryerson University, Toronto, Ont., Canada.

Wilson, E. L., and Habibullah, A., 2002. "Structural Analysis Program SAP2000", Computers \& Structures.

Yao, L., 1990. "Bridge Engineering", $1^{\text {st }}$ Edition, People's Transportation Publisher, P.R. China. Yoo, C. H., and Littrell, P. C. 1985. "Cross-Bracing Effects in Curved Stringer Bridges", ASCE Journal of Structural Engineering, 112(9): 2127-2140.

Zhang, H., 2002. "Lateral Load Distribution for Curved Steel I-Girder Bridges", Ph.D. Dissertation, Florida International University, Miami, Florida.

Zokaie, T., 2000. "AASHTO-LRFD Live Load Distribution Specifications", Journal of Bridge Engineering, 5(2): 131-138.

Zuerick, A., and Naqib, R., 1999. "Horizontally Curvedi Steel I-Girders State-of-the-Art Analysis Methods", Journal of Bridge Engineering, 4 (1): 38-47.

Zureick, A., Linzell, D., Leon, R.T. and Burrell, J., 1998. "Curved steel I-girder bridges: Experimental and analytical studies". Engineering Structures, 22(2), Elsevier Science Ltd., $180-190$ 
Mounir, E., and Kassim, M., 1997. "Finite-Element Analysis of steel I-girder Highway Bridges", Journal of Bridge Engineering, Vol. 2, No. 3.

Nakai, H. and Yoo, C.H., 1988. "Analysis and Design of Curved Steel Bridges", McGraw Hill Book Co., Inc., New York, N.Y.

Nasr, A. M. 2004. Live Load Distribution for Curved Steel I-Girder Bridges. M.Sc. Thesis, Structural Engineering Department, Faculty of Engineering, Cairo University.

Pandit, G.S., Ceradini, G., Garvarini, P., and Eremin, A.A., 1970. "Discussion of Horizontally curved girders - state of the art", Journal of Structural Division, ASCE, 96(ST2): 433-436.

Poellot, W. J., 1987. "Computer aided Design of Horizontally Curved girders by the V-load Method", Engineering Journal, American institute of steel construction, first quarter.

Salmon, C. G., and Johnson, J. E., 1996. "Steel Structures: Design and Behavior, Emphasizing Load and Resistance Factor Design", $4^{\text {th }}$ Edition, HarperCollins College Publishers Inc., New York, N.Y.

Schelling, D., Namini, A. H., and Fu, C. C., 1989. "Construction Effects on Bracing on Curved IGirders", ASCE Journal of Structural Engineering, 115(9): 2145-2165.

Shahawy, M., and Hunag, D. Z., 2001. "Analytical and field investigation of lateral load distribution in concrete slab-on-girder bridges", Structural Journal, ACI, 98 (4): 590-599.

Sheinman, I., 1982. "Large Deflection of Curved Beam with Shear Deformation. Journal of Engineering Mechanics Division", ASCE: 108(4): 636-647.

Shore, S., and Wilson, J. L., 1973. "Users' Manual for Static analysis of Curved Bridges (STACRB)", CURT Report No. T0173, Research Project HPR-2(111), Graduate Division of Civil \& Environmental Engineering, University of Pennsylvania.
Stegmann, T.H., and Galambos, T.V., 1976. "Load factor design criteria for curved steel girders of open section", Research Report 23, Civil Engineering Department, Washington University, St. Louis.

Tarshini, K.M., and Frederick, G.R., 1992. "Wheel load distribution in I-girder highway bridges", Journal of Structural Engineering, ASCE, 118(5): 1285-1294.

Tene, Y., Epstein, M., and Sheinman, T., 1975. "Dynamics of Curved Beams involving Shear Deformation. International Journal of Solids and Structures", 11(7): 827-840.

Wassef, J., 2004. "Simplified Design Method of Curved Coircrete slab-on-steel I-girder Bridges", M.A.Sc. thesis, Civil Engineering Dept., Ryerson University, Toronto, Ont., Canada.

Wilson, E. L., and Habibullah, A., 2002. "Structural Analysis Program SAP2000", Computers \& Structures.

Yao, L., 1990. "Bridge Engineering", $1^{\text {st }}$ Edition, People's Transportation Publisher, P.R. China. Yoo, C. H., and Littrell, P. C. 1985. "Cross-Bracing Effects in Curved Stringer Bridges", ASCE Journal of Structural Engineering, 112(9): 2127-2140.

Zhang, H., 2002. "Lateral Load Distribution for Curved Steel I-Girder Bridges", Ph.D. Dissertation, Florida International University, Miami, Florida.

Zokaie, T., 2000. "AASHTO-LRFD Live Load Distribution Specifications", Journal of Bridge Engineering, 5(2): 131-138.

Zuerick, A., and Naqib, R., 1999. "Horizontally Curved Steel I-Girders State-of-the-Art Analysis Methods", Journal of Bridge Engineering, 4 (1): 38-47.

Zureick, A., Linzell, D., Leon, R.T. and Burrell, J., 1998. "Curved steel I-girder bridges: Experimental and analytical studies". Engineering Structures, 22(2), Elsevier Science Ltd., $180-190$ 
Table 4.1 Effect of the presence of torsion box on the warping-to-bending stress ratio

\begin{tabular}{|c|c|c|c|c|c|c|c|c|c|c|c|c|}
\hline \multirow{2}{*}{$\begin{array}{l}\text { Bridge } \\
\text { No. }\end{array}$} & \multirow{2}{*}{$\begin{array}{l}\text { Span, } \\
\text { L (m) }\end{array}$} & \multirow{2}{*}{$\begin{array}{l}\text { No. of } \\
\text { Girders, N }\end{array}$} & \multirow{2}{*}{$\begin{array}{l}\text { Girder } \\
\text { spacing, S } \\
\text { (m) }\end{array}$} & \multirow[b]{2}{*}{$\mathrm{L} / \mathrm{R}$} & \multirow{2}{*}{$\begin{array}{l}\text { No. of } \\
\text { bracing } \\
\text { intervals }\end{array}$} & \multirow{2}{*}{$\begin{array}{l}\text { Torsion } \\
\text { box area }\end{array}$} & \multicolumn{3}{|c|}{ Vertical bracing and torsion box } & \multicolumn{3}{|c|}{ Vertical bracing only } \\
\hline & & & & & & & $\begin{array}{l}\text { Ext. } \\
\text { Girder }\end{array}$ & $\begin{array}{l}\text { Middle } \\
\text { girder }\end{array}$ & $\begin{array}{l}\text { Interior } \\
\text { girder }\end{array}$ & $\begin{array}{l}\text { Ext. } \\
\text { girder }\end{array}$ & $\begin{array}{l}\text { Middle } \\
\text { girder }\end{array}$ & $\begin{array}{l}\text { Interior } \\
\text { girder }\end{array}$ \\
\hline \multirow{4}{*}{1} & \multirow{4}{*}{10} & \multirow{4}{*}{3} & \multirow{4}{*}{3} & \multirow{4}{*}{0.3} & \multirow{4}{*}{6} & A & 0.132 & 0.131 & 0.141 & \multirow{4}{*}{0.119} & \multirow{4}{*}{0.118} & \multirow{4}{*}{0.132} \\
\hline & & & & & & $1.5 \mathrm{~A}$ & 0.132 & 0.131 & 0.139 & & & \\
\hline & & & & & & $2 \mathrm{~A}$ & 0.133 & 0.131 & 0.229 & & & \\
\hline & & & & & & $3 \mathrm{~A}$ & 0.134 & 0.211 & 0.232 & & & \\
\hline \multirow{4}{*}{2} & \multirow{4}{*}{15} & \multirow{4}{*}{3} & \multirow{4}{*}{2.5} & \multirow{4}{*}{0.3} & \multirow{4}{*}{8} & $\mathrm{~A}$ & 0.113 & 0.128 & 0.130 & \multirow{4}{*}{0.096} & \multirow{4}{*}{0.100} & \multirow{4}{*}{0.117} \\
\hline & & & & & & $1.5 \mathrm{~A}$ & 0.113 & 0.126 & 0.125 & & & \\
\hline & & & & & & $2 \mathrm{~A}$ & 0.114 & 0.125 & 0.114 & & & \\
\hline & & & & & & $3 \mathrm{~A}$ & 0.114 & 0.124 & 0.121 & & & \\
\hline \multirow{4}{*}{3} & \multirow{4}{*}{25} & \multirow{4}{*}{3} & \multirow{4}{*}{2} & \multirow{4}{*}{0.5} & \multirow{4}{*}{12} & $\mathrm{~A}$ & 0.143 & 0.154 & 0.197 & \multirow{4}{*}{0.146} & & \\
\hline & & & & & & $1.5 \mathrm{~A}$ & 0.142 & 0.151 & 0.186 & & 0.183 & 0.615 \\
\hline & & & & & & $2 \mathrm{~A}$ & 0.134 & 0.142 & 0.171 & & & \\
\hline & & & & & & $3 \mathrm{~A}$ & 0.141 & 0.149 & 0.175 & & & \\
\hline & & & & & & $\mathrm{A}$ & 0.279 & 0.277 & 0.343 & & & \\
\hline 4 & 35 & 3 & 3 & 0.7 & 12 & $1.5 \mathrm{~A}$ & 0.378 & 0.347 & 0.253 & 0.269 & 0.295 & 0.459 \\
\hline & & & & & & $2 \mathrm{~A}$ & 0.319 & 0.273 & 0.280 & & & \\
\hline & & & & & & $3 \mathrm{~A}$ & 0.281 & 0.272 & 0.305 & & & \\
\hline
\end{tabular}

Note: $A=0.0075 \mathrm{~m}^{2}$

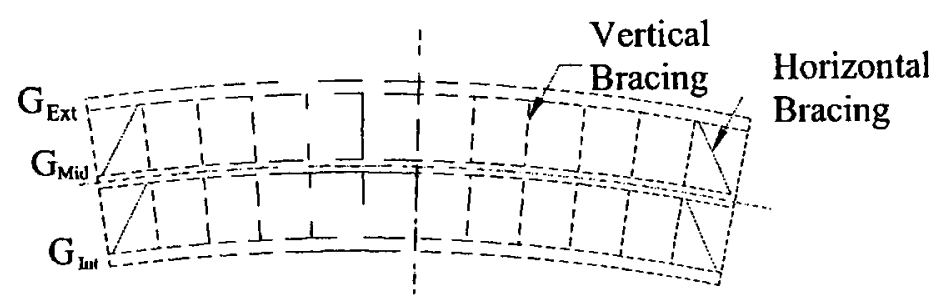

I-Girder Bridge with Torsion Box 
Table 4.2 Effect of the presence of torsion box on the moment distribution factors

\begin{tabular}{|c|c|c|c|c|c|c|c|c|c|c|c|c|}
\hline \multirow{2}{*}{$\begin{array}{l}\text { Bridge } \\
\text { No. }\end{array}$} & \multirow{2}{*}{$\begin{array}{l}\text { Span, } \\
\text { L } \\
\text { (m) }\end{array}$} & \multirow{2}{*}{$\begin{array}{l}\text { No. of } \\
\text { Girders, } \\
\text { N }\end{array}$} & \multirow{2}{*}{$\begin{array}{l}\text { Girder } \\
\text { spacing, S } \\
\text { (m) }\end{array}$} & \multirow[b]{2}{*}{$\mathrm{L} / \mathrm{R}$} & \multirow{2}{*}{$\begin{array}{l}\text { No. of } \\
\text { bracing } \\
\text { intervals }\end{array}$} & \multirow{2}{*}{$\begin{array}{l}\text { Torsion } \\
\text { box area }\end{array}$} & \multicolumn{3}{|c|}{ Vertical bracing and torsion box } & \multicolumn{3}{|c|}{ Vertical bracing only } \\
\hline & & & & & & & $\begin{array}{l}\text { Ext. } \\
\text { Girder }\end{array}$ & $\begin{array}{l}\begin{array}{l}\text { Middle } \\
\text { girder }\end{array} \\
\end{array}$ & \begin{tabular}{|l|}
$\begin{array}{l}\text { Interior } \\
\text { girder }\end{array}$ \\
\end{tabular} & $\begin{array}{l}\text { Ext. } \\
\text { girder }\end{array}$ & $\begin{array}{l}\text { Middle } \\
\text { girder }\end{array}$ & $\begin{array}{l}\text { Interior } \\
\text { girder }\end{array}$ \\
\hline \multirow{4}{*}{1} & \multirow{4}{*}{10} & \multirow{4}{*}{3} & \multirow{4}{*}{3} & \multirow{4}{*}{0.3} & \multirow{4}{*}{9} & $\mathrm{~A}$ & 0.744 & 0.341 & 0.260 & \multirow{4}{*}{1.368} & \multirow{4}{*}{0.854} & \multirow{4}{*}{0.499} \\
\hline & & & & & & $1.5 \mathrm{~A}$ & 0.727 & 0.340 & 0.263 & & & \\
\hline & & & & & & $2 \mathrm{~A}$ & 0.713 & 0.339 & 0.263 & & & \\
\hline & & & & & & $3 \mathrm{~A}$ & 0.690 & 0.336 & 0.260 & & & \\
\hline \multirow{4}{*}{2} & \multirow{4}{*}{15} & \multirow{4}{*}{3} & \multirow{4}{*}{2.5} & \multirow{4}{*}{0.3} & \multirow{4}{*}{12} & $\mathrm{~A}$ & 0.959 & 0.809 & 0.638 & \multirow{4}{*}{1.353} & \multirow{4}{*}{1.041} & \multirow{4}{*}{0.661} \\
\hline & & & & & & $1.5 \mathrm{~A}$ & 0.935 & 0.797 & 0.642 & & & \\
\hline & & & & & & $2 \mathrm{~A}$ & 0.916 & 0.785 & 0.640 & & & \\
\hline & & & & & & $3 \mathrm{~A}$ & 0.886 & 0.764 & 0.630 & & & \\
\hline \multirow{4}{*}{3} & \multirow{4}{*}{25} & \multirow{4}{*}{3} & \multirow{4}{*}{2} & \multirow{4}{*}{0.5} & \multirow{4}{*}{18} & A & 1.167 & 0.814 & 0.420 & \multirow{4}{*}{2.264} & & \\
\hline & & & & & & $1.5 \mathrm{~A}$ & 1.127 & 0.800 & 0.436 & & 1.232 & 0.039 \\
\hline & & & & & & $2 \mathrm{~A}$ & 1.105 & 0.791 & 0.444 & & & \\
\hline & & & & & & $3 \mathrm{~A}$ & 1.123 & 0.780 & 0.450 & & & \\
\hline 4 & & & & & & $\mathrm{~A}$ & 0.793 & 0.484 & 0.181 & & & \\
\hline & 35 & 3 & 3 & 0.7 & 18 & $1.5 \mathrm{~A}$ & 0.808 & 0.503 & 0.211 & 2.735 & 1.344 & -0.214 \\
\hline & & & & & & $2 \mathrm{~A}$ & 0.739 & 0.466 & 0.206 & & & \\
\hline & & & & & & $3 \mathrm{~A}$ & 1.004 & 0.641 & 0.015 & & & \\
\hline
\end{tabular}

Note: $A=0.0075 \mathrm{~m}^{2}$

87

Table 4.3 Effect of the presence of torsion box on the reaction distribution factors

\begin{tabular}{|c|c|c|c|c|c|c|c|c|c|c|c|c|}
\hline \multirow{2}{*}{$\begin{array}{l}\text { Bridge } \\
\text { No. }\end{array}$} & \multirow{2}{*}{$\begin{array}{l}\text { Span, } \\
\text { L } \\
\text { (m) } \\
\end{array}$} & \multirow{2}{*}{$\begin{array}{l}\text { No. of } \\
\text { Girders, } \\
\text { N }\end{array}$} & \multirow{2}{*}{$\begin{array}{l}\text { Girder } \\
\text { spacing, } S \\
\text { (m) }\end{array}$} & \multirow[b]{2}{*}{$\mathrm{L} / \mathrm{R}$} & \multirow{2}{*}{$\begin{array}{l}\text { No. of } \\
\text { bracing } \\
\text { intervals }\end{array}$} & \multirow{2}{*}{$\begin{array}{l}\text { Torsion } \\
\text { box area }\end{array}$} & \multicolumn{3}{|c|}{ Vertical bracing and torsion box } & \multicolumn{3}{|c|}{ Vertical bracing only } \\
\hline & & & & & & & $\begin{array}{l}\text { Ext. } \\
\text { Girder } \\
\end{array}$ & $\begin{array}{l}\begin{array}{l}\text { Middle } \\
\text { girder }\end{array} \\
\end{array}$ & $\begin{array}{l}\begin{array}{l}\text { Interior } \\
\text { girder }\end{array} \\
\end{array}$ & $\begin{array}{l}\text { Ext. } \\
\text { girder }\end{array}$ & $\begin{array}{l}\text { Middle } \\
\text { girder }\end{array}$ & $\begin{array}{l}\text { Interior } \\
\text { girder }\end{array}$ \\
\hline \multirow{4}{*}{1} & \multirow{4}{*}{10} & \multirow{4}{*}{3} & \multirow{4}{*}{3} & \multirow{4}{*}{0.3} & \multirow{4}{*}{9} & A & 1.01 & 1.25 & 0.74 & \multirow{4}{*}{1.07} & \multirow{4}{*}{1.15} & \multirow{4}{*}{0.78} \\
\hline & & & & & & $1.5 \mathrm{~A}$ & 1.00 & 1.27 & 0.73 & & & \\
\hline & & & & & & $2 \mathrm{~A}$ & 0.99 & 1.28 & 0.73 & & & \\
\hline & & & & & & $3 \mathrm{~A}$ & 0.97 & 1.31 & 0.72 & & & \\
\hline \multirow{4}{*}{2} & \multirow{4}{*}{15} & \multirow{4}{*}{3} & \multirow{4}{*}{2.5} & \multirow{4}{*}{0.3} & \multirow{4}{*}{12} & $\mathrm{~A}$ & 1.06 & 1.34 & 0.61 & \multirow{4}{*}{1.18} & \multirow{4}{*}{1.09} & \multirow{4}{*}{0.72} \\
\hline & & & & & & $1.5 \mathrm{~A}$ & 1.04 & 1.37 & 0.60 & & & \\
\hline & & & & & & $2 \mathrm{~A}$ & 1.03 & 1.38 & 0.59 & & & \\
\hline & & & & & & $3 \mathrm{~A}$ & 1.01 & 1.38 & 0.59 & & & \\
\hline \multirow{4}{*}{3} & \multirow{4}{*}{25} & \multirow{4}{*}{3} & \multirow{4}{*}{2} & \multirow{4}{*}{0.5} & \multirow{4}{*}{18} & A & 1.17 & 1.64 & 0.19 & \multirow{4}{*}{1.74} & & \\
\hline & & & & & & $1.5 \mathrm{~A}$ & 1.14 & 1.66 & 0.2 & & 1.103 & 0.156 \\
\hline & & & & & & $2 \mathrm{~A}$ & 1.12 & 1.67 & 0.20 & & & \\
\hline & & & & & & $3 \mathrm{~A}$ & 1.11 & 1.69 & 0.20 & & & \\
\hline & & & & & & A & 0.94 & 1.57 & 0.49 & & & \\
\hline 4 & 35 & 3 & 3 & 0.7 & 18 & $1.5 \mathrm{~A}$ & 0.95 & 1.70 & 0.34 & 1.83 & 1.03 & 0.13 \\
\hline & & & & & & $2 \mathrm{~A}$ & 0.87 & 1.62 & 0.51 & & & \\
\hline & & & & & & $3 \mathrm{~A}$ & 0.85 & 1.64 & 0.51 & & & \\
\hline
\end{tabular}

Note: $\mathrm{A}=0.0075 \mathrm{~m}^{2}$ 
Table 4.2 Effect of the presence of torsion box on the moment distribution factors

\begin{tabular}{|c|c|c|c|c|c|c|c|c|c|c|c|c|}
\hline \multirow{2}{*}{$\begin{array}{l}\text { Bridge } \\
\text { No. }\end{array}$} & \multirow{2}{*}{$\begin{array}{l}\text { Span, } \\
\text { L } \\
\text { (m) } \\
\end{array}$} & \multirow{2}{*}{$\begin{array}{l}\text { No. of } \\
\text { Girders, } \\
\mathrm{N}\end{array}$} & \multirow{2}{*}{$\begin{array}{l}\text { Girder } \\
\text { spacing, S } \\
\text { (m) }\end{array}$} & \multirow[b]{2}{*}{$\mathrm{L} / \mathrm{R}$} & \multirow{2}{*}{$\begin{array}{l}\text { No. of } \\
\text { bracing } \\
\text { intervals }\end{array}$} & \multirow{2}{*}{$\begin{array}{l}\text { Torsion } \\
\text { box area }\end{array}$} & \multicolumn{3}{|c|}{ Vertical bracing and torsion box } & \multicolumn{3}{|c|}{ Vertical bracing only } \\
\hline & & & & & & & $\begin{array}{l}\text { Ext. } \\
\text { Girder }\end{array}$ & $\begin{array}{l}\text { Middle } \\
\text { girder }\end{array}$ & \begin{tabular}{|l|}
$\begin{array}{l}\text { Interior } \\
\text { girder }\end{array}$ \\
\end{tabular} & $\begin{array}{l}\text { Ext. } \\
\text { girder }\end{array}$ & $\begin{array}{l}\begin{array}{l}\text { Middle } \\
\text { girder }\end{array} \\
\end{array}$ & $\begin{array}{l}\text { Interior } \\
\text { girder }\end{array}$ \\
\hline \multirow{4}{*}{1} & \multirow{4}{*}{10} & \multirow{4}{*}{3} & \multirow{4}{*}{3} & \multirow{4}{*}{0.3} & \multirow{4}{*}{9} & $\mathrm{~A}$ & 0.744 & 0.341 & 0.260 & \multirow{4}{*}{1.368} & \multirow{4}{*}{0.854} & \multirow{4}{*}{0.499} \\
\hline & & & & & & $1.5 \mathrm{~A}$ & 0.727 & 0.340 & 0.263 & & & \\
\hline & & & & & & $2 \mathrm{~A}$ & 0.713 & 0.339 & 0.263 & & & \\
\hline & & & & & & $3 \mathrm{~A}$ & 0.690 & 0.336 & 0.260 & & & \\
\hline \multirow{4}{*}{2} & \multirow{4}{*}{15} & \multirow{4}{*}{3} & \multirow{4}{*}{2.5} & \multirow{4}{*}{0.3} & \multirow{4}{*}{12} & $\mathrm{~A}$ & 0.959 & 0.809 & 0.638 & \multirow{4}{*}{1.353} & \multirow{4}{*}{1.041} & \multirow{4}{*}{0.661} \\
\hline & & & & & & $1.5 \mathrm{~A}$ & 0.935 & 0.797 & 0.642 & & & \\
\hline & & & & & & $2 \mathrm{~A}$ & 0.916 & 0.785 & 0.640 & & & \\
\hline & & & & & & $3 \mathrm{~A}$ & 0.886 & 0.764 & 0.630 & & & \\
\hline \multirow{4}{*}{3} & \multirow{4}{*}{25} & \multirow{4}{*}{3} & \multirow{4}{*}{2} & \multirow{4}{*}{0.5} & \multirow{4}{*}{18} & $\mathrm{~A}$ & 1.167 & 0.814 & 0.420 & \multirow{4}{*}{2.264} & & \\
\hline & & & & & & $1.5 \mathrm{~A}$ & 1.127 & 0.800 & 0.436 & & 1.232 & 0.039 \\
\hline & & & & & & $2 \mathrm{~A}$ & 1.105 & 0.791 & 0.444 & & & \\
\hline & & & & & & $3 \mathrm{~A}$ & 1.123 & 0.780 & 0.450 & & & \\
\hline & & & & & & $\mathrm{A}$ & 0.793 & 0.484 & 0.181 & & & \\
\hline 4 & 35 & 3 & 3 & 0.7 & 18 & $1.5 \mathrm{~A}$ & 0.808 & 0.503 & 0.211 & 2.735 & 1.344 & -0.214 \\
\hline & & & & & & $2 \mathrm{~A}$ & 0.739 & 0.466 & 0.266 & & & \\
\hline & & & & & & $3 \mathrm{~A}$ & 1.004 & 0.641 & 0.015 & & & \\
\hline
\end{tabular}

Note: $\mathrm{A}=0.0075 \mathrm{~m}^{2}$

Table 4.3 Effect of the presence of torsion box on the reaction distribution factors

\begin{tabular}{|c|c|c|c|c|c|c|c|c|c|c|c|c|}
\hline \multirow{2}{*}{$\begin{array}{l}\text { Bridge } \\
\text { No. }\end{array}$} & \multirow{2}{*}{$\begin{array}{l}\text { Span, } \\
\text { L } \\
\text { (m) } \\
\end{array}$} & \multirow{2}{*}{$\begin{array}{l}\text { No. of } \\
\text { Girders, } \\
\text { N } \\
\end{array}$} & \multirow{2}{*}{$\begin{array}{l}\text { Girder } \\
\text { spacing, S } \\
\text { (m) }\end{array}$} & \multirow[b]{2}{*}{$L / R$} & \multirow{2}{*}{$\begin{array}{l}\text { No. of } \\
\text { bracing } \\
\text { intervals } \\
\end{array}$} & \multirow{2}{*}{$\begin{array}{l}\text { Torsion } \\
\text { box area }\end{array}$} & \multicolumn{3}{|c|}{ Vertical bracing and torsion box } & \multicolumn{3}{|c|}{ Vertical bracing only } \\
\hline & & & & & & & $\begin{array}{l}\text { Ext. } \\
\text { Girder } \\
\end{array}$ & $\begin{array}{l}\begin{array}{l}\text { Middle } \\
\text { girder }\end{array} \\
\end{array}$ & \begin{tabular}{|l|}
$\begin{array}{l}\text { Interior } \\
\text { girder }\end{array}$ \\
\end{tabular} & $\begin{array}{l}\begin{array}{l}\text { Ext. } \\
\text { girder }\end{array} \\
\text { ent }\end{array}$ & $\begin{array}{l}\text { Middle } \\
\text { girder }\end{array}$ & $\begin{array}{l}\begin{array}{l}\text { Interior } \\
\text { girder }\end{array} \\
\end{array}$ \\
\hline \multirow{4}{*}{1} & \multirow{4}{*}{10} & \multirow{4}{*}{3} & \multirow{4}{*}{3} & \multirow{4}{*}{0.3} & \multirow{4}{*}{9} & A & 1.01 & 1.25 & 0.74 & \multirow{4}{*}{1.07} & \multirow{4}{*}{1.15} & \multirow{4}{*}{0.78} \\
\hline & & & & & & $1.5 \mathrm{~A}$ & 1.00 & 1.27 & 0.73 & & & \\
\hline & & & & & & $2 \mathrm{~A}$ & 0.99 & 1.28 & 0.73 & & & \\
\hline & & & & & & $3 \mathrm{~A}$ & 0.97 & 1.31 & 0.72 & & & \\
\hline \multirow{4}{*}{2} & \multirow{4}{*}{15} & \multirow{4}{*}{3} & \multirow{4}{*}{2.5} & \multirow{4}{*}{0.3} & \multirow{4}{*}{12} & A & 1.06 & 1.34 & 0.61 & \multirow{4}{*}{1.18} & \multirow{4}{*}{1.09} & \multirow{4}{*}{0.72} \\
\hline & & & & & & $1.5 \mathrm{~A}$ & 1.04 & 1.37 & 0.60 & & & \\
\hline & & & & & & $2 \mathrm{~A}$ & 1.03 & 1.38 & 0.59 & & & \\
\hline & & & & & & $3 \mathrm{~A}$ & 1.01 & 1.38 & 0.59 & & & \\
\hline \multirow{4}{*}{3} & \multirow{4}{*}{25} & \multirow{4}{*}{3} & \multirow{4}{*}{2} & \multirow{4}{*}{0.5} & \multirow{4}{*}{18} & A & 1.17 & 1.64 & 0.19 & \multirow{4}{*}{1.74} & & \\
\hline & & & & & & $1.5 \mathrm{~A}$ & 1.14 & 1.66 & 0.2 & & 1.103 & 0.156 \\
\hline & & & & & & $2 \mathrm{~A}$ & 1.12 & 1.67 & 0.20 & & & \\
\hline & & & & & & $3 \mathrm{~A}$ & 1.11 & 1.69 & 0.20 & & & \\
\hline & & & & & & $\mathrm{A}$ & 0.94 & 1.57 & 0.49 & & & \\
\hline 4 & 35 & 3 & 3 & 0.7 & 18 & $1.5 \mathrm{~A}$ & 0.95 & 1.70 & 0.34 & 1.83 & 1.03 & 0.13 \\
\hline & & & & & & $2 \mathrm{~A}$ & 0.87 & 1.62 & 0.51 & & & \\
\hline & & & & & & $3 \mathrm{~A}$ & 0.85 & 1.64 & 0.51 & & & \\
\hline
\end{tabular}

Note: $\mathrm{A}=0.0075 \mathrm{~m}^{2}$ 
Table 4.4 Effect of the presence of torsion box on the axial force in bracing members

\begin{tabular}{|c|c|c|c|c|c|c|c|c|c|c|}
\hline \multirow{2}{*}{$\begin{array}{l}\text { Bridge } \\
\text { No. }\end{array}$} & \multirow{2}{*}{$\begin{array}{l}\text { Span, } \\
\text { L (m) }\end{array}$} & \multirow[b]{2}{*}{$\begin{array}{l}\text { No. of } \\
\text { Girders, } \\
\mathrm{N}\end{array}$} & \multirow{2}{*}{$\begin{array}{l}\text { Girder } \\
\text { spacing, } \\
\text { S (m) }\end{array}$} & \multirow[b]{2}{*}{$L / R$} & \multirow{2}{*}{$\begin{array}{l}\text { No. of } \\
\text { bracing } \\
\text { intervals }\end{array}$} & \multirow{2}{*}{$\begin{array}{l}\text { Torsion } \\
\text { box area }\end{array}$} & \multicolumn{2}{|c|}{ Vertical bracing with torsion box } & \multicolumn{2}{|c|}{ Vertical bracing only } \\
\hline & & & & & & & $\begin{array}{l}\text { Max. } \\
\text { compressive } \\
\text { force }(\mathrm{kN})\end{array}$ & $\begin{array}{l}\text { Max. tensile } \\
\text { force }(\mathrm{kN})\end{array}$ & $\begin{array}{l}\text { Max. } \\
\text { compressive } \\
\text { force }(\mathrm{kN})\end{array}$ & $\begin{array}{l}\text { Max. tensile force } \\
(\mathrm{kN})\end{array}$ \\
\hline \multirow{4}{*}{1} & \multirow{4}{*}{10} & \multirow{4}{*}{3} & \multirow{4}{*}{3} & \multirow{4}{*}{0.3} & \multirow{4}{*}{9} & $\bar{A}$ & -16.07 & 17.49 & \multirow{4}{*}{-5.83} & \multirow{4}{*}{5.83} \\
\hline & & & & & & $1.5 \mathrm{~A}$ & -19.27 & 21.19 & & \\
\hline & & & & & & $2 \mathrm{~A}$ & -21.53 & 23.85 & & \\
\hline & & & & & & $3 \mathrm{~A}$ & -24.89 & 27.84 & & \\
\hline \multirow{4}{*}{2} & \multirow{4}{*}{15} & \multirow{4}{*}{3} & \multirow{4}{*}{2.5} & \multirow{4}{*}{0.3} & \multirow{4}{*}{12} & $\bar{A}$ & -49.36 & 52.15 & \multirow{4}{*}{-8.03} & \multirow{4}{*}{8.03} \\
\hline & & & & & & $1.5 \mathrm{~A}$ & -55.34 & 59.05 & & \\
\hline & & & & & & $2 \mathrm{~A}$ & -59.24 & 63.65 & & \\
\hline & & & & & & $3 \mathrm{~A}$ & -64.41 & 22.42 & & \\
\hline \multirow{3}{*}{3} & \multirow{3}{*}{25} & \multirow{4}{*}{3} & \multirow{3}{*}{2} & \multirow{3}{*}{0.5} & \multirow{3}{*}{18} & $\mathrm{~A}$ & -246.94 & 255.67 & \multirow{4}{*}{-27.23} & \multirow{4}{*}{22.42} \\
\hline & & & & & & $1.5 \mathrm{~A}$ & -262.66 & 270.78 & & \\
\hline & & & & & & $\frac{2 \mathrm{~A}}{3 \mathrm{~A}}$ & $\begin{array}{c}-273.49 \\
-2871\end{array}$ & 279.26 & & \\
\hline \multirow{4}{*}{4} & \multirow{4}{*}{35} & & & & & A & -592.26 & $\begin{array}{l}289.28 \\
615.12\end{array}$ & & \\
\hline & & 3 & 3 & 0.7 & 18 & $1.5 \mathrm{~A}$ & -630.89 & 659.62 & -54.47 & 54.47 \\
\hline & & & & & & $2 \mathrm{~A}$ & -676.64 & 684.79 & & \\
\hline & & & & & & $3 \mathrm{~A}$ & -676.64 & 714.27 & & \\
\hline
\end{tabular}

Note: $A=0.0075 \mathrm{~m}^{2}$

Table 4.5 Effect of boundary conditions on the warping-to-bending stress ratio

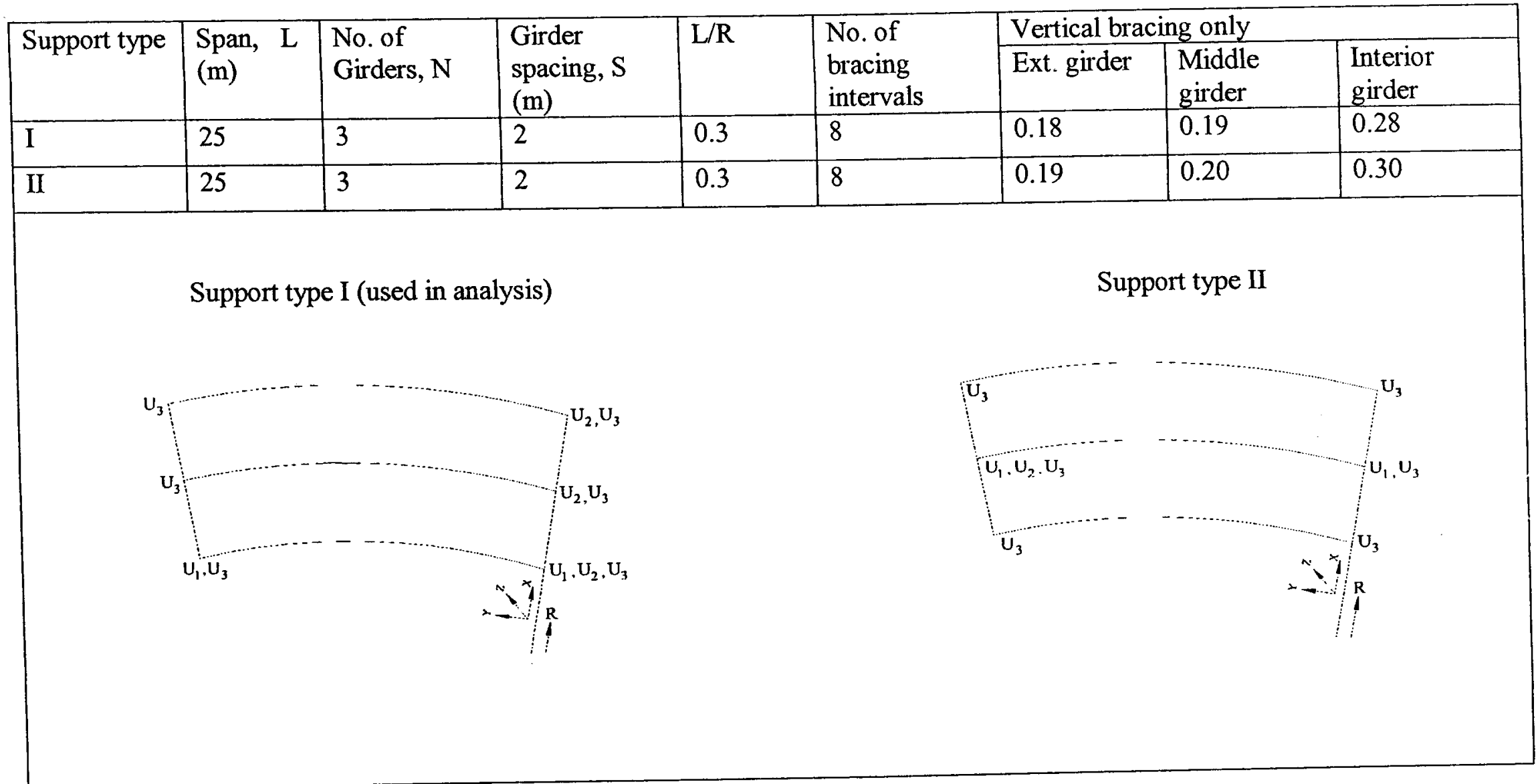


Table 4.4 Effect of the presence of torsion box on the axial force in bracing members

\begin{tabular}{|c|c|c|c|c|c|c|c|c|c|c|}
\hline \multirow{2}{*}{$\begin{array}{l}\text { Bridge } \\
\text { No. }\end{array}$} & \multirow{2}{*}{$\begin{array}{l}\text { Span, } \\
\text { L (m) }\end{array}$} & \multirow{2}{*}{$\begin{array}{l}\text { No. of } \\
\text { Girders, } \\
\text { N }\end{array}$} & \multirow{2}{*}{$\begin{array}{l}\text { Girder } \\
\text { spacing, } \\
\text { S (m) }\end{array}$} & \multirow[b]{2}{*}{$\mathrm{L} / \mathrm{R}$} & \multirow{2}{*}{$\begin{array}{l}\text { No. of } \\
\text { bracing } \\
\text { intervals }\end{array}$} & \multirow{2}{*}{$\begin{array}{l}\text { Torsion } \\
\text { box area }\end{array}$} & \multicolumn{2}{|c|}{ Vertical bracing with torsion box } & \multicolumn{2}{|c|}{ Vertical bracing only } \\
\hline & & & & & & & $\begin{array}{l}\text { Max. } \\
\text { compressive } \\
\text { force }(\mathrm{kN})\end{array}$ & $\begin{array}{l}\text { Max. tensile } \\
\text { force }(\mathrm{kN})\end{array}$ & $\begin{array}{l}\text { Max. } \\
\text { compressive } \\
\text { force }(\mathrm{kN})\end{array}$ & $\begin{array}{l}\text { Max. tensile force } \\
\text { (kN) }\end{array}$ \\
\hline \multirow{3}{*}{1} & \multirow{3}{*}{10} & \multirow{3}{*}{3} & \multirow{3}{*}{3} & \multirow{3}{*}{0.3} & \multirow{3}{*}{9} & A & -16.07 & 17.49 & \multirow{3}{*}{-5.83} & \multirow{3}{*}{5.83} \\
\hline & & & & & & $1.5 \mathrm{~A}$ & -19.27 & 21.19 & & \\
\hline & & & & & & $2 \mathrm{~A}$ & -21.53 & 23.85 & & \\
\hline \multirow[t]{3}{*}{2} & \multirow{3}{*}{15} & \multirow{3}{*}{3} & \multirow{4}{*}{2.5} & \multirow{3}{*}{0.3} & \multirow{3}{*}{12} & & & 52.15 & \multirow{3}{*}{-8.03} & \multirow{4}{*}{8.03} \\
\hline & & & & & & $1.5 \mathrm{~A}$ & -55.34 & 59.05 & & \\
\hline & & & & & & $\frac{2 \mathrm{~A}}{3 \mathrm{~A}}$ & -59.24 & $\frac{63.65}{22.42}$ & & \\
\hline \multirow{4}{*}{3} & \multirow{4}{*}{25} & \multirow{4}{*}{3} & & & \multirow{4}{*}{18} & A & $\frac{-64.41}{-246.94}$ & 255.67 & \multirow{4}{*}{-27.23} & \\
\hline & & & \multirow[t]{3}{*}{2} & \multirow{3}{*}{0.5} & & $1.5 \mathrm{~A}$ & -262.66 & 270.78 & & \multirow[t]{3}{*}{22.42} \\
\hline & & & & & & $2 \mathrm{~A}$ & -273.49 & 279.26 & & \\
\hline & & & & & & $3 \mathrm{~A}$ & -287.1 & 289.28 & & \\
\hline \multirow{3}{*}{4} & \multirow{3}{*}{35} & \multirow{3}{*}{3} & & & & A & -592.26 & 615.12 & & \\
\hline & & & 3 & 0.7 & 18 & $\frac{1.5 \mathrm{~A}}{2 \mathrm{~A}}$ & $\begin{array}{r}-630.89 \\
-676.64\end{array}$ & $\frac{659.62}{684.79}$ & -54.47 & 54.47 \\
\hline & & & & & & $\frac{2 \mathrm{~A}}{3 \mathrm{~A}}$ & \begin{tabular}{|c|}
-676.64 \\
-676.64
\end{tabular} & $\frac{0.44 .19}{714.27}$ & & \\
\hline
\end{tabular}

Note: $\mathrm{A}=0.0075 \mathrm{~m}^{2}$

Table 4.5 Effect of boundary conditions on the warping-to-bending stress ratio

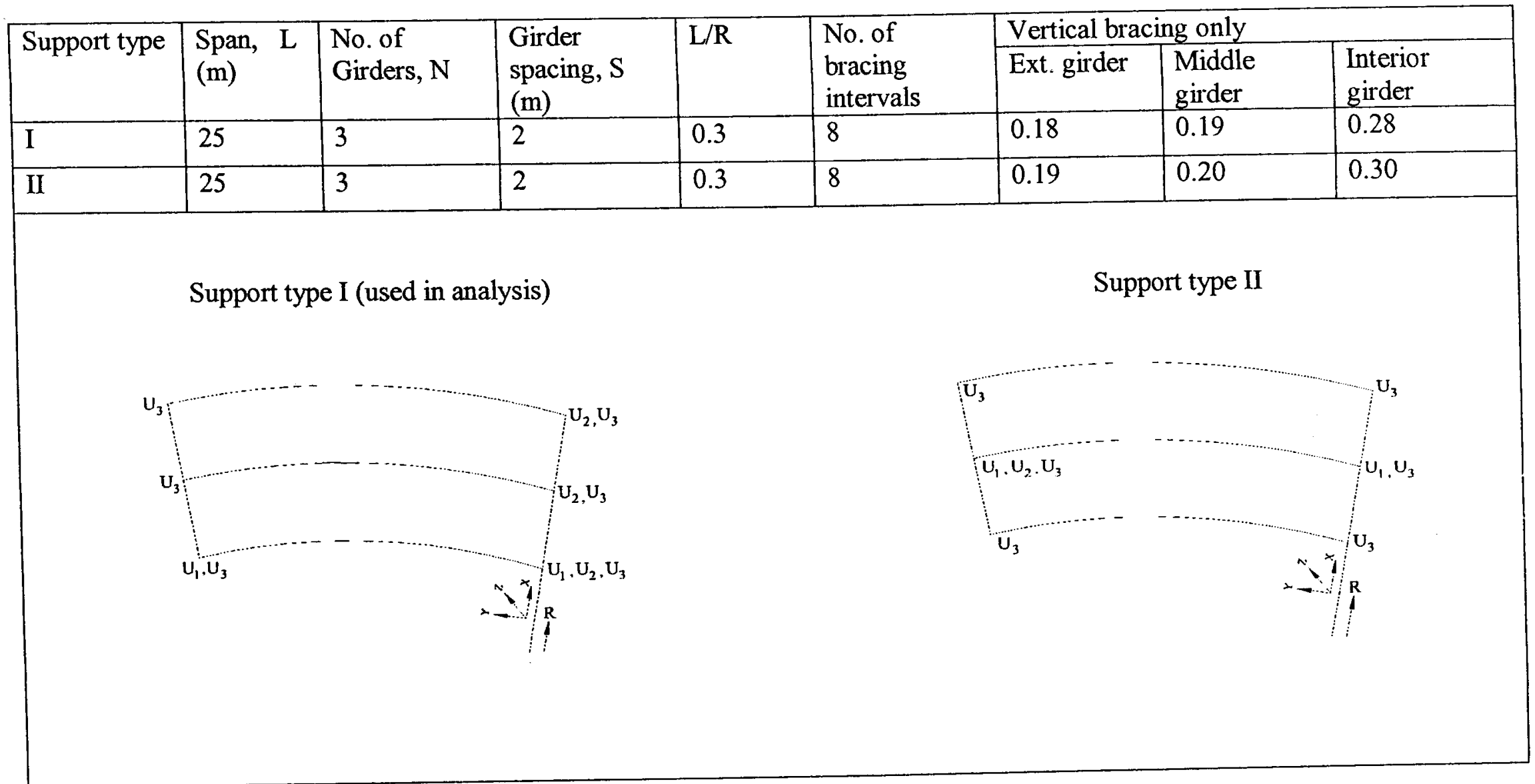




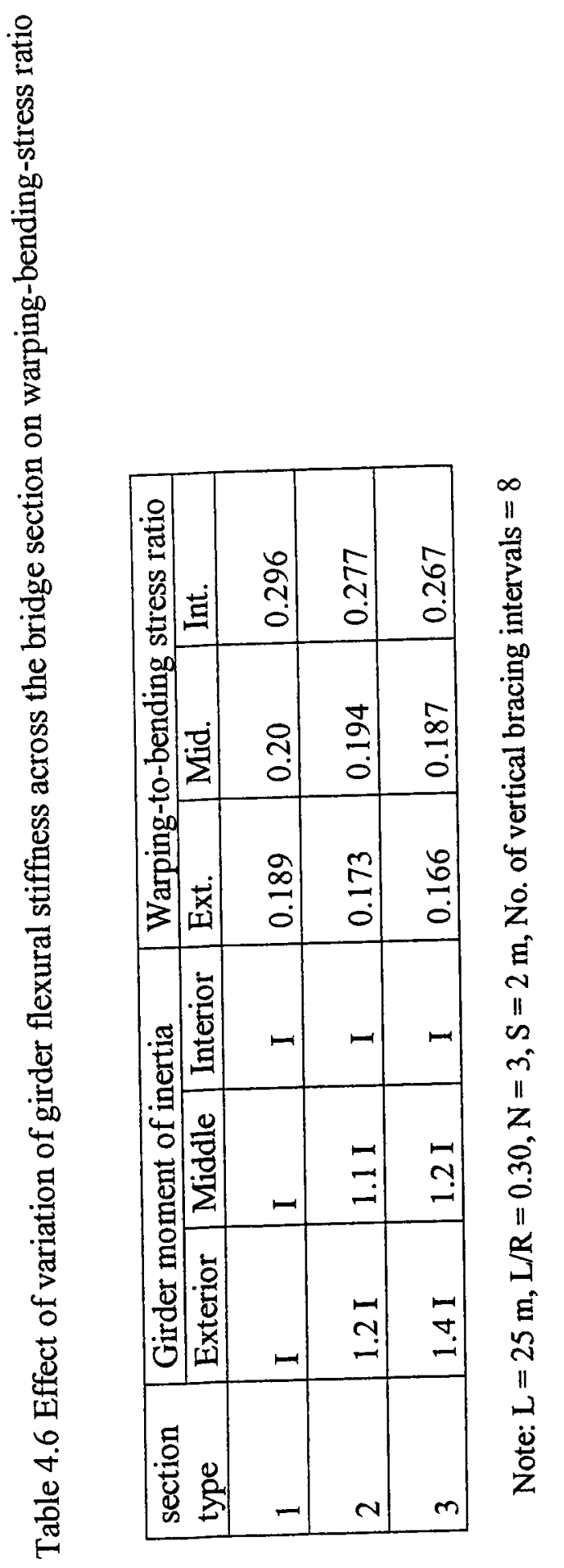

Table 4.8b: WBR for 15-m span bridge

\begin{tabular}{|c|c|c|c|c|c|c|}
\hline \multirow[b]{2}{*}{ Span, L } & \multirow[b]{2}{*}{$L / R$} & \multirow{2}{*}{$\begin{array}{l}\text { No. of } \\
\text { bracing } \\
\text { intervals, } \\
\text { S }\end{array}$} & \multirow{2}{*}{$\begin{array}{l}\text { Flange } \\
\text { width, } b_{\mathrm{f}}\end{array}$} & \multirow{2}{*}{$\begin{array}{l}\text { Warping } \\
\text { constant, } I_{w}\end{array}$} & \multicolumn{2}{|c|}{ WBK } \\
\hline & & & & & $\begin{array}{l}\text { Exterior } \\
\text { girder }\end{array}$ & $\begin{array}{l}\text { Interior } \\
\text { girder }\end{array}$ \\
\hline \multirow{5}{*}{15} & \multirow{6}{*}{0.1} & & 300 & $1.265 \times 10^{13}$ & 0.157 & 0.149 \\
\hline & & $4^{*}$ & 450 & $4.270 \times 10^{13}$ & 0.149 & 0.132 \\
\hline & & & 300 & $1.265 \times 10^{13}$ & 0.063 & 0.067 \\
\hline & & 6 & 450 & $4.270 \times 10^{13}$ & 0.058 & 0.063 \\
\hline & & & 300 & $1.265 \times 10^{13}$ & 0.040 & 0.043 \\
\hline \multirow{6}{*}{15} & & 8 & 450 & $4.270 \times 10^{13}$ & 0.037 & 0.041 \\
\hline & \multirow{5}{*}{0.2} & 4 & $\frac{300}{150}$ & $1.265 \times 10^{13}$ & $\frac{0.355}{0.303}$ & $\frac{0.313}{0.241}$ \\
\hline & & & $\frac{450}{300}$ & $\frac{4.270 \times 10^{13}}{1.265 \times 10^{13}}$ & $\frac{0.303}{0.116}$ & 0.241 \\
\hline & & $6^{*}$ & 450 & $4.270 \times 10^{13}$ & 0.113 & 0.129 \\
\hline & & & 300 & $1.265 \times 10^{13}$ & 0.076 & 0.092 \\
\hline & & 8 & $\frac{450}{300}$ & $\frac{4.270 \times 10^{13}}{1265 \times 10^{13}}$ & $\frac{0.071}{0.184}$ & $\frac{0.090}{0221}$ \\
\hline \multirow[t]{4}{*}{15} & \multirow{4}{*}{0.3} & 6 & $\frac{300}{450}$ & $\frac{1.265 \times 10}{4.270 \times 10^{13}}$ & $\frac{0.184}{0.168}$ & $\frac{0.221}{0.209}$ \\
\hline & & & 300 & $1.265 \times 10^{13}$ & 0.100 & 0.137 \\
\hline & & 8 & 450 & $4.270 \times 10^{13}$ & 0.104 & 0.150 \\
\hline & & 12 & $\frac{300}{450}$ & $\frac{1.265 \times 10^{13}}{4.270 \times 10^{13}}$ & $\frac{0.063}{0.062}$ & $\frac{0.109}{0.116}$ \\
\hline
\end{tabular}

$\bar{a}$

Note:

. 


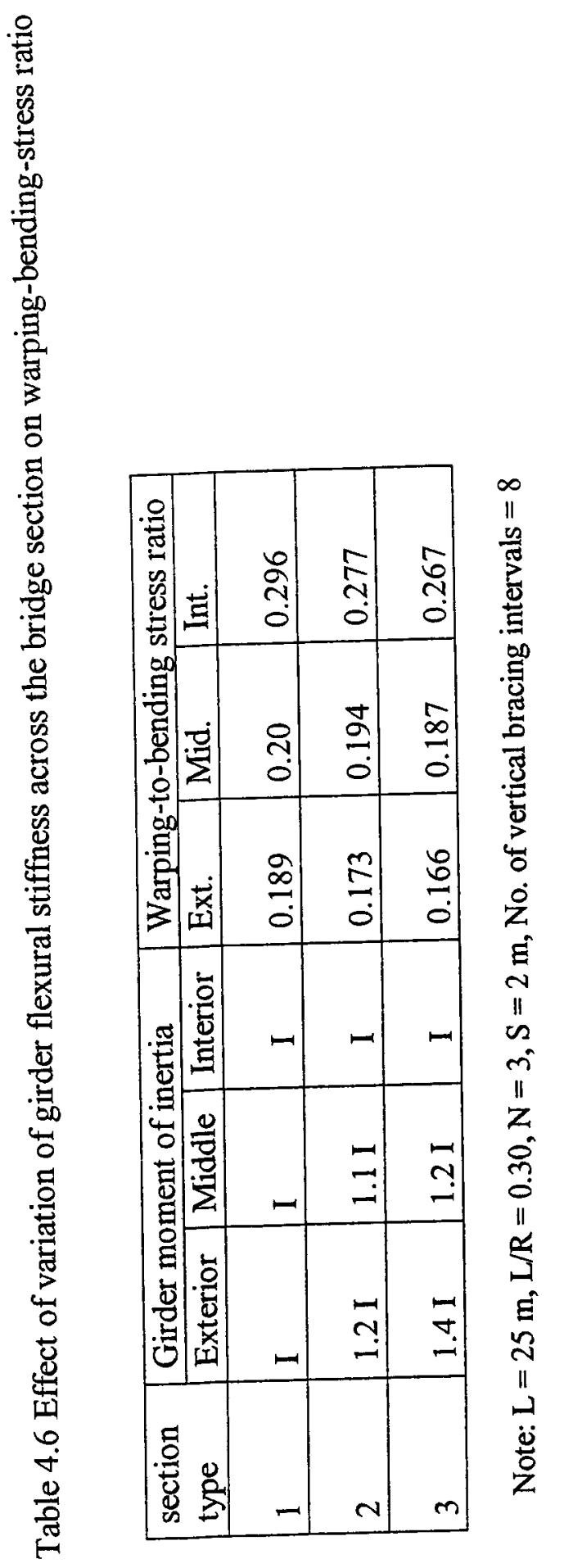

Table 4.8b: WBR for 15-m span bridge

\begin{tabular}{|c|c|c|c|c|c|c|}
\hline \multirow[b]{2}{*}{ Span, L } & \multirow[b]{2}{*}{$L / R$} & \multirow{2}{*}{ 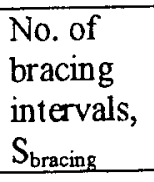 } & \multirow{2}{*}{$\begin{array}{l}\text { Flange } \\
\text { width, } b_{f}\end{array}$} & \multirow{2}{*}{$\begin{array}{l}\text { Warping } \\
\text { constant, } I_{\mathrm{w}}\end{array}$} & \multicolumn{2}{|c|}{ WBK } \\
\hline & & & & & $\begin{array}{l}\text { Exterior } \\
\text { girder }\end{array}$ & $\begin{array}{l}\text { Interior } \\
\text { girder }\end{array}$ \\
\hline \multirow{5}{*}{15} & \multirow{6}{*}{0.1} & & 300 & $1.265 \times 10^{13}$ & 0.157 & 0.149 \\
\hline & & $4^{*}$ & 450 & $4.270 \times 10^{13}$ & 0.149 & 0.132 \\
\hline & & & 300 & $1.265 \times 10^{13}$ & 0.063 & 0.067 \\
\hline & & 6 & 450 & $4.270 \times 10^{13}$ & 0.058 & 0.063 \\
\hline & & & 300 & $1.265 \times 10^{13}$ & 0.040 & 0.043 \\
\hline \multirow{5}{*}{15} & & 8 & 450 & $4.270 \times 10^{13}$ & 0.037 & 0.041 \\
\hline & \multirow{5}{*}{0.2} & 4 & $\frac{300}{150}$ & $1.265 \times 10^{13}$ & 0.355 & $\frac{0.313}{0.241}$ \\
\hline & & & $\frac{450}{300}$ & $\frac{4.270 \times 10^{13}}{1.265 \times 10^{13}}$ & 0.303 & 0.241 \\
\hline & & $6^{*}$ & 450 & $4.270 \times 10^{13}$ & 0.113 & 0.129 \\
\hline & & & 300 & $1.265 \times 10^{13}$ & 0.076 & 0.092 \\
\hline \multirow{5}{*}{15} & & 8 & 450 & $\frac{4.270 \times 10^{13}}{1265 \times 10^{13}}$ & $\frac{0.071}{0.184}$ & $\frac{0.090}{0221}$ \\
\hline & \multirow{4}{*}{0.3} & 6 & $\frac{300}{450}$ & $\frac{1.265 \times 10^{-13}}{4.270 \times 10^{13}}$ & $\frac{0.184}{0.168}$ & $\frac{0.221}{0.209}$ \\
\hline & & & 300 & $1.265 \times 10^{13}$ & 0.100 & 0.137 \\
\hline & & $8^{*}$ & 450 & $4.270 \times 10^{13}$ & 0.104 & 0.150 \\
\hline & & 12 & $\frac{300}{450}$ & $\frac{1.265 \times 10^{13}}{4.270 \times 10^{13}}$ & $\begin{array}{l}0.063 \\
0.062\end{array}$ & $\frac{0.109}{0.116}$ \\
\hline
\end{tabular}

$\bar{a}$

Note:

. 
Table 4.8c: WBR for 25-m span bridges

\begin{tabular}{|c|c|c|c|c|c|c|}
\hline \multirow[b]{2}{*}{ Span, L } & \multirow[b]{2}{*}{$L / R$} & \multirow{2}{*}{$\begin{array}{l}\text { No. of } \\
\text { bracing } \\
\text { intervals, } \\
\text { Stracing }\end{array}$} & \multirow{2}{*}{$\begin{array}{l}\text { Flange } \\
\text { width, } b_{f}\end{array}$} & \multirow{2}{*}{$\begin{array}{l}\text { Warping } \\
\text { constant, } I_{w}\end{array}$} & \multicolumn{2}{|c|}{ WBR } \\
\hline & & & & & $\begin{array}{l}\text { Exterior } \\
\text { girder }\end{array}$ & \begin{tabular}{|l|} 
Interior \\
girder
\end{tabular} \\
\hline \multirow{5}{*}{25} & \multirow{5}{*}{0.1} & & 300 & $3.516 \times 10^{13}$ & 0.344 & 0.332 \\
\hline & & 4 & 450 & $11.870 \times 10^{13}$ & 0.258 & 0.232 \\
\hline & & & 300 & $3.516 \times 10^{13}$ & 0.122 & 0.113 \\
\hline & & $6^{*}$ & 450 & $11.870 \times 10^{13}$ & 0.096 & 0.098 \\
\hline & & & 300 & $3.516 \times 10^{13}$ & 0.067 & $\begin{array}{l}0.074 \\
0.063\end{array}$ \\
\hline \multirow{5}{*}{25} & & 8 & $\frac{450}{300}$ & $\frac{11.870 \times 10^{13}}{3.516 \times 10^{13}}$ & 0.056 & $\frac{0.063}{0.258}$ \\
\hline & \multirow[t]{4}{*}{0.3} & 6 & 450 & $\frac{31.870 \times 10^{13}}{13}$ & 0.307 & 0.361 \\
\hline & & & 300 & $3.516 \times 10^{13}$ & 0.176 & 0.280 \\
\hline & & $8^{*}$ & 450 & $11.870 \times 10^{13}$ & 0.154 & 0.266 \\
\hline & & & 300 & $3.516 \times 10^{13}$ & 0.099 & 0.215 \\
\hline \multirow{5}{*}{25} & \multirow{5}{*}{0.5} & 12 & $\frac{450}{300}$ & $11.870 \times 10^{13}$ & 0.086 & 0.207 \\
\hline & & 8 & $\frac{300}{450}$ & $\frac{3.516 \times 10^{13}}{11.870 \times 10^{13}}$ & $\frac{0.465}{0.250}$ & $\begin{array}{l}0.473 \\
0.075\end{array}$ \\
\hline & & & 300 & $3.516 \times 10^{13}$ & 0.146 & 0.615 \\
\hline & & $12^{*}$ & 450 & $11.870 \times 10^{13}$ & 0.133 & 0.182 \\
\hline & & 18 & 300 & \begin{tabular}{|l|}
$3.516 \times 10^{13}$ \\
$11071^{13}$
\end{tabular} & $\frac{0.085}{0.079}$ & 0.514 \\
\hline
\end{tabular}

Note:

f bracings as per Davidson's equation 2.19.
Table 4.8d: WBR for 35-m span bridges

\begin{tabular}{|c|c|c|c|c|c|c|}
\hline \multirow[b]{2}{*}{ Span, L } & \multirow[b]{2}{*}{$L / R$} & \multirow{2}{*}{$\begin{array}{l}\text { No. of } \\
\text { bracing } \\
\text { intervals, } \\
\text { S bracing }\end{array}$} & \multirow{2}{*}{$\begin{array}{l}\text { Flange } \\
\text { width, } b_{f}\end{array}$} & \multirow{2}{*}{$\begin{array}{l}\text { Warping } \\
\text { constant, } I_{w}\end{array}$} & \multicolumn{2}{|c|}{ WBR } \\
\hline & & & & & $\begin{array}{l}\text { Exterior } \\
\text { girder }\end{array}$ & $\begin{array}{l}\text { Interior } \\
\text { girder }\end{array}$ \\
\hline \multirow{5}{*}{35} & \multirow{6}{*}{0.1} & \multirow{3}{*}{$6^{*}$} & 300 & $6.890 \times 10^{13}$ & 0.203 & 0.195 \\
\hline & & & 450 & $23.259 \times 10^{13}$ & 0.144 & 0.139 \\
\hline & & & 300 & $6.890 \times 10^{13}$ & 0.100 & 0.114 \\
\hline & & \multirow[t]{2}{*}{8} & 450 & $23.259 \times 10^{13}$ & 0.076 & 0.090 \\
\hline & & & 300 & $\frac{6.890 \times 10^{13}}{23250.10^{13}}$ & 0.053 & 0.068 \\
\hline \multirow{5}{*}{35} & & 12 & $\frac{450}{300}$ & $\frac{23.259 \times 10^{13}}{6.890 \times 10^{13}}$ & 0.044 & 0.059 \\
\hline & \multirow[t]{5}{*}{0.4} & 8 & 450 & $23.259 \times 10^{13}$ & 0.291 & 0.593 \\
\hline & & & 300 & $6.890 \times 10^{13}$ & 0.174 & 0.820 \\
\hline & & $12^{*}$ & 450 & $23.259 \times 10^{13}$ & 0.144 & 0.824 \\
\hline & & 18 & $\frac{300}{150}$ & $6.890 \times 10^{13}$ & 0.095 & 0.779 \\
\hline \multirow{5}{*}{35} & & 10 & $\frac{450}{300}$ & $\frac{23.259 \times 10^{13}}{6.890 \times 10^{13}}$ & $\frac{0.083}{0.782}$ & 0.985 \\
\hline & \multirow[t]{4}{*}{0.7} & 8 & 450 & $23.259 \times 10^{13}$ & 0.547 & 0.826 \\
\hline & & \multirow{2}{*}{$12^{*}$} & 300 & $6.890 \times 10^{13}$ & 0.299 & 0.455 \\
\hline & & & 450 & $23.259 \times 10^{13}$ & 0.233 & 0.415 \\
\hline & & 18 & $\frac{300}{450}$ & $\frac{6.890 \times 10^{13}}{23.259 \times 10^{13}}$ & $\frac{0.145}{0.122}$ & 0.258 \\
\hline
\end{tabular}

Note:
*: Number of bracings as per Davidson's equation 2.19 . 
Table 4.8c: WBR for 25-m span bridges

\begin{tabular}{|c|c|c|c|c|c|c|}
\hline \multirow[b]{2}{*}{ Span, L } & \multirow[b]{2}{*}{$L / R$} & \multirow{2}{*}{$\begin{array}{l}\text { No. of } \\
\text { bracing } \\
\text { intervals, } \\
\text { S bracing }^{\text {nat }}\end{array}$} & \multirow{2}{*}{$\begin{array}{l}\text { Flange } \\
\text { width, } b_{f}\end{array}$} & \multirow{2}{*}{$\begin{array}{l}\text { Warping } \\
\text { constant, } I_{w}\end{array}$} & \multicolumn{2}{|c|}{ WBR } \\
\hline & & & & & $\begin{array}{l}\text { Exterior } \\
\text { girder }\end{array}$ & $\begin{array}{l}\text { Interior } \\
\text { girder }\end{array}$ \\
\hline \multirow{5}{*}{25} & \multirow{5}{*}{0.1} & & 300 & $3.516 \times 10^{13}$ & 0.344 & 0.332 \\
\hline & & 4 & 450 & $11.870 \times 10^{13}$ & 0.258 & 0.232 \\
\hline & & & 300 & $3.516 \times 10^{13}$ & 0.122 & 0.113 \\
\hline & & $6^{*}$ & 450 & $11.870 \times 10^{13}$ & 0.096 & 0.098 \\
\hline & & & 300 & $3.516 \times 10^{13}$ & 0.067 & 0.074 \\
\hline \multirow{5}{*}{25} & \multirow{5}{*}{0.3} & 0 & $\frac{450}{300}$ & $\frac{11.870 \times 10^{13}}{3.516 \times 10^{13}}$ & $\frac{0.056}{0.405}$ & 0.063 \\
\hline & & 6 & 450 & $11.870 \times 10^{13}$ & 0.307 & 0.361 \\
\hline & & & 300 & $3.516 \times 10^{13}$ & 0.176 & 0.280 \\
\hline & & $8^{*}$ & 450 & $11.870 \times 10^{13}$ & 0.154 & 0.266 \\
\hline & & & 300 & $3.516 \times 10^{13}$ & 0.099 & 0.215 \\
\hline \multirow{5}{*}{25} & \multirow{5}{*}{0.5} & 12 & 450 & $11.870 \times 10^{13}$ & 0.086 & 0.207 \\
\hline & & 8 & $\frac{300}{450}$ & $\frac{3.516 \times 10^{13}}{11.870 \times 10^{13}}$ & $\frac{0.465}{0.250}$ & $\begin{array}{l}0.473 \\
0.075\end{array}$ \\
\hline & & & 300 & $3.516 \times 10^{13}$ & 0.146 & 0.615 \\
\hline & & $12^{*}$ & 450 & $11.870 \times 10^{13}$ & 0.133 & 0.182 \\
\hline & & 18 & 300 & \begin{tabular}{|l|l}
$.516 \times 10^{13}$ \\
$170 \times 10^{13}$
\end{tabular} & 0.085 & 0.514 \\
\hline
\end{tabular}

Note:

f bracings as per Davidson's equation 2.19.
Table 4.8d: WBR for 35-m span bridges

\begin{tabular}{|c|c|c|c|c|c|c|}
\hline \multirow[b]{2}{*}{ Span, L } & \multirow[b]{2}{*}{$L / R$} & \multirow{2}{*}{$\begin{array}{l}\text { No. of } \\
\text { bracing } \\
\text { intervals, } \\
\mathrm{S}_{\text {bracing }} \\
\end{array}$} & \multirow{2}{*}{$\begin{array}{l}\text { Flange } \\
\text { width, } b_{f}\end{array}$} & \multirow{2}{*}{$\begin{array}{l}\text { Warping } \\
\text { constant, } I_{w}\end{array}$} & \multicolumn{2}{|c|}{ WBR } \\
\hline & & & & & $\begin{array}{l}\text { Exterior } \\
\text { girder }\end{array}$ & $\begin{array}{l}\text { Interior } \\
\text { girder }\end{array}$ \\
\hline \multirow{5}{*}{35} & \multirow{5}{*}{0.1} & & 300 & $6.890 \times 10^{13}$ & 0.203 & 0.195 \\
\hline & & $6^{*}$ & 450 & $23.259 \times 10^{13}$ & 0.144 & 0.139 \\
\hline & & & 300 & $6.890 \times 10^{13}$ & 0.100 & 0.114 \\
\hline & & 8 & 450 & $23.259 \times 10^{13}$ & 0.076 & 0.090 \\
\hline & & & 300 & $6.890 \times 10^{13}$ & 0.053 & 0.068 \\
\hline \multirow{7}{*}{35} & \multirow{6}{*}{0.4} & 12 & $\frac{450}{300}$ & $23.259 \times 10^{13}$ & $\frac{0.044}{0.429}$ & 0.059 \\
\hline & & 8 & $\frac{300}{450}$ & $\frac{0.07010}{23.259 \times 10^{13}}$ & $\frac{0.429}{0.291}$ & $\frac{0.842}{0.593}$ \\
\hline & & & 300 & $6.890 \times 10^{13}$ & 0.174 & 0.820 \\
\hline & & $12^{*}$ & 450 & $23.259 \times 10^{13}$ & 0.144 & 0.824 \\
\hline & & & 300 & $6.890 \times 10^{13}$ & 0.095 & 0.779 \\
\hline & & 18 & 450 & $23.259 \times 10^{13}$ & 0.083 & 0.985 \\
\hline & \multirow{5}{*}{0.7} & & 300 & $6.890 \times 10^{13}$ & 0.782 & 0.965 \\
\hline \multirow[t]{4}{*}{35} & & 8 & 450 & $23.259 \times 10^{13}$ & 0.547 & 0.826 \\
\hline & & & 300 & $6.890 \times 10^{13}$ & 0.299 & 0.455 \\
\hline & & $12^{*}$ & 450 & $23.259 \times 10^{13}$ & 0.233 & 0.415 \\
\hline & & 18 & $\frac{300}{450}$ & $\frac{6.890 \times 10^{13}}{23.259 \times 10^{13}}$ & $\frac{0.145}{0.122}$ & 0.258 \\
\hline
\end{tabular}

Note:
*: Number of bracings as per Davidson's equation 2.19 . 
Table 4.9 Effect of number of girders, girder spacing and L/R ratio on warping-to-bending stress ratio

Table 4.9a: WBR for $10 \mathrm{~m}$ span bridge

\begin{tabular}{|c|c|c|c|c|c|c|c|c|c|c|c|}
\hline \multicolumn{5}{|c|}{ Bridge Dimensions } & \multirow{2}{*}{\multicolumn{7}{|c|}{ WBR }} \\
\hline $\begin{array}{l}\text { Span } \\
\text { (m) }\end{array}$ & $\begin{array}{l}\text { Girder } \\
\text { Spacing } \\
(\mathrm{m})\end{array}$ & $\begin{array}{l}\text { Span } \\
\text { Radius } \\
\text { ratio }\end{array}$ & $\begin{array}{l}\text { No. of } \\
\text { Bracing } \\
\text { Intervals }\end{array}$ & $\begin{array}{l}\text { No. of } \\
\text { Girders }\end{array}$ & & & & & & & \\
\hline L & $s$ & $L / R$ & & $\mathrm{~N}$ & $G_{E X t}$ & $G_{5}$ & $G_{4}$ & $\mathrm{G}_{3}$ & $\mathrm{G}_{2}$ & $G_{1}$ & $G_{\text {lnt }}$ \\
\hline \multirow{5}{*}{10} & \multirow{5}{*}{2} & \multirow{5}{*}{0.1} & \multirow{5}{*}{2} & 3 & 0.514 & & & & & 0.488 & 0.485 \\
\hline & & & & 4 & 0.502 & & & & 0.494 & 0.486 & 0.480 \\
\hline & & & & 5 & 0.509 & & & 0.500 & 0.489 & 0.480 & 0.475 \\
\hline & & & & 6 & 0.505 & & 0.505 & 0.494 & 0.484 & 0.475 & 0.470 \\
\hline & & & & 7 & 0.500 & 0.510 & 0.499 & 0.488 & 0.479 & 0.471 & 0.466 \\
\hline \multirow{5}{*}{10} & \multirow{5}{*}{2} & \multirow{5}{*}{0.1} & \multirow{5}{*}{$4^{*}$} & 3 & 0.092 & & & & & 0.078 & 0.082 \\
\hline & & & & 4 & 0.091 & & & & 0.084 & 0.079 & 0.072 \\
\hline & & & & 5 & 0.091 & & & 0.088 & 0.083 & 0.077 & 0.078 \\
\hline & & & & 6 & 0.094 & & 0.091 & 0.086 & 0.081 & 0.074 & 0.078 \\
\hline & & & & 7 & 0.096 & 0.093 & 0.089 & 0.084 & 0.078 & 0.071 & 0.076 \\
\hline \multirow{5}{*}{10} & \multirow{5}{*}{2} & \multirow{5}{*}{0.1} & \multirow{5}{*}{6} & 3 & 0.094 & & & & & 0.088 & 0.090 \\
\hline & & & & 4 & 0.039 & & & & 0.040 & 0.042 & 0.045 \\
\hline & & & & 5 & 0.037 & & & 0.037 & 0.039 & 0.042 & 0.045 \\
\hline & & & & 6 & 0.035 & & 0.036 & 0.037 & 0.040 & 0.043 & 0.046 \\
\hline & & & & 7 & 0.035 & 0.035 & 0.036 & 0.038 & 0.040 & 0.044 & 0.047 \\
\hline \multirow{5}{*}{10} & \multirow{5}{*}{2} & \multirow{5}{*}{0.2} & \multirow{5}{*}{4} & 3 & 0.224 & & & & & 0.176 & 0.183 \\
\hline & & & & 4 & 0.213 & & & & 0.191 & 0.175 & 0.173 \\
\hline & & & & 5 & 0.211 & & & 0.200 & 0.187 & 0.170 & 0.169 \\
\hline & & & & 6 & 0.213 & & 0.206 & 0.195 & 0.181 & 0.165 & 0.166 \\
\hline & & & & 7 & 0.212 & 0.212 & 0.201 & 0.190 & 0.176 & 0.159 & 0.158 \\
\hline \multirow{5}{*}{10} & \multirow{5}{*}{2} & \multirow{5}{*}{0.2} & \multirow{5}{*}{$6^{*}$} & 3 & 0.077 & & & & & 0.080 & 0.088 \\
\hline & & & & 4 & 0.073 & & & & 0.073 & 0.082 & 0.089 \\
\hline & & & & 5 & 0.071 & & & 0.070 & 0.071 & 0.074 & 0.081 \\
\hline & & & & 6 & 0.070 & & 0.069 & 0.069 & 0.070 & 0.074 & 0.082 \\
\hline & & & & 7 & 0.070 & 0.068 & 0.068 & 0.068 & 0.070 & 0.075 & 0.083 \\
\hline \multirow{5}{*}{10} & \multirow{5}{*}{2} & & & 3 & 0.045 & & & & & 0.050 & 0.059 \\
\hline & & & & 4 & 0.040 & & & & 0.042 & 0.045 & 0.052 \\
\hline & & 0.2 & 9 & 5 & 0.038 & & & 0.038 & 0.040 & 0.044 & 0.050 \\
\hline & & & & 6 & 0.036 & & 0.037 & 0.038 & 0.040 & 0.044 & 0.051 \\
\hline & & & & 7 & 0.036 & 0.035 & 0.035 & 0.037 & 0.040 & 0.044 & 0.052 \\
\hline & & & & 3 & 0.347 & & & & & 0.265 & 0.281 \\
\hline & & & & 4 & 0.334 & & & & 0.290 & 0.259 & 0.263 \\
\hline 10 & 2 & 0.3 & 4 & 5 & 0.328 & & & 0.305 & 0.280 & 0.249 & 0.254 \\
\hline & & & & 6 & 0.339 & & 0.317 & 0.295 & 0.270 & 0.238 & 0.248 \\
\hline & & & & 7 & 0.330 & 0.328 & 0.307 & 0.284 & 0.259 & 0.226 & 0.235 \\
\hline
\end{tabular}

*: Number of bracings as per Davidson's equation 2.19
Table 4.9a: WBR for $10 \mathrm{~m}$ span bridge (Continue...)

\begin{tabular}{|c|c|c|c|c|c|c|c|c|c|c|c|}
\hline \multicolumn{5}{|c|}{ Bridge Dimensions } & \multirow{2}{*}{\multicolumn{7}{|c|}{ WBR }} \\
\hline $\begin{array}{c}\text { Span } \\
(\mathrm{m})\end{array}$ & $\begin{array}{c}\text { Girder } \\
\text { Spacing } \\
(\mathrm{m})\end{array}$ & $\begin{array}{l}\text { Span } \\
\text { Radius } \\
\text { ratio }\end{array}$ & \multirow[t]{2}{*}{$\begin{array}{l}\text { No. of } \\
\text { Bracing } \\
\text { intervals }\end{array}$} & $\begin{array}{l}\text { No. of } \\
\text { Girders }\end{array}$ & & & & & & & \\
\hline L & $\mathrm{s}$ & $L / R$ & & $\mathrm{~N}$ & $G_{E x}$ & $Q_{5}$ & $G_{4}$ & $G_{3}$ & $\mathrm{G}_{2}$ & $G_{1}$ & $G_{m t}$ \\
\hline \multirow{5}{*}{10} & \multirow{5}{*}{2} & \multirow{5}{*}{0.3} & \multirow{5}{*}{$6^{*}$} & 3 & 0.114 & & & & & 0.119 & 0.139 \\
\hline & & & & 4 & 0.110 & & & & 0.109 & 0.123 & 0.139 \\
\hline & & & & 5 & 0.109 & & & 0.106 & 0.106 & 0.110 & 0.125 \\
\hline & & & & 6 & 0.109 & & 0.106 & 0.104 & 0.104 & 0.109 & 0.126 \\
\hline & & & & 7 & 0.110 & 0.107 & 0.104 & 0.102 & 0.103 & 0.109 & 0.129 \\
\hline \multirow{5}{*}{10} & \multirow{5}{*}{2} & \multirow{5}{*}{0.3} & \multirow{5}{*}{9} & 3 & 0.065 & & & & & 0.076 & 0.100 \\
\hline & & & & 4 & 0.059 & & & & 0.062 & 0.069 & 0.087 \\
\hline & & & & 5 & 0.065 & & & 0.063 & 0.058 & 0.066 & 0.083 \\
\hline & & & & 6 & 0.055 & & 0.055 & 0.056 & 0.059 & 0.067 & 0.086 \\
\hline & & & & 7 & 0.054 & 0.054 & 0.054 & 0.055 & 0.059 & 0.067 & 0.088 \\
\hline \multirow{4}{*}{10} & \multirow{4}{*}{2.5} & \multirow{4}{*}{0.1} & \multirow{4}{*}{2} & 3 & 0.497 & & & & & 0.487 & 0.479 \\
\hline & & & & 4 & 0.506 & & & & 0.493 & 0.479 & 0.471 \\
\hline & & & & 5 & 0.514 & & & 0.499 & 0.485 & 0.472 & 0.464 \\
\hline & & & & 6 & 0.520 & & 0.505 & 0.491 & 0.477 & 0.465 & 0.459 \\
\hline \multirow{4}{*}{10} & \multirow{4}{*}{2.5} & \multirow{4}{*}{0.1} & \multirow{4}{*}{$4^{*}$} & 3 & 0.085 & & & & & 0.080 & 0.074 \\
\hline & & & & 4 & 0.090 & & & & 0.086 & 0.079 & 0.071 \\
\hline & & & & 5 & 0.094 & & & 0.090 & 0.084 & 0.076 & 0.079 \\
\hline & & & & 6 & 0.097 & & 0.093 & 0.087 & 0.081 & 0.072 & 0.077 \\
\hline \multirow{4}{*}{10} & \multirow{4}{*}{2.5} & \multirow{4}{*}{0.1} & \multirow{4}{*}{6} & 3 & 0.040 & & & & & 0.041 & 0.044 \\
\hline & & & & 4 & 0.037 & & & & 0.038 & 0.041 & 0.044 \\
\hline & & & & 5 & 0.035 & & & 0.036 & 0.038 & 0.042 & 0.046 \\
\hline & & & & 6 & 0.045 & & 0.034 & 0.036 & 0.039 & 0.043 & 0.048 \\
\hline & & & & 3 & 0.199 & & & & & 0.181 & 0.173 \\
\hline 10 & 2.5 & 0.2 & 4 & 4 & 0.209 & & & & 0.195 & 0.176 & 0.175 \\
\hline & & & & 5 & 0.217 & & & 0.204 & 0.189 & 0.170 & 0.168 \\
\hline & & & & 6 & 0.223 & & 0.211 & 0.197 & 0.182 & 0.162 & 0.165 \\
\hline & & & & 3 & 0.074 & & & & & 0.075 & 0.081 \\
\hline 10 & 2.5 & 0.2 & $6^{*}$ & 4 & 0.071 & & & & 0.070 & 0.073 & 0.079 \\
\hline & & & & 5 & 0.070 & & & 0.068 & 0.069 & 0.073 & 0.081 \\
\hline & & & & 6 & 0.069 & & 0.068 & 0.067 & 0.069 & 0.073 & 0.083 \\
\hline & & & & 3 & 0.041 & & & & & 0.045 & 0.057 \\
\hline 10 & 2.5 & 0.2 & 9 & 4 & 0.038 & & & & 0.039 & 0.042 & 0.049 \\
\hline & & & & 5 & 0.036 & & & 0.036 & 0.039 & 0.042 & 0.050 \\
\hline & & & & 6 & 0.035 & & 0.035 & 0.036 & 0.038 & 0.043 & 0.053 \\
\hline & & & & 3 & 0.316 & & & & & 0.272 & 0.264 \\
\hline 10 & 2.5 & 0.3 & 4 & 4 & 0.325 & & & & 0.296 & 0.261 & 0.256 \\
\hline & & & & 5 & 0.339 & & & 0.312 & 0.283 & 0.247 & 0.250 \\
\hline & & & & 6 & 0.352 & & 0.326 & 0.299 & 0.270 & 0.233 & 0.245 \\
\hline
\end{tabular}


Table 4.9 Effect of number of girders, girder spacing and $\mathrm{L} / \mathrm{R}$ ratio on warping-to-bending stress ratio

Table 4.9a: WBR for $10 \mathrm{~m}$ span bridge

\begin{tabular}{|c|c|c|c|c|c|c|c|c|c|c|c|}
\hline \multicolumn{5}{|c|}{ Bridge Dimensions } & \multirow{2}{*}{\multicolumn{7}{|c|}{ WBR }} \\
\hline $\begin{array}{l}\text { Span } \\
\text { (m) }\end{array}$ & $\begin{array}{l}\text { Girder } \\
\text { Spacing } \\
\text { (m) }\end{array}$ & $\begin{array}{l}\text { Span } \\
\text { Radius } \\
\text { ratio }\end{array}$ & $\begin{array}{l}\text { No. of } \\
\text { Bracing } \\
\text { Intervals }\end{array}$ & $\begin{array}{l}\text { No. of } \\
\text { Girders }\end{array}$ & & & & & & & \\
\hline L & $s$ & $L / R$ & & $\mathrm{~N}$ & $G_{E \times t}$ & $G_{5}$ & $G_{4}$ & $\mathrm{G}_{3}$ & $\mathrm{G}_{2}$ & $G_{1}$ & $G_{\text {lnt }}$ \\
\hline \multirow{5}{*}{10} & \multirow{5}{*}{2} & \multirow{5}{*}{0.1} & \multirow{5}{*}{2} & 3 & 0.514 & & & & & 0.488 & 0.485 \\
\hline & & & & 4 & 0.502 & & & & 0.494 & 0.486 & 0.480 \\
\hline & & & & 5 & 0.509 & & & 0.500 & 0.489 & 0.480 & 0.475 \\
\hline & & & & 6 & 0.505 & & 0.505 & 0.494 & 0.484 & 0.475 & 0.470 \\
\hline & & & & 7 & 0.500 & 0.510 & 0.499 & 0.488 & 0.479 & 0.471 & 0.466 \\
\hline \multirow{5}{*}{10} & \multirow{5}{*}{2} & \multirow{5}{*}{0.1} & \multirow{5}{*}{$4^{*}$} & 3 & 0.092 & & & & & 0.078 & 0.082 \\
\hline & & & & 4 & 0.091 & & & & 0.084 & 0.079 & 0.072 \\
\hline & & & & 5 & 0.091 & & & 0.088 & 0.083 & 0.077 & 0.078 \\
\hline & & & & 6 & 0.094 & & 0.091 & 0.086 & 0.081 & 0.074 & 0.078 \\
\hline & & & & 7 & 0.096 & 0.093 & 0.089 & 0.084 & 0.078 & 0.071 & 0.076 \\
\hline \multirow{5}{*}{10} & \multirow{5}{*}{2} & \multirow{5}{*}{0.1} & \multirow{5}{*}{6} & 3 & 0.094 & & & & & 0.088 & 0.090 \\
\hline & & & & 4 & 0.039 & & & & 0.040 & 0.042 & 0.045 \\
\hline & & & & 5 & 0.037 & & & 0.037 & 0.039 & 0.042 & 0.045 \\
\hline & & & & 6 & 0.035 & & 0.036 & 0.037 & 0.040 & 0.043 & 0.046 \\
\hline & & & & 7 & 0.035 & 0.035 & 0.036 & 0.038 & 0.040 & 0.044 & 0.047 \\
\hline \multirow{5}{*}{10} & \multirow{5}{*}{2} & \multirow{5}{*}{0.2} & \multirow{5}{*}{4} & 3 & 0.224 & & & & & 0.176 & 0.183 \\
\hline & & & & 4 & 0.213 & & & & 0.191 & 0.175 & 0.173 \\
\hline & & & & 5 & 0.211 & & & 0.200 & 0.187 & 0.170 & 0.169 \\
\hline & & & & 6 & 0.213 & & 0.206 & 0.195 & 0.181 & 0.165 & 0.166 \\
\hline & & & & 7 & 0.212 & 0.212 & 0.201 & 0.190 & 0.176 & 0.159 & 0.158 \\
\hline \multirow{5}{*}{10} & \multirow{5}{*}{2} & \multirow{5}{*}{0.2} & \multirow{5}{*}{$\sigma^{*}$} & 3 & 0.077 & & & & & 0.080 & 0.088 \\
\hline & & & & 4 & 0.073 & & & & 0.073 & 0.082 & 0.089 \\
\hline & & & & 5 & 0.071 & & & 0.070 & 0.071 & 0.074 & 0.081 \\
\hline & & & & 6 & 0.070 & & 0.069 & 0.069 & 0.070 & 0.074 & 0.082 \\
\hline & & & & 7 & 0.070 & 0.068 & 0.068 & 0.068 & 0.070 & 0.075 & 0.083 \\
\hline \multirow{5}{*}{10} & \multirow{5}{*}{2} & & & 3 & 0.045 & & & & & 0.050 & 0.059 \\
\hline & & & & 4 & 0.040 & & & & 0.042 & 0.04 & 0.052 \\
\hline & & 0.2 & 9 & 5 & 0.038 & & & 0.038 & 0.040 & 0.044 & 0.050 \\
\hline & & & & 6 & 0.036 & & 0.037 & 0.038 & 0.040 & 0.044 & 0.051 \\
\hline & & & & 7 & 0.036 & 0.035 & 0.035 & 0.037 & 0.040 & 0.044 & 0.052 \\
\hline & & & & 3 & 0.347 & & & & & 0.265 & 0.281 \\
\hline & & & & 4 & 0.334 & & & & 0.290 & 0.259 & 0.263 \\
\hline 10 & 2 & 0.3 & 4 & 5 & 0.328 & & & 0.305 & 0.280 & 0.249 & 0.254 \\
\hline & & & & 6 & 0.339 & & 0.317 & 0.295 & 0.270 & 0.238 & 0.248 \\
\hline & & & & 7 & 0.330 & 0.328 & 0.307 & 0.284 & 0.259 & 0.226 & 0.235 \\
\hline
\end{tabular}

* : Number of bracings as per Davidson's equation 2.19
Table 4.9a: WBR for $10 \mathrm{~m}$ span bridge (Continue...)

\begin{tabular}{|c|c|c|c|c|c|c|c|c|c|c|c|}
\hline \multicolumn{5}{|c|}{ Bridge Dimensions } & \multirow{2}{*}{\multicolumn{7}{|c|}{ WBR }} \\
\hline $\begin{array}{c}\text { Span } \\
(\mathrm{m})\end{array}$ & $\begin{array}{c}\text { Girder } \\
\text { Spacing } \\
(\mathrm{m})\end{array}$ & $\begin{array}{l}\text { Span } \\
\text { Radius } \\
\text { ratio }\end{array}$ & $\begin{array}{l}\text { Not of } \\
\text { Bracing } \\
\text { Intervals }\end{array}$ & $\begin{array}{l}\text { No. of } \\
\text { Girders }\end{array}$ & & & & & & & \\
\hline $\mathrm{L}$ & $\mathrm{s}$ & $L / R$ & & $\mathrm{~N}$ & $G_{\text {Exx }}$ & $Q_{5}$ & $G_{4}$ & $G_{3}$ & $G_{2}$ & $G_{1}$ & $G_{\mathrm{Int}}$ \\
\hline \multirow{5}{*}{10} & \multirow{5}{*}{2} & \multirow{5}{*}{0.3} & \multirow{5}{*}{$6^{*}$} & 3 & 0.114 & & & & & 0.119 & 0.139 \\
\hline & & & & 4 & 0.110 & & & & 0.109 & 0.123 & 0.139 \\
\hline & & & & 5 & 0.109 & & & 0.106 & 0.106 & 0.110 & 0.125 \\
\hline & & & & 6 & 0.109 & & 0.106 & 0.104 & 0.104 & 0.109 & 0.126 \\
\hline & & & & 7 & 0.110 & 0.107 & 0.104 & 0.102 & 0.103 & 0.109 & 0.129 \\
\hline \multirow{5}{*}{10} & \multirow{5}{*}{2} & \multirow{5}{*}{0.3} & \multirow{5}{*}{9} & 3 & 0.065 & & & & & 0.076 & 0.100 \\
\hline & & & & 4 & 0.059 & & & & 0.062 & 0.069 & 0.087 \\
\hline & & & & 5 & 0.065 & & & 0.063 & 0.058 & 0.066 & 0.083 \\
\hline & & & & 6 & 0.055 & & 0.055 & 0.056 & 0.059 & 0.067 & 0.086 \\
\hline & & & & 7 & 0.054 & 0.054 & 0.054 & 0.055 & 0.059 & 0.067 & 0.088 \\
\hline \multirow{4}{*}{10} & \multirow{4}{*}{2.5} & \multirow{4}{*}{0.1} & \multirow{4}{*}{2} & 3 & 0.497 & & & & & 0.487 & 0.479 \\
\hline & & & & 4 & 0.506 & & & & 0.493 & 0.479 & 0.471 \\
\hline & & & & 5 & 0.514 & & & 0.499 & 0.485 & 0.472 & 0.464 \\
\hline & & & & 6 & 0.520 & & 0.505 & 0.491 & 0.477 & 0.465 & 0.459 \\
\hline \multirow{4}{*}{10} & \multirow{4}{*}{2.5} & \multirow{4}{*}{0.1} & \multirow{4}{*}{$4^{*}$} & 3 & 0.085 & & & & & 0.080 & 0.074 \\
\hline & & & & 4 & 0.090 & & & & 0.086 & 0.079 & 0.071 \\
\hline & & & & 5 & 0.094 & & & 0.090 & 0.084 & 0.076 & 0.079 \\
\hline & & & & 6 & 0.097 & & 0.093 & 0.087 & 0.081 & 0.072 & 0.077 \\
\hline \multirow{4}{*}{10} & \multirow{4}{*}{2.5} & \multirow{4}{*}{0.1} & \multirow{4}{*}{6} & 3 & 0.040 & & & & & 0.041 & 0.044 \\
\hline & & & & 4 & 0.037 & & & & 0.038 & 0.041 & 0.044 \\
\hline & & & & 5 & 0.035 & & & 0.036 & 0.038 & 0.042 & 0.046 \\
\hline & & & & 6 & 0.045 & & 0.034 & 0.036 & 0.039 & 0.043 & 0.048 \\
\hline \multirow{4}{*}{10} & & & & 3 & 0.199 & & & & & 0.181 & 0.173 \\
\hline & 25 & 02 & 4 & 4 & 0.209 & & & & 0.195 & 0.176 & 0.175 \\
\hline & & & & 5 & 0.217 & & & 0.204 & 0.189 & 0.170 & 0.168 \\
\hline & & & & 6 & 0.223 & & 0.211 & 0.197 & 0.182 & 0.162 & 0.165 \\
\hline & & & & 3 & 0.074 & & & & & 0.075 & 0.081 \\
\hline 10 & 2.5 & 0.2 & $6^{*}$ & 4 & 0.071 & & & & 0.070 & 0.073 & 0.079 \\
\hline & & & & 5 & 0.070 & & & 0.068 & 0.069 & 0.073 & 0.081 \\
\hline & & & & 6 & 0.069 & & 0.068 & 0.067 & 0.069 & 0.073 & 0.083 \\
\hline & & & & 3 & 0.041 & & & & & 0.045 & 0.057 \\
\hline 10 & 2.5 & 0.2 & 9 & 4 & 0.038 & & & & 0.039 & 0.042 & 0.049 \\
\hline & & & & 5 & 0.036 & & & 0.036 & 0.039 & 0.042 & 0.050 \\
\hline & & & & 6 & 0.035 & & 0.035 & 0.036 & 0.038 & 0.043 & 0.053 \\
\hline & & & & 3 & 0.316 & & & & & 0.272 & 0.264 \\
\hline 10 & 2.5 & 0.3 & 4 & 4 & 0.325 & & & & 0.296 & 0.261 & 0.256 \\
\hline & & & & 5 & 0.339 & & & 0.312 & 0.283 & 0.247 & 0.250 \\
\hline & & & & 6 & 0.352 & & 0.326 & 0.299 & 0.270 & 0.233 & 0.245 \\
\hline
\end{tabular}


Table 4.9a: WBR for $10 \mathrm{~m}$ span bridge (Continue...)

\begin{tabular}{|c|c|c|c|c|c|c|c|c|c|c|c|}
\hline \multicolumn{5}{|c|}{ Bridge Dimensions } & \multirow{2}{*}{\multicolumn{7}{|c|}{ WBR }} \\
\hline $\begin{array}{c}\text { Span } \\
(\mathrm{m})\end{array}$ & $\begin{array}{l}\text { Girder } \\
\text { Spacing }\end{array}$ & $\begin{array}{l}\text { Span } \\
\text { Radius } \\
\text { rtio }\end{array}$ & $\begin{array}{l}\text { No. of } \\
\text { Bracing } \\
\text { Intervals }\end{array}$ & $\begin{array}{l}\text { No. of } \\
\text { Girders }\end{array}$ & & & & & & & \\
\hline $\mathrm{L}$ & s & $L / R$ & & $\mathrm{~N}$ & $G_{E x t}$ & $G_{5}$ & $G_{4}$ & $\mathrm{G}_{3}$ & $G_{2}$ & $G_{1}$ & $G_{n t}$ \\
\hline \multirow{4}{*}{10} & \multirow{4}{*}{2.5} & \multirow{4}{*}{0.3} & \multirow{4}{*}{$6^{*}$} & 3 & 0.111 & & & & & 0.112 & 0.127 \\
\hline & & & & 4 & 0.108 & & & & 0.106 & 0.108 & 0.122 \\
\hline & & & & 5 & 0.109 & & & 0.105 & 0.103 & 0.106 & 0.124 \\
\hline & & & & 6 & 0.110 & & 0.106 & 0.102 & 0.102 & 0.106 & 0.128 \\
\hline \multirow{4}{*}{10} & \multirow{4}{*}{2.5} & \multirow{4}{*}{0.3} & \multirow{4}{*}{9} & 3 & 0.060 & & & & & 0.067 & 0.087 \\
\hline & & & & 4 & 0.056 & & & & 0.058 & 0.064 & 0.082 \\
\hline & & & & 5 & 0.054 & & & 0.055 & 0.057 & 0.064 & 0.084 \\
\hline & & & & 6 & 0.054 & & 0.054 & 0.054 & 0.057 & 0.065 & 0.090 \\
\hline \multirow{3}{*}{10} & \multirow{3}{*}{3} & \multirow{3}{*}{0.1} & \multirow{3}{*}{2} & 3 & 0.499 & & & & & 0.484 & 0.473 \\
\hline & & & & 4 & 0.509 & & & & 0.491 & 0.473 & 0.462 \\
\hline & & & & 5 & 0.518 & & & 0.498 & 0.480 & 0.464 & 0.454 \\
\hline \multirow{3}{*}{10} & \multirow{3}{*}{3} & \multirow{3}{*}{0.1} & \multirow{3}{*}{$4^{*}$} & 3 & 0.087 & & & & & 0.082 & 0.074 \\
\hline & & & & 4 & 0.092 & & & & 0.087 & 0.079 & 0.080 \\
\hline & & & & 5 & 0.096 & & & 0.091 & 0.084 & 0.075 & 0.081 \\
\hline \multirow{3}{*}{10} & \multirow{3}{*}{3} & \multirow{3}{*}{0.1} & \multirow{3}{*}{6} & 3 & 0.039 & & & & & 0.040 & 0.043 \\
\hline & & & & 4 & 0.036 & & & & 0.037 & 0.040 & 0.045 \\
\hline & & & & 5 & 0.034 & & & 0.035 & 0.037 & 0.042 & 0.047 \\
\hline \multirow{3}{*}{10} & \multirow{3}{*}{3} & & & 3 & 0.225 & & & & & 0.176 & 0.177 \\
\hline & & 0.2 & 4 & 4 & 0.214 & & & & 0.198 & 0.171 & 0.169 \\
\hline & & & & 5 & 0.222 & & & 0.207 & 0.190 & 0.168 & 0.168 \\
\hline & & & & 3 & 0.072 & & & & & 0.073 & 0.078 \\
\hline 10 & ${ }^{3}$ & 0.2 & $6^{*}$ & 4 & 0.070 & & & & 0.069 & 0.071 & 0.079 \\
\hline & & & & 5 & 0.069 & & & 0.067 & 0.068 & 0.072 & 0.078 \\
\hline & & & & 3 & 0.039 & & & & & 0.042 & 0.049 \\
\hline 10 & 3 & 0.2 & 9 & 4 & 0.036 & & & & 0.037 & 0.041 & 0.049 \\
\hline & & & & 5 & 0.035 & & & 0.035 & 0.037 & 0.042 & 0.052 \\
\hline & & & & 3 & 0.335 & & & & & 0.302 & 0.470 \\
\hline 10 & 3 & 0.3 & 4 & 4 & 0.333 & & & & 0.301 & 0.261 & 0.252 \\
\hline & & & & 5 & 0.350 & & & 0.318 & 0.285 & 0.244 & 0.248 \\
\hline & & & & 3 & 0.109 & & & & & 0.108 & 0.121 \\
\hline 10 & 3 & 0.3 & $6^{*}$ & 4 & 0.108 & & & & 0.104 & 0.105 & 0.121 \\
\hline & & & & 5 & 0.110 & & & 0.104 & 0.101 & 0.104 & 0.114 \\
\hline & & & & 3 & 0.058 & & & & & 0.062 & 0.081 \\
\hline 10 & 3 & 0.3 & 9 & 4 & 0.055 & & & & 0.055 & 0.061 & 0.081 \\
\hline & & & & 5 & 0.054 & & & 0.053 & 0.055 & 0.062 & 0.081 \\
\hline
\end{tabular}

" : Number of bracings as per Davidson's equation 2.19
Table 4.9b: WBR for $15 \mathrm{~m}$ span bridge

\begin{tabular}{|c|c|c|c|c|c|c|c|c|c|c|c|}
\hline \multicolumn{5}{|c|}{ Bridge Dimensions } & \multirow{2}{*}{\multicolumn{7}{|c|}{ WBR }} \\
\hline $\begin{array}{l}\text { Span } \\
\text { (m) }\end{array}$ & $\begin{array}{l}\text { Girder } \\
\text { Spacing }\end{array}$ & $\begin{array}{c}\text { Span } \\
\text { Radius }\end{array}$ & $\begin{array}{l}\text { No. of } \\
\text { Bracing }\end{array}$ & $\begin{array}{l}\text { No. of } \\
\text { Girders }\end{array}$ & & & & & & & \\
\hline$L$ & s & LR & & $\mathrm{N}$ & $G_{\text {EXt }}$ & $G_{5}$ & $G_{4}$ & $G_{3}$ & $G_{2}$ & $G_{1}$ & $G_{m 1}$ \\
\hline \multirow{5}{*}{15} & \multirow{5}{*}{2} & \multirow{5}{*}{0.1} & \multirow{5}{*}{$4^{*}$} & 3 & 0.167 & & & & & 0.160 & 0.154 \\
\hline & & & & 4 & 0.162 & & & & 0.160 & 0.156 & 0.152 \\
\hline & & & & 5 & 0.166 & & & 0.163 & 0.160 & 0.156 & 0.152 \\
\hline & & & & 6 & 0.168 & & 0.166 & 0.163 & 0.159 & 0.155 & 0.151 \\
\hline & & & & 7 & 0.161 & 0.168 & 0.165 & 0.162 & 0.158 & 0.154 & 0.151 \\
\hline \multirow{5}{*}{15} & \multirow{5}{*}{2} & \multirow{5}{*}{0.1} & \multirow{5}{*}{6} & 3 & 0.079 & & & & & 0.075 & 0.077 \\
\hline & & & & 4 & 0.078 & & & & 0.075 & 0.074 & 0.074 \\
\hline & & & & 5 & 0.072 & & & 0.071 & 0.069 & 0.066 & 0.064 \\
\hline & & & & 6 & 0.072 & & 0.071 & 0.071 & 0.068 & 0.065 & 0.062 \\
\hline & & & & 7 & 0.074 & 0.072 & 0.071 & 0.069 & 0.067 & 0.065 & 0.062 \\
\hline \multirow{5}{*}{15} & \multirow{5}{*}{2} & \multirow{5}{*}{0.1} & \multirow{5}{*}{8} & 3 & 0.040 & & & & & 0.041 & 0.043 \\
\hline & & & & 4 & 0.036 & & & & 0.036 & 0.037 & 0.037 \\
\hline & & & & 5 & 0.035 & & & 0.034 & 0.034 & 0.035 & 0.035 \\
\hline & & & & 6 & 0.034 & & 0.033 & 0.033 & 0.033 & 0.034 & 0.034 \\
\hline & & & & 7 & 0.035 & 0.034 & 0.033 & 0.033 & 0.033 & 0.034 & 0.034 \\
\hline \multirow{5}{*}{15} & \multirow{5}{*}{2} & \multirow{5}{*}{0.2} & \multirow{5}{*}{4} & 3 & 0.375 & & & & & 0.348 & 0.323 \\
\hline & & & & 4 & 0.368 & & & & 0.355 & 0.340 & 0.322 \\
\hline & & & & 5 & 0.378 & & & 0.379 & 0.353 & 0.339 & 0.323 \\
\hline & & & & 6 & 0.384 & & 0.372 & 0.361 & 0.348 & 0.335 & 0.319 \\
\hline & & & & 7 & 0.390 & 0.379 & 0.368 & 0.356 & 0.343 & 0.330 & 0.314 \\
\hline \multirow{5}{*}{15} & \multirow{5}{*}{2} & \multirow{5}{*}{0.2} & \multirow{5}{*}{$\sigma^{*}$} & 3 & 0.136 & & & & & 0.116 & 0.125 \\
\hline & & & & 4 & 0.124 & & & & 0.118 & 0.111 & 0.113 \\
\hline & & & & 5 & 0.130 & & & 0.115 & 0.120 & 0.114 & 0.106 \\
\hline & & & & 6 & 0.133 & & 0.128 & 0.124 & 0.118 & 0.112 & 0.105 \\
\hline & & & & 7 & 0.135 & 0.131 & 0.127 & 0.122 & 0.117 & 0.110 & 0.103 \\
\hline \multirow{5}{*}{15} & \multirow{5}{*}{2} & & & 3 & 0.076 & & & & & 0.081 & 0.092 \\
\hline & & & & 4 & 0.070 & & & & 0.071 & 0.074 & 0.078 \\
\hline & & 0.2 & 8 & 5 & 0.071 & & & 0.085 & 0.068 & 0.069 & 0.072 \\
\hline & & & & 6 & 0.070 & & 0.067 & 0.076 & 0.066 & 0.068 & 0.070 \\
\hline & & & & 7 & 0.073 & 0.070 & 0.066 & 0.078 & 0.065 & 0.067 & 0.069 \\
\hline & & & & 3 & 0.221 & & & & & 0.191 & 0.221 \\
\hline & & & & 4 & 0.216 & & & & 0.197 & 0.181 & 0.192 \\
\hline 15 & 2 & 0.3 & 6 & 5 & 0.224 & & & 0.212 & 0.198 & 0.182 & 0.182 \\
\hline & & & & 6 & 0.231 & & 0.220 & 0.208 & 0.195 & 0.179 & 0.176 \\
\hline & & & & 7 & 0.237 & 0.226 & 0.217 & 0.204 & 0.191 & 0.175 & 0.172 \\
\hline
\end{tabular}


Table 4.9a: WBR for 10m span bridge (Continue...)

\begin{tabular}{|c|c|c|c|c|c|c|c|c|c|c|c|}
\hline \multicolumn{5}{|c|}{ Bridge Dimensions } & \multirow{2}{*}{\multicolumn{7}{|c|}{ WBR }} \\
\hline $\begin{array}{l}\text { Span } \\
\text { (m) }\end{array}$ & $\begin{array}{l}\text { Girder } \\
\text { Spaaing }\end{array}$ & $\begin{array}{l}\text { Span } \\
\text { Radius }\end{array}$ & \multirow{2}{*}{$\begin{array}{l}\text { No. of } \\
\text { Bracing } \\
\text { Intervals }\end{array}$} & $\begin{array}{l}\text { No. of } \\
\text { Girders }\end{array}$ & & & & & & & \\
\hline$L$ & s & LR & & $\mathrm{N}$ & $G_{E N 1}$ & $G_{5}$ & $G_{4}$ & $G_{3}$ & $G_{2}$ & $G_{1}$ & $G_{m t}$ \\
\hline \multirow{4}{*}{10} & \multirow{4}{*}{2.5} & \multirow{4}{*}{0.3} & \multirow{4}{*}{$6^{*}$} & 3 & 0.111 & & & & & 0.112 & 0.127 \\
\hline & & & & 4 & 0.108 & & & & 0.106 & 0.108 & 0.122 \\
\hline & & & & 5 & 0.109 & & & 0.105 & 0.103 & 0.106 & 0.124 \\
\hline & & & & 6 & 0.110 & & 0.106 & 0.102 & 0.102 & 0.106 & 0.128 \\
\hline \multirow{4}{*}{10} & \multirow{4}{*}{2.5} & \multirow{4}{*}{0.3} & \multirow{4}{*}{9} & 3 & 0.060 & & & & & 0.067 & 0.087 \\
\hline & & & & 4 & 0.056 & & & & 0.058 & 0.064 & 0.082 \\
\hline & & & & 5 & 0.054 & & & 0.055 & 0.057 & 0.064 & 0.084 \\
\hline & & & & 6 & 0.054 & & 0.054 & 0.054 & 0.057 & 0.065 & 0.090 \\
\hline \multirow{3}{*}{10} & \multirow{3}{*}{3} & \multirow{3}{*}{0.1} & \multirow{3}{*}{2} & 3 & 0.499 & & & & & 0.484 & 0.473 \\
\hline & & & & 4 & 0.509 & & & & 0.491 & 0.473 & 0.462 \\
\hline & & & & 5 & 0.518 & & & 0.498 & 0.480 & 0.464 & 0.454 \\
\hline \multirow{3}{*}{10} & \multirow{3}{*}{3} & \multirow{3}{*}{0.1} & \multirow{3}{*}{$4^{*}$} & 3 & 0.087 & & & & & 0.082 & 0.074 \\
\hline & & & & 4 & 0.092 & & & & 0.087 & 0.079 & 0.080 \\
\hline & & & & 5 & 0.096 & & & 0.091 & 0.084 & 0.075 & 0.081 \\
\hline \multirow{3}{*}{10} & \multirow{3}{*}{3} & \multirow{3}{*}{0.1} & \multirow{3}{*}{6} & 3 & 0.039 & & & & & 0.040 & 0.043 \\
\hline & & & & 4 & 0.036 & & & & 0.037 & 0.040 & 0.045 \\
\hline & & & & 5 & 0.034 & & & 0.035 & 0.037 & 0.042 & 0.047 \\
\hline \multirow{3}{*}{10} & & & & 3 & 0.225 & & & & & 0.176 & 0.177 \\
\hline & 3 & 0.2 & 4 & 4 & 0.214 & & & & 0.198 & 0.171 & 0.169 \\
\hline & & & & 5 & 0.222 & & & 0.207 & 0.190 & 0.168 & 0.168 \\
\hline & & & & 3 & 0.072 & & & & & 0.073 & 0.078 \\
\hline 10 & 3 & 0.2 & $6^{*}$ & 4 & 0.070 & & & & 0.069 & 0.071 & 0.079 \\
\hline & & & & 5 & 0.069 & & & 0.067 & 0.068 & 0.072 & 0.078 \\
\hline & & & & 3 & 0.039 & & & & & 0.042 & 0.049 \\
\hline 10 & 3 & 0.2 & 9 & 4 & 0.036 & & & & 0.037 & 0.041 & 0.049 \\
\hline & & & & 5 & 0.035 & & & 0.035 & 0.037 & 0.042 & 0.052 \\
\hline & & & & 3 & 0.335 & & & & & 0.302 & 0.470 \\
\hline 10 & 3 & 0.3 & 4 & 4 & 0.333 & & & & 0.301 & 0.261 & 0.252 \\
\hline & & & & 5 & 0.350 & & & 0.318 & 0.285 & 0.244 & 0.248 \\
\hline & & & & 3 & 0.109 & & & & & 0.108 & 0.121 \\
\hline 10 & 3 & 0.3 & $6^{*}$ & 4 & 0.108 & & & & 0.104 & 0.105 & 0.121 \\
\hline & & & & 5 & 0.110 & & & 0.104 & 0.101 & 0.104 & 0.114 \\
\hline & & & & 3 & 0.058 & & & & & 0.062 & 0.081 \\
\hline 10 & 3 & 0.3 & 9 & 4 & 0.055 & & & & 0.055 & 0.061 & 0.081 \\
\hline & & & & 5 & 0.054 & & & 0.053 & 0.055 & 0.062 & 0.081 \\
\hline
\end{tabular}

* : Number of bracings as per Davidson's equation 2.19
Table $4.9 \mathrm{~b}$ : WBR for $15 \mathrm{~m}$ span bridge

\begin{tabular}{|c|c|c|c|c|c|c|c|c|c|c|c|}
\hline \multicolumn{5}{|c|}{ Bridge Dimensions } & \multirow{2}{*}{\multicolumn{7}{|c|}{ WBR }} \\
\hline $\begin{array}{c}\text { Span } \\
\text { (m) }\end{array}$ & $\begin{array}{c}\text { Girder } \\
\text { Spacing } \\
(\mathrm{m})\end{array}$ & $\begin{array}{c}\text { Span } \\
\text { Radius } \\
\text { ratio }\end{array}$ & $\begin{array}{l}\text { No. of } \\
\text { Bracing } \\
\text { Intervals }\end{array}$ & $\begin{array}{l}\text { No. of } \\
\text { Girders }\end{array}$ & & & & & & & \\
\hline L & $s$ & LR & & $\mathrm{N}$ & $G_{\text {Ext }}$ & $G_{5}$ & $G_{4}$ & $G_{3}$ & $G_{2}$ & $G_{1}$ & $G_{m t}$ \\
\hline \multirow{5}{*}{15} & \multirow{5}{*}{2} & \multirow{5}{*}{0.1} & \multirow{5}{*}{$4^{*}$} & 3 & 0.167 & & & & & 0.160 & 0.154 \\
\hline & & & & 4 & 0.162 & & & & 0.160 & 0.156 & 0.152 \\
\hline & & & & 5 & 0.166 & & & 0.163 & 0.160 & 0.156 & 0.152 \\
\hline & & & & 6 & 0.168 & & 0.166 & 0.163 & 0.159 & 0.155 & 0.151 \\
\hline & & & & 7 & 0.161 & 0.168 & 0.165 & 0.162 & 0.158 & 0.154 & 0.151 \\
\hline \multirow{5}{*}{15} & \multirow{5}{*}{2} & \multirow{5}{*}{0.1} & \multirow{5}{*}{6} & 3 & 0.079 & & & & & 0.075 & 0.077 \\
\hline & & & & 4 & 0.078 & & & & 0.075 & 0.074 & 0.074 \\
\hline & & & & 5 & 0.072 & & & 0.071 & 0.069 & 0.066 & 0.064 \\
\hline & & & & 6 & 0.072 & & 0.071 & 0.071 & 0.068 & 0.065 & 0.062 \\
\hline & & & & 7 & 0.074 & 0.072 & 0.071 & 0.069 & 0.067 & 0.065 & 0.062 \\
\hline \multirow{5}{*}{15} & \multirow{5}{*}{2} & \multirow{5}{*}{0.1} & \multirow{5}{*}{8} & 3 & 0.040 & & & & & 0.041 & 0.043 \\
\hline & & & & 4 & 0.036 & & & & 0.036 & 0.037 & 0.037 \\
\hline & & & & 5 & 0.035 & & & 0.034 & 0.034 & 0.035 & 0.035 \\
\hline & & & & 6 & 0.034 & & 0.033 & 0.033 & 0.033 & 0.034 & 0.034 \\
\hline & & & & 7 & 0.035 & 0.034 & 0.033 & 0.033 & 0.033 & 0.034 & 0.034 \\
\hline \multirow{5}{*}{15} & \multirow{5}{*}{2} & \multirow{5}{*}{0.2} & \multirow{5}{*}{4} & 3 & 0.375 & & & & & 0.348 & 0.323 \\
\hline & & & & 4 & 0.368 & & & & 0.355 & 0.340 & 0.322 \\
\hline & & & & 5 & 0.378 & & & 0.379 & 0.353 & 0.339 & 0.323 \\
\hline & & & & 6 & 0.384 & & 0.372 & 0.361 & 0.348 & 0.335 & 0.319 \\
\hline & & & & 7 & 0.390 & 0.379 & 0.368 & 0.356 & 0.343 & 0.330 & 0.314 \\
\hline \multirow{5}{*}{15} & \multirow{5}{*}{2} & \multirow{5}{*}{0.2} & \multirow{5}{*}{$\sigma^{*}$} & 3 & 0.136 & & & & & 0.116 & 0.125 \\
\hline & & & & 4 & 0.124 & & & & 0.118 & 0.111 & 0.113 \\
\hline & & & & 5 & 0.130 & & & 0.115 & 0.120 & 0.114 & 0.106 \\
\hline & & & & 6 & 0.133 & & 0.128 & 0.124 & 0.118 & 0.112 & 0.105 \\
\hline & & & & 7 & 0.135 & 0.131 & 0.127 & 0.122 & 0.117 & 0.110 & 0.103 \\
\hline \multirow{5}{*}{15} & \multirow{5}{*}{2} & & & 3 & 0.076 & & & & & 0.081 & 0.092 \\
\hline & & & & 4 & 0.070 & & & & 0.071 & 0.074 & 0.078 \\
\hline & & 0.2 & 8 & 5 & 0.071 & & & 0.085 & 0.068 & 0.069 & 0.072 \\
\hline & & & & 6 & 0.070 & & 0.067 & 0.076 & 0.066 & 0.068 & 0.070 \\
\hline & & & & 7 & 0.073 & 0.070 & 0.066 & 0.078 & 0.065 & 0.067 & 0.069 \\
\hline & & & & 3 & 0.221 & & & & & 0.191 & 0.221 \\
\hline & & & & 4 & 0.216 & & & & 0.197 & 0.181 & 0.192 \\
\hline 15 & 2 & 0.3 & 6 & 5 & 0.224 & & & 0.212 & 0.198 & 0.182 & 0.182 \\
\hline & & & & 6 & 0.231 & & 0.220 & 0.208 & 0.195 & 0.179 & 0.176 \\
\hline & & & & 7 & 0.237 & 0.226 & 0.217 & 0.204 & 0.191 & 0.175 & 0.172 \\
\hline
\end{tabular}

: Number of bracings as per Davidson's equation 2.19 
Table 4 9b: WBR for $15 \mathrm{~m}$ span bridge (Continue ...)
Table 4.9b: WBR for $15 \mathrm{~m}$ span bridge (Continue...)

\begin{tabular}{|c|c|c|c|c|c|c|c|c|c|c|c|}
\hline \multicolumn{5}{|c|}{ Bridge Dimensions } & \multirow{2}{*}{\multicolumn{7}{|c|}{ WBR }} \\
\hline $\begin{array}{l}\text { Span } \\
\text { (m) }\end{array}$ & $\begin{array}{l}\text { Girder } \\
\text { Spacing }\end{array}$ & $\begin{array}{l}\text { Span } \\
\text { Radius }\end{array}$ & $\begin{array}{l}\text { No. of } \\
\text { Bracing }\end{array}$ & $\begin{array}{l}\text { No. of } \\
\text { Girders }\end{array}$ & & & & & & & \\
\hline $\mathrm{L}$ & s & LR & & $\mathrm{N}$ & $G_{\text {Ext }}$ & $G_{5}$ & $G_{4}$ & $G_{3}$ & $G_{2}$ & $G_{1}$ & $G_{\text {nt }}$ \\
\hline \multirow{4}{*}{15} & \multirow{4}{*}{2.5} & \multirow{4}{*}{0.3} & \multirow{4}{*}{$8^{*}$} & 3 & 0.096 & & & & & 0.100 & 0.117 \\
\hline & & & & 4 & 0.093 & & & & 0.092 & 0.094 & 0.103 \\
\hline & & & & 5 & 0.098 & & & 0.091 & 0.089 & 0.091 & 0.098 \\
\hline & & & & 6 & 0.102 & & 0.096 & 0.088 & 0.087 & 0.089 & 0.096 \\
\hline \multirow{4}{*}{15} & \multirow{4}{*}{2.5} & \multirow{4}{*}{0.3} & \multirow{4}{*}{12} & 3 & 0.057 & & & & & 0.064 & 0.086 \\
\hline & & & & 4 & 0.051 & & & & 0.053 & 0.058 & 0.071 \\
\hline & & & & 5 & 0.049 & & & 0.050 & 0.051 & 0.056 & 0.066 \\
\hline & & & & 6 & 0.048 & & 0.048 & 0.048 & 0.050 & 0.055 & 0.065 \\
\hline \multirow{3}{*}{15} & \multirow{3}{*}{3} & \multirow{3}{*}{0.1} & \multirow{3}{*}{$4^{*}$} & 3 & 0.163 & & & & & 0.159 & 0.153 \\
\hline & & & & 4 & 0.167 & & & & 0.163 & 0.158 & 0.152 \\
\hline & & & & 5 & 0.170 & & & 0.166 & 0.162 & 0.156 & 0.150 \\
\hline \multirow{3}{*}{15} & \multirow{3}{*}{3} & \multirow{3}{*}{0.1} & \multirow{3}{*}{6} & 3 & 0.069 & & & & & 0.066 & 0.062 \\
\hline & & & & 4 & 0.072 & & & & 0.070 & 0.066 & 0.063 \\
\hline & & & & 5 & 0.074 & & & 0.072 & 0.069 & 0.065 & 0.061 \\
\hline \multirow{3}{*}{15} & \multirow{3}{*}{3} & \multirow{3}{*}{0.1} & \multirow{3}{*}{8} & 3 & 0.035 & & & & & 0.035 & 0.036 \\
\hline & & & & 4 & 0.034 & & & & 0.033 & 0.034 & 0.034 \\
\hline & & & & 5 & 0.036 & & & 0.034 & 0.032 & 0.033 & 0.034 \\
\hline \multirow{3}{*}{15} & \multirow{3}{*}{3} & & & 3 & 0.368 & & & & & 0.349 & 0.326 \\
\hline & & 0.2 & 4 & 4 & 0.380 & & & & 0.363 & 0.344 & 0.322 \\
\hline & & & & 5 & 0.390 & & & 0.373 & 0.356 & 0.337 & 0.315 \\
\hline & & & & 3 & 0.125 & & & & & 0.117 & 0.109 \\
\hline 15 & 3 & 0.2 & $6^{*}$ & 4 & 0.131 & & & & 0.124 & 0.116 & 0.106 \\
\hline & & & & 5 & 0.136 & & & 0.130 & 0.123 & 0.115 & 0.105 \\
\hline & & & & 3 & 0.069 & & & & & 0.070 & 0.075 \\
\hline 15 & $3^{3}$ & 0.2 & 8 & 4 & 0.070 & & & & 0.064 & 0.067 & 0.070 \\
\hline & & & & 5 & 0.073 & & & 0.069 & 0.066 & 0.065 & 0.068 \\
\hline & & & & 3 & 0.419 & & & & & 0.401 & 0.391 \\
\hline 15 & 3 & 0.3 & 6 & 4 & 0.229 & & & & 0.211 & 0.190 & 0.174 \\
\hline & & & & 5 & 0.238 & & & 0.222 & 0.204 & 0.184 & 0.169 \\
\hline & & & & 3 & 0.093 & & & & & 0.095 & 0.106 \\
\hline 15 & 3 & 0.3 & $8^{*}$ & 4 & 0.096 & & & & 0.087 & 0.090 & 0.098 \\
\hline & & & & 5 & 0.102 & & & 0.094 & 0.084 & 0.088 & 0.095 \\
\hline & & & & 3 & 0.053 & & & & & 0.058 & 0.074 \\
\hline 15 & 3 & 0.3 & 12 & 4 & 0.049 & & & & 0.051 & 0.055 & 0.066 \\
\hline & & & & 5 & 0.048 & & & 0.048 & 0.049 & 0.053 & 0.064 \\
\hline
\end{tabular}

Note:

: Number of bracings as per Davidson's equation 2.19 
Table 4.9b: WBR for $15 \mathrm{~m}$ span bridge (Continue ...)
Table 4.9b: WBR for $15 \mathrm{~m}$ span bridge (Continue...)

\begin{tabular}{|c|c|c|c|c|c|c|c|c|c|c|c|}
\hline \multicolumn{5}{|c|}{ Bridge Dimensions } & \multirow{2}{*}{\multicolumn{7}{|c|}{ WBR }} \\
\hline $\begin{array}{l}\begin{array}{c}\text { Span } \\
(m)\end{array}\end{array}$ & $\begin{array}{c}\text { Girder } \\
\text { Spacing } \\
\text { (m) }\end{array}$ & $\begin{array}{l}\text { Span } \\
\text { Radius } \\
\text { ratio }\end{array}$ & $\begin{array}{l}\text { No. of } \\
\text { Bracing } \\
\text { Intervals }\end{array}$ & $\begin{array}{l}\text { No of } \\
\text { Girders }\end{array}$ & & & & & & & \\
\hline $\mathrm{L}$ & s & LR & & $\mathrm{N}$ & $G_{\text {Ext }}$ & $G_{5}$ & $G_{4}$ & $G_{3}$ & $G_{2}$ & $G_{1}$ & $G_{\text {int }}$ \\
\hline \multirow{4}{*}{15} & \multirow{4}{*}{2.5} & \multirow{4}{*}{0.3} & \multirow{4}{*}{$8^{*}$} & 3 & 0.096 & & & & & 0.100 & 0.117 \\
\hline & & & & 4 & 0.093 & & & & 0.092 & 0.094 & 0.103 \\
\hline & & & & 5 & 0.098 & & & 0.091 & 0.089 & 0.091 & 0.098 \\
\hline & & & & 6 & 0.102 & & 0.096 & 0.088 & 0.087 & 0.089 & 0.096 \\
\hline \multirow{4}{*}{15} & \multirow{4}{*}{2.5} & \multirow{4}{*}{0.3} & \multirow{4}{*}{12} & 3 & 0.057 & & & & & 0.064 & 0.086 \\
\hline & & & & 4 & 0.051 & & & & 0.053 & 0.058 & 0.071 \\
\hline & & & & 5 & 0.049 & & & 0.050 & 0.051 & 0.056 & 0.066 \\
\hline & & & & 6 & 0.048 & & 0.048 & 0.048 & 0.050 & 0.055 & 0.065 \\
\hline \multirow{3}{*}{15} & \multirow{3}{*}{3} & \multirow{3}{*}{0.1} & \multirow{3}{*}{$4^{*}$} & 3 & 0.163 & & & & & 0.159 & 0.153 \\
\hline & & & & 4 & 0.167 & & & & 0.163 & 0.158 & 0.152 \\
\hline & & & & 5 & 0.170 & & & 0.166 & 0.162 & 0.156 & 0.150 \\
\hline \multirow{3}{*}{15} & \multirow{3}{*}{3} & \multirow{3}{*}{0.1} & \multirow{3}{*}{6} & 3 & 0.069 & & & & & 0.066 & 0.062 \\
\hline & & & & 4 & 0.072 & & & & 0.070 & 0.066 & 0.063 \\
\hline & & & & 5 & 0.074 & & & 0.072 & 0.069 & 0.065 & 0.061 \\
\hline \multirow{3}{*}{15} & \multirow{3}{*}{3} & \multirow{3}{*}{0.1} & \multirow{3}{*}{8} & 3 & 0.035 & & & & & 0.035 & 0.036 \\
\hline & & & & 4 & 0.034 & & & & 0.033 & 0.034 & 0.034 \\
\hline & & & & 5 & 0.036 & & & 0.034 & 0.032 & 0.033 & 0.034 \\
\hline \multirow{3}{*}{15} & \multirow{3}{*}{3} & \multirow{3}{*}{0.2} & & 3 & 0.368 & & & & & 0.349 & 0.326 \\
\hline & & & 4 & 4 & 0.380 & & & & 0.363 & 0.344 & 0.322 \\
\hline & & & & 5 & 0.390 & & & 0.373 & 0.356 & 0.337 & 0.315 \\
\hline & & & & 3 & 0.125 & & & & & 0.117 & 0.109 \\
\hline 15 & 3 & 0.2 & $6^{*}$ & 4 & 0.131 & & & & 0.124 & 0.116 & 0.106 \\
\hline & & & & 5 & 0.136 & & & 0.130 & 0.123 & 0.115 & 0.105 \\
\hline 15 & 3 & 0.2 & 8 & $\frac{3}{4}$ & 0.069 & & & & & 0.0067 & 0.0075 \\
\hline & & & & 5 & 0.073 & & & 0.069 & 0.066 & 0.065 & 0.068 \\
\hline & & & & 3 & 0.419 & & & & & 0.401 & 0.391 \\
\hline 15 & 3 & 0.3 & 6 & 4 & 0.229 & & & & 0.211 & 0.190 & 0.174 \\
\hline & & & & 5 & 0.238 & & & 0.222 & 0.204 & 0.184 & 0.169 \\
\hline & & & & 3 & 0.093 & & & & & 0.095 & 0.106 \\
\hline 15 & 3 & 0.3 & $8^{*}$ & 4 & 0.096 & & & & 0.087 & 0.090 & 0.098 \\
\hline & & & & 5 & 0.102 & & & 0.094 & 0.084 & 0.088 & 0.095 \\
\hline & & & & 3 & 0.053 & & & & & 0.058 & 0.074 \\
\hline 15 & 3 & 0.3 & 12 & 4 & 0.049 & & & & 0.051 & 0.055 & 0.066 \\
\hline & & & & 5 & 0.048 & & & 0.048 & 0.049 & 0.053 & 0.064 \\
\hline
\end{tabular}

Note:

* : Number of bracings as per Davidson's equation 2.19 
Table 4.9c: WBR for $25 \mathrm{~m}$ span bridge.

\begin{tabular}{|c|c|c|c|c|c|c|c|c|c|c|c|}
\hline \multicolumn{5}{|c|}{ Bridge Dimensions } & \multirow{2}{*}{\multicolumn{7}{|c|}{ WBR }} \\
\hline 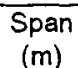 & $\begin{array}{c}\text { Girder } \\
\text { Spacing }\end{array}$ & $\begin{array}{l}\text { Span } \\
\text { Radius }\end{array}$ & \multirow{2}{*}{$\begin{array}{l}\text { No. of } \\
\text { Bracing } \\
\text { Intervals }\end{array}$} & $\begin{array}{l}\text { No. of } \\
\text { Girders }\end{array}$ & & & & & & & \\
\hline $\mathrm{L}$ & $s$ & LR & & $\mathrm{N}$ & $G_{E x t}$ & $G_{5}$ & $G_{4}$ & $\mathrm{G}_{3}$ & $G_{2}$ & $G_{1}$ & $G_{\operatorname{lnt}}$ \\
\hline \multirow{5}{*}{25} & \multirow{5}{*}{2} & \multirow{5}{*}{0.1} & \multirow{5}{*}{4} & 3 & 0.344 & & & & & 0.339 & 0.332 \\
\hline & & & & 4 & 0.353 & & & & 0.349 & 0.345 & 0.341 \\
\hline & & & & 5 & 0.357 & & & 0.354 & 0.351 & 0.347 & 0.344 \\
\hline & & & & 6 & 0.415 & & 0.411 & 0.408 & 0.404 & 0.400 & 0.396 \\
\hline & & & & 7 & 0.418 & 0.414 & 0.410 & 0.407 & 0.403 & 0.399 & 0.395 \\
\hline \multirow{5}{*}{25} & \multirow{5}{*}{2} & \multirow{5}{*}{0.1} & \multirow{5}{*}{$6^{*}$} & 3 & 0.122 & & & & & 0.118 & 0.113 \\
\hline & & & & 4 & 0.128 & & & & 0.127 & 0.125 & 0.122 \\
\hline & & & & 5 & 0.132 & & & 0.130 & 0.129 & 0.127 & 0.125 \\
\hline & & & & 6 & 0.155 & & 0.154 & 0.152 & 0.151 & 0.149 & 0.148 \\
\hline & & & & 7 & 0.156 & 0.155 & 0.154 & 0.153 & 0.151 & 0.150 & 0.148 \\
\hline \multirow{5}{*}{25} & \multirow{5}{*}{2} & \multirow{5}{*}{0.1} & \multirow{5}{*}{8} & 3 & 0.067 & & & & & 0.070 & 0.074 \\
\hline & & & & 4 & 0.065 & & & & 0.064 & 0.063 & 0.064 \\
\hline & & & & 5 & 0.069 & & & 0.067 & 0.066 & 0.064 & 0.062 \\
\hline & & & & 6 & 0.081 & & 0.080 & 0.078 & 0.077 & 0.075 & 0.064 \\
\hline & & & & 7 & 0.082 & 0.081 & 0.080 & 0.079 & 0.077 & 0.075 & 0.054 \\
\hline \multirow{5}{*}{25} & \multirow{5}{*}{2} & \multirow{5}{*}{0.3} & \multirow{5}{*}{6} & 3 & 0.405 & & & & & 0.373 & 0.258 \\
\hline & & & & 4 & 0.423 & & & & 0.406 & 0.383 & 0.348 \\
\hline & & & & 5 & 0.435 & & & 0.421 & 0.406 & 0.387 & 0.357 \\
\hline & & & & 6 & 0.505 & & 0.492 & 0.477 & 0.462 & 0.443 & 0.419 \\
\hline & & & & 7 & 0.513 & 0.500 & 0.487 & 0.473 & 0.458 & 0.441 & 0.420 \\
\hline \multirow{5}{*}{25} & \multirow{5}{*}{2} & \multirow{5}{*}{0.3} & \multirow{5}{*}{$8^{*}$} & 3 & 0.176 & & & & & 0.193 & 0.280 \\
\hline & & & & 4 & 0.190 & & & & 0.179 & 0.178 & 0.207 \\
\hline & & & & 5 & 0.198 & & & 0.190 & 0.181 & 0.168 & 0.181 \\
\hline & & & & 6 & 0.236 & & 0.228 & 0.220 & 0.211 & 0.199 & 0.189 \\
\hline & & & & 7 & 0.240 & 0.233 & 0.226 & 0.219 & 0.210 & 0.200 & 0.186 \\
\hline \multirow{5}{*}{25} & & & & 3 & 0.099 & & & & & 0.118 & 0.215 \\
\hline & & & & 4 & 0.087 & & & & 0.092 & 0.103 & 0.137 \\
\hline & 2 & 0.3 & 12 & 5 & 0.082 & & & 0.084 & 0.087 & 0.094 & 0.111 \\
\hline & & & & 6 & 0.089 & & 0.089 & 0.090 & 0.092 & 0.096 & 0.100 \\
\hline & & & & 7 & 0.088 & 0.087 & 0.087 & 0.088 & 0.089 & 0.082 & 0.099 \\
\hline & & & & 3 & 0.465 & & & & & 0.340 & 0.773 \\
\hline & & & & 4 & 0.459 & & & & 0.330 & 0.322 & 0.660 \\
\hline 20 & 2 & 0.5 & 8 & 5 & 0.454 & & & 0.353 & 0.326 & 0.306 & 0.501 \\
\hline & & & & 6 & 0.437 & & 0.416 & 0.393 & 0.366 & 0.324 & 0.425 \\
\hline & & & & 7 & 0.448 & 0.408 & 0.315 & 0.385 & 0.359 & 0.320 & 0.380 \\
\hline
\end{tabular}

Note:

* : Number of bracings as per Davidson's equation 2.19
Table 4.9c: WBR for $25 \mathrm{~m}$ span bridge (Continue...)

\begin{tabular}{|c|c|c|c|c|c|c|c|c|c|c|c|}
\hline \multicolumn{5}{|c|}{ Bridge Dimensions } & \multirow{2}{*}{\multicolumn{7}{|c|}{ WBR }} \\
\hline 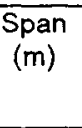 & $\begin{array}{c}\text { Girder } \\
\text { Spacing } \\
(\mathrm{m})\end{array}$ & $\begin{array}{l}\text { Span } \\
\text { Radius } \\
\text { ratioo }\end{array}$ & $\begin{array}{l}\text { No. of } \\
\text { Bracing } \\
\text { Intervals }\end{array}$ & $\begin{array}{l}\text { No. of } \\
\text { Girders }\end{array}$ & & & & & & & \\
\hline$L$ & s & L/R & & $\mathrm{N}$ & $G_{E x t}$ & $G_{5}$ & $G_{4}$ & $G_{3}$ & $G_{2}$ & $G_{1}$ & $G_{\text {nnt }}$ \\
\hline \multirow{5}{*}{25} & \multirow{5}{*}{2} & \multirow{5}{*}{0.5} & \multirow{5}{*}{$12^{*}$} & 3 & 0.146 & & & & & 0.183 & 0.615 \\
\hline & & & & 4 & 0.133 & & & & 0.141 & 0.169 & 0.533 \\
\hline & & & & 5 & 0.129 & & & 0.130 & 0.118 & 0.157 & 0.334 \\
\hline & & & & 6 & 0.143 & & 0.141 & 0.142 & 0.146 & 0.161 & 0.260 \\
\hline & & & & 7 & 0.143 & 0.140 & 0.138 & 0.138 & 0.141 & 0.154 & 0.221 \\
\hline \multirow{5}{*}{25} & \multirow{5}{*}{2} & \multirow{5}{*}{0.5} & \multirow{5}{*}{18} & 3 & 0.085 & & & & & 0.128 & 0.514 \\
\hline & & & & 4 & 0.071 & & & & 0.082 & 0.115 & 0.433 \\
\hline & & & & 5 & 0.064 & & & 0.068 & 0.078 & 0.103 & 0.294 \\
\hline & & & & 6 & 0.066 & & 0.068 & 0.071 & 0.079 & 0.100 & 0.212 \\
\hline & & & & 7 & 0.065 & 0.065 & 0.067 & 0.070 & 0.077 & 0.094 & 0.169 \\
\hline \multirow{4}{*}{25} & \multirow{4}{*}{2.5} & \multirow{4}{*}{0.1} & \multirow{4}{*}{4} & 3 & $0.35 c$ & & & & & 0.345 & 0.339 \\
\hline & & & & 4 & 0.356 & & & & 0.352 & 0.348 & 0.344 \\
\hline & & & & 5 & 0.360 & & & 0.356 & 0.352 & 0.348 & 0.344 \\
\hline & & & & 6 & 0.363 & & 0.359 & 0.355 & 0.351 & 0.347 & 0.343 \\
\hline \multirow{4}{*}{25} & \multirow{4}{*}{2.5} & \multirow{4}{*}{0.1} & \multirow{4}{*}{$6^{*}$} & 3 & 0.127 & & & & & 0.124 & 0.120 \\
\hline & & & & 4 & 0.131 & & & & 0.129 & 0.127 & 0.125 \\
\hline & & & & 5 & 0.134 & & & 0.130 & 0.131 & 0.129 & 0.127 \\
\hline & & & & 6 & 0.135 & & 0.134 & 0.132 & 0.131 & 0.129 & 0.127 \\
\hline \multirow{4}{*}{25} & \multirow{4}{*}{2.5} & \multirow{4}{*}{0.1} & \multirow{4}{*}{8} & 3 & 0.064 & & & & & 0.064 & 0.066 \\
\hline & & & & 4 & 0.068 & & & & 0.067 & 0.064 & 0.062 \\
\hline & & & & 5 & 0.071 & & & 0.069 & 0.068 & 0.066 & 0.064 \\
\hline & & & & 6 & 0.072 & & 0.071 & 0.070 & 0.068 & 0.067 & 0.065 \\
\hline \multirow{4}{*}{25} & & & & 3 & 0.435 & & & & & 0.409 & 0.380 \\
\hline & 2.5 & 0.3 & 6 & 4 & 0.495 & & & & 0.448 & 0.454 & 0.419 \\
\hline & & & & 5 & 0.443 & & & 0.428 & 0.412 & 0.393 & 0.368 \\
\hline & & & & 6 & 0.452 & & 0.437 & 0.423 & 0.407 & 0.390 & 0.368 \\
\hline & & & & 3 & 0.186 & & & & & 0.177 & 0.215 \\
\hline 25 & 2.5 & 0.3 & $8^{*}$ & 4 & 0.197 & & & & 0.187 & 0.173 & 0.180 \\
\hline & & & & 5 & 0.204 & & & 0.196 & 0.186 & 0.175 & 0.166 \\
\hline & & & & 6 & 0.209 & & 0.202 & 0.194 & 0.185 & 0.175 & 0.161 \\
\hline & & & & 3 & 0.090 & & & & & 0.101 & 0.145 \\
\hline 25 & 2.5 & 0.3 & 12 & 4 & 0.083 & & & & 0.085 & 0.091 & 0.109 \\
\hline & & & & 5 & 0.080 & & & 0.080 & 0.081 & 0.085 & 0.095 \\
\hline & & & & 6 & 0.078 & & 0.078 & 0.093 & 0.079 & 0.081 & 0.088 \\
\hline & & & & 3 & 0.390 & & & & & 0.313 & 0.815 \\
\hline 25 & 2.5 & 0.5 & 8 & 4 & 0.371 & & & & 0.343 & 0.301 & 0.442 \\
\hline & & & & 5 & 0.386 & & & 0.362 & 0.336 & 0.298 & 0.359 \\
\hline & & & & 6 & 0.398 & & 0.376 & 0.354 & 0.328 & 0.292 & 0.325 \\
\hline
\end{tabular}

*: Number of bracings as per Davidson's equation 2.19 
Table 4.9c: WBR for $25 \mathrm{~m}$ span bridge.

\begin{tabular}{|c|c|c|c|c|c|c|c|c|c|c|c|}
\hline \multicolumn{5}{|c|}{ Bridge Dimensions } & \multirow{2}{*}{\multicolumn{7}{|c|}{ WBR }} \\
\hline 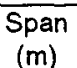 & $\begin{array}{c}\text { Girder } \\
\text { Spacing }\end{array}$ & $\begin{array}{l}\text { Span } \\
\text { Radius }\end{array}$ & \multirow{2}{*}{$\begin{array}{l}\text { No. of } \\
\text { Bracing } \\
\text { Intervals }\end{array}$} & $\begin{array}{l}\text { No. of } \\
\text { Girders }\end{array}$ & & & & & & & \\
\hline $\mathrm{L}$ & $s$ & LR & & $\mathrm{N}$ & $G_{E x}$ & $G_{5}$ & $G_{4}$ & $G_{3}$ & $\mathrm{G}_{2}$ & $G_{1}$ & $G_{l n t}$ \\
\hline \multirow{5}{*}{25} & \multirow{5}{*}{2} & \multirow{5}{*}{0.1} & \multirow{5}{*}{4} & 3 & 0.344 & & & & & 0.339 & 0.332 \\
\hline & & & & 4 & 0.353 & & & & 0.349 & 0.345 & 0.341 \\
\hline & & & & 5 & 0.357 & & & 0.354 & 0.351 & 0.347 & 0.344 \\
\hline & & & & 6 & 0.415 & & 0.411 & 0.408 & 0.404 & 0.400 & 0.396 \\
\hline & & & & 7 & 0.418 & 0.414 & 0.410 & 0.407 & 0.403 & 0.399 & 0.395 \\
\hline \multirow{5}{*}{25} & \multirow{5}{*}{2} & \multirow{5}{*}{0.1} & \multirow{5}{*}{$6^{*}$} & 3 & 0.122 & & & & & 0.118 & 0.113 \\
\hline & & & & 4 & 0.128 & & & & 0.127 & 0.125 & 0.122 \\
\hline & & & & 5 & 0.132 & & & 0.130 & 0.129 & 0.127 & 0.125 \\
\hline & & & & 6 & 0.155 & & 0.154 & 0.152 & 0.151 & 0.149 & 0.148 \\
\hline & & & & 7 & 0.156 & 0.155 & 0.154 & 0.153 & 0.151 & 0.150 & 0.148 \\
\hline \multirow{5}{*}{25} & \multirow{5}{*}{2} & \multirow{5}{*}{0.1} & \multirow{5}{*}{8} & 3 & 0.067 & & & & & 0.070 & 0.074 \\
\hline & & & & 4 & 0.065 & & & & 0.064 & 0.063 & 0.064 \\
\hline & & & & 5 & 0.069 & & & 0.067 & 0.066 & 0.064 & 0.062 \\
\hline & & & & 6 & 0.081 & & 0.080 & 0.078 & 0.077 & 0.075 & 0.064 \\
\hline & & & & 7 & 0.082 & 0.081 & 0.080 & 0.079 & 0.077 & 0.075 & 0.054 \\
\hline \multirow{5}{*}{25} & \multirow{5}{*}{2} & \multirow{5}{*}{0.3} & \multirow{5}{*}{6} & 3 & 0.405 & & & & & 0.373 & 0.258 \\
\hline & & & & 4 & 0.423 & & & & 0.406 & 0.383 & 0.348 \\
\hline & & & & 5 & 0.435 & & & 0.421 & 0.406 & 0.387 & 0.357 \\
\hline & & & & 6 & 0.505 & & 0.492 & 0.477 & 0.462 & 0.443 & 0.419 \\
\hline & & & & 7 & 0.513 & 0.500 & 0.487 & 0.473 & 0.458 & 0.441 & 0.420 \\
\hline \multirow{5}{*}{25} & \multirow{5}{*}{2} & \multirow{5}{*}{0.3} & \multirow{5}{*}{$8^{*}$} & 3 & 0.176 & & & & & 0.193 & 0.280 \\
\hline & & & & 4 & 0.190 & & & & 0.179 & 0.178 & 0.207 \\
\hline & & & & 5 & 0.198 & & & 0.190 & 0.181 & 0.168 & 0.181 \\
\hline & & & & 6 & 0.236 & & 0.228 & 0.220 & 0.211 & 0.199 & 0.189 \\
\hline & & & & 7 & 0.240 & 0.233 & 0.226 & 0.219 & 0.210 & 0.200 & 0.186 \\
\hline \multirow{5}{*}{25} & & & & 3 & 0.099 & & & & & 0.118 & 0.215 \\
\hline & & & & 4 & 0.087 & & & & 0.092 & 0.103 & 0.137 \\
\hline & 2 & 0.3 & 12 & 5 & 0.082 & & & 0.084 & 0.087 & 0.094 & 0.111 \\
\hline & & & & 6 & 0.089 & & 0.089 & 0.090 & 0.092 & 0.096 & 0.106 \\
\hline & & & & 7 & 0.088 & 0.087 & 0.087 & 0.088 & 0.089 & 0.092 & 0.099 \\
\hline & & & & 3 & 0.465 & & & & & 0.340 & 0.773 \\
\hline & & & & 4 & 0.459 & & & & 0.330 & 0.322 & 0.660 \\
\hline 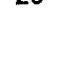 & 2 & 0.5 & 8 & 5 & 0.454 & & & 0.353 & 0.326 & 0.306 & 0.501 \\
\hline & & & & 6 & 0.437 & & 0.416 & 0.393 & 0.366 & 0.324 & 0.425 \\
\hline & & & & 7 & 0.48 & 0.408 & 0.315 & 0.385 & 0.359 & 0.320 & 0.380 \\
\hline
\end{tabular}

Note:

* : Number of bracings as per Davidson's equation 2.19
Table 4.9c: WBR for $25 \mathrm{~m}$ span bridge (Continue...)

\begin{tabular}{|c|c|c|c|c|c|c|c|c|c|c|c|}
\hline \multicolumn{5}{|c|}{ Bridge Dimensions } & \multirow{2}{*}{\multicolumn{7}{|c|}{ WBR }} \\
\hline 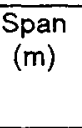 & $\begin{array}{l}\text { Girder } \\
\text { Spacing } \\
(\mathrm{m})\end{array}$ & $\begin{array}{l}\text { Span } \\
\text { Radius } \\
\text { ratio }\end{array}$ & $\begin{array}{l}\text { No. of } \\
\text { Bracing } \\
\text { Intervals }\end{array}$ & $\begin{array}{l}\text { No of of } \\
\text { Girders }\end{array}$ & & & & & & & \\
\hline$L$ & $\mathrm{~s}$ & L/R & & $\mathrm{N}$ & $G_{\text {EXI }}$ & $G_{5}$ & $G_{4}$ & $G_{3}$ & $G_{2}$ & $G_{1}$ & $G_{\text {nnt }}$ \\
\hline \multirow{5}{*}{25} & \multirow{5}{*}{2} & \multirow{5}{*}{0.5} & \multirow{5}{*}{$12^{*}$} & 3 & 0.146 & & & & & 0.183 & 0.615 \\
\hline & & & & 4 & 0.133 & & & & 0.141 & 0.169 & 0.533 \\
\hline & & & & 5 & 0.129 & & & 0.130 & 0.118 & 0.157 & 0.334 \\
\hline & & & & 6 & 0.143 & & 0.141 & 0.142 & 0.146 & 0.161 & 0.260 \\
\hline & & & & 7 & 0.143 & 0.140 & 0.138 & 0.138 & 0.141 & 0.154 & 0.221 \\
\hline \multirow{5}{*}{25} & \multirow{5}{*}{2} & \multirow{5}{*}{0.5} & \multirow{5}{*}{18} & 3 & 0.085 & & & & & 0.128 & 0.514 \\
\hline & & & & 4 & 0.071 & & & & 0.082 & 0.115 & 0.433 \\
\hline & & & & 5 & 0.064 & & & 0.068 & 0.078 & 0.103 & 0.294 \\
\hline & & & & 6 & 0.066 & & 0.068 & 0.071 & 0.079 & 0.100 & 0.212 \\
\hline & & & & 7 & 0.065 & 0.065 & 0.067 & 0.070 & 0.077 & 0.094 & 0.169 \\
\hline \multirow{4}{*}{25} & \multirow{4}{*}{2.5} & \multirow{4}{*}{0.1} & \multirow{4}{*}{4} & 3 & $0.35 c$ & & & & & 0.345 & 0.339 \\
\hline & & & & 4 & 0.356 & & & & 0.352 & 0.348 & 0.344 \\
\hline & & & & 5 & 0.360 & & & 0.356 & 0.352 & 0.348 & 0.344 \\
\hline & & & & 6 & 0.363 & & 0.359 & 0.355 & 0.351 & 0.347 & 0.343 \\
\hline \multirow{4}{*}{25} & \multirow{4}{*}{2.5} & \multirow{4}{*}{0.1} & \multirow{4}{*}{$6^{*}$} & 3 & 0.127 & & & & & 0.124 & 0.120 \\
\hline & & & & 4 & 0.131 & & & & 0.129 & 0.127 & 0.125 \\
\hline & & & & 5 & 0.134 & & & 0.130 & 0.131 & 0.129 & 0.127 \\
\hline & & & & 6 & 0.135 & & 0.134 & 0.132 & 0.131 & 0.129 & 0.127 \\
\hline \multirow{4}{*}{25} & \multirow{4}{*}{2.5} & \multirow{4}{*}{0.1} & \multirow{4}{*}{8} & 3 & 0.064 & & & & & 0.064 & 0.066 \\
\hline & & & & 4 & 0.068 & & & & 0.067 & 0.064 & 0.062 \\
\hline & & & & 5 & 0.071 & & & 0.069 & 0.068 & 0.066 & 0.064 \\
\hline & & & & 6 & 0.072 & & 0.071 & 0.070 & 0.068 & 0.067 & 0.065 \\
\hline \multirow{4}{*}{25} & & & & 3 & 0.435 & & & & & 0.409 & 0.380 \\
\hline & 2.5 & 0.3 & 6 & 4 & 0.495 & & & & 0.448 & 0.454 & 0.419 \\
\hline & & & & 5 & 0.443 & & & 0.428 & 0.412 & 0.393 & 0.368 \\
\hline & & & & 6 & 0.452 & & 0.437 & 0.423 & 0.407 & 0.390 & 0.368 \\
\hline & & & & 3 & 0.186 & & & & & 0.177 & 0.215 \\
\hline 25 & 2.5 & 0.3 & $8^{*}$ & 4 & 0.197 & & & & 0.187 & 0.173 & 0.180 \\
\hline & & & & 5 & 0.204 & & & 0.196 & 0.186 & 0.175 & 0.166 \\
\hline & & & & 6 & 0.209 & & 0.202 & 0.194 & 0.185 & 0.175 & 0.161 \\
\hline & & & & 3 & 0.090 & & & & & 0.101 & 0.145 \\
\hline 25 & 2.5 & 0.3 & 12 & 4 & 0.083 & & & & 0.085 & 0.091 & 0.109 \\
\hline & & & & 5 & 0.080 & & & 0.080 & 0.081 & 0.085 & 0.095 \\
\hline & & & & 6 & 0.078 & & 0.078 & 0.093 & 0.079 & 0.081 & 0.088 \\
\hline & & & & 3 & 0.390 & & & & & 0.313 & 0.815 \\
\hline 25 & 2.5 & 0.5 & 8 & 4 & 0.371 & & & & 0.343 & 0.301 & 0.442 \\
\hline & & & & 5 & 0.386 & & & 0.362 & 0.336 & 0.298 & 0.359 \\
\hline & & & & 6 & 0.398 & & 0.376 & 0.354 & 0.328 & 0.292 & 0.325 \\
\hline
\end{tabular}

*: Number of bracings as per Davidson's equation 2.19 
Table 4.9c: WBR for 25m span bridge (Continue .,)

\begin{tabular}{|c|c|c|c|c|c|c|c|c|c|c|c|}
\hline \multicolumn{5}{|c|}{ Bridge Dimensions } & \multirow{2}{*}{\multicolumn{7}{|c|}{ WBR }} \\
\hline $\begin{array}{c}\text { Span } \\
\text { (m) }\end{array}$ & $\begin{array}{l}\text { Girder } \\
\text { Spacing } \\
(\mathrm{m})\end{array}$ & $\begin{array}{l}\text { Span } \\
\text { Radius } \\
\text { ratio }\end{array}$ & $\begin{array}{l}\text { No. of } \\
\text { Bracing } \\
\text { Intervals }\end{array}$ & $\begin{array}{l}\text { No. of } \\
\text { Girders }\end{array}$ & & & & & & & \\
\hline $\mathrm{L}$ & $\mathrm{s}$ & $L / R$ & & $\mathrm{~N}$ & $G_{\text {Ent }}$ & $G_{5}$ & $G_{4}$ & $G_{3}$ & $G_{2}$ & $G_{1}$ & $G_{m t}$ \\
\hline \multirow{4}{*}{25} & \multirow{4}{*}{2.5} & \multirow{4}{*}{0.5} & \multirow{4}{*}{$12^{*}$} & 3 & 0.137 & & & & & 0.158 & 0.621 \\
\hline & & & & 4 & 0.129 & & & & 0.132 & 0.129 & 0.283 \\
\hline & & & & 5 & 0.126 & & & 0.125 & 0.127 & 0.138 & 0.210 \\
\hline & & & & 6 & 0.126 & & 0.124 & 0.122 & 0.123 & 0.132 & 0.182 \\
\hline \multirow{4}{*}{25} & \multirow{4}{*}{2.5} & \multirow{4}{*}{0.5} & \multirow{4}{*}{18} & 3 & 0.075 & & & & & 0.101 & 0.606 \\
\hline & & & & 4 & 0.065 & & & & 0.071 & 0.091 & 0.242 \\
\hline & & & & 5 & 0.060 & & & 0.063 & 0.068 & 0.084 & 0.166 \\
\hline & & & & 6 & 0.058 & & 0.059 & 0.061 & 0.066 & 0.079 & 0.138 \\
\hline \multirow{3}{*}{25} & \multirow{3}{*}{3} & \multirow{3}{*}{0.1} & \multirow{3}{*}{4} & 3 & 0.353 & & & & & 0.348 & 0.343 \\
\hline & & & & 4 & 0.359 & & & & 0.354 & 0.349 & 0.344 \\
\hline & & & & 5 & 0.363 & & & 0.358 & 0.353 & 0.348 & 0.344 \\
\hline \multirow{3}{*}{25} & \multirow{3}{*}{3} & \multirow{3}{*}{0.1} & \multirow{3}{*}{$6^{*}$} & 3 & 0.129 & & & & & 0.127 & 0.124 \\
\hline & & & & 4 & 0.133 & & & & 0.131 & 0.129 & 0.127 \\
\hline & & & & 5 & 0.135 & & & 0.133 & 0.131 & 0.129 & 0.127 \\
\hline \multirow{3}{*}{25} & \multirow{3}{*}{3} & \multirow{3}{*}{0.1} & \multirow{3}{*}{8} & 3 & 0.066 & & & & & 0.064 & 0.062 \\
\hline & & & & 4 & 0.070 & & & & 0.068 & 0.066 & 0.064 \\
\hline & & & & 5 & 0.072 & & & 0.070 & 0.069 & 0.067 & 0.065 \\
\hline \multirow{3}{*}{25} & \multirow{3}{*}{3} & & & 3 & 0.425 & & & & & 0.400 & 0.356 \\
\hline & & 0.3 & 6 & 4 & 0.440 & & & & 0.421 & 0.399 & 0.369 \\
\hline & & & & 5 & 0.450 & & & 0.433 & 0.415 & 0.395 & 0.370 \\
\hline & & & & 3 & 0.192 & & & & & 0.176 & 0.189 \\
\hline 25 & 3 & 0.3 & $8^{*}$ & 4 & 0.202 & & & & 0.191 & 0.178 & 0.167 \\
\hline & & & & 5 & 0.208 & & & 0.199 & 0.189 & 0.178 & 0.162 \\
\hline & & & & 3 & 0.085 & & & & & 0.092 & 0.118 \\
\hline 25 & 3 & 0.3 & 12 & 4 & 0.080 & & & & 0.081 & 0.085 & 0.096 \\
\hline & & & & 5 & 0.078 & & & 0.078 & 0.078 & 0.080 & 0.087 \\
\hline & & & & 3 & 0.485 & & & & & 0.328 & 0.741 \\
\hline 25 & 3 & 0.5 & 8 & 4 & 0.381 & & & & 0.451 & 0.312 & 0.352 \\
\hline & & & & 5 & 0.397 & & & 0.371 & 0.434 & 0.305 & 0.317 \\
\hline & & & & 3 & 0.131 & & & & & 0.144 & 0.303 \\
\hline 25 & 3 & 0.5 & $12^{*}$ & 4 & 0.126 & & & & 0.127 & 0.135 & 0.204 \\
\hline & & & & 5 & 0.126 & & & 0.123 & 0.122 & 0.128 & 0.151 \\
\hline & & & & 3 & 0.069 & & & & & 0.086 & 0.262 \\
\hline 25 & 3 & 0.5 & 18 & 4 & 0.061 & & & & 0.065 & 0.078 & 0.158 \\
\hline & & & & 5 & 0.058 & & & 0.059 & 0.063 & 0.074 & 0.127 \\
\hline
\end{tabular}

" : Number of bracings as per Davidson's equation 2.19
Table 4.9d: WBR for $35 \mathrm{~m}$ span bridge

\begin{tabular}{|c|c|c|c|c|c|c|c|c|c|c|c|}
\hline \multicolumn{5}{|c|}{ Bridge Dimensions } & \multirow{2}{*}{\multicolumn{7}{|c|}{ WBR }} \\
\hline $\begin{array}{l}\text { Span } \\
\text { (m) }\end{array}$ & $\begin{array}{l}\text { Girder } \\
\text { Spacing } \\
(\mathrm{m})\end{array}$ & $\begin{array}{c}\text { Span } \\
\text { Radius } \\
\text { ratio }\end{array}$ & $\begin{array}{l}\text { No of } \\
\text { Bracing } \\
\text { Intervals }\end{array}$ & $\begin{array}{l}\text { No of } \\
\text { Girders }\end{array}$ & & & & & & & \\
\hline $\mathrm{L}$ & $s$ & LR & & $\mathrm{N}$ & $G_{E n}$ & $\mathrm{G}_{5}$ & $G_{4}$ & $G_{3}$ & $G_{2}$ & $G_{1}$ & $G_{n t}$ \\
\hline \multirow{5}{*}{35} & \multirow{5}{*}{2} & \multirow{5}{*}{0.1} & \multirow{5}{*}{$6^{*}$} & 3 & 0.203 & & & & & 0.197 & 0.195 \\
\hline & & & & 4 & 0.211 & & & & 0.209 & 0.206 & 0.202 \\
\hline & & & & 5 & 0.215 & & & 0.214 & 0.212 & 0.210 & 0.208 \\
\hline & & & & 6 & 0.218 & & 0.216 & 0.215 & 0.214 & 0.212 & 0.211 \\
\hline & & & & 7 & 0.220 & 0.218 & 0.217 & 0.216 & 0.214 & 0.213 & 0.212 \\
\hline \multirow{5}{*}{35} & \multirow{5}{*}{2} & \multirow{5}{*}{0.1} & \multirow{5}{*}{8} & 3 & 0.100 & & & & & 0.105 & 0.114 \\
\hline & & & & 4 & 0.108 & & & & 0.105 & 0.102 & 0.098 \\
\hline & & & & 5 & 0.112 & & & 0.110 & 0.109 & 0.106 & 0.103 \\
\hline & & & & 6 & 0.114 & & 0.113 & 0.112 & 0.110 & 0.109 & 0.107 \\
\hline & & & & 7 & 0.115 & 0.115 & 0.113 & 0.112 & 0.111 & 0.110 & 0.109 \\
\hline \multirow{5}{*}{35} & \multirow{5}{*}{2} & \multirow{5}{*}{0.1} & \multirow{5}{*}{12} & 3 & 0.053 & & & & & 0.058 & 0.068 \\
\hline & & & & 4 & 0.046 & & & & 0.047 & 0.049 & 0.052 \\
\hline & & & & 5 & 0.043 & & & 0.043 & 0.045 & 0.045 & 0.046 \\
\hline & & & & 6 & 0.041 & & 0.041 & 0.041 & 0.042 & 0.042 & 0.043 \\
\hline & & & & 7 & 0.040 & 0.040 & 0.040 & 0.040 & 0.040 & 0.040 & 0.041 \\
\hline \multirow{5}{*}{35} & \multirow{5}{*}{2} & \multirow{5}{*}{0.4} & \multirow{5}{*}{8} & 3 & 0.469 & & & & & 0.410 & 0.842 \\
\hline & & & & 4 & 0.452 & & & & 0.428 & 0.390 & 0.811 \\
\hline & & & & 5 & 0.465 & & & 0.449 & 0.427 & 0.389 & 0.538 \\
\hline & & & & 6 & 0.475 & & 0.461 & 0.445 & 0.426 & 0.397 & 0.422 \\
\hline & & & & 7 & 0.483 & 0.471 & 0.457 & 0.442 & 0.424 & 0.399 & 0.378 \\
\hline \multirow{5}{*}{35} & \multirow{5}{*}{2} & \multirow{5}{*}{0.4} & \multirow{5}{*}{$12^{*}$} & 3 & 0.174 & & & & & 0.218 & 0.820 \\
\hline & & & & 4 & 0.160 & & & & 0.184 & 0.201 & 0.675 \\
\hline & & & & 5 & 0.154 & & & 0.157 & 0.163 & 0.185 & 0.349 \\
\hline & & & & 6 & 0.151 & & 0.152 & 0.153 & 0.158 & 0.172 & 0.239 \\
\hline & & & & 7 & 0.154 & 0.148 & 0.149 & 0.150 & 0.153 & 0.163 & 0.199 \\
\hline \multirow{5}{*}{35} & \multirow{5}{*}{2} & & & 3 & 0.095 & & & & & 0.143 & 0.779 \\
\hline & & & & 4 & 0.078 & & & & 0.091 & 0.127 & 0.661 \\
\hline & & 0.4 & 18 & 5 & 0.072 & $\therefore$ & & 0.077 & 0.086 & 0.111 & 0.288 \\
\hline & & & & 6 & 0.068 & & 0.070 & 0.074 & 0.081 & 0.099 & 0.172 \\
\hline & & & & 7 & 0.066 & 0.067 & 0.069 & 0.072 & 0.077 & 0.090 & 0.130 \\
\hline & & & & 3 & 0.863 & & & & & 0.737 & 0.965 \\
\hline & & & & 4 & 0.859 & & & & 0.762 & 0.720 & 0.919 \\
\hline 35 & 2 & 0.7 & 8 & 5 & 0.846 & & & 0.803 & 0.745 & 0.715 & 0.896 \\
\hline & & & & 6 & 0.839 & & 0.830 & 0.786 & 0.729 & 0.697 & 0.883 \\
\hline & & & & & 0.829 & 0.832 & 0.813 & 0.773 & 0.713 & 0.675 & 0.875 \\
\hline
\end{tabular}

Note:

: Number of bracings as per Davidson's equation 2.19 
Table $4.9 \mathrm{c}$ : WBR for $25 \mathrm{~m}$ span bridge (Continue

\begin{tabular}{|c|c|c|c|c|c|c|c|c|c|c|c|}
\hline \multicolumn{5}{|c|}{ Bridge Dimensions } & \multirow{2}{*}{\multicolumn{7}{|c|}{ WBR }} \\
\hline $\begin{array}{c}\text { Span } \\
\text { (m) }\end{array}$ & $\begin{array}{l}\text { Girder } \\
\text { Spacing }\end{array}$ & $\begin{array}{l}\text { Span } \\
\text { Radius }\end{array}$ & $\begin{array}{l}\text { No. of } \\
\text { Bracing }\end{array}$ & $\begin{array}{l}\text { No. of } \\
\text { Girders }\end{array}$ & & & & & & & \\
\hline L & $\mathrm{s}$ & LR & & $\mathrm{N}$ & $G_{E_{x t}}$ & $G_{5}$ & $G_{4}$ & $G_{3}$ & $G_{2}$ & $\mathrm{G}_{1}$ & $G_{m t}$ \\
\hline \multirow{4}{*}{25} & \multirow{4}{*}{2.5} & \multirow{4}{*}{0.5} & \multirow{4}{*}{$12^{*}$} & 3 & 0.137 & & & & & 0.158 & 0.621 \\
\hline & & & & 4 & 0.129 & & & & 0.132 & 0.129 & 0.283 \\
\hline & & & & 5 & 0.126 & & & 0.125 & 0.127 & 0.138 & 0.210 \\
\hline & & & & 6 & 0.126 & & 0.124 & 0.122 & 0.123 & 0.132 & 0.182 \\
\hline \multirow{4}{*}{25} & \multirow{4}{*}{2.5} & \multirow{4}{*}{0.5} & \multirow{4}{*}{18} & 3 & 0.075 & & & & & 0.101 & 0.606 \\
\hline & & & & 4 & 0.065 & & & & 0.071 & 0.091 & 0.242 \\
\hline & & & & 5 & 0.060 & & & 0.063 & 0.068 & 0.084 & 0.166 \\
\hline & & & & 6 & 0.058 & & 0.059 & 0.061 & 0.066 & 0.079 & 0.138 \\
\hline \multirow{3}{*}{25} & \multirow{3}{*}{3} & \multirow{3}{*}{0.1} & \multirow{3}{*}{4} & 3 & 0.353 & & & & & 0.348 & 0.343 \\
\hline & & & & 4 & 0.359 & & & & 0.354 & 0.349 & 0.344 \\
\hline & & & & 5 & 0.363 & & & 0.358 & 0.353 & 0.348 & 0.344 \\
\hline \multirow{3}{*}{25} & \multirow{3}{*}{3} & \multirow{3}{*}{0.1} & \multirow{3}{*}{$6^{*}$} & 3 & 0.129 & & & & & 0.127 & 0.124 \\
\hline & & & & 4 & 0.133 & & & & 0.131 & 0.129 & 0.127 \\
\hline & & & & 5 & 0.135 & & & 0.133 & 0.131 & 0.129 & 0.127 \\
\hline \multirow{3}{*}{25} & \multirow{3}{*}{3} & \multirow{3}{*}{0.1} & \multirow{3}{*}{8} & 3 & 0.066 & & & & & 0.064 & 0.062 \\
\hline & & & & 4 & 0.070 & & & & 0.068 & 0.066 & 0.064 \\
\hline & & & & 5 & 0.072 & & & 0.070 & 0.069 & 0.067 & 0.065 \\
\hline \multirow{3}{*}{25} & \multirow{3}{*}{3} & & & 3 & 0.425 & & & & & 0.400 & 0.356 \\
\hline & & 0.3 & 6 & 4 & 0.440 & & & & 0.421 & 0.399 & 0.369 \\
\hline & & & & 5 & 0.450 & & & 0.433 & 0.415 & 0.395 & 0.370 \\
\hline & & & & 3 & 0.192 & & & & & 0.176 & 0.189 \\
\hline 25 & 3 & 0.3 & $8^{*}$ & 4 & 0.202 & & & & 0.191 & 0.178 & 0.167 \\
\hline & & & & 5 & 0.208 & & & 0.199 & 0.189 & 0.178 & 0.162 \\
\hline & & & & 3 & 0.085 & & & & & 0.092 & 0.118 \\
\hline 25 & 3 & 0.3 & 12 & 4 & 0.080 & & & & 0.081 & 0.085 & 0.096 \\
\hline & & & & 5 & 0.078 & & & 0.078 & 0.078 & 0.080 & 0.087 \\
\hline & & & & 3 & 0.485 & & & & & 0.328 & 0.741 \\
\hline 25 & 3 & 0.5 & 8 & 4 & 0.381 & & & & 0.451 & 0.312 & 0.352 \\
\hline & & & & 5 & 0.397 & & & 0.371 & 0.434 & 0.305 & 0.317 \\
\hline & & & & 3 & 0.131 & & & & & 0.144 & 0.303 \\
\hline 25 & 3 & 0.5 & $12^{*}$ & 4 & 0.126 & & & & 0.127 & 0.135 & 0.204 \\
\hline & & & & 5 & 0.126 & & & 0.123 & 0.122 & 0.128 & 0.151 \\
\hline & & & & 3 & 0.069 & & & & & 0.086 & 0.262 \\
\hline 25 & 3 & 0.5 & 18 & 4 & 0.061 & & & & 0.065 & 0.078 & 0.158 \\
\hline & & & & 5 & 0.058 & & & 0.059 & 0.063 & 0.074 & 0.127 \\
\hline
\end{tabular}

- Number of bracings as per Davidson's equation 2.19
Table 4.9d: WBR for $35 \mathrm{~m}$ span bridge

\begin{tabular}{|c|c|c|c|c|c|c|c|c|c|c|c|}
\hline \multicolumn{5}{|c|}{ Bridge Dimensions } & \multirow{2}{*}{\multicolumn{7}{|c|}{ WBR }} \\
\hline $\begin{array}{l}\text { Span } \\
\text { (m) }\end{array}$ & $\begin{array}{l}\text { Girder } \\
\text { Spacing } \\
(\mathrm{m})\end{array}$ & $\begin{array}{l}\text { Span } \\
\text { Radius } \\
\text { ratio }\end{array}$ & $\begin{array}{l}\text { No. of } \\
\text { Bracing } \\
\text { Intervals }\end{array}$ & $\begin{array}{l}\text { No of } \\
\text { Girders }\end{array}$ & & & & & & & \\
\hline $\mathrm{L}$ & $s$ & UR & & $\mathrm{N}$ & $G_{E x \pi}$ & $G_{5}$ & $G_{4}$ & $G_{3}$ & $G_{2}$ & $G_{1}$ & $G_{m t}$ \\
\hline \multirow{5}{*}{35} & \multirow{5}{*}{2} & \multirow{5}{*}{0.1} & \multirow{5}{*}{$6^{*}$} & 3 & 0.203 & & & & & 0.197 & 0.195 \\
\hline & & & & 4 & 0.211 & & & & 0.209 & 0.206 & 0.202 \\
\hline & & & & 5 & 0.215 & & & 0.214 & 0.212 & 0.210 & 0.208 \\
\hline & & & & 6 & 0.218 & & 0.216 & 0.215 & 0.214 & 0.212 & 0.211 \\
\hline & & & & 7 & 0.220 & 0.218 & 0.217 & 0.216 & 0.214 & 0.213 & 0.212 \\
\hline \multirow{5}{*}{35} & \multirow{5}{*}{2} & \multirow{5}{*}{0.1} & \multirow{5}{*}{8} & 3 & 0.100 & & & & & 0.105 & 0.114 \\
\hline & & & & 4 & 0.108 & & & & 0.105 & 0.102 & 0.098 \\
\hline & & & & 5 & 0.112 & & & 0.110 & 0.109 & 0.106 & 0.103 \\
\hline & & & & 6 & 0.114 & & 0.113 & 0.112 & 0.110 & 0.109 & 0.107 \\
\hline & & & & 7 & 0.115 & 0.115 & 0.113 & 0.112 & 0.111 & 0.110 & 0.109 \\
\hline \multirow{5}{*}{35} & \multirow{5}{*}{2} & \multirow{5}{*}{0.1} & \multirow{5}{*}{12} & 3 & 0.053 & & & & & 0.058 & 0.068 \\
\hline & & & & 4 & 0.046 & & & & 0.047 & 0.049 & 0.052 \\
\hline & & & & 5 & 0.043 & & & 0.043 & 0.045 & 0.045 & 0.046 \\
\hline & & & & 6 & 0.041 & & 0.041 & 0.041 & 0.042 & 0.042 & 0.043 \\
\hline & & & & 7 & 0.040 & 0.040 & 0.040 & 0.040 & 0.040 & 0.040 & 0.041 \\
\hline \multirow{5}{*}{35} & \multirow{5}{*}{2} & \multirow{5}{*}{0.4} & \multirow{5}{*}{8} & 3 & 0.469 & & & & & 0.410 & 0.842 \\
\hline & & & & 4 & 0.452 & & & & 0.428 & 0.390 & 0.811 \\
\hline & & & & 5 & 0.465 & & & 0.449 & 0.427 & 0.389 & 0.538 \\
\hline & & & & 6 & 0.475 & & 0.461 & 0.445 & 0.426 & 0.397 & 0.422 \\
\hline & & & & 7 & 0.483 & 0.471 & 0.457 & 0.442 & 0.424 & 0.399 & 0.378 \\
\hline \multirow{5}{*}{35} & \multirow{5}{*}{2} & \multirow{5}{*}{0.4} & \multirow{5}{*}{$12^{*}$} & 3 & 0.174 & & & & & 0.218 & 0.820 \\
\hline & & & & 4 & 0.160 & & & & 0.184 & 0.201 & 0.675 \\
\hline & & & & 5 & 0.154 & & & 0.157 & 0.163 & 0.185 & 0.349 \\
\hline & & & & 6 & 0.151 & & 0.152 & 0.153 & 0.158 & 0.172 & 0.239 \\
\hline & & & & 7 & 0.154 & 0.148 & 0.149 & 0.150 & 0.153 & 0.163 & 0.199 \\
\hline \multirow{5}{*}{35} & \multirow{5}{*}{2} & & & 3 & 0.095 & & & & & 0.143 & 0.779 \\
\hline & & & & 4 & 0.079 & & & & 0.091 & 0.127 & 0.661 \\
\hline & & 0.4 & 18 & 5 & 0.072 & - & & 0.077 & 0.086 & 0.111 & 0.288 \\
\hline & & & & 6 & 0.068 & & 0.070 & 0.074 & 0.081 & 0.099 & 0.172 \\
\hline & & & & 7 & 0.066 & 0.067 & 0.069 & 0.072 & 0.077 & 0.090 & 0.130 \\
\hline & & & & 3 & 0.863 & & & & & 0.737 & 0.965 \\
\hline & & & & 4 & 0.859 & & & & 0.762 & 0.720 & 0.919 \\
\hline 35 & 2 & 0.7 & 8 & 5 & 0.846 & & & 0.803 & 0.745 & 0.715 & 0.896 \\
\hline & & & & 6 & 0.839 & & 0.830 & 0.786 & 0.729 & 0.697 & 0.883 \\
\hline & & & & & 0.829 & 0.832 & 0.813 & 0.773 & 0.713 & 0.675 & 0.875 \\
\hline
\end{tabular}

Note:

: Number of bracings as per Davidson's equation 2.19 
Table 4.9d: WBR for 35m span bridge (Continue...)

\begin{tabular}{|c|c|c|c|c|c|c|c|c|c|c|c|}
\hline \multicolumn{5}{|c|}{ Bridge Dimensions } & \multirow{2}{*}{\multicolumn{7}{|c|}{ WBR }} \\
\hline $\begin{array}{c}\mathcal{S p a n}_{(\mathrm{m})} \\
(\mathrm{s})\end{array}$ & $\begin{array}{l}\text { Girder } \\
\text { Spacing }\end{array}$ & $\begin{array}{l}\text { Span } \\
\text { Radius }\end{array}$ & $\begin{array}{l}\text { No. of } \\
\text { Bracing }\end{array}$ & $\begin{array}{l}\text { No of } \\
\text { Girders }\end{array}$ & & & & & & & \\
\hline$L$ & & LR & & $\mathrm{N}$ & $G_{E x t}$ & $G_{5}$ & $G_{4}$ & $G_{3}$ & $G_{2}$ & $G_{1}$ & $G_{\operatorname{lnt}}$ \\
\hline \multirow{5}{*}{35} & \multirow{5}{*}{2} & \multirow{5}{*}{0.7} & \multirow{5}{*}{$12^{*}$} & 3 & 0.286 & & & & & 0.395 & 0.426 \\
\hline & & & & 4 & 0.271 & & & & 0.284 & 0.389 & 0.395 \\
\hline & & & & 5 & 0.267 & & & 0.267 & 0.280 & 0.391 & 0.384 \\
\hline & & & & 6 & 0.278 & & 0.261 & 0.262 & 0.276 & 0.379 & 0.382 \\
\hline & & & & 7 & 0.286 & 0.272 & 0.255 & 0.258 & 0.269 & 0.362 & 0.387 \\
\hline \multirow{5}{*}{35} & \multirow{5}{*}{2} & \multirow{5}{*}{0.7} & \multirow{5}{*}{18} & 3 & 0.145 & & & & & 0.279 & 0.258 \\
\hline & & & & 4 & 0.127 & & & & 0.146 & 0.264 & 0.229 \\
\hline & & & & 5 & 0.119 & & & 0.126 & 0.146 & 0.269 & 0.223 \\
\hline & & & & 6 & 0.116 & & 0.118 & 0.124 & 0.143 & 0.259 & 0.227 \\
\hline & & & & 7 & 0.114 & 0.124 & 0.126 & 0.140 & 0.140 & 0.245 & 0.237 \\
\hline \multirow{4}{*}{35} & \multirow{4}{*}{2.5} & \multirow{4}{*}{0.1} & \multirow{4}{*}{$6^{*}$} & 3 & 0.219 & & & & & 0.218 & 0.218 \\
\hline & & & & 4 & 0.215 & & & & 0.217 & 0.217 & 0.215 \\
\hline & & & & 5 & 0.214 & & & 0.218 & 0.217 & 0.216 & 0.214 \\
\hline & & & & 6 & 0.210 & & 0.219 & 0.217 & 0.215 & 0.214 & 0.212 \\
\hline \multirow{4}{*}{35} & \multirow{4}{*}{2.5} & \multirow{4}{*}{0.1} & \multirow{4}{*}{8} & 3 & 0.116 & & & & & 0.115 & 0.118 \\
\hline & & & & 4 & 0.115 & & & & 0.115 & 0.113 & 0.115 \\
\hline & & & & 5 & 0.114 & & & 0.115 & 0.113 & 0.112 & 0.114 \\
\hline & & & & 6 & 0.114 & & 0.115 & 0.113 & 0.112 & 0.111 & 0.109 \\
\hline \multirow{4}{*}{35} & \multirow{4}{*}{2.5} & \multirow{4}{*}{0.1} & \multirow{4}{*}{12} & 3 & 0.048 & & & & & 0.051 & 0.055 \\
\hline & & & & 4 & 0.043 & & & & 0.043 & 0.044 & 0.046 \\
\hline & & & & 5 & 0.041 & & & 0.043 & 0.041 & 0.041 & 0.042 \\
\hline & & & & 6 & 0.039 & & 0.039 & 0.039 & 0.040 & 0.040 & 0.040 \\
\hline \multirow{4}{*}{35} & & & & 3 & 0.494 & & & & & 0.430 & 0.684 \\
\hline & 2.5 & 0.4 & 8 & 4 & 0.463 & & & & 0.441 & 0.416 & 0.493 \\
\hline & & & & 5 & 0.456 & & & 0.458 & 0.438 & 0.409 & 0.396 \\
\hline & & & & 6 & 0.436 & & 0.470 & 0.453 & 0.434 & 0.409 & 0.362 \\
\hline & & & & 3 & 0.164 & & & & & 0.188 & 0.344 \\
\hline 35 & 2.5 & 0.4 & $12^{*}$ & 4 & 0.155 & & & & 0.159 & 0.175 & 0.307 \\
\hline & & & & 5 & 0.150 & & & 0.151 & 0.154 & 0.164 & 0.215 \\
\hline & & & & 6 & 0.155 & & 0.148 & 0.148 & 0.149 & 0.156 & 0.183 \\
\hline & & & & 3 & 0.084 & & & & & 0.112 & 0.308 \\
\hline 35 & 2.5 & 0.4 & 18 & 4 & 0.080 & & & & 0.080 & 0.099 & 0.242 \\
\hline & & & & 5 & 0.068 & & & 0.070 & 0.076 & 0.089 & 0.146 \\
\hline & & & & 6 & 0.066 & & 0.066 & 0.068 & 0.072 & 0.082 & 0.113 \\
\hline & & & & 3 & 0.864 & & & & & 0.698 & 0.967 \\
\hline 35 & 2.5 & 0.7 & 8 & 4 & 0.851 & & & & 0.818 & 0.673 & 0.933 \\
\hline & & & & 5 & 0.839 & & & 0.820 & 0.763 & 0.656 & 0.922 \\
\hline & & & & 6 & 0.829 & & 0.848 & 0.800 & 0.743 & 0.640 & 0.922 \\
\hline
\end{tabular}

*: Number of bracings as per Davidson's equation 2.19
Table 4.9d: WBR for 35m span bridge (Continue...)

\begin{tabular}{|c|c|c|c|c|c|c|c|c|c|c|c|}
\hline \multicolumn{5}{|c|}{ Bridge Dimensions } & \multirow{2}{*}{\multicolumn{7}{|c|}{ WBR }} \\
\hline $\begin{array}{c}\text { Span } \\
(\mathrm{m})\end{array}$ & $\begin{array}{c}\text { Girder } \\
\text { Spacing } \\
(\mathrm{m})\end{array}$ & $\begin{array}{c}\text { Span } \\
\text { Radius } \\
\text { ratio }\end{array}$ & $\begin{array}{l}\text { No. of } \\
\text { Bracing } \\
\text { Intervals }\end{array}$ & $\begin{array}{l}\text { No of } \\
\text { Girders }\end{array}$ & & & & & & & \\
\hline $\mathrm{L}$ & s & LRR & & $\mathrm{N}$ & $G_{E R}$ & $G_{5}$ & $G_{4}$ & $G_{3}$ & $\mathrm{G}_{2}$ & $G_{1}$ & $G_{l n t}$ \\
\hline \multirow{4}{*}{35} & \multirow{4}{*}{2.5} & \multirow{4}{*}{0.7} & \multirow{4}{*}{$12^{*}$} & 3 & 0.275 & & & & & 0.321 & 0.433 \\
\hline & & & & 4 & 0.264 & & & & 0.270 & 0.318 & 0.424 \\
\hline & & & & 5 & 0.261 & & & 0.261 & 0.264 & 0.309 & 0.419 \\
\hline & & & & 6 & 0.259 & & 0.271 & 0.255 & 0.257 & 0.297 & 0.406 \\
\hline \multirow{4}{*}{35} & \multirow{4}{*}{2.5} & \multirow{4}{*}{0.7} & \multirow{4}{*}{18} & 3 & 0.133 & & & & & 0.189 & 0.267 \\
\hline & & & & 4 & 0.120 & & & & 0.131 & 0.190 & 0.255 \\
\hline & & & & 5 & 0.115 & & & 0.118 & 0.128 & 0.184 & 0.248 \\
\hline & & & & 6 & 0.114 & & 0.113 & 0.115 & 0.125 & 0.176 & 0.243 \\
\hline \multirow{3}{*}{35} & \multirow{3}{*}{3} & \multirow{3}{*}{0.1} & \multirow{3}{*}{$6^{*}$} & 3 & 0.236 & & & & & 0.230 & 0.239 \\
\hline & & & & 4 & 0.223 & & & & 0.218 & 0.213 & 0.214 \\
\hline & & & & 5 & 0.220 & & & 0.218 & 0.216 & 0.214 & 0.212 \\
\hline \multirow{3}{*}{35} & \multirow{3}{*}{3} & \multirow{3}{*}{0.1} & \multirow{3}{*}{8} & 3 & 0.119 & & & & & 0.111 & 0.109 \\
\hline & & & & 4 & 0.116 & & & & 0.112 & 0.110 & 0.107 \\
\hline & & & & 5 & 0.116 & & & 0.114 & 0.113 & 0.111 & 0.109 \\
\hline \multirow{3}{*}{35} & \multirow{3}{*}{3} & \multirow{3}{*}{0.1} & \multirow{3}{*}{12} & 3 & 0.044 & & & & & 0.046 & 0.049 \\
\hline & & & & 4. & 0.041 & & & & 0.041 & 0.042 & 0.043 \\
\hline & & & & 5 & 0.039 & & & 0.039 & 0.040 & 0.040 & 0.040 \\
\hline \multirow{3}{*}{35} & \multirow{3}{*}{3} & & & 3 & 0.494 & & & & & 0.419 & 0.501 \\
\hline & & 0.4 & 8 & 4 & 0.482 & & & & 0.449 & 0.418 & 0.459 \\
\hline & & & & 5 & 0.474 & & & 0.465 & 0.444 & 0.417 & 0.426 \\
\hline & & & & 3 & 0.158 & & & & & 0.172 & 0.353 \\
\hline 35 & 3 & 0.4 & $12^{*}$ & 4 & 0.152 & & & & 0.153 & 0.161 & 0.216 \\
\hline & & & & 5 & 0.144 & & & 0.148 & 0.148 & 0.153 & 0.179 \\
\hline & & & & 3 & 0.077 & & & & & 0.095 & 0.288 \\
\hline 35 & 3 & 0.4 & 18 & 4 & 0.069 & & & & 0.073 & 0.084 & 0.147 \\
\hline & & & & 5 & 0.066 & & & 0.067 & 0.070 & 0.078 & 0.109 \\
\hline & & & & 3 & 0.852 & & & & & 0.728 & 0.990 \\
\hline 35 & 3 & 0.7 & 8 & 4 & 0.839 & & & & 0.797 & 0.704 & 0.979 \\
\hline & & & & 5 & 0.829 & & & 0.834 & 0.773 & 0.683 & 0.969 \\
\hline & & & & 3 & 0.289 & & & & & 0.295 & 0.488 \\
\hline 35 & 3 & 0.7 & $12^{*}$ & 4 & 0.273 & & & & 0.262 & 0.286 & 0.474 \\
\hline & & & & 5 & 0.267 & & & 0.265 & 0.255 & 0.275 & 0.463 \\
\hline & & & & 3 & 0.125 & & & & & 0.161 & 0.299 \\
\hline 35 & 3 & 0.7 & 18 & 4 & 0.116 & & & & 0.122 & 0.157 & 0.288 \\
\hline & & & & 5 & 0.113 & & & 0.114 & 0.119 & 0.150 & 0.278 \\
\hline
\end{tabular}


Table 4.9d: WBR for 35m span bridge (Continue...)

\begin{tabular}{|c|c|c|c|c|c|c|c|c|c|c|c|}
\hline \multicolumn{5}{|c|}{ Bridge Dimensions } & \multirow{2}{*}{\multicolumn{7}{|c|}{ WBR }} \\
\hline $\begin{array}{c}\text { Span } \\
\text { (m) }\end{array}$ & $\begin{array}{l}\text { Girder } \\
\text { Spacing } \\
\text { (m) }\end{array}$ & $\begin{array}{l}\text { Span } \\
\text { Radius } \\
\text { ratio }\end{array}$ & $\begin{array}{l}\text { No of of } \\
\text { Bracing } \\
\text { Intervals }\end{array}$ & $\begin{array}{l}\text { No of } \\
\text { Girders }\end{array}$ & & & & & & & \\
\hline$L$ & & LR & & $\mathrm{N}$ & $G_{E x d}$ & $G_{5}$ & $G_{4}$ & $G_{3}$ & $G_{2}$ & $G_{1}$ & $G_{\text {nt }}$ \\
\hline \multirow{5}{*}{35} & \multirow{5}{*}{2} & \multirow{5}{*}{0.7} & \multirow{5}{*}{$12^{*}$} & 3 & 0.286 & & & & & 0.395 & 0.426 \\
\hline & & & & 4 & 0.271 & & & & 0.284 & 0.389 & 0.395 \\
\hline & & & & 5 & 0.267 & & & 0.267 & 0.280 & 0.391 & 0.384 \\
\hline & & & & 6 & 0.278 & & 0.261 & 0.262 & 0.276 & 0.379 & 0.382 \\
\hline & & & & 7 & 0.286 & 0.272 & 0.255 & 0.258 & 0.269 & 0.362 & 0.387 \\
\hline \multirow{5}{*}{35} & \multirow{5}{*}{2} & \multirow{5}{*}{0.7} & \multirow{5}{*}{18} & 3 & 0.145 & & & & & 0.279 & 0.258 \\
\hline & & & & 4 & 0.127 & & & & 0.146 & 0.264 & 0.229 \\
\hline & & & & 5 & 0.119 & & & 0.126 & 0.146 & 0.269 & 0.223 \\
\hline & & & & 6 & 0.116 & & 0.118 & 0.124 & 0.143 & 0.259 & 0.227 \\
\hline & & & & 7 & 0.114 & 0.124 & 0.126 & 0.140 & 0.140 & 0.245 & 0.237 \\
\hline \multirow{4}{*}{35} & \multirow{4}{*}{2.5} & \multirow{4}{*}{0.1} & \multirow{4}{*}{$6^{*}$} & 3 & 0.219 & & & & & 0.218 & 0.218 \\
\hline & & & & 4 & 0.215 & & & & 0.217 & 0.217 & 0.215 \\
\hline & & & & 5 & 0.214 & & & 0.218 & 0.217 & 0.216 & 0.214 \\
\hline & & & & 6 & 0.210 & & 0.219 & 0.217 & 0.215 & 0.214 & 0.212 \\
\hline \multirow{4}{*}{35} & \multirow{4}{*}{2.5} & \multirow{4}{*}{0.1} & \multirow{4}{*}{8} & 3 & 0.116 & & & & & 0.115 & 0.118 \\
\hline & & & & 4 & 0.115 & & & & 0.115 & 0.113 & 0.115 \\
\hline & & & & 5 & 0.114 & & & 0.115 & 0.113 & 0.112 & 0.114 \\
\hline & & & & 6 & 0.114 & & 0.115 & 0.113 & 0.112 & 0.111 & 0.109 \\
\hline \multirow{4}{*}{35} & \multirow{4}{*}{2.5} & \multirow{4}{*}{0.1} & \multirow{4}{*}{12} & 3 & 0.048 & & & & & 0.051 & 0.055 \\
\hline & & & & 4 & 0.043 & & & & 0.043 & 0.044 & 0.046 \\
\hline & & & & 5 & 0.041 & & & 0.043 & 0.041 & 0.041 & 0.042 \\
\hline & & & & 6 & 0.039 & & 0.039 & 0.039 & 0.040 & 0.040 & 0.040 \\
\hline \multirow{4}{*}{35} & & & & 3 & 0.494 & & & & & 0.430 & 0.684 \\
\hline & 2.5 & 0.4 & 8 & 4 & 0.463 & & & & 0.441 & 0.416 & 0.493 \\
\hline & & & & 5 & 0.456 & & & 0.458 & 0.438 & 0.409 & 0.396 \\
\hline & & & & 6 & 0.436 & & 0.470 & 0.453 & 0.434 & 0.409 & 0.362 \\
\hline & & & & 3 & 0.164 & & & & & 0.188 & 0.344 \\
\hline 35 & 2.5 & 0.4 & $12^{*}$ & 4 & 0.155 & & & & 0.159 & 0.175 & 0.307 \\
\hline & & & & 5 & 0.150 & & & 0.151 & 0.154 & 0.164 & 0.215 \\
\hline & & & & 6 & 0.155 & & 0.148 & 0.148 & 0.149 & 0.156 & 0.183 \\
\hline & & & & 3 & 0.084 & & & & & 0.112 & 0.308 \\
\hline 35 & 2.5 & 0.4 & 18 & 4 & 0.080 & & & & 0.080 & 0.099 & 0.242 \\
\hline & & & & 5 & 0.068 & & & 0.070 & 0.076 & 0.089 & 0.146 \\
\hline & & & & 6 & 0.066 & & 0.066 & 0.068 & 0.072 & 0.082 & 0.113 \\
\hline & & & & 3 & 0.864 & & & & & 0.698 & 0.967 \\
\hline 35 & 2.5 & 0.7 & 8 & 4 & 0.851 & & & & 0.818 & 0.673 & 0.933 \\
\hline & & & & 5 & 0.839 & & & 0.820 & 0.763 & 0.656 & 0.922 \\
\hline & & & & 6 & 0.829 & & 0.848 & 0.800 & 0.743 & 0.640 & 0.922 \\
\hline
\end{tabular}

Table 4.9d: WBR for 35m span bridge (Continue...)

\begin{tabular}{|c|c|c|c|c|c|c|c|c|c|c|c|}
\hline \multicolumn{5}{|c|}{ Bridge Dimensions } & \multirow{2}{*}{\multicolumn{7}{|c|}{ WBR }} \\
\hline $\begin{array}{c}\text { Span } \\
(m)\end{array}$ & $\begin{array}{l}\text { Girder } \\
\text { Spacing } \\
(\mathrm{m})\end{array}$ & $\begin{array}{l}\text { Span } \\
\text { Radius } \\
\text { ratio }\end{array}$ & $\begin{array}{l}\text { No. of } \\
\text { Bracing } \\
\text { Intervals }\end{array}$ & $\begin{array}{l}\text { No of } \\
\text { Girders }\end{array}$ & & & & & & & \\
\hline $\mathrm{L}$ & s & LRR & & $\mathrm{N}$ & $G_{E x}$ & $G_{5}$ & $G_{4}$ & $G_{3}$ & $\mathrm{G}_{2}$ & $G_{1}$ & $G_{n t}$ \\
\hline \multirow{4}{*}{35} & \multirow{4}{*}{2.5} & \multirow{4}{*}{0.7} & \multirow{4}{*}{$12^{*}$} & 3 & 0.275 & & & & & 0.321 & 0.433 \\
\hline & & & & 4 & 0.264 & & & & 0.270 & 0.318 & 0.424 \\
\hline & & & & 5 & 0.261 & & & 0.261 & 0.264 & 0.309 & 0.419 \\
\hline & & & & 6 & 0.259 & & 0.271 & 0.255 & 0.257 & 0.297 & 0.406 \\
\hline \multirow{4}{*}{35} & \multirow{4}{*}{2.5} & \multirow{4}{*}{0.7} & \multirow{4}{*}{18} & 3 & 0.133 & & & & & 0.189 & 0.267 \\
\hline & & & & 4 & 0.120 & & & & 0.131 & 0.190 & 0.255 \\
\hline & & & & 5 & 0.115 & & & 0.118 & 0.128 & 0.184 & 0.248 \\
\hline & & & & 6 & 0.114 & & 0.113 & 0.115 & 0.125 & 0.176 & 0.243 \\
\hline \multirow{3}{*}{35} & \multirow{3}{*}{3} & \multirow{3}{*}{0.1} & \multirow{3}{*}{$6^{*}$} & 3 & 0.236 & & & & & 0.230 & 0.239 \\
\hline & & & & 4 & 0.223 & & & & 0.218 & 0.213 & 0.214 \\
\hline & & & & 5 & 0.220 & & & 0.218 & 0.216 & 0.214 & 0.212 \\
\hline \multirow{3}{*}{35} & \multirow{3}{*}{3} & \multirow{3}{*}{0.1} & \multirow{3}{*}{8} & 3 & 0.119 & & & & & 0.111 & 0.109 \\
\hline & & & & 4 & 0.116 & & & & 0.112 & 0.110 & 0.107 \\
\hline & & & & 5 & 0.116 & & & 0.114 & 0.113 & 0.111 & 0.109 \\
\hline \multirow{3}{*}{35} & \multirow{3}{*}{3} & \multirow{3}{*}{0.1} & \multirow{3}{*}{12} & 3 & 0.044 & & & & & 0.046 & 0.049 \\
\hline & & & & 4 & 0.041 & & & & 0.041 & 0.042 & 0.043 \\
\hline & & & & 5 & 0.039 & & & 0.039 & 0.040 & 0.040 & 0.040 \\
\hline \multirow{3}{*}{35} & \multirow{3}{*}{3} & & & 3 & 0.494 & & & & & 0.419 & 0.501 \\
\hline & & 0.4 & 8 & 4 & 0.482 & & & & 0.449 & 0.418 & 0.459 \\
\hline & & & & 5 & 0.474 & & & 0.465 & 0.444 & 0.417 & 0.426 \\
\hline & & & & 3 & 0.158 & & & & & 0.172 & 0.353 \\
\hline 35 & 3 & 0.4 & $12^{*}$ & 4 & 0.152 & & & & 0.153 & 0.161 & 0.216 \\
\hline & & & & 5 & 0.144 & & & 0.148 & 0.148 & 0.153 & 0.179 \\
\hline & & & & 3 & 0.077 & & & & & 0.095 & 0.288 \\
\hline 35 & 3 & 0.4 & 18 & 4 & 0.069 & & & & 0.073 & 0.084 & 0.147 \\
\hline & & & & 5 & 0.066 & & & 0.067 & 0.070 & 0.078 & 0.109 \\
\hline & & & & 3 & 0.852 & & & & & 0.728 & 0.990 \\
\hline 35 & 3 & 0.7 & 8 & 4 & 0.839 & & & & 0.797 & 0.704 & 0.979 \\
\hline & & & & 5 & 0.829 & & & 0.834 & 0.773 & 0.683 & 0.969 \\
\hline & & & & 3 & 0.289 & & & & & 0.295 & 0.488 \\
\hline 35 & 3 & 0.7 & $12^{*}$ & 4 & 0.273 & & & & 0.262 & 0.286 & 0.474 \\
\hline & & & & 5 & 0.267 & & & 0.265 & 0.255 & 0.275 & 0.463 \\
\hline & & & & 3 & 0.125 & & & & & 0.161 & 0.299 \\
\hline 35 & 3 & 0.7 & 18 & 4 & 0.116 & & & & 0.122 & 0.157 & 0.288 \\
\hline & & & & 5 & 0.113 & & & 0.114 & 0.119 & 0.150 & 0.278 \\
\hline
\end{tabular}


Table 4.10 Effect of number of cross-bracing intervals

\begin{tabular}{|c|c|c|c|c|c|c|}
\hline \multirow[t]{2}{*}{$\mathrm{L} / \mathrm{R}$} & \multirow{2}{*}{$\begin{array}{l}\text { Number of } \\
\text { cross-bracing } \\
\text { spacing }\end{array}$} & \multicolumn{4}{|c|}{ Moment distribution factor } & \multirow{2}{*}{$\begin{array}{l}\text { Deflection } \\
\text { distribution factor } \\
\text { at the outer girder }\end{array}$} \\
\hline & & G1 & G2 & G3 & G4 & \\
\hline \multirow[t]{3}{*}{0.10} & 4 & 1.041 & 1.169 & 1.285 & 2.468 & 1.56 \\
\hline & $6^{*}$ & 0.922 & 1.027 & 1.126 & 1.221 & 1.40 \\
\hline & 8 & 0.835 & 0.932 & 1.021 & 1.102 & 1.23 \\
\hline \multirow[t]{3}{*}{0.30} & 6 & 0.720 & 1.130 & 1.487 & 1.804 & 4.08 \\
\hline & $8^{*}$ & 0.640 & 0.999 & 1.307 & 1.579 & 2.12 \\
\hline & 12 & 0.587 & 0.881 & 1.133 & 1.351 & 1.80 \\
\hline \multicolumn{7}{|c|}{$\begin{array}{l}\mathrm{L}=25 \mathrm{~m} \text {; four girders; girder spacing }=3 \mathrm{~m} . \\
*: \text { number of cross-bracing spacing from Eq. } 1 .\end{array}$} \\
\hline
\end{tabular}

Table 4.11 Effect of area of cross-bracings

\begin{tabular}{|c|c|c|c|c|c|c|c|c|}
\hline \multirow{2}{*}{$\begin{array}{l}\text { Bracing } \\
\text { area } \\
\left(\mathrm{mm}^{2}\right)\end{array}$} & \multirow[t]{2}{*}{$\mathrm{L} / \mathrm{R}$} & \multirow{2}{*}{$\begin{array}{l}\text { Number of } \\
\text { cross-bracing } \\
\text { intervals, Eq. } \\
2.19\end{array}$} & \multicolumn{4}{|c|}{$\begin{array}{l}\text { Moment distribution } \\
\text { factor }\end{array}$} & \multirow{2}{*}{$\begin{array}{l}\text { Deflection } \\
\text { distribution } \\
\text { factor at the } \\
\text { outer girder }\end{array}$} & \multirow{2}{*}{$\begin{array}{l}\text { Axial force } \\
\text { in bracing } \\
\text { members } \\
(\mathrm{kN})\end{array}$} \\
\hline & & & G1 & $\mathrm{G} 2$ & $\mathrm{G} 3$ & G4 & & \\
\hline \multirow{5}{*}{4300} & 0.0 & 4 & 1.00 & 1.00 & 1.00 & 1.00 & 1.00 & 11 \\
\hline & 0.1 & 6 & 0.87 & 0.96 & 1.05 & 1.13 & 1.40 & 27 \\
\hline & 0.2 & 7 & 0.78 & 0.94 & 1.10 & 1.26 & 1.74 & 91 \\
\hline & 0.3 & 8 & 0.73 & 0.94 & 1.17 & 1.39 & 2.16 & 152 \\
\hline & 0.4 & 9 & 0.71 & 0.95 & 1.22 & 1.47 & 2.57 & 189 \\
\hline \multirow{5}{*}{6400} & 0.0 & 4 & 1.00 & 1.00 & 1.00 & 1.00 & 1.00 & 15 \\
\hline & 0.1 & 6 & 0.87 & 0.96 & 1.05 & 1.13 & 1.40 & 39 \\
\hline & 0.2 & 7 & 0.79 & 0.94 & 1.10 & 1.25 & 1.72 & 118 \\
\hline & 0.3 & 8 & 0.76 & 0.95 & 1.17 & 1.38 & 2.10 & 179 \\
\hline & 0.4 & 9 & 0.73 & 0.95 & 1.22 & 1.46 & 2.54 & 211 \\
\hline \multirow{5}{*}{9600} & 0.0 & 4 & 1.00 & 1.00 & 1.00 & 1.00 & 1.00 & 21 \\
\hline & 0.1 & 6 & 0.88 & 0.96 & 1.05 & 1.13 & 1.39 & 55 \\
\hline & 0.2 & 7 & 0.81 & 0.95 & 1.10 & 1.25 & 1.70 & 148 \\
\hline & 0.3 & 8 & 0.78 & 0.95 & 1.16 & 1.37 & 2.10 & 206 \\
\hline & 0.4 & 9 & 0.75 & 0.96 & 1.22 & 1.46 & 2.51 & 231 \\
\hline \multicolumn{9}{|c|}{$\mathrm{L}=25 \mathrm{~m} ;$ four girders; girder spacing $=3 \mathrm{~m}$} \\
\hline
\end{tabular}


Table 4.10 Effect of number of cross-bracing intervals

\begin{tabular}{|c|c|c|c|c|c|c|}
\hline \multirow[t]{2}{*}{$\mathrm{L} / \mathrm{R}$} & \multirow{2}{*}{$\begin{array}{l}\text { Number of } \\
\text { cross-bracing } \\
\text { spacing }\end{array}$} & \multicolumn{4}{|c|}{ Moment distribution factor } & \multirow{2}{*}{$\begin{array}{l}\text { Deflection } \\
\text { distribution factor } \\
\text { at the outer girder }\end{array}$} \\
\hline & & G1 & G2 & G3 & G4 & \\
\hline \multirow[t]{3}{*}{0.10} & 4 & 1.041 & 1.169 & 1.285 & 2.468 & 1.56 \\
\hline & $6^{*}$ & 0.922 & 1.027 & 1.126 & 1.221 & 1.40 \\
\hline & 8 & 0.835 & 0.932 & 1.021 & 1.102 & 1.23 \\
\hline \multirow[t]{3}{*}{0.30} & 6 & 0.720 & 1.130 & 1.487 & 1.804 & 4.08 \\
\hline & $8^{*}$ & 0.640 & 0.999 & 1.307 & 1.579 & 2.12 \\
\hline & 12 & 0.587 & 0.881 & 1.133 & 1.351 & 1.80 \\
\hline \multicolumn{7}{|c|}{$\begin{array}{l}\mathrm{L}=25 \mathrm{~m} \text {; four girders; girder spacing }=3 \mathrm{~m} . \\
*: \text { number of cross-bracing spacing from } \mathrm{Eq} .1 .\end{array}$} \\
\hline
\end{tabular}

Table 4.11 Effect of area of cross-bracings

\begin{tabular}{|c|c|c|c|c|c|c|c|c|}
\hline \multirow{2}{*}{$\begin{array}{l}\text { Bracing } \\
\text { area } \\
\left(\mathrm{mm}^{2}\right)\end{array}$} & \multirow[t]{2}{*}{$\mathrm{L} / \mathrm{R}$} & \multirow{2}{*}{$\begin{array}{l}\text { Number of } \\
\text { cross-bracing } \\
\text { intervals, Eq. } \\
2.19\end{array}$} & \multicolumn{4}{|c|}{$\begin{array}{l}\text { Moment distribution } \\
\text { factor }\end{array}$} & \multirow{2}{*}{$\begin{array}{l}\text { Deflection } \\
\text { distribution } \\
\text { factor at the } \\
\text { outer girder }\end{array}$} & \multirow{2}{*}{$\begin{array}{l}\text { Axial force } \\
\text { in bracing } \\
\text { members } \\
(\mathrm{kN})\end{array}$} \\
\hline & & & G1 & G2 & $\mathrm{Q} 3$ & $\mathrm{G} 4$ & & \\
\hline \multirow{5}{*}{4300} & 0.0 & 4 & 1.00 & 1.00 & 1.00 & 1.00 & 1.00 & 11 \\
\hline & 0.1 & 6 & 0.87 & 0.96 & 1.05 & 1.13 & 1.40 & 27 \\
\hline & 0.2 & 7 & 0.78 & 0.94 & 1.10 & 1.26 & 1.74 & 91 \\
\hline & 0.3 & 8 & 0.73 & 0.94 & 1.17 & 1.39 & 2.16 & 152 \\
\hline & 0.4 & 9 & 0.71 & 0.95 & 1.22 & 1.47 & 2.57 & 189 \\
\hline \multirow{5}{*}{6400} & 0.0 & 4 & 1.00 & 1.00 & 1.00 & 1.00 & 1.00 & 15 \\
\hline & 0.1 & 6 & 0.87 & 0.96 & 1.05 & 1.13 & 1.40 & 39 \\
\hline & 0.2 & 7 & 0.79 & 0.94 & 1.10 & 1.25 & 1.72 & 118 \\
\hline & 0.3 & 8 & 0.76 & 0.95 & 1.17 & 1.38 & 2.10 & 179 \\
\hline & 0.4 & 9 & 0.73 & 0.95 & 1.22 & 1.46 & 2.54 & 211 \\
\hline \multirow{5}{*}{9600} & 0.0 & 4 & 1.00 & 1.00 & 1.00 & 1.00 & 1.00 & 21 \\
\hline & 0.1 & 6 & 0.88 & 0.96 & 1.05 & 1.13 & 1.39 & 55 \\
\hline & 0.2 & 7 & 0.81 & 0.95 & 1.10 & 1.25 & 1.70 & 148 \\
\hline & 0.3 & 8 & 0.78 & 0.95 & 1.16 & 1.37 & 2.10 & 206 \\
\hline & 0.4 & 9 & 0.75 & 0.96 & 1.22 & 1.46 & 2.51 & 231 \\
\hline \multicolumn{9}{|c|}{$\mathrm{L}=25 \mathrm{~m} ;$ four girders; girder spacing $=3 \mathrm{~m}$} \\
\hline
\end{tabular}


Table 4.14 Effect of number of cross bracing intervals on reaction distribution factors

\begin{tabular}{|c|c|c|c|c|c|}
\hline \multirow{2}{*}{$\mathrm{L} / \mathrm{R}$} & \multirow{2}{*}{$\begin{array}{l}\text { Number of cross- } \\
\text { bracing intervals }\end{array}$} & \multicolumn{4}{|c|}{ Reaction distribution factor } \\
\hline & & G1 & G2 & G3 & G4 \\
\hline \multirow{3}{*}{0.1} & 4 & 0.864 & 1.017 & 1.072 & 1.046 \\
\hline & $6^{*}$ & 0.866 & 1.014 & 1.072 & 1.047 \\
\hline & 8 & 0.866 & 1.014 & 1.073 & 1.046 \\
\hline \multirow{3}{*}{0.3} & 6 & 0.671 & 0.974 & 1.145 & 1.210 \\
\hline & $8^{*}$ & 0.672 & 0.969 & 1.141 & 1.218 \\
\hline & $12^{*}$ & 0.674 & 0.972 & 1.147 & 1.207 \\
\hline \multirow{3}{*}{0.5} & 8 & 0.450 & 0.946 & 1.236 & 1.369 \\
\hline & $12^{*}$ & 0.455 & 0.946 & 1.236 & 1.362 \\
\hline & 18 & 0.458 & 0.943 & 1.236 & 1.362 \\
\hline \multicolumn{6}{|c|}{$\begin{array}{l}\mathrm{L}=25 \mathrm{~m} ; \text { four girders; girder spacing }=3 \mathrm{~m} ; \\
*=\text { number of cross-bracings from Eq. } 1\end{array}$} \\
\hline
\end{tabular}

Table 4.15 Effect of girder spacing, $L / R$ ratio and number of girder on Moment Distribution factor $D_{M}$

Table 4.15a: Moment Distribution factors $D_{M}$ for $10 \mathrm{~m}$ span bridge

\begin{tabular}{|c|c|c|c|c|c|c|c|c|c|c|c|}
\hline \multicolumn{5}{|c|}{ Bridge Dimensions } & \multirow{2}{*}{\multicolumn{7}{|c|}{ Mom. Dist. Factor : $D_{M}$}} \\
\hline $\begin{array}{c}\text { Span } \\
(\mathrm{m})\end{array}$ & $\begin{array}{l}\text { Girder } \\
\text { Spacing }\end{array}$ & $\begin{array}{l}\text { Span } \\
\text { Radius }\end{array}$ & $\begin{array}{l}\text { No. of } \\
\text { Bracing }\end{array}$ & $\begin{array}{l}\text { No. of } \\
\text { Girders }\end{array}$ & & & & & & & \\
\hline L & & & & $\mathrm{N}$ & $G_{\text {Ext }}$ & $\mathbf{G}_{5}$ & $\mathbf{G}_{4}$ & $\mathbf{G}_{3}$ & $\mathbf{G}_{2}$ & $\mathbf{G}_{1}$ & $G_{\text {Int }}$ \\
\hline \multirow{5}{*}{10} & \multirow{5}{*}{2} & \multirow{5}{*}{0.1} & \multirow{5}{*}{2} & 3 & 1.365 & & & & & 1.234 & 1.070 \\
\hline & & & & 4 & 1.344 & & & & 1.276 & 1.179 & 1.039 \\
\hline & & & & 5 & 1.331 & & & 1.296 & 1.239 & 1.142 & 1.000 \\
\hline & & & & 6 & 1.325 & & 1.306 & 1.272 & 1.209 & 1.107 & 0.961 \\
\hline & & & & 7 & 1.327 & 1.314 & 1.289 & 1.247 & 1.178 & 1.073 & 0.925 \\
\hline \multirow{5}{*}{10} & \multirow{5}{*}{2} & \multirow{5}{*}{0.1} & \multirow{5}{*}{$4^{*}$} & 3 & 1.091 & & & & & 0.987 & 0.787 \\
\hline & & & & 4 & 0.540 & & & & 1.027 & 0.953 & 0.851 \\
\hline & & & & 5 & 1.067 & & & 1.047 & 1.008 & 0.932 & 0.745 \\
\hline & & & & 6 & 1.054 & & 1.055 & 1.041 & 0.994 & 0.909 & 0.716 \\
\hline & & & & 7 & 1.044 & 1.057 & 1.059 & 1.034 & 0.977 & 0.883 & 0.708 \\
\hline \multirow{5}{*}{10} & \multirow{5}{*}{2} & \multirow{5}{*}{0.1} & \multirow{5}{*}{6} & 3 & 1.009 & & & & & 0.918 & 0.732 \\
\hline & & & & 4 & 0.926 & & & & 0.885 & 0.827 & 0.748 \\
\hline & & & & 5 & 0.914 & & & 0.896 & 0.863 & 0.808 & 0.729 \\
\hline & & & & 6 & 0.903 & & 0.900 & 0.885 & 0.851 & 0.791 & 0.706 \\
\hline & & & & 7 & 0.923 & 0.901 & 0.898 & 0.879 & 0.838 & 0.771 & 0.681 \\
\hline \multirow{5}{*}{10} & \multirow{5}{*}{2} & \multirow{5}{*}{0.2} & \multirow{5}{*}{4} & 3 & 1.110 & & & & & 1.003 & 0.697 \\
\hline & & & & 4 & 1.199 & & & & 1.080 & 0.927 & 0.672 \\
\hline & & & & 5 & 1.197 & & & 1.119 & 1.018 & 0.879 & 0.641 \\
\hline & & & & 6 & 1.202 & & 1.145 & 1.071 & 0.973 & 0.836 & 0.607 \\
\hline & & & & 7 & 1.215 & 1.167 & 1.106 & 1.031 & 0.931 & 0.795 & 0.589 \\
\hline \multirow{5}{*}{10} & \multirow{5}{*}{2} & \multirow{5}{*}{0.2} & \multirow{5}{*}{$6^{*}$} & 3 & 1.157 & & & & & 0.976 & 0.757 \\
\hline & & & & 4 & 1.133 & & & & 1.033 & 0.864 & 0.705 \\
\hline & & & & 5 & 1.119 & & & 1.061 & 0.983 & 0.870 & 0.712 \\
\hline & & & & 6 & 1.109 & & 1.075 & 1.029 & 0.954 & 0.838 & 0.677 \\
\hline & & & & 7 & 1.105 & 1.085 & 1.056 & 1.006 & 0.926 & 0.805 & 0.638 \\
\hline & & & & 3 & 1.049 & & & & & 0.881 & 0.683 \\
\hline 10 & 2 & & & 4 & 1.027 & & & & 0.929 & 0.812 & 0.666 \\
\hline & 2 & 0.2 & 9 & 5 & 1.016 & & & 0.953 & 0.876 & 0.775 & 0.643 \\
\hline & & & & $\frac{6}{7}$ & 1.011 & 1021 & $\frac{0.968}{0.988}$ & $\begin{array}{l}0.916 \\
0.938\end{array}$ & $\frac{0.844}{0.863}$ & $\begin{array}{l}0.745 \\
0.755\end{array}$ & 0.614 \\
\hline & & & & $\frac{7}{3}$ & $\frac{1.049}{1.434}$ & $1.0 \angle 1$ & & & & 1.098 & 0.649 \\
\hline & & & & 4 & 1.425 & & & & 1.226 & 0.976 & 0.616 \\
\hline 10 & 2 & 0.3 & 4 & 5 & 1.434 & & & 1.291 & 1.119 & 0.898 & 0.574 \\
\hline & & & & 6 & 1.457 & & 1.338 & 1.202 & 1.040 & 0.833 & 0.530 \\
\hline & & & & 7 & 1.495 & 1.384 & 1.260 & 1.125 & 0.970 & 0.772 & \begin{tabular}{|l}
0.501 \\
\end{tabular} \\
\hline & & & & 3 & 1.303 & & & & & 1.031 & 0.684 \\
\hline & & & & 4 & 1.271 & & & & 1.120 & 0.883 & 0.632 \\
\hline 10 & 2 & 0.3 & $6^{*}$ & 5 & 1.256 & & & 1.161 & 1.038 & 0.867 & 0.625 \\
\hline & & & & 6 & 1.254 & & 1.186 & 1.102 & 0.986 & 0.818 & 0.580 \\
\hline & & & & 7 & 1.262 & 1.207 & 1.142 & 1.057 & 0.939 & \begin{tabular}{|l}
0.772 \\
\end{tabular} & 0.534 \\
\hline
\end{tabular}


Table 4.14 Effect of number of cross bracing intervals on reaction distribution factors

\begin{tabular}{|c|c|c|c|c|c|}
\hline \multirow{2}{*}{$L / R$} & \multirow{2}{*}{$\begin{array}{l}\text { Number of cross- } \\
\text { bracing intervals }\end{array}$} & \multicolumn{4}{|c|}{ Reaction distribution factor } \\
\hline & & G1 & G2 & G3 & G4 \\
\hline \multirow{3}{*}{0.1} & 4 & 0.864 & 1.017 & 1.072 & 1.046 \\
\hline & $6^{*}$ & 0.866 & 1.014 & 1.072 & 1.047 \\
\hline & 8 & 0.866 & 1.014 & 1.073 & 1.046 \\
\hline \multirow{3}{*}{0.3} & 6 & 0.671 & 0.974 & 1.145 & 1.210 \\
\hline & $8^{*}$ & 0.672 & 0.969 & 1.141 & 1.218 \\
\hline & $12^{*}$ & 0.674 & 0.972 & 1.147 & 1.207 \\
\hline \multirow{3}{*}{0.5} & 8 & 0.450 & 0.946 & 1.236 & 1.369 \\
\hline & $12^{*}$ & 0.455 & 0.946 & 1.236 & 1.362 \\
\hline & 18 & 0.458 & 0.943 & 1.236 & 1.362 \\
\hline \multicolumn{6}{|c|}{$\begin{array}{l}\mathrm{L}=25 \mathrm{~m} ; \text { four girders; girder spacing }=3 \mathrm{~m} ; \\
*=\text { number of cross-bracings from Eq. } 1\end{array}$} \\
\hline
\end{tabular}

Table 4.15 Effect of girder spacing, $L / R$ ratio and number of girder on Moment Distribution factor $D_{M}$

Table 4.15a: Moment Distribution factors $D_{M}$ for $10 \mathrm{~m}$ span bridge

\begin{tabular}{|c|c|c|c|c|c|c|c|c|c|c|c|}
\hline \multicolumn{5}{|c|}{ Bridge Dimensions } & \multirow{2}{*}{\multicolumn{7}{|c|}{ Mom. Dist. Factor : $D_{M}$}} \\
\hline $\begin{array}{c}\text { Span } \\
(\mathrm{m})\end{array}$ & $\begin{array}{l}\text { Girder } \\
\text { Spacing }\end{array}$ & $\begin{array}{l}\text { Span } \\
\text { Radius }\end{array}$ & $\begin{array}{l}\text { No. of } \\
\text { Bracing }\end{array}$ & $\begin{array}{l}\text { No. of } \\
\text { Girders }\end{array}$ & & & & & & & \\
\hline L & & & & $\mathrm{N}$ & $G_{\text {Ext }}$ & $\mathbf{G}_{5}$ & $\mathbf{G}_{4}$ & $G_{3}$ & $\mathbf{G}_{2}$ & $\mathbf{G}_{1}$ & $G_{\text {Int }}$ \\
\hline \multirow{5}{*}{10} & \multirow{5}{*}{2} & \multirow{5}{*}{0.1} & \multirow{5}{*}{2} & 3 & 1.365 & & & & & 1.234 & 1.070 \\
\hline & & & & 4 & 1.344 & & & & 1.276 & 1.179 & 1.039 \\
\hline & & & & 5 & 1.331 & & & 1.296 & 1.239 & 1.142 & 1.000 \\
\hline & & & & 6 & 1.325 & & 1.306 & 1.272 & 1.209 & 1.107 & 0.961 \\
\hline & & & & 7 & 1.327 & 1.314 & 1.289 & 1.247 & 1.178 & 1.073 & 0.925 \\
\hline \multirow{5}{*}{10} & \multirow{5}{*}{2} & \multirow{5}{*}{0.1} & \multirow{5}{*}{$4^{*}$} & 3 & 1.091 & & & & & 0.987 & 0.787 \\
\hline & & & & 4 & 0.540 & & & & 1.027 & 0.953 & 0.851 \\
\hline & & & & 5 & 1.067 & & & 1.047 & 1.008 & 0.932 & 0.745 \\
\hline & & & & 6 & 1.054 & & 1.055 & 1.041 & 0.994 & 0.909 & 0.716 \\
\hline & & & & 7 & 1.044 & 1.057 & 1.059 & 1.034 & 0.977 & 0.883 & 0.708 \\
\hline \multirow{5}{*}{10} & \multirow{5}{*}{2} & \multirow{5}{*}{0.1} & \multirow{5}{*}{6} & 3 & 1.009 & & & & & 0.918 & 0.732 \\
\hline & & & & 4 & 0.926 & & & & 0.885 & 0.827 & 0.748 \\
\hline & & & & 5 & 0.914 & & & 0.896 & 0.863 & 0.808 & 0.729 \\
\hline & & & & 6 & 0.903 & & 0.900 & 0.885 & 0.851 & 0.791 & 0.706 \\
\hline & & & & 7 & 0.923 & 0.901 & 0.898 & 0.879 & 0.838 & 0.771 & 0.681 \\
\hline \multirow{5}{*}{10} & \multirow{5}{*}{2} & \multirow{5}{*}{0.2} & \multirow{5}{*}{4} & 3 & 1.110 & & & & & 1.003 & 0.697 \\
\hline & & & & 4 & 1.199 & & & & 1.080 & 0.927 & 0.672 \\
\hline & & & & 5 & 1.197 & & & 1.119 & 1.018 & 0.879 & 0.641 \\
\hline & & & & 6 & 1.202 & & 1.145 & 1.071 & 0.973 & 0.836 & 0.607 \\
\hline & & & & 7 & 1.215 & 1.167 & 1.106 & 1.031 & 0.931 & 0.795 & 0.589 \\
\hline \multirow{5}{*}{10} & \multirow{5}{*}{2} & \multirow{5}{*}{0.2} & \multirow{5}{*}{$6^{*}$} & 3 & 1.157 & & & & & 0.976 & 0.757 \\
\hline & & & & 4 & 1.133 & & & & 1.033 & 0.864 & 0.705 \\
\hline & & & & 5 & 1.119 & & & 1.061 & 0.983 & 0.870 & 0.712 \\
\hline & & & & 6 & 1.109 & & 1.075 & 1.029 & 0.954 & 0.838 & 0.677 \\
\hline & & & & 7 & 1.105 & 1.085 & 1.056 & 1.006 & 0.926 & 0.805 & 0.638 \\
\hline & & & & 3 & 1.049 & & & & & 0.881 & 0.683 \\
\hline 10 & 2 & & & 4 & 1.027 & & & & 0.929 & 0.812 & 0.666 \\
\hline & & 0.2 & 9 & 5 & 1.016 & & & 0.953 & 0.876 & 0.775 & 0.643 \\
\hline & & & & $\frac{6}{7}$ & $\frac{1.011}{1.019}$ & 1021 & \begin{tabular}{|l}
0.968 \\
0.988 \\
\end{tabular} & $\frac{0.916}{0.938}$ & 0.844 & $\frac{0.745}{0.755}$ & 0.614 \\
\hline & & & & 3 & 1.434 & & & & & 1.098 & 0.649 \\
\hline & & & & 4 & 1.425 & & & & 1.226 & 0.976 & 0.616 \\
\hline 10 & 2 & 0.3 & 4 & 5 & 1.434 & & & 1.291 & 1.119 & 0.898 & 0.574 \\
\hline & & & & 6 & 1.457 & & 1.338 & 1.202 & 1.040 & 0.833 & 0.530 \\
\hline & & & & 7 & 1.495 & 1.384 & 1.260 & 1.125 & 0.970 & 0.772 & \begin{tabular}{|l}
0.501 \\
\end{tabular} \\
\hline & & & & 3 & 1.303 & & & & & 1.031 & 0.684 \\
\hline & & & & 4 & 1.271 & & & & 1.120 & 0.883 & 0.632 \\
\hline 10 & 2 & 0.3 & $6^{*}$ & 5 & 1.256 & & & 1.161 & 1.038 & 0.867 & 0.625 \\
\hline & & & & 6 & 1.254 & & 1.186 & 1.102 & $\begin{array}{l}0.986 \\
0.939\end{array}$ & $\frac{0.818}{0.772}$ & 0.580 \\
\hline & & & & 7 & 1.262 & 1.207 & 1.142 & 1.057 & & & 0.534 \\
\hline
\end{tabular}




\begin{tabular}{|c|c|c|c|c|c|c|c|c|c|c|c|}
\hline \multicolumn{5}{|c|}{ Bridge Dimensions } & \multirow{2}{*}{\multicolumn{7}{|c|}{ Mom. Dist. Factor : $D_{M}$}} \\
\hline $\begin{array}{c}\text { Span } \\
(m)\end{array}$ & $\begin{array}{c}\text { Girder } \\
\text { Spacing } \\
\text { (m) }\end{array}$ & $\begin{array}{l}\text { Span } \\
\text { Radius } \\
\text { Ratio } \\
\end{array}$ & $\begin{array}{l}\text { No. of } \\
\text { Bracing } \\
\text { Intervals }\end{array}$ & $\begin{array}{l}\text { No. of } \\
\text { Girders }\end{array}$ & & & & & & & \\
\hline $\mathrm{L}$ & $s$ & $L / R$ & & $\mathrm{~N}$ & $G_{\text {Ext }}$ & $\mathrm{G}_{5}$ & $\mathrm{G}_{4}$ & $\mathrm{G}_{3}$ & $\mathbf{G}_{2}$ & $\mathbf{G}_{1}$ & $\mathbf{G}_{\operatorname{lnt}}$ \\
\hline \multirow{5}{*}{10} & \multirow{5}{*}{2} & \multirow{5}{*}{0.3} & \multirow{5}{*}{9} & 3 & 1.165 & & & & & 0.876 & 0.609 \\
\hline & & & & 4 & 1.133 & & & & 0.994 & 0.818 & 0.586 \\
\hline & & & & 5 & 1.043 & & & 0.980 & 0.912 & 0.764 & 0.562 \\
\hline & & & & 6 & 1.119 & & 1.053 & 0.972 & 0.865 & 0.718 & 0.515 \\
\hline & & & & 7 & 1.167 & 1.116 & 1.056 & 0.978 & 0.869 & 0.715 & 0.502 \\
\hline \multirow{4}{*}{10} & \multirow{4}{*}{2.5} & \multirow{4}{*}{0.1} & \multirow{4}{*}{2} & 3 & 1.322 & & & & & 1.215 & 1.047 \\
\hline & & & & 4 & 1.299 & & & & 1.259 & 1.164 & 0.995 \\
\hline & & & & 5 & 1.283 & & & 1.276 & 1.231 & 1.121 & 0.940 \\
\hline & & & & 6 & 1.281 & & 1.285 & 1.261 & 1.197 & 1.077 & 0.891 \\
\hline \multirow{4}{*}{10} & \multirow{4}{*}{2.5} & \multirow{4}{*}{0.1} & \multirow{4}{*}{$4^{\star}$} & 3 & 0.993 & & & & & 0.914 & 0.800 \\
\hline & & & & 4 & 1.053 & & & & 1.027 & 0.957 & 0.831 \\
\hline & & & & 5 & 1.034 & & & 1.047 & 1.022 & 0.934 & 0.711 \\
\hline & & & & 6 & 1.018 & & 1.051 & 1.056 & 1.010 & 0.903 & 0.692 \\
\hline \multirow{4}{*}{10} & \multirow{4}{*}{2.5} & \multirow{4}{*}{0.1} & \multirow{4}{*}{6} & 3 & 0.918 & & & & & 0.852 & 0.754 \\
\hline & & & & 4 & 0.891 & & & & 0.865 & 0.812 & 0.721 \\
\hline & & & & 5 & 0.885 & & & 0.889 & 0.867 & 0.805 & 0.700 \\
\hline & & & & 6 & 0.787 & & 0.920 & 0.892 & 0.859 & 0.785 & 0.669 \\
\hline \multirow{4}{*}{10} & \multirow{4}{*}{2.5} & \multirow{4}{*}{0.2} & \multirow{4}{*}{4} & 3 & 1.174 & & & & & 0.997 & 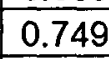 \\
\hline & & & & 4 & 1.166 & & & & 1.073 & 0.926 & 0.565 \\
\hline & & & & 5 & 1.169 & & & 1.113 & 1.022 & 0.874 & 0.604 \\
\hline & & & & 6 & 1.180 & & 1.140 & 1.075 & 0.975 & 0.822 & 0.558 \\
\hline \multirow{4}{*}{10} & & & & 3 & 1.114 & & & & & 0.962 & 0.755 \\
\hline & 25 & 02 & $6^{*}$ & 4 & 1.103 & & & & 1.029 & 0.912 & 0.727 \\
\hline & & & & 5 & 1.088 & & & 1.057 & 0.996 & 0.875 & 0.681 \\
\hline & & & & 6 & 1.079 & & 1.071 & 1.042 & 0.971 & 0.837 & 0.630 \\
\hline & & & & 3 & 1.012 & & & & & 0.867 & 0.685 \\
\hline 10 & 25 & $0 ?$ & 9 & 4 & 0.997 & & & & 0.917 & 0.807 & 0.653 \\
\hline & & & & 5 & 0.742 & & & 0.943 & 0.630 & 0.771 & 0.616 \\
\hline & & & & 6 & 0.984 & & 0.958 & 0.919 & 0.849 & 0.736 & 0.573 \\
\hline & & & & 3 & 0.781 & & & & & 1.096 & 0.647 \\
\hline 10 & 2.5 & 0.3 & 4 & 4 & 1.392 & & & & 1.219 & 0.979 & 0.594 \\
\hline & & & & 5 & 1.412 & & & 1.287 & 1.123 & 0.894 & 0.535 \\
\hline & & & & 6 & 1.451 & & 1.340 & 1.204 & 1.038 & 0.816 & 0.478 \\
\hline & & & & 3 & 1.256 & & & & & 1.023 & 0.695 \\
\hline 10 & 25 & 0.3 & $6^{*}$ & 4 & 1.235 & & & & 1.113 & 0.933 & 0.650 \\
\hline & & & & 5 & 1.226 & & & 1.156 & 1.051 & 0.875 & 0.592 \\
\hline & & & & 6 & 1.267 & & 1.217 & 1.146 & 1.030 & 0.842 & 0.545 \\
\hline
\end{tabular}

\begin{tabular}{|c|c|c|c|c|c|c|c|c|c|c|c|}
\hline \multicolumn{5}{|c|}{ Bridge Dimensions } & \multirow{2}{*}{\multicolumn{7}{|c|}{ Mom. Dist. Factor : $D_{M}$}} \\
\hline $\begin{array}{l}\text { Span } \\
(\mathrm{m})\end{array}$ & $\begin{array}{l}\text { Girder } \\
\text { Spacing } \\
(\mathrm{m})\end{array}$ & $\begin{array}{l}\text { Span } \\
\text { Radius } \\
\text { Ratio }\end{array}$ & $\begin{array}{l}\text { No. of } \\
\text { Bracing } \\
\text { Intervals }\end{array}$ & $\begin{array}{l}\text { No. of } \\
\text { Girders }\end{array}$ & & & & & & & \\
\hline $\mathrm{L}$ & $\mathrm{s}$ & $L / R$ & & $\mathrm{~N}$ & $G_{\text {Ext }}$ & $\mathbf{G}_{5}$ & $\mathbf{G}_{4}$ & $\mathbf{G}_{3}$ & $\mathbf{G}_{2}$ & $\mathbf{G}_{1}$ & $\mathbf{G}_{\operatorname{lnt}}$ \\
\hline \multirow{4}{*}{10} & \multirow{4}{*}{2.5} & \multirow{4}{*}{0.3} & \multirow{4}{*}{9} & 3 & 1.116 & & & & & 0.905 & 0.614 \\
\hline & & & & 4 & 1.097 & & & & 0.980 & 0.816 & 0.575 \\
\hline & & & & 5 & 1.091 & & & 1.019 & 0.917 & 0.761 & 0.525 \\
\hline & & & & 6 & 1.096 & & 1.044 & 0.974 & 0.870 & 0.712 & 0.471 \\
\hline \multirow{3}{*}{10} & \multirow{3}{*}{3} & \multirow{3}{*}{0.1} & \multirow{3}{*}{2} & 3 & 1.286 & & & & & 1.203 & 1.019 \\
\hline & & & & 4 & 1.258 & & & & 1.249 & 1.155 & 0.947 \\
\hline & & & & 5 & 1.243 & & & 1.264 & 1.226 & 1.104 & 0.881 \\
\hline \multirow{3}{*}{10} & \multirow{3}{*}{3} & \multirow{3}{*}{0.1} & \multirow{3}{*}{$4^{*}$} & 3 & 1.051 & & & & & 0.986 & 0.853 \\
\hline & & & & 4 & 1.029 & & & & 1.035 & 0.966 & 0.724 \\
\hline & & & & 5 & 1.003 & & & 1.051 & 1.041 & 0.941 & 0.675 \\
\hline \multirow{3}{*}{10} & \multirow{3}{*}{3} & \multirow{3}{*}{0.1} & \multirow{3}{*}{6} & 3 & 0.900 & & & & & 0.847 & 0.744 \\
\hline & & & & 4 & 0.879 & & & & 0.876 & 0.825 & 0.710 \\
\hline & & & & 5 & 0.858 & & & 0.887 & 0.876 & 0.805 & 0.668 \\
\hline \multirow{3}{*}{10} & \multirow{3}{*}{3} & \multirow{3}{*}{0.2} & \multirow{3}{*}{4} & 3 & 6.431 & & & & & 0.832 & 0.738 \\
\hline & & & & 4 & 1.145 & & & & 1.074 & 0.928 & 0.623 \\
\hline & & & & 5 & 1.147 & & & 1.113 & 1.029 & 0.870 & 0.565 \\
\hline \multirow{3}{*}{10} & \multirow{3}{*}{3} & \multirow{3}{*}{0.2} & \multirow{3}{*}{$6^{*}$} & 3 & 1.099 & & & & & 0.968 & 0.756 \\
\hline & & & & 4 & 1.080 & & & & 1.033 & 0.922 & 0.707 \\
\hline & & & & 5 & 1.062 & & & 1.060 & 1.015 & 0.883 & 0.644 \\
\hline & & & & 3 & 0.988 & & & & & 0.859 & 0.676 \\
\hline 10 & 3 & 0.2 & 9 & 4 & 0.975 & & & & 0.912 & 0.807 & 0.634 \\
\hline & & & & 5 & 0.966 & & & 0.939 & 0.884 & 0.770 & 0.583 \\
\hline & & & & 3 & 1.368 & & & & & 0.854 & 0.499 \\
\hline 10 & 3 & 0.3 & 4 & 4 & 1.371 & & & & 1.220 & 0.983 & 0.566 \\
\hline & & & & 5 & 1.401 & & & 1.290 & \begin{tabular}{|l|l|}
1.128 \\
\end{tabular} & 0.889 & 0.492 \\
\hline & & & & 3 & 1.226 & & & & & 1.023 & 0.694 \\
\hline 10 & 3 & 0.3 & $6^{*}$ & 4 & 1.209 & & & & 1.117 & 0.945 & 0.629 \\
\hline & & & & 5 & 1.205 & & & 1.159 & 1.068 & 0.884 & 0.428 \\
\hline & & & & 3 & 1.084 & & & & & 0.897 & 0.611 \\
\hline 10 & 3 & 0.3 & 9 & 4 & 1.072 & & & & 0.975 & 0.819 & 0.555 \\
\hline & & & & 5 & 1.070 & & & 1.015 & 0.924 & 0.763 & 0.489 \\
\hline
\end{tabular}




\begin{tabular}{|c|c|c|c|c|c|c|c|c|c|c|c|}
\hline \multicolumn{5}{|c|}{ Bridge Dimensions } & \multirow{2}{*}{\multicolumn{7}{|c|}{ Mom. Dist. Factor : $D_{M}$}} \\
\hline $\begin{array}{l}\text { Span } \\
(m)\end{array}$ & $\begin{array}{c}\text { Girder } \\
\text { Spacing } \\
(\mathrm{m})\end{array}$ & $\begin{array}{c}\text { Span } \\
\text { Radius } \\
\text { Ratio }\end{array}$ & $\begin{array}{l}\text { No. of } \\
\text { Bracing } \\
\text { Intervals }\end{array}$ & $\begin{array}{l}\text { No. of } \\
\text { Girders }\end{array}$ & & & & & & & \\
\hline L & $s$ & $L / R$ & & $\mathrm{~N}$ & $G_{\text {Ext }}$ & $\mathrm{G}_{5}$ & $\mathrm{G}_{4}$ & $\mathbf{G}_{3}$ & $\mathbf{G}_{2}$ & $\mathbf{G}_{1}$ & $\mathbf{G}_{\text {lnt }}$ \\
\hline \multirow{5}{*}{10} & \multirow{5}{*}{2} & \multirow{5}{*}{0.3} & \multirow{5}{*}{9} & 3 & 1.165 & & & & & 0.876 & 0.609 \\
\hline & & & & 4 & 1.133 & & & & 0.994 & 0.818 & 0.586 \\
\hline & & & & 5 & 1.043 & & & 0.980 & 0.912 & 0.764 & 0.562 \\
\hline & & & & 6 & 1.119 & & 1.053 & 0.972 & 0.865 & 0.718 & 0.515 \\
\hline & & & & 7 & 1.167 & 1.116 & 1.056 & 0.978 & 0.869 & 0.715 & 0.502 \\
\hline \multirow{4}{*}{10} & \multirow{4}{*}{2.5} & \multirow{4}{*}{0.1} & \multirow{4}{*}{2} & 3 & 1.322 & & & & & 1.215 & 1.047 \\
\hline & & & & 4 & 1.299 & & & & 1.259 & 1.164 & 0.995 \\
\hline & & & & 5 & 1.283 & & & 1.276 & 1.231 & 1.121 & 0.940 \\
\hline & & & & 6 & 1.281 & & 1.285 & 1.261 & 1.197 & 1.077 & 0.891 \\
\hline \multirow{4}{*}{10} & \multirow{4}{*}{2.5} & \multirow{4}{*}{0.1} & \multirow{4}{*}{$4^{*}$} & 3 & 0.993 & & & & & 0.914 & 0.800 \\
\hline & & & & 4 & 1.053 & & & & 1.027 & 0.957 & 0.831 \\
\hline & & & & 5 & 1.034 & & & 1.047 & 1.022 & 0.934 & 0.711 \\
\hline & & & & 6 & 1.018 & & 1.051 & 1.056 & 1.010 & 0.903 & 0.692 \\
\hline \multirow{4}{*}{10} & \multirow{4}{*}{2.5} & \multirow{4}{*}{0.1} & \multirow{4}{*}{6} & 3 & 0.918 & & & & & 0.852 & 0.754 \\
\hline & & & & 4 & 0.891 & & & & 0.865 & 0.812 & 0.721 \\
\hline & & & & 5 & 0.885 & & & 0.889 & 0.867 & 0.805 & 0.700 \\
\hline & & & & 6 & 0.787 & & 0.920 & 0.892 & 0.859 & 0.785 & 0.669 \\
\hline \multirow{4}{*}{10} & \multirow{4}{*}{2.5} & \multirow{4}{*}{0.2} & \multirow{4}{*}{4} & 3 & 1.174 & & & & & 0.997 & 0.749 \\
\hline & & & & 4 & 1.166 & & & & 1.073 & 0.926 & 0.565 \\
\hline & & & & 5 & 1.169 & & & 1.113 & 1.022 & 0.874 & 0.604 \\
\hline & & & & 6 & 1.180 & & 1.140 & 1.075 & 0.975 & 0.822 & 0.558 \\
\hline \multirow{4}{*}{10} & & & & 3 & 1.114 & & & & & 0.962 & 0.755 \\
\hline & 25 & 02 & $6^{*}$ & 4 & 1.103 & & & & 1.029 & 0.912 & 0.727 \\
\hline & & & & 5 & 1.088 & & & 1.057 & 0.996 & 0.875 & 0.681 \\
\hline & & & & 6 & 1.079 & & 1.071 & 1.042 & 0.971 & 0.837 & 0.630 \\
\hline & & & & 3 & 1.012 & & & & & 0.867 & 0.685 \\
\hline 10 & 25 & $0 ?$ & 0 & 4 & 0.997 & & & & 0.917 & 0.807 & 0.653 \\
\hline & & & & 5 & 0.742 & & & 0.943 & 0.630 & 0.771 & 0.616 \\
\hline & & & & 6 & 0.984 & & 0.958 & 0.919 & 0.849 & 0.736 & 0.573 \\
\hline & & & & 3 & 0.781 & & & & & 1.096 & 0.647 \\
\hline 10 & 2.5 & 0.3 & 4 & 4 & 1.392 & & & & 1.219 & 0.979 & 0.594 \\
\hline & & & & 5 & 1.412 & & & 1.287 & 1.123 & 0.894 & 0.535 \\
\hline & & & & 6 & 1.451 & & 1.340 & 1.204 & 1.038 & 0.816 & 0.478 \\
\hline & & & & 3 & 1.256 & & & & & 1.023 & 0.695 \\
\hline 10 & 25 & 0.3 & $\sigma^{*}$ & 4 & 1.235 & & & & 1.113 & 0.933 & 0.650 \\
\hline & & & & 5 & 1.226 & & & 1.156 & 1.051 & 0.875 & 0.592 \\
\hline & & & & 6 & 1.267 & & 1.217 & 1.146 & 1.030 & 0.842 & 0.545 \\
\hline
\end{tabular}

\begin{tabular}{|c|c|c|c|c|c|c|c|c|c|c|c|}
\hline \multicolumn{5}{|c|}{ Bridge Dimensions } & \multirow{2}{*}{\multicolumn{7}{|c|}{ Mom. Dist. Factor : $D_{M}$}} \\
\hline $\begin{array}{l}\text { Span } \\
(\mathrm{m})\end{array}$ & $\begin{array}{l}\text { Girder } \\
\text { Spacing }\end{array}$ & $\begin{array}{c}\text { Span } \\
\text { Radius }\end{array}$ & $\begin{array}{l}\text { No. of } \\
\text { Bracing }\end{array}$ & $\begin{array}{l}\text { No. of } \\
\text { Girders }\end{array}$ & & & & & & & \\
\hline L & $s$ & $L / R$ & & N & $G_{\text {Ext }}$ & $\mathrm{G}_{5}$ & $G_{4}$ & $\mathbf{G}_{3}$ & $\mathrm{G}_{2}$ & $\mathbf{G}_{1}$ & $G_{\operatorname{lnt}}$ \\
\hline \multirow{4}{*}{10} & \multirow{4}{*}{2.5} & \multirow{4}{*}{0.3} & \multirow{4}{*}{9} & 3 & 1.116 & & & & & 0.905 & 0.614 \\
\hline & & & & 4 & 1.097 & & & & 0.980 & 0.816 & 0.575 \\
\hline & & & & 5 & 1.091 & & & 1.019 & 0.917 & 0.761 & 0.525 \\
\hline & & & & 6 & 1.096 & & 1.044 & 0.974 & 0.870 & 0.712 & 0.471 \\
\hline \multirow{3}{*}{10} & \multirow{3}{*}{3} & \multirow{3}{*}{0.1} & \multirow{3}{*}{2} & 3 & 1.286 & & & & & 1.203 & 1.019 \\
\hline & & & & 4 & 1.258 & & & & 1.249 & 1.155 & 0.947 \\
\hline & & & & 5 & 1.243 & & & 1.264 & 1.226 & 1.104 & 0.881 \\
\hline \multirow{3}{*}{10} & \multirow{3}{*}{3} & \multirow{3}{*}{0.1} & \multirow{3}{*}{$4^{*}$} & 3 & 1.051 & & & & & 0.986 & 0.853 \\
\hline & & & & 4 & 1.029 & & & & 1.035 & 0.966 & 0.724 \\
\hline & & & & 5 & 1.003 & & & 1.051 & 1.041 & 0.941 & 0.675 \\
\hline \multirow{3}{*}{10} & \multirow{3}{*}{3} & \multirow{3}{*}{0.1} & \multirow{3}{*}{6} & 3 & 0.900 & & & & & 0.847 & 0.744 \\
\hline & & & & 4 & 0.879 & & & & 0.876 & 0.825 & 0.710 \\
\hline & & & & 5 & 0.858 & & & 0.887 & 0.876 & 0.805 & 0.668 \\
\hline \multirow{3}{*}{10} & \multirow{3}{*}{3} & \multirow{3}{*}{0.2} & \multirow{3}{*}{4} & 3 & 6.431 & & & & & 0.832 & 0.738 \\
\hline & & & & 4 & 1.145 & & & & 1.074 & 0.928 & 0.623 \\
\hline & & & & 5 & 1.147 & & & 1.113 & 1.029 & 0.870 & 0.565 \\
\hline \multirow{3}{*}{10} & \multirow{3}{*}{3} & \multirow{3}{*}{0.2} & \multirow{3}{*}{$6^{\star}$} & 3 & 1.099 & & & & & 0.968 & 0.756 \\
\hline & & & & 4 & 1.080 & & & & 1.033 & 0.922 & 0.707 \\
\hline & & & & 5 & 1.062 & & & 1.060 & 1.015 & 0.883 & 0.644 \\
\hline & & & & 3 & 0.988 & & & & & 0.859 & 0.676 \\
\hline 10 & 3 & 0.2 & 9 & 4 & 0.975 & & & & 0.912 & 0.807 & 0.634 \\
\hline & & & & 5 & 0.966 & & & 0.939 & 0.884 & 0.770 & 0.583 \\
\hline & & & & 3 & 1.368 & & & & & 0.854 & 0.499 \\
\hline 10 & 3 & 0.3 & 4 & 4 & 1.371 & & & & 1.220 & 0.983 & 0.566 \\
\hline & & & & 5 & 1.401 & & & 1.290 & 1.128 & 0.889 & 0.492 \\
\hline & & & & 3 & 1.226 & & & & & 1.023 & 0.694 \\
\hline 10 & 3 & 0.3 & $6^{*}$ & 4 & 1.209 & & & & 1.117 & 0.945 & 0.629 \\
\hline & & & & 5 & 1.205 & & & 1.159 & 1.068 & 0.884 & 0.428 \\
\hline & & & & 3 & 1.084 & & & & & 0.897 & 0.611 \\
\hline 10 & 3 & 0.3 & 9 & 4 & 1.072 & & & & 0.975 & 0.819 & 0.555 \\
\hline & & & & 5 & 1.070 & & & 1.015 & 0.924 & 0.763 & 0.489 \\
\hline
\end{tabular}




\begin{tabular}{|c|c|c|c|c|c|c|c|c|c|c|c|}
\hline \multicolumn{5}{|c|}{ Bridge Dimensions } & \multirow{2}{*}{\multicolumn{7}{|c|}{ Mom. Dist. Factor : $D_{M}$}} \\
\hline $\begin{array}{c}\text { Span } \\
(\mathrm{m})\end{array}$ & $\begin{array}{l}\text { Girder } \\
\text { Spacing }\end{array}$ & $\begin{array}{c}\text { Span } \\
\text { Radius } \\
\text { Ratio }\end{array}$ & $\begin{array}{l}\text { No of } \\
\text { Bracing }\end{array}$ & $\begin{array}{l}\text { No. of } \\
\text { Girders }\end{array}$ & & & & & & & \\
\hline L & & $L / R$ & & $\mathrm{~N}$ & $G_{\text {Ext }}$ & $\mathrm{G}_{5}$ & $\mathrm{G}_{4}$ & $\mathbf{G}_{3}$ & $\mathbf{G}_{2}$ & $\mathrm{G}_{1}$ & $G_{\text {Int }}$ \\
\hline \multirow{5}{*}{15} & \multirow{5}{*}{2} & \multirow{5}{*}{0.1} & \multirow{5}{*}{$4^{\star}$} & 3 & 1.241 & & & & & 1.085 & 0.922 \\
\hline & & & & 4 & 1.222 & & & & 1.133 & 1.036 & 0.931 \\
\hline & & & & 5 & 1.211 & & & 1.153 & 1.089 & 1.014 & 0.928 \\
\hline & & & & 6 & 1.202 & & 1.163 & 1.120 & 1.066 & 0.997 & 0.917 \\
\hline & & & & 7 & 1.194 & 1.169 & 1.140 & 1.102 & 1.049 & 0.981 & 0.666 \\
\hline \multirow{5}{*}{15} & \multirow{5}{*}{2} & \multirow{5}{*}{0.1} & \multirow{5}{*}{6} & 3 & 1.063 & & & & & 0.908 & 0.780 \\
\hline & & & & 4 & 1.046 & & & & 0.905 & 0.833 & 0.752 \\
\hline & & & & 5 & 1.041 & & & 0.995 & 0.942 & 0.879 & 0.806 \\
\hline & & & & 6 & 1.024 & & 0.997 & 0.961 & 0.918 & 0.862 & 0.713 \\
\hline & & & & 7 & 1.025 & 1.005 & 0.979 & 0.945 & 0.902 & 0.848 & 0.784 \\
\hline \multirow{5}{*}{15} & \multirow{5}{*}{2} & \multirow{5}{*}{0.1} & \multirow{5}{*}{8} & 3 & 1.030 & & & & & 0.909 & 0.789 \\
\hline & & & & 4 & 1.007 & & & & 0.938 & 0.864 & 0.791 \\
\hline & & & & 5 & 1.008 & & & 0.949 & 0.900 & 0.844 & 0.789 \\
\hline & & & & 6 & 1.009 & & 0.977 & 0.921 & 0.880 & 0.831 & 0.782 \\
\hline & & & & 7 & 1.003 & 0.982 & 0.956 & 0.905 & 0.867 & 0.820 & 0.772 \\
\hline \multirow{5}{*}{15} & \multirow{5}{*}{2} & \multirow{5}{*}{0.2} & \multirow{5}{*}{4} & 3 & 1.499 & & & & & 1.178 & 0.819 \\
\hline & & & & 4 & 1.467 & & & & 1.281 & 1.074 & 0.837 \\
\hline & & & & 5 & 1.448 & & & 1.353 & 1.189 & 1.031 & 0.846 \\
\hline & & & & 6 & 1.448 & & 1.352 & 1.247 & 1.130 & 0.991 & 0.826 \\
\hline & & & & 7 & 1.451 & 1.372 & 1.287 & 1.193 & 1.084 & 0.954 & 0.799 \\
\hline \multirow{5}{*}{15} & \multirow{5}{*}{2} & \multirow{5}{*}{0.2} & \multirow{5}{*}{$6^{*}$} & 3 & 1.342 & & & & & 1.024 & 0.740 \\
\hline & & & & 4 & 1.313 & & & & 1.149 & 0.969 & 0.748 \\
\hline & & & & 5 & 1.278 & & & 1.138 & 1.069 & 0.942 & 0.795 \\
\hline & & & & 6 & 1.280 & & 1.204 & \begin{tabular}{|l}
1.121 \\
\end{tabular} & 1.025 & 0.910 & 0.775 \\
\hline & & & & 7 & 1.283 & 1.223 & 1.158 & 1.083 & 0.991 & 0.879 & 0.747 \\
\hline & & & & 3 & 1.176 & & & & & 0.942 & 0.686 \\
\hline & & & & 4 & 1.135 & & & & 1.003 & 0.855 & 0.692 \\
\hline 15 & 2 & 0.2 & 8 & 5 & 1.140 & & & 1.069 & 0.930 & 0.819 & 0.696 \\
\hline & & & & 6 & 1.133 & & 1.066 & 0.969 & 0.888 & 0.792 & 0.684 \\
\hline & & & & 7 & 1.130 & 1.079 & 1.021 & 0.785 & 0.857 & 0.767 & 0.660 \\
\hline & & & & 3 & 1.475 & & & & & 1.035 & 0.604 \\
\hline & & & & 4 & 1.397 & & & & 1.186 & 0.927 & 0.621 \\
\hline 15 & 2 & 0.3 & 6 & 5 & 1.415 & & & 1.258 & 1.078 & 0.866 & 0.606 \\
\hline & & & & 6 & 1.409 & & 1.292 & 1.158 & 1.005 & 0.822 & 0.591 \\
\hline & & & & 7 & 1.412 & 1.317 & 0.890 & 1.090 & 0.951 & 0.784 & 0.570 \\
\hline & & & & 3 & 1.426 & & & & & 1.055 & 0.624 \\
\hline & & & & 4 & 1.344 & & & & 1.159 & 0.923 & 0.648 \\
\hline 15 & 2 & 0.3 & $8^{*}$ & 5 & 1.373 & & & 1.197 & 1.042 & 0.858 & 0.637 \\
\hline & & & & 6 & 1.362 & & 1.256 & 1.108 & 0.978 & 0.819 & 0.626 \\
\hline & & & & 7 & 1.355 & 1.274 & 1.183 & 1.051 & 0.933 & 0.786 & 0.606 \\
\hline
\end{tabular}

\begin{tabular}{|c|c|c|c|c|c|c|c|c|c|c|c|}
\hline \multicolumn{5}{|c|}{ Bridge Dimensions } & \multirow{2}{*}{\multicolumn{7}{|c|}{ Mom. Dist. Factor : $D_{M}$}} \\
\hline $\begin{array}{c}\text { Span } \\
(\mathrm{m})\end{array}$ & $\begin{array}{l}\text { Girder } \\
\text { Spacing } \\
(\mathrm{m})\end{array}$ & $\begin{array}{l}\text { Span } \\
\text { Radius } \\
\text { Ratio }\end{array}$ & $\begin{array}{l}\text { No. of } \\
\text { Bracing } \\
\text { Intervals }\end{array}$ & $\begin{array}{l}\text { No. of } \\
\text { Girders }\end{array}$ & & & & & & & \\
\hline $\mathrm{L}$ & $\mathrm{s}$ & $L / R$ & & $\mathrm{~N}$ & $G_{\text {Ext }}$ & $\mathbf{G}_{5}$ & $\mathbf{G}_{4}$ & $\mathbf{G}_{3}$ & $\mathbf{G}_{2}$ & $\mathbf{G}_{1}$ & $G_{\text {Int }}$ \\
\hline \multirow{5}{*}{15} & \multirow{5}{*}{2} & \multirow{5}{*}{0.3} & \multirow{5}{*}{12} & 3 & 1.315 & & & & & 0.977 & 0.576 \\
\hline & & & & 4 & 1.245 & & & & 1.063 & 0.849 & 0.592 \\
\hline & & & & 5 & 1.223 & & & 1.103 & 0.962 & 0.792 & 0.588 \\
\hline & & & & 6 & 1.206 & & 1.121 & 1.021 & 0.901 & 0.755 & 0.577 \\
\hline & & & & 7 & 1.198 & 1.134 & 1.058 & 0.968 & 0.858 & 0.725 & 0.560 \\
\hline \multirow{4}{*}{15} & \multirow{4}{*}{2.5} & \multirow{4}{*}{0.1} & \multirow{4}{*}{$4^{*}$} & 3 & 1.210 & & & & & 1.078 & 0.935 \\
\hline & & & & 4 & 1.195 & & & & 1.121 & 1.034 & 0.931 \\
\hline & & & & 5 & 1.183 & & & 1.141 & 1.088 & 1.012 & 0.915 \\
\hline & & & & 6 & 1.172 & & 1.151 & 1.121 & 1.070 & 0.991 & 0.892 \\
\hline \multirow{4}{*}{15} & \multirow{4}{*}{2.5} & \multirow{4}{*}{0.1} & \multirow{4}{*}{6} & 3 & 1.035 & & & & & 0.930 & 0.782 \\
\hline & & & & 4 & 0.942 & & & & 0.933 & 0.827 & 0.735 \\
\hline & & & & 5 & 1.013 & & & 0.980 & 0.934 & 0.871 & 0.792 \\
\hline & & & & 6 & 1.006 & & 0.981 & 0.959 & 0.916 & 0.854 & 0.775 \\
\hline \multirow{4}{*}{15} & \multirow{4}{*}{2.5} & \multirow{4}{*}{0.1} & \multirow{4}{*}{8} & 3 & 1.000 & & & & & 0.898 & 0.795 \\
\hline & & & & 4 & 0.984 & & & & 0.925 & 0.859 & 0.791 \\
\hline & & & & 5 & 0.996 & & & 0.959 & 0.896 & 0.841 & 0.781 \\
\hline & & & & 6 & 0.989 & & 0.968 & 0.940 & 0.881 & 0.827 & 0.767 \\
\hline \multirow{4}{*}{15} & \multirow{4}{*}{2.5} & \multirow{4}{*}{0.2} & \multirow{4}{*}{4} & 3 & 1.198 & & & & & 0.984 & 0.736 \\
\hline & & & & 4 & 1.421 & & & & 1.262 & 1.074 & 0.846 \\
\hline & & & & 5 & 1.408 & & & 1.305 & 1.182 & 1.029 & 0.835 \\
\hline & & & & 6 & 1.416 & & 1.335 & 1.268 & 1.127 & 0.982 & 0.798 \\
\hline \multirow{4}{*}{15} & \multirow{4}{*}{2.5} & & & 3 & 1.297 & & & & & 1.055 & 1.026 \\
\hline & & 0.2 & $6^{*}$ & 4 & 1.278 & & & & 1.138 & 0.977 & 0.786 \\
\hline & & & & 5 & 1.244 & & & 1.165 & 1.071 & 0.950 & 0.798 \\
\hline & & & & 6 & 1.251 & & 1.193 & 1.083 & 1.034 & 0.912 & 0.759 \\
\hline & & & & 3 & 1.124 & & & & & 0.928 & 0.705 \\
\hline 15 & 2.5 & 0.2 & 8 & 4 & 1.121 & & & & 0.984 & 0.852 & 0.693 \\
\hline & & & & 5 & 1.108 & & & 1.035 & 0.925 & 0.819 & 0.693 \\
\hline & & & & 6 & 1.110 & & 1.059 & 0.975 & 0.888 & 0.789 & 0.668 \\
\hline & & & & 3 & 1.410 & & & & & 0.869 & 0.636 \\
\hline 15 & 2.5 & 0.3 & 6 & 4 & 1.384 & & & & 1.185 & 0.941 & 0.626 \\
\hline & & & & 5 & 1.377 & & & 1.242 & 1.078 & 0.875 & 0.603 \\
\hline & & & & 6 & 1.381 & & 1.278 & 1.156 & 1.009 & 0.823 & 0.572 \\
\hline 15 & & & & 3 & 1.353 & & & & & 1.041 & 0.661 \\
\hline 15 & 2.5 & 0.3 & $8^{*}$ & $\frac{4}{5}$ & $\frac{1.352}{1.338}$ & & & 1.214 & $\frac{1.137}{1042}$ & $\frac{0.925}{0.867}$ & $\frac{0.660}{0.610}$ \\
\hline & & & & 6 & 1.331 & & 1.244 & 1.140 & 0.986 & 0.825 & 0.613 \\
\hline
\end{tabular}




\begin{tabular}{|c|c|c|c|c|c|c|c|c|c|c|c|}
\hline \multicolumn{5}{|c|}{ Bridge Dimensions } & \multirow{2}{*}{\multicolumn{7}{|c|}{ Mom. Dist. Factor : $D_{M}$}} \\
\hline $\begin{array}{c}\text { Span } \\
(\mathrm{m})\end{array}$ & $\begin{array}{l}\text { Girder } \\
\text { Spacing }\end{array}$ & $\begin{array}{c}\text { Span } \\
\text { Radius } \\
\text { Ratio }\end{array}$ & $\begin{array}{l}\text { No of } \\
\text { Bracing }\end{array}$ & $\begin{array}{l}\text { No. of } \\
\text { Girders }\end{array}$ & & & & & & & \\
\hline L & & $L / R$ & & $\mathrm{~N}$ & $G_{\text {Ext }}$ & $\mathbf{G}_{5}$ & $G_{4}$ & $\mathbf{G}_{3}$ & $\mathbf{G}_{2}$ & $\mathrm{G}_{1}$ & $G_{\text {Int }}$ \\
\hline \multirow{5}{*}{15} & \multirow{5}{*}{2} & \multirow{5}{*}{0.1} & \multirow{5}{*}{$4^{\star}$} & 3 & 1.241 & & & & & 1.085 & 0.922 \\
\hline & & & & 4 & 1.222 & & & & 1.133 & 1.036 & 0.931 \\
\hline & & & & 5 & 1.211 & & & 1.153 & 1.089 & 1.014 & 0.928 \\
\hline & & & & 6 & 1.202 & & 1.163 & 1.120 & 1.066 & 0.997 & 0.917 \\
\hline & & & & 7 & 1.194 & 1.169 & 1.140 & 1.102 & 1.049 & 0.981 & 0.666 \\
\hline \multirow{5}{*}{15} & \multirow{5}{*}{2} & \multirow{5}{*}{0.1} & \multirow{5}{*}{6} & 3 & 1.063 & & & & & 0.908 & 0.780 \\
\hline & & & & 4 & 1.046 & & & & 0.905 & 0.833 & 0.752 \\
\hline & & & & 5 & 1.041 & & & 0.995 & 0.942 & 0.879 & 0.806 \\
\hline & & & & 6 & 1.024 & & 0.997 & 0.961 & 0.918 & 0.862 & 0.713 \\
\hline & & & & 7 & 1.025 & 1.005 & 0.979 & 0.945 & 0.902 & 0.848 & 0.784 \\
\hline \multirow{5}{*}{15} & \multirow{5}{*}{2} & \multirow{5}{*}{0.1} & \multirow{5}{*}{8} & 3 & 1.030 & & & & & 0.909 & 0.789 \\
\hline & & & & 4 & 1.007 & & & & 0.938 & 0.864 & 0.791 \\
\hline & & & & 5 & 1.008 & & & 0.949 & 0.900 & 0.844 & 0.789 \\
\hline & & & & 6 & 1.009 & & 0.977 & 0.921 & 0.880 & 0.831 & 0.782 \\
\hline & & & & 7 & 1.003 & 0.982 & 0.956 & 0.905 & 0.867 & 0.820 & 0.772 \\
\hline \multirow{5}{*}{15} & \multirow{5}{*}{2} & \multirow{5}{*}{0.2} & \multirow{5}{*}{4} & 3 & 1.499 & & & & & 1.178 & 0.819 \\
\hline & & & & 4 & 1.467 & & & & 1.281 & 1.074 & 0.837 \\
\hline & & & & 5 & 1.448 & & & 1.353 & 1.189 & 1.031 & 0.846 \\
\hline & & & & 6 & 1.448 & & 1.352 & 1.247 & 1.130 & 0.991 & 0.826 \\
\hline & & & & 7 & 1.451 & 1.372 & 1.287 & 1.193 & 1.084 & 0.954 & 0.799 \\
\hline \multirow{5}{*}{15} & \multirow{5}{*}{2} & \multirow{5}{*}{0.2} & \multirow{5}{*}{$6^{*}$} & 3 & 1.342 & & & & & 1.024 & 0.740 \\
\hline & & & & 4 & 1.313 & & & & 1.149 & 0.969 & 0.748 \\
\hline & & & & 5 & 1.278 & & & 1.138 & 1.069 & 0.942 & 0.795 \\
\hline & & & & 6 & 1.280 & & 1.204 & 1.121 & 1.025 & 0.910 & 0.775 \\
\hline & & & & 7 & 1.283 & 1.223 & 1.158 & 1.083 & 0.991 & 0.879 & 0.747 \\
\hline & & & & 3 & 1.176 & & & & & 0.942 & 0.686 \\
\hline & & & & 4 & 1.135 & & & & 1.003 & 0.855 & 0.692 \\
\hline 15 & 2 & 0.2 & 8 & 5 & 1.140 & & & 1.069 & 0.930 & 0.819 & 0.696 \\
\hline & & & & 6 & 1.133 & & 1.066 & 0.969 & 0.888 & 0.792 & 0.684 \\
\hline & & & & 7 & 1.130 & 1.079 & 1.021 & 0.785 & 0.857 & 0.767 & 0.660 \\
\hline & & & & 3 & 1.475 & & & & & 1.035 & 0.604 \\
\hline & & & & 4 & 1.397 & & & & 1.186 & 0.927 & 0.621 \\
\hline 15 & 2 & 0.3 & 6 & 5 & 1.415 & & & 1.258 & 1.078 & 0.866 & 0.606 \\
\hline & & & & 6 & 1.409 & & 1.292 & 1.158 & 1.005 & 0.822 & 0.591 \\
\hline & & & & 7 & 1.412 & 1.317 & 0.890 & 1.090 & 0.951 & 0.784 & 0.570 \\
\hline & & & & 3 & 1.426 & & & & & 1.055 & 0.624 \\
\hline & & & & 4 & 1.344 & & & & 1.159 & 0.923 & 0.648 \\
\hline 15 & 2 & 0.3 & $8^{*}$ & 5 & 1.373 & & & 1.197 & 1.042 & 0.858 & 0.637 \\
\hline & & & & 6 & 1.362 & & 1.256 & 1.108 & 0.978 & 0.819 & 0.626 \\
\hline & & & & 7 & 1.355 & 1.274 & 1.183 & 1.051 & 0.933 & 0.786 & 0.606 \\
\hline
\end{tabular}

\begin{tabular}{|c|c|c|c|c|c|c|c|c|c|c|c|}
\hline \multicolumn{5}{|c|}{ Bridge Dimensions } & \multirow{2}{*}{\multicolumn{7}{|c|}{ Mom. Dist. Factor : $D_{M}$}} \\
\hline $\begin{array}{l}\text { Span } \\
(\mathrm{m})\end{array}$ & $\begin{array}{c}\text { Girder } \\
\text { Spacing } \\
(m)\end{array}$ & \begin{tabular}{|c|} 
Span \\
Radius \\
Ratio
\end{tabular} & $\begin{array}{l}\text { No. of } \\
\text { Bracing } \\
\text { Intervals }\end{array}$ & $\begin{array}{l}\text { No. of } \\
\text { Girders }\end{array}$ & & & & & & & \\
\hline L & $s$ & $L / R$ & & N & $G_{\text {Ext }}$ & $\mathbf{G}_{5}$ & $\mathbf{G}_{4}$ & $\mathbf{G}_{3}$ & $\mathbf{G}_{2}$ & $\mathbf{G}_{1}$ & $G_{\operatorname{lnt}}$ \\
\hline \multirow{5}{*}{15} & \multirow{5}{*}{2} & \multirow{5}{*}{0.3} & \multirow{5}{*}{12} & 3 & 1.315 & & & & & 0.977 & 0.576 \\
\hline & & & & 4 & 1.245 & & & & 1.063 & 0.849 & 0.592 \\
\hline & & & & 5 & 1.223 & & & 1.103 & 0.962 & 0.792 & 0.588 \\
\hline & & & & 6 & 1.206 & & 1.121 & 1.021 & 0.901 & 0.755 & 0.577 \\
\hline & & & & 7 & 1.198 & 1.134 & 1.058 & 0.968 & 0.858 & 0.725 & 0.560 \\
\hline \multirow{4}{*}{15} & \multirow{4}{*}{2.5} & \multirow{4}{*}{0.1} & \multirow{4}{*}{$4^{*}$} & 3 & 1.210 & & & & & 1.078 & 0.935 \\
\hline & & & & 4 & 1.195 & & & & 1.121 & 1.034 & 0.931 \\
\hline & & & & 5 & 1.183 & & & 1.141 & 1.088 & 1.012 & 0.915 \\
\hline & & & & 6 & 1.172 & & 1.151 & 1.121 & 1.070 & 0.991 & 0.892 \\
\hline \multirow{4}{*}{15} & \multirow{4}{*}{2.5} & \multirow{4}{*}{0.1} & \multirow{4}{*}{6} & 3 & 1.035 & & & & & 0.930 & 0.782 \\
\hline & & & & 4 & 0.942 & & & & 0.933 & 0.827 & 0.735 \\
\hline & & & & 5 & 1.013 & & & 0.980 & 0.934 & 0.871 & 0.792 \\
\hline & & & & 6 & 1.006 & & 0.981 & 0.959 & 0.916 & 0.854 & 0.775 \\
\hline \multirow{4}{*}{15} & \multirow{4}{*}{2.5} & \multirow{4}{*}{0.1} & \multirow{4}{*}{8} & 3 & 1.000 & & & & & 0.898 & 0.795 \\
\hline & & & & 4 & 0.984 & & & & 0.925 & 0.859 & 0.791 \\
\hline & & & & 5 & 0.996 & & & 0.959 & 0.896 & 0.841 & 0.781 \\
\hline & & & & 6 & 0.989 & & 0.968 & 0.940 & 0.881 & 0.827 & 0.767 \\
\hline \multirow{4}{*}{15} & \multirow{4}{*}{2.5} & \multirow{4}{*}{0.2} & \multirow{4}{*}{4} & 3 & 1.198 & & & & & 0.984 & 0.736 \\
\hline & & & & 4 & 1.421 & & & & 1.262 & 1.074 & 0.846 \\
\hline & & & & 5 & 1.408 & & & 1.305 & 1.182 & 1.029 & 0.835 \\
\hline & & & & 6 & 1.416 & & 1.335 & 1.268 & 1.127 & 0.982 & 0.798 \\
\hline \multirow{4}{*}{15} & & & & 3 & 1.297 & & & & & 1.055 & 1.026 \\
\hline & 25 & 02 & $\sigma^{*}$ & 4 & 1.278 & & & & 1.138 & 0.977 & 0.786 \\
\hline & & & & 5 & 1.244 & & & 1.165 & 1.071 & 0.950 & 0.798 \\
\hline & & & & 6 & 1.251 & & 1.193 & 1.083 & 1.034 & 0.912 & 0.759 \\
\hline & & & & 3 & 1.124 & & & & & 0.928 & 0.705 \\
\hline 15 & 2.5 & 0.2 & 8 & 4 & 1.121 & & & & 0.984 & 0.852 & 0.693 \\
\hline & & & & 5 & 1.108 & & & 1.035 & 0.925 & 0.819 & 0.693 \\
\hline & & & & 6 & 1.110 & & 1.059 & 0.975 & 0.888 & 0.789 & 0.668 \\
\hline & & & & 3 & 1.410 & & & & & 0.869 & 0.636 \\
\hline 15 & 2.5 & 0.3 & 6 & 4 & 1.384 & & & & 1.185 & 0.941 & 0.626 \\
\hline & & & & 5 & 1.377 & & & 1.242 & 1.078 & 0.875 & 0.603 \\
\hline & & & & 6 & 1.381 & & 1.278 & 1.156 & 1.009 & 0.823 & 0.572 \\
\hline & & & & 3 & 1.353 & & & & & 1.041 & 0.661 \\
\hline 15 & 2.5 & 0.3 & $8^{*}$ & 4 & 1.352 & & & & 1.137 & 0.925 & 0.660 \\
\hline & & & & 5 & 1.338 & & & 1.214 & 1.042 & 0.867 & 0.642 \\
\hline & & & & 6 & 1.331 & & 1.244 & 1.140 & 0.986 & 0.825 & 0.613 \\
\hline
\end{tabular}




\begin{tabular}{|c|c|c|c|c|c|c|c|c|c|c|c|}
\hline \multicolumn{5}{|c|}{ Bridge Dimensions } & \multirow{2}{*}{\multicolumn{7}{|c|}{ Mom. Dist. Factor : $D_{M}$}} \\
\hline 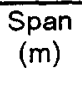 & $\begin{array}{l}\text { Girder } \\
\text { Spacing } \\
\text { (m) }\end{array}$ & $\begin{array}{l}\text { Span } \\
\text { Radius } \\
\text { Ratio }\end{array}$ & $\begin{array}{l}\mathrm{No} \text { o of } \\
\text { Bracing } \\
\text { Intervals }\end{array}$ & $\begin{array}{l}\text { No. of } \\
\text { Girders }\end{array}$ & & & & & & & \\
\hline L & $s$ & $L / R$ & & $\mathrm{~N}$ & $G_{\text {Ext }}$ & $\mathbf{G}_{5}$ & $\mathbf{G}_{4}$ & $\mathbf{G}_{3}$ & $\mathrm{G}_{2}$ & $\mathbf{G}_{1}$ & $G_{\text {Int }}$ \\
\hline \multirow{4}{*}{15} & \multirow{4}{*}{2.5} & \multirow{4}{*}{0.3} & \multirow{4}{*}{12} & 3 & 1.245 & & & & & 0.962 & 0.612 \\
\hline & & & & 4 & 1.203 & & & & 1.048 & 0.854 & 0.609 \\
\hline & & & & 5 & 1.184 & & & 1.084 & 0.959 & 0.799 & 0.593 \\
\hline & & & & 6 & 1.175 & & 1.106 & 1.018 & 0.906 & 0.759 & 0.567 \\
\hline \multirow{3}{*}{15} & \multirow{3}{*}{3} & \multirow{3}{*}{0.1} & \multirow{3}{*}{$4^{*}$} & 3 & 1.187 & & & & & 1.072 & 0.938 \\
\hline & & & & 4 & 1.173 & & & & 1.115 & 1.034 & 0.923 \\
\hline & & & & 5 & 1.158 & & & 1.135 & 1.092 & 1.010 & 0.894 \\
\hline \multirow{3}{*}{15} & \multirow{3}{*}{3} & \multirow{3}{*}{0.1} & \multirow{3}{*}{6} & 3 & 1.015 & & & & & 0.925 & 0.809 \\
\hline & & & & 4 & 0.992 & & & & 0.945 & 0.877 & 0.787 \\
\hline & & & & 5 & 0.994 & & & 0.974 & 0.935 & 0.869 & 0.697 \\
\hline \multirow{3}{*}{15} & \multirow{3}{*}{3} & \multirow{3}{*}{0.1} & \multirow{3}{*}{8} & 3 & 0.980 & & & & & 0.890 & 0.796 \\
\hline & & & & 4 & 0.988 & & & & 0.918 & 0.857 & 0.786 \\
\hline & & & & 5 & 0.980 & & & 0.955 & 0.916 & 0.840 & 0.769 \\
\hline \multirow{3}{*}{15} & \multirow{3}{*}{3} & \multirow{3}{*}{0.2} & \multirow{3}{*}{4} & 3 & 1.402 & & & & & 1.163 & 0.864 \\
\hline & & & & 4 & 1.388 & & & & 1.250 & 1.072 & 0.838 \\
\hline & & & & 5 & 1.379 & & & 1.293 & 1.181 & 1.025 & 0.811 \\
\hline \multirow{3}{*}{15} & \multirow{3}{*}{3} & \multirow{3}{*}{0.2} & \multirow{3}{*}{$6^{*}$} & 3 & 1.268 & & & & & 1.053 & 0.773 \\
\hline & & & & 4 & 1.254 & & & & 1.133 & 0.983 & 0.789 \\
\hline & & & & 5 & 1.219 & & & 1.160 & 1.079 & 0.956 & 0.786 \\
\hline & & & & 3 & 1.090 & & & & & 0.918 & 0.707 \\
\hline 15 & 3 & 0.2 & 8 & 4 & 1.098 & & & & 0.997 & 0.851 & 0.691 \\
\hline & & & & 5 & 1.088 & & & 1.029 & 0.949 & 0.819 & 0.675 \\
\hline & & & & 3 & 1.093 & & & & & 0.873 & 0.557 \\
\hline 15 & 3 & 0.3 & 6 & 4 & 1.352 & & & & 1.176 & 0.947 & 0.625 \\
\hline & & & & 5 & 1.338 & & & 1.218 & 1.066 & 0.865 & 0.579 \\
\hline & & & & 3 & 1.307 & & & & & 1.033 & 0.684 \\
\hline 15 & 3 & 0.3 & $8^{*}$ & 4 & 1.323 & & & & 1.157 & 0.931 & 0.667 \\
\hline & & & & 5 & 1.314 & & & 1.210 & 1.076 & 0.875 & 0.632 \\
\hline & & & & 3 & 1.200 & & & & & 0.954 & 0.632 \\
\hline 15 & 3 & 0.3 & 12 & 4 & 1.172 & & & & 1.037 & 0.858 & 0.615 \\
\hline & & & & 5 & 1.150 & & & 1.065 & 0.952 & 0.795 & 0.578 \\
\hline
\end{tabular}

\begin{tabular}{|c|c|c|c|c|c|c|c|c|c|c|c|}
\hline \multicolumn{5}{|c|}{ Bridge Dimensions } & \multirow{2}{*}{\multicolumn{7}{|c|}{ Mom. Dist. Factor : $\mathrm{D}_{\mathrm{M}}$}} \\
\hline $\begin{array}{l}\begin{array}{c}\text { Span } \\
(\mathrm{m})\end{array} \\
\text { (n) }\end{array}$ & $\begin{array}{l}\text { Girder } \\
\text { Spacing }\end{array}$ & $\begin{array}{l}\text { Span } \\
\text { Radius } \\
\text { Ratio }\end{array}$ & $\begin{array}{l}\text { No. of } \\
\text { Bracing }\end{array}$ & $\begin{array}{l}\text { No. of } \\
\text { Girders }\end{array}$ & & & & & & & \\
\hline L & $s$ & $L / R$ & & N & $G_{\text {Ext }}$ & $\mathbf{G}_{5}$ & $\mathbf{G}_{4}$ & $\mathbf{G}_{3}$ & $\mathbf{G}_{2}$ & $\mathbf{G}_{1}$ & $G_{\operatorname{lnt}}$ \\
\hline \multirow{5}{*}{25} & \multirow{5}{*}{2} & \multirow{5}{*}{0.1} & \multirow{5}{*}{4} & 3 & 1.506 & & & & & 1.241 & 0.967 \\
\hline & & & & 4 & 1.466 & & & & 1.319 & 1.166 & 1.007 \\
\hline & & & & 5 & 1.442 & & & 1.344 & 1.244 & 1.139 & 1.027 \\
\hline & & & & 6 & 1.502 & & 1.427 & 1.350 & 1.269 & 1.183 & 1.091 \\
\hline & & & & 7 & 1.493 & 1.433 & 1.373 & 1.311 & 1.244 & 1.173 & 1.095 \\
\hline \multirow{5}{*}{25} & \multirow{5}{*}{2} & \multirow{5}{*}{0.1} & \multirow{5}{*}{$6^{*}$} & 3 & 1.313 & & & & & 1.081 & 0.843 \\
\hline & & & & 4 & 1.279 & & & & 1.150 & 1.018 & 0.882 \\
\hline & & & & 5 & 1.258 & & & 1.173 & 1.086 & 0.996 & 0.904 \\
\hline & & & & 6 & 1.273 & & 1.210 & 1.145 & 1.078 & 1.008 & 0.934 \\
\hline & & & & 7 & 1.264 & 1.215 & 1.165 & 1.114 & 1.059 & 1.001 & 0.940 \\
\hline \multirow{5}{*}{25} & \multirow{5}{*}{2} & \multirow{5}{*}{0.1} & \multirow{5}{*}{8} & 3 & 1.168 & & & & & 0.973 & 0.771 \\
\hline & & & & 4 & 1.157 & & & & 1.044 & 0.906 & 0.790 \\
\hline & & & & 5 & 1.138 & & & 1.064 & 0.987 & 0.906 & 0.821 \\
\hline & & & & 6 & 1.150 & & 1.095 & 1.038 & 0.978 & 0.915 & 0.848 \\
\hline & & & & 7 & 1.142 & 1.100 & 1.056 & 1.010 & 0.961 & 0.853 & 0.779 \\
\hline \multirow{5}{*}{25} & \multirow{5}{*}{2} & \multirow{5}{*}{0.3} & \multirow{5}{*}{6} & 3 & 2.095 & & & & & 1.298 & 0.433 \\
\hline & & & & 4 & 1.981 & & & & 1.546 & 1.076 & 0.558 \\
\hline & & & & 5 & 1.911 & & & 1.628 & 1.324 & 0.994 & 0.634 \\
\hline & & & & 6 & 1.983 & & 1.761 & 1.528 & 1.278 & 1.007 & 0.710 \\
\hline & & & & 7 & 1.958 & 1.784 & 1.601 & 1.409 & 1.203 & 0.978 & 0.729 \\
\hline \multirow{5}{*}{25} & \multirow{5}{*}{2} & \multirow{5}{*}{0.3} & \multirow{5}{*}{$8^{*}$} & 3 & 1.838 & & & & & 1.150 & \begin{tabular}{|l|l}
0.456 \\
\end{tabular} \\
\hline & & & & 4 & 1.737 & & & & 1.357 & 0.937 & 0.529 \\
\hline & & & & 5 & 1.672 & & & 1.428 & 1.164 & 0.878 & 0.574 \\
\hline & & & & 6 & 1.690 & & 1.507 & 1.311 & 1.101 & 0.871 & 0.613 \\
\hline & & & & 7 & 1.663 & $\begin{array}{l}1.522 \\
\end{array}$ & 1.372 & 1.213 & 1.040 & 0.849 & 0.639 \\
\hline & & & & 3 & 1.631 & & & & & 1.056 & \begin{tabular}{|l}
0.423 \\
\end{tabular} \\
\hline & & & & 4 & 1.507 & & & & 1.198 & 0.859 & 0.486 \\
\hline 25 & 2 & 0.3 & 12 & 5 & 1.436 & & & 1.239 & 1.024 & 0.787 & \begin{tabular}{|l}
0.525 \\
\end{tabular} \\
\hline & & & & 6 & 1.427 & & 1.283 & 1.127 & 0.956 & 0.768 & 0.560 \\
\hline & & & & 7 & 1.398 & 1.289 & 1.171 & 1.042 & 0.901 & 0.746 & 0.572 \\
\hline & & & & 3 & 2.548 & & & & & 1.318 & 0.063 \\
\hline & & & & 4 & 2.356 & & & & 1.684 & 0.933 & 0.153 \\
\hline 25 & 2 & 0.5 & 8 & 5 & 2.235 & & & 1.811 & 1.333 & 0.788 & 0.230 \\
\hline & & & & 6 & 2.292 & & 1.969 & 1.612 & 1.214 & 0.762 & 0.284 \\
\hline & & & & 7 & 2.245 & 1.726 & 1.580 & 1.428 & 1.095 & 0.715 & 0.307 \\
\hline & & & & 3 & 2.264 & & & & & 1.232 & 0.039 \\
\hline & & & & 4 & 2.029 & & & & 1.495 & 0.876 & 0.152 \\
\hline 25 & 2 & 0.5 & $12^{*}$ & 5 & 1.895 & & & 1.566 & 1.186 & 0.745 & 0.228 \\
\hline & & & & 6 & 1.861 & & 1.627 & 1.360 & 1.054 & 0.697 & 0.242 \\
\hline & & & & 7 & 1.803 & 1.630 & 1.435 & 1.213 & 0.956 & 0.657 & 0.302 \\
\hline
\end{tabular}




\begin{tabular}{|c|c|c|c|c|c|c|c|c|c|c|c|}
\hline \multicolumn{5}{|c|}{ Bridge Dimensions } & \multirow{2}{*}{\multicolumn{7}{|c|}{ Mom. Dist. Factor : $D_{M}$}} \\
\hline $\begin{array}{l}\text { Span } \\
(\mathrm{m})\end{array}$ & $\begin{array}{l}\text { Girder } \\
\text { Spacing } \\
\text { (m) }\end{array}$ & $\begin{array}{l}\text { Span } \\
\text { Radius } \\
\text { Ratio }\end{array}$ & $\begin{array}{l}\text { No. of } \\
\text { Bracing } \\
\text { intervals }\end{array}$ & $\begin{array}{l}\text { No. of } \\
\text { Girders }\end{array}$ & & & & & & & \\
\hline L & $s$ & $L / R$ & & $\mathrm{~N}$ & $\mathrm{G}_{\mathrm{Ext}}$ & $\mathrm{G}_{5}$ & $\mathbf{G}_{4}$ & $\mathbf{G}_{3}$ & $\mathrm{G}_{2}$ & $\mathbf{G}_{1}$ & $\mathbf{G}_{\operatorname{lnt}}$ \\
\hline \multirow{4}{*}{15} & \multirow{4}{*}{2.5} & \multirow{4}{*}{0.3} & \multirow{4}{*}{12} & 3 & 1.245 & & & & & 0.962 & 0.612 \\
\hline & & & & 4 & 1.203 & & & & 1.048 & 0.854 & 0.609 \\
\hline & & & & 5 & 1.184 & & & 1.084 & 0.959 & 0.799 & 0.593 \\
\hline & & & & 6 & 1.175 & & 1.106 & 1.018 & 0.906 & 0.759 & 0.567 \\
\hline \multirow{3}{*}{15} & \multirow{3}{*}{3} & \multirow{3}{*}{0.1} & \multirow{3}{*}{$4^{*}$} & 3 & 1.187 & & & & & 1.072 & 0.938 \\
\hline & & & & 4 & 1.173 & & & & 1.115 & 1.034 & 0.923 \\
\hline & & & & 5 & 1.158 & & & 1.135 & 1.092 & 1.010 & 0.894 \\
\hline \multirow{3}{*}{15} & \multirow{3}{*}{3} & \multirow{3}{*}{0.1} & \multirow{3}{*}{6} & 3 & 1.015 & & & & & 0.925 & 0.809 \\
\hline & & & & 4 & 0.992 & & & & 0.945 & 0.877 & 0.787 \\
\hline & & & & 5 & 0.994 & & & 0.974 & 0.935 & 0.869 & 0.697 \\
\hline \multirow{3}{*}{15} & \multirow{3}{*}{3} & \multirow{3}{*}{0.1} & \multirow{3}{*}{8} & 3 & 0.980 & & & & & 0.890 & 0.796 \\
\hline & & & & 4 & 0.988 & & & & 0.918 & 0.857 & 0.786 \\
\hline & & & & 5 & 0.980 & & & 0.955 & 0.916 & 0.840 & 0.769 \\
\hline \multirow{3}{*}{15} & \multirow{3}{*}{3} & \multirow{3}{*}{0.2} & \multirow{3}{*}{4} & 3 & 1.402 & & & & & 1.163 & 0.864 \\
\hline & & & & 4 & 1.388 & & & & 1.250 & 1.072 & 0.838 \\
\hline & & & & 5 & 1.379 & & & 1.293 & 1.181 & 1.025 & 0.811 \\
\hline \multirow{3}{*}{15} & \multirow{3}{*}{3} & \multirow{3}{*}{0.2} & \multirow{3}{*}{$6^{*}$} & 3 & 1.268 & & & & & 1.053 & 0.773 \\
\hline & & & & 4 & 1.254 & & & & 1.133 & 0.983 & 0.789 \\
\hline & & & & 5 & 1.219 & & & 1.160 & 1.079 & 0.956 & 0.786 \\
\hline & & & & 3 & 1.090 & & & & & 0.918 & 0.707 \\
\hline 15 & 3 & 0.2 & 8 & 4 & 1.098 & & & & 0.997 & 0.851 & 0.691 \\
\hline & & & & 5 & 1.088 & & & 1.029 & 0.949 & 0.819 & 0.675 \\
\hline & & & & 3 & 1.093 & & & & & 0.873 & 0.557 \\
\hline 15 & 3 & 0.3 & 6 & 4 & 1.352 & & & & 1.176 & 0.947 & 0.625 \\
\hline & & & & 5 & 1.338 & & & 1.218 & 1.066 & 0.865 & 0.579 \\
\hline & & & & 3 & 1.307 & & & & & 1.033 & 0.684 \\
\hline 15 & 3 & 0.3 & $8^{\star}$ & 4 & 1.323 & & & & 1.157 & 0.931 & 0.667 \\
\hline & & & & 5 & 1.314 & & & 1.210 & 1.076 & 0.875 & 0.632 \\
\hline & & & & 3 & 1.200 & & & & & 0.954 & 0.632 \\
\hline 15 & 3 & 0.3 & 12 & 4 & 1.172 & & & & 1.037 & 0.858 & 0.615 \\
\hline & & & & 5 & 1.150 & & & 1.065 & 0.952 & 0.795 & 0.578 \\
\hline
\end{tabular}

\begin{tabular}{|c|c|c|c|c|c|c|c|c|c|c|c|}
\hline \multicolumn{5}{|c|}{ Bridge Dimensions } & \multirow{2}{*}{\multicolumn{7}{|c|}{ Mom. Dist. Factor : $D_{M}$}} \\
\hline $\begin{array}{l}\text { Span } \\
(\mathrm{m})\end{array}$ & $\begin{array}{l}\text { Girder } \\
\text { Spacing }\end{array}$ & $\begin{array}{l}\text { Span } \\
\text { Radius } \\
\text { Ratio }\end{array}$ & $\begin{array}{l}\text { No. of } \\
\text { Bracing }\end{array}$ & $\begin{array}{l}\text { No. of } \\
\text { Girders }\end{array}$ & & & & & & & \\
\hline $\mathrm{L}$ & $s$ & $L / R$ & & $\mathrm{~N}$ & $G_{E x t}$ & $\mathbf{G}_{5}$ & $\mathbf{G}_{4}$ & $\mathrm{G}_{3}$ & $\mathbf{G}_{2}$ & $\mathrm{G}_{1}$ & $G_{\operatorname{lnt}}$ \\
\hline \multirow{5}{*}{25} & \multirow{5}{*}{2} & \multirow{5}{*}{0.1} & \multirow{5}{*}{4} & 3 & 1.506 & & & & & 1.241 & 0.967 \\
\hline & & & & 4 & 1.466 & & & & 1.319 & 1.166 & 1.007 \\
\hline & & & & 5 & 1.442 & & & 1.344 & 1.244 & 1.139 & 1.027 \\
\hline & & & & 6 & 1.502 & & 1.427 & 1.350 & 1.269 & 1.183 & 1.091 \\
\hline & & & & 7 & 1.493 & 1.433 & 1.373 & 1.311 & 1.244 & 1.173 & 1.095 \\
\hline \multirow{5}{*}{25} & \multirow{5}{*}{2} & \multirow{5}{*}{0.1} & \multirow{5}{*}{$6^{*}$} & 3 & 1.313 & & & & & 1.081 & 0.843 \\
\hline & & & & 4 & 1.279 & & & & 1.150 & 1.018 & 0.882 \\
\hline & & & & 5 & 1.258 & & & 1.173 & 1.086 & 0.996 & 0.904 \\
\hline & & & & 6 & 1.273 & & 1.210 & 1.145 & 1.078 & 1.008 & 0.934 \\
\hline & & & & 7 & 1.264 & 1.215 & 1.165 & 1.114 & 1.059 & 1.001 & 0.940 \\
\hline \multirow{5}{*}{25} & \multirow{5}{*}{2} & \multirow{5}{*}{0.1} & \multirow{5}{*}{8} & 3 & 1.168 & & & & & 0.973 & 0.771 \\
\hline & & & & 4 & 1.157 & & & & 1.044 & 0.906 & 0.790 \\
\hline & & & & 5 & 1.138 & & & 1.064 & 0.987 & 0.906 & 0.821 \\
\hline & & & & 6 & 1.150 & & 1.095 & 1.038 & 0.978 & 0.915 & 0.848 \\
\hline & & & & 7 & 1.142 & 1.100 & 1.056 & 1.010 & 0.961 & 0.853 & 0.779 \\
\hline \multirow{5}{*}{25} & \multirow{5}{*}{2} & \multirow{5}{*}{0.3} & \multirow{5}{*}{6} & 3 & 2.095 & & & & & 1.298 & 0.433 \\
\hline & & & & 4 & 1.981 & & & & 1.546 & 1.076 & 0.558 \\
\hline & & & & 5 & 1.911 & & & 1.628 & 1.324 & 0.994 & 0.634 \\
\hline & & & & 6 & 1.983 & & 1.761 & 1.528 & 1.278 & 1.007 & 0.710 \\
\hline & & & & 7 & 1.958 & 1.784 & 1.601 & 1.409 & 1.203 & 0.978 & 0.729 \\
\hline \multirow{5}{*}{25} & \multirow{5}{*}{2} & \multirow{5}{*}{0.3} & \multirow{5}{*}{$8^{*}$} & 3 & 1.838 & & & & & 1.150 & 0.456 \\
\hline & & & & 4 & 1.737 & & & & 1.357 & 0.937 & 0.529 \\
\hline & & & & 5 & 1.672 & & & 1.428 & \begin{tabular}{|l|l|} 
\\
\end{tabular} & 0.878 & 0.574 \\
\hline & & & & 6 & 1.690 & & 1.507 & 1.311 & 1.101 & 0.871 & 0.613 \\
\hline & & & & 7 & 1.663 & $\begin{array}{l}1.522 \\
\end{array}$ & 1.372 & 1.213 & 1.040 & 0.849 & 0.639 \\
\hline & & & & 3 & 1.631 & & & & & 1.056 & \begin{tabular}{|l}
0.423 \\
\end{tabular} \\
\hline & & & & 4 & 1.507 & & & & 1.198 & 0.859 & \begin{tabular}{|l}
0.486 \\
\end{tabular} \\
\hline 25 & 2 & 0.3 & 12 & 5 & 1.436 & & & 1.239 & 1.024 & 0.787 & 0.525 \\
\hline & & & & 6 & 1.427 & & 1.283 & 1.127 & 0.956 & 0.768 & 0.560 \\
\hline & & & & 7 & 1.398 & 1.289 & 1.171 & 1.042 & 0.901 & 0.746 & 0.572 \\
\hline & & & & 3 & 2.548 & & & & & 1.318 & 0.063 \\
\hline & & & & 4 & 2.356 & & & & 1.684 & 0.933 & 0.153 \\
\hline 25 & 2 & 0.5 & 8 & 5 & 2.235 & & & 1.811 & 1.333 & 0.788 & 0.230 \\
\hline & & & & 6 & 2.292 & & 1.969 & 1.612 & 1.214 & 0.762 & 0.284 \\
\hline & & & & 7 & 2.245 & 1.726 & 1.580 & 1.428 & 1.095 & 0.715 & 0.307 \\
\hline & & & & 3 & 2.264 & & & & & 1.232 & 0.039 \\
\hline & & & & 4 & 2.029 & & & & 1.495 & 0.876 & 0.152 \\
\hline 25 & 2 & 0.5 & $12^{*}$ & 5 & 1.895 & & & 1.566 & 1.186 & 0.745 & 0.228 \\
\hline & & & & 6 & 1.861 & & 1.627 & 1.360 & 1.054 & 0.697 & 0.242 \\
\hline & & & & 7 & 1.803 & 1.630 & 1.435 & 1.213 & 0.956 & 0.657 & 0.302 \\
\hline
\end{tabular}




\begin{tabular}{|c|c|c|c|c|c|c|c|c|c|c|c|}
\hline \multicolumn{5}{|c|}{ Bridge Dimensions } & \multirow{2}{*}{\multicolumn{7}{|c|}{ Mom. Dist. Factor : $D_{M}$}} \\
\hline $\begin{array}{c}\text { Span } \\
(\mathrm{m})\end{array}$ & $\begin{array}{l}\text { Girder } \\
\text { Spacing }\end{array}$ & $\begin{array}{l}\text { Span } \\
\text { Radius }\end{array}$ & $\begin{array}{l}\text { No. of } \\
\text { Bracing }\end{array}$ & $\begin{array}{l}\text { No. of } \\
\text { Girders }\end{array}$ & & & & & & & \\
\hline$L$ & $s$ & $L / R$ & & $\mathrm{~N}$ & $G_{\text {Ext }}$ & $\mathbf{G}_{5}$ & $\mathbf{G}_{4}$ & $\mathbf{G}_{3}$ & $\mathbf{G}_{2}$ & $G_{1}$ & $G_{\operatorname{lnt}}$ \\
\hline \multirow{5}{*}{25} & \multirow{5}{*}{2} & \multirow{5}{*}{0.5} & \multirow{5}{*}{18} & 3 & 2.074 & & & & & 1.138 & 0.047 \\
\hline & & & & 4 & 1.864 & & & & 1.378 & 0.811 & 0.146 \\
\hline & & & & 5 & 1.731 & & & 1.436 & 1.093 & 0.690 & 0.216 \\
\hline & & & & 6 & 1.697 & & 1.490 & 1.250 & 0.972 & 0.645 & 0.265 \\
\hline & & & & 7 & 1.641 & 1.490 & 1.317 & 1.116 & 0.883 & 0.607 & 0.279 \\
\hline \multirow{4}{*}{25} & \multirow{4}{*}{2.5} & \multirow{4}{*}{0.1} & \multirow{4}{*}{4} & 3 & 1.454 & & & & & 1.237 & 1.008 \\
\hline & & & & 4 & 1.423 & & & & 1.300 & 1.170 & 1.031 \\
\hline & & & & 5 & 1.404 & & & 1.322 & 1.236 & 1.142 & 1.040 \\
\hline & & & & 6 & 2.234 & & 2.138 & 2.036 & 1.925 & 1.803 & 1.668 \\
\hline \multirow{3}{*}{25} & \multirow{4}{*}{2.5} & \multirow{4}{*}{0.1} & \multirow{4}{*}{$6^{*}$} & 3 & 1.271 & & & & & 1.080 & 0.883 \\
\hline & & & & 4 & 1.245 & & & & 1.136 & 1.025 & 0.908 \\
\hline & & & & 5 & 1.229 & & & 1.021 & 1.082 & 1.003 & 0.920 \\
\hline \multirow{4}{*}{25} & & & & 6 & 1.218 & & 1.166 & 1.112 & 1.054 & \begin{tabular}{|l|}
0.991 \\
0.961 \\
\end{tabular} & 0.924 \\
\hline & \multirow{3}{*}{2.5} & \multirow{3}{*}{0.1} & \multirow{3}{*}{8} & 3 & 1.149 & & & & 1.031 & 0.961 & 0.793 \\
\hline & & & & $\frac{4}{5}$ & $\frac{1.125}{1.111}$ & & & 1.049 & 0.982 & 0.911 & 0.0234 \\
\hline & & & & 6 & 1.766 & & 1.695 & 1.617 & 1.534 & 1.442 & 1.342 \\
\hline \multirow{4}{*}{25} & \multirow{4}{*}{2.5} & \multirow{4}{*}{0.3} & \multirow{4}{*}{6} & 3 & 1.741 & & & & & 1.162 & 0.593 \\
\hline & & & & 4 & 1.954 & & & & 1.462 & 1.157 & \begin{tabular}{|l}
0.691 \\
\end{tabular} \\
\hline & & & & 5 & 1.827 & & & 1.586 & 1.322 & 1.030 & 0.702 \\
\hline & & & & 6 & 2.890 & & 2.603 & 2.293 & 1.953 & 1.575 & 1.145 \\
\hline \multirow{3}{*}{25} & \multirow{3}{*}{2.5} & \multirow{3}{*}{0.3} & & 3 & 1.721 & & & & & 1.130 & 0.550 \\
\hline & & & $8^{*}$ & 4 & 1.644 & & & 1392 & $\frac{1.329}{1.166}$ & $\begin{array}{l}0.981 \\
0.915\end{array}$ & \begin{tabular}{|l}
0.600 \\
0.625
\end{tabular} \\
\hline & & & & 5 & $\frac{1.598}{1.572}$ & & 1.422 & $\begin{array}{l}1.392 \\
1.259\end{array}$ & \begin{tabular}{|l|l|}
1.080 \\
\end{tabular} & 0.878 & \begin{tabular}{|l}
0.625 \\
0.648
\end{tabular} \\
\hline & & & & $\frac{6}{3}$ & $\frac{1.012}{1.503}$ & & & & & 1.035 & 0.506 \\
\hline & & & & 4 & 1.412 & & & & 1.158 & 0.873 & 0.549 \\
\hline 25 & 2.5 & 0.3 & 12 & 5 & 1.362 & & & 1.198 & 1.015 & 0.807 & 0.571 \\
\hline & & & & 6 & 2.137 & & 1.949 & 1.546 & 1.504 & 1.237 & 0.929 \\
\hline & & & & 3 & 2.333 & & & & & 1.285 & \begin{tabular}{|l|l}
0.202 \\
\end{tabular} \\
\hline 25 & 2.5 & 0.5 & 8 & 4 & 2.188 & & & & 1.636 & 0.990 & 0.285 \\
\hline & & & & 5 & 2.103 & & & 1.749 & $\frac{1.341}{1892}$ & \begin{tabular}{|l|l|}
0.861 \\
1260 \\
\end{tabular} & 0.325 \\
\hline & & & & $\frac{6}{3}$ & $\frac{3.295}{2.035}$ & & 2.889 & 2.426 & & \begin{tabular}{|l|}
1.200 \\
1.203 \\
\end{tabular} & \begin{tabular}{|l|l|}
0.542 \\
0.197 \\
\end{tabular} \\
\hline 25 & & & & 4 & 1.863 & & & & 1.431 & 0.911 & 0.280 \\
\hline & 2.5 & 0.5 & $12^{\star}$ & 5 & 1.763 & & & 1.497 & 1.179 & 0.794 & 0.323 \\
\hline & & & & 6 & 1.702 & & 1.520 & 1.303 & 1.045 & 0.730 & 0.341 \\
\hline
\end{tabular}

\begin{tabular}{|c|c|c|c|c|c|c|c|c|c|c|c|}
\hline \multicolumn{5}{|c|}{ Bridge Dimensions } & \multirow{2}{*}{\multicolumn{7}{|c|}{ Mom. Dist. Factor : $D_{M}$}} \\
\hline $\begin{array}{c}\text { Span } \\
(\mathrm{m})\end{array}$ & $\begin{array}{l}\text { Girder } \\
\text { Spacing }\end{array}$ & $\begin{array}{l}\text { Span } \\
\text { Radius }\end{array}$ & $\begin{array}{l}\text { No. of } \\
\text { Bracing }\end{array}$ & $\begin{array}{l}\text { No. of } \\
\text { Girders }\end{array}$ & & & & & & & \\
\hline L & & $L / R$ & & $\mathrm{~N}$ & $G_{\text {Ext }}$ & $\mathbf{G}_{5}$ & $\mathbf{G}_{4}$ & $\mathbf{G}_{3}$ & $\mathbf{G}_{2}$ & $\mathbf{G}_{1}$ & $G_{\text {lnt }}$ \\
\hline \multirow{4}{*}{25} & \multirow{4}{*}{2.5} & \multirow{4}{*}{0.5} & \multirow{4}{*}{18} & 3 & 1.869 & & & & & 1.111 & 0.187 \\
\hline & & & & 4 & 1.706 & & & & 1.316 & 0.842 & 0.261 \\
\hline & & & & 5 & 1.611 & & & 1.373 & 1.086 & 0.735 & 0.301 \\
\hline & & & & 6 & 2.488 & & 2.232 & 1.922 & 1.545 & 1.083 & 0.507 \\
\hline \multirow{3}{*}{25} & \multirow{3}{*}{3} & \multirow{3}{*}{0.1} & \multirow{3}{*}{4} & 3 & 1.417 & & & & & 1.230 & 1.030 \\
\hline & & & & 4 & 2.468 & & & & 1.285 & 1.169 & 1.041 \\
\hline & & & & 5 & 1.377 & & & 1.306 & 1.228 & 1.140 & 1.040 \\
\hline \multirow[b]{2}{*}{25} & \multirow{3}{*}{3} & \multirow{3}{*}{0.1} & \multirow{3}{*}{$6^{*}$} & 3 & 1.241 & & & & & 1.077 & 0.906 \\
\hline & & & & 4 & 1.221 & & & & 1.126 & 1.027 & 0.922 \\
\hline \multirow{3}{*}{25} & & & & 5 & 1.208 & & & 1.145 & 1.079 & 1.006 & 0.926 \\
\hline & \multirow{2}{*}{3} & \multirow{3}{*}{0.1} & \multirow{3}{*}{8} & 3 & 1.122 & & & & & 0.978 & 0.806 \\
\hline & & & & 4 & 1.102 & & & & 1.021 & 0.932 & 0.835 \\
\hline \multirow{3}{*}{25} & \multirow{3}{*}{3} & & & $\frac{5}{3}$ & $\frac{1.091}{1.868}$ & & & 1.038 & 0.978 & 0.912 & 0.838 \\
\hline & & \multirow{2}{*}{0.3} & \multirow{2}{*}{6} & 4 & $\frac{1.868}{1.804}$ & & & & & $\frac{1.308}{1.130}$ & 0.671 \\
\hline & & & & 5 & $\frac{1.804}{1.774}$ & & & 1.559 & $\frac{1.487}{1.320}$ & $\frac{1.130}{1.048}$ & $\frac{0.720}{0.733}$ \\
\hline \multirow{3}{*}{25} & \multirow{3}{*}{3} & \multirow{3}{*}{0.3} & \multirow{3}{*}{$8^{\star}$} & 3 & 1.643 & & & & & 1.153 & 0.611 \\
\hline & & & & 4 & 1.579 & & & & 1.307 & 0.999 & 0.640 \\
\hline & & & & 5 & 1.552 & & & 1.371 & 1.168 & 0.936 & 0.668 \\
\hline \multirow{3}{*}{25} & & & & 3 & 1.420 & & & & & 1.022 & 0.560 \\
\hline & 3 & 0.3 & 12 & 4 & 1.351 & & & & 1.133 & 0.881 & 0.587 \\
\hline & & & & 5 & 1.315 & & & 1.173 & 1.010 & 0.819 & 0.595 \\
\hline & & & & 3 & 1.362 & & & & & 0.649 & 0.393 \\
\hline 25 & 3 & 0.5 & 8 & 4 & 2.079 & & & & 1.605 & 1.032 & 0.363 \\
\hline & & & & 5 & 2.023 & & & 1.714 & 1.285 & 0.903 & 0.378 \\
\hline & & & & 3 & 1.889 & & & & & 1.187 & 0.304 \\
\hline 25 & 3 & 0.5 & $12^{\star}$ & 4 & 1.755 & & & & 1.391 & 0.936 & 0.358 \\
\hline & & & & $\frac{5}{3}$ & $\frac{1.688}{1.732}$ & & & 1.462 & 1.182 & $\frac{0.830}{1.095}$ & 0.311 \\
\hline 25 & 3 & 0.5 & 18 & $\frac{3}{4}$ & $\frac{7.135}{1.605}$ & & & & 1.278 & 0.864 & 0.233 \\
\hline & & & & 5 & 1.533 & & & 1.333 & 1.084 & 0.764 & 0.350 \\
\hline
\end{tabular}




\begin{tabular}{|c|c|c|c|c|c|c|c|c|c|c|c|}
\hline \multicolumn{5}{|c|}{ Bridge Dimensions } & \multirow{2}{*}{\multicolumn{7}{|c|}{ Mom. Dist. Factor : $D_{M}$}} \\
\hline $\begin{array}{l}\text { Span } \\
(\mathrm{m})\end{array}$ & $\begin{array}{l}\text { Girder } \\
\text { Spacing }\end{array}$ & $\begin{array}{l}\text { Span } \\
\text { Radius }\end{array}$ & $\begin{array}{c}\text { No. of } \\
\text { Bracing }\end{array}$ & $\begin{array}{l}\text { No. of } \\
\text { Girders }\end{array}$ & & & & & & & \\
\hline L & s & L/R & & $\mathrm{N}$ & $G_{\text {Ext }}$ & $G_{5}$ & $\mathbf{G}_{4}$ & $\mathbf{G}_{3}$ & $\mathbf{G}_{2}$ & $\mathbf{G}_{1}$ & $G_{\ln t}$ \\
\hline \multirow{4}{*}{25} & \multirow{4}{*}{2} & \multirow{5}{*}{0.5} & \multirow{5}{*}{18} & 3 & 2.074 & & & & & 1.138 & 0.047 \\
\hline & & & & 4 & 1.864 & & & & 1.378 & 0.811 & 0.146 \\
\hline & & & & 5 & 1.731 & & & 1.436 & 1.093 & \begin{tabular}{l|l}
0.690 \\
0.645
\end{tabular} & $\frac{0.216}{0.265}$ \\
\hline & & & & 6 & 1.697 & 1490 & $\begin{array}{l}1.490 \\
1317\end{array}$ & $\frac{1.250}{1.116}$ & $\begin{array}{ll}0.972 \\
0.883\end{array}$ & \begin{tabular}{l|l}
0.645 \\
0.607
\end{tabular} & $\frac{0.265}{0.279}$ \\
\hline \multirow{4}{*}{25} & \multirow{4}{*}{2.5} & & & $\frac{7}{3}$ & 1.641 & & & & & 1.237 & 1.008 \\
\hline & & \multirow{3}{*}{0.1} & \multirow{3}{*}{4} & 4 & 1.423 & & & & 1.300 & 1.170 & 1.031 \\
\hline & & & & 5 & 1.404 & & & 1.322 & 1.236 & 1.142 & 1.040 \\
\hline & & & & 6 & 2.234 & & 2.132 & 2.036 & 1.925 & 1.803 & 1.668 \\
\hline \multirow{4}{*}{25} & \multirow{4}{*}{2.5} & \multirow{4}{*}{0.1} & \multirow{4}{*}{$6^{*}$} & 3 & 1.271 & & & & & 1.080 & 0.883 \\
\hline & & & & 4 & 1.245 & & & & 1.136 & 1.025 & 0.908 \\
\hline & & & & 5 & 1.229 & & & 1.021 & 1.082 & 1.003 & 0.920 \\
\hline & & & & 6 & 1.218 & & 1.166 & 1.112 & 1.054 & 0.991 & $\frac{0.924}{0.793}$ \\
\hline \multirow{3}{*}{25} & \multirow{3}{*}{2.5} & \multirow{3}{*}{0.1} & \multirow{3}{*}{8} & 3 & 1.149 & & & & 1031 & 0.961 & 0.793 \\
\hline & & & & $\frac{4}{5}$ & $\frac{1.125}{1.111}$ & & & 1.049 & 0.982 & 0.911 & $\begin{array}{l}0.825 \\
0.834 \\
\end{array}$ \\
\hline & & & & $\frac{5}{6}$ & 1.766 & & 1.695 & 1.617 & 1.534 & 1.442 & 1.342 \\
\hline \multirow{4}{*}{25} & \multirow{4}{*}{2.5} & \multirow{4}{*}{0.3} & \multirow{4}{*}{6} & 3 & 1.741 & & & & & 1.162 & 0.593 \\
\hline & & & & 4 & 1.954 & & & & 1.462 & 1.157 & 0.691 \\
\hline & & & & 5 & 1.827 & & & 1.586 & 1.322 & 1.030 & 0.702 \\
\hline & & & & 6 & 2.890 & & 2.603 & 2.293 & 1.953 & 1.575 & 1.145 \\
\hline \multirow{3}{*}{25} & \multirow{3}{*}{2.5} & \multirow{3}{*}{0.3} & & 3 & $\frac{1.721}{1.644}$ & & & & & 1.130 & 0.550 \\
\hline & & & $8^{*}$ & $\frac{4}{5}$ & $\frac{1.644}{1.598}$ & & & 1392 & $\frac{1.329}{1.166}$ & $\begin{array}{l}0.981 \\
0.915\end{array}$ & 0.600 \\
\hline & & & & $\frac{5}{6}$ & $\begin{array}{l}7.598 \\
1.572 \\
\end{array}$ & & 1.422 & 1.259 & 1.080 & 0.878 & 0.648 \\
\hline & & & & 3 & 1.503 & & & & & 1.035 & 0.506 \\
\hline 25 & 0 & 03 & 12 & 4 & 1.412 & & & & 1.158 & 0.873 & 0.549 \\
\hline & 2.5 & 0.3 & & 5 & 1.362 & & & 1.198 & 1.015 & 0.807 & 0.571 \\
\hline & & & & 6 & 2.137 & & 1.949 & 1.546 & 1.504 & 1.237 & $\frac{0.929}{0.029}$ \\
\hline & & & & 3 & 2.333 & & & & 1.636 & $\frac{1.285}{0.990}$ & $\begin{array}{l}0.202 \\
0.285\end{array}$ \\
\hline 25 & 2.5 & 0.5 & 8 & $\frac{4}{5}$ & $\frac{2.188}{2.103}$ & & & 1.749 & 1.341 & 0.861 & 0.2825 \\
\hline & & & & $\frac{5}{6}$ & 3.105 & & 2.889 & 2.426 & 1.892 & 1.260 & 0.542 \\
\hline & & & & 3 & 2.035 & & & & & 1.203 & \begin{tabular}{|l|}
0.197 \\
\end{tabular} \\
\hline 25 & 2.5 & 0.5 & $12^{*}$ & 4 & 1.863 & & & & 1.431 & 0.911 & 0.280 \\
\hline & & & & 5 & 1.763 & & & 1.497 & $\frac{1.179}{1045}$ & $\begin{array}{l}0.794 \\
0.730\end{array}$ & 0.323 \\
\hline & & & & 6 & 1.702 & & 1.520 & 1.303 & & & 0.341 \\
\hline
\end{tabular}

\begin{tabular}{|c|c|c|c|c|c|c|c|c|c|c|c|}
\hline \multicolumn{5}{|c|}{ Bridge Dimensions } & \multirow{2}{*}{\multicolumn{7}{|c|}{ Mom. Dist. Factor : $D_{M}$}} \\
\hline $\begin{array}{l}\text { Span } \\
\text { (m) }\end{array}$ & $\begin{array}{l}\text { Girder } \\
\text { Spacing }\end{array}$ & $\begin{array}{l}\text { Span } \\
\text { Radius }\end{array}$ & $\begin{array}{l}\text { No. of } \\
\text { Bracing }\end{array}$ & $\begin{array}{l}\text { No. of } \\
\text { Girders }\end{array}$ & & & & & & & \\
\hline L & $s$ & $L / R$ & & $\mathrm{~N}$ & $G_{\text {Ext }}$ & $G_{5}$ & $\mathbf{G}_{4}$ & $\mathbf{G}_{3}$ & $\mathrm{G}_{2}$ & $\mathbf{G}_{1}$ & $G_{\text {Int }}$ \\
\hline \multirow{4}{*}{25} & \multirow{4}{*}{2.5} & \multirow{4}{*}{0.5} & \multirow{4}{*}{18} & 3 & 1.869 & & & & & 1.111 & 0.187 \\
\hline & & & & 4 & 1.706 & & & & 1.316 & 0.842 & 0.261 \\
\hline & & & & 5 & 1.611 & & & 1.373 & 1.086 & 0.735 & 0.301 \\
\hline & & & & 6 & 2.488 & & 2.232 & 1.922 & 1.545 & 1.083 & 0.507 \\
\hline \multirow{3}{*}{25} & \multirow{3}{*}{3} & \multirow{3}{*}{0.1} & \multirow{3}{*}{4} & 3 & 1.417 & & & & & 1.230 & 1.030 \\
\hline & & & & 4 & 2.468 & & & & 1.285 & 1.169 & 1.041 \\
\hline & & & & 5 & 1.377 & & & 1.306 & 1.228 & 1.140 & 1.040 \\
\hline \multirow{3}{*}{25} & \multirow{3}{*}{3} & \multirow{3}{*}{0.1} & \multirow{3}{*}{$6^{*}$} & 3 & 1.241 & & & & & 1.077 & 0.906 \\
\hline & & & & 4 & 1.221 & & & & 1.126 & 1.027 & 0.922 \\
\hline & & & & 5 & 1.208 & & & 1.145 & 1.079 & 1.006 & 0.926 \\
\hline \multirow{3}{*}{25} & \multirow{3}{*}{3} & \multirow{3}{*}{0.1} & \multirow{3}{*}{8} & 3 & 1.122 & & & & & 0.978 & 0.806 \\
\hline & & & & 4 & 1.102 & & & & 1.021 & 0.932 & 0.835 \\
\hline & & & & 5 & 1.091 & & & 1.038 & 0.978 & 0.912 & 0.838 \\
\hline \multirow{3}{*}{25} & \multirow{3}{*}{3} & \multirow{3}{*}{0.3} & \multirow{3}{*}{6} & 3 & 1.868 & & & & & 1.308 & 0.671 \\
\hline & & & & 4 & 1.804 & & & & 1.487 & 1.130 & 0.720 \\
\hline & & & & 5 & 1.774 & & & 1.559 & 1.320 & 1.048 & 0.733 \\
\hline \multirow{3}{*}{25} & \multirow{3}{*}{3} & \multirow{3}{*}{0.3} & \multirow{3}{*}{$8^{*}$} & 3 & 1.643 & & & & & 1.153 & 0.611 \\
\hline & & & & 4 & 1.579 & & & & 1.307 & 0.999 & 0.640 \\
\hline & & & & 5 & 1.552 & & & 1.371 & 1.168 & 0.936 & 0.668 \\
\hline & & & & 3 & 1.420 & & & & & 1.022 & 0.560 \\
\hline 25 & 3 & 0.3 & 12 & 4 & 1.351 & & & & 1.133 & 0.881 & 0.587 \\
\hline & & & & 5 & 1.315 & & & 1.173 & 1.010 & 0.819 & 0.595 \\
\hline & & & & 3 & 1.362 & & & & & 0.649 & 0.393 \\
\hline 25 & 3 & 0.5 & 8 & 4 & 2.079 & & & & 1.605 & 1.032 & 0.363 \\
\hline & & & & 5 & 2.023 & & & 1.714 & 1.285 & 0.903 & 0.378 \\
\hline & & & & 3 & 1.889 & & & & & 1.187 & 0.304 \\
\hline 25 & 3 & 0.5 & $12^{\star}$ & 4 & 1.755 & & & & 1.391 & 0.936 & 0.358 \\
\hline & & & & 5 & 1.688 & & & 1.462 & 1.182 & 0.830 & 0.311 \\
\hline & & & & 3 & 1.733 & & & & & 1.095 & 0.285 \\
\hline 25 & 3 & 0.5 & 18 & 4 & 1.605 & & & & 1.278 & 0.864 & 0.333 \\
\hline & & & & 5 & 1.533 & & & 1.335 & 1.084 & 0.764 & 0.350 \\
\hline
\end{tabular}




\begin{tabular}{|c|c|c|c|c|c|c|c|c|c|c|c|}
\hline \multicolumn{5}{|c|}{ Bridge Dimensions } & \multirow{2}{*}{\multicolumn{7}{|c|}{ Mom. Dist. Factor : $D_{M}$}} \\
\hline $\begin{array}{l}\text { Span } \\
(\mathrm{m})\end{array}$ & $\begin{array}{l}\text { Girder } \\
\text { Spacing } \\
\text { (m) }\end{array}$ & $\begin{array}{l}\text { Span } \\
\text { Radius } \\
\text { Ratio }\end{array}$ & $\begin{array}{l}\text { Noo of } \\
\text { Bracin } \\
\text { Intervals }\end{array}$ & $\begin{array}{l}\text { No. of } \\
\text { Girders }\end{array}$ & & & & & & & \\
\hline L & s & $L / R$ & & $\mathrm{~N}$ & $G_{\text {Ext }}$ & $\mathrm{G}_{5}$ & $\mathbf{G}_{4}$ & $\mathrm{G}_{3}$ & $\mathbf{G}_{2}$ & $\mathrm{G}_{1}$ & $G_{\operatorname{lnt}}$ \\
\hline \multirow{5}{*}{35} & \multirow{5}{*}{2} & \multirow{5}{*}{0.1} & \multirow{5}{*}{$6^{*}$} & 3 & 1.511 & & & & & 1.170 & 0.793 \\
\hline & & & & 4 & 1.458 & & & & 1.271 & 1.081 & 0.887 \\
\hline & & & & 5 & 1.422 & & & 1.302 & 1.179 & 1.054 & 0.927 \\
\hline & & & & 6 & 1.398 & & 1.312 & 1.225 & 1.136 & 1.045 & 0.952 \\
\hline & & & & 7 & 1.381 & 1.315 & 1.249 & 1.181 & 1.113 & 1.042 & 0.969 \\
\hline \multirow{5}{*}{35} & \multirow{5}{*}{2} & \multirow{5}{*}{0.1} & \multirow{5}{*}{8} & 3 & 1.341 & & & & & 1.028 & 0.742 \\
\hline & & & & 4 & 1.294 & & & & 1.131 & 0.965 & 0.793 \\
\hline & & & & 5 & 1.263 & & & 1.158 & 1.051 & 0.941 & 0.598 \\
\hline & & & & 6 & 1.241 & & 1.167 & 1.091 & 1.013 & 0.933 & 0.850 \\
\hline & & & & 7 & 1.226 & 1.170 & 1.112 & 1.053 & 0.993 & 0.930 & 0.865 \\
\hline \multirow{5}{*}{35} & \multirow{5}{*}{2} & \multirow{5}{*}{0.1} & \multirow{5}{*}{12} & 3 & 1.278 & & & & & 1.003 & 0.723 \\
\hline & & & & 4 & 1.216 & & & & 1.067 & 0.914 & 0.758 \\
\hline & & & & 5 & 1.179 & & & 1.083 & 0.930 & 0.885 & 0.783 \\
\hline & & & & 6 & 1.155 & & 1.087 & 1.018 & 0.947 & 0.874 & 0.800 \\
\hline & & & & 7 & 1.138 & 1.087 & 1.034 & 0.981 & 0.926 & 0.870 & 0.812 \\
\hline \multirow{5}{*}{35} & \multirow{5}{*}{2} & \multirow{5}{*}{0.4} & \multirow{5}{*}{8} & 3 & 2.903 & & & & & 1.376 & 0.026 \\
\hline & & & & 4 & 2.653 & & & & 1.834 & 0.945 & 0.115 \\
\hline & & & & 5 & 2.489 & & & 1.972 & 1.420 & 0.824 & 0.238 \\
\hline & & & & 6 & 2.376 & & 2.015 & \begin{tabular}{|l}
1.631 \\
\end{tabular} & 1.220 & 0.777 & 0.322 \\
\hline & & & & 7 & 2.294 & 2.023 & 1.736 & \begin{tabular}{|l|}
1.431 \\
\end{tabular} & 1.104 & 0.751 & 0.375 \\
\hline \multirow{5}{*}{35} & \multirow{5}{*}{2} & \multirow{5}{*}{0.4} & \multirow{5}{*}{$12^{\star}$} & 3 & 2.431 & & & & & 1.240 & -0.026 \\
\hline & & & & 4 & 2.161 & & & & 1.219 & 0.852 & 0.108 \\
\hline & & & & 5 & 1.997 & & & 1.607 & 1.184 & 0.724 & 0.221 \\
\hline & & & & 6 & 1.888 & & 1.620 & 1.330 & 1.015 & 0.673 & 0.298 \\
\hline & & & & 7 & 1.838 & 1.631 & 1.402 & 1.172 & 0.922 & 0.649 & 0.350 \\
\hline & & & & 3 & 2.223 & & & & & 1.141 & -0.029 \\
\hline & & & & 4 & 1.971 & & & & 1.403 & 0.783 & 0.104 \\
\hline 35 & 2 & 0.4 & 18 & 5 & 1.818 & & & 1.467 & 1.083 & 0.664 & 0.205 \\
\hline & & & & 6 & 1.445 & & 1.476 & 1.215 & 0.929 & 0.617 & 0.274 \\
\hline & & & & 7 & 1.646 & 1.470 & $1 \cong 79$ & 1.071 & 0.844 & 0.596 & 0.322 \\
\hline & & & & 3 & 3.636 & & & & & 1.300 & -0.025 \\
\hline & & & & 4 & 3.897 & & & & 2.417 & 0.796 & 1.150 \\
\hline 35 & 2 & 0.7 & 8 & 5 & 3.895 & & & 2.901 & 1.790 & 0.578 & -0.049 \\
\hline & & & & 6 & 3.816 & & 3.106 & 2.319 & 1.439 & 0.476 & -0.044 \\
\hline & & & & 7 & 3.726 & 3.191 & 2.603 & \begin{tabular}{|l|} 
\\
\end{tabular} & 1.222 & 0.421 & -0.037 \\
\hline & & & & 3 & 2.667 & & & & & 1.080 & 1.050 \\
\hline & & & & 4 & 2.776 & & & & 1.795 & 0.666 & -0.374 \\
\hline 35 & 2 & 0.7 & $12^{\star}$ & 5 & 2.759 & & & 2.082 & 1.343 & 0.489 & -0.299 \\
\hline & & & & 6 & 2.693 & & 2.211 & 1.677 & 0.926 & 0.408 & -0.234 \\
\hline & & & & 7 & 2.617 & 2.262 & 1.862 & 1.423 & 0.934 & 0.367 & -0.183 \\
\hline
\end{tabular}

\begin{tabular}{|c|c|c|c|c|c|c|c|c|c|c|c|}
\hline \multicolumn{5}{|c|}{ Bridge Dimensions } & \multirow{2}{*}{\multicolumn{7}{|c|}{ Mom. Dist. Factor : $D_{M}$}} \\
\hline $\begin{array}{l}\text { Span } \\
(\mathrm{m})\end{array}$ & $\begin{array}{l}\text { Girder } \\
\text { Spacing } \\
(\mathrm{m})\end{array}$ & $\begin{array}{l}\text { Span } \\
\text { Radius } \\
\text { Ratio }\end{array}$ & $\begin{array}{l}\text { No. of } \\
\text { Bracing } \\
\text { Intervals }\end{array}$ & $\begin{array}{l}\text { No. of } \\
\text { Girders }\end{array}$ & & & & & & & \\
\hline L & $\mathrm{s}$ & $L / R$ & & $\mathrm{~N}$ & $\mathrm{G}_{\mathrm{Ext}}$ & $\mathbf{G}_{5}$ & $\mathbf{G}_{4}$ & $\mathbf{G}_{3}$ & $\mathbf{G}_{2}$ & $\mathbf{G}_{1}$ & $G_{\text {lnt }}$ \\
\hline \multirow{5}{*}{35} & \multirow{5}{*}{2} & \multirow{5}{*}{0.7} & \multirow{5}{*}{18} & 3 & 2.324 & & & & & 0.955 & -0.525 \\
\hline & & & & 4 & 2.409 & & & & 1.568 & 0.592 & -0.456 \\
\hline & & & & 5 & 2.360 & & & 1.811 & 1.176 & 0.436 & -0.361 \\
\hline & & & & 6 & 2.276 & & 1.846 & 1.462 & 0.955 & 0.364 & -0.279 \\
\hline & & & & 7 & 2.192 & 1.919 & 1.277 & 1.210 & 0.821 & 0.326 & -0.217 \\
\hline \multirow{4}{*}{35} & \multirow{4}{*}{2.5} & \multirow{4}{*}{0.1} & \multirow{4}{*}{$6^{*}$} & 3 & 1.450 & & & & & 1.173 & 0.888 \\
\hline & & & & 4 & 1.408 & & & & 1.254 & 1.097 & 0.935 \\
\hline & & & & 5 & 1.380 & & & 1.279 & 1.177 & 1.071 & 0.963 \\
\hline & & & & 6 & 1.362 & & 1.289 & 1.215 & 1.139 & 1.060 & 0.979 \\
\hline \multirow{4}{*}{35} & \multirow{4}{*}{2.5} & \multirow{4}{*}{0.1} & \multirow{4}{*}{8} & 3 & 1.287 & & & & & 1.045 & 0.794 \\
\hline & & & & 4 & 1.249 & & & & 1.116 & 0.978 & 0.835 \\
\hline & & & & 5 & 1.225 & & & 1.139 & 1.049 & 0.956 & 0.859 \\
\hline & & & & 6 & 1.209 & & 1.147 & 1.082 & 1.016 & 0.946 & 0.873 \\
\hline \multirow{4}{*}{35} & \multirow{4}{*}{2.5} & \multirow{4}{*}{0.1} & \multirow{4}{*}{12} & 3 & 1.211 & & & & & 0.990 & 0.761 \\
\hline & & & & 4 & 1.168 & & & & 1.045 & 0.920 & 0.790 \\
\hline & & & & 5 & 1.141 & & & 0.996 & 0.979 & 0.895 & 0.808 \\
\hline & & & & 6 & 1.123 & & 1.066 & 1.007 & 0.946 & 0.884 & 0.820 \\
\hline \multirow{4}{*}{35} & \multirow{4}{*}{2.5} & \multirow{4}{*}{0.4} & \multirow{4}{*}{8} & 3 & 2.635 & & & & & 1.391 & 0.150 \\
\hline & & & & 4 & 2.438 & & & & 1.771 & 1.042 & 0.290 \\
\hline & & & & 5 & 2.314 & & & 1.889 & 1.426 & 0.920 & 0.376 \\
\hline & & & & 6 & 2.235 & & 1.933 & 1.607 & 1.253 & 0.864 & 0.421 \\
\hline \multirow{4}{*}{35} & & & & 3 & 2.166 & & & & & 1.207 & 0.140 \\
\hline & 2.5 & 0.4 & $12^{*}$ & 4 & 1.962 & & & & 1.455 & 0.894 & 0.267 \\
\hline & & & & 5 & 1.857 & & & 1.522 & 1.172 & 0.783 & 0.348 \\
\hline & & & & 6 & 1.787 & & 1.556 & 1.298 & 1.031 & 0.733 & 0.400 \\
\hline & & & & 3 & 1.978 & & & & & 1.107 & 0.134 \\
\hline 35 & 25 & 0.4 & 18 & 4 & 1.502 & & & & 1.329 & 0.819 & 0.248 \\
\hline & & & & 5 & 1.672 & & & 1.388 & 1.071 & 0.718 & 0.321 \\
\hline & & & & 6 & 1.598 & & 1.402 & 1.185 & 0.943 & 0.672 & 0.367 \\
\hline & & & & 3 & 3.753 & & & & & 1.538 & -0.018 \\
\hline 35 & 2.5 & 0.7 & 8 & 4 & 3.851 & & & & 2.477 & 1.016 & -0.027 \\
\hline & & & & 5 & 3.773 & & & 2.916 & 1.934 & 0.792 & -0.023 \\
\hline & & & & 6 & 1.951 & & 3.058 & 2.373 & 1.588 & 0.672 & -0.017 \\
\hline & & & & 3 & 2.702 & & & & & 1.220 & -0.314 \\
\hline 35 & 2.5 & 0.7 & $12^{*}$ & 4 & 2.733 & & & & 1.847 & 0.822 & -0.240 \\
\hline & & & & 5 & 2.667 & & & 2.067 & 1.421 & 0.649 & -0.169 \\
\hline & & & & 6 & 2.568 & & 2.168 & 1.693 & 1.177 & 0.558 & -0.118 \\
\hline
\end{tabular}




\begin{tabular}{|c|c|c|c|c|c|c|c|c|c|c|c|}
\hline \multicolumn{5}{|c|}{ Bridge Dimensions } & \multirow{2}{*}{\multicolumn{7}{|c|}{ Mom. Dist. Factor : $D_{M}$}} \\
\hline $\begin{array}{l}\text { Span } \\
(\mathrm{m})\end{array}$ & $\begin{array}{c}\text { Girder } \\
\text { Spacing } \\
(\mathrm{m})\end{array}$ & $\begin{array}{l}\text { Span } \\
\text { Radius } \\
\text { Ratio }\end{array}$ & $\begin{array}{l}\text { No. of } \\
\text { Bracing } \\
\text { Intervals }\end{array}$ & $\begin{array}{l}\text { No. of } \\
\text { Girders }\end{array}$ & & & & & & & \\
\hline L & $s$ & L/R & & $\mathrm{N}$ & $G_{\text {Ext }}$ & $\mathrm{G}_{5}$ & $\mathbf{G}_{4}$ & $\mathrm{G}_{3}$ & $\mathbf{G}_{2}$ & $\mathrm{G}_{1}$ & $G_{\operatorname{lnt}}$ \\
\hline \multirow{5}{*}{35} & \multirow{5}{*}{2} & \multirow{5}{*}{0.1} & \multirow{5}{*}{$6^{*}$} & 3 & 1.511 & & & & & 1.170 & 0.793 \\
\hline & & & & 4 & 1.458 & & & & 1.271 & 1.081 & 0.887 \\
\hline & & & & 5 & 1.422 & & & 1.302 & 1.179 & 1.054 & 0.927 \\
\hline & & & & 6 & 1.398 & & 1.312 & 1.225 & 1.136 & 1.045 & 0.952 \\
\hline & & & & 7 & 1.381 & 1.315 & 1.249 & 1.181 & 1.113 & 1.042 & 0.969 \\
\hline \multirow{5}{*}{35} & \multirow{5}{*}{2} & \multirow{5}{*}{0.1} & \multirow{5}{*}{8} & 3 & 1.341 & & & & & 1.028 & 0.742 \\
\hline & & & & 4 & 1.294 & & & & 1.131 & 0.965 & 0.793 \\
\hline & & & & 5 & 1.263 & & & 1.158 & 1.051 & 0.941 & 0.598 \\
\hline & & & & 6 & 1.241 & & 1.167 & 1.091 & 1.013 & 0.933 & 0.850 \\
\hline & & & & 7 & 1.226 & 1.170 & 1.112 & 1.053 & 0.993 & 0.930 & 0.865 \\
\hline \multirow{5}{*}{35} & \multirow{5}{*}{2} & \multirow{5}{*}{0.1} & \multirow{5}{*}{12} & 3 & 1.278 & & & & & 1.003 & 0.723 \\
\hline & & & & 4 & 1.216 & & & & 1.067 & 0.914 & 0.758 \\
\hline & & & & 5 & 1.179 & & & 1.083 & 0.930 & 0.885 & 0.783 \\
\hline & & & & 6 & 1.155 & & 1.087 & 1.018 & 0.947 & 0.874 & 0.800 \\
\hline & & & & 7 & 1.138 & 1.087 & 1.034 & 0.981 & 0.926 & 0.870 & 0.812 \\
\hline \multirow{5}{*}{35} & \multirow{5}{*}{2} & \multirow{5}{*}{0.4} & \multirow{5}{*}{8} & 3 & 2.903 & & & & & 1.376 & 0.026 \\
\hline & & & & 4 & 2.653 & & & & 1.834 & 0.945 & 0.115 \\
\hline & & & & 5 & 2.489 & & & \begin{tabular}{|l|l}
1.972 \\
\end{tabular} & \begin{tabular}{|l}
1.420 \\
\end{tabular} & 0.824 & 0.238 \\
\hline & & & & 6 & 2.376 & & 2.015 & 1.631 & 1.220 & 0.777 & 0.322 \\
\hline & & & & 7 & 2.294 & 2.023 & 1.736 & 1.431 & 1.104 & 0.751 & 0.375 \\
\hline \multirow{5}{*}{35} & \multirow{5}{*}{2} & \multirow{5}{*}{0.4} & \multirow{5}{*}{$12^{*}$} & 3 & 2.431 & & & & & 1.240 & -0.026 \\
\hline & & & & 4 & 2.161 & & & & 1.219 & 0.852 & 0.108 \\
\hline & & & & 5 & 1.997 & & & 1.607 & 1.184 & 0.724 & 0.221 \\
\hline & & & & 6 & 1.888 & & 1.620 & 1.330 & 1.015 & 0.673 & 0.298 \\
\hline & & & & 7 & 1.838 & 1.631 & 1.402 & 1.172 & 0.922 & 0.649 & 0.350 \\
\hline & & & & 3 & 2.223 & & & & & 1.141 & -0.029 \\
\hline & & & & 4 & 1.971 & & & & 1.403 & 0.783 & 0.104 \\
\hline 35 & 2 & 0.4 & 18 & 5 & 1.818 & & & 1.467 & 1.083 & 0.664 & 0.205 \\
\hline & & & & 6 & 1.445 & & 1.476 & 1.215 & 0.929 & 0.617 & 0.274 \\
\hline & & & & 7 & 1.646 & 1.470 & $1 \geq 79$ & 1.071 & 0.844 & 0.596 & 0.322 \\
\hline & & & & 3 & 3.636 & & & & & 1.300 & -0.025 \\
\hline & & & & 4 & 3.897 & & & & 2.417 & 0.796 & 1.150 \\
\hline 35 & 2 & 0.7 & 8 & 5 & 3.895 & & & 2.901 & 1.790 & 0.578 & -0.049 \\
\hline & & & & 6 & 3.816 & & 3.106 & 2.319 & 1.439 & 0.476 & -0.044 \\
\hline & & & & 7 & 3.726 & 3.191 & 2.603 & 1.824 & 1.222 & 0.421 & -0.037 \\
\hline & & & & 3 & 2.667 & & & & & 1.080 & 1.050 \\
\hline & & & & 4 & 2.776 & & & & 1.795 & 0.666 & -0.374 \\
\hline 35 & 2 & 0.7 & $12^{*}$ & 5 & 2.759 & & & 2.082 & 1.343 & 0.489 & -0.299 \\
\hline & & & & 6 & 2.693 & & 2.211 & 1.677 & 0.926 & 0.408 & -0.234 \\
\hline & & & & 7 & 2.617 & 2.262 & 1.862 & 1.423 & 0.934 & 0.367 & -0.183 \\
\hline
\end{tabular}

\begin{tabular}{|c|c|c|c|c|c|c|c|c|c|c|c|}
\hline \multicolumn{5}{|c|}{ Bridge Dimensions } & \multirow{2}{*}{\multicolumn{7}{|c|}{ Mom. Dist. Factor : $D_{M}$}} \\
\hline $\begin{array}{l}\text { Span } \\
(\mathrm{m})\end{array}$ & \begin{tabular}{|c|} 
Girder \\
Spacing \\
$(\mathrm{m})$
\end{tabular} & $\begin{array}{l}\text { Span } \\
\text { Radius } \\
\text { Ratio }\end{array}$ & $\begin{array}{l}\text { No. of } \\
\text { Bracing } \\
\text { Intervals }\end{array}$ & $\begin{array}{l}\text { No. of } \\
\text { Girders }\end{array}$ & & & & & & & \\
\hline L & s & $L / R$ & & $\mathrm{~N}$ & $G_{\text {Ext }}$ & $\mathbf{G}_{5}$ & $\mathbf{G}_{4}$ & $\mathbf{G}_{3}$ & $\mathbf{G}_{2}$ & $\mathbf{G}_{1}$ & $G_{\text {Int }}$ \\
\hline \multirow{5}{*}{35} & \multirow{5}{*}{2} & \multirow{5}{*}{0.7} & \multirow{5}{*}{18} & 3 & 2.324 & & & & & 0.955 & -0.525 \\
\hline & & & & 4 & 2.409 & & & & 1.568 & 0.592 & -0.456 \\
\hline & & & & 5 & 2.360 & & & 1.811 & 1.176 & 0.436 & -0.361 \\
\hline & & & & 6 & 2.276 & & 1.846 & 1.462 & 0.955 & 0.364 & -0.279 \\
\hline & & & & 7 & 2.192 & 1.919 & 1.277 & 1.210 & 0.821 & 0.326 & -0.217 \\
\hline \multirow{4}{*}{35} & \multirow{4}{*}{2.5} & \multirow{4}{*}{0.1} & \multirow{4}{*}{$6^{*}$} & 3 & 1.450 & & & & & 1.173 & 0.888 \\
\hline & & & & 4 & 1.408 & & & & 1.254 & 1.097 & 0.935 \\
\hline & & & & 5 & 1.380 & & & 1.279 & 1.177 & 1.071 & 0.963 \\
\hline & & & & 6 & 1.362 & & 1.289 & 1.215 & 1.139 & 1.060 & 0.979 \\
\hline \multirow{4}{*}{35} & \multirow{4}{*}{2.5} & \multirow{4}{*}{0.1} & \multirow{4}{*}{8} & 3 & 1.287 & & & & & 1.045 & 0.794 \\
\hline & & & & 4 & 1.249 & & & & 1.116 & 0.978 & 0.835 \\
\hline & & & & 5 & 1.225 & & & 1.139 & 1.049 & 0.956 & 0.859 \\
\hline & & & & 6 & 1.209 & & 1.147 & 1.082 & 1.016 & 0.946 & 0.873 \\
\hline \multirow{4}{*}{35} & \multirow{4}{*}{2.5} & \multirow{4}{*}{0.1} & \multirow{4}{*}{12} & 3 & 1.211 & & & & & 0.990 & 0.761 \\
\hline & & & & 4 & 1.168 & & & & 1.045 & 0.920 & 0.790 \\
\hline & & & & 5 & 1.141 & & & 0.996 & 0.979 & 0.895 & 0.808 \\
\hline & & & & 6 & 1.123 & & 1.066 & 1.007 & 0.946 & 0.884 & 0.820 \\
\hline \multirow{4}{*}{35} & \multirow{4}{*}{2.5} & \multirow{4}{*}{0.4} & \multirow{4}{*}{8} & 3 & 2.635 & & & & & 1.391 & 0.150 \\
\hline & & & & 4 & 2.438 & & & & 1.771 & 1.042 & 0.290 \\
\hline & & & & 5 & 2.314 & & & 1.889 & 1.426 & 0.920 & 0.376 \\
\hline & & & & 6 & 2.235 & & 1.933 & 1.607 & 1.253 & 0.864 & 0.421 \\
\hline \multirow{4}{*}{35} & & & & 3 & 2.166 & & & & & 1.207 & 0.140 \\
\hline & 2.5 & 0.4 & $12^{*}$ & 4 & 1.962 & & & & 1.455 & 0.894 & 0.267 \\
\hline & & & & 5 & 1.857 & & & 1.522 & 1.172 & 0.783 & 0.348 \\
\hline & & & & 6 & 1.787 & & 1.556 & 1.298 & 1.031 & 0.733 & 0.400 \\
\hline & & & & 3 & 1.978 & & & & & 1.107 & 0.134 \\
\hline 35 & 2.5 & 0.4 & 18 & 4 & 1.502 & & & & 1.329 & 0.819 & 0.248 \\
\hline & & & & 5 & 1.672 & & & 1.388 & 1.071 & 0.718 & 0.321 \\
\hline & & & & 6 & 1.598 & & 1.402 & 1.185 & 0.943 & 0.672 & 0.367 \\
\hline & & & & 3 & 3.753 & & & & & 1.538 & -0.018 \\
\hline 35 & 2.5 & 0.7 & 8 & 4 & 3.851 & & & & 2.477 & 1.016 & -0.027 \\
\hline & & & & 5 & 3.773 & & & 2.916 & 1.934 & 0.792 & -0.023 \\
\hline & & & & 6 & 1.951 & & 3.058 & 2.373 & 1.588 & 0.672 & -0.017 \\
\hline & & & & 3 & 2.702 & & & & & 1.220 & -0.314 \\
\hline 35 & 2.5 & 0.7 & $12^{*}$ & 4 & 2.733 & & & & 1.847 & 0.822 & -0.240 \\
\hline & & & & 5 & 2.667 & & & 2.067 & 1.421 & 0.649 & -0.169 \\
\hline & & & & 6 & 2.568 & & 2.168 & 1.693 & 1.177 & 0.558 & -0.118 \\
\hline
\end{tabular}


Table 4.15d: Moment Distribution factors $D_{M}$ for $35 \mathrm{~m}$ span bridge (Continue...)

\begin{tabular}{|c|c|c|c|c|c|c|c|c|c|c|c|}
\hline \multicolumn{5}{|c|}{ Bridge Dimensions } & \multirow{2}{*}{\multicolumn{7}{|c|}{ Mom. Dist. Factor : $D_{M}$}} \\
\hline $\begin{array}{l}\text { Span } \\
(\mathrm{m})\end{array}$ & $\begin{array}{l}\text { Girder } \\
\text { Spacing }\end{array}$ & $\begin{array}{l}\text { Span } \\
\text { Radius }\end{array}$ & $\begin{array}{l}\text { No. of } \\
\text { Bracing }\end{array}$ & $\begin{array}{l}\text { No. of } \\
\text { Girders }\end{array}$ & & & & & & & \\
\hline $\mathrm{L}$ & $s$ & $L / R$ & & $\mathrm{~N}$ & $G_{\text {Ext }}$ & $G_{5}$ & $\mathbf{G}_{4}$ & $\mathbf{G}_{3}$ & $\mathbf{G}_{2}$ & $G_{1}$ & $G_{\text {lnt }}$ \\
\hline \multirow{3}{*}{35} & \multirow{4}{*}{2.5} & \multirow{4}{*}{0.7} & \multirow{4}{*}{18} & 3 & 2.350 & & & & & 1.073 & -0.389 \\
\hline & & & & 4 & 2.343 & & & & 1.610 & 0.725 & -0.291 \\
\hline & & & & 5 & 2.253 & & & 1.794 & 1.242 & 0.574 & -0.203 \\
\hline \multirow{3}{*}{35} & & & & 6 & 2.146 & & 1.839 & 1.473 & 1.031 & $\begin{array}{ll}0.493 \\
1.172\end{array}$ & $\begin{array}{l}-0.140 \\
0.800\end{array}$ \\
\hline & \multirow{2}{*}{3} & \multirow{2}{*}{0.1} & \multirow{2}{*}{$6^{*}$} & $\frac{3}{4}$ & $\frac{1.408}{1.373}$ & & & & 1.240 & 1.104 & 0.8064 \\
\hline & & & & 5 & 1.352 & & & 1.263 & 1.173 & 1.080 & 0.982 \\
\hline \multirow{3}{*}{35} & \multirow{3}{*}{3} & \multirow{3}{*}{0.1} & \multirow{3}{*}{8} & 3 & 1.250 & & & & & 1.044 & 0.830 \\
\hline & & & & 4 & 1.218 & & & & 1.104 & 0.985 & 0.859 \\
\hline & & & & 5 & 1.194 & & & 1.119 & 1.040 & 0.958 & 0.871 \\
\hline \multirow{3}{*}{35} & \multirow{3}{*}{3} & \multirow{3}{*}{0.1} & \multirow{3}{*}{12} & 3 & 1.173 & & & & & 0.984 & 0.789 \\
\hline & & & & 4 & 1.136 & & & & 1.031 & 0.922 & 0.810 \\
\hline & & & & 5 & 1.115 & & & 1.046 & 0.974 & 0.900 & 0.823 \\
\hline \multirow{3}{*}{35} & \multirow{3}{*}{3} & \multirow{3}{*}{0.4} & \multirow{3}{*}{8} & 3 & 2.454 & & & & & 1.403 & 0.295 \\
\hline & & & & 4 & 2.296 & & & & 1.727 & 1.095 & 0.400 \\
\hline & & & & 5 & 2.202 & & & 1.835 & 1.429 & 0.977 & 0.467 \\
\hline \multirow{3}{*}{35} & \multirow{3}{*}{3} & \multirow{3}{*}{0.4} & \multirow{3}{*}{$12^{\star}$} & 3 & 1.995 & & & & & 1.189 & 0.272 \\
\hline & & & & 4 & 1.833 & & & & 1.405 & 0.922 & 0.370 \\
\hline & & & & 5 & 1.765 & & & 1.469 & 1.166 & 0.821 & 0.427 \\
\hline \multirow{3}{*}{35} & & & & 3 & 1.813 & & & & & 1.086 & 0.254 \\
\hline & 3 & 0.4 & 18 & 4 & 1.668 & & & & 1.283 & 0.689 & 0.341 \\
\hline & & & & 5 & 1.579 & & & 1.339 & 1.065 & 0.753 & 0.393 \\
\hline & & & & 3 & 3.844 & & & & & 1.756 & -0.004 \\
\hline 35 & 3 & 0.7 & 8 & 4 & 3.812 & & & & 2.628 & 1.218 & -0.005 \\
\hline & & & & 5 & 3.601 & & & 2.860 & 1.990 & 0.950 & 0.000 \\
\hline & & & & 3 & 2.735 & & & & & 1.344 & -0.214 \\
\hline 35 & 3 & 0.7 & $12^{\star}$ & 4 & 2.703 & & & & 1.890 & 0.947 & -0.134 \\
\hline & & & & 5 & 2.532 & & & 2.037 & 1.444 & 0.748 & -0.074 \\
\hline & & & & 3 & 2.373 & & & & & 1.179 & -0.264 \\
\hline 35 & 3 & 0.7 & 18 & 4 & 2.294 & & & & 1.646 & 0.833 & -0.163 \\
\hline & & & & 5 & 2.119 & & & 1.737 & 1.260 & 0.659 & -0.089 \\
\hline
\end{tabular}

Table 4.16 Effect of girder spacing, $\mathrm{L} / \mathrm{R}$ ratio and number of girder on Reaction Distribution factor $R_{M}$

Table 4.16a: Reaction Distribution factors $R_{M}$ for $10 \mathrm{~m}$ span bridge

\begin{tabular}{|c|c|c|c|c|c|c|c|c|c|c|c|}
\hline \multicolumn{5}{|c|}{ Bridge Dimensions } & \multirow{2}{*}{\multicolumn{7}{|c|}{ Reaction Dist. Factor : $\mathbf{R}_{\mathbf{M}}$}} \\
\hline $\begin{array}{l}\text { Span } \\
\text { (m) }\end{array}$ & $\begin{array}{l}\text { Girder } \\
\text { Spacing }\end{array}$ & $\begin{array}{c}\text { Span } \\
\text { Radius }\end{array}$ & $\begin{array}{l}\text { No. of } \\
\text { Bracing }\end{array}$ & $\begin{array}{l}\text { No. of } \\
\text { Girders }\end{array}$ & & & & & & & \\
\hline $\mathrm{L}$ & $s$ & $L / R$ & & $\bar{N}$ & $\mathrm{G}_{\text {Ext }}$ & $G_{5}$ & $\mathrm{G}_{4}$ & $\mathrm{G}_{3}$ & $G_{2}$ & $G_{1}$ & $G_{\text {int }}$ \\
\hline \multirow{5}{*}{10} & \multirow{5}{*}{2} & \multirow{5}{*}{0.1} & \multirow{5}{*}{2} & 3 & 1.010 & & & & & 1.110 & 0.880 \\
\hline & & & & 4 & 0.975 & & & & 1.101 & 1.073 & 0.852 \\
\hline & & & & 5 & 0.954 & & & 1.088 & 1.082 & 1.047 & 0.829 \\
\hline & & & & 6 & 0.941 & & 1.078 & 1.080 & 1.065 & 1.027 & 0.809 \\
\hline & & & & 7 & 0.933 & 1.071 & 1.076 & 1.067 & 1.050 & 1.010 & 0.792 \\
\hline \multirow{4}{*}{10} & \multirow{5}{*}{2} & \multirow{5}{*}{0.1} & \multirow{5}{*}{$4^{*}$} & 3 & 1.018 & & & & & 1.096 & 0.886 \\
\hline & & & & 4 & 0.983 & & & & 1.095 & 1.060 & 0.863 \\
\hline & & & & 5 & 0.957 & & & 1.085 & 1.079 & 1.037 & 0.842 \\
\hline & & & & 6 & 0.937 & & 1.075 & 1.084 & 1.067 & 1.019 & 0.819 \\
\hline \multirow{5}{*}{10} & & & & $\frac{7}{3}$ & $\frac{0.921}{1016}$ & 1.063 & 1.082 & 1.079 & 1.056 & $\frac{1.002}{1.099}$ & $\frac{0.797}{0.885}$ \\
\hline & \multirow{4}{*}{2} & \multirow{4}{*}{0.1} & \multirow{4}{*}{6} & 4 & 0.985 & & & & 1.093 & 1.055 & $\frac{0.880}{0.867}$ \\
\hline & & & & 5 & 0.962 & & & 1.084 & 1.073 & 1.033 & 0.849 \\
\hline & & & & 6 & 0.943 & & 1.075 & 1.077 & 1.060 & 1.016 & 0.829 \\
\hline & & & & 7 & 0.928 & 1.065 & 1.077 & 1.072 & 1.049 & 1.000 & 0.809 \\
\hline \multirow{4}{*}{10} & \multirow{4}{*}{2} & \multirow{4}{*}{0.2} & \multirow{4}{*}{4} & 3 & 1.079 & & & & & 1.105 & 0.816 \\
\hline & & & & 4 & 1.037 & & & & 1.119 & 1.048 & 0.796 \\
\hline & & & & 5 & 1.011 & & & 1.115 & 1.084 & $\frac{1.016}{0.02}$ & 0.775 \\
\hline & & & & $\frac{6}{7}$ & 0.994 & & 1.108 & 1.094 & 1.060 & $\frac{0.992}{0.070}$ & $\frac{0.752}{0.730}$ \\
\hline \multirow{4}{*}{10} & \multirow{5}{*}{2} & \multirow{5}{*}{0.2} & \multirow{5}{*}{$6^{*}$} & $\frac{7}{3}$ & $\frac{0.985}{1.085}$ & 1.102 & 1.096 & 1.076 & & 1.094 & $\frac{0.730}{0.821}$ \\
\hline & & & & 4 & 1.039 & & & & 1.114 & 1.042 & 0.805 \\
\hline & & & & 5 & 1.008 & & & 1.109 & 1.085 & 1.014 & 0.785 \\
\hline & & & & 6 & 0.983 & & 1.099 & 1.098 & 1.067 & 0.992 & 0.761 \\
\hline \multirow{5}{*}{10} & & & & 7 & 0.965 & 1.087 & 1.099 & 1.088 & 1.053 & 0.972 & 0.736 \\
\hline & \multirow{4}{*}{2} & & & $\frac{3}{4}$ & 1.079 & & & & 1118 & $\frac{1.100}{1.045}$ & $\frac{0.822}{0.804}$ \\
\hline & & 0.2 & 9 & $\frac{4}{5}$ & $\frac{1.033}{1.005}$ & & & 1.112 & 1.084 & 1.014 & $\begin{array}{l}0.884 \\
0.786\end{array}$ \\
\hline & & & & 6 & 0.984 & & 1.103 & 1.096 & 1.062 & 0.991 & 0.764 \\
\hline & & & & 7 & 0.971 & 1.089 & 1.096 & 1.083 & 1.046 & 0.969 & 0.747 \\
\hline & & & & 3 & 1.141 & & & & & 1.114 & 0.745 \\
\hline & & & & 4 & 1.089 & & & & 1.146 & 1.040 & 0.725 \\
\hline 10 & 2 & 0.3 & 4 & 5 & 1.059 & & & 1.145 & 1.097 & 0.999 & 0.701 \\
\hline & & & & $\frac{6}{7}$ & $\frac{1.043}{1.038}$ & 1136 & $\frac{1.139}{1117}$ & $\frac{1.113}{1085}$ & $\frac{7.063}{1.034}$ & 0.9010 & $\frac{0.6 .55}{0.650}$ \\
\hline & & & & 3 & 1.146 & & & & & 1.105 & 0.748 \\
\hline & & & & 4 & 1.087 & & & & 1.142 & 1.036 & 0.734 \\
\hline 10 & 2 & 0.3 & $6^{*}$ & 5 & 1.049 & & & 1.139 & 1.100 & 0.999 & 0.712 \\
\hline & & & & $\frac{6}{7}$ & 1.023 & 1111 & $\frac{1.128}{1.20}$ & \begin{tabular}{|l|}
1.118 \\
1.101 \\
\end{tabular} & $\frac{1.075}{1054}$ & $\frac{0.972}{0.948}$ & 0.684 \\
\hline & & & & 7 & 1.006 & & & & & & \\
\hline
\end{tabular}


Table 4.15d: Moment Distribution factors $D_{M}$ for $35 \mathrm{~m}$ span bridge (Continue...)

\begin{tabular}{|c|c|c|c|c|c|c|c|c|c|c|c|}
\hline \multicolumn{5}{|c|}{ Bridge Dimensions } & \multirow{2}{*}{\multicolumn{7}{|c|}{ Mom. Dist. Factor : $D_{M}$}} \\
\hline $\begin{array}{l}\text { Span } \\
(\mathrm{m})\end{array}$ & $\begin{array}{l}\text { Girder } \\
\text { Spacing }\end{array}$ & $\begin{array}{l}\text { Span } \\
\text { Radius }\end{array}$ & $\begin{array}{l}\text { No. of } \\
\text { Bracing }\end{array}$ & $\begin{array}{l}\text { No. of } \\
\text { Girders }\end{array}$ & & & & & & & \\
\hline L & $s$ & $L / R$ & & $N$ & $G_{\text {Ext }}$ & $\mathrm{G}_{5}$ & $\mathbf{G}_{4}$ & $\mathbf{G}_{3}$ & $\mathbf{G}_{2}$ & $G_{1}$ & $G_{\operatorname{lnt}}$ \\
\hline \multirow{3}{*}{35} & \multirow{4}{*}{2.5} & \multirow{4}{*}{0.7} & \multirow{4}{*}{18} & 3 & 2.350 & & & & & 1.073 & -0.389 \\
\hline & & & & 4 & 2.343 & & & & 1.610 & 0.725 & -0.291 \\
\hline & & & & 5 & 2.253 & & & 1.794 & 1.242 & 0.574 & -0.203 \\
\hline \multirow{3}{*}{35} & & & & 6 & 2.146 & & 1.839 & 1.473 & 1.031 & 0.493 & -0.140 \\
\hline & \multirow[t]{2}{*}{3} & \multirow{2}{*}{0.1} & \multirow{2}{*}{$6^{*}$} & $\frac{3}{4}$ & $\frac{1.408}{1.373}$ & & & & 1240 & $\frac{1.172}{1.104}$ & $\frac{0.800}{0.964}$ \\
\hline & & & & 5 & $\frac{1.373}{1.352}$ & & & 1.263 & 1.173 & 1.080 & 0.964 \\
\hline \multirow{3}{*}{35} & \multirow{3}{*}{3} & \multirow{3}{*}{0.1} & \multirow{3}{*}{8} & 3 & 1.250 & & & & & 1.044 & 0.830 \\
\hline & & & & 4 & 1.218 & & & & 1.104 & 0.985 & 0.859 \\
\hline & & & & 5 & 1.194 & & & 1.119 & 1.040 & 0.958 & 0.871 \\
\hline \multirow{3}{*}{35} & \multirow{3}{*}{3} & \multirow{3}{*}{0.1} & \multirow{3}{*}{12} & 3 & 1.173 & & & & & 0.984 & 0.789 \\
\hline & & & & 4 & 1.136 & & & & 1.031 & 0.922 & 0.810 \\
\hline & & & & 5 & 1.115 & & & 1.046 & 0.974 & 0.900 & 0.823 \\
\hline \multirow{3}{*}{35} & \multirow{3}{*}{3} & \multirow{3}{*}{0.4} & \multirow{3}{*}{8} & 3 & 2.454 & & & & & 1.403 & 0.295 \\
\hline & & & & 4 & 2.296 & & & & 1.727 & 1.095 & 0.400 \\
\hline & & & & 5 & 2.202 & & & 1.835 & 1.429 & 0.977 & 0.467 \\
\hline \multirow{3}{*}{35} & \multirow{3}{*}{3} & \multirow{3}{*}{0.4} & \multirow{3}{*}{$12^{\star}$} & 3 & 1.995 & & & & & 1.189 & 0.272 \\
\hline & & & & 4 & 1.833 & & & & 1.405 & 0.922 & 0.370 \\
\hline & & & & 5 & 1.765 & & & 1.469 & 1.166 & 0.821 & 0.427 \\
\hline \multirow{3}{*}{35} & & & & 3 & 1.813 & & & & & 1.086 & 0.254 \\
\hline & 3 & 0.4 & 18 & 4 & 1.668 & & & & 1.283 & 0.689 & 0.341 \\
\hline & & & & 5 & 1.579 & & & 1.339 & 1.065 & 0.753 & 0.393 \\
\hline & & & & 3 & 3.844 & & & & & 1.756 & -0.004 \\
\hline 35 & 3 & 0.7 & 8 & 4 & 3.812 & & & & 2.628 & 1.218 & -0.005 \\
\hline & & & & 5 & 3.601 & & & 2.860 & 1.990 & 0.950 & 0.000 \\
\hline & & & & 3 & 2.735 & & & & & 1.344 & -0.214 \\
\hline 35 & 3 & 0.7 & $12^{\star}$ & 4 & 2.703 & & & & 1.890 & 0.947 & -0.134 \\
\hline & & & & 5 & 2.532 & & & 2.037 & 1.444 & 0.748 & -0.074 \\
\hline & & & & 3 & 2.373 & & & & & 1.179 & -0.264 \\
\hline 35 & 3 & 0.7 & 18 & 4 & 2.294 & & & & 1.646 & 0.833 & -0.163 \\
\hline & & & & 5 & 2.119 & & & 1.737 & 1.260 & 0.659 & -0.089 \\
\hline
\end{tabular}

Table 4.16 Effect of girder spacing, $L / R$ ratio and number of girder on Reaction Distribution factor $R_{M}$

T.16a: Reaction Distribution factors $R_{M}$ for $10 \mathrm{~m}$ span bridge

\begin{tabular}{|c|c|c|c|c|c|c|c|c|c|c|c|}
\hline \multicolumn{5}{|c|}{ Bridge Dimensions } & \multirow{2}{*}{\multicolumn{7}{|c|}{ Reaction Dist. Factor : $\mathbf{R}_{\mathbf{M}}$}} \\
\hline $\begin{array}{l}\text { Span } \\
\text { (m) }\end{array}$ & $\begin{array}{l}\text { Girder } \\
\text { Spacing }\end{array}$ & $\begin{array}{c}\text { Span } \\
\text { Radius }\end{array}$ & $\begin{array}{l}\text { No. of } \\
\text { Bracing }\end{array}$ & $\begin{array}{l}\text { No. of } \\
\text { Girders }\end{array}$ & & & & & & & \\
\hline $\mathrm{L}$ & $s$ & L/R & & $\mathrm{N}$ & $G_{\text {Ext }}$ & $\mathrm{G}_{5}$ & $\mathrm{G}_{4}$ & $\mathrm{G}_{3}$ & $G_{2}$ & $\mathrm{G}_{1}$ & $G_{\text {int }}$ \\
\hline \multirow{5}{*}{10} & \multirow{5}{*}{2} & \multirow{5}{*}{0.1} & \multirow{5}{*}{2} & 3 & 1.010 & & & & & 1.110 & 0.880 \\
\hline & & & & 4 & 0.975 & & & & 1.101 & 1.073 & 0.852 \\
\hline & & & & 5 & 0.954 & & & 1.088 & 1.082 & 1.047 & 0.829 \\
\hline & & & & 6 & 0.941 & & 1.078 & 1.080 & 1.065 & 1.027 & 0.809 \\
\hline & & & & 7 & 0.933 & 1.071 & 1.076 & 1.067 & 1.050 & 1.010 & 0.792 \\
\hline \multirow{5}{*}{10} & \multirow{5}{*}{2} & \multirow{5}{*}{0.1} & \multirow{5}{*}{$4^{*}$} & 3 & 1.018 & & & & & 1.096 & 0.886 \\
\hline & & & & 4 & 0.983 & & & & 1.095 & 1.060 & 0.863 \\
\hline & & & & 5 & 0.957 & & & 1.085 & 1.079 & 1.037 & 0.842 \\
\hline & & & & 6 & 0.937 & & 1.075 & 1.084 & 1.067 & 1.019 & 0.819 \\
\hline & & & & 7 & 0.921 & 1.063 & 1.082 & 1.079 & 1.056 & 1.002 & 0.797 \\
\hline \multirow{4}{*}{10} & \multirow{4}{*}{2} & \multirow{4}{*}{0.1} & \multirow{4}{*}{6} & 3 & 1.016 & & & & & 1.099 & 0.885 \\
\hline & & & & 4 & 0.985 & & & & 1.093 & 1.055 & 0.867 \\
\hline & & & & 5 & 0.962 & & & $\frac{1.084}{1.877}$ & $\frac{1.073}{1.06 n}$ & $\frac{1.033}{1016}$ & $\frac{0.849}{0.839}$ \\
\hline & & & & $\frac{6}{7}$ & $\frac{0.943}{0.928}$ & 1.065 & $\frac{1.075}{1.077}$ & $\frac{1.077}{1.072}$ & $\frac{1.060}{1.049}$ & $\frac{1.016}{1.000}$ & $\frac{0.829}{0.809}$ \\
\hline \multirow{5}{*}{10} & \multirow{5}{*}{2} & \multirow{5}{*}{0.2} & \multirow{5}{*}{4} & 3 & 1.079 & & & & & 1.105 & 0.816 \\
\hline & & & & 4 & 1.037 & & & & 1.119 & 1.048 & 0.796 \\
\hline & & & & 5 & 1.011 & & & 1.115 & 1.084 & 1.016 & 0.775 \\
\hline & & & & 6 & 0.994 & & 1.108 & 1.094 & 1.060 & 0.992 & 0.752 \\
\hline & & & & 7 & 0.985 & 1.102 & 1.096 & 1.076 & 1.040 & 0.970 & 0.730 \\
\hline \multirow{4}{*}{10} & \multirow{4}{*}{2} & \multirow{4}{*}{0.2} & \multirow{4}{*}{$6^{*}$} & 3 & 1.085 & & & & & 1.094 & 0.821 \\
\hline & & & & 4 & 1.039 & & & & 1.114 & 1.042 & 0.805 \\
\hline & & & & 5 & 1.008 & & & 1.109 & 1.085 & $\frac{1.014}{0.909}$ & 0.785 \\
\hline & & & & $\frac{6}{7}$ & 0.983 & 1087 & $\frac{1.099}{1.099}$ & $\frac{1.098}{1088}$ & $\begin{array}{l}1.067 \\
1.073\end{array}$ & $\frac{0.992}{0.972}$ & $\frac{0.761}{0.736}$ \\
\hline \multirow{5}{*}{10} & & & & $\frac{7}{3}$ & $\frac{0.966}{1.079}$ & 1.081 & & 1.088 & & 1.100 & 0.822 \\
\hline & & & & 4 & 1.033 & & & & 1.118 & 1.045 & 0.804 \\
\hline & 2 & 0.2 & 9 & 5 & 1.005 & & & 1.112 & 1.084 & 1.014 & 0.786 \\
\hline & & & & 6 & 0.984 & & 1.103 & 1.096 & 1.062 & 0.991 & 0.764 \\
\hline & & & & 7 & 0.971 & 1.089 & 1.096 & 1.083 & 1.046 & 0.969 & 0.747 \\
\hline & & & & 3 & 1.141 & & & & & 1.114 & 0.745 \\
\hline & & & & 4 & 1.089 & & & & 1.146 & 1.040 & 0.725 \\
\hline 10 & 2 & 0.3 & 4 & 5 & 1.059 & & & 1.145 & 1.097 & 0.999 & 0.701 \\
\hline & & & & 6 & 1.043 & & 1.139 & 1.113 & 1.063 & 0.967 & 0.675 \\
\hline & & & & 7 & 1.038 & 1.136 & 1.117 & 1.085 & 1.034 & 0.940 & 0.650 \\
\hline & & & & 3 & 1.146 & & & & & 1.105 & 0.748 \\
\hline & & & & 4 & 1.087 & & & & 1.142 & 1.036 & 0.734 \\
\hline 10 & 2 & 0.3 & $6^{*}$ & 5 & 1.049 & & & 1.139 & 1.100 & 0.999 & 0.712 \\
\hline & & & & $\frac{6}{7}$ & 1.023 & 1116 & $\frac{1.128}{1.120}$ & 1.118 & 1.075 & \begin{tabular}{|l|}
0.972 \\
0.948 \\
\end{tabular} & $\frac{0.684}{0.655}$ \\
\hline & & & & 7 & 1.006 & 1.770 & 1.120 & 1.101 & 1.054 & & \\
\hline
\end{tabular}


Table 4.16a: Reaction Distribution factors $\mathrm{R}_{\mathrm{M}}$ for $10 \mathrm{~m}$ span bridge (Continue...)

\begin{tabular}{|c|c|c|c|c|c|c|c|c|c|c|c|}
\hline \multicolumn{5}{|c|}{ Bridge Dimensions } & \multirow{2}{*}{\multicolumn{7}{|c|}{ Reaction Dist. Factor : $\mathbf{R}_{\mathbf{M}}$}} \\
\hline $\begin{array}{l}\text { Span } \\
(m)\end{array}$ & $\begin{array}{l}\text { Girder } \\
\text { Spacing }\end{array}$ & $\begin{array}{l}\text { Span } \\
\text { Radius }\end{array}$ & $\begin{array}{l}\text { No. of } \\
\text { Bracing }\end{array}$ & $\begin{array}{l}\text { No. of } \\
\text { Girders }\end{array}$ & & & & & & & \\
\hline$L$ & $\mathrm{~s}$ & $L / R$ & & $\mathrm{~N}$ & $G_{\text {Ext }}$ & $G_{5}$ & $G_{4}$ & $\mathrm{G}_{3}$ & $\mathrm{G}_{2}$ & $G_{1}$ & $G_{\text {int }}$ \\
\hline \multirow{5}{*}{10} & \multirow{5}{*}{2} & \multirow{5}{*}{0.3} & \multirow{5}{*}{9} & 3 & 1.138 & & & & & 1.111 & 0.751 \\
\hline & & & & 4 & 1.080 & & & & 1.147 & 1.039 & 0.734 \\
\hline & & & & 5 & 1.037 & & & 1.136 & 1.102 & 1.004 & 0.721 \\
\hline & & & & 6 & 1.019 & & 1.134 & 1.120 & 1.072 & 0.970 & 0.685 \\
\hline & & & & 7 & 1.006 & 1.118 & 1.120 & 1.100 & 1.051 & 0.944 & 0.661 \\
\hline \multirow{3}{*}{10} & \multirow{4}{*}{2.5} & \multirow{4}{*}{0.1} & \multirow{4}{*}{2} & 3 & 0.990 & & & & & 1.131 & 0.879 \\
\hline & & & & 4 & 0.951 & & & & 1.116 & 1.093 & 0.840 \\
\hline & & & & 5 & 0.928 & & & 1.099 & 1.101 & 1.063 & 0.810 \\
\hline \multirow{4}{*}{10} & & & & 6 & 0.914 & & 1.086 & 1.095 & 1.081 & 1.039 & 0.786 \\
\hline & \multirow{3}{*}{2.5} & \multirow{3}{*}{0.1} & \multirow{3}{*}{$4^{*}$} & 3 & 1.005 & & & & & $\frac{1.098}{1.079}$ & 0.897 \\
\hline & & & & -4 & 0.959 & & & 1.094 & $\frac{1.107}{1.101}$ & $\frac{1.079}{1.055}$ & 0.854 \\
\hline & & & & $\frac{5}{6}$ & 0.928 & & 1.078 & 1.103 & 1.092 & 1.033 & 0.021 \\
\hline \multirow{3}{*}{10} & \multirow{4}{*}{2.5} & \multirow{4}{*}{0.1} & \multirow{4}{*}{6} & 3 & 1.001 & & & & & 1.108 & 0.891 \\
\hline & & & & 4 & 0.963 & & & & 1.104 & 1.074 & 0.859 \\
\hline & & & & 5 & 0.936 & & & 1.091 & 1.092 & 1.048 & 0.832 \\
\hline \multirow{4}{*}{10} & & & & 6 & 0.906 & & 1.077 & 1.096 & 1.084 & 1.031 & 0.806 \\
\hline & \multirow{4}{*}{2.5} & \multirow{4}{*}{0.2} & \multirow{4}{*}{4} & 3 & 1.049 & & & & & 1.122 & 0.829 \\
\hline & & & & 4 & 1.005 & & & & 1.128 & 1.072 & 0.795 \\
\hline & & & & 5 & 0.980 & & & 1.120 & 1.103 & 1.037 & 0.760 \\
\hline \multirow{4}{*}{10} & & & & 6 & 0.964 & & 1.109 & 1.109 & 1.081 & $\frac{1.009}{1.23}$ & 0.728 \\
\hline & \multirow{3}{*}{2.5} & \multirow{3}{*}{0.2} & & 3 & 1.048 & & & & 1.122 & \begin{tabular}{|l}
1.123 \\
1.065 \\
\end{tabular} & \begin{tabular}{|l|l|}
0.829 \\
0.805 \\
\end{tabular} \\
\hline & & & $6^{*}$ & $\frac{4}{5}$ & $\frac{1.008}{0.973}$ & & & 1.111 & 1.107 & \begin{tabular}{|l}
1.037 \\
\end{tabular} & 0.771 \\
\hline & & & & 6 & 0.947 & & 1.096 & 1.115 & 1.094 & 1.013 & \begin{tabular}{|l}
0.735 \\
\end{tabular} \\
\hline & & & & 3 & 1.050 & & & & & 1.115 & \begin{tabular}{|l|l}
0.835 \\
\end{tabular} \\
\hline & & & & 4 & 1.004 & & & & 1.125 & 1.066 & 0.805 \\
\hline 10 & 2.5 & 0.2 & 百 & 5 & 0.974 & & & 1.115 & 1.103 & 1.034 & 0.775 \\
\hline & & & & 6 & 0.951 & & 1.102 & 1.111 & 1.085 & 1.009 & 0.742 \\
\hline & & & & 3 & 1.100 & & & & & 1.134 & 0.767 \\
\hline 10 & 2.5 & 0.3 & 4 & 4 & 1.051 & & & & 1.153 & 1.067 & 0.728 \\
\hline & & 0.0 & 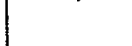 & 5 & 1.024 & & & 1.146 & 1.116 & 1.024 & 0.690 \\
\hline & & & & 6 & 1.011 & & 1.138 & 1.124 & 1.083 & $\begin{array}{l}0.989 \\
1.122\end{array}$ & $\frac{0.654}{0.772}$ \\
\hline & & & & $\frac{3}{4}$ & $\frac{1.105}{1.047}$ & & & & 1.148 & 1.065 & 0.740 \\
\hline 10 & 2.5 & 0.3 & $6^{*}$ & 5 & 1.008 & & & 1.137 & 1.123 & 1.030 & 0.702 \\
\hline & & & & 6 & 1.011 & & 1.153 & 1.165 & 1.135 & 0.857 & 0.679 \\
\hline
\end{tabular}

Table 4.16a: Reaction Distribution factors $\mathrm{R}_{\mathrm{M}}$ for $10 \mathrm{~m}$ span bridge (Continue...)

\begin{tabular}{|c|c|c|c|c|c|c|c|c|c|c|c|}
\hline \multicolumn{5}{|c|}{ Bridge Dimensions } & \multirow{2}{*}{\multicolumn{7}{|c|}{ Reaction Dist. Factor : $\mathbf{R}_{\mathbf{M}}$}} \\
\hline $\begin{array}{l}\text { Span } \\
(\mathrm{m})\end{array}$ & $\begin{array}{l}\text { Girder } \\
\text { Spacing }\end{array}$ & $\begin{array}{l}\text { Span } \\
\text { Radius }\end{array}$ & $\begin{array}{l}\text { No. of } \\
\text { Bracing }\end{array}$ & $\begin{array}{l}\text { No. of } \\
\text { Girders }\end{array}$ & & & & & & & \\
\hline$L$ & $s$ & $L / R$ & & $\mathrm{~N}$ & $G_{\text {Ext }}$ & $G_{5}$ & $G_{4}$ & $G_{3}$ & $\mathrm{G}_{2}$ & $\mathrm{G}_{1}$ & $G_{\text {int }}$ \\
\hline \multirow{4}{*}{10} & \multirow{4}{*}{2.5} & \multirow{4}{*}{0.3} & \multirow{4}{*}{9} & 3 & 1.098 & & & & & 1.129 & 0.773 \\
\hline & & & & 4 & 1.042 & & & & 1.153 & 1.066 & 0.740 \\
\hline & & & & 5 & 1.006 & & & 1.143 & 1.122 & 1.027 & 0.703 \\
\hline & & & & 6 & 0.982 & & 1.129 & 1.133 & 1.098 & 0.996 & 0.663 \\
\hline \multirow{3}{*}{10} & \multirow{3}{*}{3} & \multirow{3}{*}{0.1} & \multirow{3}{*}{2} & 3 & 0.974 & & & & & 1.152 & 0.874 \\
\hline & & & & 4 & 0.930 & & & & 1.132 & 1.111 & 0.826 \\
\hline & & & & 5 & 0.905 & & & 1.111 & 1.117 & 1.077 & 0.791 \\
\hline \multirow{3}{*}{10} & \multirow{3}{*}{3} & \multirow{3}{*}{0.1} & \multirow{3}{*}{$4^{*}$} & 3 & 0.984 & & & & & 1.130 & 0.886 \\
\hline & & & & 4 & 0.937 & & & & 1.123 & 1.099 & 0.841 \\
\hline & & & & 5 & 0.901 & & & 1.104 & 1.124 & 1.073 & 0.798 \\
\hline \multirow{3}{*}{10} & \multirow{3}{*}{3} & \multirow{3}{*}{0.1} & \multirow{3}{*}{6} & 3 & 0.987 & & & & & 1.124 & 0.889 \\
\hline & & & & 4 & 0.945 & & & & 1.116 & 1.090 & 0.850 \\
\hline & & & & 5 & 0.911 & & & 1.100 & 1.113 & 1.065 & 0.811 \\
\hline \multirow{3}{*}{10} & \multirow{3}{*}{3} & \multirow{3}{*}{0.2} & \multirow{3}{*}{4} & 3 & 1.028 & & & & & 1.140 & 0.832 \\
\hline & & & & 4 & 0.983 & & & & 1.141 & 1.092 & 0.784 \\
\hline & & & & 5 & 0.954 & & & 1.127 & 1.122 & 1.057 & 0.740 \\
\hline \multirow{3}{*}{10} & \multirow{3}{*}{3} & \multirow{3}{*}{0.2} & \multirow{3}{*}{$6^{*}$} & 3 & 1.033 & & & & & 1.126 & 0.841 \\
\hline & & & & 4 & 0.981 & & & & 1.133 & 1.088 & 0.798 \\
\hline & & & & 5 & 0.942 & & & 1.117 & 1.130 & 1.060 & 0.751 \\
\hline & & & & 3 & 1.028 & & & & & 1.132 & 0.840 \\
\hline 10 & 3 & 0.2 & 9 & 4 & 0.980 & & & & 1.135 & 1.086 & 0.799 \\
\hline & & & & 5 & 0.946 & & & 1.120 & 1.122 & 1.054 & 0.757 \\
\hline & & & & 3 & 1.058 & & & & & 1.163 & 0.779 \\
\hline 10 & 3 & 0.3 & 4 & 4 & 1.022 & & & & 1.164 & 1.092 & 0.722 \\
\hline & & & & 5 & 0.996 & & & 1.151 & 1.133 & 1.048 & 0.673 \\
\hline & & & & 3 & 1.074 & & & & & 1.141 & 0.784 \\
\hline 10 & 3 & 0.3 & $6^{*}$ & 4 & 1.015 & & & & 1.157 & 1.092 & 0.736 \\
\hline & & & & 5 & 0.974 & & & 1.139 & 1.145 & 1.059 & 0.683 \\
\hline & & & & 3 & 1.068 & & & & & 1.147 & 0.784 \\
\hline 10 & 3 & 0.3 . & 9 & 4 & 1.012 & & & & 1.161 & 1.091 & 0.737 \\
\hline & & & & 5 & 0.975 & & & 1.145 & 1.141 & 1.053 & 0.686 \\
\hline
\end{tabular}


Table 4.16a: Reaction Distribution factors $\mathrm{R}_{\mathrm{M}}$ for $10 \mathrm{~m}$ span bridge (Continue...)

\begin{tabular}{|c|c|c|c|c|c|c|c|c|c|c|c|}
\hline \multicolumn{5}{|c|}{ Bridge Dimensions } & \multirow{2}{*}{\multicolumn{7}{|c|}{ Reaction Dist. Factor : $\mathbf{R}_{\mathbf{M}}$}} \\
\hline $\begin{array}{l}\text { Span } \\
\text { (m) }\end{array}$ & $\begin{array}{l}\text { Girder } \\
\text { Spacing }\end{array}$ & $\begin{array}{l}\text { Span } \\
\text { Radius }\end{array}$ & $\begin{array}{l}\text { No. of } \\
\text { Bracing }\end{array}$ & $\begin{array}{l}\text { No. of } \\
\text { Girders }\end{array}$ & & & & & & & \\
\hline$L$ & $\mathrm{~s}$ & $L / R$ & & $\mathrm{~N}$ & $G_{\text {Ext }}$ & $G_{5}$ & $G_{4}$ & $\mathrm{G}_{3}$ & $\mathrm{G}_{2}$ & $G_{1}$ & $G_{\text {int }}$ \\
\hline \multirow{5}{*}{10} & \multirow{5}{*}{2} & \multirow{5}{*}{0.3} & \multirow{5}{*}{9} & 3 & 1.138 & & & & & 1.111 & 0.751 \\
\hline & & & & 4 & 1.080 & & & & 1.147 & 1.039 & 0.734 \\
\hline & & & & 5 & 1.037 & & & 1.136 & 1.102 & 1.004 & 0.721 \\
\hline & & & & 6 & 1.019 & & 1.134 & 1.120 & 1.072 & 0.970 & 0.685 \\
\hline & & & & 7 & 1.006 & 1.118 & 1.120 & 1.100 & 1.051 & 0.944 & 0.661 \\
\hline \multirow{3}{*}{10} & \multirow{4}{*}{2.5} & \multirow{4}{*}{0.1} & \multirow{4}{*}{2} & 3 & 0.990 & & & & & 1.131 & 0.879 \\
\hline & & & & 4 & 0.951 & & & & 1.116 & 1.093 & 0.840 \\
\hline & & & & 5 & 0.928 & & & 1.099 & 1.101 & 1.063 & 0.810 \\
\hline \multirow{4}{*}{10} & & & & 6 & 0.914 & & 1.086 & 1.095 & 1.081 & 1.039 & 0.786 \\
\hline & \multirow{3}{*}{2.5} & \multirow{3}{*}{0.1} & \multirow{3}{*}{$4^{*}$} & 3 & 1.005 & & & & & $\frac{1.098}{1079}$ & 0.897 \\
\hline & & & & $\frac{4}{5}$ & 0.959 & & & 1.094 & $\frac{1.107}{1.101}$ & $\frac{1.079}{1.055}$ & 0.854 \\
\hline & & & & $\frac{5}{6}$ & 0.928 & & 1.078 & 1.103 & 1.092 & 1.033 & 0.021 \\
\hline \multirow{4}{*}{10} & \multirow{4}{*}{2.5} & \multirow{4}{*}{0.1} & \multirow{4}{*}{6} & 3 & 1.001 & & & & & 1.108 & 0.891 \\
\hline & & & & 4 & 0.963 & & & & 1.104 & 1.074 & 0.859 \\
\hline & & & & 5 & 0.936 & & & 1.091 & 1.092 & 1.048 & 0.832 \\
\hline & & & & 6 & 0.906 & & 1.077 & 1.096 & 1.084 & 1.031 & 0.806 \\
\hline \multirow{3}{*}{10} & \multirow{4}{*}{2.5} & \multirow{4}{*}{0.2} & \multirow{4}{*}{4} & 3 & 1.049 & & & & & 1.122 & 0.829 \\
\hline & & & & 4 & 1.005 & & & & 1.128 & 1.072 & 0.795 \\
\hline & & & & 5 & 0.980 & & & 1.120 & 1.103 & 1.037 & 0.760 \\
\hline \multirow{4}{*}{10} & & & & 6 & 0.964 & & 1.109 & 1.109 & 1.081 & $\frac{1.009}{1.23}$ & 0.728 \\
\hline & \multirow{3}{*}{2.5} & \multirow{3}{*}{0.2} & & 3 & 1.048 & & & & 1.122 & $\begin{array}{l}1.123 \\
1.065 \\
\end{array}$ & \begin{tabular}{|l|l|}
0.829 \\
0.805 \\
\end{tabular} \\
\hline & & & $6^{*}$ & $\frac{4}{5}$ & $\frac{1.008}{0.973}$ & & & 1.111 & 1.107 & \begin{tabular}{|l|l}
1.037 \\
\end{tabular} & 0.771 \\
\hline & & & & 6 & 0.947 & & 1.096 & 1.115 & 1.094 & 1.013 & \begin{tabular}{|l}
0.735 \\
\end{tabular} \\
\hline & & & & 3 & 1.050 & & & & & 1.115 & \begin{tabular}{|l}
0.835 \\
\end{tabular} \\
\hline & & & & 4 & 1.004 & & & & 1.125 & 1.066 & 0.805 \\
\hline 10 & 2.5 & 0.2 & g & 5 & 0.974 & & & 1.115 & 1.103 & 1.034 & 0.775 \\
\hline & & & & 6 & 0.951 & & 1.102 & 1.111 & 1.085 & 1.009 & 0.742 \\
\hline & & & & 3 & 1.100 & & & & & 1.134 & 0.767 \\
\hline 10 & 2.5 & 0.3 & 4 & 4 & 1.051 & & & & 1.153 & 1.067 & 0.728 \\
\hline & 2.0 & 0.0 & ${ }^{\circ}$ & 5 & 1.024 & & & 1.146 & 1.116 & 1.024 & 0.690 \\
\hline & & & & 6 & 1.011 & & 1.138 & 1.124 & 1.083 & $\begin{array}{l}0.989 \\
1.122\end{array}$ & $\frac{0.654}{0.772}$ \\
\hline & & & & $\frac{3}{4}$ & $\frac{1.105}{1.047}$ & & & & 1.148 & 1.065 & 0.740 \\
\hline 10 & 2.5 & 0.3 & $6^{*}$ & 5 & 1.008 & & & 1.137 & 1.123 & 1.030 & 0.702 \\
\hline & & & & 6 & 1.011 & & 1.153 & 1.165 & 1.135 & 0.857 & 0.679 \\
\hline
\end{tabular}

Table 4.16a: Reaction Distribution factors $\mathrm{R}_{\mathrm{M}}$ for $10 \mathrm{~m}$ span bridge (Continue...)

\begin{tabular}{|c|c|c|c|c|c|c|c|c|c|c|c|}
\hline \multicolumn{5}{|c|}{ Bridge Dimensions } & \multirow{2}{*}{\multicolumn{7}{|c|}{ Reaction Dist. Factor : $\mathbf{R}_{\mathbf{M}}$}} \\
\hline $\begin{array}{c}\text { Span } \\
\text { (m) }\end{array}$ & $\begin{array}{l}\text { Girder } \\
\text { Spacing }\end{array}$ & $\begin{array}{l}\text { Span } \\
\text { Radius }\end{array}$ & $\begin{array}{l}\text { No. of } \\
\text { Bracing }\end{array}$ & $\begin{array}{l}\text { No. of } \\
\text { Girders }\end{array}$ & & & & & & & \\
\hline$L$ & $\mathrm{~s}$ & $L / R$ & & $\mathrm{~N}$ & $G_{\text {Ext }}$ & $\mathrm{G}_{5}$ & $\mathrm{G}_{4}$ & $G_{3}$ & $G_{2}$ & $G_{1}$ & $G_{\text {int }}$ \\
\hline \multirow{4}{*}{10} & \multirow{4}{*}{2.5} & \multirow{4}{*}{0.3} & \multirow{4}{*}{9} & 3 & 1.098 & & & & & 1.129 & 0.773 \\
\hline & & & & 4 & 1.042 & & & & 1.153 & 1.066 & 0.740 \\
\hline & & & & 5 & 1.006 & & & 1.143 & 1.122 & 1.027 & 0.703 \\
\hline & & & & 6 & 0.982 & & 1.129 & 1.133 & 1.098 & 0.996 & 0.663 \\
\hline \multirow{3}{*}{10} & \multirow{3}{*}{3} & \multirow{3}{*}{0.1} & \multirow{3}{*}{2} & 3 & 0.974 & & & & & 1.152 & 0.874 \\
\hline & & & & 4 & 0.930 & & & & 1.132 & 1.111 & 0.826 \\
\hline & & & & 5 & 0.905 & & & 1.111 & 1.117 & 1.077 & 0.791 \\
\hline \multirow{3}{*}{10} & \multirow{3}{*}{3} & \multirow{3}{*}{0.1} & \multirow{3}{*}{$4^{*}$} & 3 & 0.984 & & & & & 1.130 & 0.886 \\
\hline & & & & 4 & 0.937 & & & & 1.123 & 1.099 & 0.841 \\
\hline & & & & 5 & 0.901 & & & 1.104 & 1.124 & 1.073 & 0.798 \\
\hline \multirow{3}{*}{10} & \multirow{3}{*}{3} & \multirow{3}{*}{0.1} & \multirow{3}{*}{6} & 3 & 0.987 & & & & & 1.124 & 0.889 \\
\hline & & & & 4 & 0.945 & & & & 1.116 & 1.090 & 0.850 \\
\hline & & & & 5 & 0.911 & & & 1.100 & 1.113 & 1.065 & 0.811 \\
\hline \multirow{3}{*}{10} & \multirow{3}{*}{3} & \multirow{3}{*}{0.2} & \multirow{3}{*}{4} & 3 & 1.028 & & & & & 1.140 & 0.832 \\
\hline & & & & 4 & 0.983 & & & & 1.141 & 1.092 & 0.784 \\
\hline & & & & 5 & 0.954 & & & 1.127 & 1.122 & 1.057 & 0.740 \\
\hline \multirow{3}{*}{10} & \multirow{3}{*}{3} & \multirow{3}{*}{0.2} & \multirow{3}{*}{$6^{*}$} & 3 & 1.033 & & & & & 1.126 & 0.841 \\
\hline & & & & 4 & 0.981 & & & & 1.133 & 1.088 & 0.798 \\
\hline & & & & 5 & 0.942 & & & 1.117 & 1.130 & 1.060 & 0.751 \\
\hline & & & & 3 & 1.028 & & & & & 1.132 & 0.840 \\
\hline 10 & 3 & 0.2 & 9 & 4 & 0.980 & & & & 1.135 & 1.086 & 0.799 \\
\hline & & & & 5 & 0.946 & & & 1.120 & 1.122 & 1.054 & 0.757 \\
\hline & & & & 3 & 1.058 & & & & & 1.163 & 0.779 \\
\hline 10 & 3 & 0.3 & 4 & 4 & 1.022 & & & & 1.164 & 1.092 & 0.722 \\
\hline & & & & 5 & 0.996 & & & 1.151 & 1.133 & 1.048 & 0.673 \\
\hline & & & & 3 & 1.074 & & & & & 1.141 & 0.784 \\
\hline 10 & 3 & 0.3 & $6^{*}$ & 4 & 1.015 & & & & 1.157 & 1.092 & 0.736 \\
\hline & & & & 5 & 0.974 & & & 1.139 & 1.145 & 1.059 & 0.683 \\
\hline & & & & 3 & 1.068 & & & & & 1.147 & 0.784 \\
\hline 10 & 3 & 0.3 & 9 & 4 & 1.012 & & & & 1.161 & 1.091 & 0.737 \\
\hline & & & & 5 & 0.975 & & & 1.145 & 1.141 & 1.053 & 0.686 \\
\hline
\end{tabular}




\begin{tabular}{|c|c|c|c|c|c|c|c|c|c|c|c|}
\hline \multicolumn{5}{|c|}{ Bridge Dimensions } & \multirow{2}{*}{\multicolumn{7}{|c|}{ Reaction Dist. Factor: $\mathbf{R}_{\mathbf{M}}$}} \\
\hline $\begin{array}{c}\text { Span } \\
(\mathrm{m})\end{array}$ & $\begin{array}{c}\text { Girder } \\
\text { Spacing }\end{array}$ & $\begin{array}{c}\text { Span } \\
\text { Radius }\end{array}$ & \multirow{2}{*}{$\begin{array}{l}\text { No. of } \\
\text { Bracing } \\
\text { Intervals }\end{array}$} & \multirow{2}{*}{$\begin{array}{c}\begin{array}{l}\text { No. of } \\
\text { Girders }\end{array} \\
\mathrm{N} \\
\end{array}$} & & & & & & & \\
\hline $\mathrm{L}$ & $s$ & $L / R$ & & & $\mathrm{G}_{\text {Ext }}$ & $G_{5}$ & $\mathrm{G}_{4}$ & $G_{3}$ & $G_{2}$ & $G_{1}$ & $G_{\text {int }}$ \\
\hline \multirow{5}{*}{15} & \multirow{5}{*}{2} & \multirow{5}{*}{0.1} & \multirow{5}{*}{$4^{\star}$} & 3 & 1.057 & & & & & 1.075 & 0.868 \\
\hline & & & & 4 & 1.025 & & & & 1.082 & 1.032 & 0.862 \\
\hline & & & & 5 & 1.004 & & & 1.078 & 1.051 & 1.012 & 0.855 \\
\hline & & & & 6 & 0.989 & & 1.072 & 1.058 & 1.035 & 0.999 & 0.847 \\
\hline & & & & 7 & 0.976 & 1.066 & 1.061 & 1.047 & 1.024 & 0.988 & 0.837 \\
\hline \multirow{5}{*}{15} & \multirow{5}{*}{2} & \multirow{5}{*}{0.1} & \multirow{5}{*}{6} & 3 & 1.057 & & & & & 1.075 & 0.868 \\
\hline & & & & 4 & 1.024 & & & & 1.082 & 1.030 & 0.863 \\
\hline & & & & 5 & 1.005 & & & 1.078 & 1.049 & 1.010 & 0.858 \\
\hline & & & & 6 & 0.987 & & 1.073 & 1.055 & 1.032 & 0.999 & 0.855 \\
\hline & & & & 7 & 0.979 & 1.068 & 1.059 & 1.043 & 1.020 & 0.987 & 0.844 \\
\hline \multirow{5}{*}{15} & \multirow{5}{*}{2} & \multirow{5}{*}{0.1} & \multirow{5}{*}{8} & 3 & 1.061 & & & & & 1.068 & 0.871 \\
\hline & & & & 4 & 1.029 & & & & 1.078 & 1.026 & 0.868 \\
\hline & & & & 5 & 1.007 & & & 1.075 & 1.048 & 1.006 & 0.863 \\
\hline & & & & 6 & 0.992 & & 1.070 & 1.056 & 1.031 & 0.994 & 0.857 \\
\hline & & & & 7 & 0.980 & 1.064 & 1.058 & 1.044 & 1.020 & 0.984 & 0.849 \\
\hline \multirow{5}{*}{15} & \multirow{5}{*}{2} & \multirow{5}{*}{0.2} & \multirow{5}{*}{4} & 3 & 1.145 & & & & & 1.082 & 0.773 \\
\hline & & & & 4 & 1.098 & & & & 1.112 & 1.014 & 0.776 \\
\hline & & & & 5 & 1.059 & & & 1.104 & 1.063 & 0.991 & 0.783 \\
\hline & & & & 6 & 1.055 & & 1.102 & 1.067 & 1.033 & 0.970 & 0.774 \\
\hline & & & & 7 & 1.040 & 1.108 & 1.083 & 1.051 & 1.009 & 0.949 & 0.759 \\
\hline \multirow{5}{*}{15} & \multirow{5}{*}{2} & & & 3 & 1.151 & & & & & 1.075 & 0.774 \\
\hline & & & & 4 & 1.101 & & & & 1.110 & 1.008 & 0.781 \\
\hline & & 0.2 & $6^{*}$ & 5 & 1.047 & & & 1.098 & 1.063 & 0.992 & 0.799 \\
\hline & & & & 6 & 1.044 & & 1.097 & 1.068 & 1.036 & 0.970 & 0.786 \\
\hline & & & & 7 & 1.030 & 1.102 & 1.085 & 1.057 & 1.013 & 0.947 & 0.767 \\
\hline & & & & 3 & 1.148 & & & & & 1.078 & 0.774 \\
\hline & & & & 4 & 1.098 & & & & 1.113 & 1.009 & 0.780 \\
\hline 15 & 2 & 0.2 & 8 & 5 & 1.058 & & & 1.107 & 1.062 & 0.985 & 0.788 \\
\hline & & & & 6 & 1.049 & & 1.104 & 1.069 & 1.033 & 0.965 & 0.781 \\
\hline & & & & 7 & 1.032 & 1.106 & 1.085 & 1.053 & 1.009 & 0.946 & 0.769 \\
\hline & & & & 3 & 1.235 & & & & & 1.090 & 0.675 \\
\hline & & & & 4 & 1.161 & & & & 1.142 & 0.997 & 0.699 \\
\hline 15 & 2 & 0.3 & 6 & 5 & 1.128 & & & 1.155 & 1.072 & 0.954 & 0.691 \\
\hline & & & & 6 & 1.102 & & 1.152 & 1.101 & 1.031 & 0.928 & 0.686 \\
\hline & & & & 7 & 1.085 & 1.147 & 1.114 & 1.067 & 1.003 & 0.908 & 0.676 \\
\hline & & & & 3 & 1.243 & & & & & 1.082 & 0.675 \\
\hline & & & & 4 & 1.166 & & & & 1.141 & 0.992 & 0.701 \\
\hline 15 & 2 & 0.3 & $8^{*}$ & 5 & 1.126 & & & 1.151 & 1.073 & 0.952 & 0.698 \\
\hline & & & & 6 & 1.090 & & 1.146 & 1.103 & 1.036 & 0.930 & 0.695 \\
\hline & & & & 7 & 1.071 & 1.135 & 1.113 & 1.074 & 1.011 & 0.911 & 0.686 \\
\hline
\end{tabular}

\begin{tabular}{|c|c|c|c|c|c|c|c|c|c|c|c|}
\hline \multicolumn{5}{|c|}{ Bridge Dimensions } & \multirow{2}{*}{\multicolumn{7}{|c|}{ Reaction Dist. Factor : $\mathbf{R}_{\mathbf{M}}$}} \\
\hline $\begin{array}{c}\text { Span } \\
(\mathrm{m})\end{array}$ & $\begin{array}{l}\text { Girder } \\
\text { Spacing }\end{array}$ & $\begin{array}{c}\text { Span } \\
\text { Radius }\end{array}$ & $\begin{array}{l}\text { No. of } \\
\text { Bracing }\end{array}$ & $\begin{array}{l}\text { No. of } \\
\text { Girders }\end{array}$ & & & & & & & \\
\hline$L$ & $\mathrm{~s}$ & $L / R$ & & $\mathrm{~N}$ & $G_{E x t}$ & $G_{5}$ & $G_{4}$ & $\mathrm{G}_{3}$ & $\mathrm{G}_{2}$ & $G_{1}$ & $G_{i n t}$ \\
\hline \multirow{5}{*}{15} & \multirow{5}{*}{2} & \multirow{5}{*}{0.3} & \multirow{5}{*}{12} & 3 & 1.239 & & & & & 1.085 & 0.676 \\
\hline & & & & 4 & 1.164 & & & & 1.146 & 0.992 & 0.697 \\
\hline & & & & 5 & 1.123 & & & 1.154 & 1.073 & 0.952 & 0.698 \\
\hline & & & & 6 & 1.093 & & 1.148 & 1.103 & 1.034 & 0.928 & 0.695 \\
\hline & & & & 7 & 1.070 & 1.140 & 1.114 & 1.072 & 1.008 & 0.909 & 0.687 \\
\hline \multirow{4}{*}{15} & \multirow{4}{*}{2.5} & \multirow{4}{*}{0.1} & \multirow{4}{*}{$4^{*}$} & 3 & 1.036 & & & & & 1.085 & 0.880 \\
\hline & & & & 4 & 1.002 & & & & 1.087 & 1.046 & 0.865 \\
\hline & & & & 5 & 0.980 & & & 1.080 & 1.064 & 1.025 & 0.851 \\
\hline & & & & 6 & 0.963 & & 1.072 & 1.070 & 1.050 & 1.009 & 0.835 \\
\hline \multirow{4}{*}{15} & \multirow{4}{*}{2.5} & \multirow{4}{*}{0.1} & \multirow{4}{*}{6} & 3 & 1.035 & & & & & 1.084 & 0.881 \\
\hline & & & & 4 & 1.001 & & & & 1.085 & 1.045 & 0.869 \\
\hline & & & & 5 & 0.983 & & & 1.079 & 1.060 & 1.022 & 0.856 \\
\hline & & & & 6 & 0.967 & & 1.073 & 1.066 & 1.045 & 1.007 & 0.843 \\
\hline \multirow{4}{*}{15} & \multirow{4}{*}{2.5} & \multirow{4}{*}{0.1} & \multirow{4}{*}{8} & 3 & 1.040 & & & & & 1.075 & 0.884 \\
\hline & & & & 4 & 1.008 & & & & 1.081 & 1.039 & 0.873 \\
\hline & & & & 5 & 0.986 & & & 1.075 & 1.059 & 1.018 & 0.862 \\
\hline & & & & 6 & 0.969 & & 1.068 & 1.065 & 1.045 & 1.004 & 0.849 \\
\hline \multirow{4}{*}{15} & \multirow{4}{*}{2.5} & \multirow{4}{*}{0.2} & \multirow{4}{*}{4} & 3 & 1.106 & & & & & 1.094 & 0.800 \\
\hline & & & & 4 & 1.063 & & & & 1.113 & 1.033 & 0.790 \\
\hline & & & & 5 & 1.024 & & & 1.101 & 1.077 & 1.010 & 0.788 \\
\hline & & & & 6 & 1.023 & & 1.098 & 1.075 & 1.049 & 0.986 & 0.769 \\
\hline \multirow{4}{*}{15} & & & & 3 & 1.112 & & & & & 1.085 & 0.803 \\
\hline & & & & 4 & 1.066 & & & & 1.110 & 1.028 & 0.797 \\
\hline & 2.5 & 0.2 & ${ }^{6}$ & 5 & 1.010 & & & 1.092 & 1.077 & 1.012 & 0.808 \\
\hline & & & & 6 & 1.010 & & 1.089 & 1.077 & 1.054 & 0.988 & 0.783 \\
\hline & & & & 3 & 1.109 & & & & & 1.088 & 0.803 \\
\hline & & & & 4 & 1.064 & & & & 1.112 & 1.028 & 0.796 \\
\hline 15 & 2.5 & 0.2 & 8 & 5 & 1.024 & & & 1.101 & 1.075 & 1.004 & 0.796 \\
\hline & & & & 6 & 1.017 & & 1.097 & 1.077 & 1.048 & 0.981 & 0.779 \\
\hline & & & & 3 & 1.179 & & & & & 1.102 & 0.719 \\
\hline & & & & 4 & 1.120 & & & & 1.144 & 1.021 & 0.715 \\
\hline 15 & 2.5 & 0.3 & 6 & 5 & 1.085 & & & 1.147 & 1.085 & 0.979 & 0.704 \\
\hline & & & & 6 & 1.063 & & 1.142 & 1.108 & 1.050 & 0.951 & 0.686 \\
\hline & & & & 3 & 1.186 & & & & & 1.092 & 0.722 \\
\hline 15 & 25 & 03 & $8^{*}$ & 4 & 1.122 & & & & 1.139 & 1.017 & 0.722 \\
\hline 10 & 2.0 & 0.0 & 0 & 5 & 1.080 & & & 1.140 & 1.087 & 0.979 & 0.714 \\
\hline & & & & 6 & 1.051 & & 1.130 & 1.110 & 1.057 & 0.954 & 0.698 \\
\hline
\end{tabular}




\begin{tabular}{|c|c|c|c|c|c|c|c|c|c|c|c|}
\hline \multicolumn{5}{|c|}{ Bridge Dimensions } & \multirow{2}{*}{\multicolumn{7}{|c|}{ Reaction Dist. Factor: $\mathbf{R}_{\mathbf{M}}$}} \\
\hline $\begin{array}{c}\text { Span } \\
(\mathrm{m})\end{array}$ & $\begin{array}{l}\text { Girder } \\
\text { Spacing }\end{array}$ & \begin{tabular}{|c|} 
Span \\
Radius
\end{tabular} & $\begin{array}{l}\text { No. of } \\
\text { Bracing }\end{array}$ & $\begin{array}{l}\text { No. of } \\
\text { Girders }\end{array}$ & & & & & & & \\
\hline L & $s$ & $L / R$ & & $\mathrm{~N}$ & $G_{\text {Ext }}$ & $G_{5}$ & $G_{4}$ & $G_{3}$ & $\mathrm{G}_{2}$ & $G_{1}$ & $G_{\text {int }}$ \\
\hline \multirow{5}{*}{15} & \multirow{5}{*}{2} & \multirow{5}{*}{0.1} & \multirow{5}{*}{$4^{*}$} & 3 & 1.057 & & & & & 1.075 & 0.868 \\
\hline & & & & 4 & 1.025 & & & & 1.082 & 1.032 & 0.862 \\
\hline & & & & 5 & 1.004 & & & 1.078 & 1.051 & 1.012 & 0.855 \\
\hline & & & & 6 & 0.989 & & 1.072 & 1.058 & 1.035 & 0.999 & 0.847 \\
\hline & & & & 7 & 0.976 & 1.066 & 1.061 & 1.047 & 1.024 & 0.988 & 0.837 \\
\hline \multirow{5}{*}{15} & \multirow{5}{*}{2} & \multirow{5}{*}{0.1} & \multirow{5}{*}{6} & 3 & 1.057 & & & & & 1.075 & 0.868 \\
\hline & & & & 4 & 1.024 & & & & 1.082 & 1.030 & 0.863 \\
\hline & & & & 5 & 1.005 & & & 1.078 & 1.049 & 1.010 & 0.858 \\
\hline & & & & 6 & 0.987 & & 1.073 & 1.055 & 1.032 & 0.999 & 0.855 \\
\hline & & & & 7 & 0.979 & 1.068 & 1.059 & 1.043 & 1.020 & 0.987 & 0.844 \\
\hline \multirow{5}{*}{15} & \multirow{5}{*}{2} & \multirow{5}{*}{0.1} & \multirow{5}{*}{8} & 3 & 1.061 & & & & & 1.068 & 0.871 \\
\hline & & & & 4 & 1.029 & & & & 1.078 & 1.026 & 0.868 \\
\hline & & & & 5 & 1.007 & & & 1.075 & 1.048 & 1.006 & 0.863 \\
\hline & & & & 6 & 0.992 & & 1.070 & 1.056 & 1.031 & 0.994 & 0.857 \\
\hline & & & & 7 & 0.980 & 1.064 & 1.058 & 1.044 & 1.020 & 0.984 & 0.849 \\
\hline \multirow{5}{*}{15} & \multirow{5}{*}{2} & \multirow{5}{*}{0.2} & \multirow{5}{*}{4} & 3 & 1.145 & & & & & 1.082 & 0.773 \\
\hline & & & & 4 & 1.098 & & & & 1.112 & 1.014 & 0.776 \\
\hline & & & & 5 & 1.059 & & & 1.104 & 1.063 & 0.991 & 0.783 \\
\hline & & & & 6 & 1.055 & & 1.102 & 1.067 & 1.033 & 0.970 & 0.774 \\
\hline & & & & 7 & 1.040 & 1.108 & 1.083 & 1.051 & 1.009 & 0.949 & 0.759 \\
\hline \multirow{5}{*}{15} & \multirow{5}{*}{2} & \multirow{5}{*}{0.2} & \multirow{5}{*}{$6^{*}$} & 3 & 1.151 & & & & & 1.075 & 0.774 \\
\hline & & & & 4 & 1.101 & & & & 1.110 & 1.008 & 0.781 \\
\hline & & & & 5 & 1.047 & & & 1.098 & 1.063 & 0.992 & 0.799 \\
\hline & & & & 6 & 1.044 & & 1.097 & 1.068 & 1.036 & 0.970 & 0.786 \\
\hline & & & & 7 & 1.030 & 1.102 & 1.085 & 1.057 & 1.013 & 0.947 & 0.767 \\
\hline & & & & 3 & 1.148 & & & & & 1.078 & 0.774 \\
\hline & & & & 4 & 1.098 & & & & 1.113 & 1.009 & 0.780 \\
\hline 15 & 2 & 0.2 & 8 & 5 & 1.058 & & & 1.107 & 1.062 & 0.985 & 0.788 \\
\hline & & & & 6 & 1.049 & & 1.104 & 1.069 & 1.033 & 0.965 & 0.781 \\
\hline & & & & 7 & 1.032 & 1.106 & 1.085 & 1.053 & 1.009 & 0.946 & 0.769 \\
\hline & & & & 3 & 1.235 & & & & & 1.090 & 0.675 \\
\hline & & & & 4 & 1.161 & & & & 1.142 & 0.997 & 0.699 \\
\hline 15 & 2 & 0.3 & 6 & 5 & 1.128 & & & 1.155 & 1.072 & 0.954 & 0.691 \\
\hline & & & & 6 & 1.102 & & 1.152 & 1.101 & 1.031 & 0.928 & 0.686 \\
\hline & & & & 7 & 1.085 & 1.147 & 1.114 & 1.067 & 1.003 & 0.908 & 0.676 \\
\hline & & & & 3 & 1.243 & & & & & 1.082 & 0.675 \\
\hline & & & & 4 & 1.166 & & & & 1.141 & 0.992 & 0.701 \\
\hline 15 & 2 & 0.3 & $8^{*}$ & 5 & 1.126 & & & 1.151 & 1.073 & 0.952 & 0.698 \\
\hline & & & & 6 & 1.090 & & 1.146 & 1.103 & 1.036 & 0.930 & 0.695 \\
\hline & & & & 7 & 1.071 & 1.135 & 1.113 & 1.074 & 1.011 & 0.911 & 0.686 \\
\hline
\end{tabular}

\begin{tabular}{|c|c|c|c|c|c|c|c|c|c|c|c|}
\hline \multicolumn{5}{|c|}{ Bridge Dimensions } & \multirow{2}{*}{\multicolumn{7}{|c|}{ Reaction Dist. Factor : $\mathbf{R}_{\mathbf{M}}$}} \\
\hline $\begin{array}{c}\text { Span } \\
\text { (m) }\end{array}$ & $\begin{array}{l}\text { Girder } \\
\text { Spacing }\end{array}$ & $\begin{array}{l}\text { Span } \\
\text { Radius }\end{array}$ & $\begin{array}{l}\text { No. of } \\
\text { Bracinc }\end{array}$ & $\begin{array}{l}\text { No. of } \\
\text { Giders }\end{array}$ & & & & & & & \\
\hline$L$ & & $L / R$ & & $\mathrm{~N}$ & $G_{\text {Ext }}$ & $\mathrm{G}_{5}$ & $\mathrm{G}_{4}$ & $\mathrm{G}_{3}$ & $\mathrm{G}_{2}$ & $G_{1}$ & $G_{\text {int }}$ \\
\hline \multirow{5}{*}{15} & \multirow{5}{*}{2} & \multirow{5}{*}{0.3} & \multirow{5}{*}{12} & 3 & 1.239 & & & & & 1.085 & 0.676 \\
\hline & & & & 4 & 1.164 & & & & 1.146 & 0.992 & 0.697 \\
\hline & & & & 5 & 1.123 & & & 1.154 & 1.073 & 0.952 & 0.698 \\
\hline & & & & 6 & 1.093 & & 1.148 & 1.103 & 1.034 & 0.928 & 0.695 \\
\hline & & & & 7 & 1.070 & 1.140 & 1.114 & 1.072 & 1.008 & 0.909 & 0.687 \\
\hline \multirow{4}{*}{15} & \multirow{4}{*}{2.5} & \multirow{4}{*}{0.1} & \multirow{4}{*}{$4^{*}$} & 3 & 1.036 & & & & & 1.085 & 0.880 \\
\hline & & & & 4 & 1.002 & & & & 1.087 & 1.046 & 0.865 \\
\hline & & & & 5 & 0.980 & & & 1.080 & 1.064 & 1.025 & 0.851 \\
\hline & & & & 6 & 0.963 & & 1.072 & 1.070 & 1.050 & 1.009 & 0.835 \\
\hline \multirow{4}{*}{15} & \multirow{4}{*}{2.5} & \multirow{4}{*}{0.1} & \multirow{4}{*}{6} & 3 & 1.035 & & & & & 1.084 & 0.881 \\
\hline & & & & 4 & 1.001 & & & & 1.085 & 1.045 & 0.869 \\
\hline & & & & 5 & 0.983 & & & 1.079 & 1.060 & 1.022 & 0.856 \\
\hline & & & & 6 & 0.967 & & 1.073 & 1.066 & 1.045 & 1.007 & 0.843 \\
\hline \multirow{4}{*}{15} & \multirow{4}{*}{2.5} & \multirow{4}{*}{0.1} & \multirow{4}{*}{8} & 3 & 1.040 & & & & & 1.075 & 0.884 \\
\hline & & & & 4 & 1.008 & & & & 1.081 & 1.039 & 0.873 \\
\hline & & & & 5 & 0.986 & & & 1.075 & 1.059 & 1.018 & 0.862 \\
\hline & & & & 6 & 0.969 & & 1.068 & 1.065 & 1.045 & 1.004 & 0.849 \\
\hline \multirow{4}{*}{15} & \multirow{4}{*}{2.5} & \multirow{4}{*}{0.2} & \multirow{4}{*}{4} & 3 & 1.106 & & & & & 1.094 & 0.800 \\
\hline & & & & 4 & 1.063 & & & & 1.113 & 1.033 & 0.790 \\
\hline & & & & 5 & 1.024 & & & 1.101 & 1.077 & 1.010 & 0.788 \\
\hline & & & & 6 & 1.023 & & 1.098 & 1.075 & 1.049 & 0.986 & 0.769 \\
\hline \multirow{4}{*}{15} & & & & 3 & 1.112 & & & & & 1.085 & 0.803 \\
\hline & & 02 & $\sigma^{*}$ & 4 & 1.066 & & & & 1.110 & 1.028 & 0.797 \\
\hline & 2.5 & 0.2 & $6^{6 x}$ & 5 & 1.010 & & & 1.092 & 1.077 & 1.012 & 0.808 \\
\hline & & & & 6 & 1.010 & & 1.089 & 1.077 & 1.054 & 0.988 & 0.783 \\
\hline & & & & 3 & 1.109 & & & & & 1.088 & 0.803 \\
\hline 15 & & & & 4 & 1.064 & & & & 1.112 & 1.028 & 0.796 \\
\hline & 2.5 & 0.2 & 8 & 5 & 1.024 & & & 1.101 & 1.075 & 1.004 & 0.796 \\
\hline & & & & 6 & 1.017 & & 1.097 & 1.077 & 1.048 & 0.981 & 0.779 \\
\hline & & & & 3 & 1.179 & & & & & 1.102 & 0.719 \\
\hline 15 & 25 & 03 & 6 & 4 & 1.120 & & & & 1.144 & 1.021 & 0.715 \\
\hline & 2.5 & & 0 & 5 & 1.085 & & & 1.147 & 1.085 & 0.979 & 0.704 \\
\hline & & & & 6 & 1.063 & & 1.142 & 1.108 & 1.050 & 0.951 & 0.686 \\
\hline & & & & 3 & 1.186 & & & & & 1.092 & 0.722 \\
\hline 15 & 25 & 0.3 & $8^{*}$ & 4 & 1.122 & & & & 1.139 & \begin{tabular}{|l}
1.017 \\
\end{tabular} & 0.722 \\
\hline & & & & 5 & 1.080 & & & 1.140 & 1.087 & 0.979 & 0.714 \\
\hline & & & & & 1.051 & & 1.130 & 1.110 & 1.057 & 0.954 & 0.698 \\
\hline
\end{tabular}




\begin{tabular}{|c|c|c|c|c|c|c|c|c|c|c|c|}
\hline \multicolumn{5}{|c|}{ Bridge Dimensions } & \multirow{2}{*}{\multicolumn{7}{|c|}{ Reaction Dist. Factor : $\mathbf{R}_{\mathbf{M}}$}} \\
\hline $\begin{array}{l}\text { Span } \\
(\mathrm{m})\end{array}$ & $\begin{array}{l}\text { Girder } \\
\text { Spacing }\end{array}$ & $\begin{array}{l}\text { Span } \\
\text { Radius }\end{array}$ & \multirow{2}{*}{$\begin{array}{l}\text { No. of } \\
\text { Bracing } \\
\text { Intervals }\end{array}$} & $\begin{array}{l}\text { No. of } \\
\text { Girders }\end{array}$ & & & & & & & \\
\hline L & $\mathrm{s}$ & $L / R$ & & $\mathrm{~N}$ & $G_{\text {Ext }}$ & $\mathrm{G}_{5}$ & $\mathrm{G}_{4}$ & $\mathrm{G}_{3}$ & $\mathrm{G}_{2}$ & $\mathrm{G}_{1}$ & $G_{\text {int }}$ \\
\hline \multirow{4}{*}{15} & \multirow{4}{*}{2.5} & \multirow{4}{*}{0.3} & \multirow{4}{*}{12} & 3 & 1.182 & & & & & 1.095 & 0.723 \\
\hline & & & & 4 & 1.120 & & & & 1.141 & 1.016 & 0.723 \\
\hline & & & & 5 & 1.079 & & & 1.142 & 1.086 & 0.977 & 0.715 \\
\hline & & & & 6 & 1.051 & & 1.134 & 1.109 & 1.053 & 0.952 & 0.700 \\
\hline \multirow{3}{*}{15} & \multirow{3}{*}{3} & \multirow{3}{*}{0.1} & \multirow{3}{*}{$4^{\star}$} & 3 & 1.019 & & & & & 1.097 & 0.885 \\
\hline & & & & 4 & 0.984 & & & & 1.094 & 1.060 & 0.862 \\
\hline & & & & 5 & 0.959 & & & 1.085 & 1.078 & 1.037 & 0.841 \\
\hline \multirow{3}{*}{15} & \multirow{3}{*}{3} & \multirow{3}{*}{0.1} & \multirow{3}{*}{6} & 3 & 1.019 & & & & & 1.095 & 0.886 \\
\hline & & & & 4 & 0.985 & & & & 1.093 & 1.057 & 0.865 \\
\hline & & & & 5 & 0.964 & & & 1.077 & 1.073 & 1.036 & 0.850 \\
\hline \multirow{3}{*}{15} & \multirow{3}{*}{3} & \multirow{3}{*}{0.1} & \multirow{3}{*}{8} & 3 & 1.024 & & & & & 1.085 & 0.891 \\
\hline & & & & 4 & 0.991 & & & & 1.087 & 1.050 & 0.873 \\
\hline & & & & 5 & 0.967 & & & 1.079 & 1.070 & 1.029 & 0.855 \\
\hline \multirow{3}{*}{15} & \multirow{3}{*}{3} & \multirow{3}{*}{0.2} & \multirow{3}{*}{4} & 3 & 1.078 & & & & & 1.107 & 0.815 \\
\hline & & & & 4 & 1.037 & & & & 1.118 & 1.050 & 0.795 \\
\hline & & & & 5 & 0.996 & & & 1.102 & 1.090 & 1.027 & 0.784 \\
\hline \multirow{3}{*}{15} & \multirow{3}{*}{3} & \multirow{3}{*}{0.2} & & 3 & 1.084 & & & & & 1.096 & 0.819 \\
\hline & & & $6^{*}$ & 4 & 1.039 & & & & 1.114 & 1.044 & 0.803 \\
\hline & & & & 5 & 0.980 & & & 1.091 & 1.091 & 1.031 & 0.807 \\
\hline & & & & 3 & 1.082 & & & & & 1.099 & 0.819 \\
\hline 15 & 3 & 0.2 & 8 & 4 & 1.038 & & & & 1.115 & 1.043 & 0.803 \\
\hline & & & & 5 & 0.998 & & & 1.101 & 1.086 & 1.021 & 0.794 \\
\hline & & & & 3 & 1.140 & & & & & 1.115 & 0.745 \\
\hline 15 & 3 & 0.3 & 6 & 4 & 1.086 & & & & 1.146 & 1.041 & 0.727 \\
\hline & & & & 5 & 1.052 & & & 1.145 & 1.099 & 1.001 & 0.703 \\
\hline & & & & 3 & 1.146 & & & & & 1.105 & 0.750 \\
\hline 15 & 3 & 0.3 & $8^{*}$ & 4 & 1.085 & & & & 1.140 & 1.038 & 0.737 \\
\hline & & & & 5 & 1.045 & & & 1.135 & 1.101 & 1.002 & 0.717 \\
\hline & & & & 3 & 1.143 & & & & & 1.107 & 0.750 \\
\hline 15 & 3 & 0.3 & 12 & 4 & 1.084 & & & & 1.141 & 1.037 & 0.738 \\
\hline & & & & 5 & 1.045 & & & 1.138 & 1.099 & 1.000 & 0.718 \\
\hline
\end{tabular}

\begin{tabular}{|c|c|c|c|c|c|c|c|c|c|c|c|}
\hline \multicolumn{5}{|c|}{ Bridge Dimensions } & \multirow{2}{*}{\multicolumn{7}{|c|}{ Reaction Dist. Factor : $\mathbf{R}_{\mathbf{M}}$}} \\
\hline $\begin{array}{l}\text { Span } \\
(\mathrm{m})\end{array}$ & $\begin{array}{l}\text { Girder } \\
\text { Spacing } \\
\text { (m) }\end{array}$ & $\begin{array}{l}\text { Span } \\
\text { Radius } \\
\text { Ratio }\end{array}$ & $\begin{array}{l}\text { No. of } \\
\text { Bracing } \\
\text { Intervals }\end{array}$ & $\begin{array}{l}\text { No. of } \\
\text { Girders }\end{array}$ & & & & & & & \\
\hline$L$ & $\mathrm{~s}$ & $L / R$ & & $\mathrm{~N}$ & $G_{\text {Ext }}$ & $G_{5}$ & $\mathrm{G}_{4}$ & $G_{3}$ & $G_{2}$ & $\mathrm{G}_{1}$ & $G_{\text {int }}$ \\
\hline \multirow{5}{*}{25} & \multirow{5}{*}{2} & \multirow{5}{*}{0.1} & \multirow{5}{*}{4} & 3 & 1.122 & & & & & 1.066 & 0.812 \\
\hline & & & & 4 & 1.087 & & & & 1.083 & 0.997 & 0.832 \\
\hline & & & & 5 & 1.066 & & & 1.089 & 1.021 & 0.983 & 0.842 \\
\hline & & & & 6 & 1.045 & & 1.106 & 1.028 & 0.993 & 0.985 & 0.842 \\
\hline & & & & 7 & 1.035 & 1.104 & 1.037 & 1.014 & 0.984 & 0.981 & 0.845 \\
\hline \multirow{5}{*}{25} & \multirow{5}{*}{2} & \multirow{5}{*}{0.1} & \multirow{5}{*}{$6^{*}$} & 3 & 1.124 & & & & & 1.065 & 0.811 \\
\hline & & & & 4 & 1.089 & & & & 1.084 & 0.994 & 0.833 \\
\hline & & & & 5 & 1.065 & & & 1.091 & 1.021 & 0.979 & 0.844 \\
\hline & & & & 6 & 1.041 & & 1.108 & 1.030 & 0.994 & 0.984 & 0.843 \\
\hline & & & & 7 & 1.030 & 1.105 & 1.040 & 1.016 & 0.984 & 0.979 & 0.846 \\
\hline \multirow{5}{*}{25} & \multirow{5}{*}{2} & \multirow{5}{*}{0.1} & \multirow{5}{*}{8} & 3 & 1.122 & & & & & 1.066 & 0.811 \\
\hline & & & & 4 & 1.087 & & & & 1.086 & 0.995 & 0.833 \\
\hline & & & & 5 & 1.063 & & & 1.092 & 1.021 & 0.980 & 0.844 \\
\hline & & & & 6 & 1.040 & & 1.109 & 1.031 & 0.993 & 0.984 & 0.843 \\
\hline & & & & 7 & 1.029 & 1.107 & 1.040 & 1.015 & 0.983 & 0.980 & 0.846 \\
\hline \multirow{5}{*}{25} & \multirow{5}{*}{2} & \multirow{5}{*}{0.3} & \multirow{5}{*}{6} & 3 & 1.424 & & & & & 1.076 & 0.500 \\
\hline & & & & 4 & 1.327 & & & & 1.184 & 0.919 & 0.570 \\
\hline & & & & 5 & 1.266 & & & 1.207 & 1.040 & 0.879 & 0.608 \\
\hline & & & & 6 & 1.220 & & 1.233 & 1.083 & 0.975 & 0.863 & 0.625 \\
\hline & & & & 7 & 1.193 & 1.228 & 1.109 & 1.035 & 0.944 & 0.853 & 0.638 \\
\hline \multirow{5}{*}{25} & \multirow{5}{*}{2} & \multirow{5}{*}{0.3} & \multirow{5}{*}{$8^{*}$} & 3 & 1.429 & & & & & 1.075 & 0.495 \\
\hline & & & & 4 & 1.329 & & & & 1.186 & 0.916 & 0.569 \\
\hline & & & & 5 & 1.265 & & & 1.209 & 1.041 & 0.877 & 0.608 \\
\hline & & & & 6 & 1.213 & & 1.234 & 1.086 & 0.978 & 0.863 & 0.627 \\
\hline & & & & 7 & 1.182 & 1.226 & 1.111 & 1.039 & 0.948 & 0.854 & 0.640 \\
\hline & & & & 3 & 1.424 & & & & & 1.079 & 0.497 \\
\hline & & & & 4 & 1.324 & & & & 1.190 & 0.918 & 0.569 \\
\hline 25 & 2 & 0.3 & 12 & 5 & 1.260 & & & 1.212 & 1.043 & 0.877 & 0.609 \\
\hline & & & & 6 & 1.208 & & 1.237 & 1.088 & 0.977 & 0.863 & 0.626 \\
\hline & & & & 7 & 1.178 & 1.230 & 1.114 & 1.039 & 0.946 & 0.853 & 0.640 \\
\hline & & & & 3 & 1.743 & & & & & 1.100 & 0.157 \\
\hline & & & & 4 & 1.570 & & & & 1.306 & 0.848 & 0.275 \\
\hline 25 & 2 & 0.5 & 8 & 5 & 1.461 & & & 1.341 & 1.082 & 0.778 & 0.338 \\
\hline & & & & 6 & 1.381 & & 1.368 & 1.161 & 0.979 & 0.738 & 0.373 \\
\hline & & & & 7 & 1.331 & 1.353 & 1.199 & 1.082 & 0.925 & 0.718 & 0.392 \\
\hline & & & & 3 & 1.748 & & & & & 1.101 & 0.152 \\
\hline & & & & 4 & 1.566 & & & & 1.309 & 0.851 & 0.274 \\
\hline 25 & 2 & 0.5 & $12^{\star}$ & 5 & 1.453 & & & 1.344 & 1.085 & 0.778 & 0.340 \\
\hline & & & & 6 & 1.365 & & 1.368 & 1.165 & 0.983 & 0.741 & 0.378 \\
\hline & & & & 7 & 1.309 & 1.348 & 1.202 & 1.088 & 0.931 & 0.723 & 0.399 \\
\hline
\end{tabular}




\begin{tabular}{|c|c|c|c|c|c|c|c|c|c|c|c|}
\hline \multicolumn{5}{|c|}{ Bridge Dimensions } & \multirow{2}{*}{\multicolumn{7}{|c|}{ Reaction Dist. Factor : $\mathbf{R}_{\mathbf{M}}$}} \\
\hline $\begin{array}{l}\text { Span } \\
(\mathrm{m})\end{array}$ & $\begin{array}{l}\text { Girder } \\
\text { Spacing }\end{array}$ & $\begin{array}{l}\text { Span } \\
\text { Radius }\end{array}$ & \multirow{2}{*}{$\begin{array}{l}\text { No. of } \\
\text { Bracing } \\
\text { Intervals }\end{array}$} & $\begin{array}{l}\text { No. of } \\
\text { Girders }\end{array}$ & & & & & & & \\
\hline L & $\mathrm{s}$ & $L / R$ & & $\mathrm{~N}$ & $G_{\text {Ext }}$ & $G_{5}$ & $\mathrm{G}_{4}$ & $\mathrm{G}_{3}$ & $\mathrm{G}_{2}$ & $\mathrm{G}_{1}$ & $G_{\text {int }}$ \\
\hline \multirow{4}{*}{15} & \multirow{4}{*}{2.5} & \multirow{4}{*}{0.3} & \multirow{4}{*}{12} & 3 & 1.182 & & & & & 1.095 & 0.723 \\
\hline & & & & 4 & 1.120 & & & & 1.141 & 1.016 & 0.723 \\
\hline & & & & 5 & 1.079 & & & 1.142 & 1.086 & 0.977 & 0.715 \\
\hline & & & & 6 & 1.051 & & 1.134 & 1.109 & 1.053 & 0.952 & 0.700 \\
\hline \multirow{3}{*}{15} & \multirow{3}{*}{3} & \multirow{3}{*}{0.1} & \multirow{3}{*}{$4^{*}$} & 3 & 1.019 & & & & & 1.097 & 0.885 \\
\hline & & & & 4 & 0.984 & & & & 1.094 & 1.060 & 0.862 \\
\hline & & & & 5 & 0.959 & & & 1.085 & 1.078 & 1.037 & 0.841 \\
\hline \multirow{3}{*}{15} & \multirow{3}{*}{3} & \multirow{3}{*}{0.1} & \multirow{3}{*}{6} & 3 & 1.019 & & & & & 1.095 & 0.886 \\
\hline & & & & 4 & 0.985 & & & & 1.093 & 1.057 & 0.865 \\
\hline & & & & 5 & 0.964 & & & 1.077 & 1.073 & 1.036 & 0.850 \\
\hline \multirow{3}{*}{15} & \multirow{3}{*}{3} & \multirow{3}{*}{0.1} & \multirow{3}{*}{8} & 3 & 1.024 & & & & & 1.085 & 0.891 \\
\hline & & & & 4 & 0.991 & & & & 1.087 & 1.050 & 0.873 \\
\hline & & & & 5 & 0.967 & & & 1.079 & 1.070 & 1.029 & 0.855 \\
\hline \multirow{3}{*}{15} & \multirow{3}{*}{3} & \multirow{3}{*}{0.2} & \multirow{3}{*}{4} & 3 & 1.078 & & & & & 1.107 & 0.815 \\
\hline & & & & 4 & 1.037 & & & & 1.118 & 1.050 & 0.795 \\
\hline & & & & 5 & 0.996 & & & 1.102 & 1.090 & 1.027 & 0.784 \\
\hline \multirow{3}{*}{15} & \multirow{3}{*}{3} & \multirow{3}{*}{0.2} & & 3 & 1.084 & & & & & 1.096 & 0.819 \\
\hline & & & $6^{*}$ & 4 & 1.039 & & & & 1.114 & 1.044 & 0.803 \\
\hline & & & & 5 & 0.980 & & & 1.091 & 1.091 & 1.031 & 0.807 \\
\hline & & & & 3 & 1.082 & & & & & 1.099 & 0.819 \\
\hline 15 & 3 & 0.2 & 8 & 4 & 1.038 & & & & 1.115 & 1.043 & 0.803 \\
\hline & & & & 5 & 0.998 & & & 1.101 & 1.086 & 1.021 & 0.794 \\
\hline & & & & 3 & 1.140 & & & & & 1.115 & 0.745 \\
\hline 15 & 3 & 0.3 & 6 & 4 & 1.086 & & & & 1.146 & 1.041 & 0.727 \\
\hline & & & & 5 & 1.052 & & & 1.145 & 1.099 & 1.001 & 0.703 \\
\hline & & & & 3 & 1.146 & & & & & 1.105 & 0.750 \\
\hline 15 & 3 & 0.3 & $8^{*}$ & 4 & 1.085 & & & & 1.140 & 1.038 & 0.737 \\
\hline & & & & 5 & 1.045 & & & 1.135 & 1.101 & 1.002 & 0.717 \\
\hline & & & & 3 & 1.143 & & & & & 1.107 & 0.750 \\
\hline 15 & 3 & 0.3 & 12 & 4 & 1.084 & & & & 1.141 & 1.037 & 0.738 \\
\hline & & & & 5 & 1.045 & & & 1.138 & 1.099 & 1.000 & 0.718 \\
\hline
\end{tabular}

\begin{tabular}{|c|c|c|c|c|c|c|c|c|c|c|c|}
\hline \multicolumn{5}{|c|}{ Bridge Dimensions } & \multirow{2}{*}{\multicolumn{7}{|c|}{ Reaction Dist. Factor : $\mathbf{R}_{M}$}} \\
\hline $\begin{array}{l}\text { Span } \\
(\mathrm{m})\end{array}$ & $\begin{array}{l}\text { Girder } \\
\text { Spacing } \\
\text { (m) }\end{array}$ & $\begin{array}{l}\text { Span } \\
\text { Radius } \\
\text { Ratio }\end{array}$ & $\begin{array}{l}\text { No. of } \\
\text { Bracing } \\
\text { Intervals }\end{array}$ & $\begin{array}{l}\text { No. of } \\
\text { Girders }\end{array}$ & & & & & & & \\
\hline$L$ & $\mathrm{~s}$ & $L / R$ & & $\mathrm{~N}$ & $G_{\text {Ext }}$ & $G_{5}$ & $\mathrm{G}_{4}$ & $\mathrm{G}_{3}$ & $G_{2}$ & $G_{1}$ & $G_{\text {int }}$ \\
\hline \multirow{5}{*}{25} & \multirow{5}{*}{2} & \multirow{5}{*}{0.1} & \multirow{5}{*}{4} & 3 & 1.122 & & & & & 1.066 & 0.812 \\
\hline & & & & 4 & 1.087 & & & & 1.083 & 0.997 & 0.832 \\
\hline & & & & 5 & 1.066 & & & 1.089 & 1.021 & 0.983 & 0.842 \\
\hline & & & & 6 & 1.045 & & 1.106 & 1.028 & 0.993 & 0.985 & 0.842 \\
\hline & & & & 7 & 1.035 & 1.104 & 1.037 & 1.014 & 0.984 & 0.981 & 0.845 \\
\hline \multirow{5}{*}{25} & \multirow{5}{*}{2} & \multirow{5}{*}{0.1} & \multirow{5}{*}{$6^{*}$} & 3 & 1.124 & & & & & 1.065 & 0.811 \\
\hline & & & & 4 & 1.089 & & & & 1.084 & 0.994 & 0.833 \\
\hline & & & & 5 & 1.065 & & & 1.091 & 1.021 & 0.979 & 0.844 \\
\hline & & & & 6 & 1.041 & & 1.108 & 1.030 & 0.994 & 0.984 & 0.843 \\
\hline & & & & 7 & 1.030 & 1.105 & 1.040 & 1.016 & 0.984 & 0.979 & 0.846 \\
\hline \multirow{5}{*}{25} & \multirow{5}{*}{2} & \multirow{5}{*}{0.1} & \multirow{5}{*}{8} & 3 & 1.122 & & & & & 1.066 & 0.811 \\
\hline & & & & 4 & 1.087 & & & & 1.086 & 0.995 & 0.833 \\
\hline & & & & 5 & 1.063 & & & 1.092 & 1.021 & 0.980 & 0.844 \\
\hline & & & & 6 & 1.040 & & 1.109 & 1.031 & 0.993 & 0.984 & 0.843 \\
\hline & & & & 7 & 1.029 & 1.107 & 1.040 & 1.015 & 0.983 & 0.980 & 0.846 \\
\hline \multirow{5}{*}{25} & \multirow{5}{*}{2} & \multirow{5}{*}{0.3} & \multirow{5}{*}{6} & 3 & 1.424 & & & & & 1.076 & 0.500 \\
\hline & & & & 4 & 1.327 & & & & 1.184 & 0.919 & 0.570 \\
\hline & & & & 5 & 1.266 & & & 1.207 & 1.040 & 0.879 & 0.608 \\
\hline & & & & 6 & 1.220 & & 1.233 & 1.083 & 0.975 & 0.863 & 0.625 \\
\hline & & & & 7 & 1.193 & 1.228 & 1.109 & 1.035 & 0.944 & 0.853 & 0.638 \\
\hline \multirow{5}{*}{25} & \multirow{5}{*}{2} & \multirow{5}{*}{0.3} & \multirow{5}{*}{$8^{*}$} & 3 & 1.429 & & & & & 1.075 & 0.495 \\
\hline & & & & 4 & 1.329 & & & & 1.186 & 0.916 & 0.569 \\
\hline & & & & 5 & 1.265 & & & 1.209 & 1.041 & 0.877 & 0.608 \\
\hline & & & & 6 & 1.213 & & 1.234 & 1.086 & 0.978 & 0.863 & 0.627 \\
\hline & & & & 7 & 1.182 & 1.226 & 1.111 & 1.039 & 0.948 & 0.854 & 0.640 \\
\hline & & & & 3 & 1.424 & & & & & 1.079 & 0.497 \\
\hline & & & & 4 & 1.324 & & & & 1.190 & 0.918 & 0.569 \\
\hline 25 & 2 & 0.3 & 12 & 5 & 1.260 & & & 1.212 & 1.043 & 0.877 & 0.609 \\
\hline & & & & 6 & 1.208 & & 1.237 & 1.088 & 0.977 & 0.863 & 0.626 \\
\hline & & & & 7 & 1.178 & 1.230 & 1.114 & 1.039 & 0.946 & 0.853 & 0.640 \\
\hline & & & & 3 & 1.743 & & & & & 1.100 & 0.157 \\
\hline & & & & 4 & 1.570 & & & & 1.306 & 0.848 & 0.275 \\
\hline 25 & 2 & 0.5 & 8 & 5 & 1.461 & & & 1.341 & 1.082 & 0.778 & 0.338 \\
\hline & & & & 6 & 1.381 & & 1.368 & 1.161 & 0.979 & 0.738 & 0.373 \\
\hline & & & & 7 & 1.331 & 1.353 & 1.199 & 1.082 & 0.925 & 0.718 & 0.392 \\
\hline & & & & 3 & 1.748 & & & & & 1.101 & 0.152 \\
\hline & & & & 4 & 1.566 & & & & 1.309 & 0.851 & 0.274 \\
\hline 25 & 2 & 0.5 & $12^{*}$ & 5 & 1.453 & & & 1.344 & 1.085 & 0.778 & 0.340 \\
\hline & & & & 6 & 1.365 & & 1.368 & 1.165 & 0.983 & 0.741 & 0.378 \\
\hline & & & & 7 & 1.309 & 1.348 & 1.202 & 1.088 & 0.931 & 0.723 & 0.399 \\
\hline
\end{tabular}


Table 4.16c: Reaction Distribution factors $R_{M}$ for $25 \mathrm{~m}$ span bridge (Continue...)

\begin{tabular}{|c|c|c|c|c|c|c|c|c|c|c|c|}
\hline \multicolumn{5}{|c|}{ Bridge Dimensions } & \multirow{2}{*}{\multicolumn{7}{|c|}{ Reaction Dist. Factor : $\mathbf{R}_{\mathbf{M}}$}} \\
\hline $\begin{array}{l}\text { Span } \\
(\mathrm{m})\end{array}$ & $\begin{array}{l}\text { Girder } \\
\text { Spacing }\end{array}$ & $\begin{array}{l}\text { Span } \\
\text { Radius } \\
\text { Quiv }\end{array}$ & $\begin{array}{l}\text { No. of } \\
\text { Bracing }\end{array}$ & $\begin{array}{l}\text { No. of } \\
\text { Girders }\end{array}$ & & & & & & & \\
\hline $\mathrm{L}$ & $\mathrm{s}$ & $L / R$ & & $\mathrm{~N}$ & $G_{\text {Ext }}$ & $G_{5}$ & $G_{4}$ & $\mathrm{G}_{3}$ & $G_{2}$ & $G_{1}$ & $G_{\text {int }}$ \\
\hline \multirow{5}{*}{25} & \multirow{5}{*}{2} & \multirow{5}{*}{0.5} & \multirow{5}{*}{18} & 3 & 1.741 & & & & & 1.103 & 0.156 \\
\hline & & & & 4 & 1.567 & & & & 1.313 & 0.845 & 0.275 \\
\hline & & & & 5 & 1.449 & & & 1.345 & 1.084 & 0.777 & 0.344 \\
\hline & & & & 6 & 1.361 & & 1.371 & 1.166 & 0.981 & 0.739 & 0.380 \\
\hline & & & & 7 & 1.304 & 1.351 & 1.204 & 1.089 & 0.930 & 0.722 & 0.400 \\
\hline \multirow{4}{*}{25} & \multirow{4}{*}{2.5} & \multirow{4}{*}{0.1} & \multirow{4}{*}{4} & 3 & 1.097 & & & & & 1.058 & 0.846 \\
\hline & & & & 4 & 1.065 & & & & 1.074 & 1.008 & 0.854 \\
\hline & & & & 5 & 1.046 & & & 1.076 & 1.031 & 0.990 & 0.857 \\
\hline & & & & 6 & 1.033 & & 1.074 & 1.043 & 1.012 & 0.980 & 0.857 \\
\hline \multirow{4}{*}{25} & \multirow{4}{*}{2.5} & \multirow{4}{*}{0.1} & \multirow{4}{*}{$6^{*}$} & 3 & 1.099 & & & & & 1.055 & 0.846 \\
\hline & & & & 4 & 1.066 & & & & 1.074 & 1.004 & 0.855 \\
\hline & & & & 5 & 1.045 & & & 1.077 & 1.032 & 0.988 & 0.859 \\
\hline & & & & 6 & 1.030 & & 1.074 & 1.045 & 1.014 & 0.978 & 0.859 \\
\hline \multirow{4}{*}{25} & \multirow{4}{*}{2.5} & \multirow{4}{*}{0.1} & \multirow{4}{*}{8} & 3 & 1.098 & & & & & 1.056 & 0.846 \\
\hline & & & & 4 & 1.064 & & & & 1.075 & 1.005 & 0.855 \\
\hline & & & & 5 & 1.044 & & & 1.078 & 1.032 & 0.987 & 0.859 \\
\hline & & & & 6 & 1.030 & & 1.076 & 1.044 & 1.012 & 0.977 & 0.860 \\
\hline \multirow{4}{*}{25} & \multirow{4}{*}{2.5} & \multirow{4}{*}{0.3} & \multirow{4}{*}{6} & 3 & 1.339 & & & & & 1.070 & 0.591 \\
\hline & & & & 4 & 1.258 & & & & 1.156 & 0.952 & 0.634 \\
\hline & & & & 5 & 1.210 & & & 1.174 & 1.052 & 0.910 & 0.655 \\
\hline & & & & 6 & 1.178 & & 1.174 & 1.093 & 1.002 & 0.887 & 0.665 \\
\hline \multirow{4}{*}{25} & & & & 3 & 1.344 & & & & & 1.067 & 0.589 \\
\hline & 2.5 & 0.3 & $8^{*}$ & 4 & 1.260 & & & & 1.157 & 0.949 & 0.634 \\
\hline & & & & 5 & 1.206 & & & 1.174 & 1.054 & 0.908 & 0.657 \\
\hline & & & & 6 & 1.170 & & 1.172 & 1.096 & 1.006 & 0.887 & 0.669 \\
\hline & & & & 3 & 1.340 & & & & & 1.070 & 0.590 \\
\hline 25 & 2.5 & 0.3 & 12 & 4 & 1.256 & & & & 1.160 & 0.950 & 0.635 \\
\hline & & & & 5 & 1.203 & & & 1.177 & 1.055 & 0.908 & 0.658 \\
\hline & & & & 6 & 1.167 & & 1.175 & 1.097 & 1.005 & 0.886 & 0.669 \\
\hline & & & & 3 & 1.593 & & & & & 1.097 & 0.310 \\
\hline 25 & 2.5 & 0.5 & 8 & 4 & 1.452 & & & & 1.259 & 0.906 & 0.383 \\
\hline & & & & 5 & 1.363 & & & 1.285 & 1.097 & 0.838 & 0.418 \\
\hline & & & & 6 & 1.303 & & 1.279 & 1.167 & 1.019 & 0.799 & 0.432 \\
\hline & & & & 3 & 1.596 & & & & & 1.097 & 0.308 \\
\hline 25 & 2.5 & 0.5 & $12^{*}$ & 4 & 1.447 & & & & 1.261 & 0.906 & 0.386 \\
\hline & & & & 5 & 1.351 & & & 1.284 & 1.101 & 0.840 & 0.424 \\
\hline & & & & 6 & 1.285 & & 1.274 & 1.170 & 1.025 & 0.804 & 0.441 \\
\hline
\end{tabular}

Table 4.16c: Reaction Distribution factors $\mathrm{R}_{\mathrm{M}}$ for $25 \mathrm{~m}$ span bridge (Continue...)

\begin{tabular}{|c|c|c|c|c|c|c|c|c|c|c|c|}
\hline \multicolumn{5}{|c|}{ Bridge Dimensions } & \multirow{2}{*}{\multicolumn{7}{|c|}{ Reaction Dist. Factor : $R_{M}$}} \\
\hline $\begin{array}{l}\text { Span } \\
(\mathrm{m})\end{array}$ & $\begin{array}{l}\text { Girder } \\
\text { Spacing }\end{array}$ & $\begin{array}{l}\text { Span } \\
\text { Radius }\end{array}$ & $\begin{array}{c}\text { No. of } \\
\text { Bracing }\end{array}$ & $\begin{array}{l}\text { No. of } \\
\text { Girders }\end{array}$ & & & & & & & \\
\hline$L$ & $s$ & $L / R$ & & $\mathrm{~N}$ & $G_{\text {Ext }}$ & $G_{5}$ & $G_{4}$ & $G_{3}$ & $G_{2}$ & $\mathrm{G}_{1}$ & $G_{\text {int }}$ \\
\hline \multirow{4}{*}{25} & \multirow{4}{*}{2.5} & \multirow{4}{*}{0.5} & \multirow{4}{*}{18} & 3 & 1.595 & & & & & 1.096 & 0.309 \\
\hline & & & & 4 & 1.447 & & & & 1.262 & 0.904 & 0.388 \\
\hline & & & & 5 & 1.350 & & & 1.286 & 1.100 & 0.837 & 0.426 \\
\hline & & & & 6 & 1.282 & & 1.276 & 1.171 & 1.025 & 0.802 & 0.443 \\
\hline \multirow{3}{*}{25} & \multirow{3}{*}{3} & \multirow{3}{*}{0.1} & \multirow{3}{*}{4} & 3 & 1.076 & & & & & 1.060 & 0.864 \\
\hline & & & & 4 & 1.046 & & & & 1.072 & 1.017 & 0.864 \\
\hline & & & & 5 & 1.029 & & & 1.072 & 1.038 & 0.998 & 0.862 \\
\hline \multirow{3}{*}{25} & \multirow{3}{*}{3} & \multirow{3}{*}{0.1} & \multirow{3}{*}{$6^{*}$} & 3 & 1.079 & & & & & 1.056 & 0.865 \\
\hline & & & & 4 & 1.047 & & & & 1.072 & 1.014 & 0.866 \\
\hline & & & & 5 & 1.027 & & & 1.072 & 1.040 & 0.996 & 0.865 \\
\hline \multirow{3}{*}{25} & \multirow{3}{*}{3} & \multirow{3}{*}{0.1} & \multirow{3}{*}{8} & 3 & 1.077 & & & & & 1.057 & 0.865 \\
\hline & & & & 4 & 1.046 & & & & 1.073 & 1.014 & 0.866 \\
\hline & & & & 5 & 1.027 & & & 1.073 & 1.039 & 0.995 & 0.866 \\
\hline \multirow{3}{*}{25} & \multirow{3}{*}{3} & \multirow{3}{*}{0.3} & \multirow{3}{*}{6} & 3 & 1.279 & & & & & 1.074 & 0.647 \\
\hline & & & & 4 & 1.210 & & & & 1.145 & 0.974 & 0.671 \\
\hline & & & & 5 & 1.169 & & & 1.158 & 1.061 & 0.932 & 0.681 \\
\hline \multirow{3}{*}{25} & \multirow{3}{*}{3} & \multirow{3}{*}{0.3} & \multirow{3}{*}{$8^{*}$} & 3 & 1.283 & & & & & 1.070 & 0.647 \\
\hline & & & & 4 & 1.218 & & & & 1.141 & 0.969 & 0.672 \\
\hline & & & & 5 & 1.163 & & & 1.156 & 1.063 & 0.932 & 0.685 \\
\hline & & & & 3 & 1.280 & & & & & 1.073 & 0.648 \\
\hline 25 & 3 & 0.3 & 12 & 4 & 1.207 & & & & 1.147 & 0.972 & 0.674 \\
\hline & & & & 5 & 1.161 & & & 1.159 & 1.064 & 0.931 & 0.685 \\
\hline & & & & 3 & 1.493 & & & & & 1.097 & 0.409 \\
\hline 25 & 3 & 0.5 & 8 & 4 & 1.369 & & & & 1.236 & 0.946 & 0.450 \\
\hline & & & & 5 & 1.292 & & & 1.255 & 1.111 & 0.877 & 0.465 \\
\hline & & & & 3 & 1.491 & & & & & 1.103 & 0.406 \\
\hline 25 & 3 & 0.5 & $12^{\star}$ & 4 & 1.362 & & & & 1.236 & 0.946 & 0.455 \\
\hline & & & & 5 & 1.284 & & & 1.257 & 1.118 & 0.887 & 0.454 \\
\hline & & & & 3 & 1.491 & & & & & 1.101 & 0.408 \\
\hline 25 & 3 & 0.5 & 18 & 4 & 1.362 & & & & 1.236 & 0.943 & 0.458 \\
\hline & & & & 5 & 1.277 & & & 1.252 & 1.113 & 0.881 & 0.476 \\
\hline
\end{tabular}


Table 4.16c: Reaction Distribution factors $R_{M}$ for $25 \mathrm{~m}$ span bridge (Continue...)

\begin{tabular}{|c|c|c|c|c|c|c|c|c|c|c|c|}
\hline \multicolumn{5}{|c|}{ Bridge Dimensions } & \multirow{2}{*}{\multicolumn{7}{|c|}{ Reaction Dist. Factor : $R_{M}$}} \\
\hline $\begin{array}{l}\text { Span } \\
(\mathrm{m})\end{array}$ & $\begin{array}{l}\text { Girder } \\
\text { Spacing }\end{array}$ & $\begin{array}{l}\text { Span } \\
\text { Radius } \\
\text { aus }\end{array}$ & $\begin{array}{l}\text { No. of } \\
\text { Bracing }\end{array}$ & $\begin{array}{l}\text { No. of } \\
\text { Girders }\end{array}$ & & & & & & & \\
\hline $\mathrm{L}$ & $\mathrm{s}$ & $L / R$ & & $\mathrm{~N}$ & $G_{\text {Ext }}$ & $G_{5}$ & $G_{4}$ & $\mathrm{G}_{3}$ & $G_{2}$ & $G_{1}$ & $\mathrm{G}_{\text {int }}$ \\
\hline \multirow{5}{*}{25} & \multirow{5}{*}{2} & \multirow{5}{*}{0.5} & \multirow{5}{*}{18} & 3 & 1.741 & & & & & 1.103 & 0.156 \\
\hline & & & & 4 & 1.567 & & & & 1.313 & 0.845 & 0.275 \\
\hline & & & & 5 & 1.449 & & & 1.345 & 1.084 & 0.777 & 0.344 \\
\hline & & & & 6 & 1.361 & & 1.371 & 1.166 & 0.981 & 0.739 & 0.380 \\
\hline & & & & 7 & 1.304 & 1.351 & 1.204 & 1.089 & 0.930 & 0.722 & 0.400 \\
\hline \multirow{4}{*}{25} & \multirow{4}{*}{2.5} & \multirow{4}{*}{0.1} & \multirow{4}{*}{4} & 3 & 1.097 & & & & & 1.058 & 0.846 \\
\hline & & & & 4 & 1.065 & & & & 1.074 & 1.008 & 0.854 \\
\hline & & & & 5 & 1.046 & & & 1.076 & 1.031 & 0.990 & 0.857 \\
\hline & & & & 6 & 1.033 & & 1.074 & 1.043 & 1.012 & 0.980 & 0.857 \\
\hline \multirow{4}{*}{25} & \multirow{4}{*}{2.5} & \multirow{4}{*}{0.1} & \multirow{4}{*}{$6^{*}$} & 3 & 1.099 & & & & & 1.055 & 0.846 \\
\hline & & & & 4 & 1.066 & & & & 1.074 & 1.004 & 0.855 \\
\hline & & & & 5 & 1.045 & & & 1.077 & 1.032 & 0.988 & 0.859 \\
\hline & & & & 6 & 1.030 & & 1.074 & 1.045 & 1.014 & 0.978 & 0.859 \\
\hline \multirow{4}{*}{25} & \multirow{4}{*}{2.5} & \multirow{4}{*}{0.1} & \multirow{4}{*}{8} & 3 & 1.098 & & & & & 1.056 & 0.846 \\
\hline & & & & 4 & 1.064 & & & & 1.075 & 1.005 & 0.855 \\
\hline & & & & 5 & 1.044 & & & 1.078 & 1.032 & 0.987 & 0.859 \\
\hline & & & & 6 & 1.030 & & 1.076 & 1.044 & 1.012 & 0.977 & 0.860 \\
\hline \multirow{4}{*}{25} & \multirow{4}{*}{2.5} & \multirow{4}{*}{0.3} & \multirow{4}{*}{6} & 3 & 1.339 & & & & & 1.070 & 0.591 \\
\hline & & & & 4 & 1.258 & & & & 1.156 & 0.952 & 0.634 \\
\hline & & & & 5 & 1.210 & & & 1.174 & 1.052 & 0.910 & 0.655 \\
\hline & & & & 6 & 1.178 & & 1.174 & 1.093 & 1.002 & 0.887 & 0.665 \\
\hline \multirow{4}{*}{25} & & & & 3 & 1.344 & & & & & 1.067 & 0.589 \\
\hline & 2.5 & 0.3 & $8^{*}$ & 4 & 1.260 & & & & 1.157 & 0.949 & 0.634 \\
\hline & & & & 5 & 1.206 & & & 1.174 & 1.054 & 0.908 & 0.657 \\
\hline & & & & 6 & 1.170 & & 1.172 & 1.096 & 1.006 & 0.887 & 0.669 \\
\hline & & & & 3 & 1.340 & & & & & 1.070 & 0.590 \\
\hline 25 & 2.5 & 0.3 & 12 & 4 & 1.256 & & & & 1.160 & 0.950 & 0.635 \\
\hline & & & & 5 & 1.203 & & & 1.177 & 1.055 & 0.908 & 0.658 \\
\hline & & & & 6 & 1.167 & & 1.175 & 1.097 & 1.005 & 0.886 & 0.669 \\
\hline & & & & 3 & 1.593 & & & & & 1.097 & 0.310 \\
\hline 25 & 2.5 & 0.5 & 8 & 4 & 1.452 & & & & 1.259 & 0.906 & 0.383 \\
\hline & & 0 & & 5 & 1.363 & & & 1.285 & 1.097 & 0.838 & 0.418 \\
\hline & & & & 6 & 1.303 & & 1.279 & 1.167 & 1.019 & 0.799 & 0.432 \\
\hline & & & & 3 & 1.596 & & & & & 1.097 & 0.308 \\
\hline 25 & 2.5 & 0.5 & $12^{*}$ & 4 & 1.447 & & & & 1.261 & 0.906 & 0.386 \\
\hline & & & & 5 & 1.351 & & & 1.284 & 1.101 & 0.840 & 0.424 \\
\hline & & & & 6 & 1.285 & & 1.274 & 1.170 & 1.025 & 0.804 & 0.441 \\
\hline
\end{tabular}

Table 4.16c: Reaction Distribution factors $\mathrm{R}_{\mathrm{M}}$ for $25 \mathrm{~m}$ span bridge (Continue...)

\begin{tabular}{|c|c|c|c|c|c|c|c|c|c|c|c|}
\hline \multicolumn{5}{|c|}{ Bridge Dimensions } & \multirow{2}{*}{\multicolumn{7}{|c|}{ Reaction Dist. Factor : $R_{M}$}} \\
\hline $\begin{array}{l}\text { Span } \\
(\mathrm{m})\end{array}$ & $\begin{array}{l}\text { Girder } \\
\text { Spacing }\end{array}$ & $\begin{array}{l}\text { Span } \\
\text { Radius }\end{array}$ & $\begin{array}{c}\text { No. of } \\
\text { Bracing }\end{array}$ & $\begin{array}{l}\text { No. of } \\
\text { Girders }\end{array}$ & & & & & & & \\
\hline$L$ & $\mathrm{~s}$ & $L / R$ & & $\mathrm{~N}$ & $G_{\text {Ext }}$ & $G_{5}$ & $G_{4}$ & $G_{3}$ & $G_{2}$ & $G_{1}$ & $G_{\text {int }}$ \\
\hline \multirow{4}{*}{25} & \multirow{4}{*}{2.5} & \multirow{4}{*}{0.5} & \multirow{4}{*}{18} & 3 & 1.595 & & & & & 1.096 & 0.309 \\
\hline & & & & 4 & 1.447 & & & & 1.262 & 0.904 & 0.388 \\
\hline & & & & 5 & 1.350 & & & 1.286 & 1.100 & 0.837 & 0.426 \\
\hline & & & & 6 & 1.282 & & 1.276 & 1.171 & 1.025 & 0.802 & 0.443 \\
\hline \multirow{3}{*}{25} & \multirow{3}{*}{3} & \multirow{3}{*}{0.1} & \multirow{3}{*}{4} & 3 & 1.076 & & & & & 1.060 & 0.864 \\
\hline & & & & 4 & 1.046 & & & & 1.072 & 1.017 & 0.864 \\
\hline & & & & 5 & 1.029 & & & 1.072 & 1.038 & 0.998 & 0.862 \\
\hline \multirow{3}{*}{25} & \multirow{3}{*}{3} & \multirow{3}{*}{0.1} & \multirow{3}{*}{$6^{*}$} & 3 & 1.079 & & & & & 1.056 & 0.865 \\
\hline & & & & 4 & 1.047 & & & & 1.072 & 1.014 & 0.866 \\
\hline & & & & 5 & 1.027 & & & 1.072 & 1.040 & 0.996 & 0.865 \\
\hline \multirow{3}{*}{25} & \multirow{3}{*}{3} & \multirow{3}{*}{0.1} & \multirow{3}{*}{8} & 3 & 1.077 & & & & & 1.057 & 0.865 \\
\hline & & & & 4 & 1.046 & & & & 1.073 & 1.014 & 0.866 \\
\hline & & & & 5 & 1.027 & & & 1.073 & 1.039 & 0.995 & 0.866 \\
\hline \multirow{3}{*}{25} & \multirow{3}{*}{3} & \multirow{3}{*}{0.3} & \multirow{3}{*}{6} & 3 & 1.279 & & & & & 1.074 & 0.647 \\
\hline & & & & 4 & 1.210 & & & & 1.145 & 0.974 & 0.671 \\
\hline & & & & 5 & 1.169 & & & 1.158 & 1.061 & 0.932 & 0.681 \\
\hline \multirow{3}{*}{25} & \multirow{3}{*}{3} & \multirow{3}{*}{0.3} & \multirow{3}{*}{$8^{*}$} & 3 & 1.283 & & & & & 1.070 & 0.647 \\
\hline & & & & 4 & 1.218 & & & & 1.141 & 0.969 & 0.672 \\
\hline & & & & 5 & 1.163 & & & 1.156 & 1.063 & 0.932 & 0.685 \\
\hline & & & & 3 & 1.280 & & & & & 1.073 & 0.648 \\
\hline 25 & 3 & 0.3 & 12 & 4 & 1.207 & & & & 1.147 & 0.972 & 0.674 \\
\hline & & & & 5 & 1.161 & & & 1.159 & 1.064 & 0.931 & 0.685 \\
\hline & & & & 3 & 1.493 & & & & & 1.097 & 0.409 \\
\hline 25 & 3 & 0.5 & 8 & 4 & 1.369 & & & & 1.236 & 0.946 & 0.450 \\
\hline & & & & 5 & 1.292 & & & 1.255 & 1.111 & 0.877 & 0.465 \\
\hline & & & & 3 & 1.491 & & & & & 1.103 & 0.406 \\
\hline 25 & 3 & 0.5 & $12^{\star}$ & 4 & 1.362 & & & & 1.236 & 0.946 & 0.455 \\
\hline & & & & 5 & 1.284 & & & 1.257 & 1.118 & 0.887 & 0.454 \\
\hline & & & & 3 & 1.491 & & & & & 1.101 & 0.408 \\
\hline 25 & 3 & 0.5 & 18 & 4 & 1.362 & & & & 1.236 & 0.943 & 0.458 \\
\hline & & & & 5 & 1.277 & & & 1.252 & 1.113 & 0.881 & 0.476 \\
\hline
\end{tabular}




\begin{tabular}{|c|c|c|c|c|c|c|c|c|c|c|c|}
\hline \multicolumn{5}{|c|}{ Bridge Dimensions } & \multirow{2}{*}{\multicolumn{7}{|c|}{ Reaction Dist. Factor : $\mathbf{R}_{M}$}} \\
\hline $\begin{array}{l}\text { Span } \\
(\mathrm{m})\end{array}$ & $\begin{array}{l}\text { Girder } \\
\text { Spacing }\end{array}$ & $\begin{array}{c}\text { Span } \\
\text { Radius }\end{array}$ & \multirow{2}{*}{$\begin{array}{l}\text { No. of } \\
\text { Bracing } \\
\text { Intervals }\end{array}$} & $\begin{array}{l}\text { No. of } \\
\text { Girders }\end{array}$ & & & & & & & \\
\hline$L$ & $s$ & $L / R$ & & $\mathrm{~N}$ & $G_{\text {Ext }}$ & $G_{5}$ & $G_{4}$ & $G_{3}$ & $G_{2}$ & $G_{1}$ & $G_{\text {int }}$ \\
\hline \multirow{5}{*}{35} & \multirow{5}{*}{2} & \multirow{5}{*}{0.1} & \multirow{5}{*}{6} & 3 & 1.179 & & & & & 1.080 & 0.741 \\
\hline & & & & 4 & 1.135 & & & & 1.106 & 0.973 & 0.785 \\
\hline & & & & 5 & 1.107 & & & 1.119 & 1.005 & 0.960 & 0.809 \\
\hline & & & & 6 & 1.087 & & 1.120 & 1.031 & 0.983 & 0.956 & 0.823 \\
\hline & & & & 7 & 1.072 & 1.116 & 1.044 & 1.011 & 0.970 & 0.955 & 0.832 \\
\hline \multirow{5}{*}{35} & \multirow{5}{*}{2} & \multirow{5}{*}{0.1} & \multirow{5}{*}{$8^{*}$} & 3 & 1.177 & & & & & 1.082 & 0.741 \\
\hline & & & & 4 & 1.133 & & & & 1.108 & 0.974 & 0.785 \\
\hline & & & & 5 & 1.105 & & & 1.120 & 1.006 & 0.960 & 0.809 \\
\hline & & & & 6 & 1.085 & & 1.121 & 1.032 & 0.982 & 0.956 & 0.823 \\
\hline & & & & 7 & 1.070 & 1.118 & 1.045 & 1.010 & 0.970 & 0.954 & 0.833 \\
\hline \multirow{5}{*}{35} & \multirow{5}{*}{2} & \multirow{5}{*}{0.1} & \multirow{5}{*}{12} & 3 & 1.178 & & & & & 1.082 & 0.740 \\
\hline & & & & 4 & 1.134 & & & & 1.109 & 0.973 & 0.784 \\
\hline & & & & 5 & 1.106 & & & 1.121 & 1.005 & 0.959 & 0.809 \\
\hline & & & & 6 & 1.084 & & 1.122 & 1.033 & 0.982 & 0.955 & 0.824 \\
\hline & & & & 7 & 1.069 & 1.118 & 1.045 & 1.011 & 0.970 & 0.953 & 0.834 \\
\hline \multirow{5}{*}{35} & \multirow{5}{*}{2} & \multirow{5}{*}{0.4} & \multirow{5}{*}{8} & 3 & 1.829 & & & & & 1.098 & 0.073 \\
\hline & & & & 4 & 1.641 & & & & 1.330 & 0.790 & 0.239 \\
\hline & & & & 5 & 1.526 & & & 1.373 & 1.039 & 0.731 & 0.332 \\
\hline & & & & 6 & 1.445 & & 1.372 & 1.138 & 0.942 & 0.712 & 0.391 \\
\hline & & & & 7 & 1.387 & 1.358 & 1.183 & 1.049 & 0.888 & 0.704 & 0.431 \\
\hline \multirow{5}{*}{35} & \multirow{5}{*}{2} & \multirow{5}{*}{0.4} & & 3 & 1.831 & & & & & 1.101 & 0.068 \\
\hline & & & & 4 & 1.640 & & & & 1.336 & 0.790 & 0.235 \\
\hline & & & $12^{\star}$ & 5 & 1.520 & & & 1.378 & 1.042 & 0.730 & 0.331 \\
\hline & & & & 6 & 1.436 & & 1.375 & 1.143 & 0.944 & 0.711 & 0.391 \\
\hline & & & & 7 & 1.375 & 1.359 & 1.187 & 1.053 & 0.890 & 0.704 & 0.433 \\
\hline & & & & 3 & 1.829 & & & & & 1.103 & 0.068 \\
\hline & & & & 4 & 1.637 & & & & 1.339 & 0.789 & 0.235 \\
\hline 35 & 2 & 0.4 & 18 & 5 & 1.517 & & & 1.381 & 1.043 & 0.728 & 0.331 \\
\hline & & & & 6 & 1.433 & & 1.379 & 1.144 & 0.943 & 0.709 & 0.392 \\
\hline & & & & 7 & 1.371 & 1.362 & 1.189 & 1.053 & 0.889 & 0.703 & 0.433 \\
\hline & & & & 3 & 1.756 & & & & & 0.785 & -0.459 \\
\hline & & & & 4 & 1.822 & & & & 1.341 & 0.519 & -0.318 \\
\hline 35 & 2 & 0.7 & 8 & 5 & 1.784 & & & 1.522 & 1.027 & 0.461 & -0.206 \\
\hline & & & & 6 & 1.717 & & 1.574 & 1.239 & 0.907 & 0.438 & -0.125 \\
\hline & & & & 7 & 1.649 & 1.575 & 1.334 & 1.118 & 0.830 & 0.425 & -0.069 \\
\hline & & & & 3 & 1.747 & & & & & 0.790 & -0.463 \\
\hline & & & & 4 & 1.812 & & & & 1.347 & 0.517 & -0.323 \\
\hline 35 & 2 & 0.7 & $12^{*}$ & 5 & 1.771 & & & 1.530 & 1.031 & 0.459 & -0.209 \\
\hline & & & & 6 & 1.701 & & 1.581 & 1.247 & 0.910 & 0.437 & -0.124 \\
\hline & & & & 7 & 1.629 & 1.580 & 1.342 & 1.124 & 0.834 & 0.427 & -0.064 \\
\hline
\end{tabular}

\begin{tabular}{|c|c|c|c|c|c|c|c|c|c|c|c|}
\hline \multicolumn{5}{|c|}{ Bridge Dimensions } & \multirow{2}{*}{\multicolumn{7}{|c|}{ Reaction Dist. Factor : $\mathbf{R}_{M}$}} \\
\hline $\begin{array}{l}\begin{array}{l}\text { Span } \\
(m)\end{array} \\
\text { (m) }\end{array}$ & $\begin{array}{l}\text { Girder } \\
\text { Spacing }\end{array}$ & $\begin{array}{l}\text { Span } \\
\text { Radius }\end{array}$ & $\begin{array}{l}\text { No. of } \\
\text { Bracing }\end{array}$ & $\begin{array}{l}\text { No. of } \\
\text { Girders }\end{array}$ & & & & & & & \\
\hline$L$ & $s$ & $L / R$ & & $\mathrm{~N}$ & $G_{\text {Ext }}$ & $G_{5}$ & $G_{4}$ & $G_{3}$ & $G_{2}$ & $G_{1}$ & $G_{\text {int }}$ \\
\hline \multirow{5}{*}{35} & \multirow{5}{*}{2} & \multirow{5}{*}{0.7} & \multirow{5}{*}{18} & 3 & 1.745 & & & & & 0.792 & -0.463 \\
\hline & & & & 4 & 1.809 & & & & 1.352 & 0.516 & -0.323 \\
\hline & & & & 5 & 1.767 & & & 1.536 & 1.033 & 0.456 & -0.208 \\
\hline & & & & 6 & 1.695 & & 1.588 & 1.251 & 0.909 & 0.434 & -0.123 \\
\hline & & & & 7 & 1.621 & 1.585 & 1.347 & 1.126 & 0.833 & 0.424 & -0.063 \\
\hline \multirow{4}{*}{35} & \multirow{4}{*}{2.5} & \multirow{4}{*}{0.1} & \multirow{4}{*}{6} & 3 & 1.148 & & & & & 1.056 & 0.796 \\
\hline & & & & 4 & 1.111 & & & & 1.083 & 0.983 & 0.824 \\
\hline & & & & 5 & 1.086 & & & 1.092 & 1.015 & 0.968 & 0.838 \\
\hline & & & & 6 & 1.069 & & 1.092 & 1.036 & 0.995 & 0.961 & 0.847 \\
\hline \multirow{4}{*}{35} & \multirow{4}{*}{2.5} & \multirow{4}{*}{0.1} & \multirow{4}{*}{$8^{\star}$} & 3 & 1.147 & & & & & 1.058 & 0.796 \\
\hline & & & & 4 & 1.109 & & & & 1.084 & 0.983 & 0.824 \\
\hline & & & & 5 & 1.085 & & & 1.093 & 1.016 & 0.968 & 0.839 \\
\hline & & & & 6 & 1.068 & & 1.093 & 1.036 & 0.994 & 0.961 & 0.848 \\
\hline \multirow{4}{*}{35} & \multirow{4}{*}{2.5} & \multirow{4}{*}{0.1} & \multirow{4}{*}{12} & 3 & 1.147 & & & & & 1.058 & 0.795 \\
\hline & & & & 4 & 1.110 & & & & 1.084 & 0.981 & 0.824 \\
\hline & & & & 5 & 1.085 & & & 1.093 & 1.015 & 0.966 & 0.840 \\
\hline & & & & 6 & 1.067 & & 1.093 & 1.037 & 0.995 & 0.960 & 0.849 \\
\hline \multirow{4}{*}{35} & \multirow{4}{*}{2.5} & \multirow{4}{*}{0.4} & \multirow{4}{*}{8} & 3 & 1.667 & & & & & 1.078 & 0.255 \\
\hline & & & & 4 & 1.519 & & & & 1.259 & 0.853 & 0.370 \\
\hline & & & & 5 & 1.425 & & & 1.295 & 1.052 & 0.794 & 0.434 \\
\hline & & & & 6 & 1.361 & & 1.296 & 1.132 & 0.969 & 0.769 & 0.473 \\
\hline \multirow{4}{*}{35} & & & & 3 & 1.669 & & & & & 1.080 & 0.251 \\
\hline & 25 & 0.4 & $12^{\star}$ & 4 & 1.516 & & & & 1.263 & 0.852 & 0.368 \\
\hline & & & & 5 & 1.418 & & & 1.298 & 1.055 & 0.794 & 0.435 \\
\hline & & & & 6 & 1.349 & & 1.296 & 1.136 & 0.973 & 0.770 & 0.476 \\
\hline & & & & 3 & 1.668 & & & & & 1.081 & 0.251 \\
\hline 35 & 2.5 & 0.4 & 18 & 4 & 1.514 & & & & 1.265 & 0.851 & 0.369 \\
\hline & & & & 5 & 1.416 & & & 1.301 & 1.054 & 0.793 & 0.436 \\
\hline & & & & 6 & 1.347 & & 1.299 & 1.137 & 0.971 & 0.769 & 0.477 \\
\hline & & & & 3 & 1.803 & & & & & 0.916 & -0.280 \\
\hline 35 & 2.5 & 0.7 & 8 & 4 & 1.795 & & & & 1.371 & 0.692 & -0.143 \\
\hline & & & & 5 & 1.717 & & & 1.496 & 1.116 & 0.620 & -0.051 \\
\hline & & & & 6 & 1.630 & & 1.513 & 1.277 & 0.996 & 0.579 & 0.005 \\
\hline & & & & 3 & 1.798 & & & & & 0.917 & -0.285 \\
\hline 35 & 2.5 & 0.7 & $12^{*}$ & 4 & 1.787 & & & & 1.377 & 0.691 & -0.145 \\
\hline & & & & 5 & 1.706 & & & 1.504 & 1.121 & 0.621 & -0.048 \\
\hline & & & & 6 & 1.610 & & 1.516 & 1.282 & 0.999 & 0.581 & 0.012 \\
\hline
\end{tabular}




\begin{tabular}{|c|c|c|c|c|c|c|c|c|c|c|c|}
\hline \multicolumn{5}{|c|}{ Bridge Dimensions } & \multirow{2}{*}{\multicolumn{7}{|c|}{ Reaction Dist. Factor : $\mathbf{R}_{\mathbf{M}}$}} \\
\hline $\begin{array}{l}\text { Span } \\
(\mathrm{m})\end{array}$ & $\begin{array}{l}\text { Girder } \\
\text { Spacing }\end{array}$ & $\begin{array}{l}\text { Span } \\
\text { Radius } \\
\text { adis }\end{array}$ & $\begin{array}{l}\text { No. of } \\
\text { Bracing }\end{array}$ & $\begin{array}{l}\text { No. of } \\
\text { Girders }\end{array}$ & & & & & & & \\
\hline $\mathrm{L}$ & $\mathrm{s}$ & $L / R$ & & $\mathrm{~N}$ & $G_{\text {Ext }}$ & $G_{5}$ & $\mathrm{G}_{4}$ & $G_{3}$ & $\mathrm{G}_{2}$ & $G_{1}$ & $G_{\text {int }}$ \\
\hline \multirow{5}{*}{35} & \multirow{5}{*}{2} & \multirow{5}{*}{0.1} & \multirow{5}{*}{6} & 3 & 1.179 & & & & & 1.080 & 0.741 \\
\hline & & & & 4 & 1.135 & & & & 1.106 & 0.973 & 0.785 \\
\hline & & & & 5 & 1.107 & & & 1.119 & 1.005 & 0.960 & 0.809 \\
\hline & & & & 6 & 1.087 & & 1.120 & 1.031 & 0.983 & 0.956 & 0.823 \\
\hline & & & & 7 & 1.072 & 1.116 & 1.044 & 1.011 & 0.970 & 0.955 & 0.832 \\
\hline \multirow{5}{*}{35} & \multirow{5}{*}{2} & \multirow{5}{*}{0.1} & \multirow{5}{*}{$8^{*}$} & 3 & 1.177 & & & & & 1.082 & 0.741 \\
\hline & & & & 4 & 1.133 & & & & 1.108 & 0.974 & 0.785 \\
\hline & & & & 5 & 1.105 & & & 1.120 & 1.006 & 0.960 & 0.809 \\
\hline & & & & 6 & 1.085 & & 1.121 & 1.032 & 0.982 & 0.956 & 0.823 \\
\hline & & & & 7 & 1.070 & 1.118 & 1.045 & 1.010 & 0.970 & 0.954 & 0.833 \\
\hline \multirow{5}{*}{35} & \multirow{5}{*}{2} & \multirow{5}{*}{0.1} & \multirow{5}{*}{12} & 3 & 1.178 & & & & & 1.082 & 0.740 \\
\hline & & & & 4 & 1.134 & & & & 1.109 & 0.973 & 0.784 \\
\hline & & & & 5 & 1.106 & & & 1.121 & 1.005 & 0.959 & 0.809 \\
\hline & & & & 6 & 1.084 & & 1.122 & 1.033 & 0.982 & 0.955 & 0.824 \\
\hline & & & & 7 & 1.069 & 1.118 & 1.045 & 1.011 & 0.970 & 0.953 & 0.834 \\
\hline \multirow{5}{*}{35} & \multirow{5}{*}{2} & \multirow{5}{*}{0.4} & \multirow{5}{*}{8} & 3 & 1.829 & & & & & 1.098 & 0.073 \\
\hline & & & & 4 & 1.641 & & & & 1.330 & 0.790 & 0.239 \\
\hline & & & & 5 & 1.526 & & & 1.373 & 1.039 & 0.731 & 0.332 \\
\hline & & & & 6 & 1.445 & & 1.372 & 1.138 & 0.942 & 0.712 & 0.391 \\
\hline & & & & 7 & 1.387 & 1.358 & 1.183 & 1.049 & 0.888 & 0.704 & 0.431 \\
\hline \multirow{5}{*}{35} & \multirow{5}{*}{2} & \multirow{5}{*}{0.4} & \multirow{5}{*}{$12^{\star}$} & 3 & 1.831 & & & & & 1.101 & 0.068 \\
\hline & & & & 4 & 1.640 & & & & 1.336 & 0.790 & 0.235 \\
\hline & & & & 5 & 1.520 & & & 1.378 & 1.042 & 0.730 & 0.331 \\
\hline & & & & 6 & 1.436 & & 1.375 & 1.143 & 0.944 & 0.711 & 0.391 \\
\hline & & & & 7 & 1.375 & 1.359 & 1.187 & 1.053 & 0.890 & 0.704 & 0.433 \\
\hline & & & & 3 & 1.829 & & & & & 1.103 & 0.068 \\
\hline & & & & 4 & 1.637 & & & & 1.339 & 0.789 & 0.235 \\
\hline 35 & 2 & 0.4 & 18 & 5 & 1.517 & & & 1.381 & 1.043 & 0.728 & 0.331 \\
\hline & & & & 6 & 1.433 & & 1.379 & 1.144 & 0.943 & 0.709 & 0.392 \\
\hline & & & & 7 & 1.371 & 1.362 & 1.189 & 1.053 & 0.889 & 0.703 & 0.433 \\
\hline & & & & 3 & 1.756 & & & & & 0.785 & -0.459 \\
\hline & & & & 4 & 1.822 & & & & 1.341 & 0.519 & -0.318 \\
\hline 35 & 2 & 0.7 & 8 & 5 & 1.784 & & & 1.522 & 1.027 & 0.461 & -0.206 \\
\hline & & & & 6 & 1.717 & & 1.574 & 1.239 & 0.907 & 0.438 & -0.125 \\
\hline & & & & 7 & 1.649 & 1.575 & 1.334 & 1.118 & 0.830 & 0.425 & -0.069 \\
\hline & & & & 3 & 1.747 & & & & & 0.790 & -0.463 \\
\hline & & & & 4 & 1.812 & & & & 1.347 & 0.517 & -0.323 \\
\hline 35 & 2 & 0.7 & $12^{\star}$ & 5 & 1.771 & & & 1.530 & 1.031 & 0.459 & -0.209 \\
\hline & & & & 6 & 1.701 & & 1.581 & 1.247 & 0.910 & 0.437 & -0.124 \\
\hline & & & & 7 & 1.629 & 1.580 & 1.342 & 1.124 & 0.834 & 0.427 & -0.064 \\
\hline
\end{tabular}

\begin{tabular}{|c|c|c|c|c|c|c|c|c|c|c|c|}
\hline \multicolumn{5}{|c|}{ Bridge Dimensions } & \multirow{2}{*}{\multicolumn{7}{|c|}{ Reaction Dist. Factor : $\mathbf{R}_{M}$}} \\
\hline $\begin{array}{l}\text { Span } \\
\text { (m) }\end{array}$ & $\begin{array}{l}\text { Girder } \\
\text { Spacing }\end{array}$ & $\begin{array}{l}\text { Span } \\
\text { Radius }\end{array}$ & $\begin{array}{l}\text { No. of } \\
\text { Bracing }\end{array}$ & $\begin{array}{l}\text { No. of } \\
\text { Girders }\end{array}$ & & & & & & & \\
\hline$L$ & $s$ & $L / R$ & & $\mathrm{~N}$ & $\mathrm{G}_{\mathrm{Ext}}$ & $G_{5}$ & $G_{4}$ & $G_{3}$ & $G_{2}$ & $G_{1}$ & $G_{\text {int }}$ \\
\hline \multirow{5}{*}{35} & \multirow{5}{*}{2} & \multirow{5}{*}{0.7} & \multirow{5}{*}{18} & 3 & 1.745 & & & & & 0.792 & -0.463 \\
\hline & & & & 4 & 1.809 & & & & 1.352 & 0.516 & -0.323 \\
\hline & & & & 5 & 1.767 & & & 1.536 & 1.033 & 0.456 & -0.208 \\
\hline & & & & 6 & 1.695 & & 1.588 & 1.251 & 0.909 & 0.434 & -0.123 \\
\hline & & & & 7 & 1.621 & 1.585 & 1.347 & 1.126 & 0.833 & 0.424 & -0.063 \\
\hline \multirow{4}{*}{35} & \multirow{4}{*}{2.5} & \multirow{4}{*}{0.1} & \multirow{4}{*}{6} & 3 & 1.148 & & & & & 1.056 & 0.796 \\
\hline & & & & 4 & 1.111 & & & & 1.083 & 0.983 & 0.824 \\
\hline & & & & 5 & 1.086 & & & 1.092 & 1.015 & 0.968 & 0.838 \\
\hline & & & & 6 & 1.069 & & 1.092 & 1.036 & 0.995 & 0.961 & 0.847 \\
\hline \multirow{4}{*}{35} & \multirow{4}{*}{2.5} & \multirow{4}{*}{0.1} & \multirow{4}{*}{$8^{*}$} & 3 & 1.147 & & & & & 1.058 & 0.796 \\
\hline & & & & 4 & 1.109 & & & & 1.084 & 0.983 & 0.824 \\
\hline & & & & 5 & 1.085 & & & 1.093 & 1.016 & 0.968 & 0.839 \\
\hline & & & & 6 & 1.068 & & 1.093 & 1.036 & 0.994 & 0.961 & 0.848 \\
\hline \multirow{4}{*}{35} & \multirow{4}{*}{2.5} & \multirow{4}{*}{0.1} & \multirow{4}{*}{12} & 3 & 1.147 & & & & & 1.058 & 0.795 \\
\hline & & & & 4 & 1.110 & & & & 1.084 & 0.981 & 0.824 \\
\hline & & & & 5 & 1.085 & & & 1.093 & 1.015 & 0.966 & 0.840 \\
\hline & & & & 6 & 1.067 & & 1.093 & 1.037 & 0.995 & 0.960 & 0.849 \\
\hline \multirow{4}{*}{35} & \multirow{4}{*}{2.5} & \multirow{4}{*}{0.4} & \multirow{4}{*}{8} & 3 & 1.667 & & & & & 1.078 & 0.255 \\
\hline & & & & 4 & 1.519 & & & & 1.259 & 0.853 & 0.370 \\
\hline & & & & 5 & 1.425 & & & 1.295 & 1.052 & 0.794 & 0.434 \\
\hline & & & & 6 & 1.361 & & 1.296 & 1.132 & 0.969 & 0.769 & 0.473 \\
\hline \multirow{4}{*}{35} & & & & 3 & 1.669 & & & & & 1.080 & 0.251 \\
\hline & 25 & 0.4 & $12^{\star}$ & 4 & 1.516 & & & & 1.263 & 0.852 & 0.368 \\
\hline & & & & 5 & 1.418 & & & 1.298 & 1.055 & 0.794 & 0.435 \\
\hline & & & & 6 & 1.349 & & 1.296 & 1.136 & 0.973 & 0.770 & 0.476 \\
\hline & & & & 3 & 1.668 & & & & & 1.081 & 0.251 \\
\hline 35 & 2.5 & 0.4 & 18 & 4 & 1.514 & & & & 1.265 & 0.851 & 0.369 \\
\hline & & & & 5 & 1.416 & & & 1.301 & 1.054 & 0.793 & 0.436 \\
\hline & & & & 6 & 1.347 & & 1.299 & 1.137 & 0.971 & 0.769 & 0.477 \\
\hline & & & & 3 & 1.803 & & & & & 0.916 & -0.280 \\
\hline 35 & 2.5 & 0.7 & 8 & 4 & 1.795 & & & & 1.371 & 0.692 & -0.143 \\
\hline & & & & 5 & 1.717 & & & 1.496 & 1.116 & 0.620 & -0.051 \\
\hline & & & & 6 & 1.630 & & 1.513 & 1.277 & 0.996 & 0.579 & 0.005 \\
\hline & & & & 3 & 1.798 & & & & & 0.917 & -0.285 \\
\hline 35 & 2.5 & 0.7 & $12^{*}$ & 4 & 1.787 & & & & 1.377 & 0.691 & -0.145 \\
\hline & & & & 5 & 1.706 & & & 1.504 & 1.121 & 0.621 & -0.048 \\
\hline & & & & 6 & 1.610 & & 1.516 & 1.282 & 0.999 & 0.581 & 0.012 \\
\hline
\end{tabular}




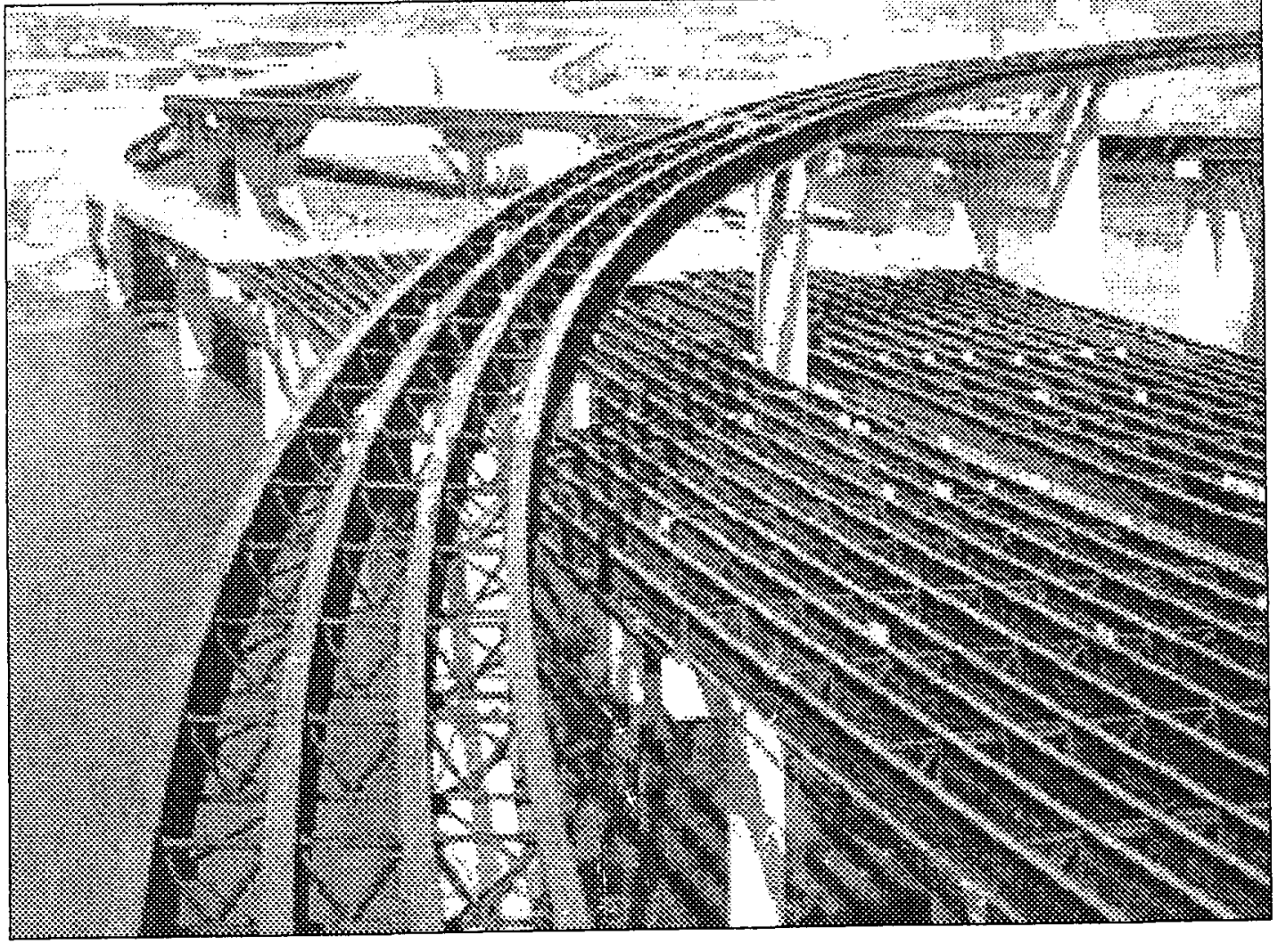

Figure 1.1 View of curved and straight steel I-girder bridges during erection

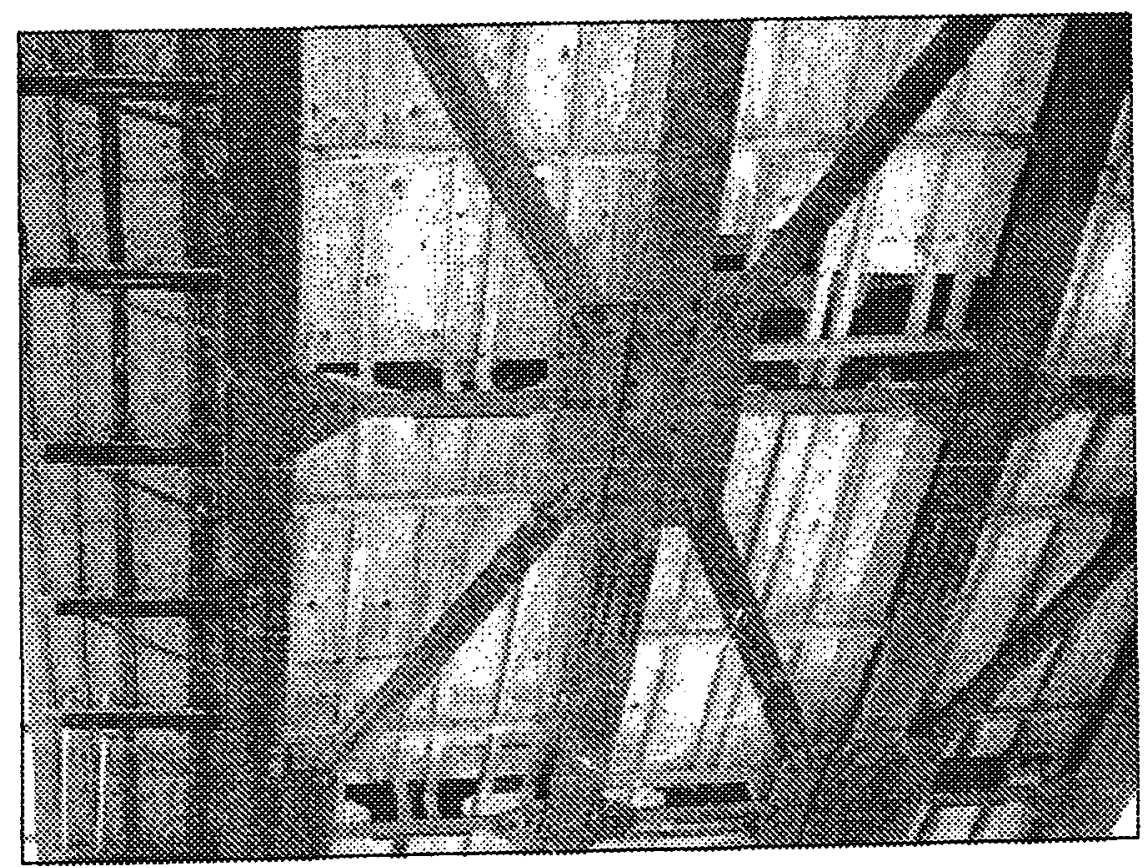

Figure 1.2 Horizontal bracing in curved steel I-girder bridge 


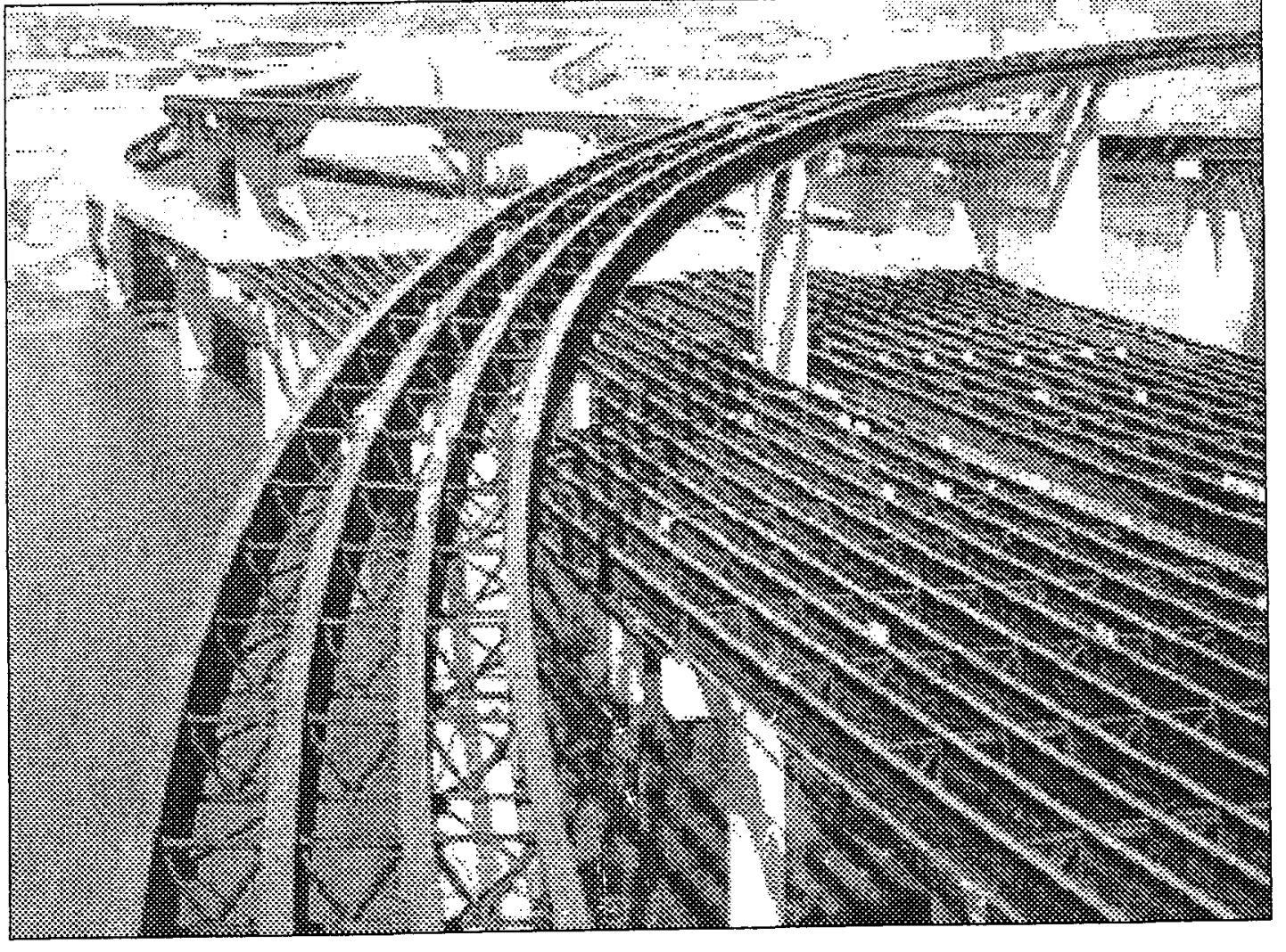

Figure 1.1 View of curved and straight steel I-girder bridges during erection

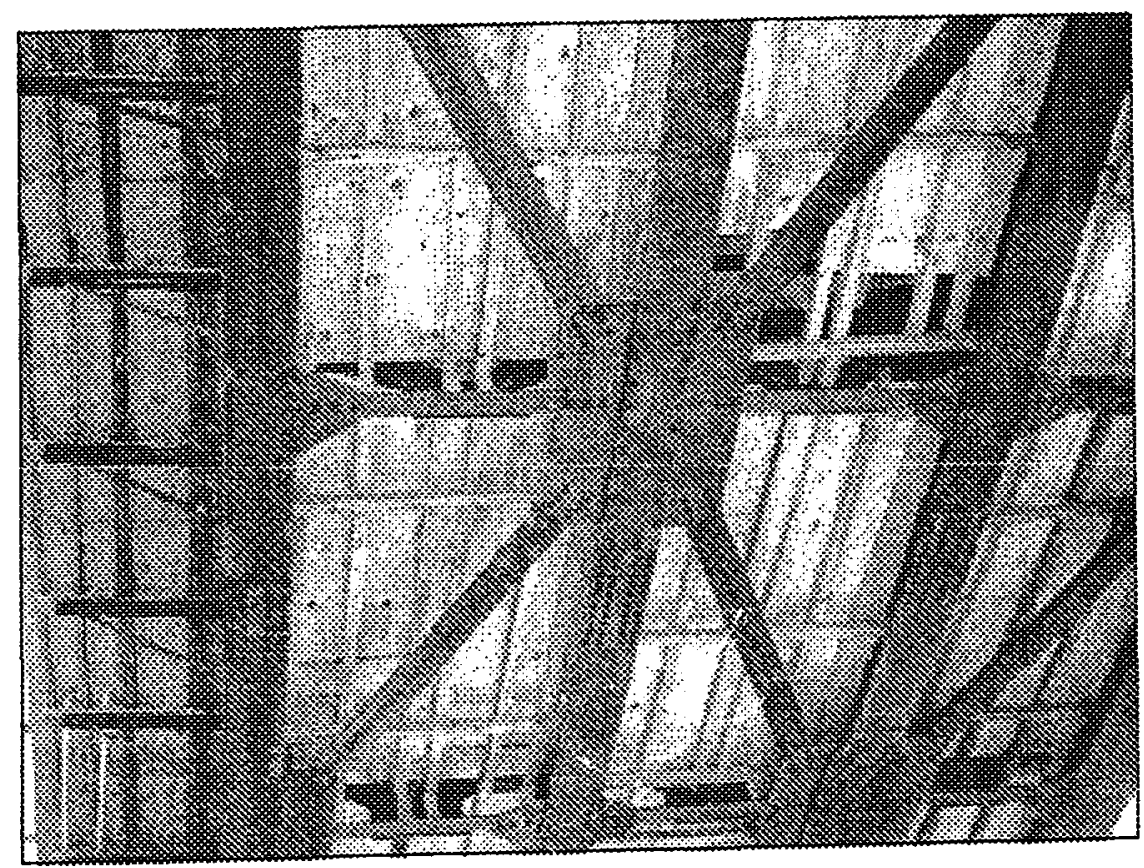

Figure 1.2 Horizontal bracing in curved steel I-girder bridge 


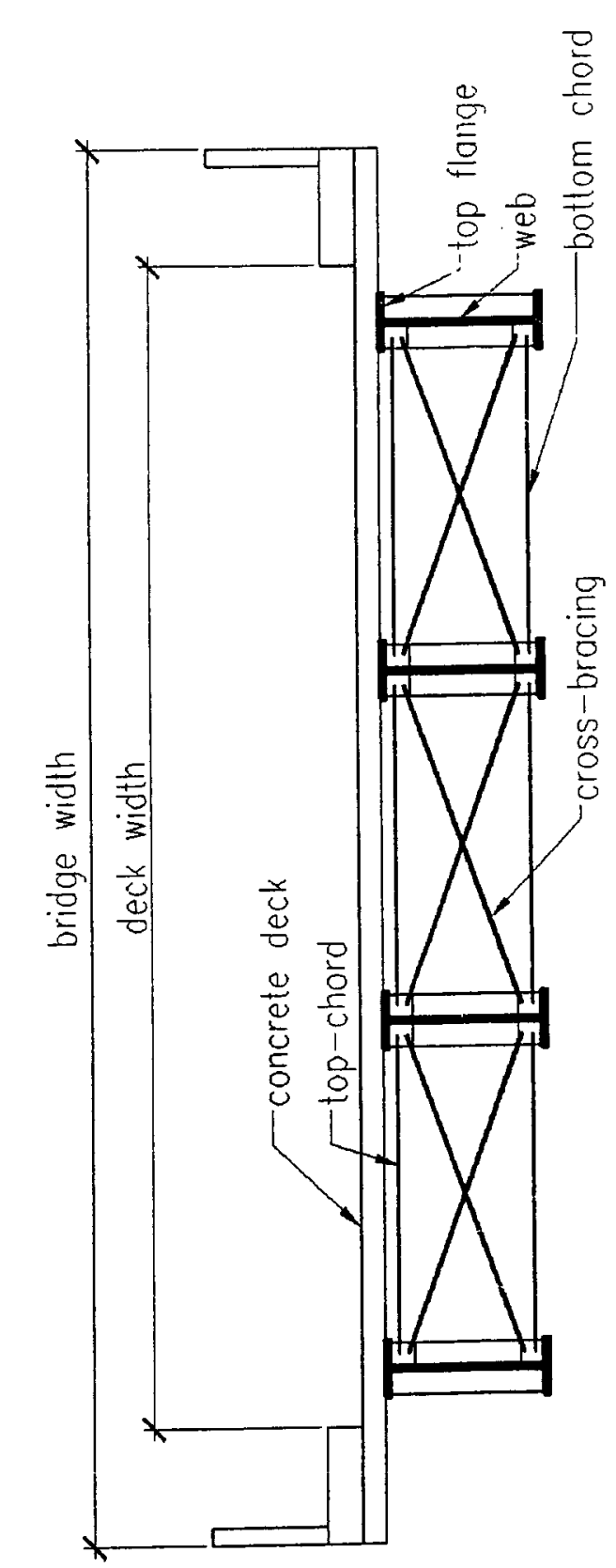

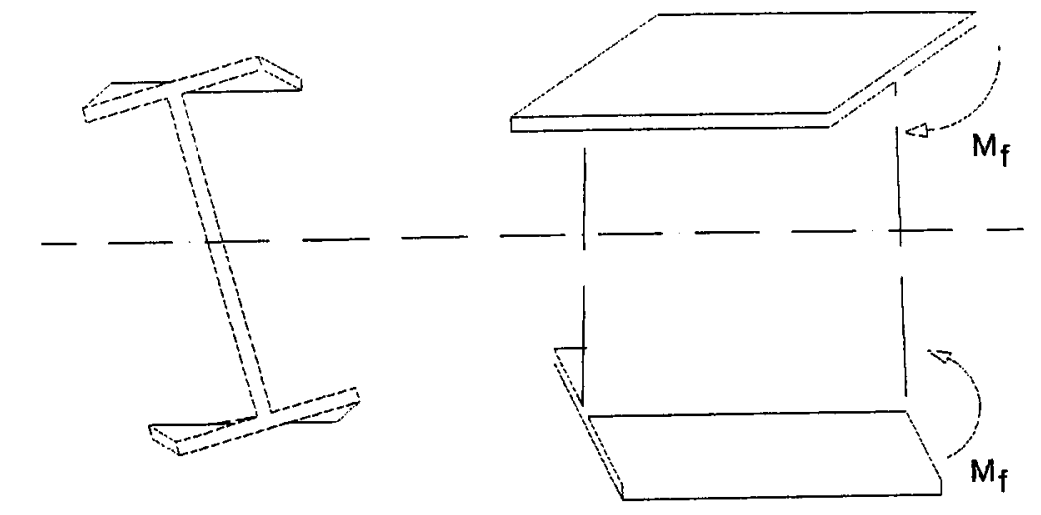

Figure 2.1 Warping of steel I-section

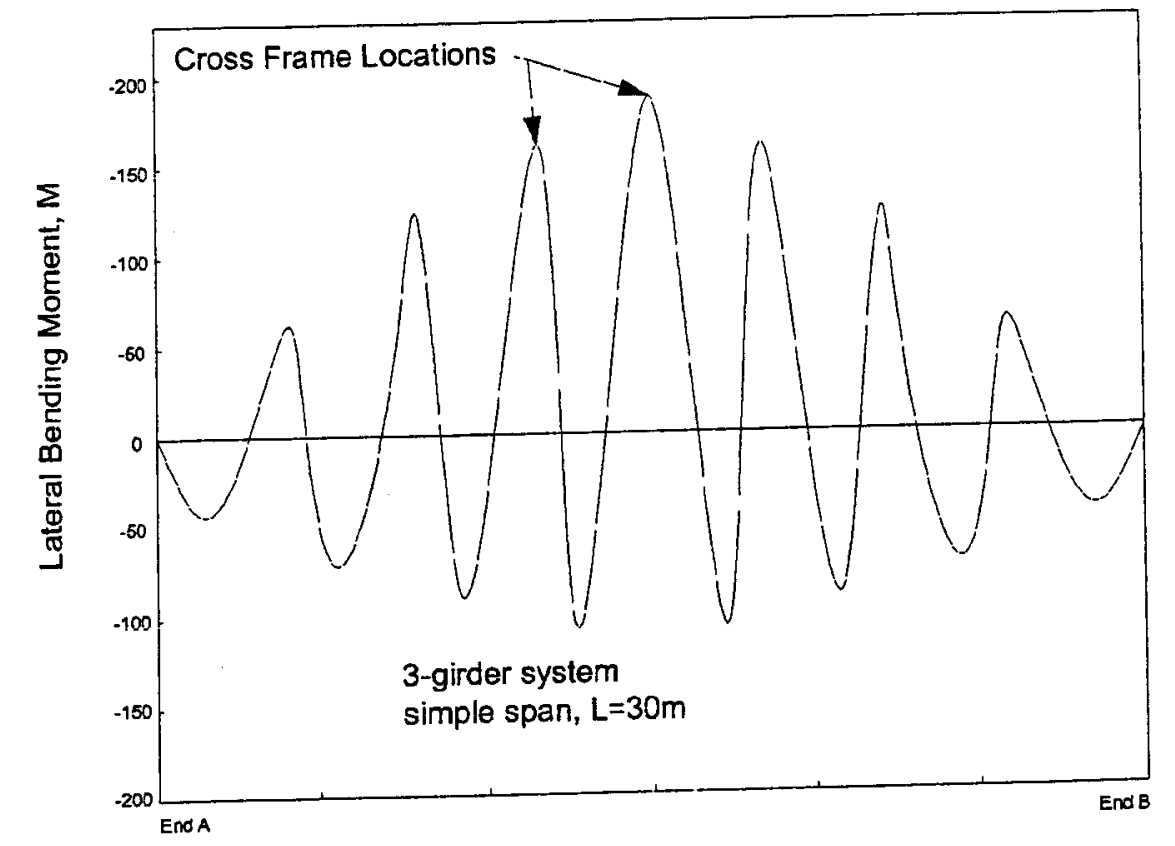

Figure 2.2: Cross frames (bracings) effect on lateral bending moments in flanges. 


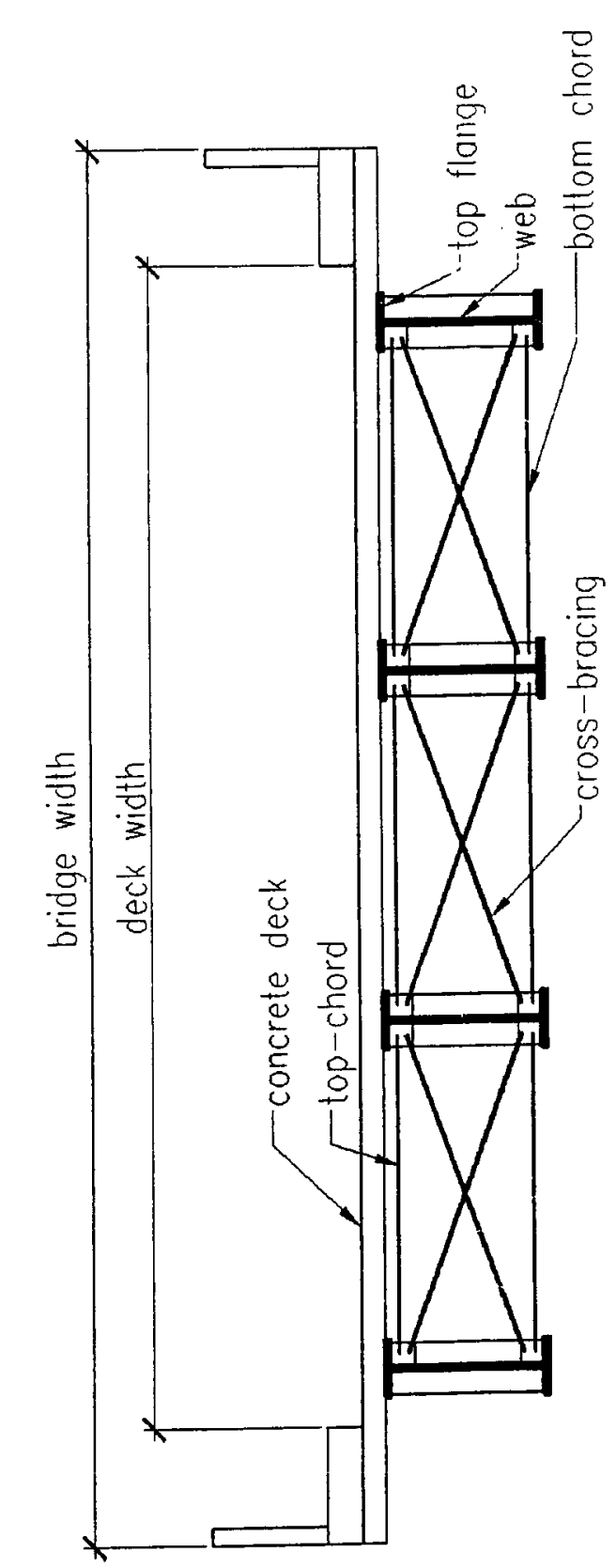

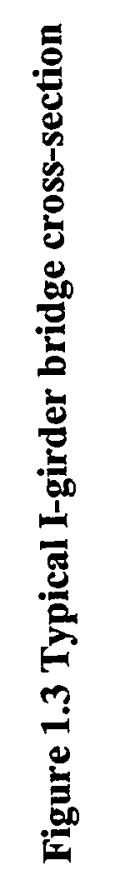

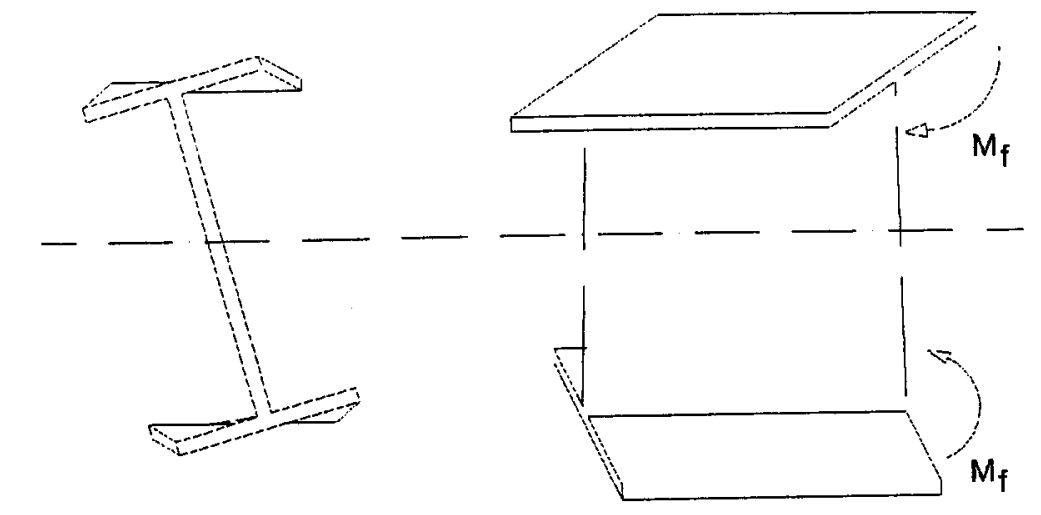

Figure 2.1 Warping of steel I-section

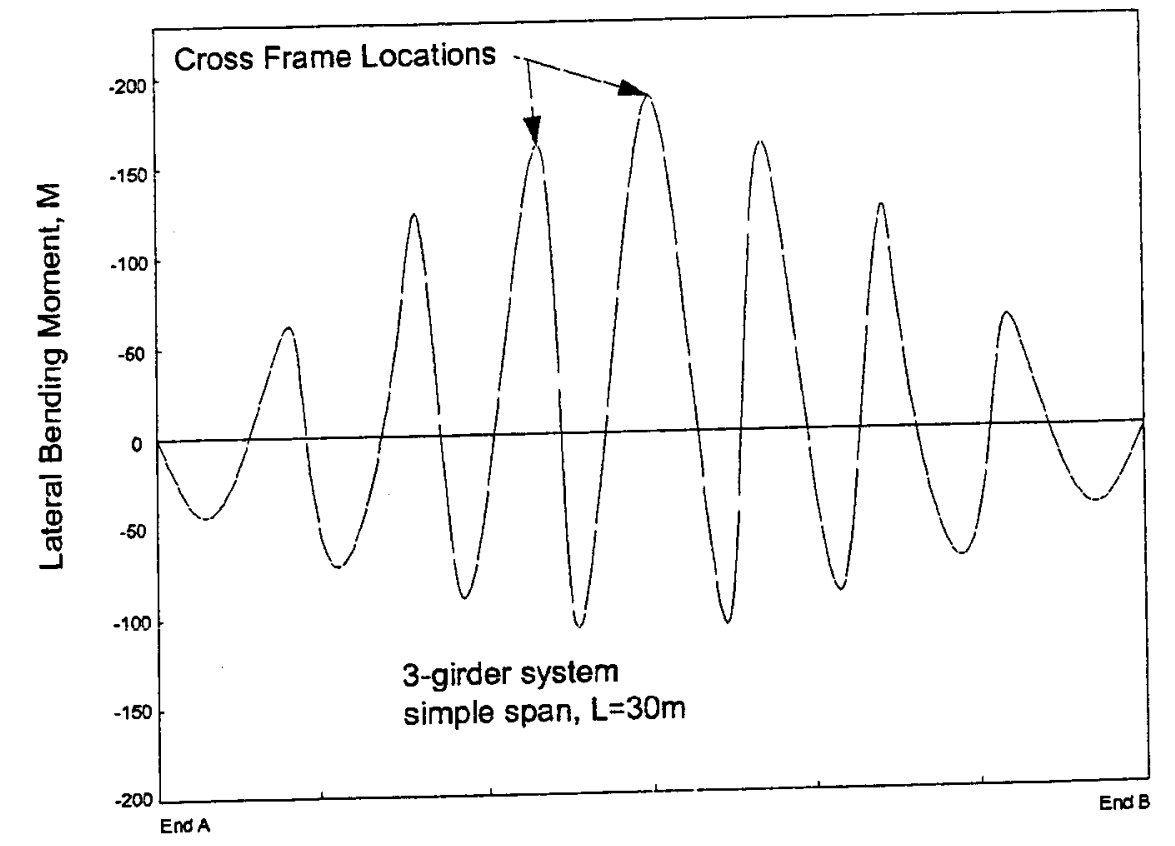

Figure 2.2: Cross frames (bracings) effect on lateral bending moments in flanges. 


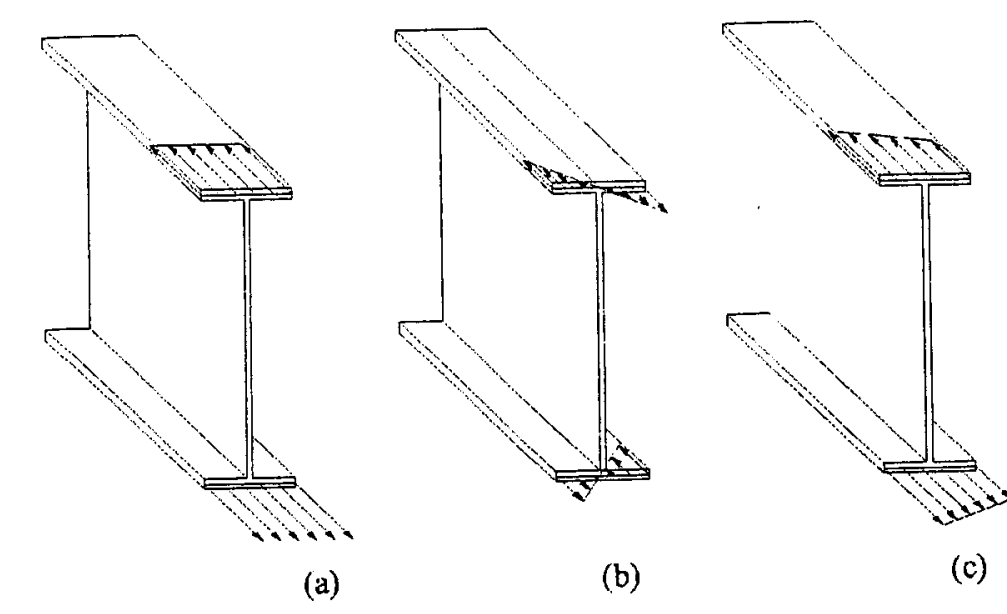

a) Major axis bending stress

b) Warping stress

c) Combined bending and warping stres

Figure 2.3: Normal stress distribution in curved I-girder flanges

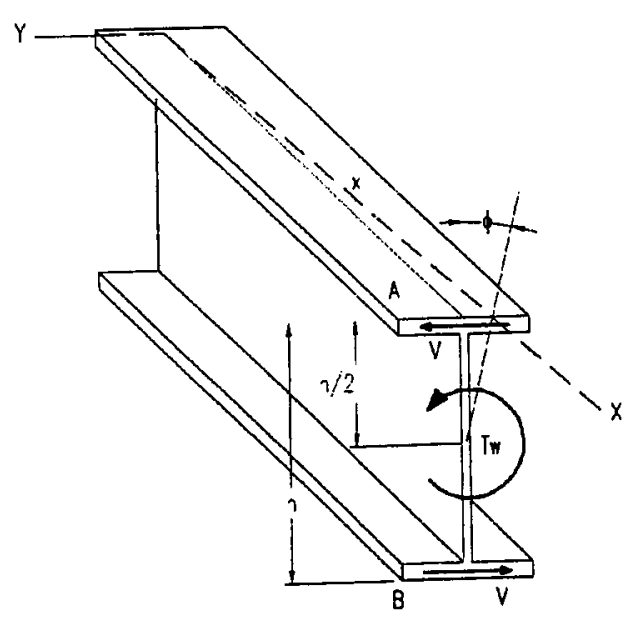

Figure 2.4 Effect of warping moment applied to I-girder

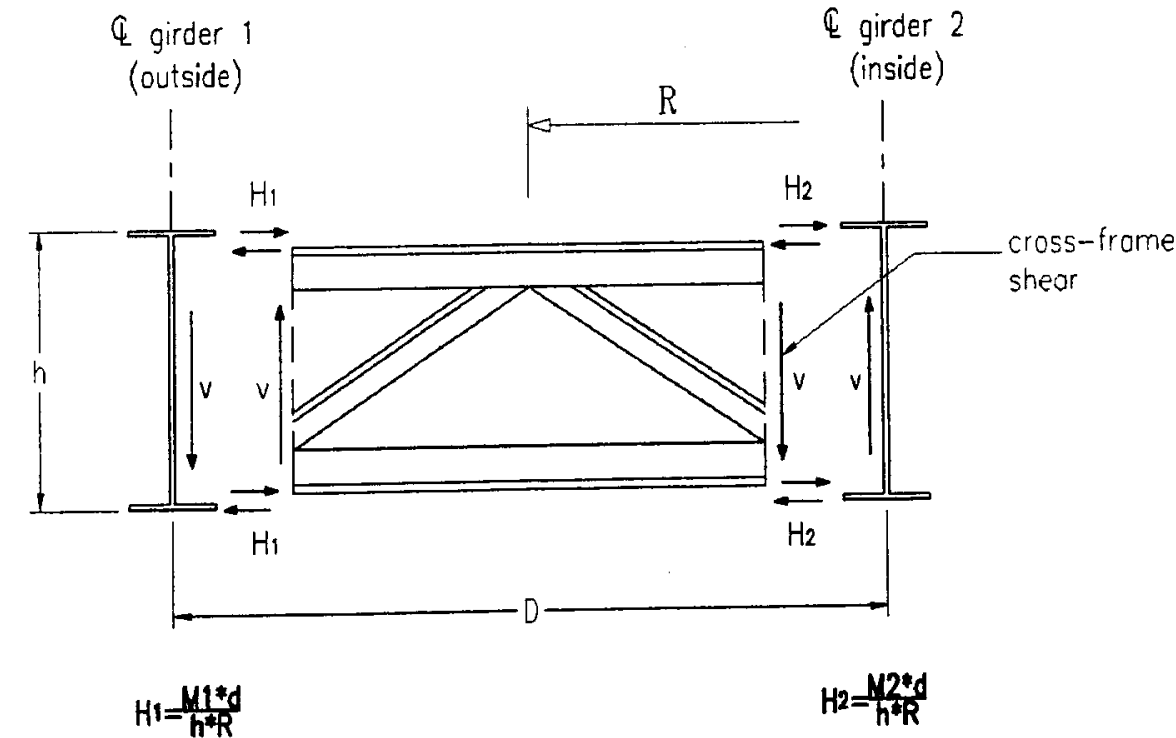

Figure 2.5: V-Load on girder

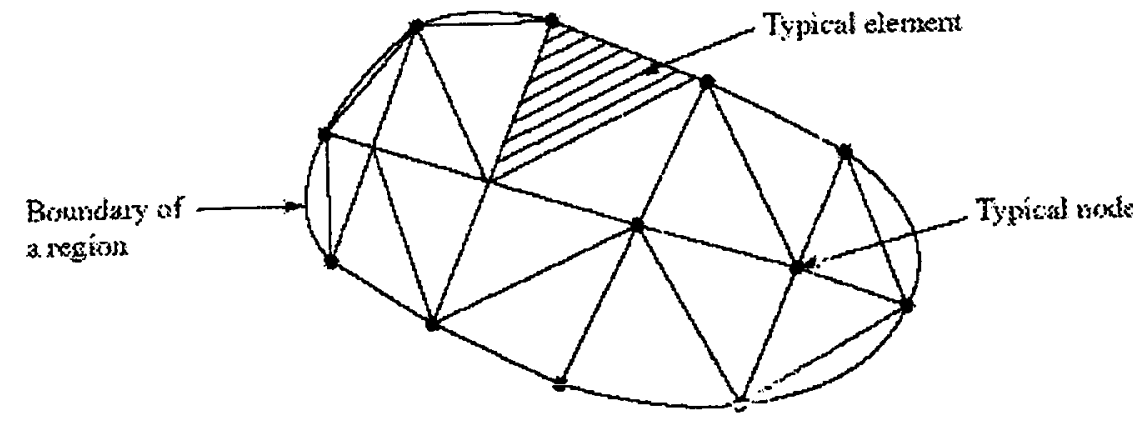

Figure 2.6: Assemblage of finite subdivisions 


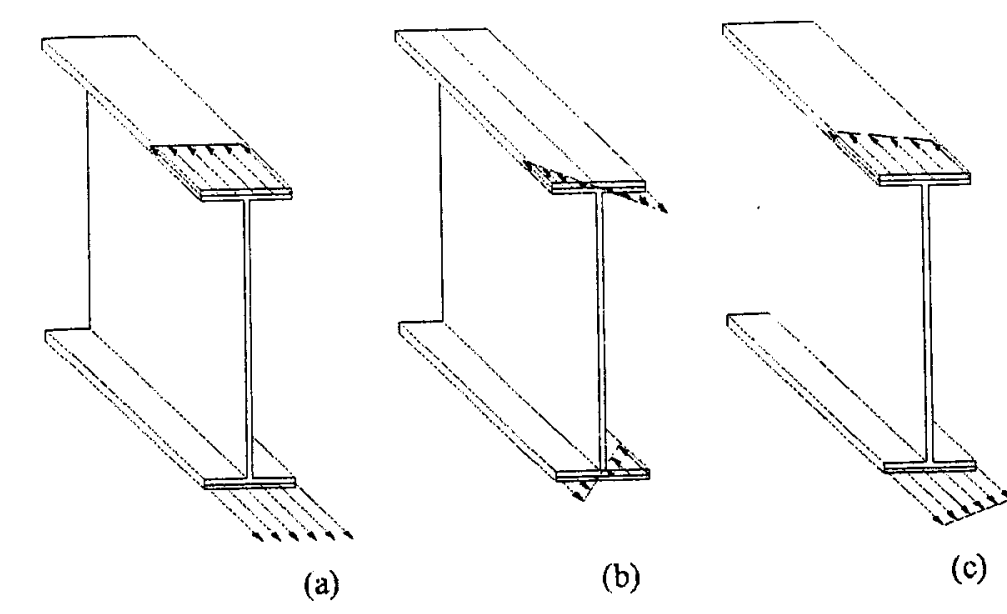

a) Major axis bending stress

b) Warping stress

c) Combined bending and warping stres

Figure 2.3: Normal stress distribution in curved I-girder flanges

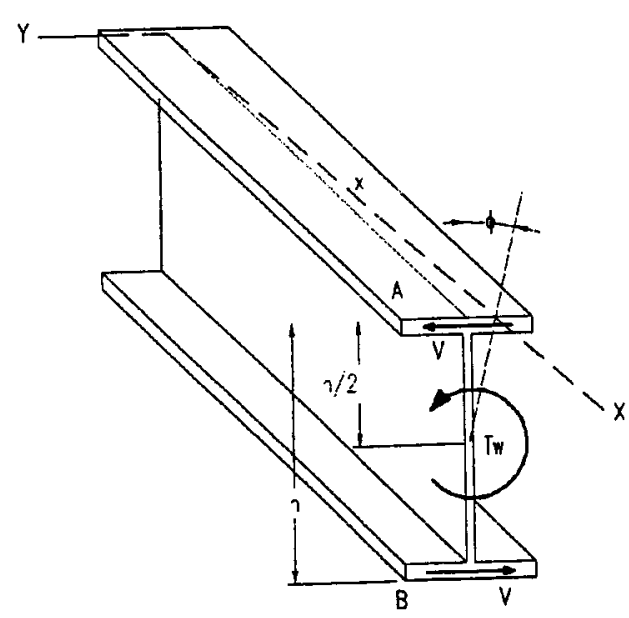

Figure 2.4 Effect of warping moment applied to I-girder

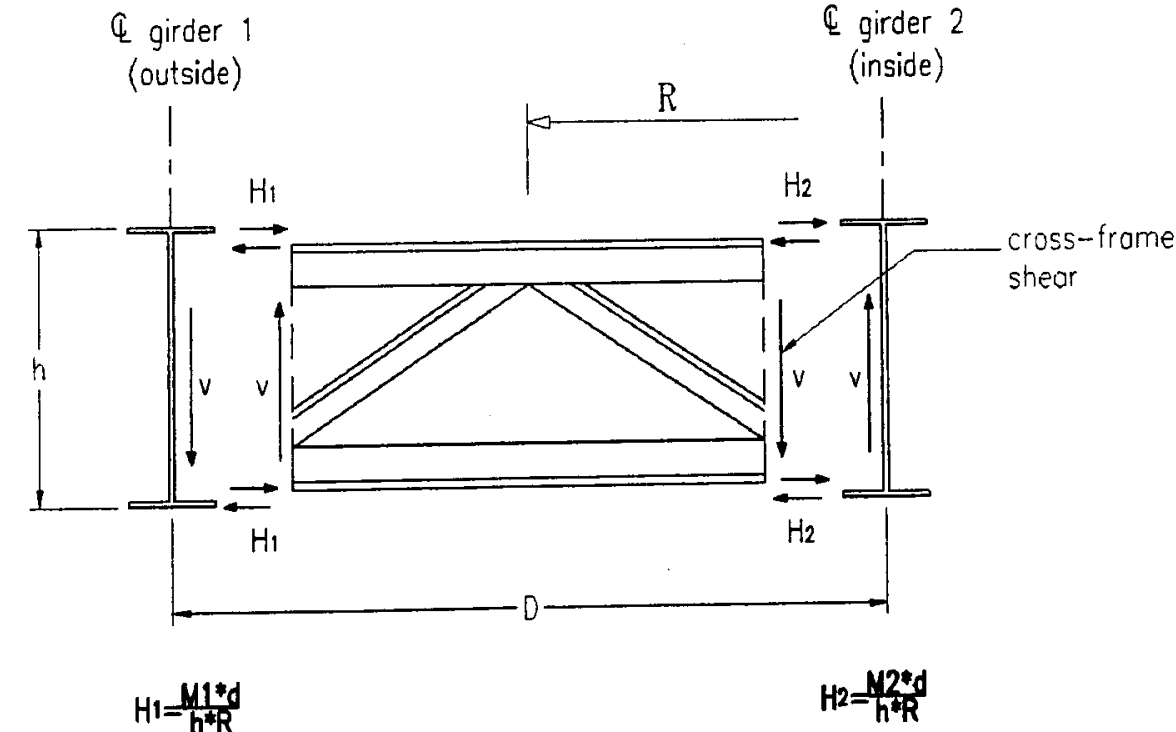

Figure 2.5: V-Load on girder

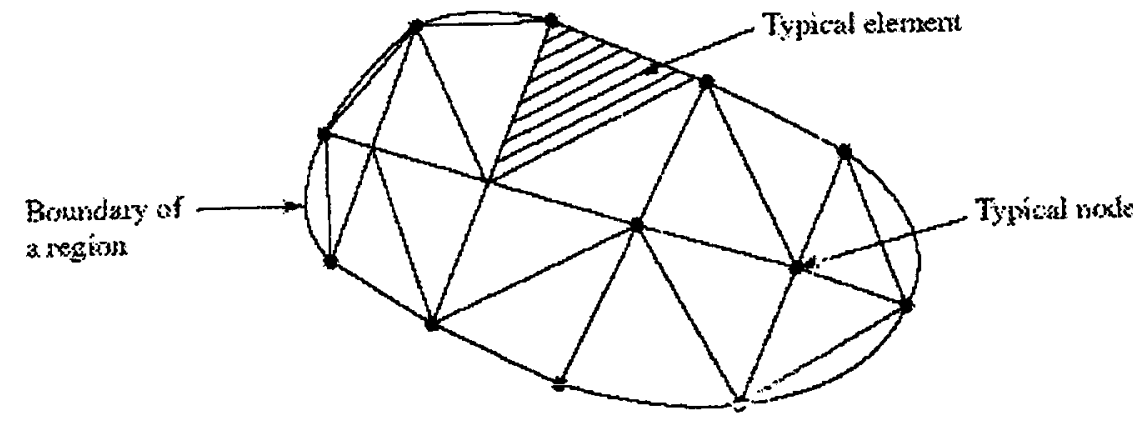

Figure 2.6: Assemblage of finite subdivisions. 


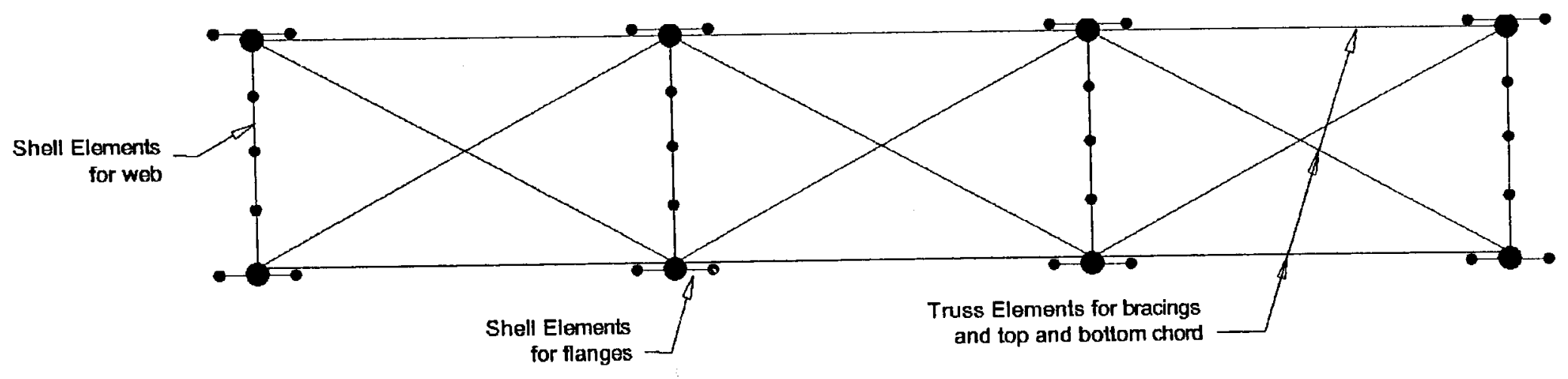

Figure 3.1 Finite element representation of bridge cross section at construction phase without deck slab
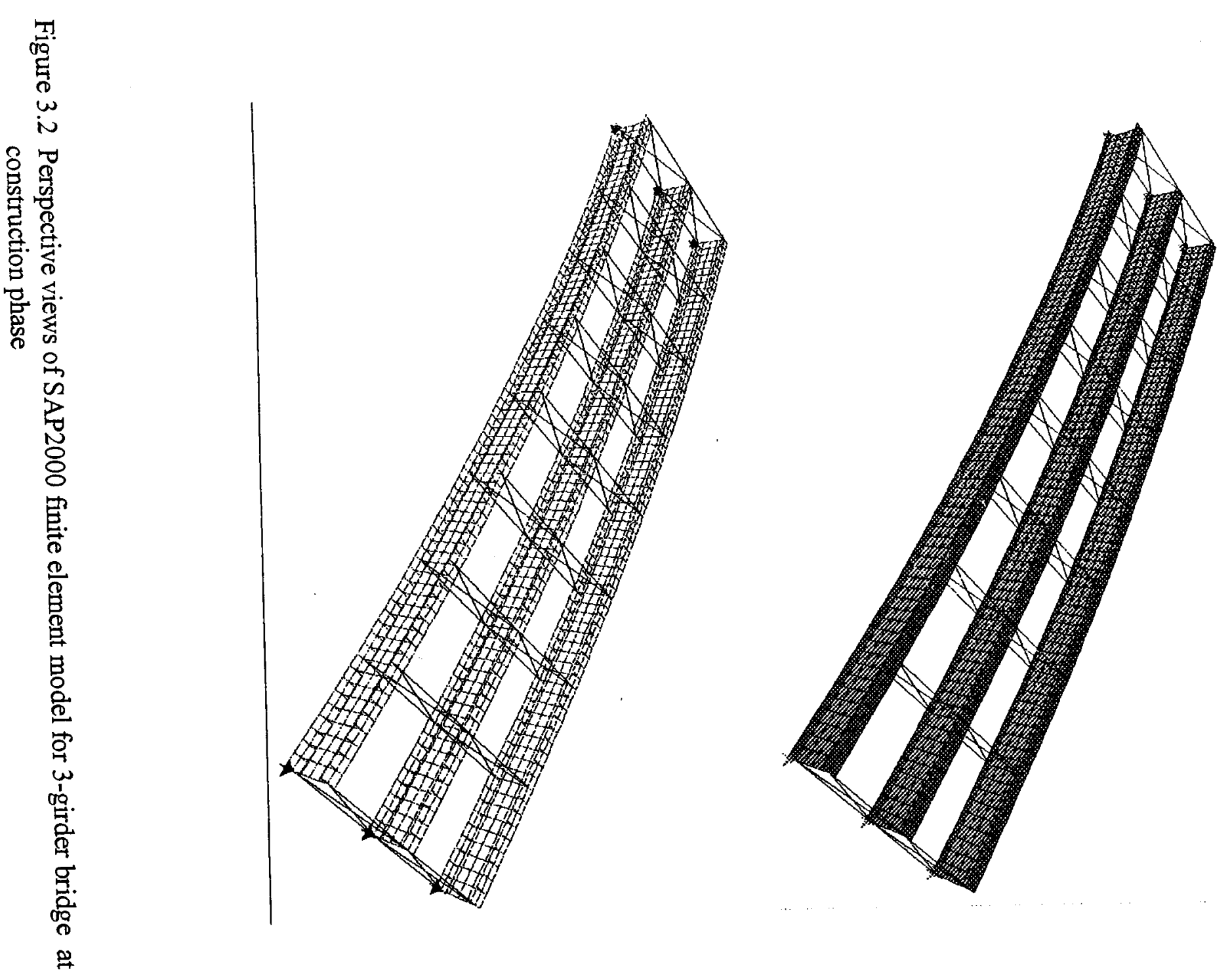


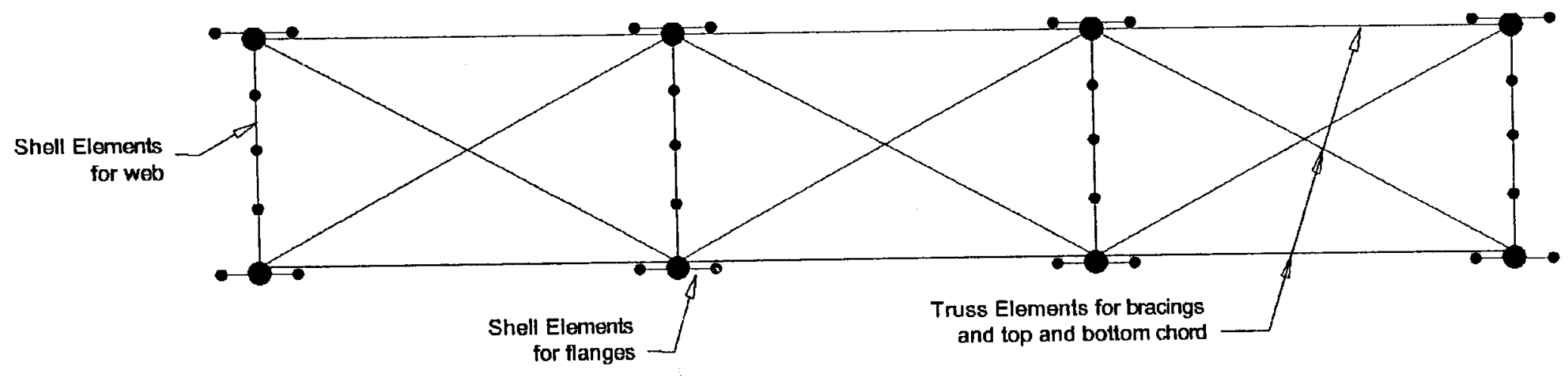

Figure 3.1 Finite element representation of bridge cross section at construction phase without deck slab
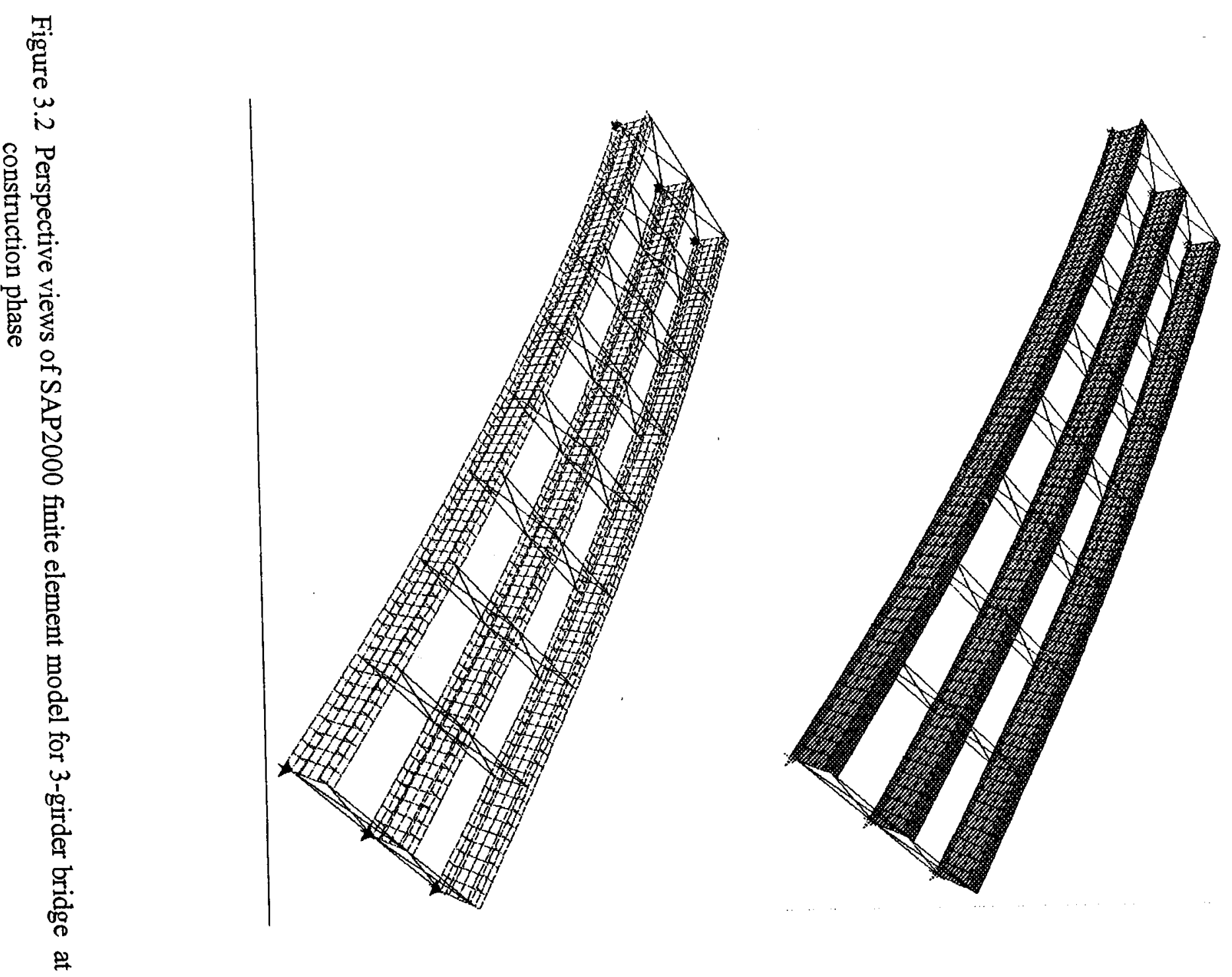


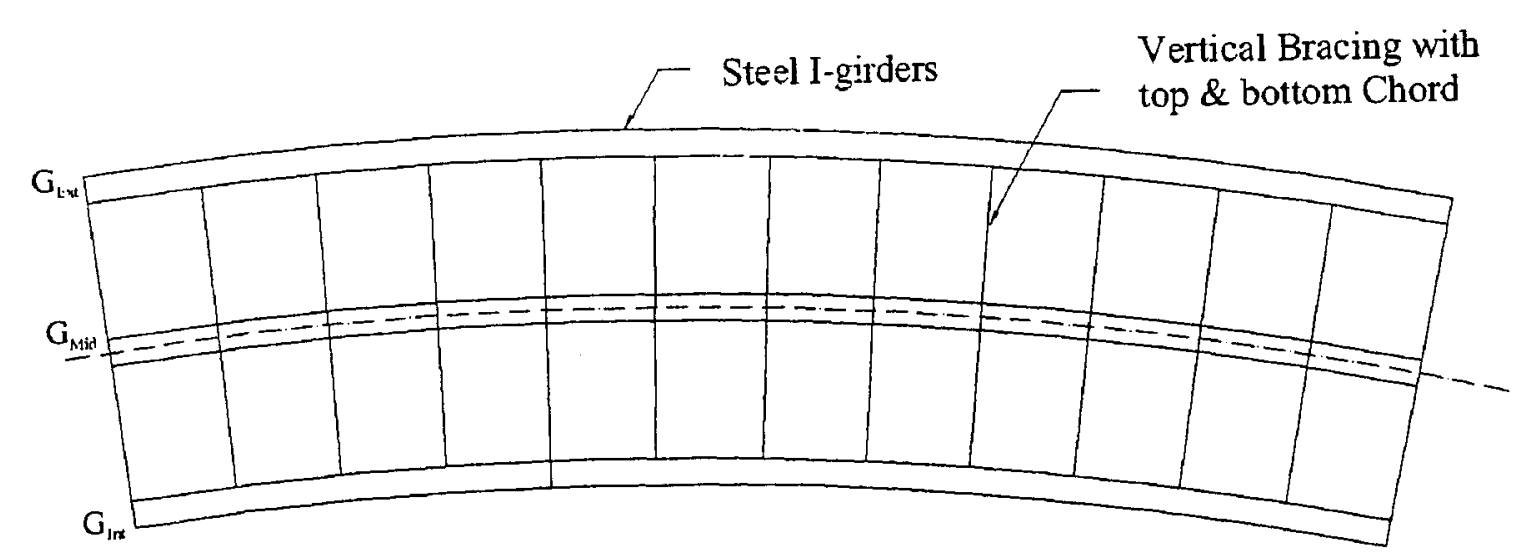

Typical Curved Steel I-girders Bridge

Figure 3.3 Steel I-girders bridge with raciial cross bracings

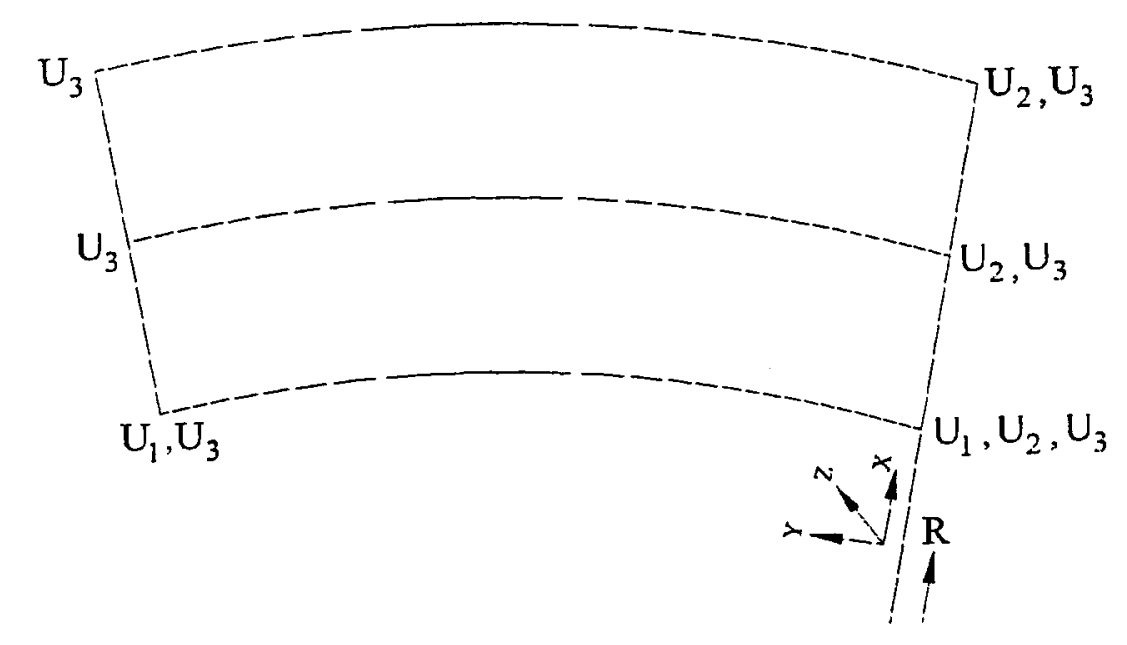

Figure 3.4 Boundary conditions for the finite element models

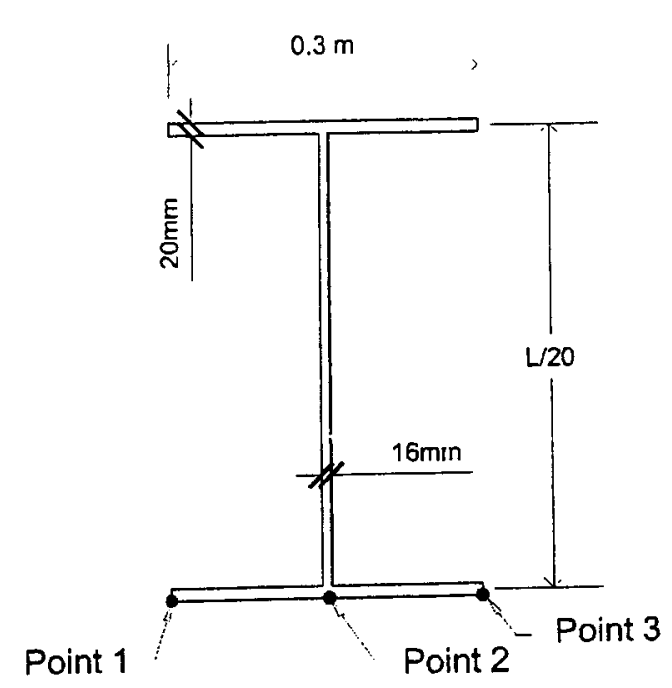

Figure 3.5 Cross-Section dimensions of the steel girder 


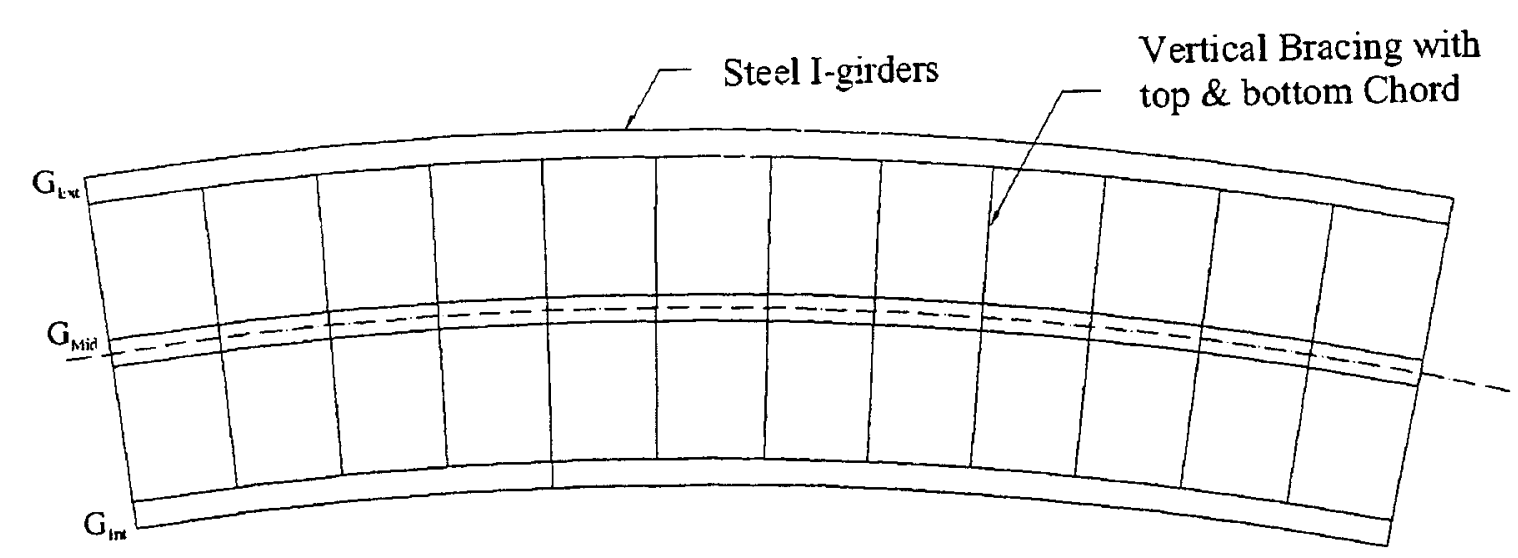

Typical Curved Steel l-girders Bridge

Figure 3.3 Steel I-girders bridge with raciial cross bracings

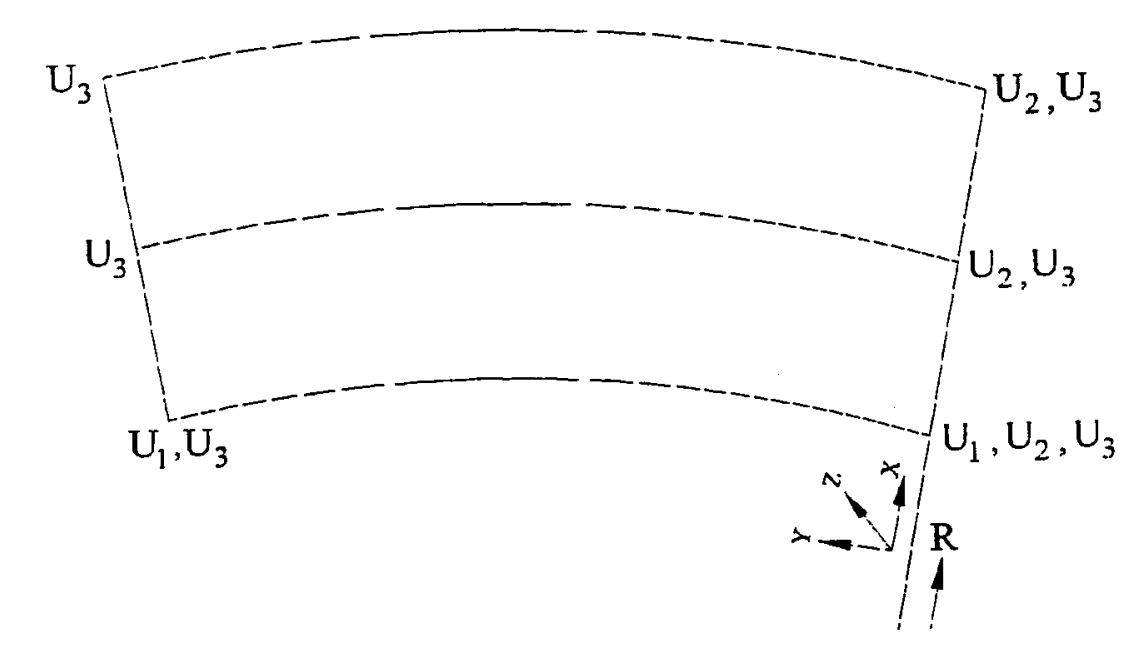

Figure 3.4 Boundary conditions for the finite element models

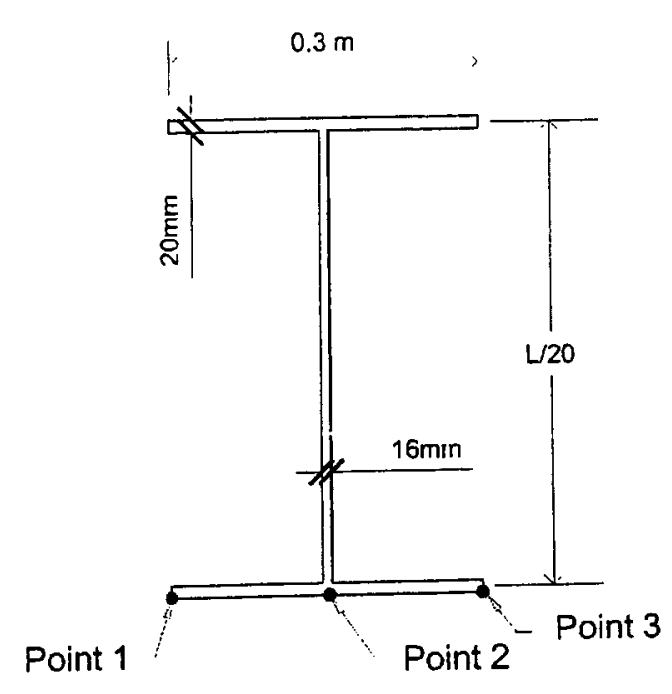

Figure 3.5 Cross-Section dimensions of the steel girder 


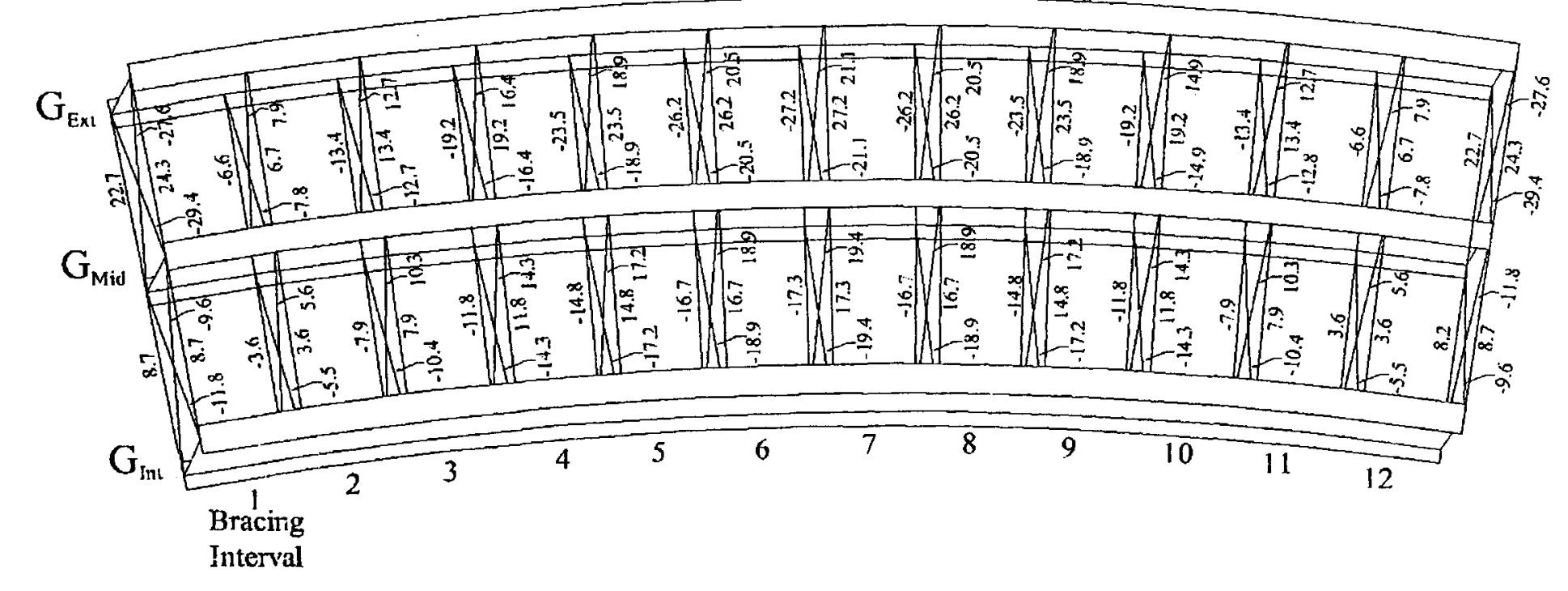

Figure 4.1 Axial forces in bracing members of a $25-\mathrm{m}$ span bridge with vertical bracings only

Note:
$L=25 \mathrm{~m}, \mathrm{~N}=3 \mathrm{~m}, \mathrm{~S}=2 \mathrm{~m}, \mathrm{~L} / \mathrm{R}=0.5$, No. of bracing intervals $=12$

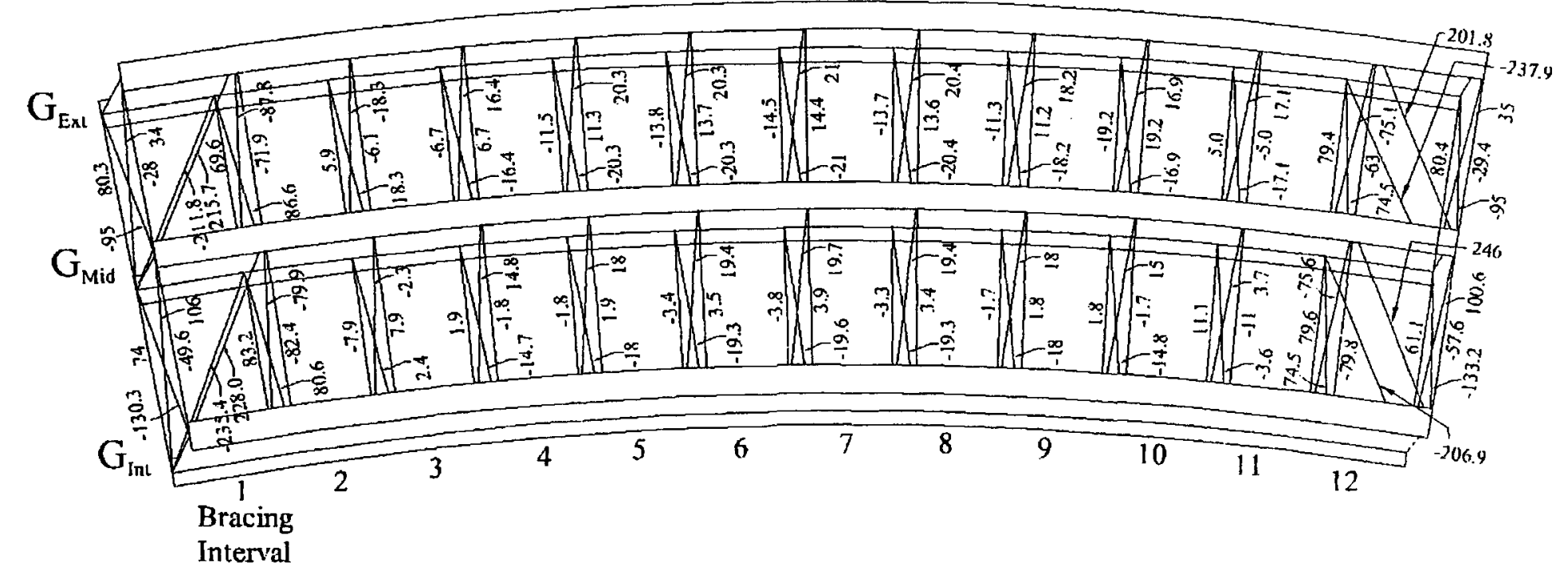

Figure 4.2 Axial forces in bracing members of a $25-\mathrm{m}$ span bridge with vertical bracings and torsion box

Note:

$\mathrm{L}=25 \mathrm{~m}, \mathrm{~N}=3 \mathrm{~m}, \mathrm{~S}=2 \mathrm{~m}, \mathrm{~L} / \mathrm{R}=0.5$, No. of bracing intervals $=12$

Sectional area of the torsion box horizontal bracing: $A=0.0075 \mathrm{~mm}^{2}$ 


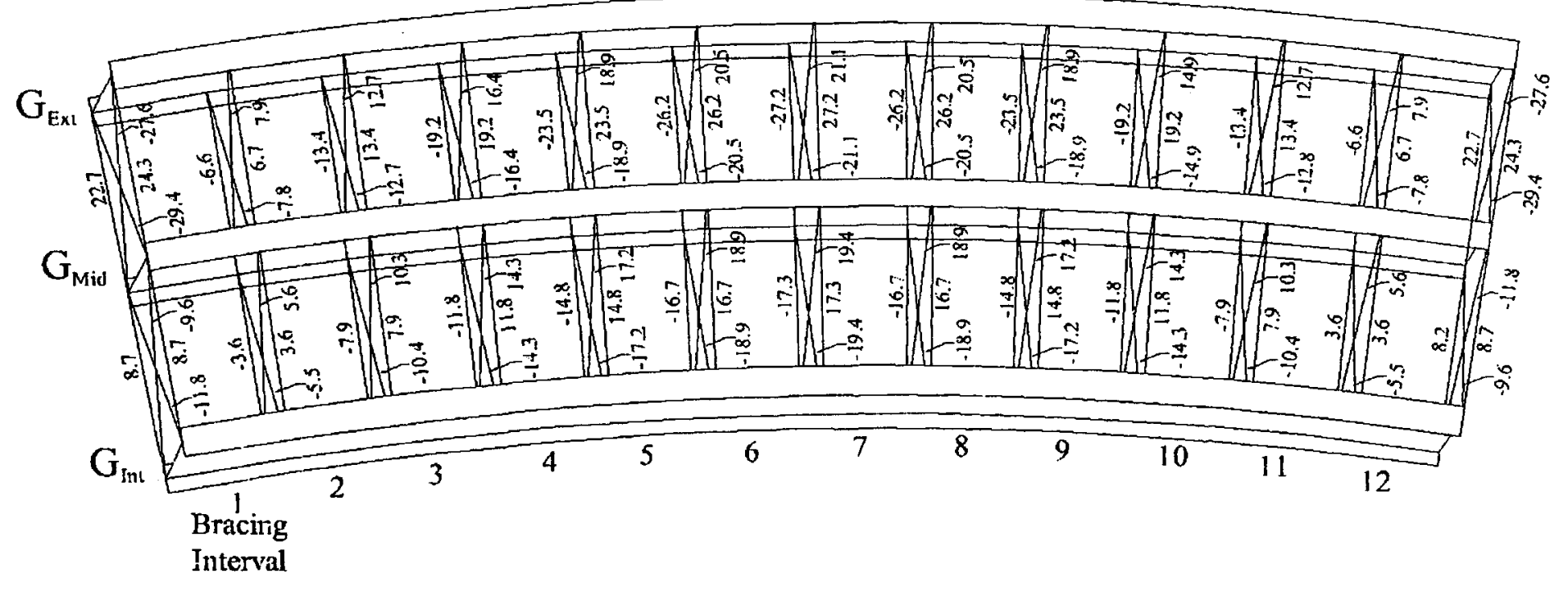

Figure 4.1 Axial forces in bracing members of a $25-\mathrm{m}$ span bridge with vertical bracings only

Note:

Note:
$\mathrm{L}=25 \mathrm{~m}, \mathrm{~N}=3 \mathrm{~m}, \mathrm{~S}=2 \mathrm{~m}, \mathrm{~L} / \mathrm{R}=0.5$, No. of bracing intervals $=12$

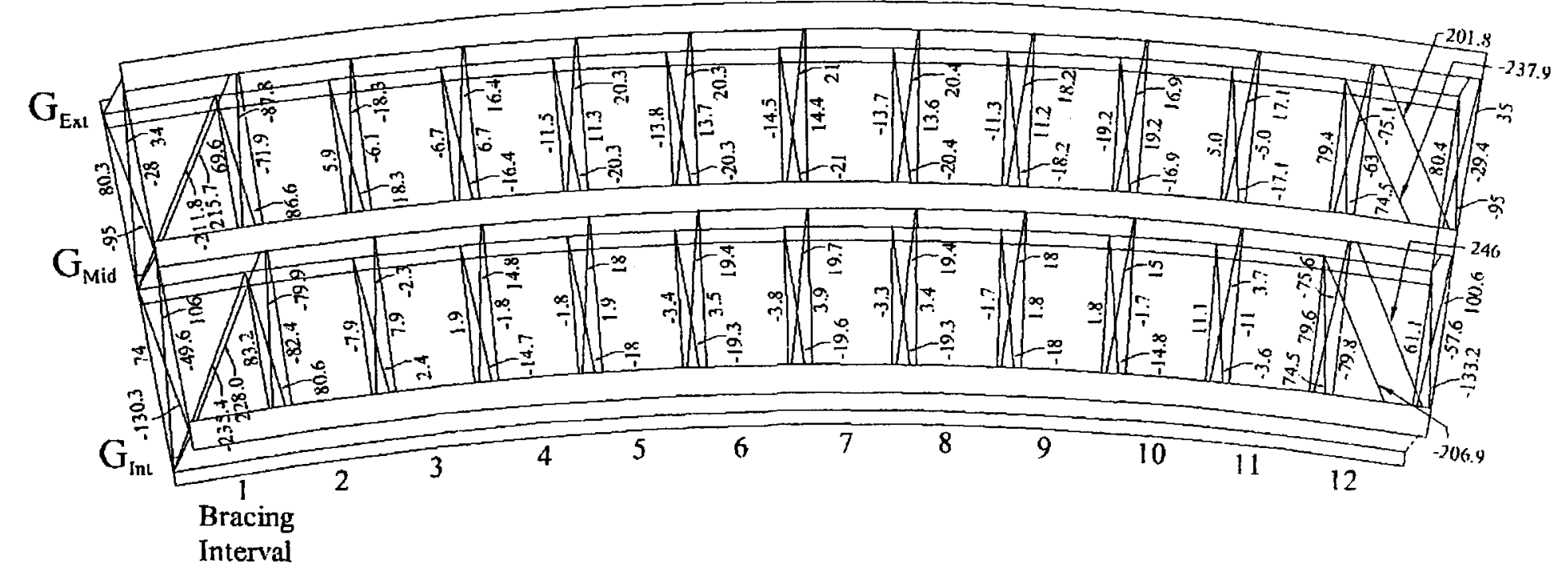

Figure 4.2 Axial forces in bracing members of a $25-\mathrm{m}$ span bridge with vertical bracings and torsion box

Note:

$\mathrm{L}=25 \mathrm{~m}, \mathrm{~N}=3 \mathrm{~m}, \mathrm{~S}=2 \mathrm{~m}, \mathrm{~L} / \mathrm{R}=0.5$, No. of bracing intervals $=12$

Sectional area of the torsion box horizontal bracing: $A=0.0075 \mathrm{~mm}^{2}$ 


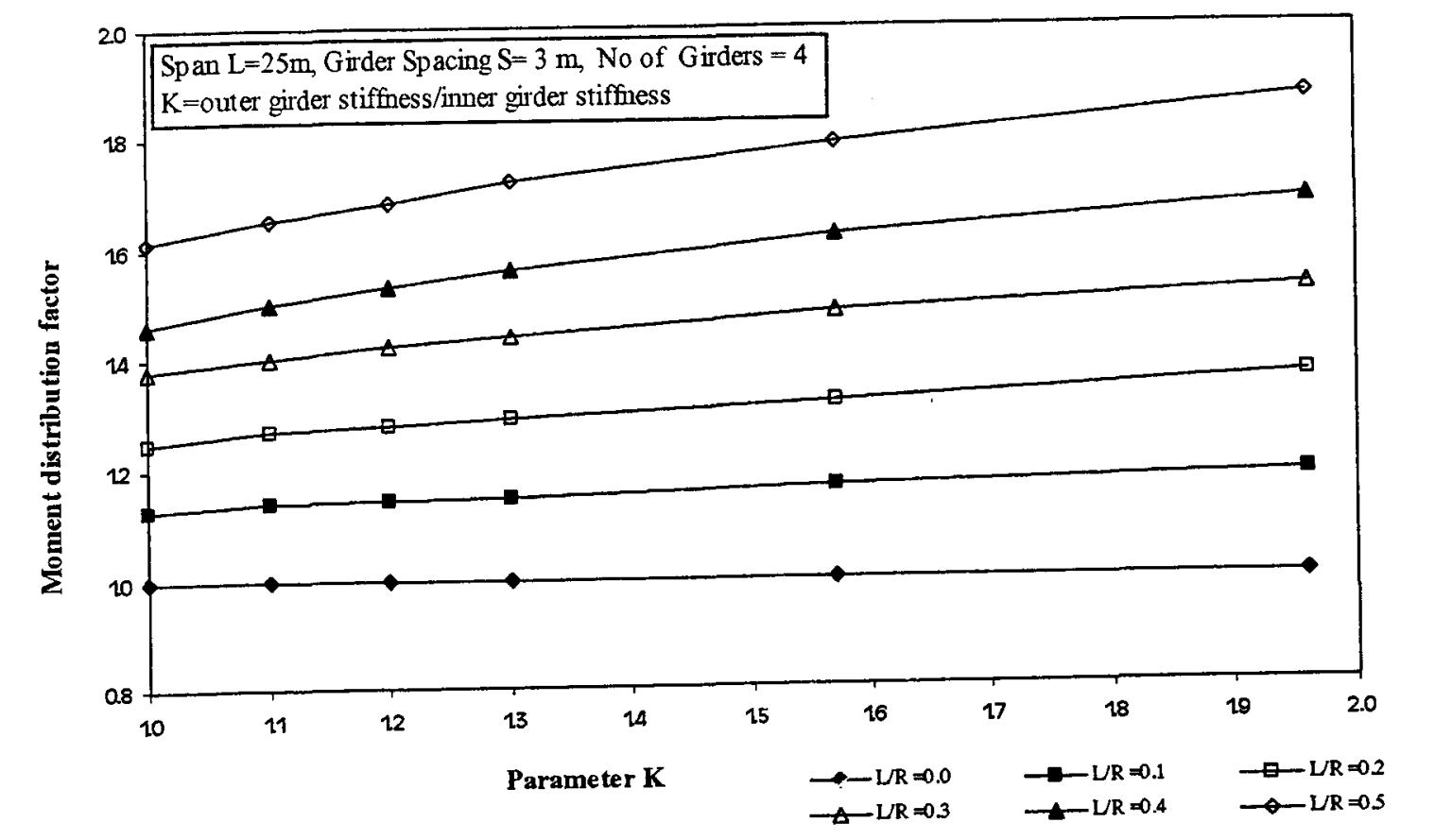

Figure 4.3 Effect of variation of girder stiffness on moment distribution factor of the outer girder

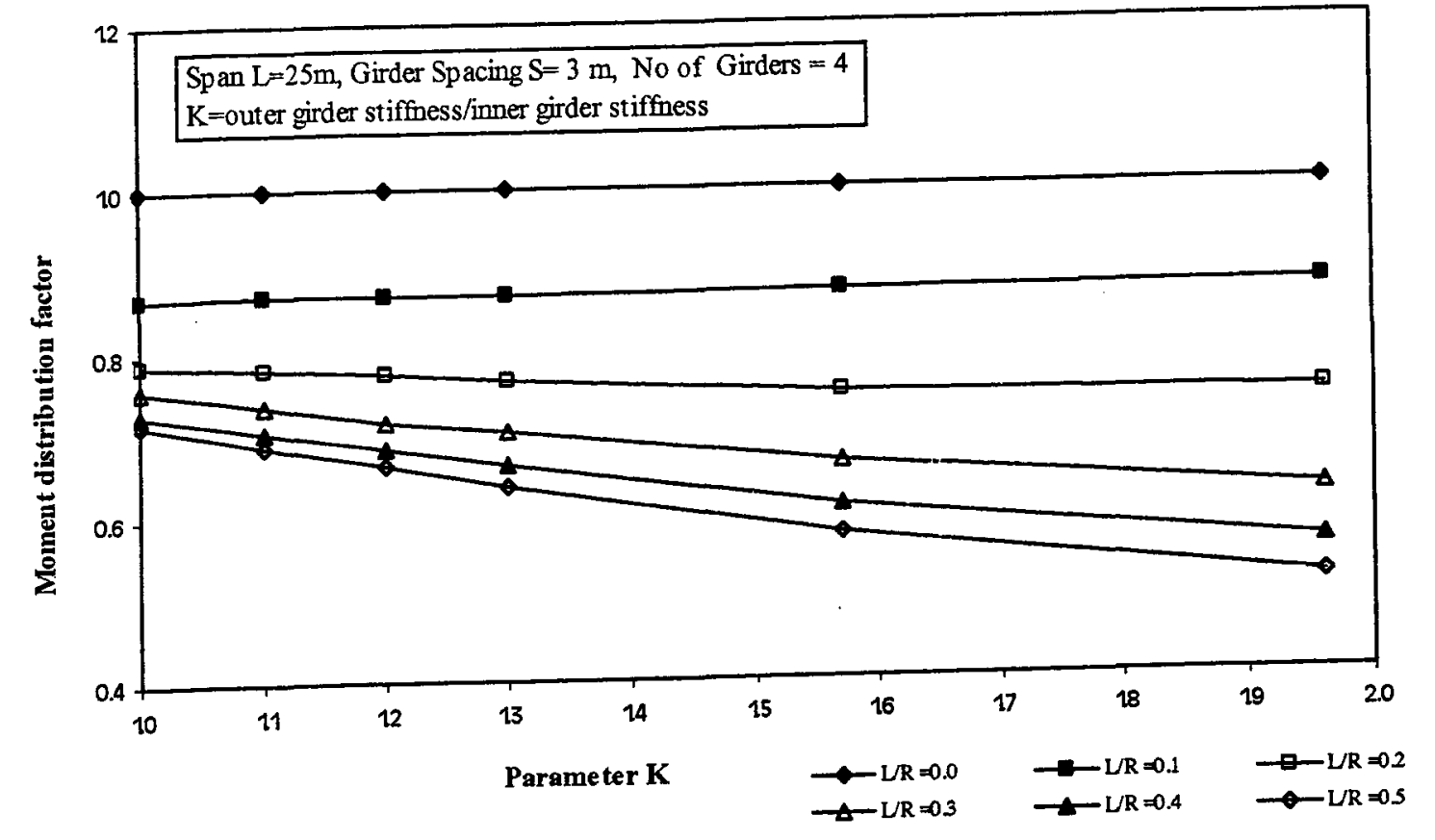

Figure 4.4 Effect of variation of girder stiffness on moment distribution factor of the inner girder

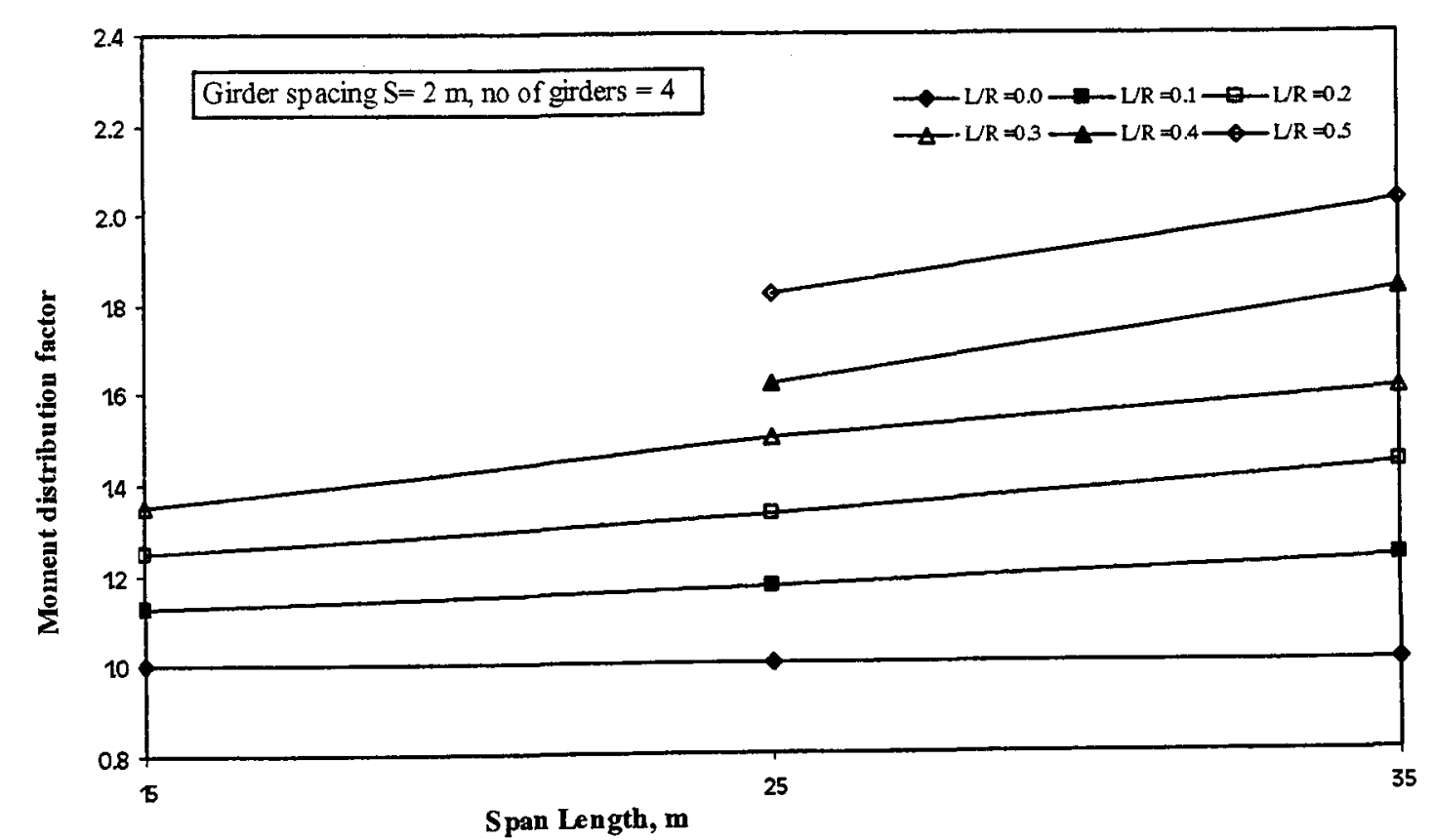

Figure 4.5 Effect of span length on moment distribution factor for the outer girder of curved steel I-girder bridges

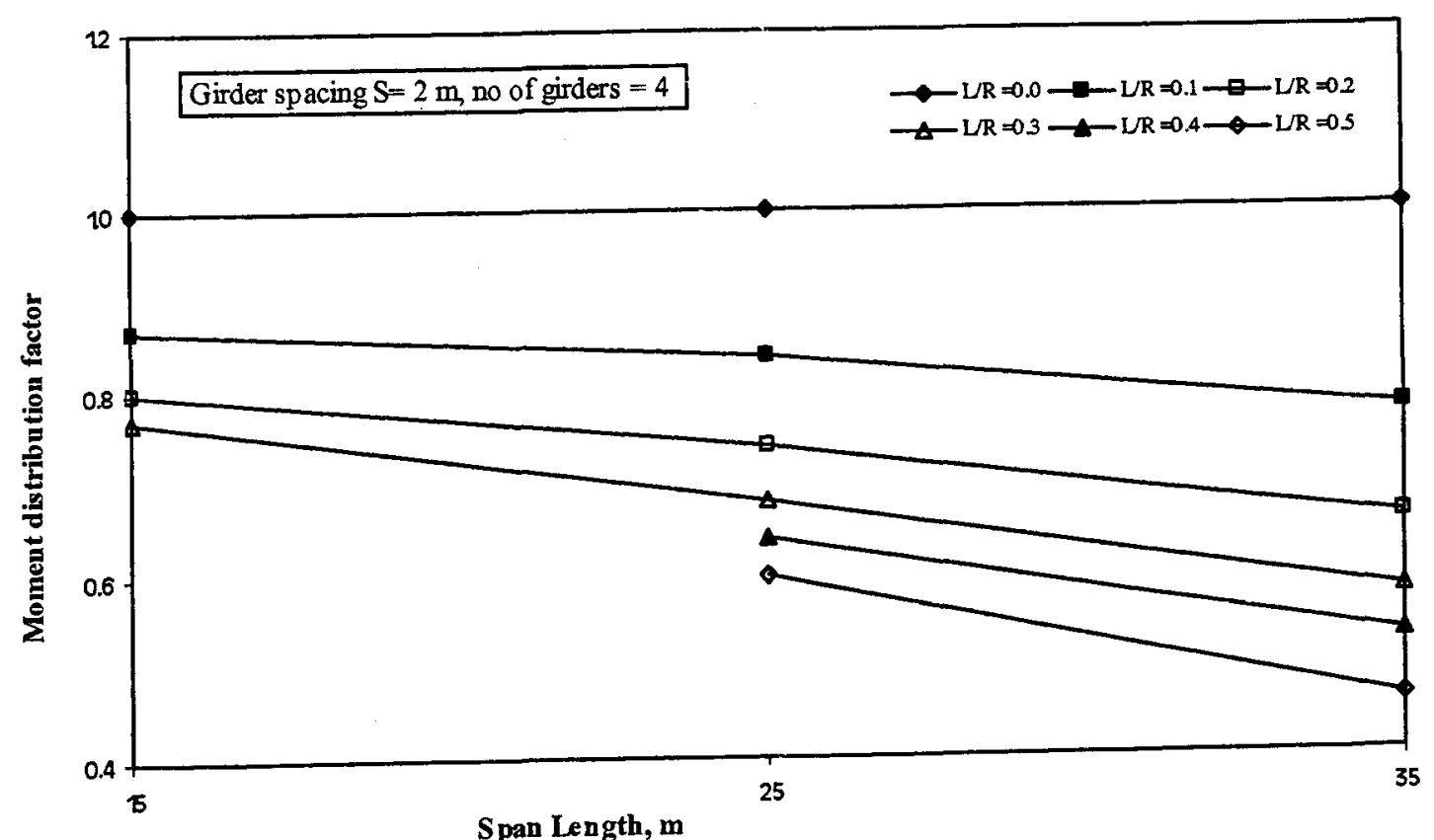

Figure 4.6 Effect of span length on moment distribution factor for the inner girder of curved steel I-girder bridges 


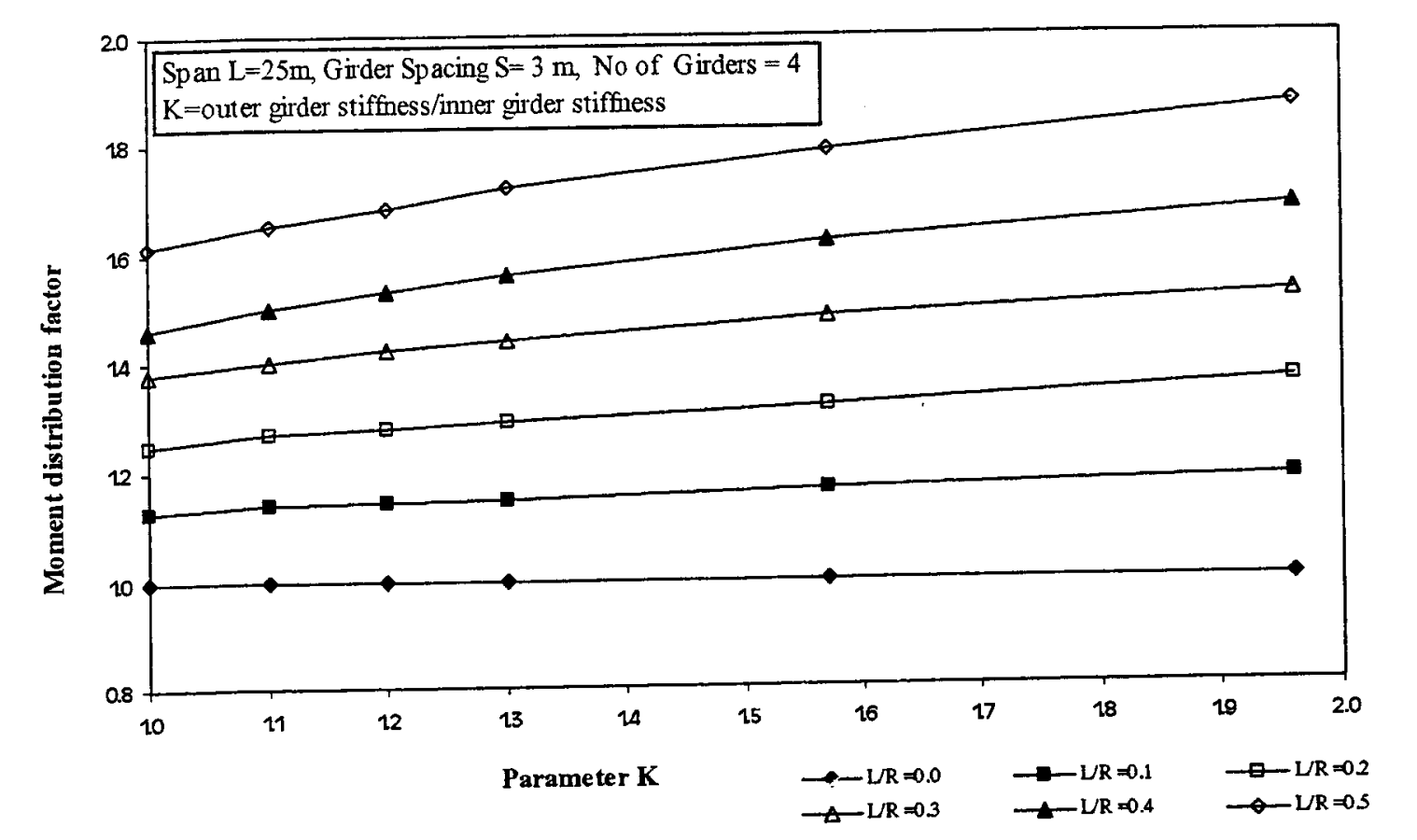

Figure 4.3 Effect of variation of girder stiffness on moment distribution factor of the outer girder

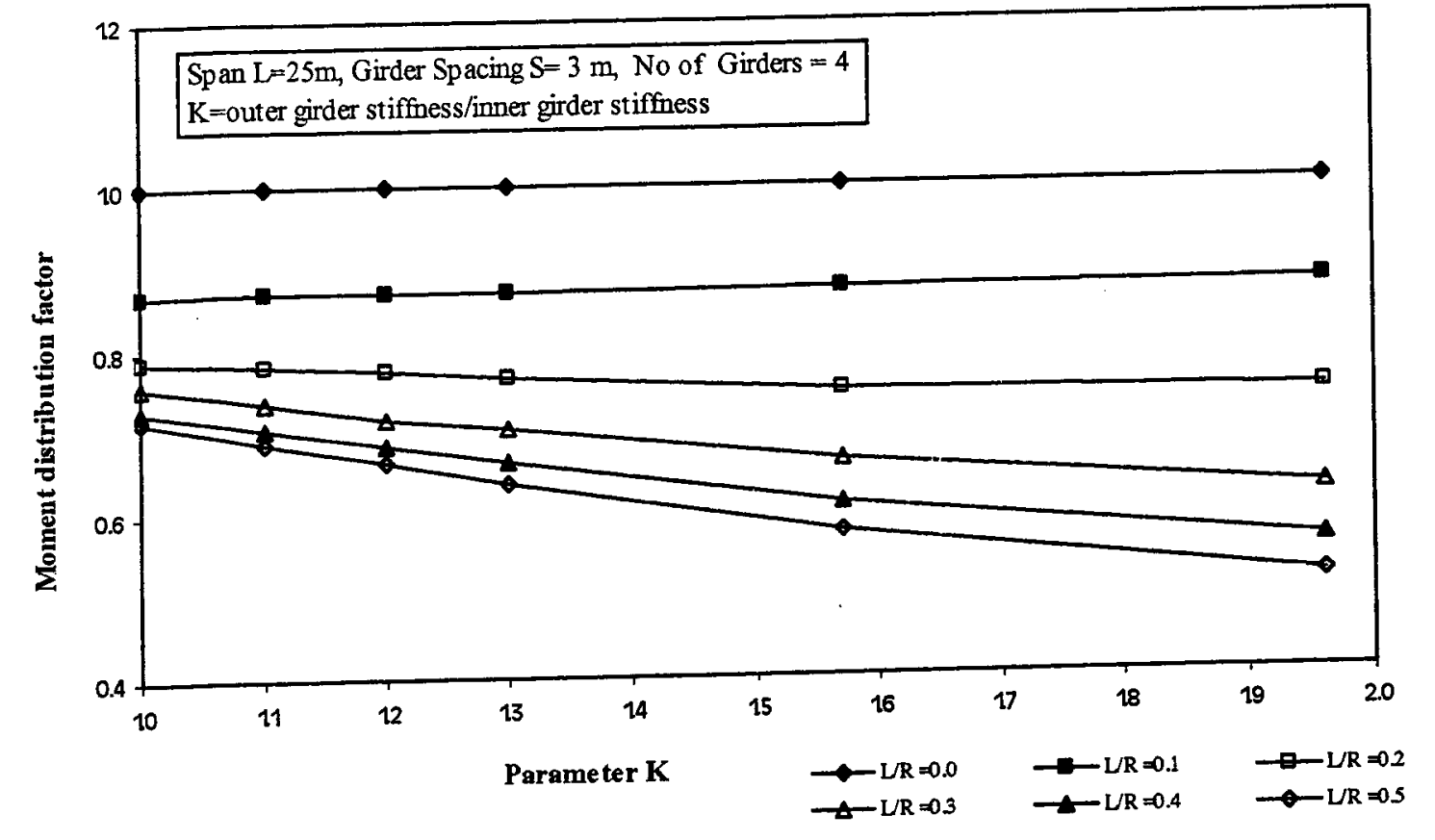

Figure 4.4 Effect of variation of girder stiffness on moment distribution factor of the inner girder

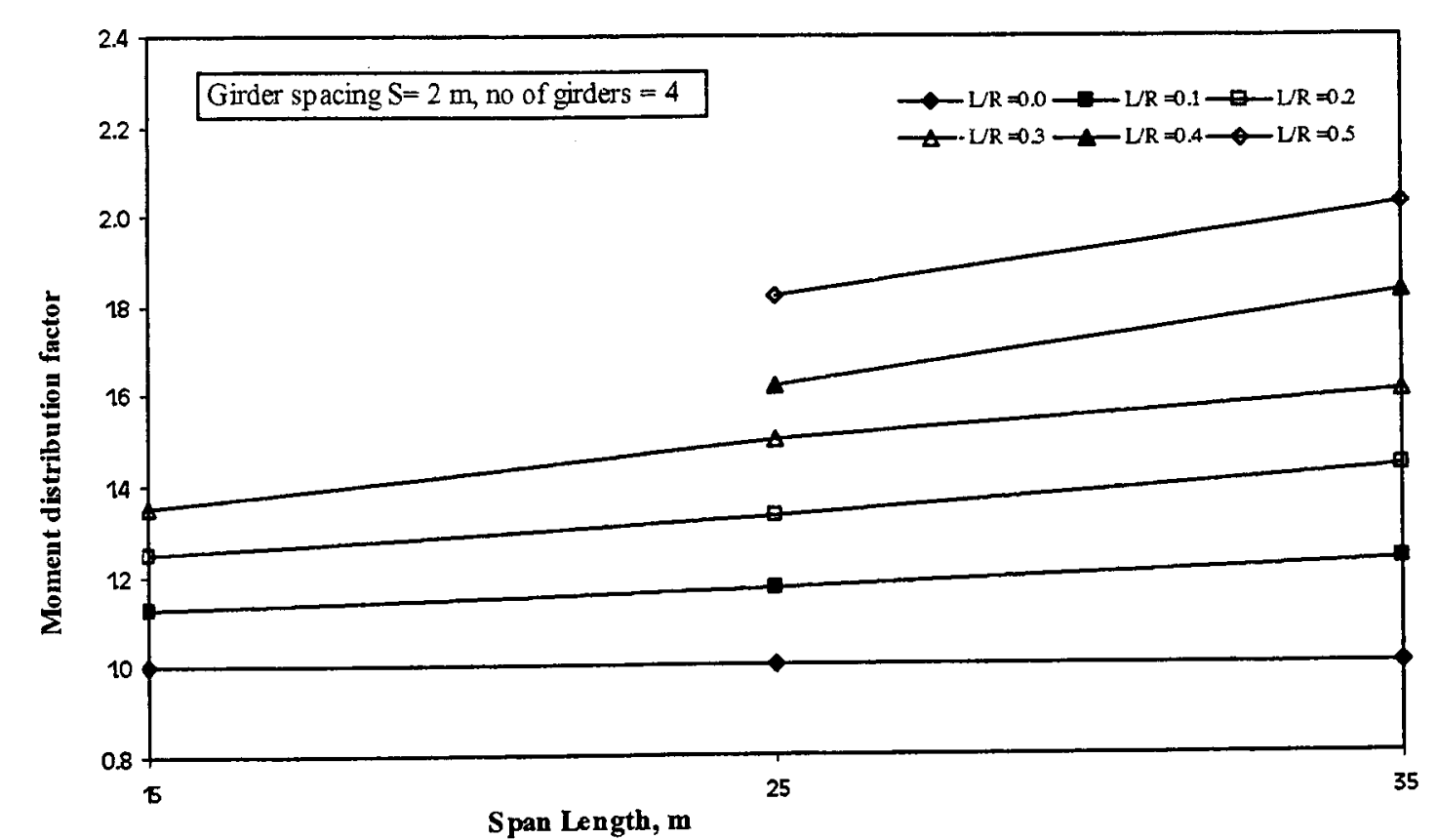

Figure 4.5 Effect of span length on moment distribution factor for the outer girder of curved steel I-girder bridges

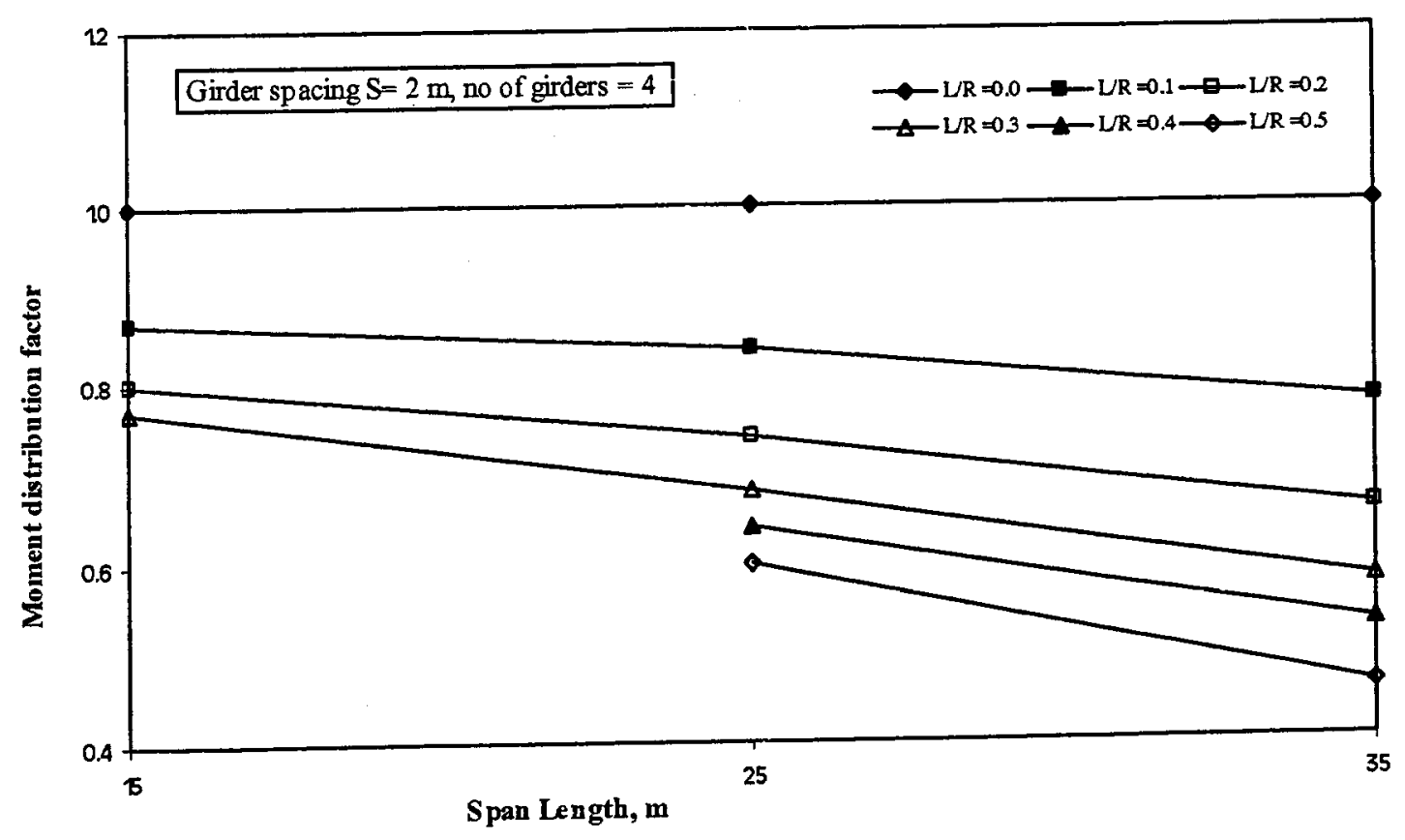

Figure 4.6 Effect of span length on moment distribution factor for the inner girder of curved steel I-girder bridges
PROPERTY OF

RYERSON UNIVERSITY LIBRARY 


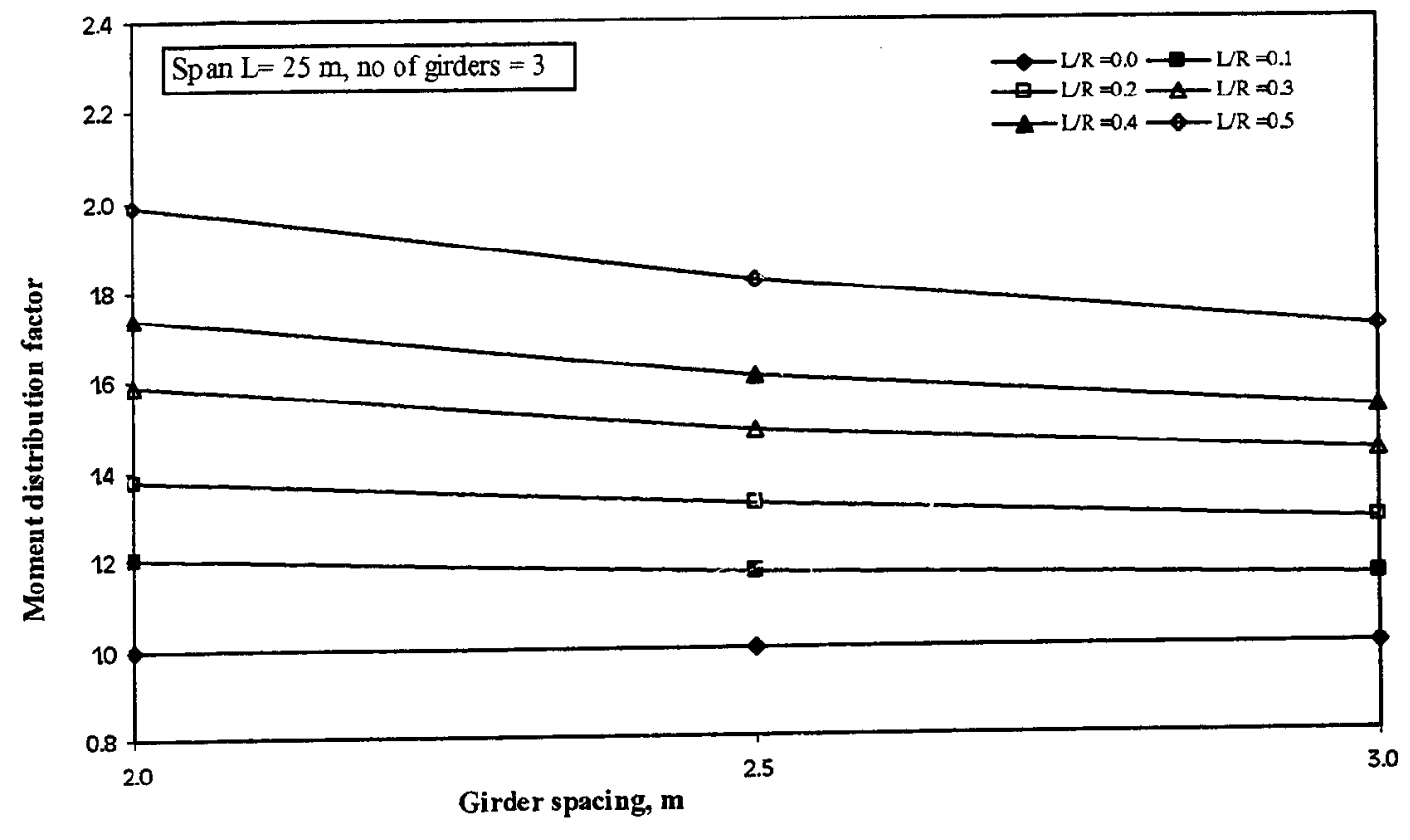

Figure 4.7 Effect of girder spacing on moment distribution factor for the outer girder of curved steel I-girder bridges

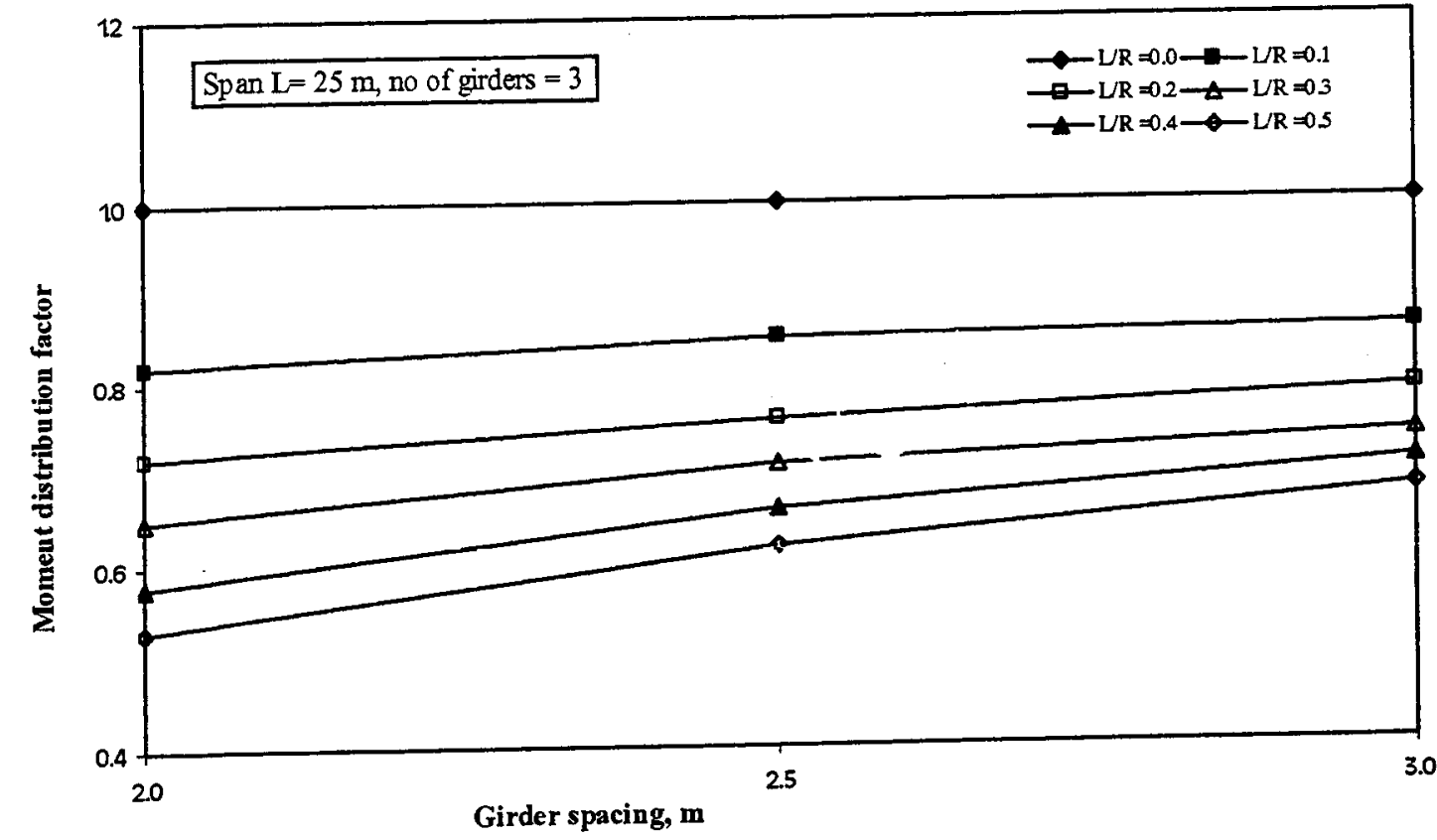

Figure 4.8 Effect of girder spacing on moment distribution factor for the inner girder of curved steel I-girder bridges

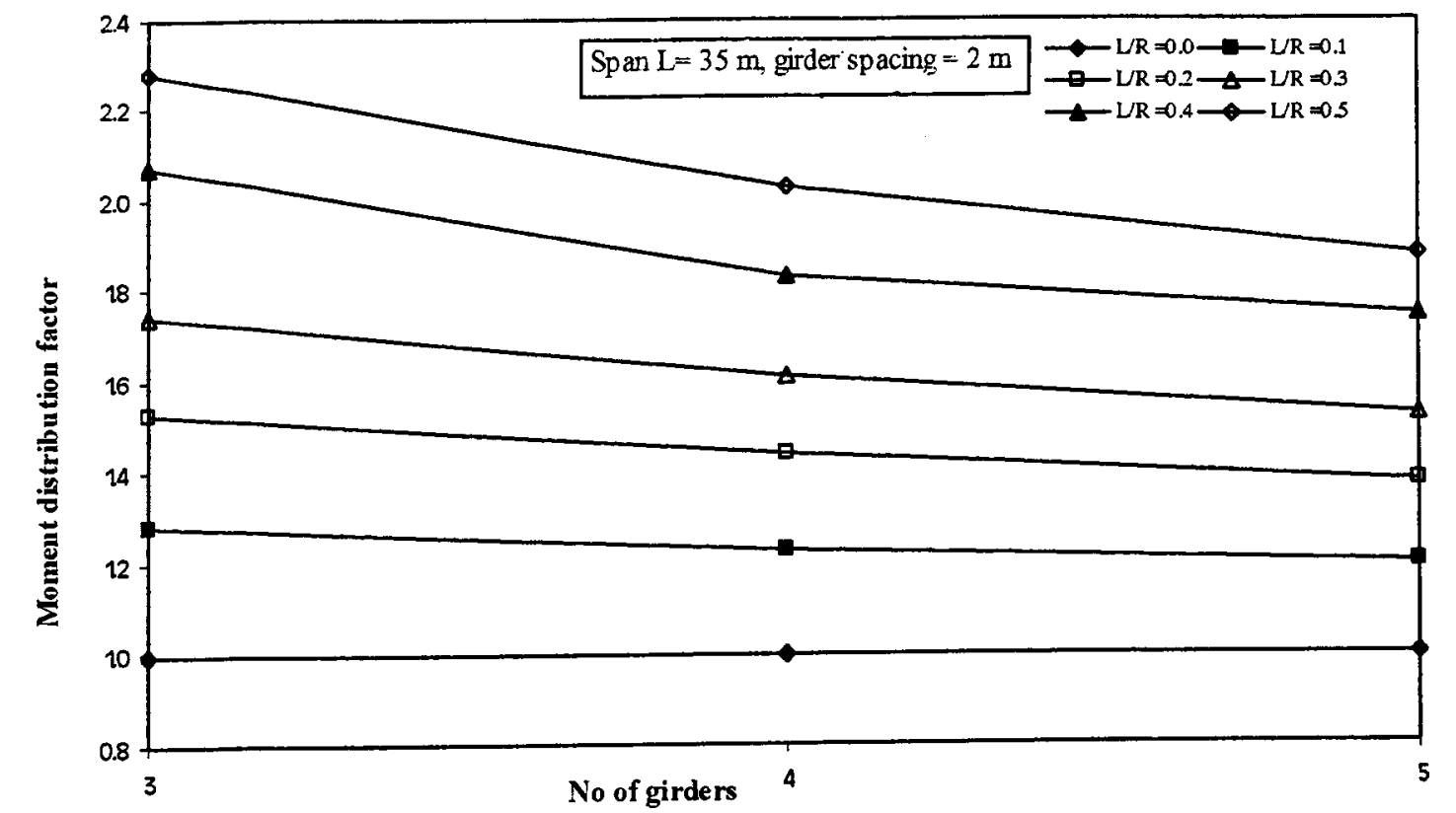

Figure 4.9 Effect of number of girders on moment distribution factor for the outer girder of curved steel I-girder bridges

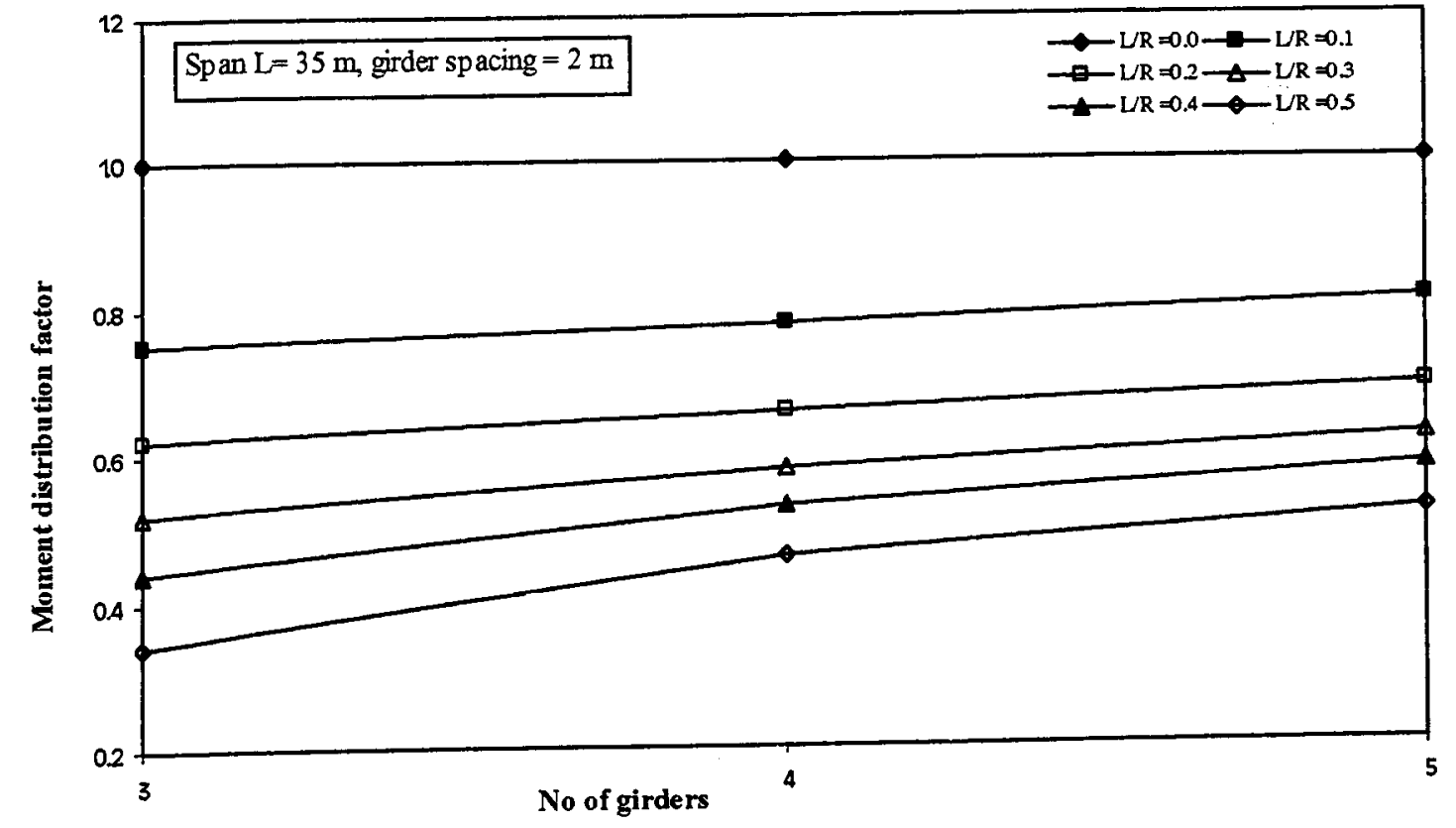

Figure 4.10 Effect of number of girders on moment distribution factor for the inner girder of curved steel I-girder bridges 


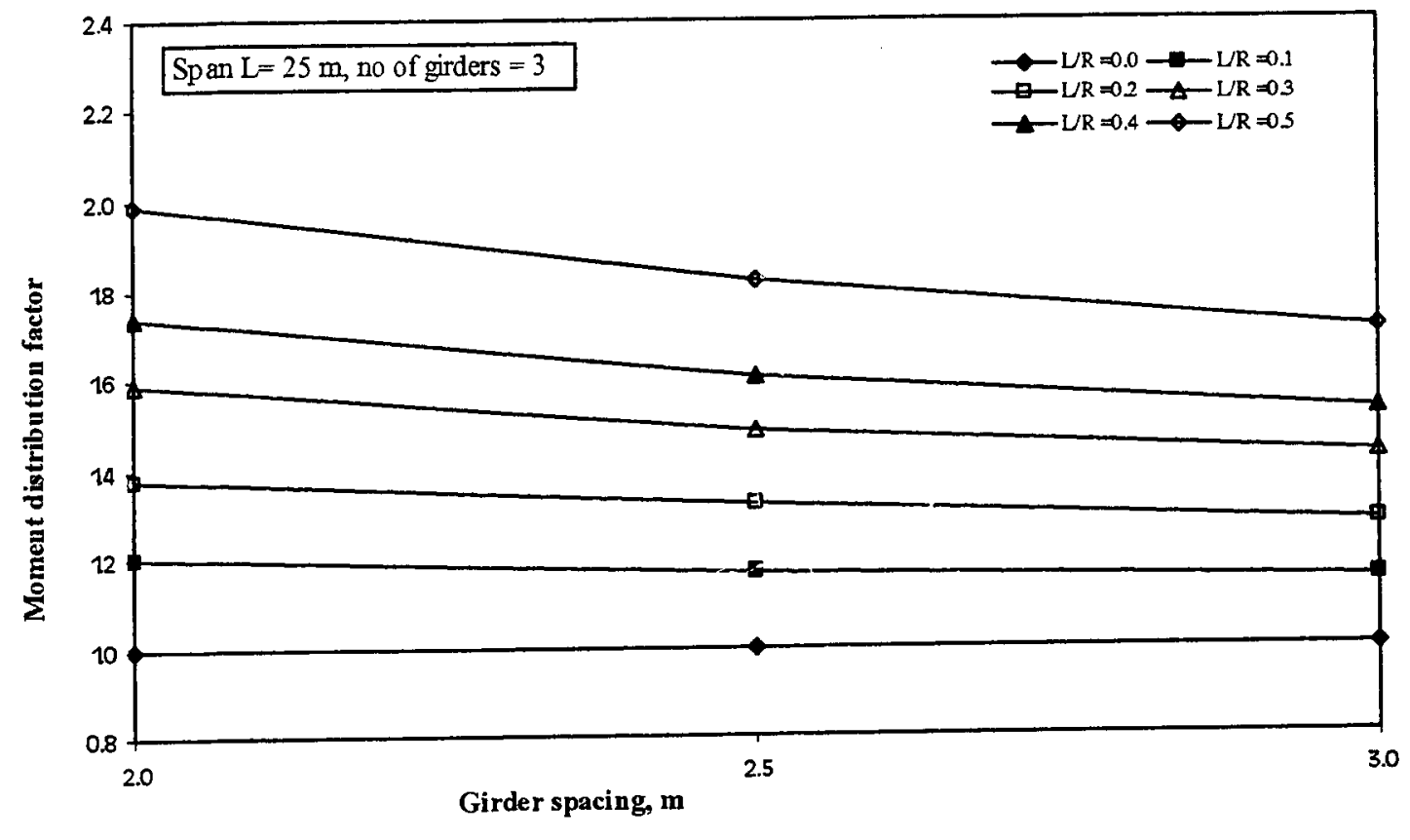

Figure 4.7 Effect of girder spacing on moment distribution factor for the outer girder of curved steel I-girder bridges

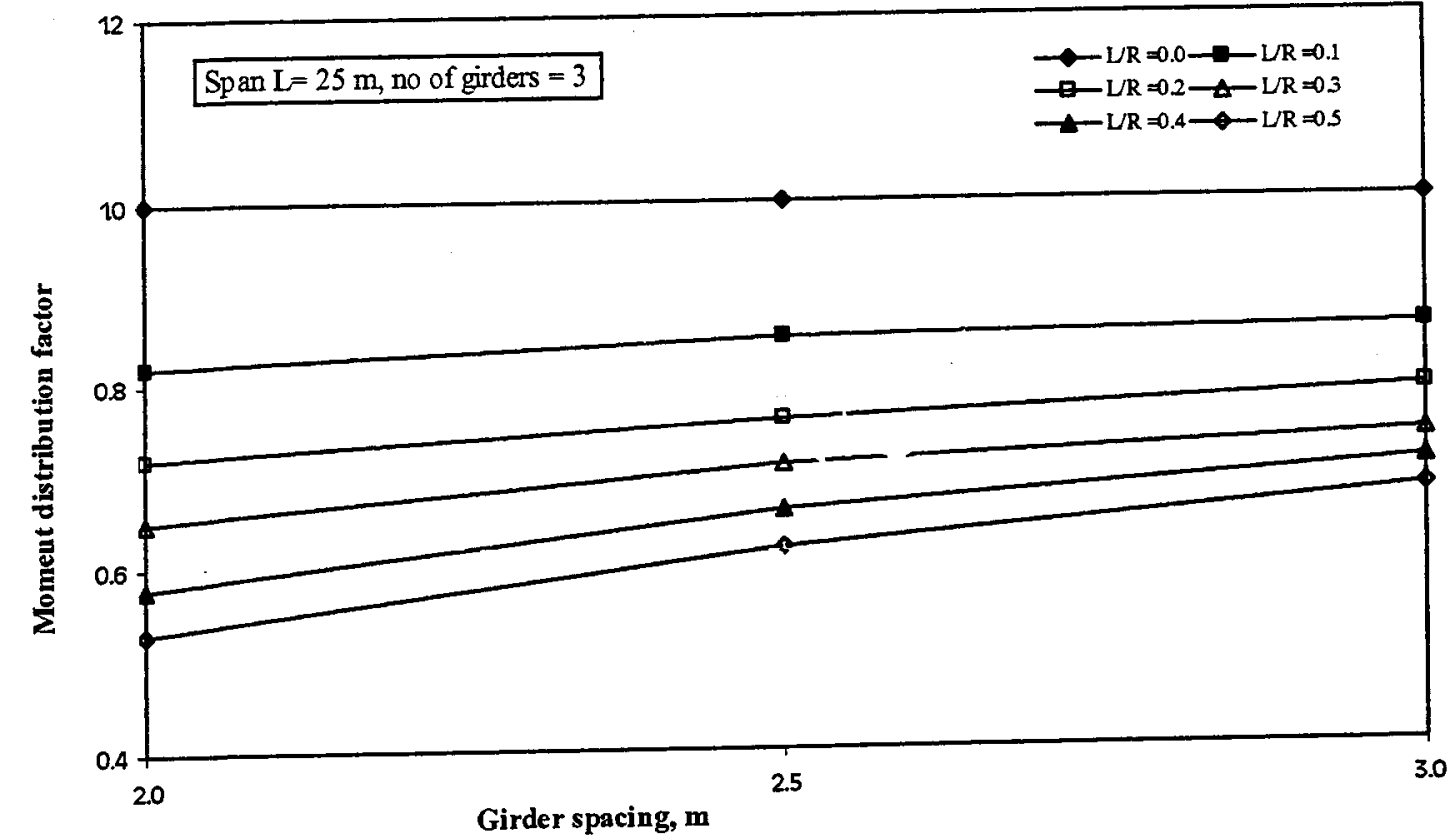

Figure 4.8 Effect of girder spacing on moment distribution factor for the inner girder of curved steel I-girder bridges

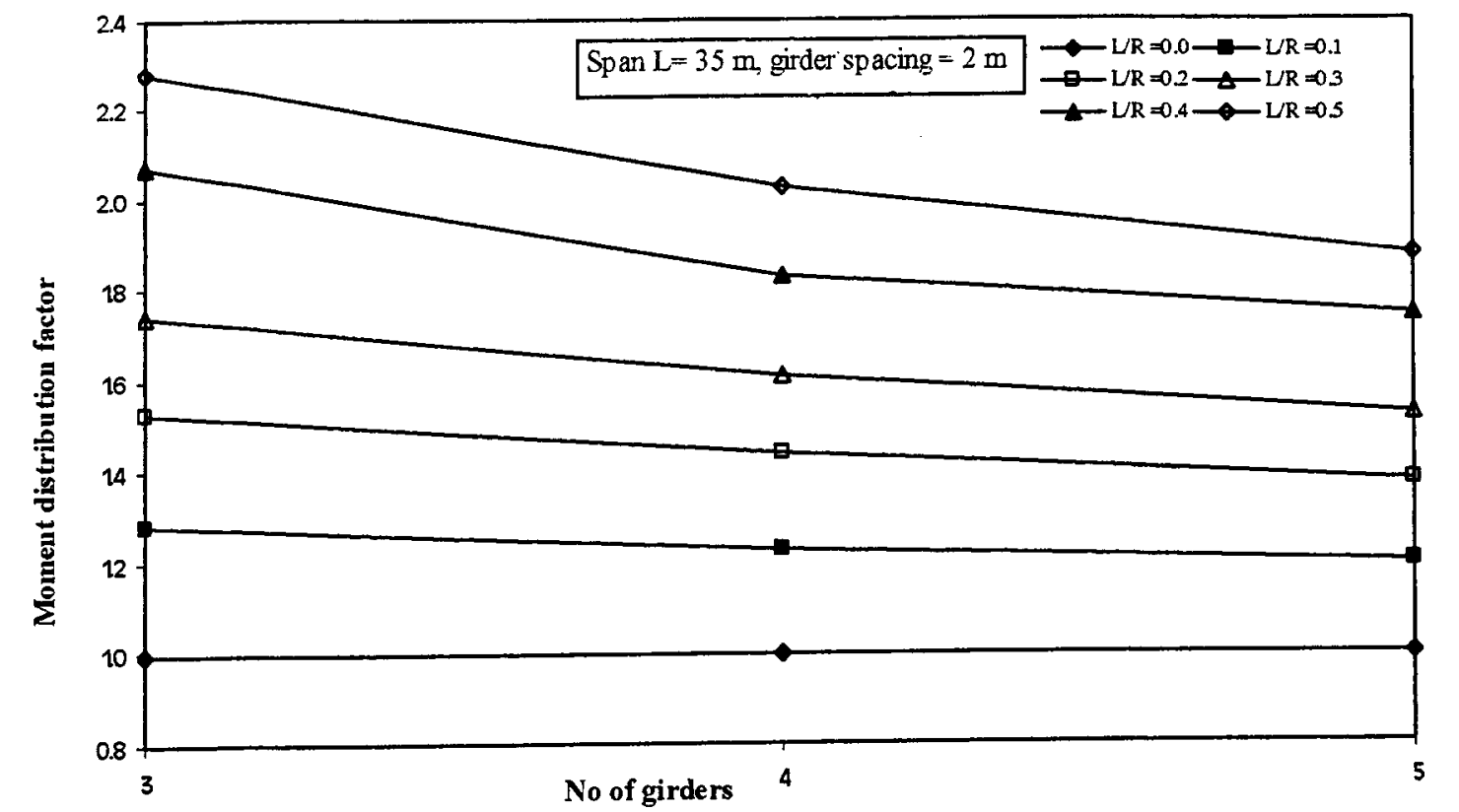

Figure 4.9 Effect of number of girders on moment distribution factor for the outer girder of curved steel I-girder bridges

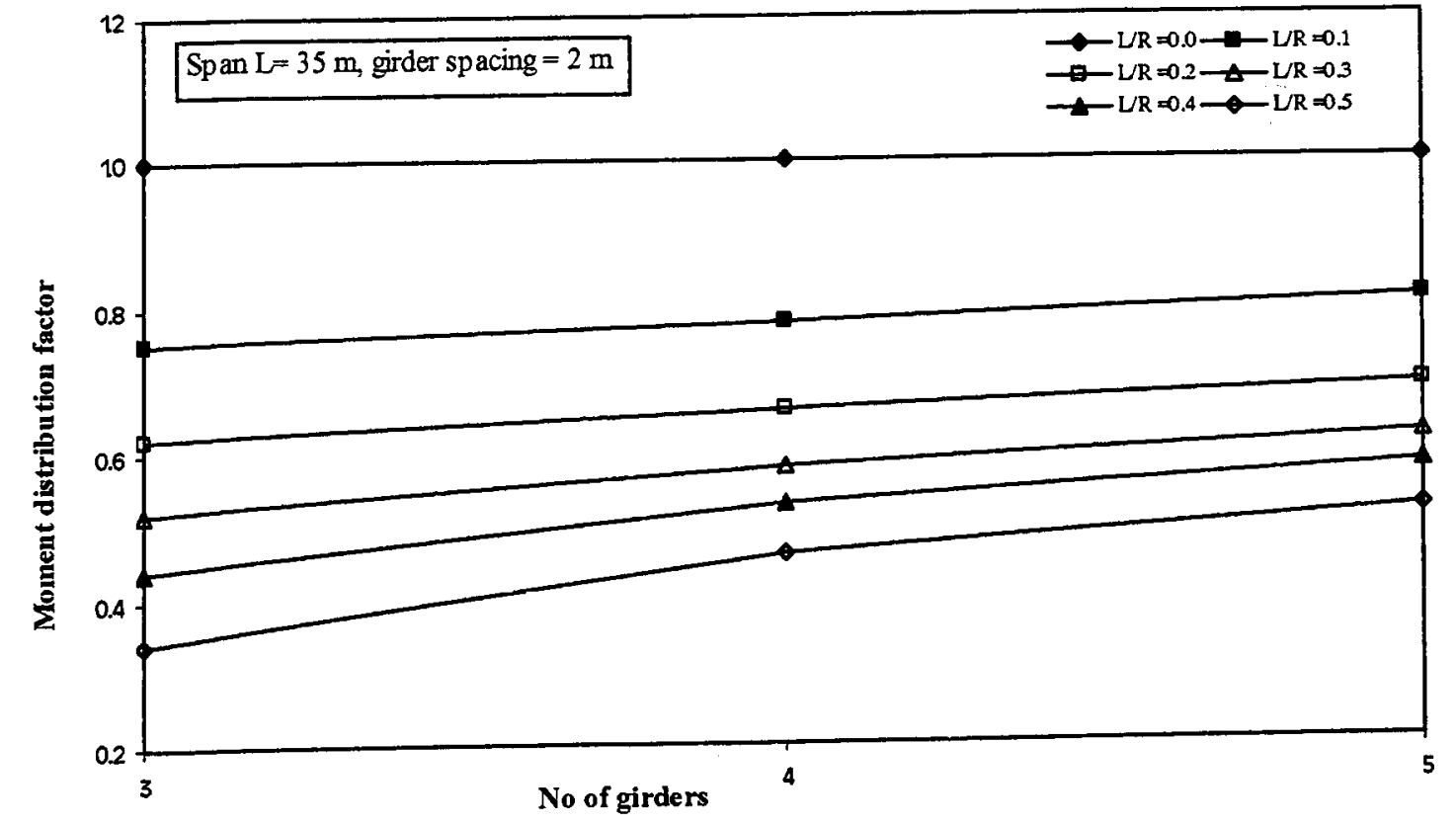

Figure 4.10 Effect of number of girders on moment distribution factor for the inner girder of curved steel I-girder bridges 


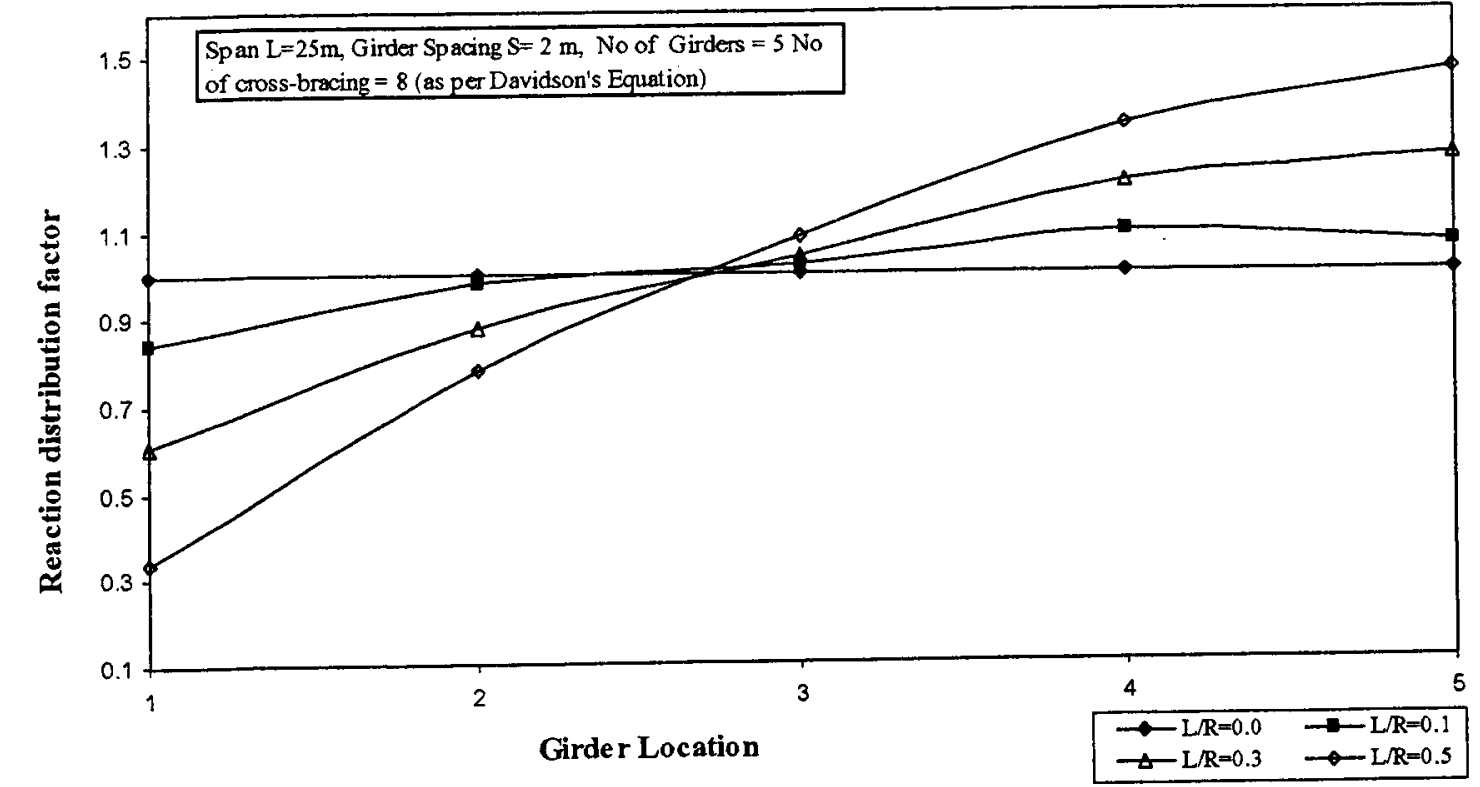

Figure 4.11 Effect of curvature on reaction distribution factor

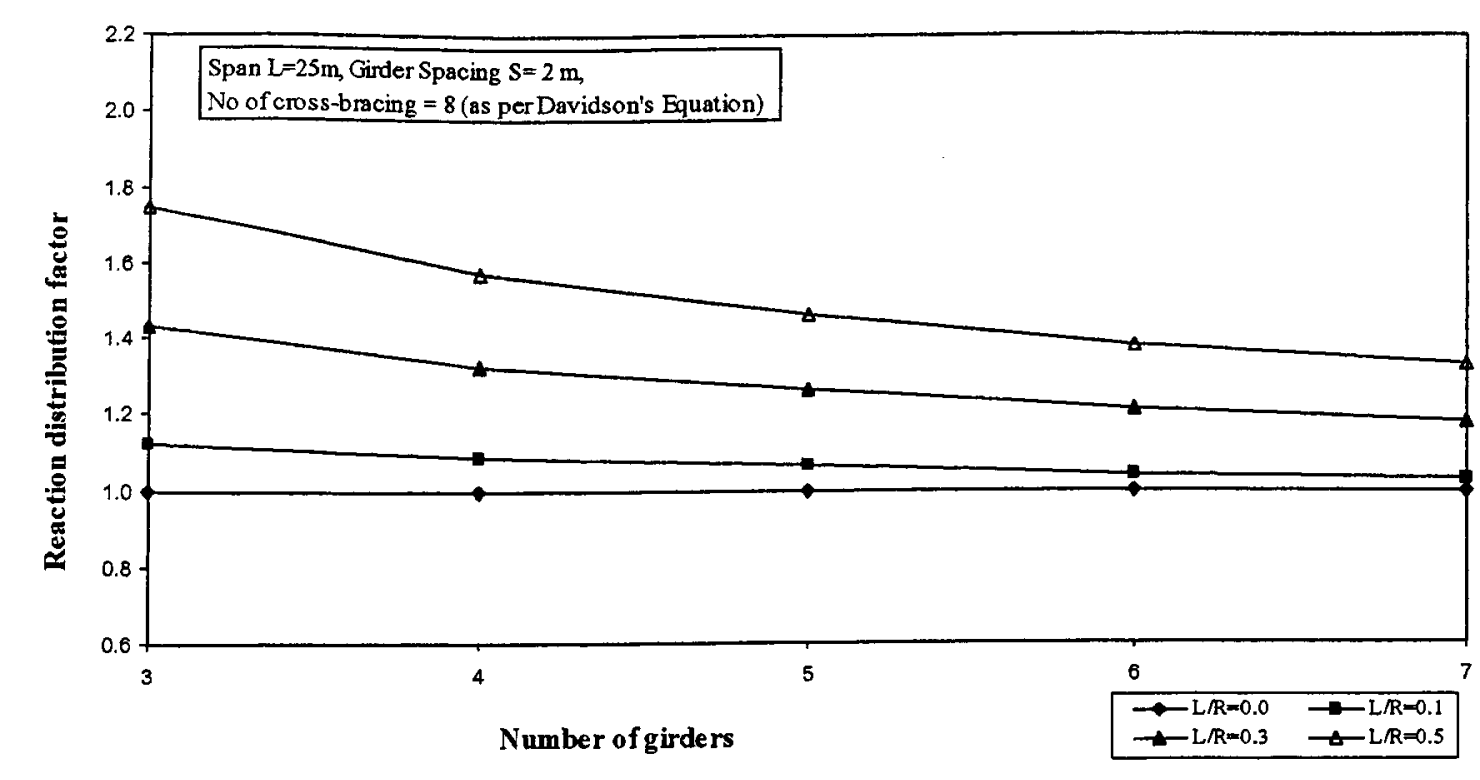

Figure 4.12 Effect of number of girders on reaction distribution factor for outer girder

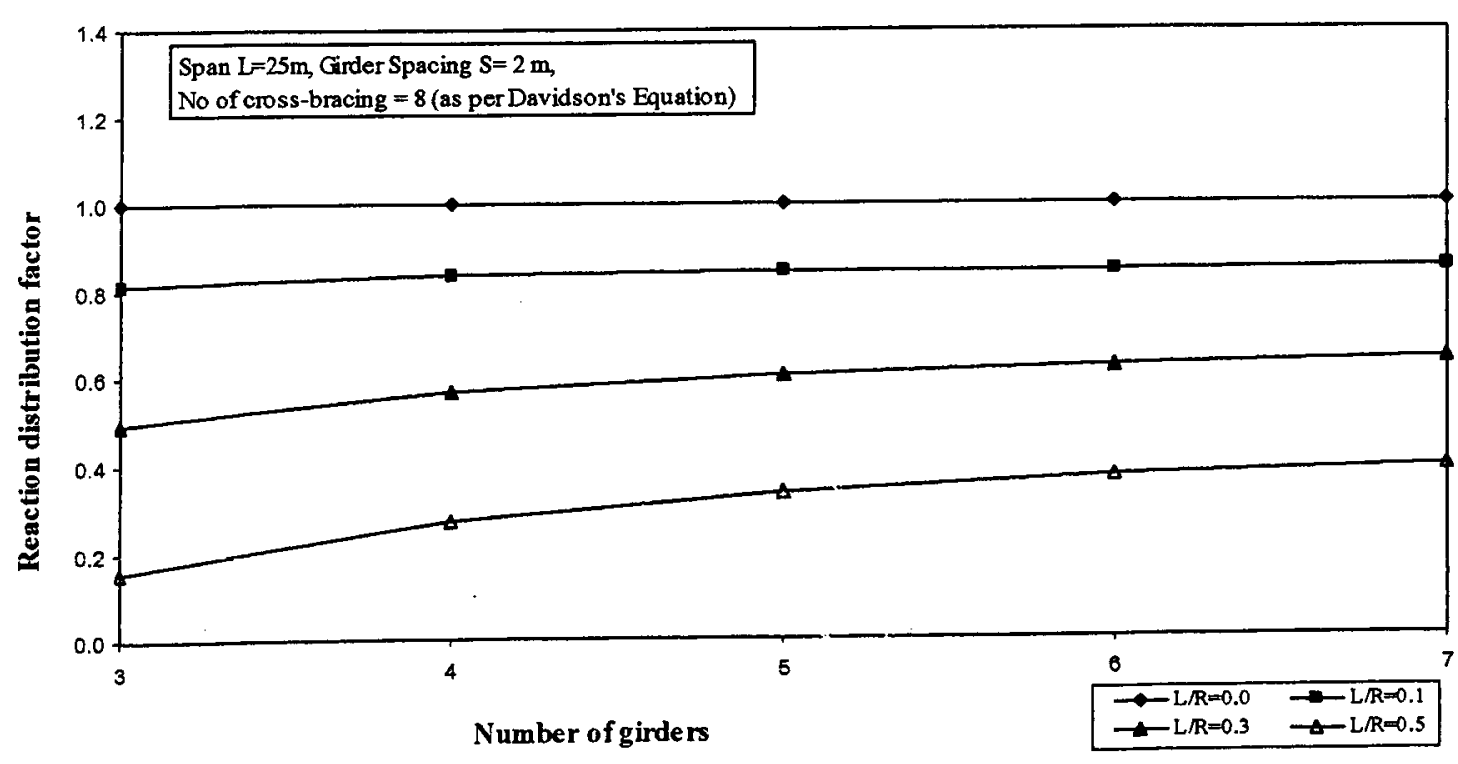

Figure 4.13 Effect of number of girders on reaction distribution factor for inner girder 


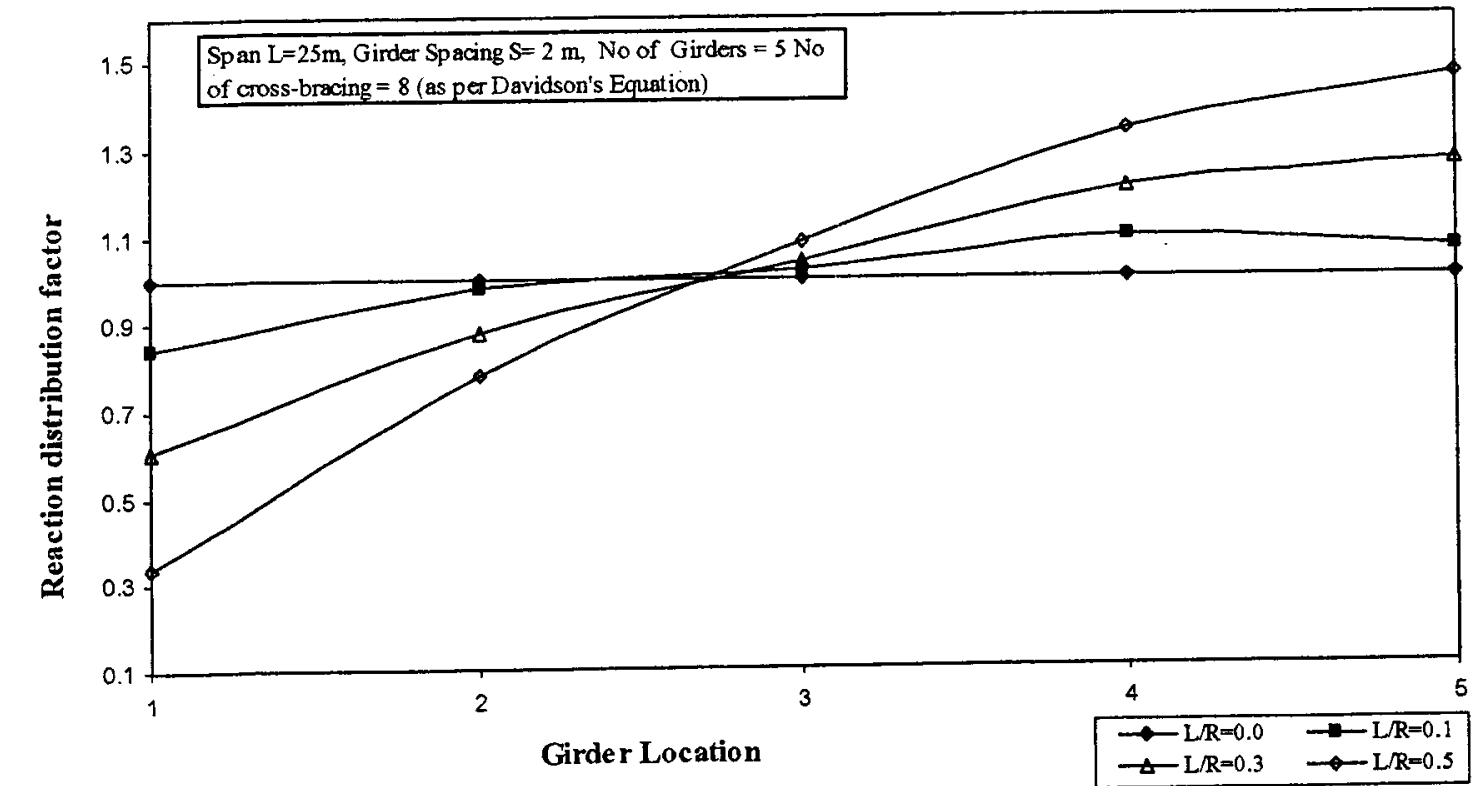

Figure 4.11 Effect of curvature on reaction distribution factor

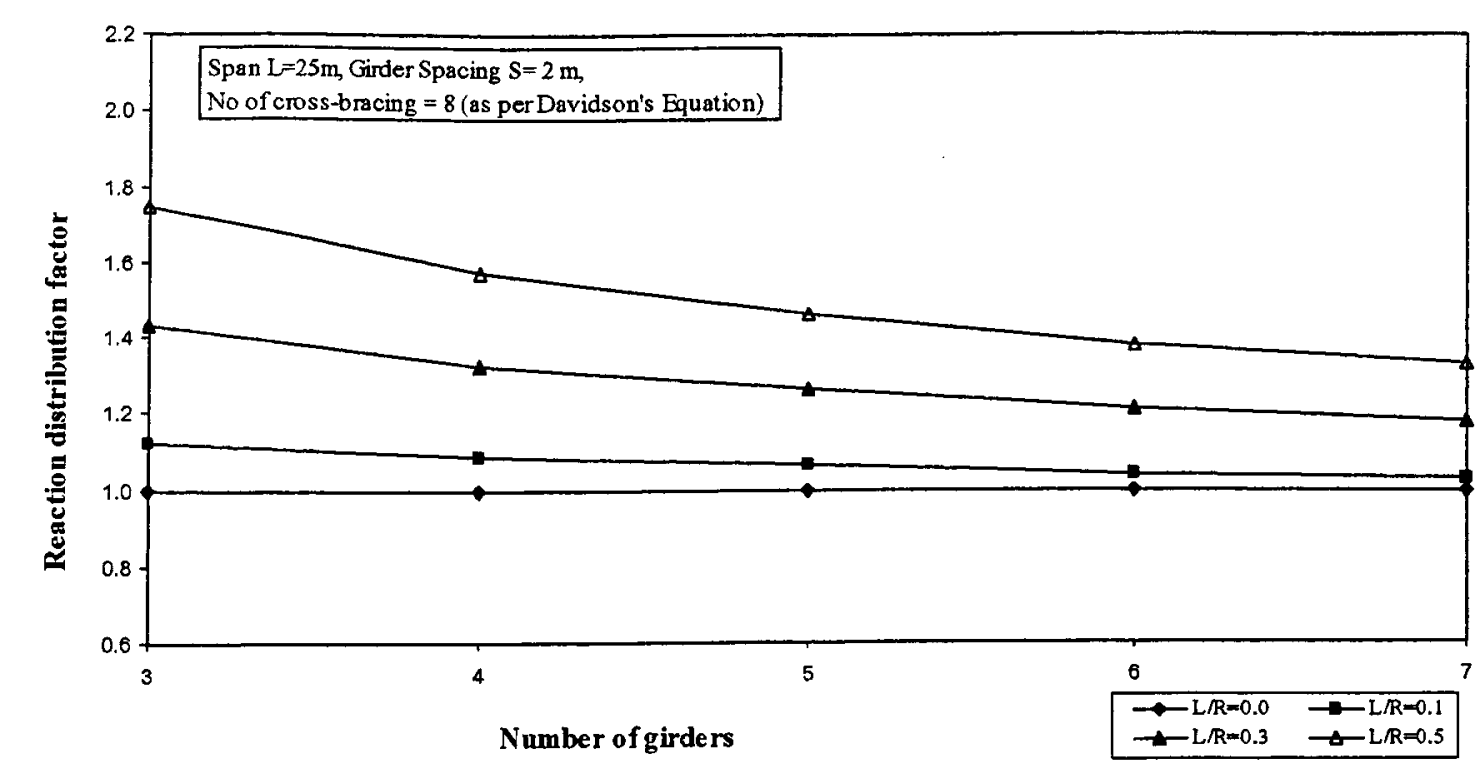

Figure 4.12 Effect of number of girders on reaction disiribution factor for outer girder

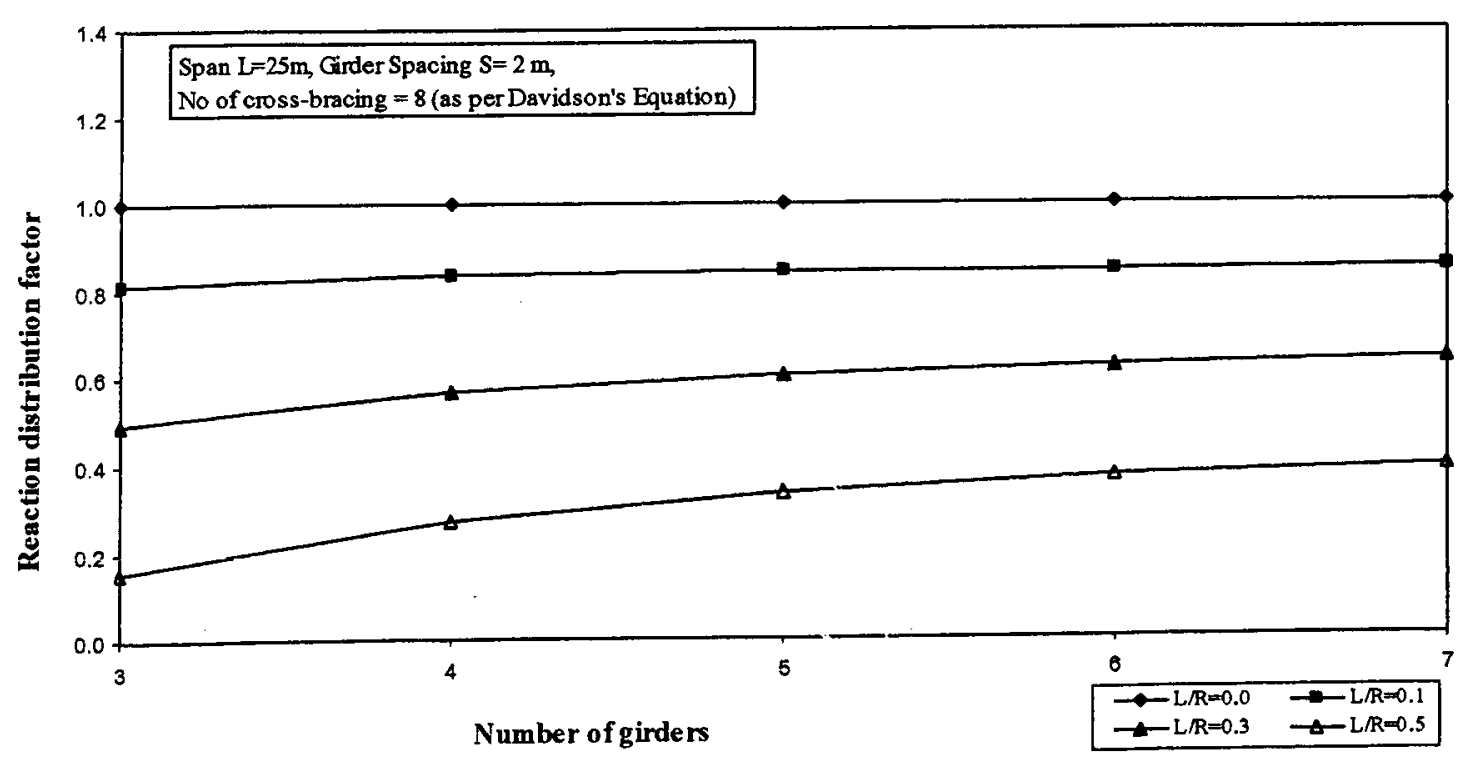

Figure 4.13 Effect of number of girders on reaction distribution factor for inner girder 


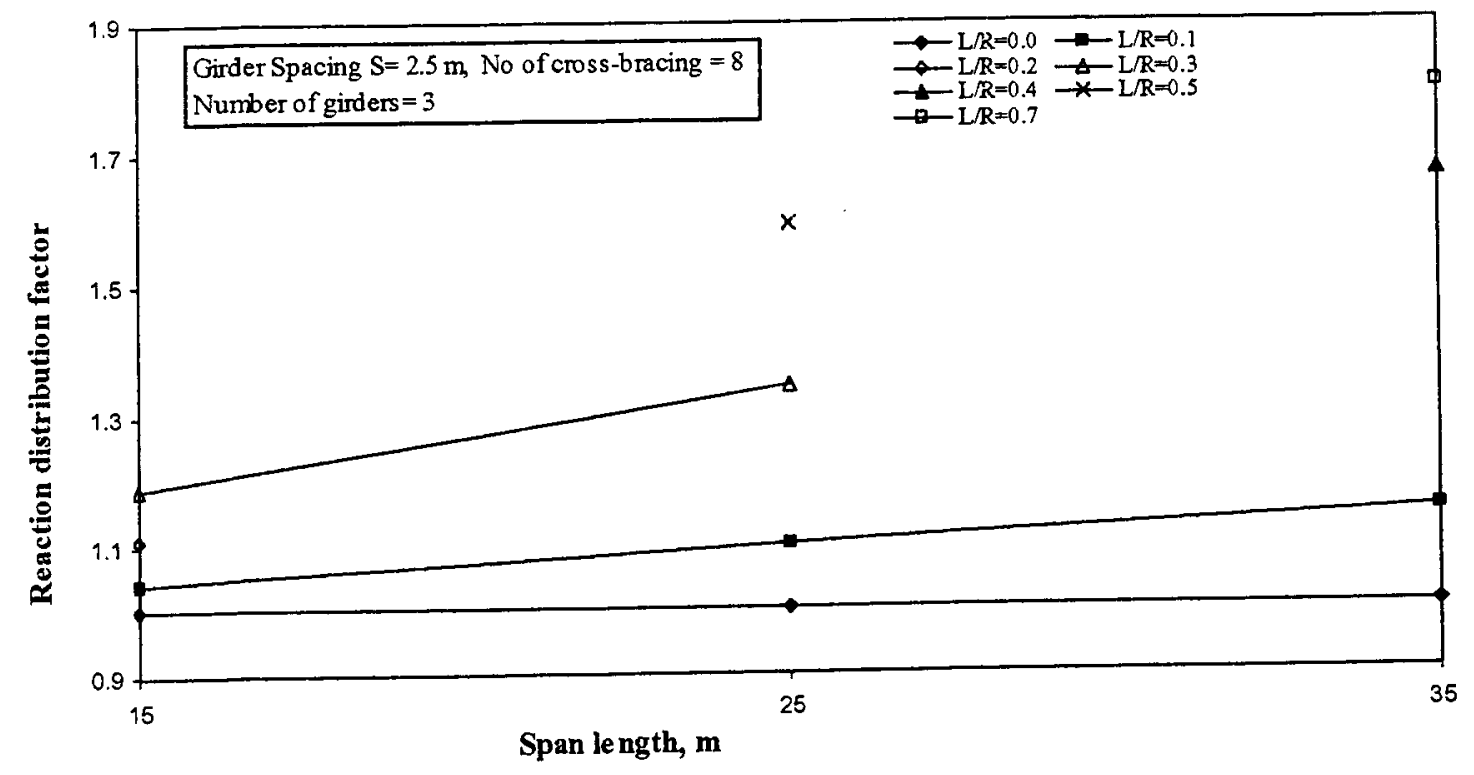

Figure 4.14 Effect of bridge span on reaction distribution factor for outer girder

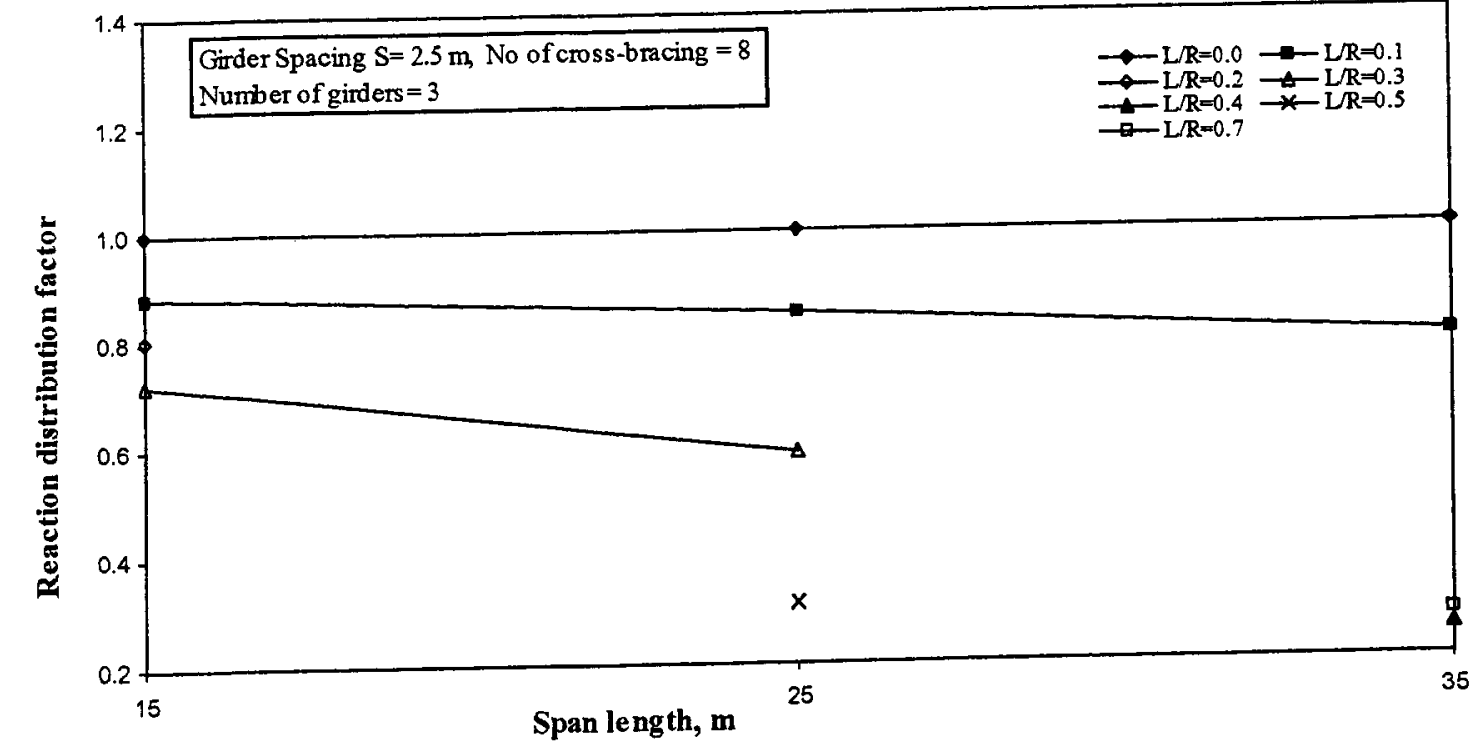

Figure 4.15 Effect of bridge span on reaction distribution factor for inner girder

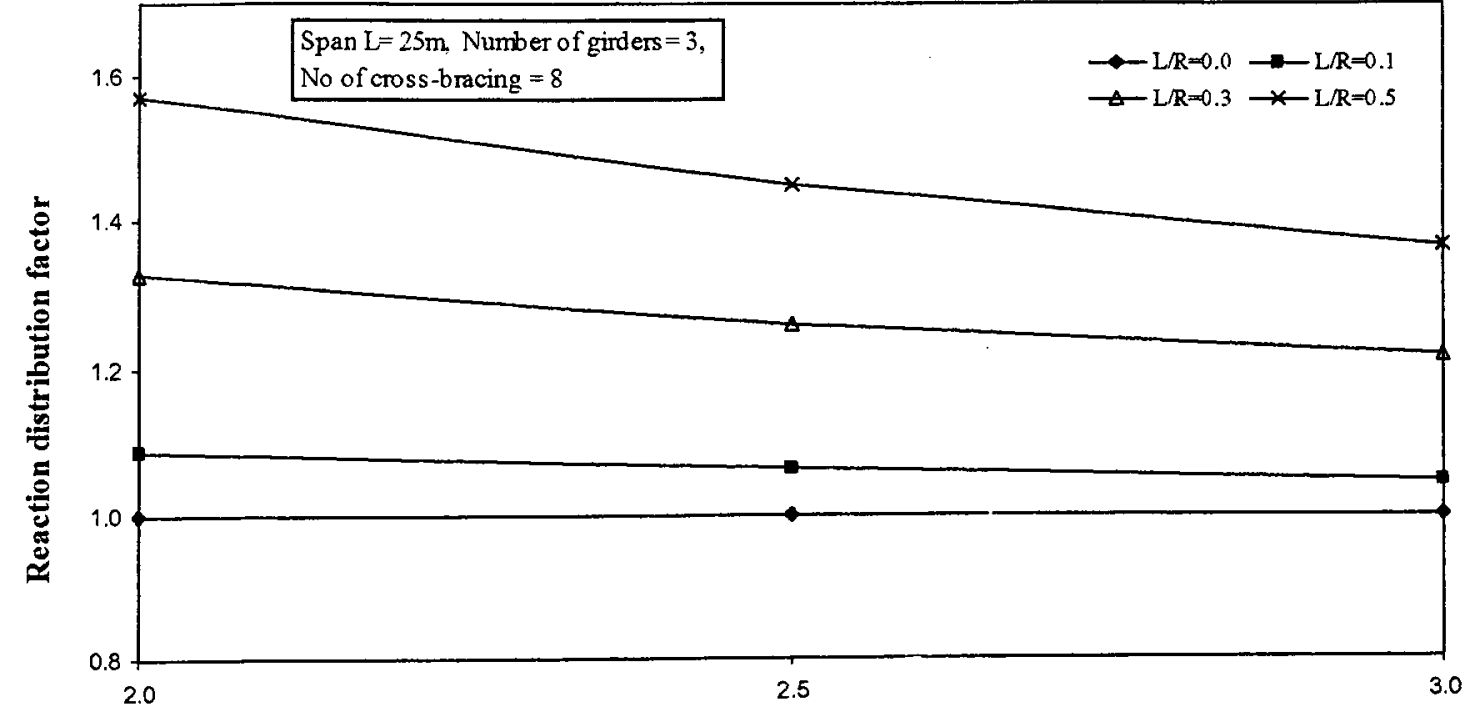

Girder spacing, m

Figure 4.16 Effect of girder spacing on reaction distribution factor for outer girder

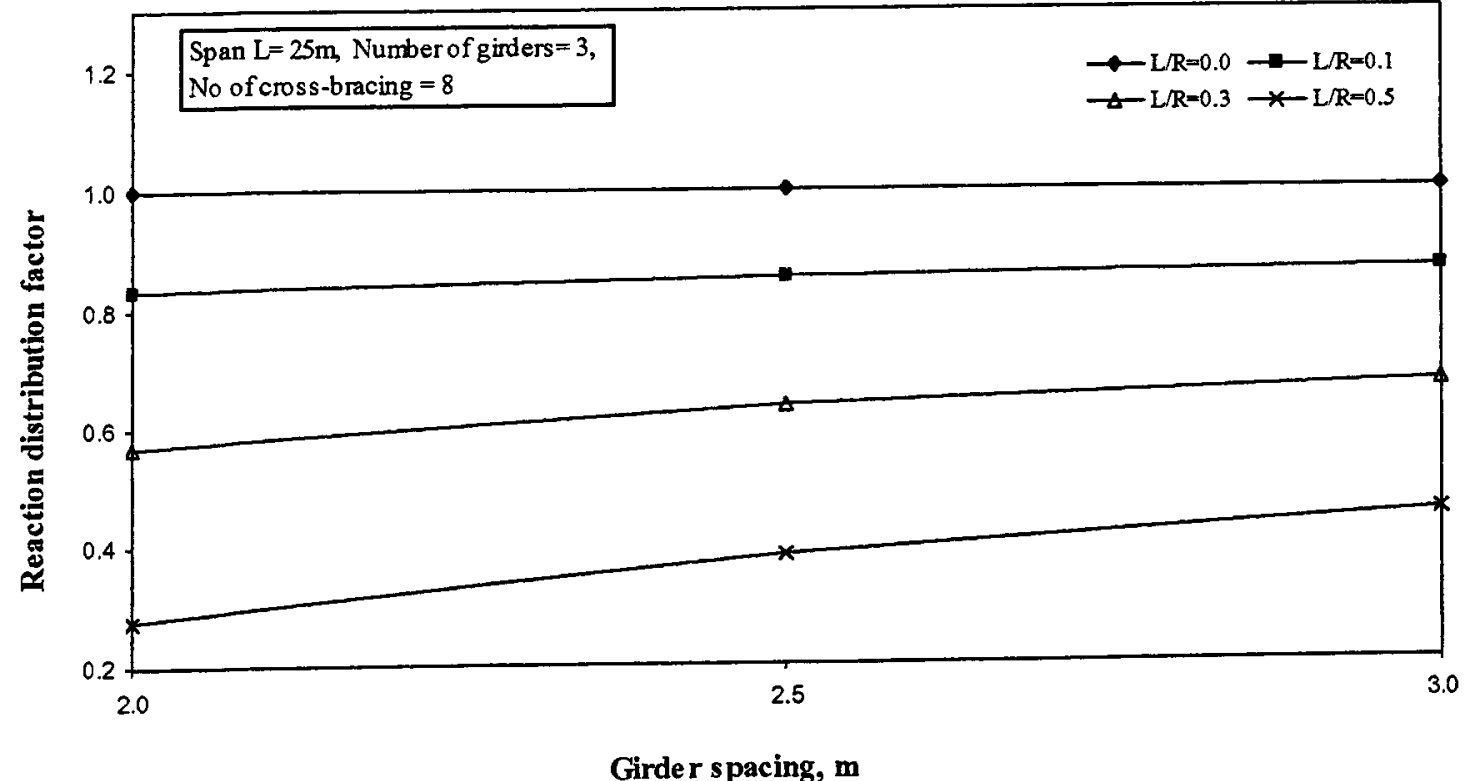

Figure 4.17 Effect of girder spacing on reaction distribution factor for inner girder 


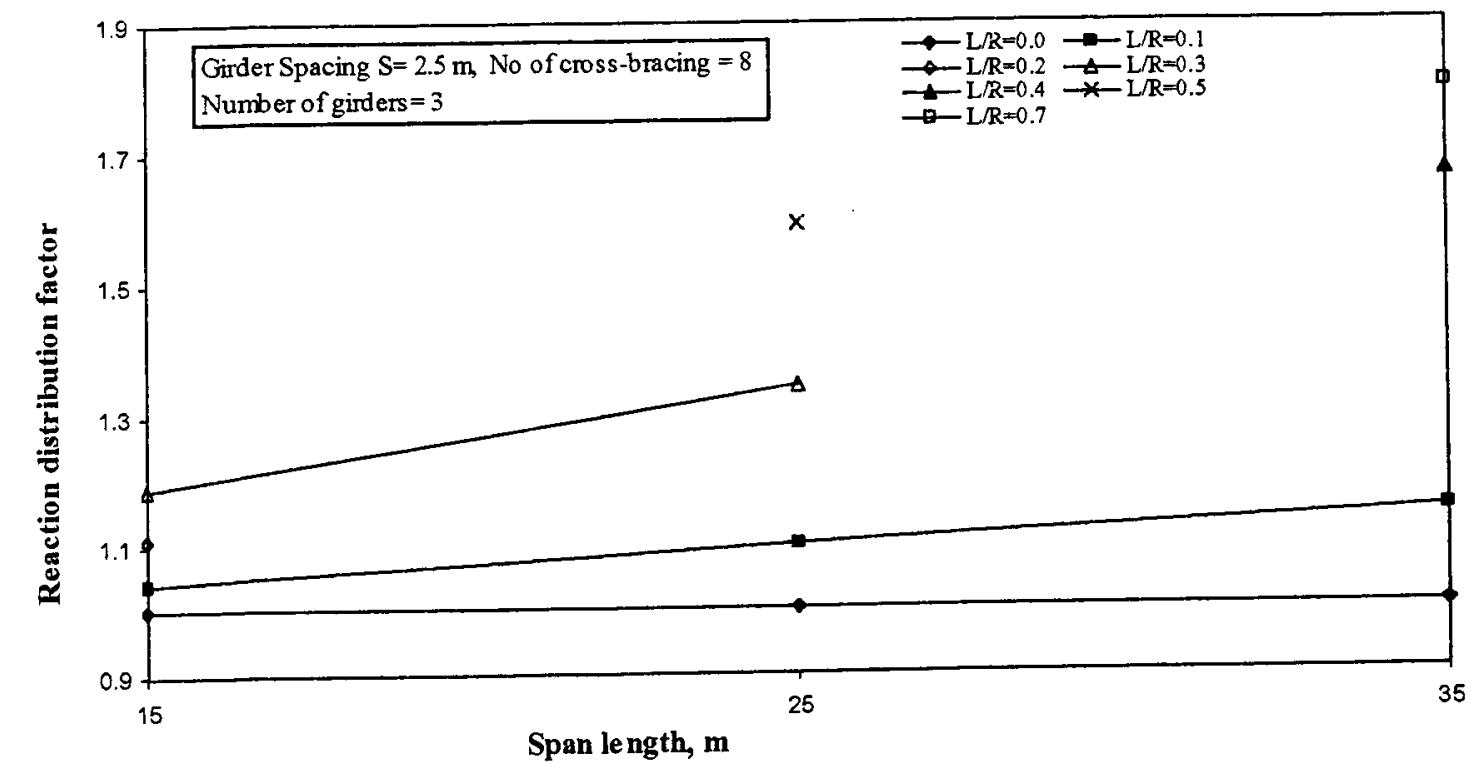

Figure 4.14 Effect of bridge span on reaction distribution factor for outer girder

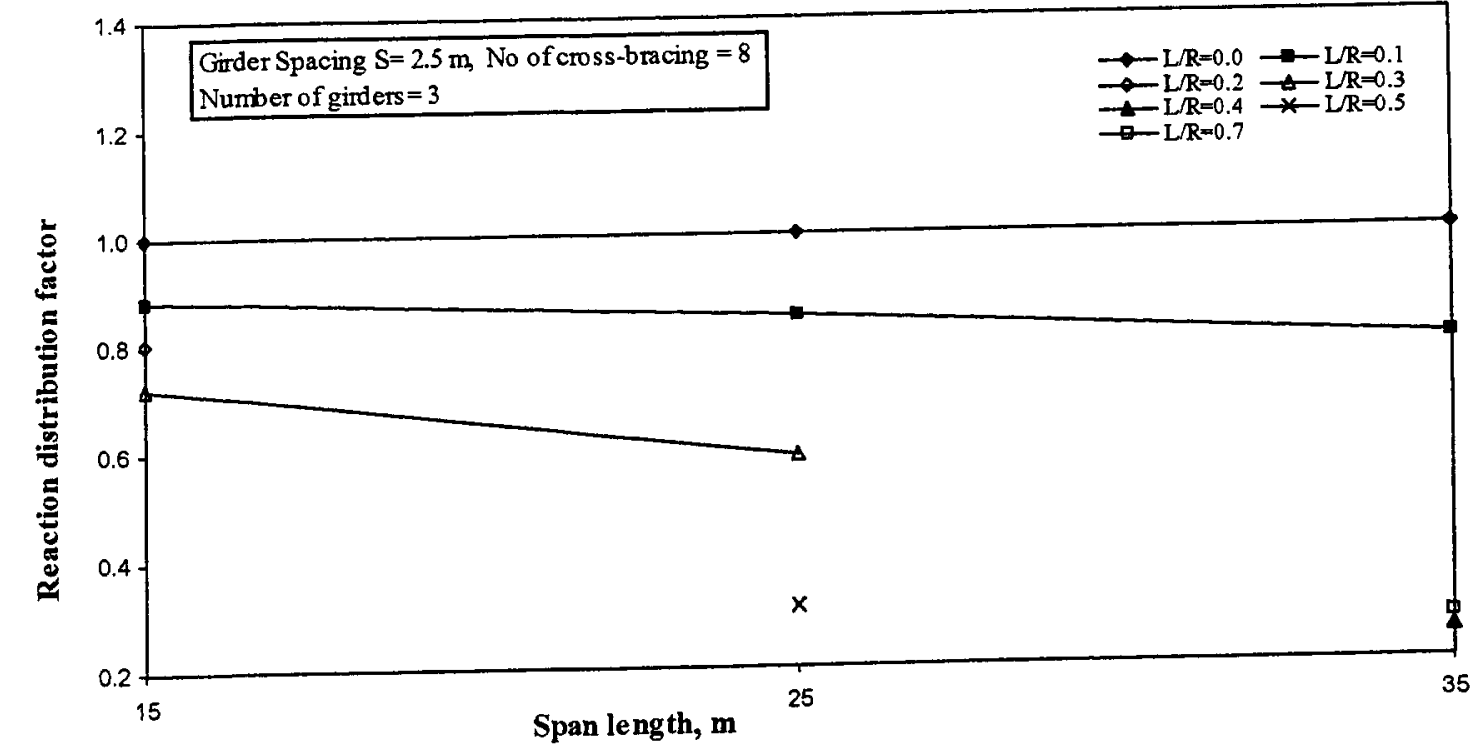

Figure 4.15 Effect of bridge span on reaction distribution factor for inner girder

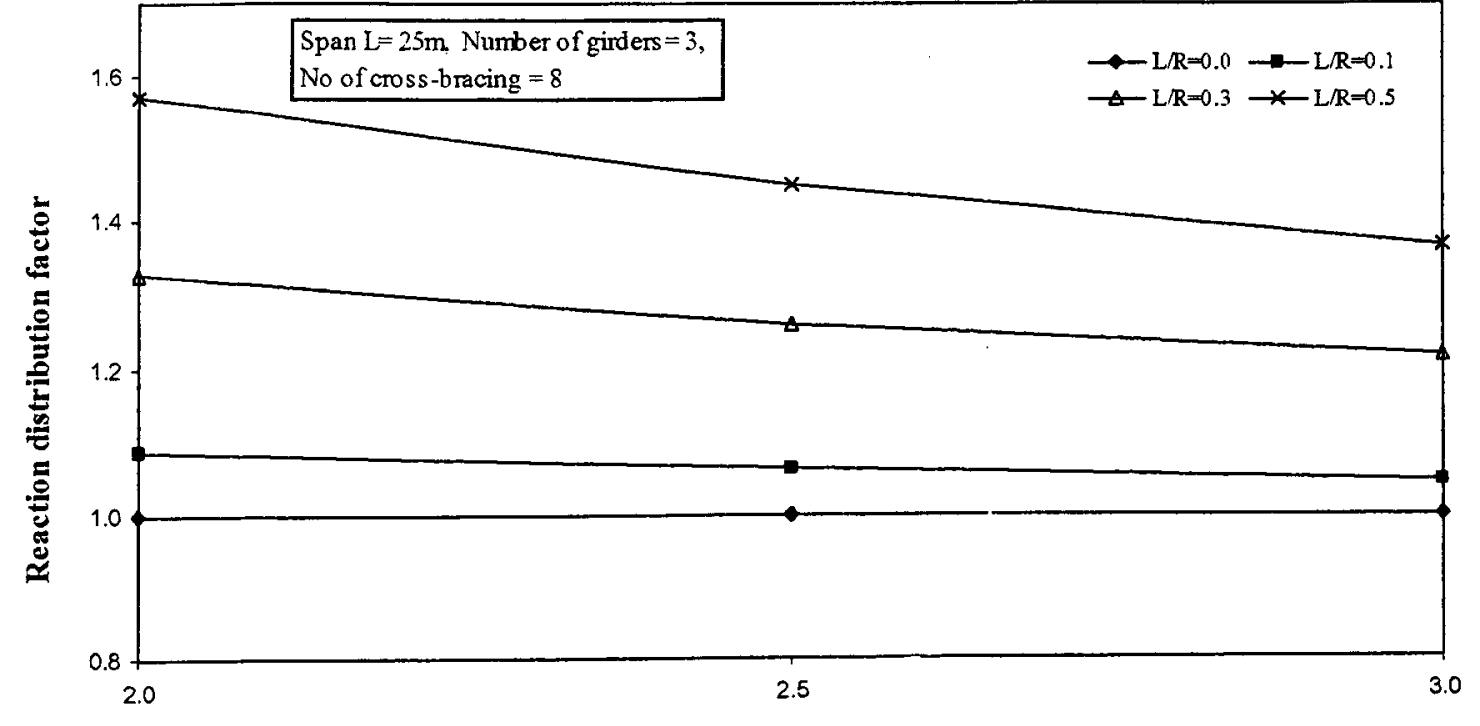

Girder spacing, $m$

Figure 4.16 Effect of girder spacing on reaction distribution factor for outer girder

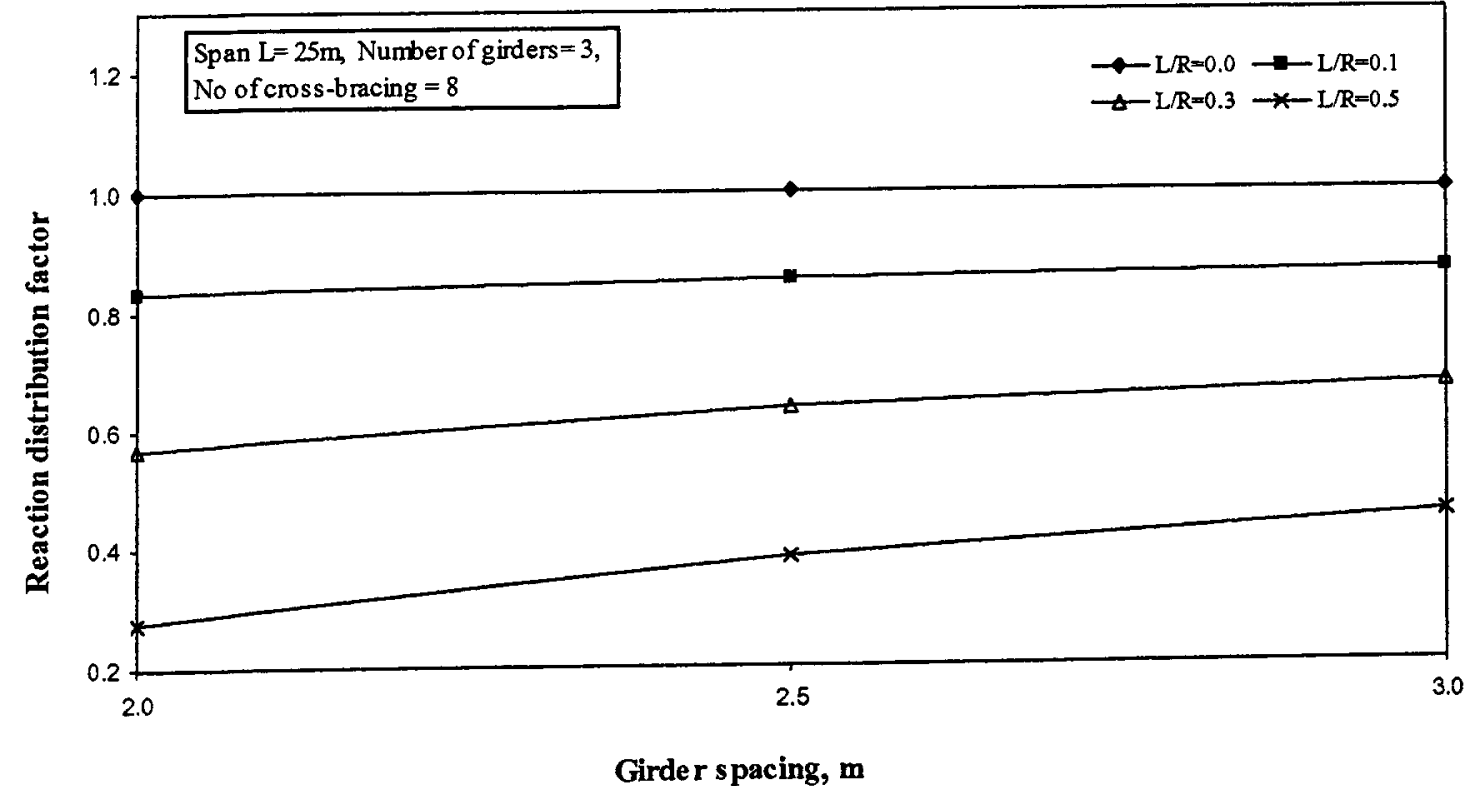

Figure 4.17 Effect of girder spacing on reaction distribution factor for inner girder 